\title{
The Leff Dictionary of Law: A Fragment
}

\author{
Arthur Allen Leff $†$
}

A

A. The first letter of the English alphabet.

The English indefinite article ("an" before an " $h$ " or a vowel), distinguished from the definite article "the." While usually singular, " $a$ " is not necessarily so; it may be used in the same sense as "any" and be applied to more than one object, e.g., "A wild animal is there for the taking."

The usual form of the Latin preposition meaning (depending upon context) "from," "away from," "of," "out of," "by," "because of"-and more. Before words beginning with a vowel or an " $h$ ", "ab" was ordinarily used, and before a "c" or a "t", "abs."

In French and Law French, a preposition meaning, depending on the context, "at," "for," "in," "of," "on," "to," "with,"-and more. "A" becomes "au" when it immediately precedes and is thus combined with the masculine singular definite article "le," and it becomes "aux" when it does the same with the masculine plural "les."

In the tax-law-slang phrase " $A$ ' reorganization" or " $A$ ' reorg.", " $A$ " refers to a type of tax-free corporate transaction. See corporate reorganization.

In legal hypotheticals " $a$ ", usually capitalized, is ordinarily one of the important parties, with a composite personality more aggressive than that of any other letter, e.g., "A hits $\mathrm{B}$, " "A offers to $\mathrm{B}$," and so on. $C f . \mathrm{b}, \mathrm{c}, \ldots$ z.

A.A. Abbreviation of administrative assistant, Alcoholics Anonymous, and many other things.

AAA. Abbreviation of Agricultural Adjustment Administration, American Arbitration Association, American Automobile Association, and doubtless much else.

AALS. Abbreviation for Association of American Law Schools.

$a$ and $b$. Police shorthand for assault and battery.

$A$ and $\mathbf{H}$. Insurance industry abbreviation for accident and health insurance.

a aver et tener ( ). Law French for to have and to hold.

ab ( ). A Latin preposition. See a.

ABA. Abbreviation for American Bar Association, American Banking Association-and others.

\footnotetext{
† Late Southmayd Professor of Law, Yale University
} 
abacinate. See abbacinate.

abaction ( ). Stealing cattle more than one at a time, usually in whole herds. In American parlance, cattle rustling. See also abactor.

ab actis ( ). A clerk or recorder who takes down words as spoken, especially in courtroom settings. A modern court stenographer could be so labelled.

abactor ( ). One who commits abaction, i.e., a cattle rustler. The Latin is abigeus. A person who took only one beast at a time was called fur.

abandon. See abandonment.

abandoned property. Property of any kind as to which a sometime possessor or owner has behaved as described under abandonment. Ordinarily, abandoned property is available to whoever appropriates it, but there are instances in which an abandonment by one person will give another particular person title good against all the world, e.g., abandonment by the owner of a chattel would give title to the finder. See also abandonee.

abandoned well. See generally abandonment. One is not always permitted just to abandon property. When, e.g., an oil well is no longer in use, because it was a dry hole, or has been emptied, or whatever, many states require that the well be plugged to prevent seepage of oil, gas, or water from one stratum to another.

abandonee. A person to whom property or other rights are abandoned. Ordinarily, abandonment implies relinquishment to anyone or everyone. But there are numerous circumstances in which abandonment of something by one person will have the practical or even legal effect of vesting that thing in a particular other person, who thus may usefully be called an abandonee. See also abandoned property.

abandonment. As a legal conclusion, to say that there has been an abandonment of something is to say that a person has permanently lost whatever rights in the something (it could be real or personal property, or a relationship to another person) he once might have had. This legal conclusion of abandonment is, in a large number of legal contexts, based upon a finding that the alleged abandoner had knowingly and intentionally decided permanently to sever all his ties with a thing or person, not in favor of any particular transferee but to everyone or anyone. The closest everyday language equivalent would be "throw away."

In other legal contexts, however, an abandonment may be found even if the alleged abandoner were not shown to have such intent; certain objective acts taken by him will themselves work an abandonment, even in some instances if the acts were inadvertent (e.g., abandonment of copyright). The closest everyday-language equivalent here would be "lost" (and a less confusing word for the process might be forfeiture).

In those instances where the word abandonment is used, therefore (see entries beginning abandonment of), there are characteristically two kinds of problems: (a) is the intention of the alleged abandoner relevant to the 
finding of abandonment; and (b) if so, to what extent and how easily will the relevant intention to abandon be inferred, without more, from the alleged abandoner's objective acts or failures to act. (These issues are also implicated in dealing with the various meanings of waiver.)

It should be recognized, however, that many rights cannot be lost by physical withdrawal even if coupled with intent to abandon. It is unlikely, for instance, that the owner of fee interest in land would lose that title by abandonment; he would retain a fee, unless it were affirmatively lost to someone else by way of a process additional to abandonment, e.g., adverse possession. And not all property may be just abandoned, with no steps taken to haul it away or render it safe, e.g., it is ordinarily unlawful to get rid of an automobile by leaving it in the street, and certain steps must be made to render safe an abandoned well.

abandonment of child. This ordinarily requires both physical desertion and intention to abandon. The latter may be implied from the mere physical desertion, but usually some additional evidence of intent to effect an abandonment will be required. To the extent that the parent's actual intention to abandon is thus made relevant, the surface purposes of the law governing child abandonment would seem to be contradicted, or at least deeply qualified. For if the interests of the child, rather than the "property" interests of the parent in the child, are being served, then the subjective intent of the physically abandoning parent would seem barely relevant; the child will be affected by the objective indicia of abandonment whatever the parent's hopes for future return. There is, therefore, growing judicial and scholarly adherence to an objective definition of child abandonment.

abandonment of copyright. Under copyright law in effect until 1978, mere publication of a work without obtaining a copyright might effect an abandonment thereof. No evidence of intent to abandon copyright was necessary, but some level of mere inadvertance might prevent a finding of abandonment, especially in connection with a publication as to which a good faith but nonetheless defective or unsuccessful attempt to effect copyright had been made. Under the post-1978 Act, one is given a substantial period of time after publication to effect copyright, and it would seem that abandonment of copyright by publication will occur much less frequently.

abandonment of homestead. Ordinarily requires both physical relinquishment of the homestead property, and intention to effect abandonment, with the latter not lightly inferred from the former.

abandonment of invention. Similar to abandonment of copyright, but factually a more complex issue because of the intricacy of the patent-law equivalent of the copyright concept of publication.

abandonment of lien. Creditor conduct inconsistent with continuance of a lien. It is not always necessary that the creditor intend the dissolution of the lien for it to be found that he has effected an abandonment thereof.

abandonment of patent. A possible but rarely sustained defense to an in- 
fringement of patent suit that the holder of an actually issued patent has abandoned it by acts inconsistent with the holding of a patent, e.g., allowing use of the invention by unlicensed third parties, failing to sue others for infringement, etc. Abandonment of patent is not lightly implied.

abandonment of property. See abandoned property; abandonment; abandonment to insurer.

abandonment of spouse. See desertion.

abandonment of trademark or tradename. Merely allowing the mark or name to "lie fallow" will not work an abandonment; enough more must be shown to permit the inference of intent permanently to give up the mark or name.

abandonment of use. A concept in the law of zoning: One with the right to put his property to a nonconforming use may lose that right by ending that use.

abandonment to insurer. Notification by an insured to an insurer that, because of the extent of damage to the insured property, he will take the insurance proceeds and the insurer can have whatever is left of the insured property. The insured's right so to behave will depend on the terms of the insurance contract he has purchased. With respect to marine insurance, see fifty per cent rule.

abannition ( ). Archaic term for the archaic punishment of banishment.

ab ante ( ). In advance, beforehand.

ab antecedente ( ). Same as ab ante.

ab antiquo ( ). From olden times; of old; from antiquity.

abatable. Capable of being abated. See abate.

abatable nuisance. A nuisance which can be eliminated. In fact, of course, all nuisances can be eliminated, if one is willing to pay the cost, including the cost of foregoing the profit from the abated activity. Hence the use of the term "abatable nuisance" often implies that the nuisance at issue could be ended at some reasonable cost, or should be ended at almost any cost, which further implies that a court would or should order its abatement. See also abate.

abatamentum ( ). See abatement of freehold.

abate. A word with at least three separate meanings, the distinctions among which are, alas, legally significant. The first meaning is to destroy, quash, kill, end forever. This meaning is intended, for example, when it is said that a nuisance, or (sometimes) a legal action, is to be abated.

A second meaning of abate, which also applies to legal action, is closer to "stop in its tracks," "temporarily derail," or (even) "slow down." The idea is that the abated thing is seriously interfered with, stayed, put into a coma perhaps, but that there are methods available to one who wishes to resusci- 
tate it. It is this meaning of abate which seems to be involved in plea in abatement: an objection to some formal aspect of a pleading which, if sustained, will "end" the action-but only until the proponent successfully repleads.

Naturally, these first and second senses of abate will tend to merge as raising an action from the legal equivalent of death becomes, in modern practice, easier. If bringing a "new" action after the original action is "killed" is no more difficult in fact than getting a temporarily derailed, or stayed, action back on the tracks, then it makes little practical difference whether abate has its first or second meaning. Hence the old distinction between "abate" as used in law (first meaning) and as used in equity (second meaning) is of decreasing modern importance.

There is, however, still a third meaning of abate: decrease; lessen; soften the impact of. This meaning applies in formulations like abatement of debt and tax abatement. In practice, and quite surprisingly, the first, most absolute meaning of abate-kill, destroy, etc.-sometimes almost merges with this third "softer" meaning, as where abatement of nuisance frequently turns out in practice to mean something like "cut down the annoying aspects of the alleged nuisance as much as one feasibly can." And see abatement of tax.

abatement of action. See abate.

abatement of bequest. An example of the meaning of abate, "to decrease or lessen." The phrase refers to a process designed to deal with the situation which arises when a testator makes bequests which, added together, exceed the total amount in the estate available for distribution. The normal abatement, in the absence of other testamentary directions, would involve a ratable decrease of each bequest: e.g., if legatees $\mathrm{L}^{1}, \mathrm{~L}^{2}$, and $\mathrm{L}^{3}$ were by the will left respectively $\$ 20,000, \$ 30,000$, and $\$ 50,000$ (the legacies together totalling $\$ 100,000$ ), but only $\$ 70,000$ were available for distribution, the legacies payable would each be abated to $70 \%$ of the originally stated amounts. Hence $\mathrm{L}^{1}$ would get $\$ 14,000, \mathrm{~L}^{2}$ would get $\$ 21,000$, and $\mathbf{L}^{3}$ would get $\$ 35,000$.

abatement of cause of action. In general, see abate. There is a special use of the term, however, which refers to the total extinguishment of a cause of action which depends upon the life of a particular person when that particular person dies, e.g., (in most jurisdictions) when the plaintiff in an action of defamation dies.

abatement of debt. A process similar to that described under abatement of bequest where, however, the insufficient fund is to go to creditors rather than to legatees.

abatement of freehold. This was said to have occurred when a stranger wrongfully entered a freehold after the death of the previously seised ancestor or testator, but before the entry of the heir or devisee. The latter's 
interest was not totally destroyed; he had legal remedies, notably a writ of entry, to procure the ouster of the abator.

abatement of nuisance. In general, see abate; nuisance. The phrase may refer to a physical act performed by a person injured by the nuisance, or by the owner of the nuisance, whether or not in either case done pursuant to court order. The phrase may also be used to refer to a court order that a nuisance be abated.

abatement of tax. A decrease in an assessed tax, frequently because of error or illegality in the original taxing process. But the decrease may under many common circumstances be $100 \%$ of the tax assessed; hence a tax may be "abated" also in the sense of "voided" or "eliminated."

abator. The interloper whose actions bring about an abatement of freehold. Possibly the term is also usable to describe someone who brings about an abatement of nuisance.

ab auctoritate ( ). From authority. See argumentum ab auctoritate.

abavia ( ). See abavus.

abavus ( ). A great-great grandfather. Abavia is the form for great-great grandmother.

abbacinate ( ). To blind by holding red hot irons before the eyes of the victim. The Latin is abbacinare ( ).

abbacy. See abbey.

abbess. See abbey.

abbey. The buildings and other lands (sometimes called abbey lands) of a Roman Catholic monastic order of monks or nuns, for the most part referring to the property of those orders organized under the Benedictine rule. The leader is called an abbot if the inhabitants are monks, an abbess if nuns. "Abbacy" may refer to the abbey, or to the abbot's rights, powers, and jurisdictions, i.e., "abbacy" sometimes bears roughly the same relation to "abbot" as "bishopric" bears to "bishop." Until the expropriation of church lands by Henry VIII in the early sixteenth century, a significant fraction of English land was concentrated in abbeys.

abbey-lands. See abbey.

abbot. See abbey.

abbreviate. As a verb ( ), "to shorten." As a noun ( ), a rarely used equivalent of abstract.

abbreviatio placitorum ( ). A collection of records of some English judicial proceedings which took place prior to the keeping of the Year Books (i.e., prior to the late thirteenth century). The earliest cases included are from the reign of Richard I (1189-1199).

abbrochment. Sometimes spelled abroachment or abbroachment. See forestalling (the market). 
ABC test. $\Lambda$ test for whether an employer is covered by workman's compensation law: If the persons he employes are (a) free of his control; (b) work away from his place of business; and (c) are customarily engaged in independent trades or professions, there is no coverage.

ABC transaction. A term used in tax law to describe one method of financing a real property (especially oil and gas) investment. The aim of the game is to substitute a lease for a mortgage such that the long term purchaser/investor realizes no taxable income during the life of the lease. The Internal Revenue Service has pretty much robbed the $A B C$ transaction of its tax advantage.

abdicate. To give up, or relinquish, a position of (usually high) responsibility and status before the expiration of the normal term. Its use is today normally confined to acts of reigning monarchs, but it is sometimes used of other high officials, though with some irony, e.g., Richard Nixon's "abdication." Abdicate may also be used to refer by extension to a failure or refusal to carry out a responsibility, e.g., "He abdicated his duty to care for the child."

abduction. The luring away by fraud or persuasion, or the carrying away by force or threat of force, of one person from another who has some legally cognizable right to the company of, or control over, the abducted. Insofar as abduction constitutes a crime or tort, its ambit is almost wholly confined to the family relationship, e.g., abduction of wife, ward, or child. It was never necessary that the purpose of the abduction be unlawful for legal sanction to attach. Indeed, the widest historical ambit of the offense seems to have involved the abduction of female children or wards for purpose of lawful marriage. Moreover, the offense being "to the relationship" and not to the person abducted, the latter's consent constituted no defense; thus even abduction effected by nonfraudulent persuasion might be unlawful. In modern times this distinction has become less important, as abduction has tended to refer mostly to removal of children under a certain age who cannot, in fact or at least in law, validly consent to the abduction (or, usually, to the intended purpose, e.g., cohabitation or marriage). Abduction of a spouse (other than by force-see kidnapping) has ceased to be of much practical importance, except in those jurisdictions which still recognize a cause of action in tort for alienation of affections.

abearance ( ). Behavior. In Blackstone, one of the two named species of the genus "preventative criminal procedure" was the magistrate-required recognizance (or bond) with sureties to keep the peace. See bond to keep the peace. The other was the "recognizance for good abearance." It covered not only breaches of the peace, but also certain other acts against good morals, e.g. "haunting bawdy-houses with women of bad fame." The closest modern equivalent to these "good abearance" requirements is to be found in the conditions attached to probation and parole. Indeed, the key 
modern change seeems to lie in the requirement that the restricted person be convicted of a crime before he can be bound to "be of good abearance."

aberemurder. In old English law, the most plain and downright kind of murder, to be distinguished from other less culpable kinds of homicide, e.g., the kind that took place in a barroom brawl. Sometimes written "aberemurdrum."

aberrant ( ). See abnormal; deviant.

abet ( ). To aid, help effectuate, facilitate someone else's action. Its most common use in law is with respect to abetting someone else's crime, for which the legal tag is aiding and abetting. See also abetter; accessory; and accomplice.

abetter. Generally, one who abets. An ancient use of the word referred to one who falsely and with malice accused another of murder or other felony, i.e., a perpetrator of a gross form of the tort of malicious prosecution.

ab extra ( ). From outside, e.g., evidence not in writing used to explain it would be "ab extra" evidence.

abeyance. In ordinary language "in abeyance" means "left hanging," or "not settled." Title in something is said to be "in abeyance" or "abeyant" when there is no existing person in whom it is vested. At common law it was a maxim that a fee could not be "in abeyance." And it is possible that the idea of title in abeyance is more generally a legal impossibility (except, perhaps, with respect to titles of nobility) inasmuch as if the question ever arose who owned something, i.e., had the ultimate power to control it, someone would eventually be found to do so. Ordinarily, then, what "in abeyance" really means is that it is not then necessary to determine exactly who "owns" something, because another or others have for the time being rights so extensive in the property that ultimate ownership is still an unimportant question.

abiaticus ( ). A grandson in the male line, i.e., a son's son. Sometimes spelled aviaticus.

abide. One primary meaning is "to dwell"; one abides in an abode. This is the primary meaning in phrases like abiding conviction, abiding faith, and abiding place. Another legal meaning of abide connects with the idea of obeying, willingly putting oneself in conformity with, e.g., to "abide the judgment" of a court. But there is a flavor of "await" in some contexts. For instance, the common phrase "costs to abide the event [or result]" found in appellate decisions which reverse and remand for further proceedings, means that the costs of the appellate proceeding (though not necessarily all costs of the whole proceeding) are to be paid by whichever party finally loses after those further proceedings are completed. Hence the phrase can be read to mean "the determination of who pays costs will await the final determination of the underlying action."

abiding conviction. A conviction, i.e., a belief, which is settled, fixed, "come 
home for good," so to speak. The phrase is sometimes used in instructing juries as to the state of belief they must have to convict beyond a reasonable doubt. Sometimes abiding faith is used. $C f$. abide.

abiding faith. Essentially the same as abiding conviction, i.e., settled belief, i.e., "faith" is not to be taken in its religious sense as in contrast to conclusions reached on the basis of empirical evidence.

abiding place. A place where one lives; an abode. See abide; domicil; residence.

abigeus ( ). Same as abactor.

ability. May refer (as may its cognate able) to any one of three linked concepts: 1. ability may mean natural ability, i.e., having the mental and physical equipment to do something, e.g., a person may not have the physical or intellectual ability to understand a proposed contract; 2 . ability may mean legal ability, i.e., a person may not be legally authorized to effectuate a legal act, e.g., a lower-level employee may not have the authority to enter into a contract which will bind his employer. Often meanings (1) and (2) are linked, e.g., an infant is legally unable to enter into a contract because his natural inability is by law presumed; 3 . in a very common legal usage, ability may mean financial ability; the person may lack the economic wherewithal to carry out an economic obligation. See, e.g., able buyer. See also capacity; competency; and entries beginning with, or containing, those words, e.g., criminal capacity; mental competency.

ability grouping. See tracking.

ability to act [or perform]. See ability; capacity.

ability to pay [debts]. See ability; insolvency.

ability-to-pay principle (of taxation). See taxation.

ability to support. An issue when divorce is sued for on grounds of nonsupport. The idea is that if the respondent can't support the complainant, he or she does no wrong by not doing so. In determining ability to support, however, there are ordinarily taken into account not only present earnings and wealth, but also earning power, i.e., if the respondent is physically and mentally able to work and earn, and if jobs exist, then he or she has "ability to support" even if not then owning or earning anything.

ab impossibili. From impossibility. See argumentum ab impossibili.

ab inconvenienti. From inconvenience. See argumentum ab inconvenienti.

ab initio ( ). From the beginning. Sometimes used to imply "thoroughly," i.e., as a rough equivalent of "from first to last," e.g., "The whole idea was silly $a b$ initio." See also trespass ab initio; unlawful ab initio.

ab initio mundi ( ). From the beginning of the world. The phrase appears (in translation) in many modern general releases, where reference is made to all claims of any kind or description which the releasing party may have 
against [the] released party "from the beginning of the world to the date hereof." As such, its use is an interesting example of a particular kind of legal drafting, one in which, out of caution, one specifies a range of coverage far in excess of the matter really at hand (usually a particular, recent claim is being released) because the area of excess is so far from the then present interest of either party as to make the expansive drafting appear to both of them as essentially cost free. Upon occasion, however, later developments make this expansive kind of drafting substantively and unpleasantly significant, e.g., when the giver of the release has forgotten another wholly unrelated earlier claim which, by its terms, the expansive release discharges. $C f$. a coelo ad centrum.

ab intestato ( ). Inheritance by intestate succession, i.e., from one who left no will. (The other form of inheritance, pursuant to a will, is referred to as ex testamento.)

ab intra ( ). From within. The obverse of ab extra.

ab invito ( ). Unwillingly; against one's will. A conveyance or transfer "ab invito" would therefore, unless mandated by law, ordinarily be invalid, since most such transactions are not legally binding if the result of force or threat of force.

abishering ( ). A privilege, sometimes conferred as part of a feudal grant, to be free of amercements within the stipulated location, and sometimes to receive or share in amercements collected from others. Also written "abishersing," "mishering," and "mishersing." Indeed, according to the Oxford English Dictionary, "abishering" is just an error in Rostel for "mishering."

abjudicate ( ). To deprive of title by judgment of a court. In early law, the term was widely used to designate what happened to the title of the losing party in an action founded on a writ of right. The Latin is "abjudicatio" ( ).

abjuration ( ). A formal renunciation or abandonment, ordinarily by oath. The most common use of the term in a legal context is in the phrase "abjuration of the realm," found in the oath to leave England forever, sworn by a person who had claimed sanctuary; the oath was required as a condition of his departing from his safe but confining spot. In modern times, abjuration is sometimes used to signify voluntary expatriation, i.e., abandonment of citizenship (e.g., one must "abjure" foreign allegiance when applying for U.S. citizenship), or even (though rarely) mere change of domicil.

able. See ability.

able-bodied. Whether or not a person is able-bodied depends on the use to which his body is to be put. If the question is military service, the body must be up to the demands of military activities. If earning a living is concerned, the person need only not be disabled to the point that he cannot do so. It would be a very rare context, therefore, in which being "able-bodied" would require physical perfection. 
able buyer. One with the financial and other ability to complete a purchase. It is usually not sufficient to constitute the status of able buyer if the person has only the possibility of raising the necessary money, either from sale or encumbrance of other property, or by borrowing from third parties under no obligation to lend. See also ready, willing, and able.

able seaman. A "rank" of merchant seaman, defined in the United States Shipping Code (46 U.S.C. $§ 672$ ). The rough British equivalent is "able-bodied seaman."

able to pay. Upon occasion a person will promise to pay "when able." This has ordinarily been interpreted as a valid conditional promise (i.e., not the clearly illusory promise that "when willing" would be), and that the promisor need not pay until, by some objective criteria, he is "able" to do so. It is in formulating those criteria of objective ability, and discovering if they are met, that most of the trouble lies, and thus an "able to pay" term can easily lead to expensive, fact-dependent litigation.

ablocate ( ). To rent out; to lease.

abnegate. To surrender or relinquish a claim, right or position. Especially in the form "abnegation," the word carries a flavor of humility and submission.

abnormal. Not normal, i.e., varying from some average, typical, ordinary state. There is no necessary implication that this variance is large or to be deplored, but in common usage the word implies substantial variation from the norm (to the point of qualitative difference or even opposition, e.g., "He's abnormal."), and it is a term almost always disapproving or perjorative. It should be noted that such a use of "abnormal" implies that "normal" (average, ordinary) and "good" are close to synonymous, which, of course, is not necessarily the case. An abnormal body temperature is indeed usually a bad one, because the human body can endure only a very restricted internal temperature range. An "abnormal" Nazi Storm Trooper, however, would most likely be a much better person than the "normal" variety. In brief, finding that something is abnormal only begins one's analysis. See also deviant.

abnormally dangerous. More dangerous than is usual with places, persons, or things of that general variety. The possibilities for legal significance are obvious, e.g., one may have no tort liability toward one who has knowingly continued to work in a place which is normally a dangerous place, but may if it is abnormally dangerous even for such a place. And statutes and often labor contracts give employees the right to cease work if their work place becomes "abnormally dangerous."

abnormal profit. See normal profit.

abogado ( ). One of the Spanish terms for "advocate" and the one which a member of the bar in the United States will generally use to describe himself to Spanish speaking communities. 
ab olim ( ). In ages past; formerly.

abolish. To eliminate, end, destroy utterly, and, by usual implication, to do so permanently. An office may be abolished ("The court of common pleas is hereby abolished,") as can a longstanding, deeprooted institution (e.g., slavery).

abolition. See abolish.

abolitionists. A term currently used to describe those persons interested in penology who espouse the abolition of prisons except for dangerous criminals, with "dangerous" defined so as to exclude more than three-quarters of current prison inmates from the category.

abominable and detestable crime against nature. A rather enthusiastic euphemism (sometimes shortened to "abominable crime") found in many nineteenth-century (and some current) statutes, referring to a not fully specified range of sexual crimes. The term seems to include any sexual relations between a human animal and a non-human animal involving any orifice of either. It also seems to include any sexual relations between two males, certainly any that involves penetration of the penis of one into the anus of the other, and most likely any penetration of the mouth too. It may also include any sexual act which involves the penetration of the male penis into any female orifice other than the vagina. It does not, at least traditionally, seem to cover sexual activities between females. Given the ambiguities noted above about what activities are covered, statutes employing it have been constitutionally challenged, sometimes successfully, on the ground of vagueness. Moreover, it is not clear how far the relatively recent constitutional doctrine of marital privacy will affect the prosecution of such acts between married couples. See also bestiality; buggery; sodomy.

aborigines ( ). A general term for the original inhabitants of a country, e.g., the American Indians in the United States, or the Ainu in Japan.

aborticide. A rarely used synonym for the crime of abortion.

abortifacient ( ). Anything used to bring about an abortion, but generally understood as referring to some drug or other ingested substance rather than to some physical object like a scappel or coat hanger.

abortion. Most broadly, to bring about an abortion is to interrupt the development of something so that it does not reach its fully developed and viable stage. Thus one can abort an airplane takeoff or, even more figuratively, a social movement (e.g., "The aborted student movement of the sixties."). Moreover, since the product of an abortion process is likely to be badly deformed by this interruption of its normal development, one can refer to any particularly badly bungled product as an "abortion."

The most common use of "abortion," however, and the one with most legal significance, is to refer to the interruption of the development of a human fetus so that it leaves the womb before it is capable of surviving outside. This can come about spontaneously, see miscarriage, but willfully 


\section{Leff Dictionary of Law}

to bring it about has often constituted a felony, the crime of abortion. In the early 1970s, however, severe Federal constitutional constraints were placed upon jurisdictions seeking to render the abortion of a human fetus criminal so that, roughly speaking, at present the state cannot declare abortion illegal at all with respect to fetuses in the first three months of pregnancy, and can do so only very exceptionally with respect to second-trimester fetuses. It is only with respect to final-trimester fetuses that a state can even approach the previously prevailing criminal-law total ban on the practice of abortion.

Abortion Act. One of the Uniform Laws, now superceded by the Revised Abortion Act, which is itself most likely superannuated by recent constitutional doctrine. See abortion.

abortionist. One who brings about an abortion. Most commonly used to refer to one who does so regularly, for compensation, and unlawfully. This last implication-of illicitness-may fade as the vastly increased scope and magnitude of lawful abortion becomes reflected in ordinary language.

abortive trial. A trial which, through the fault of neither party, fails to produce a verdict.

about. A word which, like more or less, approximately, and even de minimus non curat lex (to pick just three of the many possible examples), is used to cope with the fact that language is often more precise and accurate than the living acts it seeks to describe. To take an instance, let us say that $\mathrm{V}$ agrees to sell to $\mathrm{P}$ one thousand tons of steel. About one thing we can be reasonably sure: $\mathrm{V}$ will not succeed in doing so exactly. He will be at least a few pounds over or under. Nor, of course, is weight the only described quantity of potential legal significance unlikely, in practice, to be precisely met; it is also unlikely that $\mathrm{V}$ would be able to deliver land perfectly equalling one thousand acres, or that he could sail smack on the next high tide. Or rather, in each case, $\mathrm{V}$ could be precise and exact in meeting the magnitude specifications, but only at a cost in money, care, and time which nobody involved in the transaction really wants to see expended. That does not mean the magnitudes are of no importance, of course, but only that some variation is of little consequence given the cost and bother of compliance. In legal instruments, various techniques are adopted in an attempt to cope with this problem of necessary inexactitude. Perhaps the most common strategy is to remain silent as to the fact and extent of permissible variance, assuming no real problem will ever arise, leaving the solution of any problem that does arise to common sense accommodations. In such a situation, the parties (or courts, if it comes to that) will usually be able to figure out what is an important variation in the particular context. For example, if a contract were to read " 10,000 widgits each 1 c.m. \pm .0001 " it would be quite plain that a .0002 variation would be totally unacceptable with respect to widgit size while being quite acceptable with respect to widgit number. (That does not necessarily mean that the buyer would not complain abut the two-widgit shortage, or even deduct the price of the missing 
two, but that failing to deliver exactly 10,000 would not justifiably "bust the deal," the way a .002 variation in size would.)

It is not clear how much adding words like "about" or "more or less" changes the result, at least in those contexts (which are the most widespread) in which some range of variation would be permissible in any event. (Indeed, even adding "precisely" or "exactly" to the contract would most likely be unavailing to invalidate a delivery five pounds short on a 1000 ton order.) The chief practical effect of adding "about" would seem to be that within the applicable range of permissible variation, no price adjustment would be expected; if one got two fewer or two more widgits (or even acres) than called for, the parties would be deemed to have accepted the risk of that amount of variation either way. The chief prudential purpose of "about," "more or less," etc. is to make clear that the parties do not really expect perfect exactness in situations where a bad faith claim to the contrary might be feared. Consider, for example, how wise Shylock in The Merchant of Venice would have been to specify "about one pound of flesh," given the potential defense, later successfully pressed by debtor's counsel, that taking any amount more or less than one pound would be a fatal breach by the creditor.

The word "about" also has a special use as a term describing location. Thus something or someone "in or about" a place (e.g., a house or a factory) may not be exactly "in" or "on" but contiguous to, or just near to, that place. This has significance with respect to Workmen's Compensation laws. The same is true of something carried "on or about" the body of a person, e.g., burglar's tools or an illegal concealed weapon: It need not be precisely on the body, but it has to be very closely connected (e.g., in a satchel carried by the accused).

about to. An expression used to indicate extreme imminence; an occurrence just on the point of happening. Its use leads to ambiguity when the indicated occurrence itself is too complex a happening to be instantaneously accomplished. Someone "about to" contract, for instance, may be actually in the precontractual bargaining phases of a relationship, or already on the point of eliciting the magic "I accept your offer." Someone about to "remove property" may have just decided to do so, or just hired a truck, or just lifted up the first item for loading, or just completed loading, or just started the loaded truck-and so on. Thus "about to" must be taken to mean little more than "very soon," with legal significance dependent upon its specific context.

above. The primary meaning is spatial: "Above" means higher than. With respect to hierarchical organizations like courts, however, spatial position also denotes superior right and power: A court "above" is one with the right to control a court below. Also, when reference is made in a writing to a previous portion thereof, it is sometimes referred to as "above" (e.g., "The case of Jones $v$. Smith, above" (or "cited above" or "The above-cited case of ...")), even though in modern printed works, unlike ancient scrolls, some- 
thing previous in a text is not necessarily spatially higher. Lawyers and judges are fond in this context of using supra, which is just the Latin for "above." See also below and infra. "Bail above" has a technical meaning all its own.

ab ovo ( ). Literally "from the egg," i.e., from the beginning, i.e., a more richly metamorphic equivalent of ab initio. Whether the metaphoric reference is to the Roman custom of starting dinner with an egg, or amounts to an implied answer to the classic "which came first" question from the chicken's point of view, is by now indeterminate.

Abp. Abbreviation of Archbishop.

Abr. Abbreviation for abridgment.

abreaction ( ). A term in psychology, especially psychotherapy, referring to a process of reducing emotional tension by being brought in some way to re-experience a now suppressed happening (e.g., infantile trauma) which originally generated the tension. See also catharsis, for which "abreaction" is sometimes loosely used as a synonym.

abridge. To cut down, shorten. As a process carried out on written works, this is often accomplished merely by the selective elimination of portions of the work being abridged. Thus, for instance, it is proper to speak of one "abridging" his pleading. But frequently the process of condensation requires actual rewriting to decrease the bulk while preserving the basic content of the work. See also abridgment. "Abridge" can also refer to a process applied to things other than writings, e.g., liberties may be said to be "abridged" when they are limited by governmental action, and a reduction of awarded damages by subsequent order of a court is sometimes called "abridgment of damages." In copyright law, the position was once taken that an abridged version of a work was not an infringement of its copyright, but that has not been the law since the nineteenth century.

abridgment. In general, a shortened version of a work; what results from the process of abridging it. There is a more particular legal meaning of the word, however: "Abridgement" was also used by early writers almost interchangeably with the word "digest" to describe a shortened compilation and explication of the common law, e.g., Viner's Abridgment (24 volumes; late eighteenth century). A list of the major abridgments and digests of English law may be found in Jowitt (1977) under "Abridgment."

abridgment of damages. See abridge. $C f$. remittitur.

abroach ( ). See broach.

abroachment ( ). See forestalling (the market).

abroad. In international law and conflict of laws, "abroad" refers to a place other than that of the forum state. In an island like Great Britain, that would necessarily imply "overseas," and in common non-legal American usage that implication still exists, i.e., if a person in New York were to say 
he was going "abroad" one would assume he meant Europe, Asia, etc., rather than Canada or Mexico. Technically, however, those latter places would still be "abroad." It would be almost inconceivable, however, for a New Yorker to mean by "abroad" Oklahoma or Nebraska, even though they do provide different law and forums.

abrogatio legis ( ). The repeal or annulment of a law.

abrogation. The rendering of a provision in a legal document, or a rule of law, statutory or decisional, void, annulled, superceded, of no further force or effect. With respect to a contract, lease, etc., the parties can amend to abrogate any provision thereof, or a court might strike a particular provision, e.g., as unconscionable. Abrogation of a rule of law can be express or implied. If the former, the actor with the power to do so will just announce that the particular provision is no longer in force. At present, express abrogation effected on a statutory rule by a legislature would more likely be described as repeal, while express abrogation done to a court-made rule by a court would tend to be called overruling. If a court were to abrogate a statute, it could ordinarily do so only on grounds of unconstitutionality, and it would call the process something like "declaring unconstitutional." In fact, only the express legislative elimination of a judicial rule of law would be likely to be called "abrogation" these days. Abrogation, however, need not be done expressly. A statutory rule may lose its force because a later statute enacts a provision in conflict with it, even if the legislature did not in so many words declare the previous provision abrogated or repealed. Implied abrogation might also take place if a legislature passed a statute dealing with the same matter as a previous judge-made rule, even if the previous rule were not alluded to at all by the statute. Moreover, a court may very well abrogate or overrule a previous judge-made rule in a subsequent decision without announcing the overruling expressly, indeed without mentioning the effectively overruled ruling at all. And, of course, a statute declaring a particular statute unconstitutional may well effectively abrogate a large number of similar statutes which were not technically involved at all in the particular constitutional ruling. Last, it may be proper to describe a statute as "abrogated" when the purpose it was to serve is no longer possible, e.g., a statute regulating the hunting of a particular animal species which has subsequently ceased to exist. Naturally, in all these kinds of implied abrogations, difficult questions will arise as to whether in the particular instance the subsequent action in fact abrogated the prior rule, and if so to some extent, to what extent. The answers will frequently turn on very nice questions of contractual, legislative, and judical intent.

Some ancient, overfine, and generally no longer used distinctions among "derogation," "rogation," "subrogation," "dispensation," and "antiquation" are reproduced and discussed in the entry "Abrogation" in Jowitt (1977).

abscond. To slip away clandestinely, and ordinarily to go into hiding thereafter, usually for the purpose of avoiding the reach of the law. A debtor who goes into hiding, or slips out of the jurisdictional reach of his creditors with 
the intent to frustrate their collection efforts, is often referred to as an "absconding debtor," in which case the creditors may be entitled to use special procedures to ferret him and his property out. One particular kind of "debtor," the kind who achieves that status through embezzlement, is almost always said to have "absconded" when [he] takes off with his loot.

absconding debtor. See abscond.

absence. See absent.

Absence as Evidence of Death Act. One of the Uniform Laws. Adopted in only a few jurisdictions.

absence for seven years. See presumption of death.

absence from the state. See absent from [or out of] the state.

absence of jurisdiction. See want of jurisdiction.

absent. As an adjective, means "away" or "not present." In some contexts, it can imply nonexistence, e.g., "There is absent any motive for murder." Used as a verb, e.g., "He absented himself from the trial," the word indicates an intentional act. See also absent from [or out of] the state.

absente ( ). Absent. In old reports, a word used to indicate judges not present at the argument.

absentee. Sometimes implies that a person so denominated is not only not present in a particular relevant place, but cannot be found anywhere. But in other contexts there is no implication of hiddenness, e.g., "absentee voter" or "absentee landlord." See also absentee ownership.

absenteeism. Persistent tendency by an employee not to show up for work. If no valid justification is offered, absenteeism is ordinarily sufficient grounds for the employee's discharge, and, as a form of worker misconduct, grounds for denial of unemployment compensation.

absentee landlord. See absentee ownership.

absentee ownership. A situation in which the "owner," that is the person with the ultimate right to control a source of wealth, does not directly exercise that control, though he receives profits or rents from the property. The separation may be geographic (as with English owners of Irish estates in the eighteenth and nineteenth centuries) or conceptual (as with stockholders of modern corporations). There is some implication that absentee ownership contributes to exploitation (in the bad sense), but there is no clear evidence that active on-the-spot owners are likely to be less exploitative. The objection to absentee ownership may be nothing but a special case of the objection to any separation between labor and the fruits thereof. See labor theory of value.

Absentees' Property Act. One of the Uniform Laws. Adopted in only a few jurisdictions.

absente veo ( ). In the absence of the defendant. 
absent from [or out of] the state. A phrase important for purposes of most statutes of limitations (see limitation of actions) and not quite as selfexplanatory as it might seem. Many such statutes contain a provision that the running of the statute is tolled (i.e., suspended) while the defendant is "absent from the state" or "absent out of the state." In some jurisdictions, however, mere temporary absences don't count. In others, the defendant is not "absent" for this purpose if service of process could nonetheless have been successfully effected upon him during his absence. In most instances it has been held that the tolling applies even to defendants who were nonresidents at the time the cause of action accrued.

absentia. See in absentia; administration durante absentia.

absent without leave. See AWOL.

absinthe ( ). An alcoholic beverage flavored with, among other things, the aromatic herb wormwood. Genuine absinthe (there are innocuous imitations) is allegedly capable of turning a brain to mush and a liver to stone substantially more quickly than ordinary alcohol, and is therefore banned in the United States.

absoile. See assoil.

absolute. A word frequently used in legal contexts. As will be seen in the specific entries beginning with "absolute" which follow, its principal function is to negative any possible implication that the particular legal act (e.g., acceptance, conveyance, delivery, judicial decree) might in some way be temporary, conditional, restricted, partial, encumbered, or unperfected. The word is sometimes used even when that which it modifies contains within itself a message of absoluteness, e.g., fee simple absolute. As will also be seen from the ensuing entries, however, not all "absolute" things are identically, or even equally, "absolute." Nonetheless, with respect to rights and property interests, the central implication from the use of the word is that the interest is total and unqualified, such that no other person may lawfully interfere with its enjoyment without the consent of the owner.

As a philosophical term preceded by the definite article, it is roughly equivalent to "the ultimate reality," in contradistinction to the mere appearances of the finite world.

absolute acceptance. "Acceptance" here is short for acceptance of bill of exchange, which will be "absolute" (i.e., unqualifed) unless conditions or qualifications are affirmatively written on the bill.

absolute advantage. A term in economics, especially common in the language of international trade. A country or region is said to have an "absolute advantage" over another when it can supply gooods or services more cheaply. For instance, Honduras has an absolute advantage over Switzerland in the production of bananas, while Switzerland has an absolute advantage over Honduras in the supply of financial services. It makes economic sense for Honduras to produce bananas and buy its financial services 
elsewhere, and for Switzerland to do the same in reverse. Indeed it is this variation in advantage which fuels international trade.

It is often the case that a country can produce more than one thing more cheaply than another, i.e., have multiple absolute advantages, e.g., Honduras may be able to produce both bananas and wicker baskets more cheaply than Switzerland. If, however, Honduras can produce bananas very much more cheaply, and wicker baskets only a bit more cheaply than Switzerland, it is economically wise for Honduras to concentrate on banana production. In that product it is said to have not only an absolute advantage but a comparative advantage too, i.e., its absolute advantage is comparatively greater in bananas vis-a-vis wicker baskets.

It should be mentioned that advantages, whether comparative or absolute, are not necessarily permanent; it can be wise to produce something in which one has no advantage, if that will give one a valuable advantage in time. Moreover, producing only one thing, even if one has a strong comparative advantage in its production, can be a mistake for the same reasons it can be a mistake to put all one's eggs in one basket, or all one's investment assets into the securities of one company.

The language of absolute and comparative advantage is also sometimes used to describe relationships between firms, e.g., "United States Steel has an absolute advantage over Aluminum Corporation of America in the production of steel plate."

absolute assignment. An assignment which transfers title outright, and not just as security for an obligation.

absolute conveyance. An unconditional conveyance, meant to finally vest title in the recipient. That does not mean, of course, that the conveyance could under no circumstances be revised or undone, e.g., on the grounds of fraud; it does mean that the transfer is not a conditional conveyance. Moreover, it should be emphasized that a conveyance which is not "absolute" is not therefore in some way defective or ineffective. If, for example, a conveyance is made subject to conditions, it will still vest subject to those conditions.

absolute convenant. A covenant (promise) not stated as being subject to any conditions.

absolute deed. See absolute conveyance.

absolute deed as mortgage. An absolute conveyance which is no such thing. The instrument delivered has the form of an absolute deed, but it is understood to be, and given effect as, a conveyance only for security, i.e., a conveyance subject to the condition that if the debt be paid, the property again belongs to the putative conveyor.

absolute delivery of deed. Actual manual delivery of a deed, with intention of giving up all rights in the deeded property and vesting them in the grantee. The hand delivery part seems to have little modern legal significance; mailing the deed with the same intent would seem to have the same effect as a hand-to-hand transmission. 
absolute divorce. Technically, denotes nothing more than does the word divorce unmodified. The modifier "absolute" is most likely attached to distinguish the final decree of dissolution of the marriage from less thorough or less final attempts to cope with marital breakdowns, e.g., divorce a mensa et thoro; judicial separation. More particularly, in England and in at least some U.S. jurisdictions, it is the practice to enter decrees of "divorce" that nonetheless do not become final for some stated period (perhaps in the hope of a last-minute reconciliation). In English practice, that preliminary non-yet-final order is called a rule nisi which, after the requisite time has passed, becomes a rule absolute. One might theorize that it was an easy progression from "rule [of divorce] absolute" to "divorce absolute" to calling the final situation an "absolute divorce."

absolute estate. An estate in real property of which the owner has total, unconditional, unqualified dominion and control, including the right to transfer, either inter vivos, or by will, to whomever he chooses (in default of which the estate descends upon his death to his heirs). This "absoluteness" is, of course, still constrained by general law, e.g., the owner of an absolute estate has no more right to commit a nuisance thereon than the owner of, say, a life interest. See also absolute interest; absolute rights.

absolute gift. A final, vested gift, i.e., an absolute conveyance made with donative intent.

absolute guaranty. An unconditional guaranty. It is not necessary, of course, that it be totally unlimited or unrestricted, e.g., "payment of the debt of $\$ 10,000$ presently owing from $\mathrm{X}$ to $\mathrm{Y}$ is hereby guaranteed" may also be described as an "absolute guaranty."

absolute interest. An interest in property in general akin to an absolute estate in real property. See also absolute rights.

absolute liability. In general, see strict liability. When, in a Motor Vehicle Financial Responsibility Act or similar statute, it is provided that upon the happening of an accident the insurer's liability becomes "absolute," it means that the insurer may not raise against a third-party claimant any defense to its obligation based upon the terms of its contract with, or statements made to it by, the insured party.

absolutely. The adverbial form of absolute, frequently used to mean "certainly" or "without a doubt," e.g., (from the Constitution) "No State shall [impose any import or export duties] . . . except what may be absolutely necessary for executing its inspection Laws ....." or (colloquially) "So you know this man?" "Absolutely."

absolutely privileged communication. See absolute privilege.

absolute monarchy. See absolutism; monarchy.

absolute monopoly. A species of monopoly in which one firm controls the entire output of a service or commodity for which there is no substitute. This is an exceedingly rare situation in any real economic world of any 
complexity and development. It may be best to consider absolute monopoly, like most absolutes, as a theoretical construct, the limit toward which all monopolization tends but cannot reach. See also oligopoly.

absolute nuisance. A nuisance for which one is liable without reference to negligence, and as to which contributory negligence is no defense.

absolute owner. The owner of an absolute interest in property. For certain purposes, e.g., with respect to property insurance, it is not improper for a person owning property jointly or even severally with another to describe himself as "absolute owner" thereof. Moreover, at least for insurance-law purposes, a vendee in possession of property under an executory contract may also properly be described as an "absolute owner."

absolute pardon. A pardon to which no conditions are attached.

absolute privilege. In the law of defamation, a total immunity to liability on account of written or spoken words, even if knowingly and intentionally false, and communicated with malice. Examples include statements by judges in the course of judicial proceedings, and by Gongressmen during legislative proceedings.

absolute right. A right may be called "absolute" merely to distinguish it from one which is relative, or contingent, or not yet finally vested. See absolute. But there is another, further meaning of "absolute right" in which "absolute" almost means "natural" (in the sense of natural law), i.e., not given by positive law, but prior and perhaps superior to it. It is sometimes said, for instance, that the right to do with one's property what one will, to enter into contracts, and to refuse to enter into contracts are "absolute rights" in this more absolute sense. The attendant implication is that these rights cannot be taken from a person, or their exercise severely limited, without the person's consent. Indeed, it has sometimes been thought that injuries inflicted on another by the exercise of these "absolute rights" are not actionable. There are, however, no rights "absolute" in this strong sense. One is not entitled to do whatever one wishes with one's property (see, e.g., common law tort; nuisance; zoning.) One is not entitled to make any contract (see, e.g., illegal contract; antitrust acts.) One is not even under all circumstances entitled not to enter into a contract (see, e.g., Civil Rights Bill; common carrier). Indeed, in almost every imaginable situation it has been held that law can interfere with a person's rights. Nonetheless, certain rights do seem more "absolute" than others. They may remain in fact only relative, but it seems that more governmental explicitness, explanation, justification, and, often, due process of law, is required to affect them than to affect other citizen activities.

absolute rule. Same as rule absolute.

absolute warranty. In a sale of personalty, a warranty to which no conditions are attached. In a deed of real estate it is, in effect, an assurance that the 
title being conveyed by the grantor is the paramount title, and that the grantee and his heirs will never be ousted by a claimant with a better right.

absolution. In Canon Law, official forgiveness and remission of sins. In Civil Law, acquittal of an alleged crime.

absolutism. In political discourse, a mode of government in which some very large fraction of total and final power is held by a person, or by a relatively small group, class, or faction. It is necessarily not a very precise concept, as it is impossible to stipulate how large a fraction of ultimate power must be in the hands of how small a group for the result to be called an absolutism. It is difficult to imagine an actual government in which a single person had the actual power to do anything; at some point aggregations of others would be likely to succeed in checking at least some impulses of the "absolute" ruler, and he would respond to some extent to that risk by some degree of self-restraint. But Stalinist Russia and Hitler Germany may have come close to being historical examples of absolute absolutisms. Perhaps the best way to understand the term is to see it as what one uses to describe that form of government most sharply distinguishable from a polyarchy or checks-and-balances kind of political system.

absolve. In one sense, roughly the same as acquit, but not suggesting as strongly that the absolution is the result of some legal proceeding. It would be proper, for instance, to say, "His employer absolved him of any responsibility for the accident." "Absolve" may also be used to mean "set free" or "release," e.g., one can be absolved of a debt or other obligation.

absorb. To sop up, or draw into itself. In some uses, the implication is that an absorbing person is the gainer, e.g., "Over the years he absorbed all of her wealth." But it is also possible to use the word to signify the taking onto oneself a cost or burden, e.g., "OK, you pay the postage and I'll absorb the tax."

absorbed tax. A tax on goods or a transaction not separately charged to the buyer (but reflected, ordinarily, in the overall price charged).

absque ( ). One of the Latin words for the preposition "without."

absque aliquo inde reddendo ( ). Latin for "without receiving any rent therefrom," a phrase identifying a free grant of lands from the Crown.

absque damno. See injuria abseque damno.

absque hoc ( ). Literally, "without this," a term of art used in common law pleading. See special traverse. When the pleading was in Law French, "sans ceo quo" was used.

absque impetitione vasti ( ). See without impeachment of waste.

absque injuria. See damnum absque injuria.

abstention. A doctrine under which federal courts will not enjoin or interfere with certain state administrative or judicial processes, especially state criminal prosecutions, in the absence of specially compelling factors. What those 
factors are or ought to be is, as one might imagine, hotly debated and still unsettled.

abstinence. In general, self-denial, especially of some pleasurable activity. Abstinence may be indulged in either out of a belief that the superficially pleasing (e.g., alcohol or sex) is really destructive of body or soul or that present abstinence will lead to the opportunity for more or better pleasure in the future, e.g., delaying the gratifications that can be bought with money by saving it instead of instantly consuming what it can buy, perhaps lending it out or using it productively in the meantime. It has been said that interest and profit is the economic return to abstinence. See agio theory of interest. It should be noted that the first ground for abstinence is really a special case of the second.

abstract. As a verb: (1) to remove, with an implication of stealth, and hence a further implication of wrongfulness e.g., "The teller abstracted certain sums from the Jones account"; (2) to abridge by selecting from a larger work only those details relevant to a particular purpose (see, e.g., abstract of a fine).

As a noun: "abstract" refers to such resulting abridgement.

abstracter. One whose profession is to prepare abstracts of title.

abstract idea. It would be hard to imagine an idea which was not to some degree abstract. Nonetheless, the phrase is sometimes used to describe, with a touch of disapproval, ideas which appear incapable of any practical application. $C f$. abstract question; abstraction.

There is also a more particular legal meaning: an "abstract idea" is one which has not been rendered sufficiently tangible (e.g., by being written down) to be accorded copyright protection. But some "abstract ideas" may still be accorded legal protection against theft, e.g., by contract, or as trade secrets.

abstraction. A taking, with an implication of wrongfulness. See abstract.

An all pervasive intellectual technique in which one treats a complex entity or process or, indeed, any pile of empirical data, as if it were much simpler than one knows it to be. The technique itself is quite complex, but its basic move is to think and talk about something as if many things about it are not relevant for then present purposes, i.e., as if for present purposes they don't exist. We do that every time we talk about classes of things as if there were no differences among the members of the class, e.g., as if the class "cow" was made up of identical cows. In fact, of course, every cow is what she is, but for some purpose (e.g., not running into them with cars) they can be treated as "the same." Similarly, a chemist may choose to think of a gas as composed of perfectly elastic spheres of mathematical-point dimension which exert no force on each other except by collision. Or an economist may choose to think about transactions between people as being free of transaction costs. Or a lawyer may think about a rule of law as if all persons to whom it is addressed identically know about and understand it. 
In each case, the "as if" clause is in fact false, and known to be so, but for some purpose it may be wise, or even necessary, not to think about that. The chemist, for instance, may be making only gross calculations for some purpose to which the inaccuracy of ignoring a great deal of what modern science knows about atoms and molecules is of no practical importance. The danger in each instance is in falling into the belief that differences unimportant in one context are necessarily also unimportant in another, e.g., if an economist tried to apply directly what he learned about the behavior of persons in the absence of transaction costs to actual transactions, from which such costs are never absent, and are frequently significant. See also model. But it should also be remembered, especially by lawyers, that some "as if" beliefs are central to decisions of basic political import, e.g., that all persons are entitled to equal treatment by a legal system despite the actual differences among them, i.e., as if those differences (in loveability, or intelligence, or whatever) did not exist.

abstract of a fine. In the now obsolete common-law conveyancing method of levying a fine, the abstract consisted of a summary of the requisite writ of covenant, and the "concord," which together set forth the names of the parties, the real property being conveyed, and the basic terms of the agreement.

abstract of judgment. A short summary of the essentials of a judicial judgment.

abstract of record on appeal. A brief description of the previous history of a case being appealed, based on the record below, sufficient to show that the questions presented on appeal were presented in the prior proceedings, and sufficient also to render understandable what those quesitons were. Not all jurisdictions require this form of abstract of record, though it is always required that the appellant, in one way or other, let the appeals court know what he thinks the issues rightly on appeal are. If the appellee considers the appellant's abstract incomplete or misleading, he may file his own, which is sometimes called an "additional abstract."

abstract of title. A short account of the public record evidence of title to real property, containing a synopsis of all instruments and incidents (including conveyances, wills, liens, encumbrances, and judgments) bearing upon the state of the title. The abstract of title is prepared to be delivered by the vendor to the purchaser of real property, accompanied by a certificate of abstracter (and an opinion of vendor's counsel, based on the abstract), and receipt of an up-to-date abstract is ordinarily a precondition of the purchaser's obligation to go through with the purchase. In modern American practice, the requirement to deliver an abstract of title has to some extent been replaced by the practice of securing either a title insurance policy, or an opinion of counsel for the vendor based upon his own title search and not on another's abstract, assuring the purchaser that he will receive the 
interest being conveyed to him, free of all claims and encumbrances except those listed in the policy or opinion letter.

abstract on appeal. See abstract of record on appeal.

abstract question. A generally perjorative characterization of a matter raised by a judge or lawyer which does not bear on, or depend upon, the practical issue being discussed or decided. To characterize a question to the same general purpose, the modifiers "academic," "hypothetical," and "theoretical" are also often used. Sometimes "abstract question" is used to characterize what is presented by an action that does not constitute a case or controversy. And at least one meaning of "moot question" is essentially identical. It should be noted that the disapproving connotation depends upon importing "abstract" or "academic" discourse into a practical situation; there is nothing wrong, of course, with the discussion by academics of academic questions, or with the pervasive practice of practicing lawyers of chatting about the abstract when in, rather than at, the bar. See also hypothetical case.

abstract term. In traditional logic, a term that is a name of the common nature of many individuals, considered apart from the differences among the individuals, e.g., "humanity." The availability in ordinary language of abstract terms simultaneously serves efficient thinking and sets the stage for dangerous error. For an abstract term does not describe a set of identical individuals, but a group of individuals all of whom have one or more features in common. Thus the deployment of the abstract term is sensible only with respect to those situations to which the common aspects have relevance, and to which the unshared aspects do not. With respect to the abstract term "humanity," for example, the mere fact that all the members of the class are mortal, mammals, dependent on oxidation processes, etc. does not mean that no distinctions can intelligently be made among them for particular purposes, e.g., whether voting should be permitted no matter how young the "human" is, or freedom of contract should be allowed no matter how stupid (or crafty). Many particular legal problems deeply implicate the idea of the abstract term, e.g., equal protection, but the significance is much more fundamental, touching on the nature of law. See abstraction; category; classification; logical fallacies.

absurd. The word has no more precise a legal meaning than it has a general one. It is one of the words one uses to convey strong disagreement with the utility or intelligence of an act or belief. There are two primary branches of the critique "absurd," the logical and causal. One can say of a unit of discourse that it is absurd in the sense that it involves a serious logical error, e.g., the affirmance and denial of the same proposition. But one can also call an act absurd meaning that it is a very stupid way to go about getting the result one wants, e.g., if the aim of a statute is the relief of the poor, it might be called "absurd" to go about it by taxing indigents.

The most common legal use of "absurd," however, is as the semantic 
equivalent of raising one's voice during argument. That is, it is frequently the case that a legal writer, especially a judge, will call an intepretation or a course of behavior "absurd" when he cannot think of, or at any rate express, any other more particular or proper reason for avoiding it. Thus, the correct answer to the rhetorical "Would it not be absurd?" is often "No, as it happens, it would not." Hence, whatever one might think about using the word "absurd" oneself in legal argument, one should be rendered very suspicious when one encounters it.

abuse ( ). 1. The misue or overuse of a thing, causing damage to it. 2. The use of something out of improper motives or for an impermissible purpose, to the injury of another person. See, e.g., abuse of process. 3. When used to describe speech, "abuse" denotes harsh, harmful, berating, nasty discourse directed an another person. 4. In some contexts, "abuse" has distinctly sexual connotations. For instance, child abuse, while it may in statutes encompass several forms of improper physical injury to children, also is frequently used to refer to an adult's sexual activity with a child which may or may not fall short of sexual penetration. See also carnal abuse. And "self-abuse" is a standard euphemism for masturbation.

As a verb, abuse ( ) refers to the act of bringing about an abuse.

abuse of discretion. In numerous legal contexts, it is said that a person, usually but not necessarily a governmental official, has the discretion to do one thing or another, or not to act at all. Thus, many things are said to be "within the sound discretion" of a trial judge, or that it is "within the discretion of a district attorney" whether to prosecute or not. Moreover, there are arrangements called discretionary trusts, the trustees of which may be almost untrammeled in their discretion as to investments and disbursements. But no legal discretion is ever total, i.e., subject to no corrective action by any hierarchically superior institution. A trial judge or district attorney or trustee of a discretionary trust who made his "discretionary" decision as he did because he had been bribed to do so, would clearly be subject to correction (and discipline). The term "abuse of discretion," then, has no fixed meaning. It is what one calls a discretionary decision when one is about to set it aside for one reason or another. Depending on the context, those reasons will vary. Some discretionary powers may be so broadly conceived that only proven corruption will suffice to work an "abuse of discretion." Others may be considerably more circumscribed, so that a mere finding of "gross error" or even "lack of sufficient evidentiary support" will amount to an "abuse." But the word "discretion" would have no scope at all if the superior agency could successfully describe what was merely a decision different that the one it would have made as "an abuse of discretion."

abuse of distress. Using a chattel or animal, possession of which one has acquired by distraint (or distress), instead of merely retaining possession to enforce a duty owed by the owner thereof. One who is guilty of an abuse of distress thereby commits conversion of the chattel or animal. 
abuse of privilege. See excess of privilege.

abuse of process. A tort, the gist of which is the use of civil or criminal process to accomplish an ulterior end not properly attainable thereby, e.g., having someone arrested for a crime in order to force him to pay a debt. This tort is distinguishable from another, malicious prosecution, in that to make out an action for malicious prosecution one must prove that the process was initiated wrongfully (without probable cause, for instance or without any credible belief in its eventual success); but it will state a cause of action for "abuse of process" even if the process is justified, even, indeed, if the action is ultimately successful, if the process was initiated for an improper ulterior purpose.

abusive language. See abuse. "Abusive language" has been found, if extensive and intense enough, to constitute "cruelty" sufficient to justify divorce.

abut ( ). To end at, touch, as in "The lot abuts the highway." There is an old distinction in legal terminology that ends of lands were said to "abut," while sides of lands were said [to] "adjoin," but inasmuch as it is relatively arbitrary which part is an "end" and which a "side," the distinction is more curious than useful. And it may also once have been the case that land said to be "abutting" something had to be physically touching, actually contiguous, with it-unlike adjacent or adjoining land. In some usages, "abutting owner" was restricted to an owner whose property touches on public land, e.g., a highway.

abutments ( ). The structures at each end of a bridge which are in contact with the solid land masses on either side of the chasm the bridge was built to span.

abuttal ( ). The part of land which abuts another, equivalent to "boundary" or "border" as used of the relationship of lands of different states or nations.

abutting owner. See abut. See also fronting and abutting.

A/C. Abbreviation of account. Others are " $a / c$," "acc't," and "acc."

academic. When used to describe a school, or a course of study at one, the word is used to distinguish the program from a commercial or vocational program. Also used to describe a matter of no practical significance, e.g., "Since he's now dead, it's academic whether he is sane enough to write a new will." $C f$. abstract question.

academic freedom. A term of uncertain scope, generally describing the right of teachers not to be interfered with in connection with their professional duties. The core meaning most likely refers to the right of a teacher not to be fired or disciplined because what he teaches is politically or ideologically distasteful to his employers. It was, for example, a central complaint about McCarthyism that its insistence that teachers be fired if they were communists (or "reds," or "pinkos") was a violation of "academic freedom." It is not clear, however, that there are, at least as a matter of constitutional law, 
any special rights that academics have that are not shared by everyone else. It is true, for example, that under the first amendment a teacher cannot be fired by a state university merely because of his expressed political beliefs, but that is true of any government clerk too. Moreover, both can be fired for certain kinds of talk, a teacher for teaching that the earth is flat in geography class, and a clerk for verbally abusing his superior. Of course, teachers, like all other workers, can secure more rights than they have under the Constitution by contracting for them, and many teachers, particularly in universities, have done just that. In addition, teachers' professional organizations and accrediting organizations will bring sanctions against any educational institution which expresses or implements too narrow an idea of what academic freedom includes.

academic question. See abstract question.

academic year. Typically officially or unofficially reckoned from September through June, i.e., from when classes start after the long summer vacation to when they stop again before the next one. Hence, such years are named with two numbers, e.g., "the 1981-82 academic year."

academy. A word used with some frequency in the name of a school (e.g., "Deerfield Academy"), though only rarely applied to a college or university (but see "United States Military Academy"), or to a public school. "Academy" may once have described an institution fitting someplace between high school and college, but the word presently has no such special descriptive power, i.e., if one wants to call a school an academy one can do so, no matter what kind of school it is, high or primary, public or private.

accedas ad curiam. An old writ out of chancery directed to a sheriff for the purpose of removing an action of replevin from a feudal court (e.g., the Court Baron) or a local court (e.g., the hundred court) to a royal court.

accede ( ). To come to or assume a title or office, e.g., "He acceded to the Dukedom upon his father's death." Also to assent or agree to (with perhaps an implied touch of reluctance). See also accession.

accelerant. See boosted fire.

accelerated depreciation. See depreciation.

accelerated option. An insurance-industry term. Many life insurance policies provide that the insured may apply the dividends payable to him under the policy, as well as its cash surrender value, to the premiums owing, so as to pay up the policy prior to its maturity, or even to create endowment payments.

acceleration clause. A provision [in] an instrument of debt stipulating that upon any default in the performance of the obligations of the debtor, the whole debt will, at the creditor's option or automatically, become immediately due. Such a clause may operate quite harshly, for it is frequently the case that the debtor is able shortly to remedy his default but is in no position immediately to discharge the entire obligation. Hence there has been 
some statutory activity, especially in the context of consumer transactions, looking toward guaranteeing the debtor some time to make good his default without being subjected to the full rigor of the acceleration clause. Of course, creditors have much of the time forgone implement[ing] the clause when the circumstances of the debtor's breach seemed to justify leniency. See also acceleration of maturity.

For the treatment of the equivalent of acceleration clauses in real property mortgages, see equity of redemption.

acceleration endowment. See endowment insurance.

acceleration of estate. When a future estate vests more quickly than stipulated because a prior estate failed to come into existence, or terminated prematurely, it is said to have "accelerated." For instance, in a testamentary conveyance "to wife for life, then to $X$," if the wife renounces the will and elects to take her dower or statutory share instead, $\mathrm{X}$ will take immediately as if the wife had died, and X's estate would be said to have accelerated. But an estate is not "accelerated" just because a prior estate did not last as long as expected, e.g., when a young and healthy life tenant dies shortly after coming into his life estate.

acceleration of maturity. Essentially the same meaning of "acceleration" as in an acceleration clause, except that the acceleration of obligation is pursuant to the payee's discretion, the exercise of which need not be made dependant upon any default by the obligor.

acceleration of remainder. See acceleration of estate.

accept. See acceptance.

acceptance. Most generally, the favorable or at least resigned reception of a thing, idea, or proposition. In many contexts, e.g., that of the law of contracts with its "acceptance of offer," the meaning of the word approaches "agreement." The difficulty with the term (as with, e.g., "abandonment") lies in determining how much the acts or words effecting the "acceptance" must be based upon some knowledge and appreciation by the doer of what he is doing, and the legal significance thereof. Many "acceptances" in law are quite formal, almost ritual, acts, designed to bind the doer without much justification for later inquiry into his state of mind. See, e.g., acceptance of bill of exchange. In other contexts, however, the "acceptance" must be determined by examination of sometimes ambiguous words and actions. See, e.g., acceptance of goods. And see generally the entries beginning with "acceptance" below for examples of the sometimes treacherous variations in the meaning of the term.

acceptance by mail. See acceptance of offer.

acceptance for honor. See bill of exchange.

acceptance house. See bill of exchange.

acceptance in blank. See bill of exchange. 
acceptance of bill of exchange. See bill of exchange.

acceptance of charter. As with any other grant of rights, powers, responsibilities, etc., the grant of a corporate charter must be "accepted." That acceptance, however, may be express or implied from the actions of the grantee. Under older practice, when a corporate charter was specially granted to a particular person or persons, there was need for some manifestation of acceptance. Under practice pursuant to modern corporation laws, however, under which a specific formal application for a corporate charter is made, it is just assumed that when a charter applied for is issued it is accepted.

acceptance of check. See bill of exchange.

acceptance of dedication. See dedication.

acceptance of deed. Tender or even delivery of a deed to property is not sufficient to pass title thereto; there must be some manifestation, by word or act, by the recipient that he accepts the tender or delivery. There is rarely a problem in making out this acceptance, inasmuch [as] a very clear "acceptance" is completing the tender of a deed by formally taking possession of it, and the script of the usual real estate closing provides for the formal acting out of that mode of "acceptance of deed."

acceptance of draft. See bill of exchange.

acceptance of gift. Some manifestation by the donee of a gift that he is content to receive it. As usual, this state of mind may be explicit or implicit, and expressed by words or deeds, notably by exercising dominion over the subject matter of the gift. In the case of a gift inter vivos, where actual delivery is ordinarily required to render the gift valid, manual acceptance by the donee will tend to supply the evidence of acceptance. But in other contexts no such obvious dramatization of acceptance is necessarily provided, e.g., with respect to a testamentary gift. Certainly, not all gifts should by presumed to be accepted by the donee, for some gifts carry responsibilites along with them; others may, if accepted, divest the donee of a preferable legal entitlement (e.g., a testamentary gift to a widow which, if accepted, will prevent her from taking her statutory share of the estate); and still others, if accepted, may have unacceptable tax consequences. So it is not at all foolish to require that there be some evidence that the donee has indeed accepted this "free benefit," for it may be for him neither free nor even, in the net, a benefit.

acceptance of goods. In the law of sales, the buyer's "acceptance" of the goods may effect a loss of certain claims and defenses which he might otherwise have, e.g., that the goods did not conform to the specifications in the contract of sale. A great many commercial disputes involve whether the buyer has in the particular case "accepted" the goods, i.e., whether he has expressed, under conditions of sufficient knowledge and understanding, that he is content to receive the goods as fulfilling the seller's obligation. The U.G.C. addresses itself explicitly to what will constitute "acceptance of 
goods;" indeed, § 2-606 is so titled, and ensuing Code sections deal with other special problems involving such "acceptance."

acceptance of issue. See similiter.

acceptance of nomination. A nomination to political office, and indeed the office itself, is frequently enough [of] a burden rather than a benefit, that one may not lightly presume that the proposed nominee will accept the nomination. Hence, to avoid the confusion to the electoral process of having a person unwilling to campaign or serve involved in an election, it is often provided by law that a formal written "acceptance of nomination" must be filed by the nominated candidate with some government officer before his name will be permitted on the ballot. $C f$. acceptance of office.

acceptance of offer. One of the critical moves in the contract formation process. Assuming the existence of consideration, and parties with legal capacity, the acceptance of an offer creates a contract. "Accept" in this context, then, is closely cognate to "agree," and thus runs into all the difficulties to be expected when the idea of agreement is broached. The situtation is this: The offeror projects toward the offeree words proposing a transaction, i.e., the "offer." The offeree replies with other words. Are those words an "acceptance" such that there now exists a contract, and if so, what are the terms thereof? The first question involves the content of the offeree's replying words: How closely need they approximate the words of the offer, how much in the way of new matter may be added, before the reply is not an "acceptance" of the offer, but a "counteroffer," i.e., a new offer which must now be accepted by the original offeror (now the new offeree) before a contract will arise? See also battle of the forms. The second cluster of problems may arise even when there is no possible claim that the offeree's reply could be construed as a counteroffer, e.g., when it takes the form of an oral "I accept your offer," or a written signature on the offering document. The key question then is this: What is the relevance, if any, of the offeree's subjective understanding or intention once he has apparently agreed to the offer? The modern answer, which is sometimes called the "objective theory of contract," has been that if the offeree, having received a communication which a reasonable person in his position would understand to be an offer, communicates a reply (which may take the form of words or deeds) which a reasonable person in the position of the offeror would take to be an acceptance, then [he] has accepted the offer, and is bound to all of the terms thereof. This is the case even if (a) he did not subjectively understand the terms of the offer (or indeed that it was one); or (b) he did not subjectively mean to accept the offer. This view of "acceptance of an offer" constitutes an almost perfect exemplar of the philosophical concept of a performative utterance.

The U.C.C., notably in \$§ 2-204, 2-206, and 2-207, contains provisions directed toward offer and acceptance and some of the problems mentioned above, at least with respect to contracts for the sale of goods. Moreover, the rigor of this objective theory has from time to time been softened with re- 
spect to persons having formal capacity to contract, but arguably lacking full power to protect themselves in the making of contracts, e.g., consumers.

acceptance of office. A manifestation of willingness to serve in a capacity to which one was appointed or elected, ordinarily taking the form of going in and getting on with the job. $C f$. acceptance of nomination.

acceptance of performance. Perhaps more accurately put, acceptance of less than performance. When one is legally entitled to some performance and knowingly accepts some other or lesser performance, then one may thereby lose claims arising out of the other party's failure to perform exactly as obligated, e.g., an acceptance of goods when one knows that the goods delivered are not the goods promised. How knowledgeable the accepting party must be to bring about such loss of the right to demand full and perfect performance, and the conditions under which that loss will turn out to be permanent, are complex questions. Cf. estoppel; waiver. Sometimes the questions are explicitly dealt with by statute. See acceptance of goods.

acceptance of plea. When the defendant in a criminal action seeks to plead guilty, that plea must be made to a judicial officer for his formal acceptance. It is the duty of the judge to ascertain that the plea was made voluntarily, not under coercion, and increasingly of late (especially in the federal courts) accurately, i.e., that it is not a plea of guilty to something not done by the defendant, offered by him solely to avoid the risk of conviction of a more serious offense. See plea bargain.

acceptance of risk. A rarely used variant expression for the tort concept of assumption of risk.

acceptance of service. May be used merely to describe the cooperative behavior of a person to whom service of process is tendered by a process server, e.g., holding out a hand to take the proffered paper rather than waiting to have it formally thrust at him. But more commonly the term refers to a formal acknowledgement of service of process made even though service has not actually been effected, so as to allow the formalities of service to be dispensed with. The jurisdiction so conferred is the same as would arise from actual, physical service.

acceptance supra protest. See bill of exchange.

accepter ( ). Also spelled "acceptor." May be used to describe anyone effecting a legal acceptance of some sort or other, but the most common legal reference is to one who accepts a bill of exchange.

accepting wagers. Taking bets on matters of chance, e.g., the outcome of a horse race before it is run. The implication is that the acceptance of wagers is a more or less regular activity, and as such it is usually statutorily declared a criminal (ordinarily misdemeanor) offense (in which statutes "accepting wagers" may be part of the definition of the offense). See bookmaking. Not all wagering, however, is unlawful. In some jurisdictions the 


\section{Leff Dictionary of Law}

government itself lawfully accepts wagers, as in the case of a state lottery, and other jurisdictions have specifically validated the practice even when privately operated, though ordinarily under extensive governmental regulation, e.g., in the gambling casinos of Nevada and New Jersey. Moreover, not all accepting of wagers on matters of chance is seen as unlawful gambling. Insurance companies, after all, in effect regularly "bet" that insured events will not come to pass more frequently than the premiums they charge can cover. And stock market operations also include a large element of attempting to outguess other persons about unpredictable future states of the world. Indeed, it has been stated that "the gambling known as business looks with haughty disdain upon the business known as gambling." See A. Bierce.

acceptor ( ). See accepter.

acceptor for honor. See bill of exchange.

acceptor supra protest ( ). See bill of exchange.

access ( ). In general, "a way to get there." The destination may be a piece of land, in which case the access may be an easement of access over someone else's land. Or it may be a murder victim whose availability to the suspect is relevant, e.g., "He had both motive and access." A very common legal use of "access" has to do with the frequently important question (e.g., in actions for divorce on the ground of adultery) whether a husband could possibly have impregnated his wife at the relevant time. See presumption of access.

accessary ( ). Variant spelling of accessory.

accessio ( ). In Roman law, a method of acquiring property, which includes what would be covered by both accession and accretion in AngloAmerican law.

accession ( ). 1. Most broadly, a doctrine by which the owner of property gets title to everything his property produces, or that is attached to it, either naturally or artificially. "Adjunction" is sometimes used synonomously. Hence the doctrine encompasses such diverse things as the addition to real property produced by the gradual deposit of solid matter by running water (see also accretion; alluvion; avulsion; reliction), the acquisition by the landholder of personal property immovably attached to reality (see fixtures); the right of an owner of a female domestic animal to its young as born; and, even more generally, the right of the owner of property to its income. Naturally, ownership of all accessions can be fixed by contract, and that contract may be express or implied. Hence, it may be provided that the owner of the impregnating male domestic animal is entitled to some part of the value of the young born to the other's female, and it would, after all, ordinarily require a mistake of some kind for a person to add property or labor to another's property without there being some express or implied agreement as to payment therefore, or ownership of the improving addi- 
tions. Nonetheless, in the apparent absence of any such agreement, the tendency of the law is still to give title to produce of or attachments to property to the owner thereof (as in the law of fixtures), though perhaps not as automatically or rigidly as under earlier law. See also accessio; accretion; specification. 2. In international law, accession to a treaty is essentially the same as adherence to one. 3. Accession may also refer to the coming into possession of a position or dignity, e.g., "At the accession of George V ...."

accession rate. A term in economics for the number of additional employees hired during a specified period, expressed as a percentage of total employment. It is considered an important indicator of business activity, for the higher the accession rate the higher the rate at which business is purchasing labor for current and future production. Also called "hiring rate."

accessio possessionis ( ). See tacking.

accessory ( ). In the criminal law, an accessory is, most generally, a person in some manner involved criminally in the perpetration of a crime, but not actually present at the time and place the crime is committed. The presently important subcategories of the status are "accessory before the fact" and "accessory after the fact." The former refers to a person who, having the requisite scienter for the commission of a crime, in some way aids the principal criminal actor, but only prior to the actual commission thereof. The requisite participation is often hard to distinguish from that required for conviction as a conspirator. "Accessory after the fact" refers to a person who, with knowledge that a felony has been committed, with intent to do so in any way procures or attempts to procure the felon's escape. This ordinarily requires a more active role in the escape than that which would support a conviction for misprison of felony. Many modern criminal statutes treat an accessory before the fact the same as an actual perpetrator of the crime. Being an accessory after the fact is usually made an offense with a lesser penalty, and may not constitute an offense at all if the crime involved is only a misdemeanor. In earlier times, the law of accessories was much more significant, for an accessory could not be tried until the principal offenders had been convicted or outlawed. And there was even a category "accessory of the fact," being a person present at the crime, but not very actively engaged therein except, perhaps, in expressing encouragement. Both this third category of accessory, and the need for prior conviction of the principals, are now essentially abolished. See also abet; accomplice; aiding and abetting; conspiracy.

accessory after the fact. See accessory.

accessory at the fact. See accessory.

accessory before the fact. See accessory.

accessory building. A structure on the same land as another building which it complements or serves, e.g., a garage may be an "accessory building" to a 
dwelling house. It may not, however; the question of what constitutes an "accessory building" is ordinarily litigated in zoning cases governed by a statute that uses the term, and the results are not wholly predictable.

accessory contract. A contract made in contemplation of another contract, often as a step toward the effectuation of that other contract, e.g., a subcontract. See also accessory obligation.

accessory obligation. An obligation relevant but subordinate to another, not necessarily between the same parties, e.g., the obligation of a surety. See also accessory contract.

accessory use. Another term (like accessory building) usually found in zoning cases. It refers to a use of the zoned property relevant and useful to the primary permitted use and therefore itself permitted, e.g., a swimming pool on a residential lot.

accident. 1. A state of affairs or incident brought about by accidental means. Though the connotation is not necessary, perhaps because of the ubiquitous term "automobile accident," there is frequently some implication of violence or injury also connected to the term. See accidental for a more thorough discussion. See also inevitable accident; unavoidable accident. 2. In Aristotelian terminology, a property of a thing or concept which it has but need not have, i.e., a property not necessary to make it what it is. See Encyclopedia of Philosophy under heading "Logical Terms, Glossary Of." This meaning of the term is not particularly important in law (or, for that matter, in logic either these days). It does occasionally show up, however, in 19 th century and earlier opinions by judges wrestling with questions about "essences," including the legendary mutual mistake case involving the famous cow, "Rose $2 \mathrm{~d}$ of Aberlone," Sherwood v. Walker, 66 Mich. 568, 33 N.W. 919 (1887).

accidental bodily injury. See accidental.

accidental cause. A term frequently used to describe a cause to which no human negligence contributed, e.g., storms and earthquakes. $C f$. inevitable accident; unavoidable accident. See also accidental.

accidental death. See accidental.

accidental death and dismemberment insurance. A policy of accident insurance covering accidental death and accidental maiming, i.e., the loss of some discrete part of the body, e.g., hand, leg, eye, etc.

accidental death benefit. See accident insurance; double indemnity.

accidental injury. See accidental.

accidental means. A distinction sometimes used to be made between "accidental death" and "death by accidental means" as those terms figured in life and accident insurance policies. A death could be "accidental," in the sense of not forseeable, predictable, or intended, and still not be (as the policy required) "by accidental means," when the nearest cause was not 
itself an "accident." Hence, in one case in which the insured died of sunstroke after voluntarily going out in the sun to play golf, it was held that the rays of the sun were not "accidental means" of death within the policy, though the death was the accidental result of the exposure. This distinction has now been generally (and blessedly) abandoned.

accidental result. See accidental means.

accident and health insurance. A policy of accident insurance which also pays stipulated benefits when the insured becomes non-accidentally ill.

accident insurance. An insurance coverage under which the insurer will pay for losses occasioned by accidental personal injury or death. The policy may cover only accidents, or the accident coverage may be part of a broader policy, e.g., the accidental death benefit provided in some life insurance policies pursuant to which the beneficiary receives a larger amount (frequently the face amount-see double indemnity) if the death was accidental. The payment may be in a fixed amount, or may be designed to replace some portion of lost income, or to pay medical expenses, or some combination thereof. The key limitation in this policy coverage is that it seeks to exclude death or injury or incapacity brought about by "illness" as distinguished from accident, and to that end language on the order of "loss resulting directly and independently of all other causes, from bodily injuries effected solely through accidental means" is often included in the policy. Naturally, the distinction between inherent illness and external accident is frequently difficult to draw (on which see accidental; accidental means). The critical factor is most likely whether the claimant can point to an "accident" in its most ordinary-language sense-a fall, a crash, a bang, etc.-as in "automobile accident." See accident. Some accident policies are limited to particular kinds of accidents, e.g., vehicle accidents, but some are not, and are therefore called general accident policies.

accident policy. See accident insurance.

accident proneness. An apparent tendency of some people to be involved in more than their likely share of accidents. This may be a result of pure bad luck, but it is sometimes theorized that such people are inherently more reckless or clumsy than others, or that they have a subconscious desire to be hurt.

accident report. There is commonly a statutory duty placed upon all persons involved in accidents involving vehicles (including airplanes and boats) leading to more than trivial property, or any bodily, injury, to file with the police or other regulatory agency a report thereof. Many automobile accident (self-insuring and liability) insurance policies contain a similar requirement to file such a report with the insurance company. Many governmental and private enterprises also require by internal rule that employees involved in accidents, whether leading to injury of self, a fellow employee, or a member of the public, file reports thereof with superiors. As all of these accident reports are a rich source of admissions and declarations 


\section{Leff Dictionary of Law}

against interest, and are thus admissible under exceptions to the hearsay rule in subsequent litigation growing out of the accident, they are important to a great deal of tort and insurance litigation.

accipitare ( ). To pay a feudal relief.

acclamation ( ). See voice vote.

accola ( ). In feudal law, a sort of tenant farmer who came from out of the country (or perhaps even vicinity) to till land. An "accola" was thus distinguished from an "incola," who was an inhabitant of the place. "Accola" seems to have come in time to refer to any non-free agricultural tenant.

accollade ( ). The term is now used generally to describe some award, honor or compliment paid to a person, e.g., "The Medal of Honor is the nation's ultimate accolade." The word originally referred to the ceremony of conferring knighthood, especially the formal striking ( $c f$. accole, Fr. for "blow") on the shoulder, at one time with the fist, and later with the flat of a sword.

accomenda ( ). An ancient maritime contract pursuant to which an owner of goods entrusted them to the master of ship to sell for their joint account. The terms of the contract were such that the owner recovered his cost first out of the sales price, and then he and the master shared whatever profits there [were] over that.

accommodated indorser. See accommodation party.

accommodated party. See accommodation party.

accommodation. A process, or the result of one, in which a person moves from a situation he perceives as at the least exceedingly distasteful, and perhaps intolerable, to one he perceives he can "live with." Reaching accommodation implies that the affected individual has made some change in himself in order to endure, but in many contexts it is also implied that other changes in the situation have occurred, e.g., when two people "reach an accommodation," the clear implication is that they have settled their dispute mutually giving ground. There is a tendency to treat accommodation generally as a healthy process, because it functions as a conflict resolution mechanism, but the tendency should often be resisted: Not all conflict is a bad thing, for it frequently comes from a refusal to learn to live with evil, which refusal may be a good thing even counting the discomfort caused the refuser. Also, a favor. See accommodation party for "accommodation" in the context of commercial paper and negotiable instruments.

accommodation acceptance. See accommodation party.

accommodation bill. See accommodation party.

accommodation indorser. See accommodation party.

accommodation land. Land purchased upon which to erect buildings or other "accommodations" (e.g., an outhouse) to increase the value thereof, or of adjoining land. 
accommodation line. In the insurance industry, business taken on by a company as an "accommodation," i.e., a favor to a valued agent or broker, which would otherwise, under the usual standards of the company, be rejected.

accommodation maker. See accommodation party.

accommodation note. See accommodation party.

accommodation paper. See accommodation party.

accommodation party. According to U.C.C. $\$ 3-415$, an accommodation party is "one who signs the [negotiable] instrument in any capacity for the purpose of lending his name to another party to it." The key factor in receiving "accommodation party" status used to be that the accommodation party received no consideration for thus aiding the other party, the accommodated party, with his own credit. Under the U.G.C., however, the critical factor is not that the accommodation party is unpaid, but that he signs as a surety, and is subject to the different rules governing sureties in the law of commercial paper. An accommodation party may sign as an accommodation indorser, acceptor, maker, or drawer, and there may be, therefore, various sorts of accommodation paper, e.g., bills, notes, checks, etc.

accommodation train. A "local," as contrasted with an "express," but with some implication of its being a very local train indeed. What the railroad is most likely "accommodating" itself to is intense local political power along the accommodated route.

accommodation works. Bridges, gates, fences, roads, etc., erected and maintained by railroads for the benefit of the owners and users of property adjoining the railroad right of way. These are ordinarily required by the terms of a conveyance, or by a separate contract, or by law.

accompanied by licensed driver. Some preliminary auto driver's licenses (see learner's permit) require that the licensee not drive unless he is "accompanied by" a licensed driver, i.e., that the latter be actually present and reasonably capable of rendering advice and assistance.

accompany. To be closely associated with in space or time or both; to go along with. When a statute uses "accompanied," e.g., "threatening words accompanied by menacing gestures," it does not necessarily require simultaneity; very close temporal contiguity may be sufficient.

accomplice ( ). A broad term for a person associated with one or more others in the commission of a crime. Includes principals (in first degree and in second degree), aiders and abettors (see aiding and abetting), accessories and, loosely, almost everyone "involved." Because of its breadth of meaning, the word is not usually used technically, though it may show up in some statutes, e.g., those requiring that a person not be convicted solely on the basis of the testimony of an "accomplice." 


\section{Leff Dictionary of Law}

accomplish. To complete an act or attain an end, whether the performance of an obligation or some other act.

accompt. Variant form of account. Cf. comptroller; controller.

accord ( ). Agreement. See also accord and satisfaction.

accordance. Agreement. Very commonly employed in the phrase "in accordance with" specifications, rules, statutes, wishes, desires, instructions, etc. A way of saying "done properly and as directed."

accord executory. See accord and satisfaction.

according to law. The same as in accordance with law.

according to the tenor. In accordance with the tenor.

accordion word. A term occasionally found in a judicial opinion to describe a word, e.g., "assets," the meaning of which can (like the bellows of an accordion) be expansive or narrow depending upon the context.

accouchement ( ). The process of giving birth to a child.

account. A claim by one person on another, arising out of some transaction between them (e.g., loan, sale of goods) which created a debtor-creditor relationship, ordinarily evidenced by an entry on the books of the creditor. It is usual to refer to the parties as account debtor and account creditor. See also book account; mutual account; open account.

Also, a common law action to compel the defendant to account for, i.e., to state the amount and eventually pay over money of the plaintiff held by the defendant, usually in some special capacity, e.g., as agent or bailiff (though the action also lay between merchants). For various reasons, this common law action (also called accounts render) lost much of its vitality early, and was generally superceded by the equity action for an accounting. See $S$. Milsom (1969). Both the old action of account and its modern law-side equivalents, and the equity action for an accounting, are ordinarily best fitted for complicated situations requiring thorough investigation of what in fact is owed. They would hardly ever be necessary, for instance, for an ordinary commercial book account.

Also, as in "bank account" and "brokerage account," i.e., a regular relationship with an institution, ordinarily financial or governmental.

accountable. Liable to be "called to account," i.e., subject to being held responsible for something. See also liable; responsible.

accountable receipt. A form of receipt in writing by which the person receiving money or chattels not only acknowledges receipt, but makes himself accountable to pay or deliver some or all of that which he received to some third party.

account acknowledged. See account stated.

accountant. A member of a skilled trade or profession, learned and trained to create and maintain the financial records of an individual or organization. 
These operations range from reasonably simple and mechanical acts of organized entry of financial data, all the way through complex and detailed cost-accounting procedures. Especially because of growing governmentally mandated record keeping and reporting requirements, but also because of the internal needs of complex modern business and finance itself, accountants are indispensible to industry and commmerce. See also certified public accountant.

accountant's lien. A lien given by statute to an accountant to keep possession of books, records, or papers of a client upon which he has worked, until he has been paid what he is owed for his work. It does not entitle the accountant to sell the liened items, but only to keep them from the client. $C f$. attorney's lien; warehouseman's lien.

account book. A book in which accounts are kept. See also book of account. account creditor. See account.

account current. See current account.

account debtor. See account.

account for. In ordinary language, the term means to explain, most usually the cause of something, e.g., "The drought in June accounts for the rotten crop." But it also means to render an accounting, i.e., to describe the present status of something, usually a fund, over which one has been given power or responsibility.

In addition, to account for can mean to pay over, e.g., "The trustee was ordered to account to the beneficiaries for the loss occasioned by his negligence," i.e., to make amends or restitution.

accounting. What an accountant does for a living. Also an action, usually "in equity," to secure the determination, statement, and eventual payment of an account.

The action is particularly suited to disputes in which the claim is complex or uncertain; for simple accounts, in which the claim is for a reasonably certain amount, the investigative capacity of the action for an accounting is unnecessary. Thus, where a modern action in contract or debt is sufficient, the equity action will not be entertained.

accounting cost. "Accounting cost" differs from economic cost mainly by not treating as costs either opportunity cost or the costs of the effects of an action outside the entity whose books are being kept. $C f$. externality.

accounting office. See General Accounting Office.

account number. An identification number assigned to an account (3). The federal government favors use of the Social Security number of an individual as the account number for all his accounts, thereby easing its job of coordinating and correlating all of its interactions with that individual. Many private institutions have also found the Social Security number to be a convenient choice for account number, especially those obligated by stat- 
ute to report on the account holder's transactions (e.g., receipts of interest and dividends) to tax authorities.

account of whom it may concern. See on account of whom it may concern. account render. See account.

account rendered. A statement from a creditor to a debtor stating what is claimed to be owed. The most common ordinary language term is "bill," as in, "The bill from Sears just came in."

account settled. See account stated.

accounts payable. See accounts receivable.

accounts receivable. These are accounts owed to a (non-financial) business enterprise by its customers, and appear on the firm's books under that heading. They arise out of the business practice of shipping goods before receiving payment, which may not be due until ten to ninety days or even longer after shipment. The corresponding entries on the buyer's books would be accounts payable. See also accounts receivable financing.

accounts receivable financing. A method of receiving ready cash for one's accounts receivable before they are payable. Assume that a business enterprise is owed $\$ 10,000$, payable ninety days in the future. It could make good use of that $\$ 10,000$ now, perhaps to buy for a good cash price more goods to sell during a busy season. It may, therefore, sell its accounts receivable, i.e., sell its right to receive the payment thereof when it is due. This is ordinarily called factoring. Or it may merely pledge its accounts receivable, as security for a loan. This is also sometimes called factoring, but also called discounting. In either case, of course, the firm will not receive the full face value of its accounts. The financing party is foregoing the use of its money while it awaits the accounts' payment, and it will naturally want to get paid for that, as well as for the risk that it will not get paid at all. Hence it will charge "interest," either explicitly or by advancing or paying less than the face value of the accounts purchased, i.e., taking them at a discount. How much will be charged depends on general interest rates, and on the likelihood that the accounts will be paid cither by the account debtors or by the account creditor from whom the accounts were bought. The extent of that non-payment risk depends, of course, on the creditworthiness of the account debtors and of the creditor, and on the terms of the agreement between the financing party and the seller or pledgor of the accounts. If, for instance, the financing party is not to have any recourse against the seller with respect to unpaid accounts, then he will charge more for the increased risk of non-repayment. It should also be noted that when accounts are "sold," but there is recourse against the seller for any amounts not collected, the "sale" is hard to distinguish from a pledge.

accounts receivable insurance. An insurance policy which pays the loss suffered by a business when it is unable to collect its accounts receivable because of the destruction of its records. The usual peril used to be a fire 
burning up business books. Currently available policies also cover the risk that a computer memory core will erase itself, or otherwise become expensively amnesiac.

account stated. An agreement between two persons that one owes something to another, from which a promise to pay is ordinarily implied. (sometimes also called account settled, though that term might more properly be confined to accounts stated in which one of the parties has a duty to account to the other, e.g., an agent to his principal). The account stated frequently comes into being between persons who have many transactions with each other, leading to debts in both directions, some of which are disputed. The value of the account stated is that it can be sued upon by the person showing the net in his favor, and neither party may look behind a valid account stated so as to litigate the underlying transactions which it was designed to supersede. Sometimes "account stated" is used as shorthand for "suit upon a debt evidenced by an account stated," e.g., "Plaintiff brought an action for [or "on"] account stated."

accouple ( ). To tie or otherwise join together two theretofore unconnected entities, including people, i.e., to accouple may mean to marry.

accredit ( ). In international law, used to describe two processes concerning envoys to another country: (a) the process by which the envoy's own country authorizes him to act for it; and (b) the process by which the other country formally accepts the envoy, entitling him to the privileges and immunities of his status. See also diplomatic immunity; accredited.

accredited. When said of an educational institution, the term means that an organization with the power to do so has formally declared that the institution has met certain criteria which by law are required for its lawful, valid performance of certain ends. For instance, a law school must ordinarily be accredited by the American Bar Association before its graduates will be entitled to be admitted to the bar. In some cases, however, accreditation confers no right except to claim and advertise that accreditation, e.g., a law school accredited by the Association of American Law Schools.

accredulitare ( ). See purgation by oath.

accrescere ( ). To grow.

accretion ( ). A method by which riparian land, i.e., land touching upon water, may increase. Water sometimes carries particles of solid material which are deposited in such a way that land touching on the water is augmented. This accreted land belongs to the owner of the land to which it attaches itself or, if it never quite attaches (forming, instead, an island), to the owner of the water over the surface of which it peeps. See also accession; alluvion; avulsion; reliction. The person whose land is washed away only to accrete to another just loses it, unless, of course, it washes back.

The word "accretion" may also be used figuratively to describe some other physical or social process by which a thing or fund slowly grows. It is 


\section{Leff Dictionary of Law}

frequently dangerously imprecise to do so, however: When, e.g, the beneficiary of a life interest in securities is entitled to all "accretions," does that mean dividends, or capital gains, or both?

accroach ( ). An older word for "encroach" (see encroachment). In its old form, it seems to have had the special implication of power exercised without right or lawful authority.

accrual ( ). That which is accrued. For "accrual clause," see clause of accrual.

accrual basis. A method of accounting in which revenue is recorded in the period in which it is earned, whether or not it is actually collected in that period, and expenses are recorded when incurred, even if not paid until a later period. For instance if, on December 15, 1978, a company sold $\$ 10,000$ worth of finished goods, and also bought $\$ 5,000$ worth of raw materials, but didn't receive the $\$ 10,000$, or disburse the $\$ 5,000$, until January 15,1979 , it would record the $\$ 10,000$ credit and the $\$ 5,000$ debit as 1978 transactions. If one kept one's books on a "cash basis," however, one would not record the $\$ 10,000$ sale or the $\$ 5,000$ purchase until the monies were actually paid, i.e., they would be treated as 1979 transactions. Most businesses, and almost all large ones, keep their books on an accrual basis, and most are required to do so for income tax purposes. Naturally, sticky accounting problems inhere in deciding when revenues are "earned," expenses "incurred," and, for that matter, when both are "paid."

accrual of cause of action. See accrue. The concept is often important because a cause of action may "accrue" for the purposes of starting a statute of limitations running before any injury is apparent to the potential plaintiff.

accrue ( ). Something may be said to have accrued when, because of some act or (if the applicable statute or agreement so provides) merely through passage of time, a legal right may be founded upon it. Thus, e.g., interest may "accrue," i.e., become payable to the creditor, every ninety days, or a dividend on corporate stock may "accrue" when and as voted by the board of directors. And a cause of action may "accrue" when the necessary elements have been completed, e.g., for battery as soon as his knuckles meet your mouth, or for breach of contract as soon as plaintiff's performance has been tendered and defendant has refused to tender his. In these contexts (see also accrued water rights), the meaning of the term is close to "ripened," or even "vested."

accrued and unpaid taxes. "Accrued" in this phrase has pretty much the normal meaning of accrue, except that in some situations a tax may be "accrued" even if not payable until a later date. Thus, e.g., in a contract for the sale of real property, if the purchaser agrees to pay all taxes "accrued to the date of the conveyance," that would ordinarily include the ratable portion of property taxes to that date, even though not actually due and payable until after the conveyance date. 
accrued dividend. See accrue. A dividend payable with respect to common stock ordinarily "accrues" when the board of directors of the corporation says it does, e.g., "a dividend payable on June 1, 1978 to holders of record of the common stock on May 1, 1978." Thus it may be said to accrue in favor of such holders of record on May 1st, even though not payable, (or suable for) until after June 1st. See ex-clividend; accumulated dividend. Cf. accrued interest.

accrued interest. See accrue. It is ordinarily the case that one who buys a corporate debt instrument will find the price adjusted to take account of the interest "accrued" (in the accrued and unpaid taxes sense) to the date of his purchase, even though not payable until after the issuance or sale of the instrument.

accrued water rights. See accrue. In this context, "accrued" has a meaning particularly close to be vested, for the accrued rights are treated specially in, or even exempted from, whatever statutory provision is passed to affect rights to appropriated waters.

accruer clause. See clause of accrual.

accruing. When used as a modifier, has roughly the same meaning as ripening or accumulating.

Acct (or Acc't). Very common abbreviation for account. See also A/C.

acculturation. The process by which an individual, especially an infant, is brought to learn and internalize the characteristic beliefs and behavior patterns of his society.

The term is also used of groups which come into contact with other cultural groups, to describe their process of accommodation or assimilation.

accumulate. Rather a broad word, capacious enough to encompass some of the meanings of, e.g., accrete and accrue. It can mean "pile up," i.e., what happens when there is an in-flow but, at least temporarily, no out-flow. Frequently the term is important when a fiduciary is given the right or duty to "accumulate," i.e., to take the produce of the corpus of a trust (interest, dividends, etc.) and reinvest it, without necessarily making any current distributions to any beneficiary. See also accumulation.

accumulated dividend. This is a dividend which may be said to be accrued in the same sense as accrued interest. It is a much less common phenomenon, however, because as a general rule there is no obligation for a corporation to declare any dividend at all, let alone at any given time. Thus dividends ordinarily become "accrued" only during the period (usually quite short) between declaration by the corporation and payment. Since the corporation can avoid being obliged to pay a dividend it cannot afford merely by not declaring it, it will be relatively uncommon for a declared dividend to remain unpaid. There are, however, obligations called "dividends" which are not really discretionary at all, e.g., promised payments with respect to deposits in savings banks which payments are "really" interest. And the in- 
struments governing the rights of holders of preferred stock usually provide that while there is no duty to pay the promised preferred dividend, no dividend may be paid to holders of common stock until all promised regular dividends missed in the past are paid to the holders of the preferred stock. In that sense, then, there can be "accrued dividends" on preferred stock.

accumulated profits tax. A way of referring to those provisions of [the] Internal Revenue Code designed to penalize corporations which accumulate earnings beyond the needs of the business so as to avoid distributions to shareholders, who would thereupon be taxed on what they had received. It is a particular temptation to a close corporation so to accumulate, because the accumulated profits go to increase the value of the corporate stock which, when sold, will be taxed to the corporate owners only at ordinarily much lower capital gains rates. The tax law provisions are very intricate.

accumulated surplus. See surplus.

accumulation. What results when someone or something commences to accumulate. For steps taken at law to make sure that the impulse to produce accumulations does not get out of hand, see rule against accumulations.

accumulative. For this, and most terms so beginning, see cumulative and ensuing entries.

accumulative sentences. See consecutive sentences.

accusation ( ). In ordinary language, an expressed allegation that another has done something bad, made to the accused or to others. In law, "accusation" is more frequently used to refer to a formal charge that a person has committed a criminal offense. It encompasses at least formally filed charges (including the complaint and information), and also charges made to police and prosecutors by victims or other accusers of crime. Depending on local procedures, these latter may be informal, or require reduction to written or even affidavit form. An indictment is also a form of accusation.

accusatorial ( ). A term sometimes used to distinguish the common law system of criminal procedure from the civil law system, which is called inquisitorial. See also adversary system.

accusatory ( ). That stage of a criminal investigation carried on by police or other prosecutorial investigators after a particular suspect has been identified. The accusatory part of an indictment is that part which names the crime with which the defendant is charged.

accuse. See accusation.

accused. A person against whom an accusation of criminal activity has been brought, primarily used to refer to one who is the subject of a formal accusation, e.g., information or indictment. One may properly refer to the accused in a criminal case as the defendant, but it is not proper to call a defendant in a civil case an accused. See also alleged perpetrator. 
accustomed. Usual, ordinary, that which one is used to, e.g., "He was accustomed to having two drinks before dinner, which was served precisely at six." See also customary and entries so beginning.

AC-DC ( ). In modern sexual slang, refers to a person who is willing to take sexual satisfaction homosexually or heterosexually. Sometimes also used to refer to a homosexual who is willing to take either the active or passive role in sexual activity. See also androgyny.

acephalous ( ). Literally, "without a head," and by extension, "leaderless," with an implication of "just drifting."

ac etiam ( ). Literally, "and also." The words were once commonly used to introduce a statement of the real cause of action being sued upon when, in order to give the court jurisdiction, it was necessary to allege a fictitious cause of action first. For instance, the writ of trespass quare clausaum fregit gave jurisdiction to the Court of Common Pleas, but an "ac etiam" followed by additional allegations was tacked on to the writ to give some idea of what actually was the gist of the action. The use of an ac etiam clause became unnecessary when the fictitious forms of action were abolished by statute in 1832 . See generally legal fiction.

achat ( ). A purchase, or "deal," or contract. Also "achate."

achator (or achetor). See achat.

acherset ( ). An old English grain measure, thought to be roughly equivalent to one "quarter" measure, i.e., around eight bushels.

acia ( ). Hate; malice. Same as atia.

acid-test ratio. See current ratio.

acknowledge ( ). To perform an act which means "Yes, that's right, that's true; I must say, that's the case." In law, the term usually refers to some formal act made to clarify, authenticate, and make more certain a prior act by the person doing the acknowledging. See acknowledgment. But one can acknowledge a state of affairs informally and even unwillingly, e.g., "When these facts were brought to his attention, he acknowledged by blushing that he had been lying."

acknowledged before or to me. Language which almost always appears in the certificate of acknowledgment of the person or persons in whose presence a formal acknowledgment is made, testifying that the acknowledging party's act was made in the physical presence of the person certifying it.

acknowledgment. The principal noun form for the process of acknowledging, i.e., an admission or confirmation that a fact is as stated or alleged. In legal contexts, "acknowledgment" almost always refers to a formal statement before one or more witnesses by the purported signer of a legal instrument that he did indeed sign it, sometimes adding other circumstances, e.g., that it was signed "of his own free will, with the intention thereby to ...." When "acknowledgment" is used, it almost always implies that the state- 
ment was made under oath, but that is not strictly necessary. See, e.g., acknowledgment of will. See also certificate of acknowledgment, which is the formal statement signed by the party or parties before whom the "acknowledgment" was made.

Acknowledgment Act. One of the Uniform Laws. It deals with the requisite formalities for effecting an acknowledgment, and has been enacted by about a third of the states.

acknowledgment money. A sum payable by a copyhold tenant to the successor of the lord of whom he held the land, upon the death of the prior lord. It was, therefore, a form of death tax, but it went to the decedent's estate (or to his successor), rather than coming from it (or him). The term implies clearly, however, that the new lord, in accepting his tenant's acknowledgment of lordship, was thereby also acknowledging, i.e., confirming, the tenancy of the taxpayer. Similar payments (see, e.g., fine) became due from persons holding freehold and other feudal tenancies upon the lord's death.

acknowledgment of child born out of wedlock. See acknowledgment of paternity.

acknowledgment of debt. A statement by a debtor communicated to his creditor which admits the existence of the debt. The statement may expressly state an intention to pay the debt, but will usually imply such an intention. Such acknowledgments are legally most important with respect to alleged debts barred by either the debtor's discharge in bankruptcy or by the running of the applicable statute of limitations, for in some jurisdictions, under some circumstances, the "acknowledgment of debt" will revive the obligation to pay the otherwise barred debt. But the question is very heavily regulated by statute, and the governing rules go every which way as to whether the acknowledgment must be in writing, whether it must contain a new explicit promise to pay, whether the acknowledgment revives the whole prior debt or is limited to the amount acknowledged, etc. Sometimes the "acknowledgment" is really just a proposal for an accord (see accord and satisfaction), inasmuch as the debtor acknowledges the debt but only if the creditor agrees to be bound by certain conditions imposed by the terms of the acknowledging document. This variety of acknowledgment of debt is often called a "conditional acknowledgment" [of debt].

acknowledgment of paternity. An acknowledgment, but one carrying less [of] an implication of any need for a formal, intentional, deliberate act. A child may be acknowledged as one's own with all the formality of a sworn affidavit or an admission in open court, but more casual verbal statements, or even conduct toward and treatment of the putative descendant, will sometimes work an acknowledgment of paternity. The establishment of the relationship is important, of course, in divers legal contexts, e.g., claims for rights to intestate succession, support, etc.

acknowledgment of will. Under some statutory schemes, a testator must acknowledge under oath that the will and his signature thereon are genuine. 
It is also quite customary to say to the testator in the presence of the attesting witnesses something like "Do you acknowledge this to be your last will and testament?" to which his affirmative answer would be an acknowledgment. And if one or more of the witnesses did not see him sign, the testator will ordinarily have formally to acknowledge to them, before their signatures, that his signature is genuinely his.

\section{ACLU. See American Civil Liberties Union.}

a coelo ad centrum ( ). From the heavens to the center of the earth. Another, fuller form is "Cugus est solum ejus est usque ad coelum et ad inferos," i.e., "The owner of the soil owns to the heavens and to the lowest depths (of the earth)." This may be true in most situations, but like all rights of "ownership" it is not quite as absolute as it sounds. For instance, it is not trespass to fly an airplane over private property (though it may be nuisance if one flies too close), and water-rights law clearly contemplates the use by people of water flowing under other people's land.

acolyte ( ). Someone, ordinarily a youth, who assists at a religious service, especially a Roman Catholic mass; a sort of assistant to a priest, also sometimes called "altar boy." By extension, "acolyte" is sometimes used to mean something like disciple or adherent, e.g., "He is one of Professor Smith's acolytes," or "He is an acolyte at the altar of legal formalism."

a consiliis ( ). Of counsel; a counsellor.

acquaintance. When used to describe a person, it ordinarily refers to someone in a relationship with oneself someplace between having met once or twice and being friends. When, however, one says that he is acquainted with the contents of a document, the implication ordinarily is of rather thorough familiarity, though perhaps less than would be procured through deep study.

acquainted. See acquaintance.

acquest ( ). A civil law term for property acquired by purchase, as distinguished from gift or inheritance.

acquets ( ). (Fr.) In French law (and, with variations, in other related systems, including that of Louisiana), property acquired other than by inheritance during marriage by either husband or wife, which thereafter belongs one half to each of the marriage parties. $C f$. community property. Apparently conquets are the same as acquets, and sometimes the phrase acquets and conquets is used, apparently implying nothing more than either "acquets" or "conquets" alone.

acquiesce ( ). See acquiescence.

acquiescence ( ). Perhaps best defined as "the state of being willing to put up with." It does not necessarily entail agreeing with a state of affairs, much less actively promoting it, but only being unwilling to take any substantial steps to bring about a change. (Of course, it is assumed that the party has knowledge of the event in which he is said to acquiesce.) Thus 
one may be said to have acquiesced in the marriage of one's daughter to "that no good commie loafer" by visiting them after the first grandchild arrives, and trying hard to be at least polite. But under some circumstances acquiescence may have legal significance. For instance, if, under a contract giving one the power to cancel for, say, late deliveries, one keeps getting late deliveries and keeps keeping quiet, one may be found to have "acquiesced" and thereby lost the power to cancel upon still another late delivery. One may similarly acquiesce in a custom of a trade or business. That is, some acquiescences may raise an estoppel or, in a loose sense, amount to a waiver. And $c f$. laches.

In tax practice, "acquiescence" has a more particular meaning. It refers to a formal announcement by the Internal Revenue Service that it will apply the law as interpreted by the Tax Court, at least for the time being. It is not necessarily a statement that the IRS people agree, but only that they will go along. The IRS also makes formal announcements of nonacquiescence. With respect to decisions of the Courts of Appeals, perhaps out of delicacy, formal announcements are not ordinarily made, though on occasion a statement amounting to a nonacquiescence will be issued.

acquiescence in custom. See acquiescence.

acquietandis plegiis ( ). An old writ which a surety could sue out to force a creditor to release him when the debt of the principal debtor had been satisfied.

acquietantia ( ). Acquittance; discharge (noun).

acquietatus ( ). Acquitted. See acquit. See also paid; discharge.

acquired. In ordinary language, acquire refers both broadly and loosely to the inception of a particular relationship between a person (including a juridical person, like a corporation) and property such that the former owns or has rights to use the latter. The term is not particularly specific as to the exact moment [the] relationship commences, exactly what must happen to render the property "acquired," what kinds of relationships are included, or what kinds of property may be involved. And all of these imprecisions may cause difficulty in legal contexts. For instance, if something of legal importance (e.g., tax liability) turns on the exact time property was "acquired," since acquisition may involve several steps and substantial elapsed time, some context-specific rules will have to be evolved, e.g., "property is acquired for tax purposes when reduced to possession, even if full payment has not yet been made." Or, despite the breadth of the ordinary meaning of acquired, embracing as it does all methods of gaining ownership or control over all forms of things of value, the word still might be used such that a statute making all property "acquired" after marriage community property would not include property "acquired" as compensation for tort, or by inheritance. In brief, the more particular legal meaning of acquired in any particular legal context will have to be determined not in general terms but 
with respect to the context; the term in law is not necessarily used to the full extent of its ordinary language ambit.

Nonetheless when "acquired" is used in law it is clear that something broader than "purchased," "inherited," "earned," etc. is intended. And it is often quite clear what describing something as "acquired" is meant to distinguish it from: something already possessed. Hence one speaks of a person's "acquired characteristics" to distinguish them from his inborn, genetically determined ones, and by easy extension, one might use "acquired property" to distinguish it from that already owned at the relevant legal moment, e.g., marriage.

acquired allegiance. That which a naturalized alien has toward his country of naturalization, i.e., an allegiance with which he was not born.

acquired corporation. See acquiring corporation.

acquired federal lands. Lands owned by the federal government which were never public lands (also called "lands in the public domain"), or which were conveyed away to private owners and then reacquired by the government. The distinction between "acquired federal lands" and "public lands" is sometimes legally significant, e.g., with respect to the rules and procedures governing their conveyance, opening to mineral exploitation, etc.

acquiring corporation. In talking about the merger of corporations, it is sometimes useful to distinguish between the "acquiring corporation" and the "acquired corporation," i.e., between the buyer and the bought. When Corporation A buys all of the assets or stock of Corporation B, it is usually clear that $\mathrm{A}$ is the "acquiring corporation." Sometimes, however, the transaction between the two corporations is more ambiguous, e.g., when $A$ buys all of the assets of $B$ in exchange for stock of $A$ which, when distributed to B's stockholders, gives them a controlling interest in A, any distinction between acquiring and acquired corporation may be so blurred as to be analytically counter-productive.

acquisition. Something that has been acquired. The most common use of the word in a legal context is to refer to the taking over of one firm by another. There are in legal practice diverse technical ways in which that can be effected, for which see corporate reorganization; merger of corporations.

acquisition by __. See under method of acquisition specified, e.g., for "acquisition by conquest" see conquest.

acquit ( ). For the most common legal meaning, see acquittal. The word can also be used to mean "carry out a task," as in, "Faced with a challenge, he acquitted himself well."

acquitare ( ). To acquit; to pay. See also discharge (verb).

acquittal. The most common modern legal use is to refer to the act of finding a person not guilty at the trial of a criminal charge. The term may also be used, however, to describe being freed from criminal charges in other ways, e.g., when the prosecuting official decides not to go forward, especially 


\section{Leff Dictionary of Law}

when he formally enters a nolle prosequi. One might also loosely refer to a party "acquitted" in a civil action, though one would ordinarily be tempted to use the terminology only if the cause were quasi-criminal, e.g., an action charging actual fraud, or an intentional physical tort like battery.

An ancient meaning referred to the duty of a mesne lord to free his tenant of all feudal service the latter might otherwise owe anyone other than the mesne lord with respect to the same lands.

acquittance ( ). Something delivered to an obligor to evidence the extinguishment of an obligation. A written receipt, for instance, is an acquittance of a debt, given by the creditor to the debter. A release would be another form of acquittance. There is an implication that an acquittance must deal with an entire obligation, but a receipt given for part payment of a larger debt might properly be considered an "acquittance" for that part; it is sometimes called an "acquittance pro tanto."

acquittance pro tanto ( ). See acquittance.

acre ( ). A measure of area, usually applied to land, equal to 160 square rods, which is the same as 4,840 square yards, which is the same as 43,560 square feet. There are 640 acres in a square mile. See also section. In very old texts "acre" may refer not to a measured area at all, but just to any more or less level field.

acreage ( ). The number of acres in a parcel of land. Frequently, however, the term is used just to mean the same as "tract of land," e.g., "I have acreage down by the old Mashaw place."

acreage allotment. A regulatory technique used from time to time (especially under the Agricultural Acts) to decrease the production of agricultural products by paying farmers to take acreage out of productive use, i.e., to settle for some share of a total acreage "allotted" to a crop, so as to raise the prices received by all producers. In effect, it was an attempt by the government to cartelize the agriculture industry so that, by collusive restriction on supply, revenue could be increased beyond the market-set total. As might be guessed, this attempt to force a cartel upon an industry with as many "firms" as there were devoted to agriculture was not notably successful, for every member of the cartel had not only reason to cheat (i.e., to produce and sell as much as possible at the new higher price), but reasonably easy means to do so too, e.g, by taking out of production one's worst acreage and more intensively cultivating what was left. Nonetheless, some acreage allotment agricultural regulation still exists, e.g., with respect to tobacco.

acreage contribution letter. A common agreement in the oil and gas business, by which $\mathrm{X}$ agrees to drill a test well in a particular location, and tell $\mathrm{Y}$ all that he learned from the drilling, in return for which $\mathrm{Y}$ agrees to assign to $\mathrm{X}$ certain leases $\mathrm{Y}$ owns in the vicinity of the drilling.

acreage selection clause. A common provision in oil and gas leases. The pattern is that the lessee, for a price, gets a short term lease (60-90 days) on a 
large tract of land, upon which he then makes geological surveys. The acreage selection clause empowers him thereafter to extend his lease on certain acreage within the larger tract (usually for an additional payment).

acre foot. A cubic measurement of water, equal to that amount of water which will cover one acre of land to a depth of one foot, i.e., 325,850 gallons.

acre right. The share of a citizen of a New England town in the common lands thereof.

across. From one side of a thing to the other. Occasionally in a legal context the word will be interpreted to encompass a right to enter (especially real property) and come out again at some point on the same, or on a perpendicular, side.

ac si ( ). "As if," a term appearing in old statutes, e.g., the Statute of Uses, having the same effect as "shall be deemed," i.e., to assert that while $\mathrm{X}$ is not $Y$ it shall nonetheless be treated as if it were.

act. As a verb, its most important legal use is to refer to something done by a person, as contrasted with his remaining passive. The word covers both the ordinary actions of life, and formal and deliberate legal acts, e.g., "I execute this my last will and testament as my own free act." See, however, active and passive for the dangers of assuming that it takes an "act" (in the sense of moving away from apparent inertial quietude) to generate legal consequences.

As a noun, the most common legal use of the term is as a near or total synonym for statute. And sometimes the result of a private but formal, deliberate, and consciously legal action will also be called an "act," e.g., a deed.

acta ( ). Recorded proceedings of a deliberative body, either legislative or judicial.

acta diurnia ( ). "Done this day." An old formula once frequently used at the signing of an instrument. May also be used to mean "daily minutes" [of a meeting].

acting. See act. Also, when used to modify an office, e.g, "acting president" or "acting professor," it refers to one who has the powers and duties of an office or status, but not formal title to it. It is usually the case that "acting" status will be temporary; the incumbent will either be formally confirmed in it, or else someone else will.

acting as. When followed by a status, role, office, or other legal capacity, the term describes an act done in that capacity rather than one done in the actor's natural capacity. For instance, "acting as agent," when found in a pleading, is sufficient to allege that acts actually done by the agent are binding upon his employer, the principal, e.g., "Jones, acting as agent for Smith, entered into a contract with plaintiff, by which . . ." Similar introductory terms include "acting for," and "acting under authority of." 
acting for. See acting as.

acting out. The term has a technical psychoanalytic meaning having to do with the analytic situation, but it is also used as "sophisticated" slang to refer to someone indulging himself in almost any aggressive or otherwise obnoxious behavior, e.g., it might be said of a six year old who has just belted his three year old sister, "He's just acting out his sibling conflict."

acting under authority of. See acting as.

acting within the scope of his office or employment. See scope of employment.

act in pais. See in pais.

actio ( ). The usual translation is "action," as in "legal action," "action in trespass," etc. Hence the word shows up in Latin in almost as many contexts as it does in English.

First, "actio," standing alone, or in the term "legis actio," often refers to one of a small group of the very earliest legal proceedings in Roman law, the leges actiones.

But "actio" also appears in the name of a large number of later Romancivil law actions, e.g., "actio furti," etc. Even in modern civil law, e.g., today's French law, a particular kind of legal action may have some such name in the ordinary speech of lawyers and judges though it may be technically "a proceeding pursuant to $\S 453.47$ of the Civil Code."

In addition, a common law action, especially at a time when the law language was at least half Latin, might also be called an "actio" for short, and some of them might resemble civil law actiones too. Whether this is because there was actual early influence of Roman law on indigenous law, or because certain early common law commentators (e.g., Bracton) decided to categorize independently generated common law in the more elegant civil law framework, is not clear.

In any event, in the ensuing pages there are a number of entries which begin with or include the word actio. Some refer to Roman law actions, some to modern civil law actions, some to common law actions, some to roughly similar actions in Roman, civil, and common law, and some to other phrases that just happen to use the word actio. No attempt has been made to be exhaustive about any of these actio categories, and only the most important (or at least most frequently mentioned) of the Roman-civil law uses have been included. And in almost every case the entry will do little more than roughly indicate what the "actio" was about, necessarily leaving readers with a need for more substantial information to get it elsewhere.

actio ad exhibendum ( ). A Roman-civil law action to compel a person to exhibit a thing (which might be a title document) in his possession or power. It was an action preparatory to another action for the recovery of a thing, movable or immovable. 
actio adjecticiae qualitatis ( ). A Roman-civil law action brought with respect to a contract made not by the plaintiff himself, but by his agent.

actio aedilicia ( ). A Roman-civil law action for (roughly) breach of an implied warranty of quality.

actio aestimatoria ( ). See actio quanti minoris.

actio arbitraria ( ). In Roman-civil law, a kind of action in which the judgment was that the defendant do something (e.g., deliver a certain thing to the plaintiff), in default of which the defendant must pay a particular sum to the plaintiff. The amount to be paid was sworn to by the plaintiff as the true value, and while the judge was not bound to accept the plaintiff's suggested amount, the clear intent of the provision was to coerce performance out of the defendant.

actio auctoritatis ( ). A Roman-civil law action for breach of warranty which, when successful, permitted the purchaser to recover from the seller twice the amount he had paid.

actio bonae fidei ( ). In Roman-civil law, an action involving a question of "good faith," i.e., an action in which the judge was authorized to take account of ethical aspects of the behavior of the parties so as to come up with an equitable decision.

actio calumniae ( ). A Roman-civil law action to restrain, or to collect damages for the infliction of, what common lawyers would call the tort of malicious prosecution.

actio civilis ( ). "Civil action," as contrasted with actio criminalis, i.e., criminal action; a Latin term found in early common law cases and commentaries.

actio contrario ( ). In Roman-civil law, a "contrary" action, i.e., a counterclaim or cross-action. The term may show up in early common law cases.

actio criminalis ( ). The Latin term for criminal law in both Roman-civil law and early common law.

actio damni injuria ( ). Means broadly "action for damages"; the Romancivil law action encompassed much of what we would now call intentional and negligent tort.

actio de dolo ( ). Any one of a number of Roman-civil law actions involving some species or degree of fraud or deceit.

actio directa ( ). See actio utilis.

actio empti ( ). An early Roman-civil law action available to a buyer against a defaulting seller.

actio ex contractu ( ). In Roman-civil law and early common law Latin, an action founded on "contract" (whatever that might have meant at the applicable times).

actio ex delicto ( ). In Roman-civil law and early common law Latin, an 
action arising out of fault or misconduct, what would most likely be, for us, a "tort." Other names for this kind of action are "ex maleficio" and "ex poenalis" (because a penalty was often exacted).

actio ex maleficio ( ). See actio ex delicto.

actio furti ( ). A Roman-civil law action (of which there were several varieties) which amounted to a civil action with respect to stolen goods.

actio honoraria ( ). A general term for any one of those actions of Romancivil law which were introduced by Roman officials called praetors and aediles. They tended to be more flexible and (very loosely speaking) "equitable" than the older actions, and by the time of Justinian had almost totally supplanted earlier actions.

actio in factum ( ). A Roman-civil law action adapted to a particular set of facts by means of analogy to an established action. Their similarities to the development of the common law actions on the case have been frequently remarked but, so far as one can tell, the two developments are in detail not all that close. See also actio utilis.

actio in personam ( ). A Roman-civil law action against a person, as contrasted with an "actio in rem," i.e., an action "against," or for the recovery of, a thing. For the common-law story, see in rem action.

actio in rem ( ). See actio in personam.

actio judicati ( ). A Roman-civil law species of judicial execution (of a judgment).

actio mixta ( ). In Roman-civil law (and in occasional common law writings) a "mixed action." What was mixed varied; it could be an action combining a recovery of damages with the imposition of a penalty, or one having both in personam and in rem aspects, or perhaps other mixtures.

action. There are three terms regularly in use to refer to the general process of litigation, "action," "suit," and "proceeding," the meanings of which, alas, are not quite identical. The most important old distinction, that "actions" were "at law" while "suits" were "in equity," has pretty much melted away. And any significant distinction there may once have been between "action" as referring to the right or power to seek judicial redress, with "suit" referring to steps actually taken in pursuance thereof, seems also to have almost disappeared; though it most likely still sounds better to say of a claim not yet brought, "He has an action," rather than "He has a suit," today one can say indifferently, "He brought an action" or "He brought a suit."

Distinctions, however, do remain, principally between "suit" on the one side, and "action" and "proceeding" interchangeably on the other. For example, "suit" would be a very odd choice of word to refer to a criminal case, but "criminal action" or "criminal proceeding" would be as proper a locution as "prosecution." Similarly, "administrative action" and "administrative proceeding" are commonly used while "administrative suit" is not. 
Still further, reference to ancillary or preliminary judicial interventions would more likely be tagged "action" or "proceeding" than "suit," e.g., "action for a stay" or "proceeding to compel discovery"- though "suit for a preliminary injunction" is not out of the question.

The critical point, however, is that while subtle distinctions among the three terms may still exist, it would be unwise, given the modern quasiinterchangeability among them, to decide anything of substance solely on the basis of which of the words is involved. It might indeed be the case that a legislature which referred to "all suits" meant to exclude criminal matters, or one that referred to "all actions" or "all proceedings" meant to include them, but one would be silly to conclude that solely from the word the legislature used.

Also, action ( $)$ is French not only for action, but for a share of stock. Common stock is "action ordinaire" ( ); and preferred stock is "action prioritaire" ( ).

actionable ( ). An activity or state of affairs with respect to which an action will lie. The term is sometimes used redundantly, e.g., "actionable defamation," i.e., where the term being modified already imports the idea of actionability; if words are not actionable they are not in law "defamation," however rotten they may be. At other times, the modifier "actionable" has a clear function, e.g., in "actionable wrong": to refer to an injury about which the law will do something.

actionable per quod. See defamation.

actionable per se. See defamation.

actionable wrong. See actionable.

action against the state. Determining whether a legal proceeding is "against the state" is important in several legal contexts. For example, a "state," in both the international-law sense of "sovereign state" or "nation," and in the domestic sense of constituent state of the United States, cannot ordinarily be sued without its permission. See sovereign immunity. Moreover, a U.S. state is protected by the Eleventh Amendment to the Constitution from being sued in Federal Court by a citizen of another state. Hence, determining whether a suit is "against the state" will sometimes determine whether an alleged wrong can be legally righted at all.

But even in the event that a state has chosen to allow itself to be sued, one must still determine if the action is "against the state," for it is almost universally the case that special rules and procedures are required for such suits, e.g., special courts (e.g., the U.S. Court of Claims), special (usually shorter) statutes of limitation, special pre-suit notification provisions. As one might guess, a large body of technical law has therefore grown up around whether or not an action is "against the state," e.g., under what circumstances a suit against a named state officeholder is "really" one "against the state." This law is uniform neither from state to state nor from context to context, e.g., the against-the-state lore under the Eleventh 
Amendment is not necessarily applicable to a question of when special presuit notification provisions will apply to the action.

action against the United States. See action against the state.

action at common law. Same as action at law.

Action governed by the Anglo-American legal system rather than some other legal system, e.g., the continental civil-law system.

An action based upon decisional rather than statutory law.

action at law. A legal proceeding to be distinguished from one brought "in equity." See law and equity. Some critical matters still depend upon the distinction, e.g., whether a party is entitled to a jury trial under the Seventh Amendment to the Constitution.

actiones ( ). Plural form of the Latin "actio."

actiones nominatae ( ). "Named actions," i.e., those actions for which the medieval chancery had well-established form writs, e.g., debt and trespass. These were distinguished from actions for which chancery would have to draw up a more particularized writ, for which see action on the case.

action for see "divorce."

See under kind of action, e.g., for "action for divorce"

action for death. See wrongful death.

action in equity. Same as suit in equity. See also action at law.

actio non ( ). Contraction of what were the opening operative words (actionem non habere debet) of a special plea in bar, when pleadings were in Latin, i.e., until the mid-seventeenth century. Even after the coming of pleading in English, "actio non" remained the technical name of that part of a special plea denying that the plaintiff had a claim. "Si actionem" was the technical name of the end of the plea.

action not otherwise provided for. A phrase commonly appearing in statutes which divide up actions for some purpose (e.g., length of applicable limitations period, courts with initial jurisdiction) to take care of any action which may not have been specifically assigned, as in "all actions not otherwise provided for herein shall be brought within three years ...."

action of - See under kind of action, e.g., for "action of debt" see "debt."

actio non accrevit infra sex annos. See non accrevit infra sex annos.

action on the case. Most legal actions in medieval England were commenced by procuring from the Chancery a particular writ from a list of standardized ones, e.g., debt, which was to meet one's need, e.g., to recover a sum certain owed, evidenced in a particular manner. See actiones nominatae. Very early, however, certainly by the time of Bracton, writs taking account of more particular facts and not fitting exactly the terms of the now standard writs were being issued. (It was once thought that this power came 
from the in consimili casu (i.e., "in a like case") clause of the Statute of Westminster II, but this has been shown to be false). In any event, these actions on the case eventually grew into most of the law of assumpsit, which itself (by complex interplay with the law of trespass) branched off to form eventually what we now call the law of negligence. And at least as early as the beginning of the nineteenth century, a reference to "action on the case," "trespass on the case," or just plain "case" would refer to an action beginning to look like the modern law of negligence.

actio noxalis ( ). A Roman-civil law action against a person on account of injury inflicted on the plaintiff by the defendant's slave (or child or wife).

action penal. See penal action.

action pending. See pending action.

action personalis ( ). See personal action.

actio personalis [quae oritur ex delicto] moritur cum persona ( ). A personal action (arising out of a tort) dies with the person. The extent to which at common law this was true in its more general or even in its limited-to-torts form is not wholly clear, except that it was never the case that every personal action would terminate finally if either party thereto died. In any event, at present the "rule" has been everywhere almost wholly abrogated by statute. See survival acts. The only significant exception involves defamation. The ordinary Anglo-American rule is that there is no cause of action in anyone else for defamation of a dead person, that a cause of action for defamation of a living person will not survive his death, and (though this is less clear) that an action already commenced will be dismissed upon the death of the defamed plaintiff.

action possessory. See possessory action.

action quasi in rem. See quasi in rem action.

action real. See real action.

action sur le case ( ). Law French for action on the case.

action to quiet title. See quieting title.

actio pignoratitia ( ). Roman-civil law action based on a contract of pledge. actio poenalis ( ). See actio ex delicto.

actio praejudicialis ( ). A Roman-civil law "preliminary" action, i.e., one which was instituted to settle some matter necessary to the correct determination of a later "main" action. The term also shows up in early common law writings.

actio praetoria ( ). See Roman-civil law.

actio pro socio. A Roman-civil law action by one partner against another or others to enforce their partnership agreement.

actio quanti minoris ( ). Also called "actio aestimatoria." A Roman-civil 


\section{Leff Dictionary of Law}

law action by which the plaintiff sought to have the price of purchased goods decreased on account of defects in them.

actio quod metis causa ( ). A Roman-civil law action in which the plaintiff alleged that he had been forced by duress to deliver or promise a thing to another.

actio redhibitoria ( ). See redhibitory action.

actio stricti juris ( ). The general name of any one of those actions in Roman-civil law which had to be enforced exactly as formulated, with little room for flexibility or "equity." The transactions involved tended themselves to be highly formalized.

actio utilis ( ). Very roughly, in the Roman-civil law an "equitable" action, as contrasted with an "actio directa," a fully formulated "legal" action, the actiones utiles being formulated on analogy to the actiones directoe. Drawing parallels to the development of "law" and "equity" in the common law, and the history of the action on the case, is tempting but most likely of limited utility. See also action in factum.

actio venditi ( ). A Roman-civil law action available to a seller to enforce a contract of sale against a buyer.

active bond. A British term for a bond which bears a fixed rate of interest from its date of issue.

active cause. An active cause (see causation) is one that brings about an effect by an act rather than by a failure to act. It is possible that there is a place in the law for a distinction between active and passive cause, but the usage is fraught with analytical danger. For every failure to act is, as much as an act, causative of what comes thereafter, or, more briefly put, every failure to act is an act. Hence it ought not necessarily be concluded that an active cause is culpably responsible for a legally significant effect, or even more responsible than a non-act. The question is one not of kinetics but of legal duty. It may be as much a wrong to keep still in the face of impending results as to change one's position to bring them about.

It is true that once the question is looked at from the point of view of legal duty, there does appear to be a legal bias against creating legally enforceable affirmative duties to act. For example, it is still presently the law almost everywhere in the United States that one can, without liability, sit on a dock and watch an easily savable baby drown, whereas one may be held guilty of negligence if one undertakes a rescue and then botches it. Moreover, it is only exceptionally one's duty to volunteer information in a commercial transaction, however much one might be liable for any inaccuracy actually spoken. This tendency against making action a duty may be justified in various ways, e.g., that it is easier to be sure of a person's requisite knowledge when he acts than when he doesn't (did he see the drowning baby?), or that people have some right (or at least rightness) in any achieved position, and should not be forced to modify it. There may also be 
some deep old historical distinctions at work here, e.g., the problem of assigning malfeasance and nonfeasance to appropriate forms of action.

But the critical point is that whatever weight these reasons may have, they ought not necessarily be conclusive; there is no absolute bar against making a failure to act the responsible, culpable cause of an impermissible effect. For example, it does not necessarily follow (though courts, including the Supreme Court, seem sometimes to have so concluded) that a school board which watches a long-standing pupil-assignment policy inexorably produce increasing racial segregation has no liability because it did not actively cause the segregation, for it is a perfectly sensible use of language to say that its act of not acting is causing the segregation.

active concealment. A halfway-house legal construct for situations in which there ordinarily is liability for false statement, but no duty affirmatively to disclose a true state of affairs, e.g., when you are selling a house being systematically digested by termites, it is the usual (though eroding) rule that you have no legal duty to volunteer the information, though you must not aver the contrary. "Active concealment" in such a situation could take the form of heading off the buyer's intended trip to inspect the basement by leading him firmly into the kitchen for coffee and distraction. Similarly, it would be active concealment to cover the termite holes with wood filler and paint, or (changing the context), to remove from the buyer-inspectable files of a business to be sold papers which might unsettle any purchaser's high hopes. In any event, once "active concealment" is established, it generally has the same legal effect as misrepresentation.

active duty. See active service.

active member. One may formally be a member of a group or organization but, under an applicable statute, have fewer duties or responsibilities than other members who thus would have greater rights, privileges, or remunerations. See, e.g., active service (in the armed forces)-but the same distinction would hold for an active member of a local police or sheriffs force. Also, it was held constitutionally required for conviction under the Smith Act that the defendant be proved an "active member" of the Communist Party, not merely a "nominal, passive, inactive or purely technical member."

active negligence. Negligent action, as distinguished from any failure to act. But see active cause for the ambiguities and dangers of the distinction.

active progress. A term occurring in some statutes, e.g., "a labor dispute in active progress." It is hard to know what could have been thought to have been added to the meaning of "in progress" by the interpolation "active."

active receivership. A receivership in which the receiver does not just hold and protect property, but has affirmative duties, e.g., actually running a business in his receivership.

active reserves. See active service. 


\section{Leff Dictionary of Law}

active service. A person on "active service" in the Armed Forces is not necessarily engaged in fighting or even preparing for it. He is merely performing some duties, as distinguished from being in civilian life waiting to be called or recalled to active service. One who is in the "active reserves" is in civilian life, but nonetheless ordinarily engages in some regular training regimen, e.g., one night per week and two weeks during the summer.

active trust. A trust in which the trustee has active duties with respect to the management of the property forming the corpus of the trust. See also passive trust.

active use. The same as active trust, expressed in the legal terminology of an older day. The Statute of Uses did not apply to an active use.

activity. Doing something, as contrasted with passivity, or just sitting there.

act malum in se. See mala in se.

act malum prohibitum. See mala prohibita.

act of bankruptcy. Prior to the Bankruptcy Reform Act of 1978, a debtor had to have committed or allowed, within four months of the creditors' petition, one or more of a list of six acts before he could be involuntarily thrust into bankruptcy proceedings. The acts were (1) fraudulent conveyance; (2) preference; (3) suffering an involuntary lien on his property (and not having it removed within 30 days); (4) assignment for benefit of creditors; (5) involuntarily permitting the appointment of a third party to take charge of his property; (6) admitting in writing his inability to pay debts as they mature and his willingness to be adjudged bankrupt. Lawyers would sometimes make shorthand references in the form "He committed the second act" as a way of describing the debtor's action. The 1978 Act abolished the requirement of an act of bankruptcy as a precondition to an involuntary bankruptcy proceeding.

act of commission. Doing something, as opposed to an "act of omission" which involves failing to do something. See also active cause.

Act of Congress. A statute enacted into law by the federal government.

act of dominion. An act by which a person evinces his taking dominion, i.e., ownership, of a thing, e.g., accepting a deed to real property in modern practice, or in older practice accepting a twig while standing on the land being conveyed. But acts of dominion need be neither formal nor dramatic; driving a new car away from the showroom and eating an ice cream cone are also acts of dominion.

act of God. An event which occurs without human intervention which, moreover, no reasonable human intervention could prevent, nor human prescience reasonably predict. Obvious cases of acts of God include mighty tempests, earthquakes, the natural deaths of human beings, lightning, and the eruption of volcanoes. The late J.A. MacLachlan of Harvard used to 
define it, impiously but usefully, as "that which no reasonable God would do."

While it is generally the case that no human is liable for damage done or performance prevented by an act of God (and many standard contracts explicitly provide that obligations so prevented give rise to no action for breach), that is not necessarily always the result. Certainly the periodic happening of acts of God is predictable, even if their individual timing is not. Hence a contract may provide an obligation in terms so absolute that no failure, however caused, will relieve a party of non-performance, and it is common practice in many contracts specifically to deal with allocation of losses caused by act of God. And when the obligation undertaken is precisely to avoid or mitigate the act of God the loss through act of God is not excused, it would hardly avail a builder of lightning rods, for instance, or storm cellars, to argue that the failure of their products to do their job was, nonculpably, the result of an act of God. See also vis major.

act of grace. A more or less general amnesty and/or pardon declared by a monarch to mark some important royal accasion, e.g., coronation, marriage, recovery from illness. In modern limited monarchies, though the act of grace might formally still be the monarch's, it ordinarily requires legislative enactment, and is more the act of the actual government than the titular ruler.

act of indemnity. A law passed to legalize actions by public officials which were illegal when taken, or to insulate the officials against punishments or penalities for such acts. The laws are almost wholly directed to what almost everyone would consider technical violations of law, and are not some sort of legislative pardon for substantial illegalities. And there is some doubt whether, at least in the U.S., more than minor technical violations could be constitutionally reached by a subsequently enacted act of indemnity, or whether such nunc pro tunc validation of an unlawful act could oust any private claim based upon the initial illegality.

act of insolvency. Another term for act of bankruptcy.

act of law. Ordinarily used in contradistinction to an act of a party or the parties to a transaction, i.e., automatically, not necessarily as the person involved might have wanted it, e.g., "because of the Spouse Protection Act one quarter of his estate passed by act of law to his hated wife, despite the terms of his will."

act of legislature. Ordinarily a statute, though other legislative actions (e.g., the censure of a member) might be so described.

Act of Oblivion. An act of Parliament passed in 1660 which was in effect an act of indemnity covering (except for certain named persons) all actions taken from 1645 to date, i.e., from the beginning of the rebellion against Charles I to the Restoration under Charles II. Unlike most acts of indemnity, however, this statute covered illegalities which were exceedingly non- 
technical from the royal point of view, and was more like an almost-general amnesty.

act of omission. See act of commission.

Act of Parliament. A statute passed by the Parliament of the United Kingdom.

Act of Settlement. An act of Parliament of 1700, the principal purpose of which was to confirm the royal succession to the Protestant line of William and Mary, i.e., to exclude the Stuart (Catholic) line of succession overthrown by the deposition of James II in the Glorious Revolution of 1688 . It also provided that any sovereign in the new succession who became or married a Roman Catholic would thereby vacate the throne.

The Act of Settlement, however, contained other important provisions not directly related to religion or the succession. Judges were thenceforth to hold office during good behavior, not at the will of the sovereign. The sovereign could not prevent anyone, by pardon, from being impeached (see impeachment). And no one holding a paid office under, or receiving a pension from, the Crown could become a member of the House of Commons.

act-of-state doctrine. The doctrine of international law that an act of the sovereign nation, especially within its own territory, cannot be questioned or made the subject of legal proceedings in the courts of any other sovereign. It is, in effect, an international sovereign immunity doctrine. It was suggested in the Sabbatino case that the doctrine is binding on U.S. Courts as a matter of U.S. constitutional law, but it is not yet clear whether that idea will finally prevail.

Act of Supremacy. An English statute of 1558 establishing the supremacy of the Crown in ecclesiastical matters.

Act of Uniformity. An English statute of 1662, the most recent important version of a line of statutes providing for the use of a uniform prayer book for Church of England services. The book mandated by the 1662 Act was essentially the same as the modern Book of Common Prayer.

Act of Union. Usually refers to the 1706 and 1707 English statutes confirming the Articles of Union between England and Scotland, an agreement whereby the two kingdoms were united into one under the name of Great Britain. (The Act did not, however, wholly integrate the law or legal system of Scotland into that of England.)

Act of Union may also refer to a statute of 1536 by which Wales was for the first time incorporated into England and made subject to English law.

And Act of Union may refer to the Union with Ireland Act of 1800 , by which Ireland, up to then a distinct Kingdom, was coalesced with Great Britain to form the United Kingdom. See Ireland for the subsequent (mostly awful) developments.

Acton Burnel ( ). A 1283 English "statute" (actually an order of King in council, with Commons taking no part) designed to give merchants a speedy 
remedy for the collection of debts. The provision is named after the place of its promulgation.

act on petition. A form of English summary proceeding once used in the High Court of Admiralty, but now superceded.

actor. In Roman law, roughly equivalent to "manager" or "steward" or "bailiff." Later came to include any representative of a party in litigation.

act through. To use the agency of another person to bring about an effect, the implication being that the agent is just a conduit for the principal's skill.

actual. A modifier which, together with its adverbial form, "actually," is frequently used in legal discourse. At first glance the use often seems redundant, e.g., in "actual payment" and "actual delivery" what does each "actual" add? But the presence of the words "actual" or "actually" uniformly signals a state of the law such that it will be sometimes important to distinguish between different legally relevant meanings of the term being modified. For example, "actual delivery" implies that there are other kinds of delivery, e.g., "presumed delivery," "constructive delivery," "implied delivery," "symbolic delivery," or "potential delivery," all with legal significance from that of the particular act described as "actual delivery." "Actual" and "actually" are most frequently used to signal a concretely physical act as contrasted to a communicative or symbolic one; a present act as contrasted to a potential, uncompleted or future one; or a directly provable act as contrasted to an assumed, implied, or informed one. But what alternative situation "actual" or "actually" is in any particular instance meant to distinguish is often a subtle and complex question, and the particular entries beginning with "actual" and "actually" below should be consulted. And see generally constructive and entries [s]o beginning.

actual authority. In the law of agency, the primary meaning of actual authority is authority knowingly and intentionally given by a principal to an agent to act on behalf of, and bind, the principal. But it has frequently been held that if the agent would reasonably believe himself to have particular authority he has it, and it is "actual authority" that he has for all relevant legal purposes, and that this is so even if the principal had no intention to give such authority, indeed wanted strongly not to. (The analogy is to a contract which would subsist even if one party did not intend it, if the other party would reasonably believe that a contract had been created.) Hence, for all the analytic confusion it may cause, the term "actual authority" includes both express authority and "implied authority." "Actual authority," therefore is used to distinguish both express and implied authority from apparent authority, i.e., authority which not the agent but the person dealing with the agent would reasonably believe the agent to have.

actual bias. In a judge or juror, an existing state of mind of bias for or against one of the parties, as distinguished from an inference which might be drawn 
from, e.g., a blood, marital, business, or previously hostile relationship he might have to one of the parties.

actual bona fide. There seem to be two uses of this locution. The first is just a matter of combining two ideas, e.g., an "actual bona fide possessor" is one who is both one in "actual possession" (as contrasted to, say, constructive possession) and in "bona fide possession" (i.e., in possession in good faith). The second use, however, seems to [be] just for intensification or emphasis. For example, in "actual bona fide purchases," neither "bona fide" nor "purchaser" is changed from its usual meaning by "actual," which thus seems to mean no more than "really."

actual cash value. One would think that ordinarily "actual cash value" should be synonymous with fair market value, i.e., the price for which the item would be bought and sold on the market on the relevant date, e.g., the date it was stolen for purposes of a property-insurance policy. And that amount would be the same as the replacement or reproduction cost; even if goods must be specially constructed, there is no reason in theory why one could not determine the market price of reproducing something. Nor should it in theory make any difference that the goods being valued were used goods. One would just look to the fair market value of goods as used as the subject goods on the used-goods market (or, for goods needing special construction, to the construction-of-goods-that-used market.)

In fact, of course, it is usually delusive to attempt to determine the value of something by looking to its actual market price because it is only exceptionally the case that there is any actual market for the goods in question. It is not foolish to declare that one knows the "market value" on particular date of Number 2 Hard Winter Wheat, or 100 shares of General Motors common stock, but those goods are exceptional; they are fungible, i.e., not subject to much in the way of product differentiation, and are traded in an open, efficient national auction market. Few goods are, and more important, the goods for which there is essentially no efficient market are the ones most frequently involved in proceedings to determine their "actual cash value," notably the used goods of everyday life which are stolen and destroyed, the nonfungible family house which burns down.

Hence, in almost all legal contexts (e.g., insurance, takings by eminent domain, determinations under appraisal clauses in contracts) "actual cash value" cannot really be fair market value, but must instead be some construct, some attempt to come up with an equivalent to the conceptually correct, but empirically nonexistent "market price." One is, in effect, trying to come up with a shadow price and actual cash value really has to mean imaginary or virtual cash value. A common technique for this when used goods are involved is to award what is in effect book value, i.e., cost less depreciation (with the depreciation rate, as usual, being an only not-quitearbitrary figure). Or (an important distinction especially in times of extensive inflation) one looks to the current market price for replacing the (say, stolen) goods if new, and then discounts for the depreciation of the used 
goods actually involved. For instance, let us say that a suit, purchased for $\$ 200$, is stolen two years later. It is insured against theft, the policy promising to pay the "actual cost value" of stolen goods. On the date of the theft, because of inflation, it is not crazy to say something like "it costs $\$ 250$ to buy a $\$ 200$ suit these days." There is, of course, no real market for two year old suits. So a fair rough approximation of "actual cash value" might involve the following reasoning:

(1) Suits depreciate one quarter every year;

(2) a $\$ 200$ suit after 2 years would be "worth" $\$ 100$;

(3) a $\$ 250$ suit should be "worth" $\$ 125$;

(4) one should pay the claimant $\$ 125$.

Naturally, in times of inflation the insurance companies would prefer paying "book value" only, and it is not clear to what extent courts will force them to pay the higher inflation-sensitive figure.

actual change of possession. Under most pre-U.C.C. versions of the statute of frauds, one of the happenings that would render an otherwise unenforceable unwritten contract for sale of goods enforceable was actual receipt by the buyer of some of the goods. Partly because of the usual wording of the statutes, and partly for reasons of policy, it was generally held that the receipt had to be actual and physical rather than symbolic, e.g., still in the seller's warehouse but with a sign attached indicating the buyer's ownership. Under the U.C.C. version of the Statute of Frauds ( $\$ 2-201$ ), otherwise unenforceable contracts are enforceable with respect to goods which have been "received and accepted," with the meaning of the latter phrase the subject of $\S 2-606$.

actual compulsion. Real compulsion, as contrasted to the kind which might be presumed or inferred from the relationships between the persons involved, e.g., parent and child, employer and employee, publisher and author.

actual controversy. A term used in the Declaratory Judgment Act where it has come to mean a controversy neither moot, nor feigned, nor solely hypothetical and speculative. See case or controversy for the constitutionallaw context.

actual damages. Substantially the same as compensatory damages.

actual delivery. A term ordinarily used to describe manually or physically putting the item into the possession of another, as contrasted with symbolic or constructive delivery. (Caution: The modern sale-of-goods-law consequences of the various possible modes of "delivery" and "acceptance" [are] governed in detail by divers sections of the U.G.G., which should be consulted.)

One further complication. Manual delivery to a person's agent is naturally delivery to that person. But in some contexts, notably insurance, it has sometimes been held that the act of putting an insurance policy out of control of the sender amounted to "actual delivery" to the other person, even if neither he nor his agent had received it. 
actual escape. See constructive escape.

actual eviction. The physical dispossession of a tenant, as contrasted with a constructive eviction. But it does not require the application of physical force; if at the insistence of a landlord claiming the right to evict the tenant leaves, he has been "actually evicted."

actual force. In criminal statutes defining various types of robbery, "actual force" is held to require at least some personal force inflicted on the victim. See constructive force. Also (together with "actual violence"), the term is sometimes used to describe the infringement upon the victim necessary to transform the threatened violence of assault into the completed violence of battery.

actual fraud. See fraud.

actual induction. The moment at which a person becomes a member of the armed forces. At least for purposes of subjecting the alleged inductee to military law, it does not take place until the oath of induction is taken.

actual knowledge. To have "actual knowledge" of something is really to be aware of the relevant state of affairs. Depending on the context, the "actual" may be added to distinguish the situation from negligently not knowing, or from willfully seeking not to find out, or from "having" the knowledge only through the actual knowledge of an agent. It should be pointed out that these forms of knowledge other than "actual" may nonetheless, depending on the applicable law, have the same legal effect as "actual knowledge." See actual notice; knowledge.

actual loss. Roughly the same as actual cash value in one context, and roughly the same as actual damages in another.

actually. The adverbial form of actual. Also used colloquially to mean "but the truth is" as in "It might appear easy to write a dictionary. Actually . . . ."

actually cognizant. To be "actually cognizant" is to have actual knowledge.

actually collected. In some contexts, the "actually" is used to distinguish collection from mere potentiality, e.g., an amount promised in a promissory note is not actually collected until the note is actually paid. In other contexts, the "actually" is added to indicate that costs of collection are to be deducted when determining what amount was "actually collected."

actually paid. Paid in cash or its equivalent (e.g., a certified check), rather than "paid" by a promissory note or, in some contexts, by uncertified check. See also U.C.C. $§ 2-511$ on modes of payment in sales of goods.

actual malice. See malice.

actual [military] service. See active service.

actual necessity. Given the ordinary meaning of necessary, it would appear that "actual" is almost wholly redundant except perhaps occasionally, e.g., when "actual necessity" appears in an eminent domain statute, to empha- 
size that the taking authority exercise[s] interpretative restraint in determining for what public purposes to take.

actual notice. The term notice comes variously modified in legal contexts, e.g., as "actual notice," constructive notice, express notice, implied notice, personal notice, etc. In each use there is some idea that a person learn of something legally relevant, and it would be intellectually pleasant to report that "actual notice" uniquely anchored one end of the notice spectrum, such that it would be essentially identical in meaning to actual knowledge, or at least mean putting the recipient into possession of the relevant facts. Alas, that is not the case, and it is clear that in many contexts "actual notice" would include, e.g., actual knowledge or notice of such facts which would lead a reasonable person to an investigation which would eventuate in actual knowledge. Hence, one cannot generalize easily from context to context about the ambit of "actual notice," especially since numerous statutes go to great lengths to spell out what they mean by particular varieties of notice and knowledge, e.g., U.C.C. § 1-201(25)-(27).

actual occupation. See actual possession.

actual ouster. Essentially the same as actual eviction.

actual pecuniary injury. There are occasional statutes which use this phrase, e.g., to allow a new trial to be ordered if the victorious plaintiff is nonetheless awarded less than his "actual pecuniary injury." The decisions are split, however, on whether the phrase means, roughly, out-of-pocket losses, or, more broadly, all easily measurable damages, e.g., including the contract action plaintiff's expected profits. It is reasonably clear, however, that the phrase is designed at least to exclude more speculative damages, e.g., pain and suffering.

actual possession. Clearly, the term is used in contradistinction to the constructive possession which the law gives to every owner of legal title. The state of affairs which most clearly satisfies the meaning of "actual possession" is physical control over a piece of property, e.g., holding a diamond ring in one's hand (or strongbox), or having one's body and abode physically on a clearly marked tract of land. And this done through an agent and (for most purposes) through a tenant will be sufficient. In some situations however "actual possession" may require more or less than physical possession. For example, one who puts up a sign claiming ownership of a tract of land good for little except hunting and fishing may be in "actual possession" for purposes of a statute using the term protecting such lands from trespass, even though the owner's visits are highly sporadic, or even nonexistent, at the time the question arises. And one would certainly be in "actual possession" of the contents of a safe deposit box for, say, bankruptcy purposes. On the other extreme, enclosing and actually farming a tract of land may be deemed not "actual possession" for purposes of having the property declared one's homestead (and thus exempt from execution by 


\section{Leff Dictionary of Law}

creditors) if one has a home in which one actually lives on another noncontiguous tract.

As usual, then, the meaning of the term is highly dependent upon the context [in which] it is used, and that requires guessing the legal purposes being served. If the government, evincing an intention to foster land use, gives title to people for five years in "actual possession" of land, one would expect that actually living there and using the land would be required, not just a speculative sign-posting or even fencing by an absent speculator. But the latter activities might still subject the speculator to special taxes on owners "in actual possession." As usual, one must look to the relevant decisions, even though which the relevant ones are is the hardest of questions.

actual residence. Generalization would, once again, be risky, for whether a place is an actual residence will once again turn on the purpose with which the term is used. For example, a university student who moved with wife and family into a private house would almost undoubtedly have his "actual residence" there for voting purposes, even if he had a fixed intention to move "back home" after his educational stay was over, i.e., one can clearly have an "actual residence" which is not a domicil. On the other hand, the same student might nonetheless be an "actual resident" of [the] state to which he expected eventually to return, this time for purposes of being entitled to a scholarship available only to "actual residents" of that state. All one can say with certainty is that mere transient physical presence is not "actual residence," and actually living in a place with no present expectation of going elsewhere is.

actual sale. The "actual" is clearly added to distinguish sale from mere contract to sell. But if a contract provides, e.g., for payment of brokerage upon "actual sale," it may be held that procuring a valid contract of sale will suffice to earn the commission, the "actual" being interpreted as used to distinguish the valid-contract stage from the mere coming-forward-with buyer stage. And see equitable conversion (contract for sale of real property will, for almost all legal purposes, be treated as actual sale).

actual seisin. Title (to real property) coupled with actual possession. To be distinguished from seisin in law which is title carrying with it the right to immediate possession, e.g., when there is no adverse possessor, the form of seisin possessed by an heir prior to entry by him or his tenant.

actual seizure. Requires more than some kind of symbolic "seizure," e.g., filing a notice of lien. Physically taking possession of the object seized will do, of course, but as usual one need only be as "physical" as the circumstances allow: If, e.g., you are "seizing" a thousand ton machine, you needn't pick it up and take it away.

actual service. When used in the context of service of process, "actual" is used to distinguish this type of service from less personal kinds, e.g., service by mail, by publication, etc., i.e., from constructive service of process. 
In the armed-forces context, "actual service" means essentially the same as active service.

actual settler. The term, when used in U.S. statutes pertaining to "actual settlers" on public lands, refers to a particularly personal and physical form of actual possession: The "actual settler" must be physically on the land (not just contemplating a move there), it must be he who is personally there, and the presence must be substantially continuous.

actual total loss. See total loss.

actual use. A phrase used in automobile liability insurance policies, e.g., the

Standard Family Combination Automobile Policy, provides coverage to "any other person using such automobile with the permission of the named insured, provided his actual operation or (if he is not operating) his actual use thereof is within the scope of such permission." It is clear under that formulation (it was not as clear under prior versions of the provision) that "actual use" is not restricted to actual operation (i.e., as driver). Some question remains whether the actual use during which the accident took place had to be specially authorized, or whether general authority to use would do, but non-specific authority has generally been found sufficient. See actual and, for the customs-duty context, in actual use.

actual value. Essentially identical with actual cash value.

actual violence. See actual force.

actual waste. A form of waste perhaps better named active waste, i.e., wilfully or negligently doing affirmative injury to property (e.g., cutting down trees, leveling buildings) rather than just letting the property run down.

actuarial solvency. See insolvency.

actuary. An expert in the application of the mathematics of probability and statistics to practical problems of divers businesses, especially insurance. Particularly in the highest reaches of insurance companies, actuaries are highly skilled, and highly valued; even middle-level actuary-qualifying examinations are reputedly harder than any other profession-entry tests, making the law and accounting examinations, e.g., look like child's play.

actus Dei ( ). Act of God.

Actus non facit reum, nisi mens sit rea ( ). Literally "an act does not make one guilty unless the mind [of the actor] is guilty." This is the Latin-maxim form of the important rule of Anglo-American criminal law that criminal liability cannot be imposed unless the actor had a mental state amounting in culpability at least to negligence. The proposition announced by the maxim is, in fact, regularly violated by actual law, though only under special conditions. See guilty knowledge; mens rea.

a.c.v. Insurance industry abbreviation for actual cash value.

ad. ( ). Latin preposition meaning "to," "toward," "for," "until," "up to," "on account of," "about"-and more. 
A.D. Abbreviation for Anno Domini, Latin for "in the year of our Lord," i.e., the year it is counting from the traditionally ascribed year of Christ's birth. "B.C." is the abbreviation for "before Christ," i.e., all earlier years. "C.E." (common era) and "B.C.E." (before the common era) are sometimes used for A.D. and B.C. respectively by those wishing to eschew Christian terminology.

ad admittendum clericum ( ). A writ directed to a Bishop commanding him to take such action as would be necessary to put a clergyman into possession of his ecclesiastical position. The writ was ordinarily issued after an action of quare impedit had been decided in favor of the clergyman.

ad aliud examen ( ). "To another examination [or "trial"]." A litigant who wished to object in a superior Royal court that an action was being prosecuted against him in a tribunal lacking jurisdiction (e.g., and most significantly, an ecclesiastical court) would complain that he was being unlawfully drawn "ad aliud examen." If the litigant made out his case, a writ of prohibition would issue to the other court and party.

ad alium diem ( ). A common phrase in the Yearbooks, meaning "at another day."

Adamson Act. The informal name of a Federal Statute (45 U.S.C. §§ 65-66) establishing an eight-hour day for railroad workers, important because of its early date (1916).

adapted. The word can mean either "naturally fitted for," e.g., "Such wood is adapted to use in building," or "not naturally fitted for but changed so as to do the job," e.g., "The X-flange is adapted for use with the Y-fitting."

ad assisas capiendas ( ). "At the summoning of the assizes," is the literal translation; the reference is primarily to the assizes, those of mort d'ancestor and novel disseisin.

a datu ( ). "From the date." Also "a dato."

ad audiendam considerationem curiae ( ). "To hear the judgment of the court."

ad audiendum et determindum ( ). "For hearing and decision."

ad audiendum judicium. See capias ad audiendum judicium.

ad bancum ( ). "At the [judge's] bench."

ad barram ( ). "At the bar," i.e., the courtroom kind.

ad barram evocatus ( ). "Called to the bar," i.e., admitted to the right to practice law.

A.D.C. Abbreviation of aide-de-camp.

ad colligendum bona defuncti. See letters ad colligendum bona defuncti. ad communem legem ( ). An old writ of entry, to be brought by the holder 
of the reversion after the death of a life tenant who had wrongfully alienated.

ad commune nocumentum ( ). "To the common nuisance."

ad comparendum et ad standum juri ( ). "To appear and abide the court's decision."

ad computandum. See capias ad computandum.

ad consulendum, ad defendendum regem ( ). According to Blackstone, the two reasons for which peers are created are "to counsel, and to defend, the King."

ad credulitare. See purgation by oath.

ad crumenam. See argumentum ad crumenam.

ad culpa ( ). "Until misconduct," as in "He may stay in possession ad culpa."

ad curiam ( ). "To the court," said, e.g., of an argument or motion.

add. To increase in size or quantity (e.g., "He added a violinist to the orchestra."); to conjoin (e.g., "He added a garage to the house."); to combine two or more mathematical quantities to produce a sum (e.g., "He added two and two and came up with four.").

ad damnum clause ( ). That paragraph or portion of a formal complaint in which the plaintiff sets forth the value of his damages, ordinarily in money terms, for which he prays recovery. Modern lawyers are likely to use "ad damnum" as shorthand for the amount formally requested, e.g., "My ad damnum was a hundred grand."

added damages. Same as punitive damages.

added value tax. See value added tax.

ad deliberandum ( ). "To deliberate." See also habeas corpus ad deliberandum et recipiendum.

addendum ( ). Something added on, or appended, especially to a written work, e.g., "The work contains as an addendum a list of English Kings."

addict ( ). The primary meaning today is habitual user of some intrinsically addicting substance like narcotics, e.g., "heroin addict." The term is also used more loosely, however, to mean one who habitually overuses something, e.g, "cliché addict."

addiction. That which an addict has.

ad diem ( ). "At a [or "the"] day."

addition. The mathematical operation of combining two or more numbers to produce a sum.

Words added to a person's name to reflect rank or facilitate exact identification, e.g., Arthur Wellesley, Duke of Wellington; John Jones, husband 
of Harriet Jones; Howard Hooghkirk, carpenter; John Carroll, of Carrollton. These "additions" have no legal significance.

Some new matter made a part of a document. To be an "addition," the added matter need not be physically attached to the original instrument so long as its conceptual connection is made clear. See also codicil.

Under an insurance policy covering "buildings and additions," the additions need not be in existence when the policy is written, or physically attached later to buildings then in existence, or smaller or less imposing than the existent buildings, but the additions (at least) cannot be new structures totally unconnected physically or functionally with the existing buildings. Cf. appurtenance.

additional. Something is "additional" which has been added to something else, though it need not be physically attached, e.g., an additional term agreed to after the creation of a contract and becoming a part thereof. Sometimes a distinction is sought to be made between additional and amendatory matter (of a contract or statute), i.e., between matter which changes and matter which adds. But the distinction is not very useful, inasmuch as every added term also changes the contract or statute from what it was before the addition was made.

additional abstract. See abstract of record on appeal.

additional allowances. Allowances of costs to a prevailing party, awarded at the discretion of the court (e.g., if he finds that the losing party had been frivolous in litigating the matter) in addition to those ordinarily allowed under the relevant statute or rule. Under some circumstances, these may include attorneys' fees.

additional arbitrator. See third arbitrator.

additional burden. See additional servitude.

additional instructions. These are instructions to jury given it after it has retired to reach a verdict. The judge can additionally instruct within wide discretion, but the same formalities must be observed as with the original instructions, e.g., both parties must be notified and present, etc.

additional insurance. See contribution between insurers; double insurance; excess insurance; other insurance clause.

additional insured. Under the usual automobile liability insurance policy, an "additional insured" is a person using the vehicle with, and within the scope of, the permission of a named insured.

additional liability. See superadded liability.

additional premium. An insurance premium in excess of that originally stipulated, paid in exchange for additional coverage, e.g., adding flood coverage to a fire insurance policy.

A payment made by a mortgagor to a mortgagee for the privilege of pay- 
ing off the principal of the mortgage early and thereby decreasing the aggregate interest paid. Sometimes just called a "premium."

additional servitude. In the law of eminent domain, when land is taken for a particular public use and then it is put to another use, the change may be significant enough to constitute an "additional servitude" which will require additional condemnation proceedings and additional payment, e.g., when an easement is taken for a walkway and then an automobile road is constructed. Naturally, whether the actual use is such that it amounts to an "additional servitude" is a matter of contention, and often litigation, between the landowner and condemnor.

additional term. See adjourned term.

additional work. Whether, under a construction contract, work demanded from the builder is "additional work" (calling for additional payment) or was already called for by the contract, is a matter of frequent contention between the parties.

addition theorum. See probability.

additur ( ). A jury comes in with a verdict for plaintiff, awarding a particular amount of money damages. If the trial judge sees no reason to overturn the jury's verdict on liability, but considers the amount of damages awarded materially inaccurate, the judge may grant a new trial. But he may instead announce that he will grant a new trial unless the party benefited by the jury's erroneous damage award will accept a different, more accurate one. This judicial power is known as "additur" if consent to a higher award is procured from the defendant, and is called remittitur $(\quad)$ if consent to a smaller award is wrenched from the plaintiff. In neither instance is consent of the other party also required.

add-on clause. A provision originating in corporate mortgage forms but later extended to consumer financing instruments, pursuant to which all property from time to time procured from the same seller becomes security for payment of the entire aggregate debt until it is fully paid off. Hence, e.g., if a person buys a television set for $\$ 500$ in 1979 from XYZ store and then, in 1980 , when only $\$ 100$ is still owed, buys a stereo set for $\$ 300$, if, in 1981 , by which time $\$ 200$ more has been paid, the buyer defaults, the seller may repossess both stereo and television set, even though more than the whole price of the television set was paid by the time of the default. In a majority of states such clauses are now, with respect to consumer transactions, either prohibited, or modified by law such that the liens on earlier purchases are released as the total price of each is paid.

add-on interest. In loan arrangements, one way of stating and providing for repayment. The interest for the entire period is calculated in advance and added to the amount borrowed; then that sum is divided by the number of payments to be made to arrive at the amount of each payment. If, e.g., $\$ 1000$ is borrowed at $6 \%$ interest to be repaid in 12 monthly payments, one 
adds the $\$ 60$ in interest to the $\$ 1000$ principal, divides the $\$ 1060$ sum by 12 , and comes up with a required monthly payment of $\$ 88.33$. For the "real" interest rate being paid on this kind of loan, see annual percentage rate.

address. "To speak to," with some modern implication that the occasion is formal and the listerners are multiple.

Also what you should write on the envelope along with the addressee's name in order to get a letter successfully delivered.

Also a legislative device to initiate the removal of judicial or executive officers for alleged misconduct. (In the U.S., of course, only the impeachment process provided by the Constitution is available for Federal judges and other covered officers.)

Also, in equity practice, the name of the bill's formal identification of the court in which it is brought.

Finally, when either house of the English Parliament wishes to make known its wishes or opinions to the sovereign, the message they prepare and formally send is called an "address."

adduce ( ). To present, or bring forward, as in "adducing evidence" or "adducing arguments."

adeem ( ). To effect an ademption.

ademption ( ). The extinction of the right to receive a legacy by some happening other than modification or cancellation of the will containing it. The most common occasion for ademption is some act by the testator evidencing his desire to revoke the legacy, particularly the testator's inter vivos payment of money or delivery of property with intent to have that transfer take the place of the legacy, i.e., to prepay it prior to his death. But if the legacy is, e.g., of a specific animal which dies, or specific corporate securities which the testator sells, then too the legacy will ordinarily be treated as "adeemed." See also advancement.

adequacy. See adequate.

adequacy of consideration. See adequate consideration.

adequate ( ). Sufficient; enough; an act or quantity which will suffice for the particular purpose.

adequate care. In the context of negligence law, essentially the same as reasonable care.

adequate cause. See adequate provocation.

adequate compensation. One of the terms descriptive of that to which one whose property is taken by eminent domain is entitled, essentially equivalent to "fair compensation" or "just compensation."

adequate consideration. In contract law, a price that is not so disproportionate to the value of the other performance as to shock the conscience of the court (cf. unconscionability) or otherwise evince bad faith, overreaching, or 
fraud. But it must be kept in mind that, except under special statutes or circumstances, a contract is not unenforceable for want of consideration if there is any consideration present; i.e., "adequate consideration" is not prerequisite to a valid contract.

adequate legal remedy. See adequate remedy at law.

adequate provocation. In many jurisdictions, a homicide which would be classified as murder will be reduced to manslaughter if it was committed after "adequate provocation" (sometimes described as "adequate cause" or "reasonable provocation") coming from the victim. This provocation, to be "adequate," should be something which would so enrage or otherwise impassion an ordinary man that it would render him incapable of the reflection requisite for "true" murder. Hence, comparatively trivial provocations like insulting words or gestures or even slight batteries would not ordinarily amount to adequate provocation. Contrast self-defense, which is an excuse, not just a mitigation, of homicide.

adequate remedy at law. One of the reasons a court will refuse to exercise equitable jurisdiction, e.g., the issuance of an injunction, or an order of specific performance, is that the plaintiff has an "adequate remedy at law," i.e., the ordinary rules and procedures of law (as contrasted to equity) would grant a remedy sufficient to protect and vindicate plaintiff's right, e.g., money damages, or rescission and restitution. The apparent source of the rule lies in the originally solely supplementary and corrective jurisdiction of the English chancellors. At the present time, "adequate remedy" is more a term of art than a factual description, i.e., in whole categories of cases the plaintiff will be deemed to have, or not to have, an "adequate remedy at law" without regard to the actual situation. For instance, a typical court will order specific performance of a contract to sell land if an award of damages would be as adequate a remedy as it ever is, e.g., with respect to a tract house in a housing development. And the same court will refuse specific performance for most chattels (but see unique chattel) even though under the circumstances (especially given unrecoverable transaction costs) damages alone will not come close to making the plaintiff whole. But when no frozen category (land, commercial chattel) applies, courts will inquire into the factual adequacy of the legal remedy in ascertaining whether to grant an equitable remedy.

adeu ( ). Variant spelling of adieu.

ad exhaeredationem ( ). "To the disinheriting" or "to the injury of the inheritance"; formal words in an old writ of waste.

ad faciendum et recipiendum. See habeas corpus ad faciendum et recipiendum.

ad filum aquae ( ). "To the thread [i.e., center] of the water." Ordinarily, when the border between two tracts of real property is a river or stream, 


\section{Leff Dictionary of Law}

the title of each of these riparian proprietors runs to the middle of the stream separating them.

ad filum viae ( ). "To the middle of the way," i.e., to the center of a road. A term, like ad filum aquae, used to describe the ownership reach of adjoining landowners, in this instance when the border between them is a road or path. If the road is public, it may also describe the reach of the contiguous landowner's duties of repair.

ad fin ( ). Abbreviation of ad finem ( ), "to the end." It is used to indicate to a reader who has been cited to a reference to read from the place cited to the end of the chapter, section, etc., e.g., "See Leff, Swindling and Selling, ch. 2, pp. 13 ad fin (1976)." It is more usual in modern legal citation, however, to name the actual pages being cited, e.g., "Leff, Swindling and Selling 13-16 (1976)." Also see et seq.; ff.

ad finem. See ad fin.

adfines. Same as affines.

ad gaolas deliberandas ( ). See jail delivery.

ad' gravamen. See gravamen.

ad grave damnum ( ). "To the great damage," a frequent term in divers pleadings.

adherence ( ). In international law, "adherence" technically describes the act by which a state accepts or joins a treaty originally made between or among other states. It is often used more loosely, to include also the act of becoming an original party to a treaty. There also used to be a distinction between "adherence," which meant accepting only certain specified portions of a treaty, and accession, which meant becoming bound to all of it, but it is doubtful that that distinction is still widely recognized.

adhering. Supporting, or cleaving to. The most famous American context is Article 3, $₹ 3$ of the Constitution: "Treason against the United States, shall consist only in levying War against Them, or, in adhering to their Enemies, giving them Aid and Comfort."

adhesion contract. A species of contract marked out for greater judicial scrutiny (including invalidation and judicial modification) than the ordinary kind, on the ground that one of the parties, typically a consumer, is not given the opportunity to "make" the contract or shape its terms, but rather must either "adhere" to it as presented or not at all, on a take-it-or-leave-it basis. This state of affairs is said to arise because of inequality of bargaining power between the profferor of the contract and the "weaker" party. The concept must be used with caution, however. One set of legal responses would be proper with respect to "adhesion contracts" used by all members of a particular industry such that a consumer could not acquire certain goods or services at all except on a particular set of terms. But the same response might not be proper if each member of an industry refused to 
change the terms of its own contract, but the contracts of each were not identical, such that a consumer could get materially different terms by choosing to deal with one competitor rather than another. To be concrete, the situation in which all automobile manufacturer's put a disclaimer of warranty into their unmodifiable contracts would seem different from one in which half disclaim all warranties and half do not, or at least would "undisclaim" if paid extra.

ad hoc. "For this" or "for this particular purpose," e.g., "In the action touching on the child's inheritance, the court appointed an ad hoc guardian and attorney," i.e., persons appointed to serve in those roles for the particular litigation.

Pro hac vice is essentially identical in meaning, but is used almost exclusively to describe an attorney who is allowed to appear in a particular proceeding in a jurisdiction where he is not a member of the bar. The law reports will often say something like "Leon Silverman, Esq., appearing for the plaintiff pro hac vice, by special leave of the court."

"Ad hoc," however, has a more figurative and perhaps more important use, as a rough equivalent of "arbitrary" or "unprincipled." To say of a judge or (more likely) an administrator that "he decides everything ad hoc," is to accuse him of behavior not governed by, or predictable from, articulated rules. But it should be recalled that all decisions must be to some extent ad hoc, i.e., to some extent tailored to the particular situation under consideration. $C f$. cadi jurisprudence.

ad hominem ( ). See argumentum ad hominem.

ad idem. See consensus ad idem.

adieu ( ). In French, the term means roughly what "farewell" means in English. In Law French it seems to have been the rough equivalent of the Latin sine die, and as frequently used in the Year Books at the end of a case it implied the final dismissal, i.e., a very strong "good-bye."

ad ignorantiam. See argumentum ad ignorantiam.

ad indefinitum ( ). Indefinitely; for as far along as one can see.

ad inferos usque ad coelum ( ). Roughly, "From heaven to hell," once said to be the vertical reach of the ownership rights of an owner of real property. See a coelo ad centrum.

ad infinitum ( ). To infinity; on and on and on.

ad inquirendum ( ). An old writ instructing the recipient to investigate or inquire into something.

ad int. Abbreviation of ad interim.

ad interim ( ). Temporary; for the time being, e.g., "Harry will be ad interim chairman, till we can hold an election."

ad interim alimony. See temporary alimony. 
ad interim copyright. Prior to the new Copyright Act of 1976, the author of a book published in English in a foreign country could get five years of U.S. copyright protection, called an "ad interim copyright," by registering the book with the Copyright Office within six months of its foreign publication. Under the 1976 Act, ordinary copyright protection may be procured for these foreign-published books, and all ad interim copyrights obtained after 1972 automatically get it.

ad invidiam ( ). See argumentum ad invidiam.

adiratus ( ). Something lost or strayed; in Bracton, pecuniary compensation for stolen goods.

aditus ( ). An approach or way, especially a public way.

a divisione. See argumentum a divisione.

adjacent ( ). This word, together with adjoining, ordinarily implies physical touching, contiguity, with something else. Hence "adjacent land" or (even more so) "adjoining land" would usually refer to lands sharing at least part of a common boundary. But in numerous contexts both terms can also be seen to include merely nearby parcels, e.g., a statute specially assessing "adjacent property" for an improvement benefiting a particular neighborhood may be found to include property benefiting from, but not actually contiguous to, the improvement. To get the message across that truly contiguous property is intended, it might be necessary to use terms like "immediately adjacent" or "actually adjoining."

adjection ( ). Something added on, i.e., an old form of addition.

adjective law. See procedural law.

adjoining. See adjacent.

adjoining and communicating additions. Especially in insurance contracts, the words "and communicating" are added to make clear that the "additions" covered must be in some physical contact with the structures to which they were added. Adjoining alone might not be legally sufficient to get that message across sufficiently to convince a judge.

adjourn. To postpone, or put over to a future time, e.g., "The meeting is adjourned until June 5th." If the meeting is of some ad hoc group, and it is adjourned sine die, i.e., with no new date set, "adjourn" means in effect "end for good." When a continuing body, e.g., the Governing Board of the Yale Law School, is involved, and no particular new date is set, then, depending on the context, the adjournment lasts until the next proper call of a meeting, or until the next regularly scheduled meeting. If the adjournment comes at the end of a regularly scheduled period of more-or-less continuous meetings of a body (e.g., a regular legislative session or term of court), it lasts until the next regularly scheduled term or session begins, and in that case it is usually called a "final adjournment." See also adjournment sine 
die, and see pocket veto for a special constitutional-law meaning of "adjournment."

adjournatur ( ). "It is adjourned." In old reports the term ordinarily showed the conclusion of a case.

adjourned term. If a term of court is adjourned and then starts up again prior to the next regular term thereof, the continued portion is called an "adjourned term." If the term has ended, but a new one is convened prior to the next regular term, that is usually called an "additional term."

adjournment. See adjourn.

adjournment day. Either the day on which, or the day to which, a court or legislature adjourns. A very common special use of the term referred to that day set by English judges to try issues of fact not then ready for trial.

adjournment sine die ( ). When a continuing body adjourns "sine die," or just without setting a new date for meeting, that is an "adjournment sine die." When it comes at the end of a regular session of a legislature, or a regular term of court, it is the same as a "final adjournment," i.e., the body will not (except on extraordinary call) meet again until the next regularly scheduled session or term.

adjournment subject to call. Essentially the same as adjournment sine die. adjournment without day. The same as adjournment sine die-with the Latin translated.

adjudge ( ). Essentially the same as adjudicate, except that the ordinary legal speaker would be much more likely to describe a criminal defendant as "adjudged guilty" than "adjudicated guilty." (But that speaker would be even more likely to describe the defendant as "found guilty.") In addition, while "adjudicate" and "adjudication" can, in some contexts, refer to a process of judging prior to decision or entry of judgment, something described as adjudged would almost certainly mean decided, with the implication that a judgment had been formally entered.

adjudicate ( ). Essentially the same as adjudge, with the slight distinctions there noted. See also adjudication.

adjudication. This term may once have referred to the final (though perhaps subject to appeal) judicial decision of a matter, even with judgment formally entered. In modern usage, however, while saying that "there has been an adjudication of the matter" or "it has been adjudicated" would clearly have that meaning, "adjudication" can also be used as a rough synonym for "litigation," e.g., "the matter is in adjudication now."

The term is also used to denominate that method of third-party-aided dispute resolution in which the third party has the role of bindingly deciding the issue between the disputants, usually by establishing facts and applying rules. It is used in contradistinction to, e.g., mediation and conciliation. 


\section{Leff Dictionary of Law}

adjudication in bankruptcy. Until the Bankruptcy Reform Act of 1978, the determination that a person was a bankrupt was called an "adjudication in bankruptcy." Under the new Act, the same determination is called an "order for relief."

adjudicative power. See judicial power.

adjudicatory ( ). A term used to distinguish the quasi-judicial functions of certain administrative agencies from their regulatory functions. The NLRB, e.g., promulgates rules for union representation elections, sends officers to oversee them, and so forth, all as part of its regulatory business. But the Board also has adjudicatory functions, for it will also adjudicate allegations of irregularities in [those] elections, and may even appear as a party before its own adjudicative officers.

adjunction. See accession.

ad jura regis ( ). A writ brought by one holding a living (usually clerical) from the King against one seeking to oust him from it (to the prejudice of the King's title).

adjuration ( ). Solemnly putting someone on oath to do something; thus, by extension, solemn entreaty or advice, e.g., "He adjured his son to mend his evil ways."

adjure. See adjuration.

adjust. To modify something so as to fit it for a particular purpose. There are at least two special and common legal uses of the word. One, primarily found in tax law, is to describe a particularly modified later state of a defined concept. "Adjusted basis," e.g., refers to the basis (i.e., usually, the cost) of property to which subsequent capital improvement is added and from which subsequent allowable depreciation is deducted. Similarly, gross income, as defined, less legally allowable exclusions, etc. becomes "adjusted gross income," itself subject to further manipulations on its way to becoming "taxable income."

The second important legal use of "adjust" is essentially as a synonym for "settle" as in settle a dispute or claim. The buried larger concept seems to be something like "adjust the views of the contending parties until a position is reached satisfactory to both." Hence a "claims adjuster," also called a "claim representative" or "insurance adjuster" (and often just called "adjuster"), is a person whose job it is to investigate, bargain and eventually bring about the adjustment of claims against an insurance or other business on behalf of either the claimant or person claimed from (see public adjuster). And an "adjusting agency" or "adjustment agency" may mean a business which, on behalf of a debtor, arranges a settlement satisfactory to his creditors.

But "adjustment agency" may also be synonymous with "collection agency," i.e., a business which collects debts. This points up a development over time in the meaning of "adjust" such that it now may also be used as a 
synonym for "pay," i.e., with no necessary mutual modification of the amount. Hence "he adjusted his debts prior to arranging further borrowing" may just mean he paid them off in full.

adjustable policy. See reporting policy.

adjusted basis. See adjust.

adjusted gross income. See adjust.

adjuster. See adjust.

adjusting agency. See adjust.

adjustment. See adjust.

adjustment bond. A bond issued in connection with the reorganization of a corporation, so called because it is a device for readjusting the relative interests of the various classes of securities holders. Other securities, e.g., common and preferred stock, are also sometimes issued.

adjustment clause. See burned and unburned clause.

adjustment securities. Corporate securities issued during a corporate reorganization.

See adjustment bond.

adjutant general. High ranking officer in army and national guard units, ordinarily charged with administrative duties involving official records and personnel.

adlegiare. See purgation by oath.

ad lib ( ). Abbreviation of the Latin ad libitum, "at pleasure" or "at will," now used as an English term meaning extemporaneous or "off the cuff," e.g., "He got up and ad libbed a few words of thanks."

ad litem ( ). "For the purpose [or "during the pendency"] of the litigation" with the additional implication "and not otherwise or thereafter." The most important modern use is in guardian ad litem.

ad lucrandum vel perdendum ( ). "For profit or loss," a phrase emphasizing the wide scope of power granted in old powers of attorney, especially those enabling the appointed party to confess judgment against the grantor (which were usually called "warrants of attorney" and are now usually described as powers of attorney to confess judgment and are contained in cognovit notes).

Adm. An abbreviation of "admiral," "admiralty," "administrator."

admanuensis ( ). A person who takes his oath laying his hand on the Bible. Should not be confused with amanuensis.

admeasurement. A process of calculating or measuring, and then allocating, something of value, usually real property, to a person entitled to a particular share, e.g., when execution is sought against a debtor who is entitled to 
keep some amount of homestead free from claims of creditors, a necessary process prior to execution would be an "admeasurement of homestead."

admeasurement of dower. The process of admeasurement applied to ascertaining a widow's dower, and also the name of a writ commanding the process. An older writ gave the same name to a writ by an heir against a widow, by which the heir claimed that she had been assigned too much as dower. The Latin name of that writ was "de admensuratione dotis" ( ).

admeasurement of homestead. See admeasurement.

admeasurement of pasturage. An ancient writ to determine the relevant rights of persons holding pasture land jointly or in common.

ad medium filum aquae. See ad filem aquae.

ad medium filum viae. See ad filum viae.

ad melium inquirendum ( ). An old writ directing another or further inquiry, especially to a coroner directing another inquest.

admensuratione dotis. See admeasurement of dower.

adminicular ( ). Corroborative or auxiliary, as in "adminicular evidence."

administer. To give to, as in "He administered poison to the victim (or "justice to the litigants")." Or, to manage, or run, e.g., a business, a government agency, or a decedent's estate.

administered estate. A decedent's estate, the administration of which by its administrator or executor has been completed, i.e., all proper debts and administrative expenses have been paid, and the remainder of the estate distributed to those entitled thereto.

administered price theory. A theory proposed by some economists that the prices charged by most or at least many large industrial corporations are "administered," i.e., not set by market forces but by actual or tacit collusion among the firms (which are all "price makers" rather than "price takers") making up the industry. These administered prices are supposed to be set with reference to cost factors and to be much less responsive to market conditions than competitively determined prices, but they are not immune from market forces, and their very possibility depends upon imperfect competition. There is some evidence from some industries of apparent imperviousness of prices to changes in market conditions, but the administered price theory cannot be said to have been either widely or generally proved or disproved.

administration. The process of administering. "The administration" refers to the then incumbent government or, more particularly, to the executive branch thereof, sometimes specified by the chief executive, e.g., "the Eisenhower administration."

administration ad colligendum ( ). Temporary administration of a decedent's estate, ordered when the ordinary processes of appointment, e.g., 
because of a will contest, would not come up with an administrator quickly enough to protect and preserve the estate. The administrator so appointed is usually called, not surprisingly, a "temporary administrator."

administration ad litem ( ). When the estate of a decedent is or should be involved in some legal proceeding prior to the appointment of an executor or regular administrator, the court with jurisdiction over the estate may appoint an "administrator ad litem," i.e., an administrator for the purpose of, or during the pendency of, the litigation.

administration cum testamento annexo ( ). Administration "with will annexed," i.e., administration of a decedent's estate when the decedent did leave a will, but did not name an executor, or named one who for one reason or another did not qualify and serve. This kind of administrator is almost always referred to as "administrator c.t.a."

administration de bonis non ( ). Short form of administration de bonis non administratis ( ), i.e., "administration of goods not administered." When an executor does not qualify, or for any reason (e.g., resignation, removal or death) ceases to serve in the administration of a decedent's estate, the court will appoint an administrator, and an "administration de bonis non" thus comes into being. This administrator is almost always referred to as an "administrator d.b.n."

administration de bonis non cum testamento annexo ( ). That form of administration of a decedent's estate which eventuates when an administrator is appointed to succeed an executor. I imagine that such an administrator may be referred to as "administrator d.b.n.c.t.a." but the mind reels.

administration durante absentia ( ). "Administration during absence," i.e., administration of the estate of a decedent during the absence of the person most entitled to the appointment as administrator. Sometimes also called "administration pendente absentia" ( ). Nowadays, unless this likely administrator were expected back very shortly, he would be likely to be passed over for another.

administration durante animo vitio ( ). "Administration during unsound mind," i.e., administration of a dececlent's estate during the absence of a next of kin entitled to the administration who, because of unsound mind, cannot actually do the administration on his own. Nowadays it would be the ordinary practice just to pass over the incompetent and appoint a competent administrator.

administration durante minoritate administratoris ( ). "Administration during the administrator's minority," i.e., administration of a decedent's estate during the minority of the named executor, or person normally entitled to appointment as administrator. Nowadays it would be the ordinary. practice just to pass over the minor and appoint an administrator of full age. Indeed, unless perhaps the minor executor were very shortly going to achieve his majority, this would also be the modern course of action if the 
named executor were a minor, though in earlier days a temporary substitute, called an "administrator pendente minoritate executoris," ( ) or an "administrator minori aetate" ( ) would once have been appointed.

administration expenses. The person charged with administration of estate of any kind will naturally incur and pay expenses of various sorts in connection therewith, e.g., rent on leased property part of the estate, insurance premiums, attorneys' fees, bank charges, etc. The number and type of these authorized expenses will vary depending on the kind of estate administered (e.g., between an estate in bankruptcy and a decedent's estate) and on the terms of the particular governing statute. As a general rule, these administration expenses, if proper, receive the highest priority, i.e., they come first out of the estate, with all other lawful disbursements (except, under some circumstances, taxes) coming only later, out of what is left.

administration minori aetate. See administration durante minoritate administratoris.

administration of estate. The process of protecting and managing an estate for the benefit of, and with fiduciary duty toward, another person or persons, with the expectation that the estate will eventually come to an end, and its remaining assets, if any, will be distributed to others who will then own them outright. The kinds of estates which may be involved are various-debtors, bankrupts, incompetents, decedents, trust settlors, all generate estate administrations-and the detailed rules governing what is proper administration are equally diverse (from kind to kind and jurisdiction to jurisdiction). Moreover, the names of the administrators are also divers; executor, administrator, trustee, guardian, receiver are all used to describe persons engaged in the "administration of an estate." See also administrator of a decedent's estate.

administration pendente absentia. See administration durante absentia.

administration pendente lite ( ). "Administration during litigation," the litigation referred to being the contest over the decedent's will. Hence pendente lite administration (also sometimes called "special administration") is often temporary, lasting only until the will contest is ended and an executor or more permanent administrator of a decedent's estate is installed.

administration pendente minoritate executoris. See administration durante minoritate administratoris.

administration pro tem ( ). Administration "for a time" or "for the time being." See temporary administrator.

administration without probate. See executor de son tort; independent executor.

administrative act. See ministerial act.

administrative agency. The broadest term in use to describe an entity (which 
could be, but rarely is, a single official) wielding governmental authority. A large number of names may be given to administrative agencies, e.g., "board," "commission," "department," "bureau," "authority," "administration," "institute"-and more. There may be some tendency to refer by the term to the independent agencies of the Federal government, but it is only a tendency, and the term is certainly not so restricted in actual use.

administrative appeal. The term is employed for two sharply different procedures: (1) a formal appeal taken within an administrative agency, from a lower to a higher officer thereof; and (2) an appeal to a court from a final decision of an administrative agency.

administrative assistant. Anyone who assists someone in administering something could be so called. But the most important current context is Congressional, where "administrative assistant" refers to the ordinarily highest ranking member (though sometimes the legislative assistant is of equal rank) of the staff of a member of Congress. Thus, "the A.A.," as the administrative assistant is usually called, is the equivalent of "head of office" or "chief of staff," and frequently a person of substantial influence and power.

administrative board. See administrative agency.

administrative capacity. The term, in the context "employed in an administrative capacity," has a specially defined meaning under the Fair Labor Standards Act. See also ministerial act.

administrative commission. See administrative agency.

administrative discretion. See ministerial act.

administrative employee. An employee in business or government who may have an important role but is supposed to lack managerial or discretionary authority. The real existence of a real being fitting that description is problematic. See discretion; ministerial act.

administrative law. The law pertaining to administrative agencies. The term includes both law about such agencies, e.g., statutes and judicial decisions relating to the scope of the agency's authority, the procedures to be used by the agency in carrying out its adjudicatory and rulemaking functions, the law governing appeals from agency decisions to courts, and so on, law of such agencies, i.e., their internal procedures and substantive rules, including the "common-law" of agency adjudicatory decisions.

administrative law judge. A public officer carrying out for an administrative agency under administrative law those functions carried out by a judge. They are not, however, "Article-Three Judges," and until recently, were called "hearing examiners."

administrative officer. Most broadly, an employee in government or business charged with administering an enterprise. See administrative employee. More narrowly, an officer in the executive branch of the U.S. government, 
as contrasted with the judicial and legislative branches. Most narrowly, an officer of an administrative agency. Only context can indicate which is meant in a particular case.

administrative offices of court. See court administrative offices.

administrative order. The administrative agency equivalent of an order of court.

administrative ordinance. See executive ordinance.

administrative power. The power to administer the laws, i.e., to apply them to practical situations. This power is mostly lodged in the executive branch of government (including administrative agencies) where, however, it must ordinarily be exercised subject to legislative (and constitutional) control, though the U.S. Constitution provides for some executive power not subject to legislative or judicial control. The power will generally include not just management and control, but investigation and enforcement against recalcitrant persons, though the latter powers may ultimately require the invocation of judicial power.

administrative practice. Practice of administrative law, either internally by or before an administrative agency or, before a court, about such law or practice. See also administrative procedure.

administrative procedure. The procedural law used by administrative agencies to govern their own activities, both adjudicatory and other. In the Federal government, the basic statute governing administrative procedure is the Administrative Procedure Act (5 U.S.C. $\$ 1001$ et seq.) and some states govern their own agencies by statutes modeled (sometimes loosely) on that Act.

Administrative Procedure Act. See administrative procedure.

administrative proceeding. Any reasonably formal proceeding in or before an administrative agency, often used to distinguish the activity from a judicial proceeding.

administrative remedy. A remedy granted by an administrative agency, or by a court enforcing (perhaps with modifications) the agency's order.

administrative reports. Published opinions and orders of administrative agencies, almost wholly of their adjudicatory activities. The equivalent of law reports, but for an administrative agency.

administrative review. The term can mean either the review within an administrative agency of the decision of an officer or employee thereof, or the judicial review of a decision or judgment of an administrative agency.

administrative system. A term sometimes used to describe the general mission of an administrative agency or agencies, e.g., "The FCG operates an administrative system for the regulation of the airwaves."

administrative tribunal. The administrative agency equivalent of a court, 
usually implying the equivalent of trial court. Some agencies have permanent tribunals, while others employ administrative law judges supplied as needed from a pool serving more than one agency.

administrator. Most broadly, anyone who administers. In some legal contexts, administrator is frequently used as synonomous with administrative officer. The most common legal referent for "administrator," however, is the administrator of a decedent's estate.

administrator ad colligendum. See administration ad colligendum.

administrator c.t.a. See administration cum testamento annexo.

administrator cum testamento annexo. See administration cum testamento annexo.

administrator d.b.n. See administration de bonis non.

administrator de bonis non. See administration de bonis non.

administrator de bonis non cum testamento annexo. See administration de bonis non cum testamento annexo.

administrator durante animo vitio. See administration durante animo vitio.

administrator durante minoritate administratoris. See administration durante minoritate administratoris.

administrator of absentee. An administrator of a decedent's estate, except that in this instance the person whose estate is involved is only presumably a decedent, having disappeared for the requisite period. See presumption of death.

administrator of a decedent's estate ( ). Most people when they die both own assets and owe debts, i.e., they leave an "estate." See estate of decedent. In many cases a decedent's estate is handled privately, with no formal legal intervention of any kind. If, e.g., Mr. Mortis dies owning some personal effects, and owing some money to a few people, his widow and children, if any, will divvy up what he left and pay off what he owes, and whether one is technically required by law to do so or not, no one will go near a court. But when the estate is more substantial and complex it is the practice of a court with jurisdiction (usually a probate court) to appoint (technically: "issue letters of administration to") an "administrator," whose job it will be to care for and manage the estate, pay all of its proper debts and then distribute whatever is left to those entitled to it-under the applicable intestate laws if the decedent left no will, or to those named in the will if the decedent left one. In the usual case, the court will choose as administrator the next of kin (usually spouse or adult child) of the decedent, or at least some close relation, though if the estate is large, or objection or contest is raised by, or expected from, some claimant against the estate (or, it is sometimes alleged, if some political crony of the judge needs the administrator's fee), an independent, i.e., non-family, administrator will be appointed. 
When the person with the role of administrator is named in the will of the decedent (and accepted by the court), he is called an executor.

administrator pendente absentia. See administration durante absentia.

administrator pendente lite. See administration pendente lite.

administrator pendente minoritate executoris. See administration durante minoritate administratoris.

administrator's right of retainer. In its earliest use the phrase referred to the right of the administrator of a decedent's estate who was also a creditor thereof to "retain" from the estate the amount it owed him. It is now also used to cover the administrator's right to deduct from the amount otherwise payable to a distributee of the estate the amount the distributee owes the estate. (There is also an essentially identical "executor's right of retainer.")

administrator with the will annexed. See administration cum testamento annexo.

administratress. Rarely encountered variant form of administratrix.

administratrix. The name given to a female administrator of a decedent's estate.

admiral. The highest rank in the U.S. Navy, the equivalent of "general" in the Army. There are ordinarily three grades: admiral, vice-admiral, and rear admiral (in descending order of rank), roughly equivalent to general, lieutenant general, and major general. (The naval rank of commodore-very roughly equivalent to brigadier general-is presently not in active use.) There is also a rank higher than plain "admiral" called "admiral of the fleet," this being the equivalent of General of the Army, both "five star" ranks. While one or two military officers of such rank may still be alive, no new ones are presently being created.

\section{Admiral of the Fleet. See admiral.}

admiralty. See maritime law.

admiralty court. See admiralty jurisdiction; maritime law. For England, see High Court of Admiralty.

admiralty jurisdiction. See maritime law. In the U.S., the Constitution (Art. III, $\S 2$ ) specifically gives the Federal courts jurisdiction over "all Cases of admiralty and maritime Jurisdiction."

admiralty law. See maritime law.

admissible evidence. Evidence which, when offered in any legal proceeding, may properly be heard and considered by the trier of fact. Why, one might ask, should any proffered evidence ever be not admissible? There are several general grounds.

First, some evidence is said to be "irrelevant," i.e., to have no bearing upon the existence of any fact at issue in the proceeding. It is rare, however, that any evidence actually offered has no such bearing; it is almost always 
possible to construct a chain of inference eventually connecting the offered evidence to some issue in the case. Hence, a ruling that certain evidence is "irrelevant" ordinarily means one of two other things. A ruling that certain evidence is irrelevant is often a ruling about the substantive law of the case. For instance, if a party offers evidence that the defendant orally warranted certain goods, but the substantive law has it that a written disclaimer of warranty defeats all earlier oral warranties, when the judge refuses to admit testimony about the oral warranty, he is merely announcing and applying the substantive law.

By "irrelevant," however, the judge may really mean that while the proffered evidence does to some substantial extent make the truth or falsity of an issue in the case [more] or less probable, it still, for one reason or another, should not be admitted, e.g., that it is excessively time-consuming to hear this evidence on the issue, given its unimportance to the overall case, or that the evidence offered will, if admitted, unavoidably carry with it other facts which are highly prejudicial but under the substantive law not at all relevant to the case (e.g., that the defendant in an automobile-tort case is filthy rich). This meaning of "irrelevant" is sometimes expressed by the term "immaterial," but the usage is really quite fluid, and "immaterial" may also be used to mean essentially the same as "irrelevant" in its broadest reach.

Sometimes, however, evidence which is clearly both relevant and material is still ruled inadmissible because of some other rule [or] policy of the law. The most obvious example involves evidentiary privileges, e.g., the privilege of a party to prevent his attorney from testifying as to matters discussed between them. (See attorney and client privilege.) It is frequently the case, of course, that the attorney's testimony would be highly relevant and material, often dispositive, but the law considers the sanctity of the attorney-client relationship sufficiently important to outweigh the loss of good evidence entailed by recognizing the privilege. The same is true of hearsay. This last kind of inadmissible evidence is sometimes called "incompetent evidence," but once again the usage is not at all stabilized, and when an attorney objects to evidence as "incompetent" he may just be saying "I don't want it in, but I'm not quite able instantly to articulate now the grounds why." Indeed, an attorney at a trial will often be heard to say "objection, your Honor; the evidence is incompetent, irrelevant, and immaterial," when, in default of being able to think of a more precise ground (e.g., hearsay, or privilege), he just wants to touch all bases.

In any event, the Federal courts (mainly in the Federal Rules of Evidence) and all state courts have elaborate rules (usually at least partly codified) about what evidence is "admissible evidence."

admission. There are two important uses of this term in the language of litigation. One refers to what is more precisely called a "judicial admission," i.e., an admission of a fact relevant in a lawsuit which will render that fact established for purposes of the action. This admission may be made in sev- 
eral ways. The most pervasive and invisible of these is to keep silent about something in a pleading or during a trial. For example, if I am sued for breach of contract, and I do not plead fraud or duress, or, having pleaded it offer no evidence on it, I in effect "admit," for purposes of my defense, that there was no fraud or duress in the making of the contract, and I will be bound to that thereafter (unless I can properly amend, replead, or offer further evidence).

An admission may also be made more explicitly in a pleading. If a plaintiff alleges in his complaint that the defendant is a "resident of New York," and the defendant in his answer either explicitly admits the truth of that residency allegation, or (in almost all procedural systems) merely fails to deny it, the fact of his New York residency will be taken as established (again, subject to permissible amending or unpleading powers). Moreover, there are various procedural devices (e.g., request for admissions; pretrial stipulations) designed to elicit these binding admissions. And, of course, a party may (frequently when so requested by a judge) just admit something in open court (e.g., "Counselor, do you deny that your client sent this letter?" "No, your Honor, he sent it all right, but it doesn't mean what it seems to mean.").

In the law of evidence, however, "admission" also has an important meaning-it is short for "party admission" and as such denominates the following important exception to the hearsay rule: A statement which would otherwise be inadmissible hearsay will be admissible if the declarant whose statement is offered is a party (or in privity with a party) to the action at which the statement is offered. Unlike a declaration against interest (another hearsay exception) any relevant party statement is admissible, even if it were not "against interest" when made. (Naturally, it is likely to be against the party's interest when offered, else why would the other party be offering it?) Hence if a person once said to a tax collector, "This old house? Why it's hardly worth $\$ 20,000$," the tax collector can testify to that statement in a subsequent action to take the same property under the power of eminent domain, in which action the landowner is claiming that the old house is worth at least $\$ 100,000$. But such [a] statement, even though admissible, is not binding on a party, the way a judicial admission would be. It is open to the party to try to convince the trier of fact that he was shaving the truth to the tax collector, and that the true value is $\$ 100,000$.

The distinction between "party admission" and "declaration against interest" is important to keep in mind, especially since many lawyers and judges, to the despair of those trying to keep things straight, have the terrible habit of referring loosely to both as an admission against interest. See also admit.

admission against interest. A common and confusing locution which obliterates the important distinctions between a "declaration against interest" and a "party admission." See admission. 
admission by demurrer. When one files a demurrer (or any otherwise named modern motion in the nature of a demurrer) what one is saying, in effect, is "even if everything he says in his pleading is true, I still ought to win." That is, for purposes of the demurrer, everything properly pleaded is treated as if it were true. But if the demurrer is overruled, then the facts again become not admitted and must be proved, i.e., an "admission by demurrer" is neither a judicial admission nor an evidentiary admission: The facts are as if they had never been admitted.

admission of a lien. See admit.

admission of new state into Union. See admit.

admission of party. See admission.

admission tax. An excise tax imposed upon the sale of an admission ticket.

admission ticket. A license granted by the proprietor of an exhibition or performance of some kind, e.g., a theatrical or musical performance, or a sporting event, entitling the holder (usually the purchaser) to attend the event. It is not treated as an interest in real property (e.g., a short-term lease), even though a specific seat or location is often stipulated; the relationship between the proprietor and ticket holder is contractual only. The terms printed on the ticket may be part of their contract but, as with all contracts, the terms of the actually subsisting contract may also be supplied otherwise, e.g., by custom. Hence, e.g., it may legally be the case that one cannot get one's money back if it rains part way through an outdoor concert, but that one can if the prima ballerina doesn't show up, all without any mention made on the ticket. Some tickets, however, do deal with such questions explicitly, e.g., the four-and-a-half-innings-is-an-official-game provision of the typical baseball ticket "rain check."

admission to bail. See admit.

admission to membership. See admit.

admission to probate. See probate.

admission to the bar. The formal grant, usually taking the form of a formal order of court, of a privilege to the practice of law, issued by the jurisdiction within which the practice is to take place. Each jurisdiction may impose its own requirements of education, knowledge, residence, and moral character, with compliance often determined by examination (see bar examination; character committee). The standards applied may not, of course, any more than those for any other governmental action, violate the Constitution, e.g., there could be no "whites only" requirement. But the various jurisdictions otherwise have very wide discretion in setting their own requirements.

admit. To admit a person is to allow or bring about his entry into a place or a status. Thus one can be admitted to bail, to membership in a club, to the bar or, for that matter, into someone's heart. For formal admissions formal 


\section{Leff Dictionary of Law}

rules are ordinarily prescribed by law. Sometimes, to admit a person into a place thereby also changes his status; one admitted into one's home is not (at least until ordered to leave) a trespasser, and an alien admitted into the U.S. has a different status from one who slipped across the border.

admittance ( ). In general, a synonym for admission, e.g., in the ubiquitous sign "No admittance."

The term also has a special (now mostly archaic) legal meaning as the name of the final stage in the acquisition of an English copyhold tenancy.

admitted assets. An insurance-industry term for those assets permitted by the relevant regulatory authority to be taken into account in assessing the financial condition of an insurance company for various purposes. The formulae are often quite complex, but the trend is to consider as not part of "admitted assets" categories of highly contingent or very non-liquid assets, the idea being that what should especially count for insurance companies are assets upon which they can lay their hands swiftly and surely for the payment of claims.

admittendo clerico ( ). An old writ to an ecclesiatical officer, usually a Bishop, to establish the right of the King to present to a benefice, i.e., to fill a clerical position. Also a writ issuing on behalf of the victorious party in an action quare impedit.

admittendo in socium ( ). An old writ to procure the association of Knights and other gentlemen of the country to the justices on circuit for the holding of an assize.

admonition. A formal warning or piece of advice, e.g., by a judge to jurors reminding them of what their duty is.

admonitio trina. See trina admonitio.

admortization ( ). Putting land into mortmain. Also written "amortization."

admr. (or adm'r). Abbreviations for administrator.

admx (or adm'x.). Abbreviations of administratrix.

ad nauseam ( ). Roughly "till it makes you sick of it," e.g., "He protested his innocence ad nauseam."

ad nocumentum liberi tenementi sui ( ). "To the nuisance of his freehold tenement," formal words used in an assize of nuisance.

adolescence ( ). Technically, the period of a person's life between the onset of puberty and the age of legal majority. More figuratively, what one calls a person who behaves neither like a child nor like a grownup, but either simultaneously or in rapid oscillation, like both. When a statute particularly singles out adolescence, care is ordinarily taken also to specify by chronological age.

adopt. To make one's own that which was not before, as an idea, a position, an 
attitude, or even a person (see adoption of child). By extension it can also mean "to approve."

adopted child. See adoption of child.

adoption. See adopt; adoption of child.

adoption act. A statute governing the process of adoption of child. One of the uniform statutes is the Uniform Adoption Act, but it has been enacted by only a few states.

adoption by acknowledgment. Not really "adoption" at all in the sense of adoption of child, but a method for the legitimation of a natural child under statutes that provide that if a father acknowledges that a child born out of wedlock is his, it becomes his legitimate child.

adoption by deed or agreement. A procedure provided by some statutes whereby an adoption of child may be effected by a writing prepared, executed, and otherwise in conformity with requisite formalities, often including recordation.

adoption of child. The formal legal procedure by which one makes a person not so related biologically into one's "child" in contemplation of law. In most jurisdictions the procedure is subject to very close oversight and regulation, at least with respect to minor children, ordinarily requiring a court order to make the adoption final. (Less stringent requirements may attend the adoption of a close relative, e.g., a nephew, or the child of one's then spouse.)

The adopted child is today ordinarily treated for all legal purposes as if it were a biological child of the adoptive parent, but a problem may still arise with respect to wills and trusts referring to "children" of a person, or his "heirs," or his "issue," whether adopted children were meant to participate. As usual, the intention of the testator or settlor will govern if it can be ascertained, but if that intention is not fairly ascertainable, the tendency seems [to] be to include the adopted child.

adoption of foreign corporation. The process by which a foreign corporation becomes a domestic corporation, i.e., by getting a new charter in the new state.

adoption of judgment. Some self-serving uses of a judgment will terminate the user's right thereafter to appeal or otherwise attack it, e.g., using it to seek some legal redress against a third party, or using its terms defensively against the original other party.

adoption of statute. This may once have referred only to the legislative portion of the process of enactment of a statute, i.e., the portion prior to the executive's role, but it is now also used synonymously with enactment. Hence, "date of adoption," when said of a statute, ordinarily refers to the date upon which the whole process was completed and the statute became law. 


\section{Leff Dictionary of Law}

adoptive child. A child who has been adopted; the parent is called an "adoptive parent."

adoptive parent. See adoptive child.

ad ostium ecclesiae ( ). "At the church door," i.e., at one's marriage, most of which were once in England there solemnized. This public ceremony became a convenient place to perform important legal ceremonies ancillary to marriage, e.g., the establishment of dower ad ostium ecclesiae.

ad perpetuam ( ). "In perpetuity," or "forever"; a term used, e.g., in medieval grants of immunity from feudal duties of various kinds.

ad prosequendum. See habeas corpus ad prosequendum.

ad quem ( ). "To which," e.g., a court "ad quem" was one to which a case was removed.

ad querimoniam ( ). "At the complaint [of]."

adquieto ( ). To end; to put to rest; to satisfy or pay off (a debt). See quietus.

ad quod curia concordavit ( ). "To which the court agreed," a tag found in old reports.

ad quod damnum ( ). An old writ issued to a sheriff directing that he make inquiry to discover "to what damage" a particular Royal action would contribute. Among the various actions the effects of which were to be checked were issuances of Royal licences to uphold a market or fair; to alienate into mortmain; or to build or divert a road.

ad quod non fuit resporsum ( ). "To which there was no answer," a phrase found in old reports.

ADR. Abbreviation of Asset Depreciation Range; American Depositary Receipts.

ad recipiendum. See habeas corpus ad deliberandum et recipendum; habeas corpus ad faciendum et recipiendum.

ad referendum ( ). To be referred; to be put over for subsequent attention. ad rem ( ). See right ad rem.

ad respondendum ( ). See capias ad respondendum; habeas corpus ad respondendum.

adrift. Floating on water and not within the control of anyone (if, as with a ship, anyone were aboard). Ships and goods adrift are, in maritime law, subject to salvage. See also flotsam.

ads. Abbreviation for ad sectam. See also "ats."

ad satisfaciendum. See capias ad satisfaciendum; habeas corpus ad satisfaciendum.

ad sectam ( ). "At the suit of," almost always seen in one of its abbreviated 
forms, "ads." or "adsm." It is used when the defendant in a lawsuit is, for one reason or another, to be listed first, e.g., when Cover sues Fiss, the normal listing would be "Cover v. Fiss," whereas the "ad sectam" listing would have it "Fiss ads. Cover."

adsm. Abbreviation of ad sectam.

ad subjiciendum. See habeas corpus.

ad terminum annorum ( ). "For a term of years."

ad terminum panere ( ). To postpone to another term.

ad terminum qui praeterit. An old writ of entry, to be brought "for a term which has passed," i.e., by the landlord of premises which were still being occupied by a tenant whose term had expired.

ad testificandum. See habeas corpus ad testificandum.

ad tractandum et consilium independendum ( ). An old writ issued at the beginning of every Parliament, summoning judges and other high officers of state to "attend and give good counsel" in the House of Lords.

adult. For legal purposes, one who has reached the age of majority. More generally, a "grown-up," which status may come earlier or much later.

adult children. Children who have reached the age of majority. When children become "adult children," almost all special rights and duties subsisting between them and their parents cease, though there are occasional instances of statutes imposing on adult children a duty to support their parents.

adulter ( ). Variant form of "adulterer."

adultera ( ). Variant form of "adulteress."

adulterant ( ). Material added to something else which makes the latter adulterated.

adulterare ( ). A verb encompassing divers bad acts, meaning, depending on the context, adultery, adulteration, forgery, or some other species of falsification.

adulterated. Something is "adulterated" ("debased" is a rough equivalent) when something else is added to it which makes it less pure, wholesome, or valuable. It is not necessary (though it may be sufficient) that the added substance be itself harmful (e.g., packed ham into which water has been pumped may be found "adulterated"), or even that it be itself less costly (e.g., mercury may be more valuable than the fish into which it finds its way), so long as the resulting product is not all and only what it is presented to be. But usually adulteration will result in a product either cheaper and less good (or affirmatively bad) for you than one to which no additional material was added. In some cases, e.g., "adulterated butter" or "adulterated drug," much more particular descriptions of what renders the product "adulterated" are supplied by statute.

adulterated butter. See adulterated. 


\section{Leff Dictionary of Law}

adulterated coinage. Also called "debased coinage." Coinage of money in which valuable metals, e.g., gold and silver, have had added to them less valuable "base" metals, e.g., lead. The purpose, of course, is to create a greater apparent value for the coins than their actual content would support, and the debasing was usually carried out by governments; Henry VIII, e.g., financed the end of his reign by debasing English coinage (thereby contributing to a significant inflation), and it has been argued that modern governments achieve the same purpose by increasing the papermoney supply. If, however, the coins are known to contain a particular percentage of less valuable metal, or indeed are "base coins," i.e., known to be wholly made out of base metals, then they are neither "adulterated" nor "debased."

adulterated drug. See adulterated; adulteration.

adulterated food. See adulterated; adulteration.

adulteration. The process of rendering something adulterated. It should be noted that for conviction under most statutes dealing with "adulteration," it is not required that anyone intended to adulterate nor, frequently, even that the adulteration have occurred through negligence.

adulterer ( ). A person who commits adultery. In modern usage, may include males and females.

adulteress. A female who commits adultery.

adulterine bastard. The child of a married woman by a man other than her husband. As "adultery" has come to include sexual relations by a married man with a woman not his wife, whether she is married or not, the term "adulterine bastard" has sometimes come to include a child born to an unmarried woman by a married man. This makes little difference as no legal consequences presently seem to attach to adulterine bastardy that do not attach to plain old bastardy. See adultery; bastard.

adulterium ( ). A fine once imposed for adultery.

adulterous bastard. See adulterine bastard.

adultery ( ). At common law, sexual intercourse between a man and a married woman other than his wife. If both were married, it was sometimes called "double adultery," but if the man [was] married and the woman was not, "adultery" was not committed. Presently, by statute in most jurisdictions it is "adultery" if either or both are married. In many places adultery is the basis for tort and criminal action, and almost everywhere it is (subject to certain defenses) grounds for divorce. See also adulterine bastard.

In ecclesiastical law, improper intrusion into a bishopric was also called "adultery."

ad usum et commodum ( ). "For the use and benefit."

ad val. Abbreviation of ad valorem.

ad valorem ( ). "According to the value," as in "ad valorem tax." 
ad valorem duty. See ad valorem tax.

ad valorem tax ( ). A tax on the value of something, ordinarily expressed as a percentage to be applied to that value, e.g., a tax of " $8 \%$ on the value of steel shipped into the U.S." The ad valorem tax may be contrasted with a "specific tax," e.g., " $\$ 25$ per ton of steel." Customs duties are very commonly ad valorum taxes, but sales taxes and most property taxes are too, e.g., "the new property tax rate is 15 mills for each $\$ 1000$ of assessed value." The obvious problem with the administration of an ad valorem tax is that the property involved has to be valued, and that opens the way to error, corruption, and arbitrariness. (Other types of taxes, of course, have their own problems.)

advance. To "advance" something, usually a sum of money, is to deliver it before it is "earned" by the recipient's counter performance, and thus "an advance" means that which is delivered. In a sense, an advance is always a loan in that it is understood that it ought to be given back if the counter performance is not eventually forthcoming, but that does not mean that an advance is something delivered before due; one can, after all, be obliged by contract to make a loan. Thus, to pick one of the most important ordinary uses of "an advance," an author may by agreement with his publisher be entitled to receive an advance payment of some of the royalties he expects to earn from the sale of the work when completed, and the author need not commence work until he receives his advance. It is ordinarily understood that he must return the advance if he writes nothing, or nothing up to the specification of the contract, but it is also ordinarily agreed that the advance is to repaid only out of royalties earned, e.g., if the advance is $\$ 10,000$, and the book is published but yields only $\$ 8,000$ in royalties, the author is not legally obliged to repay $\$ 2,000$ to the publisher. (In practice, authors sometimes keep the advance even if they never produce, but that is usually not the understanding but the result of publisher sloth or grace, or of the fact that the cost of the lawsuit to get it back would exceed the amount of the advance.)

Sometimes (as with advances by landlords to agricultural tenants) a statute gives the landlord a lien on crops to secure his advances.

advance bid. Under the rules of some judicial sales, after bidding is closed at the auction it may be reopened if someone makes an "advance bid," i.e., a bid "advancing" over the prior high bid by some specified amount, usually $10 \%$.

advance bill. See advance note.

advanced age. Old age.

advancement. A gift, i.e., an expenditure not legally required, made by a parent to or on behalf of his child, with intention that the value thereof be deducted from the amount that child would otherwise receive if the parent died intestate. If the parent dies leaving a will, the doctrine of "advance- 


\section{Leff Dictionary of Law}

ment" does not apply (unless, of course, the will so directs). But see ademption for the effect of prior gifts on some legacies.

advance note. A note or bill given by the master of a ship to a seaman who has signed on, i.e., agreed to join the crew, promising to pay to the order of the seaman an advance against his wages, ordinarily one month's, if the seaman goes to sea pursuant to this agreement. The drawee was often the shipowner.

advance payment. See advance.

advance refinancing. In real estate operations, paying of an existing mortgage with the proceeds of a new one before the first becomes due. It may be done even at a higher interest rate if the borrower believes that at a still later date, when a new mortgage will be required, e.g., by a possible buyer of the property, the rate of interest would be even higher.

advance refunding. A procedure principally used by the U.S. Treasury to encourage present holders of U.S. obligations not to switch their funds to other investments by offering specially good terms to present holders to exchange their bonds, etc. for new ones shortly before maturity.

advances. See advance. "Advances" also refers generally to movements forward, and sometimes more particularly to such movements in the social sense, e.g., "He made advances to her, vowing his love, but she repulsed them all." "Sexual advances" is a term used either as a euphemism for, or description of, activity not quite amounting to sexual assault.

advance sheets. Paperbound pamphlets carrying reports of the most recently decided cases, issued as frequently as every week so as to be available to the bench and bar much before the final hard-bound volumes of legal reports are issued. $C f$. slip sheet.

advent. The time period from the Sunday nearest November 30th through Christmas day, one of those periods (lent being another) deemed by church and old common law to have special holiness. Thus, for instance, no marriage could be performed during advent without special license.

adventitious. Not inherent and unexpected in a thing or course of events, i.e., extra, or added, e.g., "His singleminded pursuit of great wealth had the adventitious effect of getting his daughter married into the higher aristocracy."

ad ventrem inspiciendum ( ). See de ventre inspiciendo.

adventurae maris ( ). "Adventures [or risks] of the sea." See adventure.

adventure. A somewhat archaic term for what today one would call a venture, i.e., an undertaking with an element of risk. As used, the term did not, as it does today, necessarily connote something romantic (though romance was not excluded). Thus, "stockholders" in Elizabethan trading companies were called "adventurers," but so were those who did the actual exploring and colonizing. "Adventure" survives today in the language of marine insurance 
where a "marine adventure," i.e., a voyage, might be the insured event. See also gross adventure; joint venture.

adventurer. In most legal contexts, especially older ones, an "adventurer" is nothing more romantic than a person with a stake in an enterprise, i.e., in modern terms, a stockholder, partner, joint venturer, etc. See also adventure.

ad verecundiam. See argumentum ad verecudiam.

adversary ( ). Opponent; the opposite party in any contest, including litigation.

adversary proceeding ( ). A legal proceeding at which an adversary appears, as contrasted to an ex parte proceeding.

adversary system. A phrase used to distinguish the common law legal system from some others, e.g., the civil law system in some of its aspects, with respect to the manner in which actions are commenced and facts proved. The idea is that an adversary system depends upon adversaries, i.e., persons with conflicting stakes in an outcome, to put the system into motion and to bring to the attention of the trier all necessary facts and arguments. It is argued that the partisan participants in an adversary system do not present "the truth," but each side instead presents a one-sided version of what it wishes and has convinced itself is truth in the particular case-albeit all within some significant rules barring the too enthusiastic presentation of actual falsity. From those two "untrue" presentations made by partisan lawyers the trier is supposed to determine what the truth is, and where justice lies. There is always a strong pool of belief that this system is defective, and that truth would more likely be determined by non-partisan investigation than by symmetrically skewed partisan presentations, but the common law system remains strongly adversary. See also accusatorial; inquisitorial.

adversary trial. The most important adversary proceeding. See also adversary system.

adverse ( ). An adjective which in most legal contexts means against, contrary to, in conflict with. But special connotations arise in particular legal contexts, and the terms below which begin with "adverse" should be individually consulted.

adverse claim. In mining law, a formal assertion under oath filed with a government land office claiming the right to issuance of a patent to land or mining rights therein to oneself instead of to another claimant.

In bankruptcy law, a claim of right to keep property already in possesion, made against a trustee or receiver in bankruptcy who might assert the right to recover it for the bankrupt estate.

For the use of "adverse claim" in the law of adverse possession, see that entry. 
adverse enjoyment. The equivalent of adverse possession, but for an easement. See also adverse user.

adverse interest. Numerous statutes use the term "adverse interest," especialy in the formulations "parties [or "persons"] with an adverse interest [or "adversely interested"]." (The same idea is often expressed more concisely by reference to "adverse parties.") In general, it is reasonably easy to determine who a person with an "adverse interest" is, e.g., if $\mathrm{X}$ and $\mathrm{Y}$ both claim title to a piece of land, or $\mathrm{X}$ is suing $\mathrm{Y}$ for breach of contract, then $\mathrm{X}$ and $\mathrm{Y}$ are persons or parties with interests adverse to each other's. But sometimes adverseness of interest is not that obvious, e.g., if a statute provides that all "adverse parties" be served with a notice of appeal, is a coplaintiff an "adverse party" when the other co-plaintiff decides to appeal? Inasmuch as he might be actually disadvantaged by the appeal, some courts have said yes. But the answer is not foreordained.

As usual, whether a person or class of persons is to be included in the term as used in any particular statute will have to depend on the terms of the statute, and on what one can glean from it about its purpose.

adversely interested. See adverse interest.

adverse parties. See adverse interest.

adverse possession. If a person goes into open, visual, actual possession of real property, claiming a valid, lawful right therein as against the whole world, and stays in that status for a sufficient period (the length of which is set by statute and varies from jurisdiction to jurisdiction, but is rarely if ever less than 10 years, and may be as many as 50 ), he will acquire a fee title as total as if he had gotten it by valid conveyance, i.e., good against everyone including the one-time "true owner" (i.e., the owner by deed and conveyance, the "record owner"). The possession must be "adverse," i.e., not recognizing title in any one else, e.g., a lessee is not an adverse possessor because his occupancy will be seen as with the permission of the lessor. (But a lessee who holds over after a lease and shows no recognition of the previous lessor may thus start the running of the period leading to title by adverse possession.) Similar considerations govern possessions by fiduciaries, agents, etc. Also, the possession must be "open," i.e., not covert; but it is not necessary that the true owner have actual knowledge of the adverse possession, though it is required that he have some level of notice.

In modern legal language, prescription is loosely used to describe generally the process of acquiring, and the acquisition of, title to any real property interest by adverse possession. But the more narrow historical use of the term "prescription" was to refer to that method of acquiring title to easements, incorporeal hereditaments, and other types of non-physical real property; and the process was described not as "adverse possession" but "adverse user."

adverse use. Same as adverse user. See adverse possession.

adverse user. See adverse possession. 
adverse witness. May merely refer to a witness appearing on behalf of one's opponent. But it may also be used (confusingly) as a synonym for hostile witness.

adversus bonos mores ( ). "Contrary to good morals."

advertise ( ). To advertise is to attempt widely to disseminate information. The primary present use of the term is to describe the process by which sellers and makers of goods call them to the attention of potential buyers, but "advertise" is also used in many legal contexts to refer to a method of giving public notice, e.g., a requirement that parties contemplating the settlement [of] a class-action lawsuit so advertise the fact and the terms thereof. What medium is chosen (e.g., newspaper, billboard, television, etc.) is, in both commercial and legal contexts, a question of reaching as much of the relevant audience as possible subject to cost constraints. While judges would certainly like to assure that all persons affected by a legal event actually learn of it, even then cost must be taken into account, and no judge would order, e.g., the prime time television announcement of a pending case settlement even though that would certainly reach more people than a densely printed announcement at the back of The New York Times or, a fortiori, the New York Law Klaxon.

advertisement ( ). See advertise.

advertising. The process of, and business devoted to, trying to convince potential customers that one's goods are better, cheaper, or both than those of one's competitors.

Advertising is highly controversial. Its primary function is to let people know that certain products exist, that they have certain specified characteristics, where they can be acquired, and how much they cost-information without which no modern economy, capitalist or socialist, could possibly operate. But advertising is also used to persuade people to buy, and that generates most of the criticism. First, advertising is sometimes flatly false, i.e., out-and-out lies ("Clearopore cures acne on one application") are sometimes told; laws must be passed (and harder, enforced) to try to cope with this.

But bare-faced lies are comparatively rare in mass-market selling, for it is too easy most of the time to discover the lie after one product-buying test; it is thus economically inefficient in most businesses to rely on open mendacity. Hence, much of the craft of advertising goes into portraying a product in such a way that customers will be attracted to it but cannot easily discover the falsity, if any, in the mode of attraction, e.g., by promising freedom from non-existent evils ("Does she hate your lips-or is it the breath behind them?") or ones which will cure themselves ("Two drops of Smootho before bed, and your bloodshot eyes will purify"), or by selling things which are indeed necessary to a clearly desired end as if they are sufficient to produce it (e.g., selling an effective acne remedy to a teenager whose moribund sex life is the product not only of spottiness, but of igno- 
rance, ugliness, vulgarity, inexperience, and poverty). Sometimes the technique is to associate the product with some blessed state, but not causally, i.e., to imply that all the Beautiful people drink Gusto Beer, not that drinking it will make one beautiful.

The extent to which a modern public is actually fooled is unclear. Advertising is to modern consumption what the spoor of the buffalo is to huntergatherers; one tends to get pretty sophisticated about the whole thing. Moreover, there are other people working for other products at the same time. But advertisers certainly do continue to seek, at enormous expense, to influence consumer choice, and it may be significant that much of advertising is devoted to selling particular brands of what seem to dispassionate observers to be functionally identical. Perhaps the chief danger of very extensive advertising is that all advertisers tend together to generate one common message: Happiness comes from things that can be bought. This does tend to put people who want to disseminate information about non-buyable "goods" (clear water; good character) at a disadvantage, for it is hard to sell (i.e., get paid for) pure information, i.e., messages not attached to any other saleable product.

advertising a lottery. In jurisdictions which make it unlawful to hold a lottery, it is also forbidden to advertise one held someplace else, even if it is lawful where held. One would expect such laws to fade (through repeal or nonenforcement) as more and more states sponsor government-run lotteries.

advertising by lawyers. Until the late 1970's, any advertising of their services by lawyers, except for the most pallied kinds (e.g., entries in authorized law listings; a chaste sign on one's door) was considered unethical. The Supreme Court then ruled that it was unconstitutional totally to ban such advertising; at least availability and price information must be permitted. Lawyers have since begun to advertise even on television. But there has as yet been no wild scramble in that direction, perhaps because a large part of the bar still perceives the process as either unseemly, personally uneconomic, or both.

advice. An opinion communicated to another as to the propriety or effectiveness of the latter's past or future courses of action. It is strongly implied in most contexts that the person giving the advice has no power to compel the recipient to follow it, for which relation words like order, command or direction would be chosen. Thus employees give advice, and agents, lawyers, physicians, etc.

advice and consent. Article II, $\S 2$ of the Constitution gives the President the power "to make Treaties" and to appoint ambassadors, judges and other government officers "by and with the Advice and Consent of the Senate." The "consent," which is obviously the operative part of the Senate's power, requires an affirmative vote of two-thirds of the Senators present.

The term is very old. When Henry II issued his Assize of the Forest in 1184 , it recited that it was enacted "by the advice and consent of the arch- 
bishops, bishops, barons, earls and nobles of England," and there are even traces of the phrase in eighth-century royal conveyances.

advice of counsel. A reason often given by a layman to a media reporter, or to a judicial or investigatory officer, as to why he did, or is doing or not doing something, especially not answering a question, e.g., "Did you kill your wife?" "On advice of counsel, I decline to answer."

"Advice of counsel" is also a defense to a claim of malicious prosecution.

advisare vult. See curia advisare vult.

advise ( ). To give advice.

advise and consent. What the Senate does under its power of advice and consent.

advised. The state of having received the necessary advice, i.e., to be informed. The expression "well advised" means "it would be smart to," as in "He would be well advised to plead guilty."

advisedly ( ). An adverb describing an action taken or conclusion reached after careful consideration rather than lightly or impulsively. Also part of a common cliché used to emphasize that a term employed is indeed meant to mean what the hearer might otherwise doubt, e.g., "Cato is a traitor-and I use the term advisedly."

advisement ( ). A word almost never used except as part of the term "take under advisement," which refers to the process of reserving a question for later decision after further thought. The most common use is by and about judges, e.g., "The court, having heard argument on the motion, took it under advisement."

adviser. Anyone who gives advice, but more frequently a person who does so on a regular basis, e.g., a lawyer, [an] investment adviser, etc. The implication is that the adviser has no power to force anyone to take his advice.

advising bank. In the context of letters of credit, the bank which gives notice of the issuance of credit by another bank. See U.C.C. $§ 5-103$.

advisory ( ). An adjective used in legal contexts to emphasize that the advice or direction given is in the particular instance not binding on the recipient thereof, e.g., advisory instruction; advisory opinion; advisory verdict.

advisory committee. See advisory council.

advisory council. Federal, and to a lesser extent state, government is honeycombed by organizations called "advisory councils" and "advisory committees," etc. These range from groups which are truly and wholly advisory, i.e., they give advice which, with impunity may or may not be taken, all the way to groups which, either because of the terms of the particular statute, the prestige or independent political power of the members, or even the members' access to the press, are able much of the time to turn their advice 
into command, i.e., which are in law or in effect operating organs of government.

advisory instruction. Where the jury by statute or constitution is at least formally the judge of both fact and law in a criminal case, the instructions to the jury delivered by the judge are only "advisory," i.e., technically not binding on the jury.

advisory judgment. A loose locution for the decision of a court rendering an advisory opinion, misleading because no true judgment, i.e., juridical act determining a party's rights or liabilities, is actually issued.

advisory jury. See advisory verdict.

advisory opinion. In some states there is a procedure whereby a governmental body, ordinarily the legislature but sometimes the executive, can frame a question of law (usually pertaining to the constitutionality or legal propriety of a contemplated statute) and submit it to the state's highest court for determination and reply. The U.S. Supreme Court, relying on the "case and controversy" language of Article III, $\S 2$, of the Constitution, decided early that it could not give advisory opinions.

advisory verdict. Courts sitting in equity, admiralty, etc. need not submit questions of fact to juries. Nonetheless, under certain circumstances such courts may empanel an "advisory jury" to make findings of fact which, though not technically binding on the judge, he will ordinarily accept. See, e.g., Fed. R. Giv. P. 39(c). The procedure is particularly common in maritime cases, where common-law causes of action (i.e., those for which the parties are entitled to a jury) are often tried together with causes of action tried to the judge, with some facts being relevant to both the jury and nonjury causes.

advocacy ( ). The act of arguing in favor of, pleading for, supporting, seeking to bring about-but by verbal rather than physical or otherwise coercive means. On the other hand, expression is required, and mere passive belief or adherence is not "advocacy," a matter of some importance with respect to statutes making "advocacy" of unlawful activity, e.g., overthrowing the government by force and violence, a crime.

advocate ( ). Generally, one who undertakes advocacy. But the more particular legal reference is to a member of the bar, a lawyer, in his role as a litigator.

advoutry ( ). A variant form of the word adultery.

advow. See avow.

advowee ( ). See advowson.

advowee paramount. See advowson.

advowry. See avowry.

advowson ( ). An ordinarily transferable and inheritable right in perpetuity, 
legally treated as real property, to make the "presentation" of a particular religious position, a benefice, to a clergyman of one's choice whenever a vacancy occurs. The holder of this right, the "advowee" (also called the "patron"), presents his nominee to the Bishop of the relevant diocese (hence it is sometimes called a "presentative advowson") who must install him if ecclesiastically qualified, the advowee having the right to compel the installation of a qualified nominee.

An advowson may be either "appendant" or "in gross." An appendant advowson is attached to a corporeal hereditament, e.g., a manor and its land, and passes with it unless the contrary is expressly stated. An "advowson in gross" is the property of a person, i.e., not attached to any corporeal estate, and passes separately to the heirs of the advowee. The British sovereign is called "advowee paramount." When the advowee is himself the Bishop who must install the nominee, the advowson is called "collative," and the acts of presentation and installation are one [and] the same.

An advowson was termed "donative" when the benefice might be presented by the patron without need to go through a Bishop; these were confined to advowsons held by the Crown or under special royal license, and have all by statute been transformed into presentative advowsons.

All of the foregoing is thoroughly regulated in England by reasonably modern statutes, and advowsons never played any substantial role in the U.S., even before the Revolution. They were for a long period important property in England, however, for the holder of an advowson was thereby enabled to provide for a younger son, a son-in-law, or a family friend or connection out of the ecclesiastical revenues accruing to the benefice conferred.

advowson appendant. See advowson.

advowson collative. See advowson.

advowson donative. See advowson.

advowson in gross. See advowson.

advowson presentative. See advowson.

advowtry ( ). Another old term for adultery.

AEC. See Atomic Energy Commission.

aegroto. ( ). A term sometimes found in early reports meaning "sick" or indisposed. (Also the likely source of the English slang term "grotty," meaning tacky or rundown.)

ael ( ). See aiel.

aequitas ( ). "Equity," or "good conscience." For terms beginning "aequitas," see equity and terms so beginning.

aequus ( ). Equal; just.

aequus et bonus ( ). Justice and right. 
Aeronautics and Space Act. A federal statute, 42 U.S.C. $\S 2451$ et seq., the basis of the U.S. outer-space programs. The Act instituted, among other agencies, the Aeronautics and Space Administration and the Aeronautics Act Space Council.

Aeronautics and Space Administration [Council]. See Aeronautics and Space Act.

aesthetics ( ). That branch of philosophy dealing with the nature of the beautiful, or more generally, with theories about art (in its broadest sense). The subject is little explored in legal contexts. But see aesthetic zoning; elegantia juris.

aesthetic zoning. A kind of zoning which is explicitly designed to regulate the appearance of an area, e.g., a regulation providing that in a particular neighborhood then filled only with traditional Cape Cod cottages no modern glass and steel homes are to be built, or one providing that clothes lines open to public view are not to be used. Used with moderation, aesthetic zoning has been generally upheld. $C f$. Landmark legislation.

aet. See aetas.

aetas ( ). "Age." Frequently seen in old reports in the abbreviated form "aet.," e.g., "Plaintiff, aet. 19."

aetate probanda. See de aetate probanda.

aetheling ( ). A pre-Norman rank of high nobility in England, most likely a prince of the blood under the Saxon Kings.

A.F.D.C. Abbreviation of Aid to Families With Dependent Children. See welfare programs.

afeer. See affeer[e].

afeerer. See affeer[e].

affair. Any matter of concern, including business ("man of affairs"); government ("affairs of state," "public affairs"); social relationships of divers kinds, e.g., ("They gave a big affair [i.e., party] in connection with the engagement," "He had an affair [i.e., sexual dalliance] with Cornu's wife"); and various combinations (e.g., the great political crisis surrounding the attempt by Henry VIII to divorce Catherine of Aragon in order to marry Anne Boleyn, which eventuated in the English break with the Papacy, was called by contemporaries, perhaps with consciousness of the pun, "The King's Great Affair"). ("Affair" is still French for "lawsuit.")

affearment. See affeer[e].

affect. To affect ( ) is to bring about a modification of any kind in something else, be it an object, a person, or a situation; a cause "affects." $A n$ affect $($ ) is that modifcation.

"Affect" as a noun, however, when pronounced ( ), is an important psychological concept, for which see flattened affect. 
It should be noted that in many legal contexts "affected" implicitly means "materially affected," "significantly affected," or at least "non-trivially affected." For strictly speaking every happening can be traced so as in theory to affect everything else.

affected. See affect.

affected by intoxicant [or drugs]. Essentially, "drunk" [or "high"]. For some purposes, e.g., certain insurance or traffic laws, "affected by intoxicants" may refer to a state less dramatic than what is ordinarily meant by "drunk" or "intoxicated," but when some distinction is meant it is ordinarily made more precise by other contractual or statutory language, or by judicial interpretation.

affected with a public interest. See business affected with a public interest.

affecting commerce. Under the commerce clause of the Constitution, the Federal government has the right to regulate interstate and international commerce. The Supreme Court eventually ruled that Federal power extended not only to transactions which crossed a border, but also to transactions taking place within one state if they materially affected another. But there had grown up law which distinguished acts "in commerce" from those "affecting commerce," with the narrower interpretation being given to statutes using the "in commerce" formulation. Hence to make clear that Congress wished to give the widest jurisdiction to, say, an administrative agency it was deemed necessary, or at least legislatively prudent, to amend certain older statutes. Thus, e.g., $\S 5$ of the Federal Trade Commission Act (15 U.S.C. $\S 45)$ was amended in 1975 to replace every instance of "in commerce" with "in or affecting commerce."

affection. In ordinary language, positive and tender feelings; liking; but generally connoting a calmer and less intense emotion than passion or even love. See also love and affection.

In medical terminology, "affection" is just a variant term of affliction.

affectus ( ). Intent; tendency; disposition of mind.

affeer[e] ( ). To determine and assess when no statutory or customary amount was stipulated, the amount of an amercement (roughly speaking, a fine) imposed in a feudal court (e.g., a court-baron, hundred court, or court-leet) or, sometimes, in an inferior post-feudal one, the steward of the court (or the justice) would swear in one or more solid citizens as "affeerers" who would make the assessment; Shakespeare, for example, was an affeerer in Stratford-on-Avon.

affere. See affeer[e].

affiance ( ). To enter into an engagement to marry, after which each of the parties becomes the other's "fiancé" (if male) or "fiancée" (if female). These agreements were until quite recently enforceable contracts, at least in the sense that money damages could be recovered for their breach. See breach of promise. 
affiant ( ). One who executes an affidavit.

affidatio ( ). An oath of fealty.

affidavit ( ). Any ex parte written statement subscribed under oath or affirmation. "Affidavit" is also frequently defined (so as to distinguish it from deposition) as being "voluntary," but the distinction is tenuous. Admittedly, a deposition is often taken under legal process, i.e., the deponent is obliged to respond, but most depositions are actually taken by agreement between parties, and many types of affidavits (see terms beginning affidavit of, below) are required by law.

In criminal proceedings, "affidavit" is sometimes used in place of the more common "complaint" or "information."

affidavit for attachment. An affidavit which must in almost all jurisdictions be executed by a plaintiff seeking a writ of attachment. The affidavit must ordinarily set out some ground why property of the defendant should be seized or otherwise made nontransferable prior to hearing or judgment, e.g., it is about to be hidden or destroyed. See attachment for the current constitutional status of attachments sought to be made on the basis of affidavit only.

affidavit of circulation. See Newspaper Publicity Law.

affidavit of copyright claimant. Under the "manufacturing clause" of the Copyright Act prior to its 1978 amendment, severe disabilities attached to copyrightable works manufactured (e.g., printed) abroad. Hence as part of the copyrighting process, the applicant had to submit an affidavit swearing to U.S. manufacture. The new Act contains a far less stringent manufacturing, clause which, moreover, is to expire on July 1, 1982.

affidavit of defense. In some jurisdictions the term used in place of affidavit of merits. See Fed. R. Civ. P. 56(e).

affidavit of good faith. In various legal situations statutes or court rules require that a party file an affidavit swearing that he is not doing during the proceeding anything he ought not to be doing, e.g., a party seeking to appeal the decision of a lower court may have to file an affidavit that he is not taking his appeal for purposes of delay. Similarly, mortgagors are sometimes required to file an affidavit that they are not giving the mortgage to defeat, defraud, hinder, or delay creditors.

Requiring such affidavits might on the surface seem rather silly, but it is fair to say that many people who would be perfectly willing both to appeal solely for delay, and to give a mortgage in order to harm particular creditors, would not be equally willing solemnly to lie, i.e., to commit perjury about what they were doing. This is especially so since a lawyer is much more explicitly told by the Code of Professional Responsibility to stop his client's perjury than his dilatory tactics or fraudulent conveyance, and lawyers are usually necessary to these transactions. All of this does not mean that false affidavits are never filed, especially since it does not often 
take much for a person to convince himself of his own actual good faith. But, even if action is rarely if ever taken against the false affiant, these affidavits of good faith are not without legal utility.

affidavit of merits. Also often called "affidavit of defense." An affidavit by a defendant that he in fact has a meritorious defense (and sometimes that the one he has is "not just technical"). It is required in some jurisdictions when the defendant is trying to prevent a speedy victory for the plaintiff, e.g., when he is seeking to set aside a default judgment, or prevent a summary judgment, in favor of the plaintiff. See Fed. R. Civ. P. 56(e). It is, then, a species of affidavit of good faith, i.e., it forces the defendant to swear to something which otherwise he could lightly and merely strategically allege, e.g., by unsworn answer to a complaint.

affidavit of no collusion. A kind of affidavit of good faith native to interpleader actions, in which the plaintiff states that the bill is not being filed in collusion with either of the defendants. In modern practice, it will usually be sufficient just to allege "no collusion" in the bill of interpleader itself (though in some jurisdictions the bill itself may require verification, i.e., some species of oath).

affidavit of title. A sworn declaration by a seller of real property that the title being conveyed is free from defects. See also warranty deed.

affidavit on demurrer. A species of affidavit of good faith which must in some jurisdictions be filed to support a demurrer, stating that the demurrer was not filed merely for delay, but that the defendant believes that he has a good defense on the law, i.e., it is an affidavit of merits addressed specifically to belief in the existence of a legal (as contrasted to a factual) defense.

affidavit to hold to bail. An affidavit by the plaintiff or someone else acquainted with the facts, clearly showing indebtedness or other right in the plaintiff, required before the court will order arrest of the plaintiff in a civil action. Taking custody of a civil defendant is today exceedingly rare, ordinarily used only when the defendant is in contempt of court, and is when permitted at all ordinarily surrounded by procedural safeguards which exceed a mere affidavit requirement.

affidavit upon information and belief. See information and belief.

affile. The older term for "put on file," which today we have shortened to "file."

affiliate. As a verb, to affiliate ( ), as ordinarily used today in legal contexts, means to join or become connected, but in a non-physical sense, e.g., "The independent union was then affiliated with the AFL-CIO." Cf., however, filiation proceeding.

As a noun, "affiliate" ( ) is mostly used to describe a person or a business entity which is in the relationship defined under affiliated.

affiliated ( ). This term is used in various legal contexts to describe a legally significant relationship among distinct juridical entities, e.g., persons, part- 
nerships, corporations. Thus, e.g., an "affiliated corporation" is defined for many securities law purposes as a corporation "controlling, controlled by, or under common control with" another corporation, for which the law will provide, inter alia, special reporting and accounting requirements. But another definition of "affiliation" or "affiliated corporation" may be employed under the income tax laws, or under the Bankruptcy Act (for which see 11 U.S.C. § 101(2)). That is, "affiliation" and "affiliated" always describe some relationship, but it is not necessarily the same one each time, even when the same word, e.g., "corporation," is modified.

affiliated corporation[s]. See affiliated.

affiliated group. Short for "affiliated group of corporations," tax-law term for a set of corporations entitled to file a consolidated return. See also affiliated.

affiliation. See generally affiliate; affiliated; filiation proceeding. One special use: Under the Smith Act, "affiliation" with an organization advocating the overthrow of the government by force and violence was made relevant to criminal conviction. The Supreme Court ruled that whatever "affiliation" usually meant, in the criminal law context adhering to, and furthering the illegal objectives of, the organization would be required. Bridges v. Wixon, 326 U.S. 135 (1945).

affiliation proceeding. See filiation proceeding.

affines ( or ). Relatives by marriage. See affinity. (If "affines" were still Latin, "affinis" would be its singular, but it's now passed into English and its singular has become "affine.")

affinis ( ). See affines.

affinitas ( ). "Related by marriage." See affines; affinity. "Affinatis affinatis" refers to the very distant relationship between persons linked only by the marriage of blood relations, e.g., between the husband's brother and the wife's sister.

affinity. In ordinary language, "affinity" is used as almost synonymous with "taste," (e.g., "He has an affinity for French cooking), or with "mysterious power to attract" (e.g., "He has a real affinity for accidents.").

The chief legal use of "affinity," however, is to describe a relationship between two or more persons based on marriage rather than blood, or consanguinity. Thus, e.g., a spouse's brother or sister and the other spouse are "affines" (i.e., "brother-in-law" or "sister-in-law"). In almost all jurisdictions a judge or juror may be disqualified if he is within some degree of kinship, whether of affinity or consanguinity, with a party or counsel.

affirm ( ). Most generally, to state that something is truly the case, e.g., "He affirmed his interest in the property."

Also, when a contract is breached, the innocent party ordinarily has the power either to rescind, or to sue for damages. When he does the latter it is sometimes said that he has elected to "affirm the contract and sue for breach." 
Affirm also means to confirm, ratify, or actively refrain from overturning an action by one lower in a hierarchy, especially a judicial one, as in "The Supreme Court affirmed the judgment of the Court of Appeals."

Most narrowly used, "to affirm" is to make a solemn statement in specified form, with the purpose and effect of a sworn statement but not under oath. This option to swearing has been everywhere supplied by law to accommodate people who will not, because of religious beliefs, swear under oath. Knowingly to affirm falsely is the same as knowingly to swear falsely, i.e., to commit perjury.

affirmance. See affirm. The most common legal use of the term is to describe the action of an upper court when it approves a lower court's decision.

affirmance of judgment. See affirm. It should be noted that not every failure by a higher court to overturn a lower-court judgment is an affirmance, though it may have the same effect on the parties' interest. Discretionary refusal to hear an appeal (e.g., as when the Supreme Court denies certiorari), or dismissal of an appeal for failure to meet some appellate procedural requirement, is not an affirmance, at least for the purposes of using the action as precedent; "affirmance of judgment" implies at least some attention having been given to the merits. See also denial of certiorari.

affirmant. One who affirms, especially one who makes a solemn statement but not under oath, i.e., a non-swearing species [of] affiant or deponent.

affirmation. See generally affirm. In the law of sales, to affirm something was sometimes considered the same as, (but, alas, sometimes to be distinguished from) warranting it. See warranty.

affirmation of consequent. A fallacious argument which takes the form of asserting that if the consequent of a conditional statement is true, so is the antecedent. For example, the following argument is valid: If (1) all horses are white; and (2) Rampage is a horse; then (3) Rampage is white. But continuing the argument: (1) Rampage is a horse; (2) Rampage is white; (3) therefore all horses are white is invalid, indeed ridiculous. Judging from such an example, one would think affirming the consequent would never occur but it happens all the time; consider, for instance (1) Cohen is a Jew; (2) Cohen is greedy; (3) all Jews are greedy.

affirmative ( ). An "answer in the affirmative" is a "yes." It may be express or implied (but ordinarily from something other than silence). Also it is sometimes said that a party who has the job in litigation of bringing forth evidence on, or proof of, a proposition "has the affirmative."

But the chief use of the term is as a variant of "active," i.e., descriptive of a requirement or course of behavior which entails explicitly doing something oneself, rather than merely remaining passive, or at most resisting someone else's activity. See also the entries below beginning with "affirmative."

affirmative action. Though the term has had some currency in other legal con- 
texts (e.g., in the National Labor Relations Act, where it refers to the NLRB's power to take "affirmative action" to carry out the purposes of the Act), the most important present-day legal use of the term is in the context of civil rights. More particularly, it is clearly present law that under various statutes, executive orders, constitutional interpretations, etc., an entity which has previously been guilty of unlawful discrimination (on the basis of race, sex, age, etc.) is permitted and may be ordered to undertake an act or program of affirmative action to undo, or at least mitigate, the effects of such prior discrimination. $C f$. active cause. Hence, e.g., if it has been found that a school board discriminated against Black students by assigning them to segregated schools, and thus all the individual schools in the district are presently either all Black or non-Black, a court may order the school board to take affirmative action to desegregate the schools, e.g., to abandon its "neighborhood school" policy and move students around, perhaps by bussing them out of their segregated neighborhoods. (Some types of voluntary "affirmative action" seem to be permitted even if prior unlawful discrimination has not been proven. See Weber case.)

What kinds of affirmative actions will be ordered or permitted vary, of course, depending on the costs of alternatives, their ultimate effectiveness, and the context in which the discrimination has operated, e.g., if the discrimination were in employment rather than schooling, bussing would not be effective, but modified hiring rules would. Whatever the context, however, in seeking to give particular content to "affirmative action," numerous recurrent problems have arisen, mostly centered on the fact that an attempt affirmatively to undo past illegal discrimination will ordinarily impose upon other people what they perceive as unfair costs, what has been characterized as "reverse discrimination." Let us say, for instance, that a police force had been unlawfully discriminating against Black applicants. The Court orders it, of course, no longer to do so, but also orders that one quarter of all future applicants hired be Black until Blacks make up at least $15 \%$ of the force. From the point of view of a non-Black applicant who would on the basis of the force's ordinary employment standards have been hired, it appears that he has been discriminated against for being non-Black. Similarly, a school child sent on an hour-a-day bus ride to integrate a school rendered segregated ten years before his birth would frequently be seen by his parents as unfairly treated.

In any event, the constitutional ambit of lawful affirmative action in the divers contexts (e.g., race compared to sex; education compared to employment; governmental discrimination as compared to "private" discrimination; "forced" (because of previous finding of discrimination) as compared to "voluntary") is still in the process of determination in the courts. See, e.g., Bakke case, Weber case. It is clear that the more speedy and powerful the particular affirmative action technique chosen (e.g., bussing; employment "quotas" rather than "targets"- see quotas and targets), the less popular it is likely to be with the general electorate, and the more likely it is to be unchosen, or forbidden, by statute, while less dramatic choices (e.g., vastly 
expanded searches for qualified members of previously disfavored groups; the use of targets rather than quotas; the use of "magnet schools") will have an easier political time. But, as noted, the constitutional situation is still fluid.

affirmative authorization. Frequently used to describe an authorization (see authorize) explicitly or particularly given, as contrasted with one given implicitly or generally. Thus, if a statute said "Any landowner may build a dam on a navigable stream on his land," that would clearly be an "affirmative authorization" for dam building. But if there were no statute specifically in point (and thus the authorization, if any, would have to be inferred from silence against a background of ordinary property rights), or if the statute merely said "landowners may use navigable streams on their land," then one would most likely not describe a dam as "affirmatively authorized."

affirmative charge. A term of art for a statement by a judge to a jury in a criminal case which has the same purpose and effect as a directed verdict of acquittal on the count to which the charge was directed.

affirmative defense. Let us say that a party is sued for breach of contract. The plaintiff pleads the making of the contract, the defendant's breach, and the plaintiff's damages. The defendant may deny any or all of those allegations, and win the lawsuit if the plaintiff fails to establish them. But the defendant may, whether he denies them or not, raise certain new allegations of his own, upon the proof of which he is entitled to win even if the plaintiff proves his allegations. These are "affirmative defenses," of which there are many, e.g., unconscionability, fraud, duress, mistake, release, statute of limitations, etc. The defendant ordinarily has the burden of proof with respect to affirmative defenses (though the question is not free from constitutional doubt with respect to "affirmative defenses" like insanity in criminal cases.)

affirmative easement. The easement which gives the holder thereof the right to do something on someone else's land which otherwise would be improper, e.g., a right to walk across it, or dump one's garbage on it. It is distinguished from a "negative easement," which is a right to prevent someone from doing something with respect to his land which he would otherwise be entitled to do, e.g., one may have a negative easement such that one's next door neighbor may not build a house on his land which interferes with your view.

affirmative marketing [plan]. A requirement by the Department of Housing and Urban Development pursuant to the Civil Rights Act of 1968 that persons wishing to avail themselves of federal government funds or guarantees for real property development not only not discriminate against minority buyers and tenants, but take steps to attract members of such groups to their properties. 
affirmative plea. A term, mostly used in equity practice, for what is essentially the same as an affirmative defense.

affirmative pregnant. See negative pregnant.

affirmative proof. Evidence going to establish a proposition, as contrasted to the establishment of a proposition by failure of proof to the contrary.

affirmative proof of loss. See proof of loss.

affirmative relief. As a technical term, relief given to a defendant in connection with a lawsuit, either as the result of a successful counterclaim, or just in connection with the initial suit, e.g., perhaps, an award of attorneys fees.

Otherwise, it is just relief (to a plaintiff) which is affirmative, e.g., specific performance.

affirmative representation. A representation that a particular fact is true, as compared to, e.g., failing to mention it, or failing to deny it, or asserting it by implication.

affirmative statute. A statute which orders or directs someone to do something; a "negative statute" prohibits or forbids. Many statutes, and most of any length, do both, e.g., in the Ten Commandments the "Thou Shalts" are "positive" and the "Thou Shalt Nots" are "negative."

affirmative warranty. The same as affirmative representation, but for a warranty (especially as that term is used in insurance law).

affix ( ). To attach, or join to, more or less permanently. One can affix one's signature to a document by writing it thereon, and one can affix one sheet of paper to another with a staple or sticky tape; but quaere as to a paper clip. See also affixed to the freehold; fixture.

affixed to the freehold. Something so permanently associated with land or a building thereon as to pass with it when it is transferred. A planted tree, for instance, is affixed to the freehold, while a bonsai in a pot most likely is not. But the question is often a complicated one, especially when chattels installed in buildings are concerned. See fixture.

affliction. A disease or other unhappy or painful condition.

afforce. See afforce the assize.

afforce the assize. When the jury of an assize did not agree, efforts were made to "afforce the assize," i.e., to put pressure on the jury to come up with a verdict. The heat applied could be considerable, e.g., starving the jurors until they agreed, or adding new jurors until there were twelve who would agree.

affray ( ). A fight in public with weapons. In medieval and Elizabethan times, the image that the word "affray" would most likely generate would be of public armed encounters between knights, lords and other landowners, their families, and their retainers. The scene that opens Romeo and Juliet, for instance, would be understood by the audience as the very picture of a 
medieval affray. Trespass vi et armis also must originally have involved an affray of this kind. But riotous violence within towns by townsmen, apprentices, students, guilds, etc. would also be called "affrays." In time, the term seems to have come to cover every violent quarrel in public involving more than mere heated words, especially if weapons were drawn or flourished, even if they were never actually used.

affreighter ( ). From the French "affreteur," and meaning (in maritime law) the person to whom a vessel is chartered by charter party. The more common modern term is charterer.

affreightment ( ). A term roughly equivalent to the more common charter party.

affretement ( ). Variant form of affreightment.

affront ( ). An insult or indignity; "to affront" is to inflict one.

A.F.L. [or AF of L]. Abbreviation for American Federation of Labor, the largest association of craft unions. In the 1950's it merged with the CIO, i.e., the "Congress of Industrial Organizations," the largest association of industrial unions, to form the AFL-GIO.

aforce. Variant spelling of afforce.

aforesaid ( or ). A reference in legalese to something mentioned earlier in the same writing, e.g., "The aforesaid vendor," "the aforesaid 1979 Chevrolet Malibu," "the aforesaid 28,437 tons of wheat." In almost every instance the use of "aforesaid" is wholly unnecessary, as there is absolutely no chance that the reader would without it be confused as to which Vendor, Malibu, or 28,437 tons of wheat was referred to. The only advantage of "aforesaid" (and words like it, e.g., herein, "hereinbefore") is that, like a wax seal, it does tend to make the reader aware of the fact that something of legal consequence is most likely going on. But one cannot say much else in favor of it.

aforethought. "Thought about earlier," or "thought of in advance." In law, it is essentially a synonym for premeditation and prepense. See also with malice aforethought.

a fortiori ( ). "Even stronger" or "even more so." The term, and a fortiori the concept for which it stands, is very widely used in legal reasoning. For it represents one species of the argumentative move by which one manages to get someone else to accept a more extreme position than the one needed for the job of persuasion at hand, and then shows him that if he is willing to go that far, surely he is willing to go less far. For example, "So you accept the fact that he's entitled to defend himself from threatened injury? Then $a$ fortiori he's entitled to defend himself from threatened death." To put it another way, if you can get someone to agree with you about any particular point on the slippery slope, everything downhill from there is an "a fortiori case." 


\section{Leff Dictionary of Law}

African. A citizen or resident of Africa, but today also used to denote a person whose ancestors were African, i.e., American Negroes, or Blacks.

Afro-American. A term for an American Negro or Black, on the label-formation model of Irish-American, German-American, Italian-American, etc.

aft. A nautical term, short for after, referring to the rear of the ship, or at least to that portion of the ship rear of the person speaking, as in "Ask the Captain to come aft and confer with the Admiral."

after. The term can be used spatially, to mean "behind" or "to the back of," as in the afterdeck of a ship (see aft). But the more common use of the term is temporal, to refer to a point in time later than another, e.g., "It is already after 10:00 p.m." In general, when a legal act is to be done "after" a particular time, the time specified is excluded, e.g., a debt "To be paid after June 1,1980 " would ordinarily not be due until June 2nd; "on or after" is ordinarily used to make clear a June 1, 1980 payment date. Similarly, if payment is to be made " 60 days after June 1, 1980," June 1st itself would ordinarily not be counted. But, as usual, context could change the general rule.

after-acquired property clause. In many mortgage instruments there is a provision whereby the lien of the mortgage is made to apply not only to property then owned by the mortgagor, but to all, or all of some specified type of, property acquired by the mortgagor after the date of the mortgage. This has the advantage not only of providing additional security to the mortgagee as the originally mortgaged property depreciates, but also obviates any question about whether improvements or additions to the property are covered by the mortgage. As one can imagine, this can be misleading to other later creditors, especially when chattels are the subject of the mortgage and special statutory provisions sometimes exist with respect to these clauses. $C f$. add-on clause.

after-acquired title. Let us say that Jones conveys Halfacre to Smith by a deed warranting, reciting, or importing that he has title thereto, i.e., gives something more than a mere quit-claim deed. Unfortunately, Jones does not have title. Subsequently, however, he gets it. This is "after-acquired title" and, as a general rule, Jones will not thereafter be able to set up this new title as against Smith (or against anyone holding title from Smith). Indeed Smith and his grantees may get an order in equity to compel Jones to convey again by new deed.

after-born child. A child born after some happening of legal significance, e.g., the making of a will or execution of a deed, with respect to which the child's appearance might have significance, e.g., to give him a share of the testator's estate even though only the earlier born children were mentioned in the will. The most common use of "after-born child" is as a synonym for posthumous child.

after dark. A term which is sometimes used as a synonym for "after sundown" 
or "nighttime," etc. When precision is required it is an unwise choice of words, since the coming of darkness is a gradual process, and it is thus awfully difficult to know when "after dark" starts. "After 9:00 p.m." or "after sundown" (sundown at least having a precise technical meaning) is safer drafting, especially for criminal statutes (e.g., "Arson committed after dark shall carry an additional sentence of . . . ."), vulnerable to a vagueness finding.

after date. Some promissory notes provide that they are payable "five years after date." If the note were executed on June 30,1975 , that would make it payable July 1, 1980. (See after.) If, however, the note is just made payable "after date," that has usually been held to mean it is payable on demand. See also demand paper.

after demand. See demand paper.

after-discovered evidence. See newly discovered evidence.

aftermath. The old technical meaning was a second crop grass during one season, or the right to take such crop. Nowadays the term is used only metaphorically, to mean "consequence" or "result," e.g., "As an aftermath of the fire, a new sprinkler system was installed," or "In the aftermath of the scandal, the whole commission resigned."

after maturity. See indorsement after maturity.

after nightfall. See after dark.

afternoon. That portion of a day which starts precisely at noon and ends, much less precisely, with the coming of evening.

after possibility of issue extinct. See fee tail after possibility of issue extinct.

after sight. See sight draft.

after the death. Words which, when used in a conveyance of real property, indicate that the conveyed estate vests immediately, but right to its enjoyment is postpaid during the life of another, e.g., "To Doe, and after the death of Doe, to Roe and his heirs," means that Roe gets an immediate estate in fee, subject to Doe's life estate.

after the fact. See accessory.

after the passage of this act. This term seems clear enough, but hides at least one ambiguity: If the statute is passed on June 1st to take effect September 1st, is "after the passage of the act" in June or September? The answer will depend on context, but one would expect most courts to choose June 1 st, and require something like "after the effective date of this act" to indicate September 1st.

afterward. Essentially the same as after, but temporally not spatially after.

against. Given our adversary system, "against" usually shows up in law as meaning "in opposition to" or "contrary to," e.g., "He filed a brief against 


\section{Leff Dictionary of Law}

the defendant" or "He came out against Jones's interpretation." The state of being formally against another in a legal proceeding is usually signified by the Latin versus, e.g., "The great case of Jones versus Smith."

But in ordinary English "against" also means "in contact with," e.g., "He was leaning against the wall," and the context sensitivity of "against" can be seen by comparing "He held him against it" with "He held it against him."

against evidence. See verdict against the evidence.

against her will. See against the will.

against interest. See declaration against interest.

against my estate. See my estate.

against public policy. See public policy.

against the form of the statute. A technical phrase found in criminal indictments, alleging contravention of the statute making the action criminal. One would hope, and today perhaps expect, that substituting something like "against the statute" or "violating the statute" would not render the indictment insufficient, but in criminal-law pleading one never knows.

against the peace and dignity of the state. A modern derivative form of the ancient contra pacem clause; found, and sometimes legally required, in a criminal indictment. Whatever real significance such terms might once have had, they are today mere formalisms.

against the weight of the evidence. See verdict against the evidence.

against the will. Certain acts are criminal only if done without the consent of the other person involved. An appropriation of property, e.g., is not robbery or theft if its owner or possessor freely wishes the transfer to take place, nor is sexual intercourse rape if both parties desire it. Hence most criminal indictments will allege in some words that the act was "against the will" of the victim. It is clear that in this context "against the will" means almost the same as without consent, i.e., without some explicit or implicit affirmative desire, i.e., an act (e.g., sexual intercourse) may be "against the will" of the victim even if, because of insanity, the administration of drugs, etc., the victim has no will at all. And, of course, the assenting will of the other party cannot be procured by unlawful threat; a person who, greeted with "your money or your life," chooses to give up the money has not "consented" to the transfer and it is clearly "against the will."

agalma ( ). The figure or design on a seal.

agard ( ). Law French for "award."

In old reports one often finds "nul agard" (no award) or "nul fait agard" (no award was made).

age[d] ( ). The length of time something has lived or existed is its "age." It may then be described as "sixteen years old," or "sixteen years of age," or "age[d] sixteen." 
When pronounced ( ), however, the word indicates that the subject has attained relatively advanced years, but how advanced that must be in any particular context is necessarily uncertain. Some people act old or "aged" at fifty; some centenarians are hale, hearty, and mentally alert. Moreover, almost everyone is "aged" as a football player by forty-five; fisherman may reach their peak in their seventies. Hence, if legal significance is to be attached to advanced years (e.g., a duty to support "aged parents"), it is advisable to do more than just use the term "aged." And in criminal law (e.g., a statute providing increased punishment for robbing "aged persons"), it may be unconstitutionally vauge (see vagueness) not to do more. But see age of majority for the problems which arise when, for legal purposes, one measures age solely in terms of elapsed time.

agency. The relationship between two persons such that one, the agent may so act as to subject the other, the principal, to legally enforce-able relationships with, and liabilities to, third parties. The term also refers to the body of law concerned with such relationships.

The relationship of agency is one of the most important and pervasive in practical life. Almost all business transactions-contracts, sales, leases-are effected by agents, and a particular kind of agent, a "servant," does much of the world's work on behalf of a special kind of principal called a "master" (see master and servant). Members of partnerships act bindingly on behalf of each other, and a corporation too, having no biological existence of its own, must act only through agents. Further, under some circumstances family members can also bind each other with respect to third parties.

Moreover, since the critical issue with respect to most agency situations is the situation of the third party, agency can arise not only consciously and intentionally, e.g., when Jones hires or otherwise contracts with Smith to be his agent and enter into transactions on Jones's behalf (see actual authority; agency in fact; express agency), but also when Jones allows things to develop such that a third party would reasonably believe that Smith had such power (see apparent authority; agency by estoppal). And the power to bind another may be a mere consequence of a particular legal status, e.g., a person can under some circumstances bind a spouse to pay for certain purchases.

Hence, the "law of agency," even when it is deemed to include the law of "master and servant," hardly covers all agency relationships and attendant legal rules, which are scattered throughout much of law (including, where it appears as "conspiracy," criminal law).

See also administrative agency.

agency action. Any action by an administrative agency.

agency by estoppal. The kind of agency which arises when person $\mathrm{P}$ allows person $A$ to appear to a reasonable third person, $T$, as someone who has the power to act on P's behalf. For example, let us say that $P$ enters into an arrangement with $\mathrm{A}$ whereby $\mathrm{A}$ will solicit orders for P's product and pass them on to $\mathrm{P}$ for acceptance or rejection. It is clearly understood between $\mathbf{P}$ 
and $\mathrm{A}$ that $\mathrm{A}$ cannot bind $\mathbf{P}$ to sell anything. But $\mathbf{P}$ allows $\mathrm{A}$ to display P's company name on his wall and forms, to mail acceptances to buyers over A's signature, etc. If T comes in and A takes and accepts T's proffered deal, it would most likely be held that an agency by estoppal had arisen between $P$ and $A$, and that therefore $P$ could not thereafter rely on A's actual lack of authority to refuse to fill T's order. See also apparent authority; estoppal. The same result would ordinarily follow even if $P$ had no relationship at all with $\mathrm{A}$, so long as $\mathrm{P}$ might be found to have sufficient notice of A's activities, or to be otherwise remiss (at least negligent) in not taking steps to stop A's pretence.

agency by [or of] necessity. An agency, i.e., a power to bind another, given as a matter of law to some persons in some circumstances, e.g., a dependent, deserted or ignored spouse may have the power to buy goods requisite to decent survival and bindingly charge the cost to the absent spouse. Also, an agent may have "agency by necessity" to go beyond his actual authority in an emergency e.g., in his principal's absence to order a ship to leave a port about to be embargoed. This "agency by necessity" is sometimes called an implied agency resting on implied authority. That, however, is just confusing; "implied" should be reserved for things implied in fact, whereas this agency by necessity is nothing more than a rule of law imposing powers and duties regardless of anyone's factual concurrence.

agency by operation of law. An agency relationship implied in law without reference to any agreement between principal and agent. Certain insurance agents, e.g., have the power to bind their principals no matter what their actual agreement is or appears to be. An agency by necessity is also a species of "agency by operation of law."

agency contract. A term used to describe an important form of arrangement whereby oil companies produce oil in foreign countries. See concession for details.

agency coupled with an interest. See power coupled with an interest.

Agency for International Development. Usually known by its acronym "AID," this is a federal agency with a large role in the administration of the U.S. foreign aid program (for which see 22 U.S.C. $\S 2351$ et seq.).

agency in fact. An agency relationship arising by agreement between principal and agent. The term is used (along with express agency) to distinguish this actual agency from, e.g., agency by estoppel; agency by necessity; agency by operation of law.

agency of auctioneer. See auctioneer.

agency of the United States. An entity (which may be a single individual) which has the power as agent to bind the U.S. as principal. Where used in a statute the term either denotes or connotes something like "high agency" or "high agent," i.e., an entity of substantial importance and power, e.g., the Interstate Commerce Commission acting as such. (It should be noted 
that the concept of agency by estoppel is severely limited in its application to the U.S. government as principal.)

agency proceeding. Essentially the same as agency action, but with implied special reference to the rulemaking and adjudicatory functions of the administrative agency.

agency-shop. See closed shop.

agency to sell. An agency relationship in which the agent has the power to sell goods of, or on behalf of, the principal. It can be implied in fact from the agent's power to effect other business of the principal to which sale of goods is a usual incident. When real property is involved, it is rare that the agent will have implied-in-fact authority, real property ordinarily being sold by special agency or authorization. See real estate broker.

agenda ( ). A list, frequently written and sometimes circulated in advance, of matters to be discussed or acted on at a meeting, also giving the order of consideration. There is some recent research indicating that, under many common voting circumstances (especially when more than two more-or-less permanent factions are in the electorate), the order of the agenda can have an effect on the substantive outcomes.

agent. An "agent" is a person in a legal relationship with another, the principal, such that the agent is given the authority to, and legally can, effect with third parties transactions which are binding for and on the principal. See generally agency. The scope of authority given agents may vary enormously, from the power to effect a small, particular transaction ("Hey kid, run down to the corner and get me a pack of cigarettes; tell Louie to put it on my tab."), to power to run an entire complex business.

It is also said that an agent is in a fiduciary relationship to the principal, and this is true in at least the widest sense that an agent cannot treat his principal as he would treat any other person with whom he had no special relationship, i.e., at arm's length. He owes some loyalty to his principal, at least not to betray his interests or his reposed secrets to a third party for the agent's own gain. But the width and intensity of the agent's fiduciary responsibility will also vary very widely; a lawyer, for instance, can almost never act against the interests of his client-principal, even after their relationship has been severed, while (subject to some limitations) a real estate broker can represent a new principal against an old one with impunity.

See also independent contractor.

agent and patient. A person who finds himself as legally authorized to carry out a dual role as person doing ("agent") and person done to ("patient," in the older sense of the word cognate to "passion" as in "the Passion of Christ," i.e., what He suffered at the crucifixion). The usual example is that of person $A$, a creditor of $B$, who thereafter appoints $A$ his executor. In administering B's estate, $A$ is authorized as executor to pay all of its debts, which will include the one owed to himelf as creditor. 
agent entrusted with goods. See commercial agent.

agent for. When one enters into a contract with an agent acting on behalf of a principal, it is the ordinary understanding that if the principal defaults on the contract, one's remedy is against the principal only. But that is not a necessary result; in some cases the agent may also be a party to, or otherwise personally liable on, the contract. Hence, it is better practice to make the status of the agent clear. Terms like "agent for," "as agent," or "agent of," which are frequently appended to the agent's signature are not especially well-suited to the task, leaving too much ambiguity in close contextual or factual cases. Better would be "as agent only" or "without personal liability" or some such explicit tag. In the corporate sphere, appended terms like "as agent," "agent," or "President" will ordinarily be deemed to exclude the signer's personal liability, but even there greater explicitness wouldn't hurt.

agent not authorized to collect. A term which, at least if so printed on an invoice as reasonably to constitute notice to a buyer, is sufficient to warn him not to pay the agent, and to render him liable to pay again to the seller should his incautious payment to the seller's agent not reach the seller.

agent of. See agent for.

agent of insured [insurer]. See insurance agent.

agent provocateur ( ). A French term now part of English referring to a person who infiltrates a group on behalf of its enemy, especially the then government, and causes the group to take unlawful actions which expose its members to negative sanctions, either loss of public support or criminal punishment. An underground police officer who joins a group of young political radicals and brings them to stop talking and posturing and blow up a building instead is an agent provocateur. Under some circumstances his involvement might generate a successful defense of entrapment. But the fact questions are difficult, e.g., it is not thought to amount to entrapment if the undercover officer merely does not dissuade an illegal act, or merely takes part in carrying it out; it is almost necessary to show that no unlawful act would have taken place but for the acts of the agent provocateur.

agent's actual authority. See actual authority.

agent's apparent authority. See actual authority; apparent authority.

agent's express authority. See actual authority; express authority.

agent's implied authority. See actual authority; implied authority.

agent's incidental authority. See incidental authority.

agent's lien. A lien given to some agents against property of the principal in the agent's possession or control, to secure the agent for payment of expenditures properly made, or compensation properly earned, in connection with the agency. The terms of these liens vary. Some agents may charge against the principal's cash, or sell his property to satisfy their claims, but an attor- 
ney, e.g., may only withhold his client's goods and papers until satisfied. See attorney's lien.

agent to receive service of process. Persons, especially corporations which must procure a certificate of permission before doing business in a state other than their own, are ordinarily required by law to appoint in that state an agent to receive service of process. This is to assure that personal service of process, leading to jurisdiction in personam, can be effected upon them.

In some states, statutes provide that merely by doing an act in the state, e.g., driving an automobile on the state's highways, one automatically appoints a state official as agent to receive service of process (at least with respect to an accident involving the car in the state).

As permissible methods of acquiring in personam jurisdiction have expanded in recent years (see, e.g., long arm statute), the significance of these mandatory "agencies" has contracted.

age of choice. See age of discretion.

age of consent. The age at which a person may validly consent to marriage, or sexual intercourse (which would otherwise be statutory rape for her partner). The age varies widely among jurisdictions, but is never higher than the age of majority, and [is] usually lower, sometimes very much lower, e.g., twelve.

age of discretion. An age, usually fourteen, at which in many states a minor is entitled to choose or at least be consulted in the appointment of a guardian. Also called "age of election."

age of election. See age of discretion.

age of majority. The chronological age at which a person ceases to be a "minor," and, subject to whatever legal disabilities minority carries with it (e.g., inability to vote, to drink intoxicating liquors, to drive on the public highways, to make valid contracts, conveyances and wills) while benefiting from whatever rights minority brings (e.g., to be supported by one's parents). Especially since the 1971 enactment of the Twenty-sixth Amendment to the Constitution, making eighteen the voting age in Federal and state elections, eighteen has become the age of majority for most other purposes too. The notable exceptions are automobile driving, marrying, and taking part in lawful sexual relations (see age of consent), where the requisite age tends to be lower, and drinking intoxicating liquors, where it often remains higher.

The use of "age of majority" to determine legal rights and liabilities is a particularly clear example of a legal system's occasionally overwhelming need for certainty and easy administration, even at the cost of some substantial injury to accuracy and particularized justice. The age-of-majority concept is obviously designed to protect persons not yet mature enough to fend for themselves, i.e., to protect themselves against harmful experiences and relationships. But it is obvious that nothing magical happens on a person's 
eighteenth birthday; some people who are seventeen, or sixteen or even younger are in fact perfectly capable of negotiating canny contracts, even sexual ones, while some over eighteen (or over forty for that matter) are not. Hence the law's choice of a particular age as a surrogate for competence, while most likely roughly separating those needing extra care from those not, is nonetheless both overinclusive and underinclusive, i.e., it gives special status to some people who don't need it, and fails to give it to some who do. But the cost-in transactional uncertainty and of factual determination - of not using this chronological-age bright-line surrogate for factual competency, but instead letting the matter turn on the actual ability of the particular person to care for his own interests, is considered so great as to justify this relatively crude age-of-majority approach.

age of nurture. The portion of childhood prior to seven years of age. See also infant.

age of reason. Sometimes said to be reached when a child reaches seven, at which point it may be able to act responsibly, i.e., appreciate the consequences of its acts and control them. This age choice is at best crudely approximate (see age of majority), and in innumerable particular instances and situations flatly false.

At common law, children under seven were irrebuttably presumed to be incapable of committing a crime, and between seven and fourteen rebuttably so presumed. Modern criminal statutes have many age gradations governing criminal responsibility and the treatment (see juvenile delinquency), but nowhere are children under seven criminally responsible.

age prayer. An old "motion" by an infant party to a real action, praying that the proceedings be stayed until he reached his majority.

ager ( ). Old term for "land," or "a field"; linguistically connected to acre, but most likely without any precise area specification.

agere non potest ( ). "He cannot maintain an action," a Latin tag found in old reports.

aggravated ( ). When used in law, e.g., in a criminal statute, the term means something like "a nastier kind of," e.g., "aggravated arson" may describe arson involving threat to human life; "aggravated assault" may be assault with intent to kill; "aggravated" larceny may be armed larceny from the person of the victim, i.e., armed robbery. But many other things may also be the aggravating feature, e.g., "aggravated assault" in some jurisdictions includes assault to commit rape, and "aggravated larceny" may also refer to burglary from a dwelling house. And a previous conviction of the same offense may "aggravate" a subsequent occurrence. All one knows is that when "aggravated" is added to the name of a crime it means that it is thought to be worse and to deserve a harsher penalty.

In ordinary speech, aggravated can be used to mean "made worse," but it is also commonly and imprecisely used to mean "irritated" or "annoyed," 
as in "His whining aggravated me," and "Who needs that kind of aggravation?"

aggravated arson. See aggravated.

aggravated assault. See aggravated.

aggravated battery. See aggravated.

aggravated damages. See aggravation of damages.

aggravated larceny. See aggravated.

aggravated rape. See aggravated.

aggravation. See aggravated; aggravation of damages.

aggravation of damages ( ). Making damages worse than they might otherwise have been; it refers to divers and dissimilar matters [and] situations of legal significance. If, e.g., a trespasser not only sets foot on another's land, but levels the house or rapes the daughter, that will be pleaded as "matter in aggravation of damages." Also, if a tortious act increases a preexisting injury, that too may "aggravate damages." But malice or other evil intent may also lead to an "aggravation of damages," i.e., to higher awarded damages designed to punish the wrongdoer, i.e., to exemplary or punitive damages. Finally, the term may refer to the role of the plaintiff in increasing his own damages, e.g., by unreasonably failing to seek medical treatment, the rule being that the tortfeasor is not responsible for that portion of the plaintiff's injury.

aggregate. "To aggregate" $(\quad)$ is to combine together, either physically or conceptually, previously separate things; "an aggregate" ( ) or "an aggregation" ( ) is what results. See, e.g., aggregate income.

aggregate corporation. See corporation aggregate.

aggregate income. Income from various sources which are to be treated for various purposes, e.g., entitlement to payments under welfare laws or income taxation, as a single amount, e.g., the income of husband and wife fling a joint return.

aggregatio mentium ( ). See meeting of the minds.

aggregation. In general, see aggregate.

In Federal civil procedure there is an "aggregation doctrine" pursuant to which the individual claims of multiple plaintiffs, e.g., in a class action, may not be aggregated to produce the requisite jurisdictional amount for a suit based on diversity of citizenship.

aggressor ( ). The aggressor in a fight or other incident is the one who "starts up," or who at least "keeps it going" after the other has sought to stop things. In various legal contexts the "aggressor" is considered the culpable, or more culpable, person involved in an unlawful happening.

Hidden in this otherwise straightforward definition, however, are grievously difficult questions of causation and blame. When two small boys 
are separated after a schoolyard altercation, they are both likely to say "He started [it]," and both likely to be sincere. Boy A means that Boy B called him "a fairy," and Boy B means that Boy A, untouched, punched him in the mouth. Similarly, in an International Law context, Lebanon will accuse Israel of being "the aggressor," i.e., that it moved and used its armed forces across the Lebanese border, while Israel will call Lebanon "the aggressor," i.e., that Lebanon allowed, and even aided the movement of non-Lebanese terrorists across the Israeli border.

The central hidden questions of "aggression," therefore, are not causal or factual; in any reasonably close case it is too easy to point to some activity on the part of the other party which "really" started the altercation which led to, say, the other party's death. The real question is what actual causes will be allowed, i.e., in ethics and law, to count as justifications for another's infliction of injury. It may sometimes be necessary to be quite arbitrary, e.g., "mere words never justify physical assault." At other times detailed definitions may have to be used, e.g., "Only the following acts of a government, known to be willful and intentional, shall justify armed invasion: (1) . ..."

Altogether, no particular allocation of the epithet "agressor" is likely to satisfy everyone in any reasonably close case. But it should be recalled that not all cases are close, and the man in a bar who, having had his opinion of the Red Sox quietly contradicted, cleaves the skull of the speaker, is without a doubt, for any relevant legal purpose, the "agressor."

aggrieved. In ordinary language, "injured"; "feeling injured"; "made unhappy." But merely being factually aggrieved in that sense may not be enough to render one "aggrieved" or an "aggrieved person" [or "party"] for legal purposes. One may be made very unhappy by the decision in a case between Doe and Roe, but that will not give one the right to appeal if neither Roe nor Doe wants to. In some cases, even palpable physical or financial injury will not make one "aggrieved" in law, for an applicable statute may contain an implied modifier like "directly" or "materially," e.g., a statute giving rights to persons "aggrieved" by a zoning decision may not give any to one whose property will certainly decline in value, but only because the neighborhood will not be as lovely as it once was.

aggrieved party [or person]. See aggrieved.

aging of accounts. A process of classifying accounts receivable by age, e.g., less than 30 days old, 30 to 60 days old, over 90 days old, so as better to estimate the percentage thereof which will be ultimately collected, done on the theory that the older the account the less likely it is finally to be paid. Financial institutions which lend money taking accounts receivable as collateral are extremely interested in the age of those accounts, as are regulatory agencies, e.g., bank examiners, in determining the quality of assets listed by the institutions being supervised. 
agio. A term for the premium paid for the exchange of one kind of money over another, particularly relevant to the practice of currency arbitrage.

agist ( ). See agister.

agister ( ). One who for payment accepts as bailee the animals of others for pasturing on land in his possession. He may have an "agister's lien" for payment of amounts owed him.

agister's lien. See agister.

agistment. See agister.

agitator. When applied to a person, the term means "one who stirs things up," but the implication is that what is stirred up is trouble, and the term, while not necessarily alleging unlawful activity, is nevertheless usually used perjoratively. Common uses are "labor agitator" (on behalf of unions or unionization), "political agitator" (in favor of usually radical change), and "seditious agitator" (the same, but with an implication of illegality). Most common is "outside agitator," the idea being that everything would have been fine but for the intrusion of willful outsiders, e.g., "Our Negroes were purely happy until those outside agitators stirred them up." As one can imagine, one man's "agitator" is another man's "fighter for truth and justice."

agnates ( ). See cognates.

agnati ( ). See cognates.

agnatic. See cognates.

agnation. See cognates.

agnomen ( ). An identifying tag added to someone's name, ordinarily familiar or slangy, e.g., "Mac the Knife," or "Shorty Schwartz." In Roman times, agnomens were often honorific, e.g., "Scipio Africanus" i.e., "The Scipio who had all those great victories in Africa." $C f$. cognomen.

agnostic ( ). One who neither believes nor disbelieves in the existence of God. Compare atheist.

agrarian ( ). Pertaining to land, and by extension to farming and rural matters, e.g., "agrarian reform" which usually means redistribution of rights in land so as to benefit the poor, especially by cutting up and distributing large estates, or by seizing them to be held in common by larger groups.

In Roman Law, the "Agrarian Laws" referred to those laws passed throughout Roman history providing for the allocation of public lands (especially those acquired by conquest) to the Roman people.

agrarian laws. See agrarian.

agrarian murder. See parking place murder.

agrarian reform. See agrarian.

a gratia ( ). "By grace," i.e., not of right, but as an indulgence of favor. 
agreavit ( ). "He agreed," a term sometimes found in old reports.

agree. The process of attaining agreement.

agreed. Came to agreement.

agreed case. See agreed statement of facts.

agreed order. After it has rendered its decision a court will often command counsel for both parties to "settle order" or "settle order on notice." That means that they should get together to see if they can come up with an order of court, the form and details of which are satisfactory to both. If they can, it becomes an "agreed order," which the court will then enter. (If not, the judge will formulate his own order, either with or without further proceedings.)

agreed price. A price reached through the process of agreement, as contrasted to a price set by government (including judicial) order, or by some other third party with power to impose a price on buyer and seller.

agreed statement of facts. A process for expediting the judicial decision of a legal controversy when the parties are not in any material dispute about the facts, but disagree only as to the legal significance thereof. The parties may get together, after pleading is completed, and file with the court a jointly agreed statement of all facts relevant to the court's decision, and on the basis of which the court should decide the case. In this process the parties may, better to frame the issue in the determination of which they are interested, even agree to imaginary facts, though this process ought not go so far as to constitute a feigned case. And, strictly speaking, the parties cannot by agreement confer jurisdiction upon a court which would not have it on the real facts. (There is a similar process in some courts whereby even pleadings can be dispensed with, and decision may be had upon an "agreed case.")

It should be noted that there are other procedural techniques for achieving the same or similar result-the avoidance of having to prove facts at a trial-e.g., demurrer (and motions in the nature thereof), summary judgment motions (usually after discovery), and stipulation of facts.

agreed value. See generally agreed price. The additional implication is that the agreed value is not necessarily the actual value, but both parties wish it to be the value used, e.g., for calculating the amount to be paid by an insurer.

agreement. The process of agreement seems to require that two persons actually reach a substantially identical state of belief or intention about facts and (if legally relevant) their rights and obligations in connection therewith. $A n$ agreement, however, refers only to the apparent result of such a process and result. See contract. Agreement, however, is a broader term than "contract," for an agreement may lack one of the requisites of a contract, e.g., consideration, and still be properly called an agreement. See, e.g., the definition of "agreement" in U.C.C. § 1-201(3). 
agreement against public policy. See public policy.

agreement by specialty. See specialty.

agreement for insurance. See binder.

agreement for lease. A contract to enter into a lease, as contrasted to the lease itself. It is sometimes hard to tell the two apart, which is occasionally a legally important thing to be able to do, e.g., for purposes of a Statute of Frauds under which a lease is a covered "interest in real property" and an "agreement for lease" is not.

agreement not to be performed within one year. This is one category of agreement covered by the original and most subsequent versions of the Statute of Frauds. The critical thing to remember is that the provision is supposed (by most interpreters) to apply only to contracts which by their terms cannot be performed within a year, e.g., a contract calling for delivery fourteen months in the future, not to those just very unlikely to be so quickly performed, e.g., a contract to construct a large bridge. But a contract to employ a man "for life" could by the terms of the contract be "performed" within a year if he died that quickly, and thus most courts have not found a for-life contract to be within the statute. (The fact that the fourteen-month employee could also die in eight months has been met with the argument that in that case, though there would be no liability on the decedent's estate, that contract was not "completed" or "performed" but only "excused" within the year.)

In any event, this misbegotten provision has been variously and massively interpreted by courts for centuries, and almost no generalization about it is safe for any particular jurisdiction.

agreement of conveyance. A term which could not be worse chosen any time it turns out (and the occasions are not rare) that an agreement to convey has different legal consequences from an actual conveyance, for the words are almost perfectly equivocal as to which is meant. Luckily, because of the doctrine of equitable conversion, less turns on the distinction than one would otherwise expect. See also deed. $C f$. agreement of sale.

agreement of sale. A term bearing all the potential for mischief of agreement of conveyance, but generally understood to refer to a document by which a sale is actually made, with "agreement to sell" left to describe the contract pursuant to which a sale will some time in the future be made.

agreement to receive [or give] a bribe. An agreement to take part in the crime of bribery; itself frequently a separate criminal offense.

agreement to sell. See agreement of sale.

agreement under seal. See contract under seal.

agreements mala in se. See mala in se.

agreements mala prohibita. See mala prohibita.

agrees to pay mortgage debt. A phrase which, when used between vendor and 


\section{Leff Dictionary of Law}

purchaser of real property, will lead to an assumption of mortgage by the purchaser, rather than a mere taking "subject to" the mortgage.

agrément ( ). In the language of diplomacy, the formal acceptance of a foreign country's diplomatic representative.

agri ( ). An old term for arable (i.e., farmable) land held in a common.

agribusiness. A term used to refer to the whole process of producing and distributing agricultural commodities, ordinarily employed by people trying to counter whatever sympathy remains for "the sturdy farmer" by suggesting that farm goods in an advanced western society are as much the product of large, complex, bureaucratic organizations as are industrial products. Hence, e.g., when a proposal is made to give some tax break with respect to the production of an agricultural product the people in favor of the break will speak of "the plight of the farmer," while the opponents will talk about "a giveaway to agribusiness."

Agricultural Acts. Also once called "Agricultural Adjustment Acts," these are Federal statutes (found mostly in 7 U.S.C.) designed to control and regulate the prosperity of U.S. farmers, and they involve a variety of price and production control devices, including payments for taking land out of cultivation, direct subsidies, controls on entry into the farming business, etc. The Acts are frequently modified, adjusted, and amended as the circumstances (of both nature and politics) fluctuate.

Agricultural Adjustment Acts. See Agricultural Acts.

agricultural commodities. This term ordinarily describes commodities of the farm, e.g., wheat and pork, not commodities for the farm, e.g., chemical fertilizers and plows.

agricultural employment. See farm laborer.

agricultural fair. See state fair.

agriculturalist. A fancy word for farmer, or a descriptive one for an expert in agriculture, e.g., a government farm agent, or an academic specializing in agriculture.

agricultural labor. See farm laborer.

agricultural lands. Land used or usable for any kind of agriculture, but nowadays used essentially to designate any land neither urban [n]or suburban.

agricultural parity. See parity.

agricultural worker. See farm laborer.

agriculture. Like farming, a word with which it is now essentially synonymous, "agriculture" is used both commonly and in most statutes broadly to include not only the sowing and reaping of crops, but anything else productive a city person might imagine going on out there "in the country," e.g., animal husbandry, grazing, viniculture, apiculture, etc.

agt (or ag't). Abbreviations of agent. 
A.I.A.. Abbreviation for American Institute of Architects.

AICPA. Abbreviation for "American Institute of Certified Public Accountants," their principal professional organization.

aid. Help and support, as in "foreign aid," "federal aid to education," etc. It need not be merely financial aid, e.g., "the Aussies aided in the invasion of Sicily." See also aiding and abetting. And see aids for the feudal "tax."

AID. The very widely used abbreviation of Agency for International Development.

See also artificial insemination (for the abbreviation written A.I.D.).

aid and abet. See aiding and abetting.

aid and comfort. A phrase, the most important situs of which is the definition of treason in Article III, $\S 3$ of the Constitution (for which see adhering). Giving "aid and comfort" has been held to require at least some affirmative overt act which would tend to help out an enemy of the U.S.

aid bonds. Bonds issued by governmental units to aid a private enterprise which is expected to produce a public benefit.

aide. "Assistant," or "helper," especially in the military (e.g., aide-de-camp), i.e., an officer serving as an assistant to a higher officer. But the term is used by extension much more widely (e.g., "He was contacted by Senator Ribicoff's chief aide, and . . . .").

aide-de-camp ( ). See aide.

aider by verdict. The cure of a defect in a pleading by a verdict at trial. Let us say, e.g., that the plaintiff in a negligence action fails to plead negligence. The defendant, despite every opportunity to do something (e.g., move for dismissal, or judgment on the pleadings) does nothing, and a trial is held at which rafts of evidence of the defendant's negligence are admitted. The jury finds for the plaintiff. The defendant cannot then try to rely on the original pleading defect. (The modern Federal locus of this wholesome rule is Fed. R. Civ. P. 15.)

aiding and abetting. A familiar crime which consists of helping, counseling, facilitating, strengthening, assisting (and so on-each local statute will have its own list) another in the commission of a crime. If actually present and taking part, one is ordinarily indictable as a principal too, and some of these assisting and furthering activities also can engender accessory status. There may once have been some distinction between "aiding" and "abetting," but since both are always charged together, whatever distinction there might once have been is gone. Naturally, of course, one convicted of the crime of aiding and abetting must, as with any crime, be proved to have the requisite scienter, i.e., accidentally or unknowingly helping out a felon is not "aiding and abetting."

aiding an escape. A criminal offense consisting of helping (with the requisite criminal scienter) a prisoner to cease, at least temporarily, being one. 
aid of the king. A special variety of aid-prayer in old practice: When a tenant of the King had a demand for rent made on him by someone else, he might petition for the King's formal assistance.

aid-prayer ( ). In real actions under English law, when a person claiming superior title sought to oust one holding derivative title (e.g., a life tenant, or the incumbent in a benefice), the latter might file a petition asking that the person with the fuller title (e.g., the holder of the fee in remainder or reversion [for the life tenant], or the patron [for the benefice holder]) be joined as a party and help to defend the title.

aids. Payments (regulated by Magna Charta, and abolished in 1660) made by feudal tenants to their lords, perhaps once voluntarily but at least as early as the reign of Henry II (1154-1189) considered due as of right in several categories: to ransom the lord from captivity; to pay the expenses of knighting the lord's eldest son, and to get up a dowry for his eldest daughter; and (somewhat later) to help out in paying the aids extracted by the lord's own lords. (During the feudal period powerful lords would sometime get away with other aids, e.g., for paying his debts in general.) See also fifteenths.

Extraordinary grants voted by the House of Commons to the Crown were also called "aids," and parliamentary taxes continued to be so called until 1688.

aid societies. Organizations, usually of women churchmembers, which aided the work of the church, especially in raising and distributing charitable and missionary funds. Sometimes called for short "ladies aid."

aiel ( ). Law French for "grandfather." Also sometimes spelled "aieul," "ail," "aile," and "ayle."

Also the name of a writ leading to a possessory assize available to an heir upon the death of the grandfather or grandmother. See assize of mort d'ancestor.

aielesse ( ). Law French for "grandmother."

A.I.H. See artificial insemination.

ail. To ail is to be ill.

ailment. A sickness, with some slight connotation that it is chronic rather than acute.

ailours ( ). Law French for "otherwise" or "elsewhere."

aim. To intend; to attempt to hit or achieve something (e.g., "He aimed to inherit early, so he aimed the gun carefully at his uncle's head."). Also that which is intended to be hit or achieved.

A.I.M.A. Insurance industry abbreviation for as interest may appear.

aineese. See ainesse.

ainesse ( ). The feudal French word for esnecy, i.e., primogeniture. Also written "aineese." 
ainsi ( ). French and Law French for "thus," "hence," etc.

airbill. As defined in U.C.C. $§ 1-201(6)$, a bill of lading used for shipments by airplane.

aircraft. A vehicle for travelling in the air, i.e., a flying machine. In most contexts (notably life and accident insurance policies excluding aircraft-related causes) the term includes not only ordinary winged and wheeled selfpowered airplanes, but gliders, seaplanes, dirigibles, balloons, etc.

Aircraft Financial Responsibility Act. One of the Uniform Laws, enacted by only a few states, one of them, however, being California.

aire. See justices in eyre.

airline. See carrier by air.

airman. Very broadly defined in the Federal Aviation Act to include not only flying personnel, but mechanics, repairmen, inspectors, dispatchers, etc., indeed almost everyone who has anything to do with airplanes and moving them.

air navigation facility. Very broadly defined in the Federal Aviation Act to include any structure or device having anything to do with guiding or controlling the flight, landing or take-off of aircraft.

air piracy. Under 49 U.S.C. § 1472(i), seizure by force or violence or threat thereof of any aircraft in flight is made the crime of air piracy with very stiff penalties attached.

airplane. See aircraft.

air pollution. See pollution.

airport. A flat place with some facilities (e.g., maintained runways, lights) to aid the regular landing of aircraft. Almost all of them are minutely regulated under the Federal Aviation Act.

airport of entry. A port of entry for aircraft.

air rights. While the right of a landowner no longer really runs a coelo ad centrum, i.e., upwards to the heavens (e.g., airplanes can without permission fly over), it is clear that one cannot do anything one wishes over a person's land any more than on it. Hence, airplanes cannot fly so low as to destroy the use of the land (absent, of course, express or implied agreement), and no adjacent landowner can maintain a structure jutting over his neighbor's property line. These air rights are often, especially in central city locations, very valuable, and are sometimes sold or leased, e.g., when the owner of a building sells or leases the right to build a bigger building over or right on top the first. And, of course, easements can be granted, e.g., to utilities to string power lines.

airship. See aircraft.

airspace. See air rights; navigable airspace. 
air traffic rules. Rules governing traffic of aircraft on take-off, landing, or in the airways, most importantly, but not exclusively, promulgated under the Federal Aviation Act.

airways. Routes upon which aircraft fly, subject, almost like roads, to government regulation, especially under the Federal Aviation Act, pursuant to which portions of the navigable airspace of the U.S. may be designated "federal airway."

aisement. (Also "aismentum"; "aisiamentum"; "esamentum.") Older terms for easement.

aisne. ( ). Also written "eigne." Law French for eldest; first born. Aisne file ( ) is "eldest daughter"; aisne fitz ( ) is "eldest son."

a.k.a. [or a/k/a]. Abbreviation of "also known as." See alias.

akin ( ). Once meant "related by blood," a meaning which survives in "kinfolk" and "kin of," etc. But "akin" is today used more generally to mean "like" or "showing resemblance," as in "He had manners akin to a hog's."

al. Abbreviation of the Latin alius, i.e., "another." See et al.

Also a Law French preposition meaning "at the," "to the," or "with the," as in al armes and al barre.

Alabama Claims. The Alabama was a warship built in England during the American Civil War for use by the Confederate States. After the war, the U.S. claimed damages from the English for the Alabama's injuries to U.S. shipping. The governments agreed to international arbitration, and in 1872 the arbitrators found against the English and awarded the U.S. over three million pounds. As part of the settlement, the two countries agreed to rules covering their behavior as neutrals during each other's wars, which have since become absorbed into general international law.

a la grande grevaunce ( ). Law French for "to the great grievance," a term found in old pleadings and writs.

alaric. See Law of Alaric.

al armes ( ). A term found in Law French pleadings, meaning "with arms," i.e., with weapons.

a latere ( ). From the side, collaterally, as in collateral descent.

alba firma ( ). In old English law, "white rent," i.e., rent paid in silver money, rather than in grain or other provisions, or in base-metal money, this latter kind being called reditus nigri, i.e., "black rent."

al barre. Law French for "at the bar" (of a court).

albus liber ( ). The "white book," an ancient compilation of the laws and customs of the City of London.

alcalde ( ). In Spain and its colonies, an administrative-judicial officer something like the English Justice of the Peace. 
alcoholic. An alcoholic is one who is addicted to alcohol (see addict). It is no longer constitutionally permitted to render the mere status of being an alcoholic criminal, but acts performed by alcoholics and others under the influence of alcohol are still punishable. It is presently thought that alcoholism is the product both of physical (perhaps genetic) predisposition, and social factors. See also drunk; drunkenness.

alcoholic beverage. Any drink containing any alcohol will make one drunk if enough is ingested. In certain statutes, however, only liquids containing more than a certain percentage (in the U.S., by volume; in some other countries, by weight) of alcohol are treated as "alcoholic beverages" or "alcoholic liquors," e.g., beer containing less than $3.2 \%$ alcohol is frequently not so treated.

alcoholic liquor. See alcoholic beverage.

alcoholism. See alcoholic.

Alcoholism and Intoxication Treatment Act. One of the Uniform Laws, enacted in about a dozen states.

al common ley ( ). Law French for "at common law."

alderman. In pre-Norman England, an important nobleman, with substantial judicial functions, e.g., sitting with a Bishop at trial and handling civil causes while the Bishop dealt with spiritual ones.

In the U.S. today, an alderman is a town or city officer, usually a member of a local body with legislative powers.

ale. See beer.

alea ( ). A game of chance, or just the chancy aspects of a venture. See aleatory contract.

aleatory. See aleatory contract.

aleatory contract ( ). Broadly, any contract the performance of which by either party is dependent upon a fortuitous or uncertain event. (Note that this is to be distinguished from the "aleatory" feature of almost all contracts, that profitability may depend on chance.) The concrete example most frequently given is the insurance contract: The insured party must pay premiums, but the insurer need not do anything at all unless the insured event, say a fire, or a death, takes place during the relevant time period. But there are non-insurance aleatory contracts too, e.g., a contract by which one agrees to buy 5000 tons of wheat (or 5000 shares of stock) if but only if the market price goes above or below a particular level.

Though some "aleatory contracts" are obviously perfectly lawful and enforceable, in many jurisdictions, some are not, e.g., a contract to pay $\$ 10,000$ if the other party is dealt three aces when one is dealt only three kings. For those kinds of aleatory contracts, and the grave difficulties in coming up with a clear conceptual distinction between them and the lawful, enforceable kind, see gambling contract. 
aleir ( ). Same as adlegiare, for which see purgation by oath.

alenage. See alnage.

aler ( ). Another spelling of aller (French for "to go"), frequently found in old reports in Law French, in phrases like "aler a dieu" (literally "go to God," but meaning "case dismissed," "you are free to go," etc.) and "aler sans jour" (literally "go without day" but meaning "case dismissed finally" or "for good," i.e., a Law French form of the Latin sine die).

aler a Dieu ( ). See aler.

aler sans jour ( ). See aler.

aleu. Variant spelling of alleu.

Alfred's Code. See Dome Book.

algarum maris. See ligan.

algorithm ( ). A procedure for carrying out a complicated operation by carrying out a precise series of simpler steps. Thus "multiply 8 by 8 and then take that product and multiply it by 8 " would be an algorithm for "get the cube of 8. " But it might also be noticed that "multiply 8 by 8 " itself has an algorithm, viz., "add 8 to 8 to 8 to 8 to 8 to 8 to 8 to 8 ." Similarly, the operation "decide this case of alleged breach of contract" might be said to have an algorithm of very roughly the form "Determine whether the defendant made a promise for which there was consideration which he did not carry out for which failure he has no legally recognized excuse or defense." And each of those steps might also have algorithms, e.g., "ask twelve randomly selected citizens to decide upon hearing and looking at the parties whether certain words were spoken or not," etc.

It is frequently impossible to state a total algorithm for a very complex process, especially when neither the end nor the intermediate processes are thoroughly defined or understood, and thus much of law is at best imperfectly algorithmic, e.g., "Decide if X is lying" is really not reducible to a series of simple steps.

al huis d'esglise ( ). A law French equivalent of ad ostium ecclesiae.

A.L.I. Abbreviation for American Law Institute.

alia ( ). "Other things," as in inter alia. "Among other things." Cf. et al.

alia enormia ( ). "Other injuries," a term usually found at the end of the complaint in an action of trespass, used to cover any injuries in addition to those specifically mentioned earlier in the pleading which might be sought to be proved at the trial. The complaint might allege, e.g., that the defendant with force of arms broke into the Plaintiff's land, cut down trees, killed pigs, broke fences, "et alia enormia," with the proof at the trial showing that the defendant also set fire to the barn (perhaps, in fact, accidentally). There is some evidence that these "alia enormia" clauses were the real gravamen of the complaint, the other force-of-arms, etc. stuff just being there to get jurisdiction into the royal courts. In any event, such 
clauses, (though hardly in Latin) are still in use today in all kinds of litigation, to cover the possibility that one might have left something out in the more particularized part of one's pleading; at the end of an automobileaccident complaint, e.g., one might expect to find, after a list of the plaintiff's broken bones and contused flesh, something like "and other great and grievous permanent bodily injuries." The discovery process will, in modern practice, serve eventually to make more specific the actually claimed injuries, but the plaintiff's attorney still does not want to have to replead (or move after trial to conform the pleading to the proof) if some injury he didn't initially mention turns out to be provable. And in some jurisdictions with strong notions of notice pleading, the injury-alleging portion of the complaint is in its entirety little more than an alia enormia clause.

alia juris. Under the authority of someone else (e.g., parent or guardian) for legal purposes. The term is not quite the opposite of "sui juris," for one can be "not sui juris," e.g., insane, and still not be "alia juris," because no guardian or other legal representative has been appointed.

aliamentia ( ). An old legal term for a liberty of passage, opening in a hedge, drainage waterway, etc. supplied or maintained for a tenant's accommodation.

alias ( ). Found today almost wholly in the formation "John Jones, alias Johnny Jones, Jonesy Jones, Spike Jones," where "alias" is short for "alias dictus" ( ) meaning "also called" or "also known as." This practice is of some importance in criminal pleading, where there is always the danger that some judge will find that the defendant's name "really" is "Johnny Jones," and an indictment naming "John Jones" is therefore defective. Locutions other than "alias" used to achieve the same purpose include "also known as" and its common abbreviation "aka" (sometimes written "a/k/ a").

alias dictus. See alias.

alias execution. See alias process.

alias process. When some court process (it could be a subpoena, a summons, a warrant, or a writ) expires in effectiveness before it can be used, or is used but does not completely achieve what it was supposed to do (e.g., a summons could not be served on all the defendants, or a writ of execution was unsuccessful in garnering enough property to cover a judgment), a second or subsequent document may be issued, which will be called an "alias" one, e.g., "alias summons," "alias subpoena," "alias warrant," "alias writ," etc.).

alias subpoena. See alias process.

alias summons. See alias process.

alias warrant. See alias process.

alias writ. See alias process. 


\section{Leff Dictionary of Law}

alias writ of execution. See alias process.

alibi ( ). "Elsewhere," "someplace else." A strategy of defense to a charge of crime, that the accused could not have done the crime at place $\mathrm{X}$, because he was at that time at place $Y$. In some jurisdictions, notice must be given of intention to raise an "alibi defense," sometimes coupled with the names of "alibi witnesses." The term has also gone over into ordinary (i.e., nonlegal) speech, where it still primarily means "I wasn't there." But there is some evidence that in statements like "I've got an alibi," and "Don't try to alibi your way out of it," the word is beginning to mean "defense" or "excuse" generally.

alien ( ). Strictly, one who is not a citizen of a particular political entity, e.g., nation, state, city, etc. But in the U.S. "alien" refers to persons not citizens of the nation; if one were referring to a Californian in some New Jersey proceeding, one would call him "a non-citizen of New Jersey," never "an alien."

See also alienate for "alien" used as a verb.

alienable. See alienate.

alienage ( ). The status of being an alien.

alien amy. See alien enemy.

alienate ( ). (The synonym "alien" is often used.) Voluntarily to sell, give, or otherwise transfer or pass title to property to someone else. Almost anything one can own one can alienate, i.e., most property is "alienable" ( ), though one can certainly take property subject to terms making it inalienable, or enter into a contract forbidding transfer. (But see restraint on alienation for a strong policy of law against giving too wide scope to such provisions.)

Moreover, some things are by law inalienable, e.g., certain lands owned by Indian tribes. Also, though one in a sense "owns" oneself, one cannot, because of the Thirteenth Amendment to the Constitution, alienate oneself. See also inalienable rights.

Another (not particularly legal) meaning of "alienate" is roughly equivalent to "estrange" or "render unfriendly."

alienated. See generally alienate. For the now rare use of the term as a rough equivalent for "insane," see alienist.

alienation. See generally alienate. See also alienation of affections; alienist.

There is also an important and widely used modern employment of "alienation" to refer, not very precisely, to some feeling of powerlessness or meaninglessness, i.e., as a rough synonym for anomie. The general idea is that people in a complex, bureaucratic world, estranged from any belief in any divine purpose for them or the world, increasingly come to feel that there is no point to anything. The contemporary modishness of the word may also be traced to the discovery (in the 1930's) of certain early writings by Karl Marx, in which he used a German word which can be translated 
as "alienation" to describe the feelings of workers allegedly reduced to mere object-making tools by the capitalist mode of production. While this modern use of "alienation" may be waning, it is still widely heard. $C f$. angst.

alienation clause. In insurance parlance, especially in fire insurance and similar policies, a clause which renders the policy void if the property, or the insured person's interest in it, is alienated, i.e., transferred to someone else, without the insurer's consent. The idea, of course, is that some property owners are more risky to insure against fire, etc. than others. See moral hazard.

Also, in real property talk, a clause in a mortgage permitting the lender to demand payment of the total outstanding mortgage upon transfer of the mortgaged property.

alienation in mortmain. See mortmain.

alienation of affections. A cause of action still available in many jurisdictions (though widely abolished during this century) for a person who has had his spouse lured away from the marital household. At common law, and by most statutes, it only lay for husbands whose wives' affections had been alienated, but it may now be socially, or even Constitutionally, requisite that both spouses have the cause of action (assuming that the cause will survive at all very much longer.)

This action for alienation of affections is interesting in at least two ways. First, the word "alienation" in it bridges both primary older meanings of the term, i.e., the affections are transferred to another, and the "errant" spouse is rendered hostile to the prior partner. Second, the cause of action itself seems to be one of the last modern vestiges (but $c f$. interference with advantageous relationships), of those medieval causes of action (see, e.g., abduction) in which a person had, so to speak, "property" in a human relationship. In such causes, a party is given a legal remedy to redress interference by a third party with a relationship with another person, there being no obligation to prove that the other party was in any way harmed by the third party, i.e., the fact that the spouse or "abducted" ward was enthusiastic about the alienation was certainly no defense.

alienation office. A public office in London where persons using the now obsolete system of real property conveyance known as the common recovery paid the required fees.

alien declarant. An alien resident of the U.S. who, pursuant to stipulated procedures, has made declaration of intention to become a citizen. Not surprisingly, an alien who hasn't declared is called an "alien nondeclarant."

alienee ( ). The person to whom property is alienated, i.e., the transferee. The transferor is the "alienor."

alien enemy. An alien whose citizenship is in a nation at war with ours. An alien whose country is at peace is an "alien friend," or, in the older Frenchderived term, "alien amy" ( ). The actual hostility or friendliness of the 
individual person involved is irrelevant to the attribution of status, though it may affect the rigor with which special restrictions are placed on him.

alien friend. See alien enemy.

alien immigrant. A person who has arrived in the U.S. from a foreign country and has not become a citizen by naturalization.

alienist ( ). A term, now almost wholly obsolete but current at least into the 1930 's, for that kind of physician we would now call a "psychiatrist" or "psychoanalyst" or "analyst," i.e., a physician specializing in the diagnosis and treatment of mental afflictions and diseases.

alien nondeclarant. See alien declarant.

alieno loco ( ). "Another place."

alienor. See alienee.

Alien Property Custodian Act. An Act (50 (App.) U.S.C. \& 1 et seq.) pursuant to which the U.S. may seize and vest in a Federal official, called the "Alien Property Custodian," property of any kind of any alien enemy. Large amounts of property, especially German, were vested pursuant to this Act during the Second World War.

Alien Registration Act. A Federal statute (8 U.S.C. § 1301 et seq.) pursuant to which substantially all aliens must register, be fingerprinted, and be subjected to other continuing forms of regulation while in the U.S.

alienus ( ). "Another's"; "belonging to another," as in "alienus homo," ("another's man," i.e., a slave) and "alienus res" ("another's property.")

alieu. Another spelling of alleu.

alighting from. A common term in automobile accident insurance policies, extending coverage to accidents occuring to persons getting out of vehicles.

alii e contra. See et alii e contra.

alimony. A payment judicially ordered (though often based on prior agreement of the parties) usually incident to divorce (though sometimes incident to judicial separation, or annulment of marriage), to be made from one spouse to the other for the latter's support. Until recently, most statutes permitted alimony only from men to women, but that is almost certainly unconstitutional, and will change. The award may be of periodic payments in definite amounts in perpetuity (or until remarriage or some other signifcant change of the recipient's situation), or may be of a single sum paid all at once or in a few installments; this latter is called "alimony in gross." Alimony ordered after judgment is sometimes called "permanent alimony," but in fact alimony decrees can almost always be reopened to take account of significant new developments. Sometimes a trust is established out of which alimony payments are to be made, this to guard the recipient against the notorious difficulty of actually collecting the alimony ordered. It is also common to order the payment of "temporary alimony" (also called "ali- 
mony ad interim" and "alimony pendente lite") during the pendency of the proceeding, and to order the alimony payer also to pay the legal expenses of the payee, this last sometimes called "suit money."

Given the current speed of developments in the area of divorce, and male-female relationships in general, the details of the law of alimony [are] likely to be unstable for some time. See also palimony for an emerging analogue to alimony, growing out of a prior relationship not quite officially marital.

alimony ad interim. See alimony.

alimony in gross. See alimony.

alimony pendente lite. See alimony.

aliquot share ( ). A phrase often appearing in wills and trusts, referring to a definite, most frequently equal, share of a larger fund, e.g., "All the rest and remainder of my said estate to be distributed in aliquot shares to my children then surviving in proportion to the number of children each then has surviving."

aliunde ( ). From another place; from outside; extrinsic. See evidence aliunde. The so-called "aliunde rule" is that evidence of juror misconduct must come from some source other than the jurors themselves before any juror will be allowed to impeach the jury's verdict.

aliunde rule. See aliunde.

alive. The central meaning, something like "neither inanimate nor dead," is easy enough. With respect to human beings, however, very tricky conceptual problems arise at both ends of life's temporal spectrum, i.e., the borderlands between not-yet-alive and alive, and between alive and dead, are not nearly as clear as a lawyer would like them to be.

At the life-death border, modern medical technology has made it possible to continue many of a person's physiological processes, e.g., breathing, circulation of blood, heartbeat, long past the point where he would ever return to consciousness and reasonably full human behavior; a person in deep coma can today be kept from "death," but only as some sort of biological preparation. In light of the costs, both emotional and material, of these radical mechanical interventions, at what point can the machines lawfully be shut off on the ground that the person is "really" dead. (The question is particularly important since many organs of the freshly dead can now be transplanted to save the lives of others.)

At the pre-alive-alive border, similar problems exist, though they are socially rather than technologically induced. At what point, should a foetus not yet born be treated as "alive," i.e., entitled to the protection accorded already born humans? Long ago it was decided that, for purposes of estate and inheritance law, an infant en ventre so mere, i.e., not yet born, was "alive" for most purposes beneficial to it. It has also been decided that a child injured in its mother's womb might itself, at least if born alive, have a 
cause of action in tort against the wrongdoer. In current abortion law, a foetus is entitled to full protection in the last trimester of pregnancy, some perhaps in the middle trimester, and none in the first trimester, its rights depending on its viability, i.e., theoretical ability to live outside its mother if then delivered.

Important to all these legal problems is the recognition that they are legal (and ethical) problems, dependent not on any deceptively "natural" biological definition of life, but on social and legal decisions. In "nature," things just are; only people classify. Thus, if a person is to be treated as no longer "alive" when his brain waves are flat (even if his heart still beats) it should be because people decide that, all in all, that is for the best, for him and for everyone else. Similarly, the relevant legal question ought not to be whether a foetus is "alive" or "a person" from the moment of conception, or the moment of viability, etc., as if the question were one of natural rather that social decision. A legal decision will still have to be made to whom the law ought to give protection and at what cost, paid by who, and in these borderlands, while "natural" classification remains persuasive and useful as a basis for legal classification, it cannot be dispositive.

See also entries beginning with live and lives.

all. A word used to indicate that every member of a class or group is to be included in whatever treatment is specified, e.g., "all male persons over the age of eighteen shall register for the draft." The word is an attempt at classificatory comprehensiveness. But attempts are also sometimes made in legal contexts to be even more comprehensive than comprehensive, to convey the same idea by some more striking term like "all and sundry" or "all and singular," (i.e., the whole set and every member thereof) or some totally redundant legalism like "each and every." This testifies to the difficulty of making "all" mean "all" in the face of occasional contextual pressures toward a less comprehensive result.

all actions not otherwise provided for. See action not otherwise provided for.

all and singular. See all.

allegata et probata ( ). Things alleged and proved; pleading and proof.

allegation ( ). In ordinary language, something asserted; in legal contexts the primary reference is to assertions in pleadings of things to be proved.

In ecclesiasteral law, an "allegation" is roughly the same as a complaint.

allegations upon information and belief. See information and belief.

allege ( ). To make an allegation.

alleged ( or ). The past tense of allege, but usually with the special connotation, especially in legal contexts, that the speaker is not endorsing the fact stated but merely reporting that it had been made, e.g., "The alleged embezzler smiled as he denied any wrongdoing." Sometimes it becomes 
rather a quaint formality as when police detectives on television news primly refer to the fellow on the other end of the handcuffs, who they firmly believe to be an ax murderer, as "the alleged perpetrator."

allegiance ( ). A duty of loyalty and obedience to laws, owed by a citizen to his government. It should be noted that, at least in the U.S., the duty of allegiance is a very narrow one. While treason and attempting to overthrow the government by force and violence probably violate a citizen's allegiance, there is no obligation to be supportive of any particular administration or, indeed, of the institution of government itself. And, in any event, there is no general crime of "unallegiance" or anything like that. But $o f$. oath of allegiance; loyalty oath.

Allen charge. A kind of charge (approved by the Supreme Court in Allen v. U.S., 164 U.S. 492 (1896)) delivered to a jury theretofore unable to reach a verdict of guilt or innocence in a criminal case because one or a few jurors were holding out. It is designed to break the impasse and prevent a hung jury (hence its other names, "dynamite charge," and "shotgun charge"). The gist of the charge is that while each juror must be individually convinced, absolute certainty is not required, that the jury has a duty to reach a verdict if it conscientiously can, and that each juror should listen to the others' views with a disposition to be convinced, especially taking into account the number of jurors who are convinced. Though at least one populous state, California, recently disapproved the use of such charges, versions of the Allen charge are in use in almost every State and Federal jurisdiction.

aller ( ). French for "to go." In Law French, sometimes spelled "aler."

aller al eau ( ). Law French for "let him go to the water," i.e., sending the defendant to the ordeal of trial by water.

aller sans jour. Law French equivalent of adjournment sine die.

alleu ( ). Also spelled "aleu" and "allieu." An allodial estate.

all events test. In income tax law, the test for determining whether an item of income or expense should be included by an accrual basis taxpayer in a particular taxable year is (a) whether all the events have occurred which fix the right to receive or duty to make the payment; and (b) whether the amount can be determined with reasonable accuracy.

all faults. See as is.

all fours. See on all fours.

alliance ( ). A joining together of two persons or groups, usually to carry out a common purpose or purposes. The term is usually used in law to refer to an alliance between nations, e.g., "The Triple Alliance." But the alliance need be neither formal, permanent, nor international. It is quite proper to refer to an "alliance" of labor unions against passage of a particular statute, or to an "alliance" established by intermarriage between families. 
allies. Persons or groups joined in some formal or informal alliance, especially nations on the same side in a war. In the Second World War, "the Allies" referred to the good guys (The U.S., Great Britain, etc.), "the Axis" to the bad guys (Germany, Japan, Italy, etc.).

allieu. Still another spelling of alleu.

all-inclusive clause. See cover-all clause

allision ( ). When a moving vessel runs into another not under way, that is technically called an "allision," to be distinguished from "collision" which properly involves vessels which are both under way. The distinction is almost totally unimportant, and the word "allision" is hardly ever seen today (if indeed it ever was).

alloc. See allocatur.

allocable ( ). That which can be allocated to, or associated with, something else, e.g., if one sold to someone else a "two-thirds share, together with all allocable interest to date, in the aforesaid mortgage" one would be selling not only two-thirds of the principal amount, but the interest earned thereon. Similarly, "buyer to pay all allocable taxes" would mean that the taxes on the thing or part of a thing bought by the buyer would be for him to pay.

allocate ( ). To direct or apportion something; to allot, as in, "The administrator was directed to allocate the dwindling supplies of heating oil to the areas of most pressing need." See also allocable.

allocation. An allocated thing or portion thereof.

allocation [of resources]. See efficiency.

allocatur ( ). "Let it be allowed," a term in old reports indicating an order allowing or granting some motion or other application. Sometimes abbreviated "alloc."

allocution ( ). The formal name of the pre-sentencing procedure dear to movie and television scriptwriters, at which the judge asks the convicted criminal if he has anything to say why sentence should not be pronounced against him. It has the practical advantage of preserving in the record, by the defendant's reply, evidence of his presence and freedom to speak.

allod ( ). Also written "alod," "alode," "alodes." See allodial.

allodia ( ). See allodial.

allodial ( ). A form of land ownership in which the title holder owns the land as absolutely and outright as it can be held, i.e., not, as in feudal or feudalderived tenure, even formally as the holder of an estate of or from someone else. (Land so held is called an "allodium" (or an "allod"), the plural of which is "allodia.") In the U.S., though there was once some feudal-type tenure, substantially all land is held allodially; only on a total failure of any heirs will the land go back to the state, and not to it as lord, but via escheat. In England it is still technically true that land cannot be held allodi- 
ally, but for all important practical purposes the holder of a fee simple has an estate of equal scope and dignity.

allograph ( ). See autograph.

alloign. See eloign.

allonge ( ). A piece of paper so firmly attached to a bill of exchange or promissory note that it becomes a part thereof. On it, valid endorsements may be written when there is no room left on the instrument itself. How firmly attached it must be may (as usual) turn out to be a sticky question; a paper clip pretty clearly will not do; paste will; a staple is questionable. See U.C.C. $\S 3-202(2)$ and comment 3.

allopathic ( ). See homeopathic.

allot ( ). Essentially the same as allocate. That which is allotted to one is an "allotment," i.e., an allocation.

allotment ( ). See allot. See also Indian allotment for a special use of the term.

allotment certificate. A document issued to a person who has subscribed for securities of a corporation, stating the amount to which he is entitled, the price to be paid, the payment and delivery schedule, etc. It is a contract binding on both parties.

allotment note. Also called "allotment ticket," a legally approved form by which a British seaman can assign and arrange for payment of part or all of his wages to certain close relatives. It takes roughly the form of a bill of exchange, i.e., it is drawn by the seaman and accepted by his employer. There is undoubtedly some equivalent device available to U.S. seamen.

allotment system. In England, a system whereby certain lands, in very small parcels, are allotted to certain persons or groups, usually these days as "allotment gardens" in or near cities and towns. See also Indian allotments.

allotment ticket. See allotment note.

allow. A word of many meanings. In legally relevant contexts, it is most prominently used as roughly synonomous with: (a) the verb "permit," as in "I will allow you to cross my property"; (b) "give a discount" or "accept this amount less," as in "I will allow you $10 \%$ if you pay by June 1st"; and (c) (in the context of judicial action) "rule in favor of," "grant," as in, "motion allowed" and "all costs allowed to the plaintiff."

allowable. In general, "that which may be allowed" or "permitted." But it is also a key term in oil and gas law, where "the allowable" refers to the amount of oil or gas which a well, leasehold, field, or geographic area is permitted to produce under the rules of an applicable governmental regulatory commission (of which there is always at least one).

allowance. "That which is allowed" in all meanings of allow, though particularly the judicial one. In addition, a periodic payment from one member of 
a family to another, especially from parent to child, e.g., "He gave each of his children an allowance of five dollars a week to teach them personal thrift." See also family allowance; widow's allowance.

allowance pendente lite. See alimony; pendente lite.

all prior endorsements guaranteed. See prior endorsements guaranteed.

all right, title, and interest. The term ordinarily used in a conveyance of any kind to get across the idea that whatever it is the grantor has in the property, he is conveying all of it to the grantee. As usual, this broadest meaning might be defeated by a limiting context, but it would take quite a context to do the trick.

all risk insurance. A kind of insurance policy which protects against so many perils that it is more efficient to write it in "all risks except $X, Y, \& Z$ " form rather than by listing the risks insured against. An insurance policy covering a home, e.g., might protect against all risks except earthquake and atomic attack. And the typical life insurance policy is really an all-risk policy, covering as it usually does almost any source of death except a very few, e.g., while piloting a private plane.

All Saints Day. November 1st, i.e., the day after Halloween.

all taxes. At least when found in a legal document, this only occasionally means all taxes; much more frequently it is the equivalent of "all of those kinds of taxes we were likely to have had in mind when we did this deal," e.g., when a contract for the sale of stock contains the phrase "all taxes to be paid by the purchaser" that would mean that the purchaser would pay all transfer taxes, but not that he would pay any income tax payable by the seller consequent to his sale of the stock. But in a will instruction that the executor was to pay "all taxes" due from the estate, "all" would come close to meaning all.

all the rest, residue, and remainder. See residuary clause.

all title and interest. See all right, title, and interest.

allurement. Something enticing. The term is sometimes used to describe what attracted the child for purposes of the attractive nuisance doctrine.

alluvio maris ( ). Alluvion from the sea.

alluvion ( ). When riparian land is augmented by accretion the new material is properly called "alluvion." The new land (i.e., not just the process) is also often called "accretion." "Alluvion" is also sometimes used to describe the augmentation caused by avulsion. See also accession.

All Writs Act. A statute (28 U.S.C. § 1651) pursuant to which the federal appellate courts are authorized to "issue all writs necessary or appropriate in aid of their respective jurisdictions . . . " It is a very old statute (a predecessor version figured in Marbury v. Madison), and remains a very important locus of federal judicial power. 
ally ( or ). See alliance; allies.

almoign tenure ( ). Also written "almoin." See frankalmoign tenure.

almoner ( ). Also written "almner" and "almer." One in charge of dispensing alms to the poor, usually in the employ of a King, bishop, or other great lord. Though there are, at least in England, ceremonial survivals of the role (the English Crown still has a hereditary Grand Almoner), the job is really now handled more impersonally by something like a Department of Welfare.

alms ( ). An old but not quite obsolete term for charitable donations to relieve the misery of the poor and unfortunate. Insofar as the term is still used, it tends to connote face-to-face charitable giving.

alms fee. In pre-Norman England, written "almesfeoh." See Peter's pence.

almshouse. Older charitable bequests were often made to found, endow, or contribute to an "almshouse," i.e., a residential dwelling for the poor.

alnage ( ). Also written "alenage." A once important English tax on woolen cloth, imposed in the name of the King by an "alnager." It was abolished in 1699.

alone. By oneself; without any companion.

along. A not very precise term meaning something like "following the contour of the longer axis," as in, "They walked along the wall bordering the estate." There is no need that the object or border be touched. When used in a conveyance, e.g., "starting at the north[w]est corner of the churchyard, and then proceeding along the public highway," the term would mean up to the edge of the highway property; if the way were private it would mean to the midpoint. A conveyance "along the shore" or "along the bank" of a river or stream would, without more, tend to exclude the water itself from the property conveyed. But as usual, the context will powerfully affect the legally operative meaning of the word.

alongside. In maritime parlance, the term means "as close as possible" to a ship.

along the bank [or shore]. See along.

also. A word of myriad meanings, the principal one, however, being "this too," as in, "He brought a gun, and also bullets for it."

also known as. See alias.

alta proditio ( ). High treason.

alta via ( ). "High way," i.e., highway or high road. "Alta via regia" ( ) is the King's highway, over happenings on which the royal courts early took jurisdiction.

alter. See alteration.

alteration. A change, amendment, or modification. The term may be used with 
respect to a physical object, or a writing. A contract, e.g., may be altered by agreement of the parties, as may a trust pursuant to powers reserved to the settlor, and leased premises if permitted by the lease. Alteration in law usually refers to an act by a person with some licit connection to the item altered, not to the act of a stranger, which is properly called "spoliation." Naturally, alteration without the assent of the other party, or the owner, is either ineffective (as with a contract) or tortious, or even criminal (e.g., when the item altered is a brand on someone else's cattle). When an alteration of some kind is sought to be given legal significance, it is usually required that it be material; a nail in the wall of leased premises will not be deemed an "alteration."

Probably the most common legal use of the term "alteration" occurs in the law of commercial paper, where it refers to a change made in a bill of exchange or promissory note, for the details and effect of which see U.C.C. $\$ 3-407$.

See also mutilation; obliteration.

alteration of [negotiable] instrument. See alteration.

altercation ( ). A heated, angry conflict or argument. The primary connotation is of a dispute considerably short of an affray, i.e., one does not use or display deadly weapons in an "altercation," though finally coming to the blows is not totally excluded from the ambit of the term.

alter ego ( ). "Alter ego" means "the other self" or "the other I," i.e., a person having a very strong form of agency, totally representing another, e.g., during a voyage the master of a ship may be said to be the "alter ego" of the owner. But no one is ever totally the alter ego of anyone else; even during the voyage the master cannot licitly dally with the owner's wife.

alter ego doctrine. A doctrine pursuant to which a court, deciding that a corporation has been but the alter ego of its stockholders, will hold them responsible for their acts done in the corporation's name, i.e., will be led into disregarding corporate entity with respect to the claim of some injured third party. As one can imagine, since one of the major purposes of doing business in corporate form is precisely to use it as one's business alter ego, special and extreme disregard or abuse of corporate form will be required before the alter ego doctrine may be successfully invoked.

alternat ( ). A practice of diplomatic protocol worked out to cope with situations in which several persons (e.g., representatives of sovereign nations) have equal right to symbolic primacy (e.g., in order of entering a room, sitting at a table, or signing a document), but it is impossible simultaneously to give each of them equal position. Thus, if no round table is available, and someone thus has to sit at the head, seating might be rotated from time to time. Or, since a treaty cannot be signed first by everyone, it might be set up such that each signatory signs at least one copy first, usually the one he gets to take home.

alternate. To alternate $($ ) is to choose first from one group of things or op- 
tions, then from another, then from the first, etc., e.g., "It is ordered that the police department alternate in hiring between white and non-white applicants until all available positions are filled."

An alternate $(\quad)$ is a person chosen to replace or stand in for the regular holder of some position if he becomes unable to serve, e.g., an "alternate juror" who is chosen to sit with the jury and function in place of a regular juror should he have to be discharged, e.g., because of illness, prior to the jury's decision.

alternate juror. See alternate.

alternate valuation date. For estate tax purposes, property may be valued as of the date of death, or the executor may affirmatively choose to value it as of the "alternate valuation date," which may be either six months after death, or the date the property is sold, whichever is first.

alternating custody. See custody of child.

alternative. An "alternative" or "alternative course of action" is one among two or more possibilities, the doing of which will exclude doing any of the others, i.e., one can do one alternative or another. Until a choice is made, however, one "has alternatives," i.e., has more than one option. In a number of legal contexts, rights, etc. are framed in the alternative, for some instances of which see the entries beginning with "alternative," below.

alternative allegations. See alternative pleading; $c f$. disjunctive allegations.

alternative contract. A contract pursuant to which one or both parties can properly perform by rendering any one of two or more performances, e.g., "Seller shall deliver either a Queen Anne breakfront or 12 cases of Chateau Mouton Rothschild 1972." Also called "alternative obligation."

alternative cost. See opportunity cost.

alternative damages. A provision of a contract permitting an injured party to choose among forms of damages for breach, e.g., between actual provable damages and the amount provided in a liquidated damages clause.

alternative judgment. A judgment which gives the party against whom it is rendered a choice of what to do in order to obey. Ordinarily such judgments are defective as lacking in sufficient certainty. But in replevin actions it is very common for the judgment to order the defendant either to restore to the plaintiff the property at issue, or pay over to him its value.

alternative obligation. See alternative contract.

alternative payees. What arises when a bill of exchange, promissory note, or other security is made payable "to $\mathrm{X}$ or $\mathrm{Y}$ (or $\mathrm{Z}$, etc.)."

alternative pleading. A pleading in which there are set forth two or more statements by way of claim or defense which not only are not quite consistent, but may be mutually exclusive. A famous (and most likely apocryphal) example is the answer filed to a complaint charging damage to a borrowed kettle: (1) I never borrowed it; (2) it was damaged when I borrowed it; (3) 


\section{Leff Dictionary of Law}

I returned it undamaged. Whatever the sufficiency of alternative pleading in time past, under Fed. R. Civ. P. 8(e)(2) and other modern procedural codes, such pleading is perfectly proper.

alternative relief. In modern pleading (see, e.g., Fed. R. Giv. P. 8(a)), a party may pray for relief in the alternative, e.g., for an injunction against, or damages because of, activities of the defendant.

alternative remainders. A remainder to one or another, e.g., "To my wife for life, remainder to my niece Gussie if she be then unmarried, or to my nephew Herman if the said Gussie shall be then married."

alternative sentence. A sentence in a criminal case giving the convicted person a choice of punishment. The only modern alternative sentences of any significance are those traffic-court sentences in "10 days or $\$ 100$ " form. (An indigent, however, cannot constitutionally have his sentence extended merely because of his inability to pay a fine.)

alternative tax. Under the income-tax laws, an option available to taxpayers calculating the tax to be paid on long-term capital gains.

alternative writ [of mandamus]. A common law writ doing the job more generally done these days by an order to show cause. It was in the form of a command that the addressee take a particular action or come into court to show cause to the court why he shouldn't, and was in early practice the opening pleading [in] numerous actions. See also mandamus; praecipe.

alto et basso ( ). "High and low," a phrase appearing in old agreements to submit questions "high and low," i.e., from top to bottom, i.e., all of them, to arbitration.

altruism. A form of behavior in which an individual apparently subordinates his own interests to those of another, e.g., by jumping into storm-tossed waters to save a life.

altum mare ( ). "The high sea." "Super altum mare" meant "on the high sea," an allegation about where an incident took place, serving to give jurisdiction to courts of Admiralty and others which would not otherwise have it. Sometimes the allegation was a legal fiction.

alumna ( ). Female graduate of a school or college. A male graduate is an "alumnus" ( ). The plurals are "alumnae" ( ) for females, and "alumni" ( ) for males.

a luy [or lui] et a res heires a tout jours ( ). Law French for "to him and his heirs forever"; one form of the operative words of a conveyance in fee simple. "Heiritiers" ( ) might be substituted for "heires," and "toujours" ( ) for "a tout jours."

a.m. (or A.M.). The abbreviation of ante meridiem, i.e., "before noon." "After noon" in Latin is "post meridiem," abbreviated "p.m." (or "P.M.").

A.M. is also the abbreviation of the Latin "artiem magister," i.e., "master of arts," the graduate degree coming after a bachelor's degree and 
before a doctorate. The degree is frequently today referred to as an "M.A.," i.e., in an abbreviation of the English translation.

A.M.A. Abbreviation of "American Medical Association," the primary national professional organization of physicians.

a majori ad minus ( ). See argumentum a majori ad minus.

amalgamation. The bringing together of divers entities, e.g., corporations or unions, so as to form a new, single, undifferentiated entity. Despite the number of entities named "Amalgamated Widgits," "Amalgamated Clothing Workers Union," etc., the word amalgamated is only infrequently used as descriptive of a legal transaction, merger, consolidation, and corporate reorganization being the legally preferred terms for the process by which jural entities are amalgamated.

Amalphitan Code. An eleventh-century codification of Mediterranean maritime law, allegedly prepared in Amalfi (Italy). In time much of it passed into the general body of international maritime law.

amanuensis ( ). A human machine for reducing oral dictation to writing, for making additional copies of documents and, under the personal direction of another, for executing the latter's signature.

ambasciator ( ). A term appearing in medieval writings, describing an agent or servant sent about on his master's business; an ambassador, but without the modern indication that the master is a sovereign state and the business diplomatic.

ambassador. Once defined (by one taking advantage of the now archaic meaning of "lie" as "to reside temporarily") as "A person sent to lie abroad for his country." Ordinarily the highest ranking representative of one sovereign state to another, employed to treat with the other about, and generally oversee, the interests of his sovereign with the other. Most ambassadors are quasi-permanently in residence in another nation, usually in its capital city, but there are ambassadors to international jural entities which are not nations (e.g., Ambassador to the United Nations), and even today (it was once common), an "ambassador extraordinary," i.e., a special ambassador sent to do a particular job, e.g., negotiate a treaty, may occasionally be appointed. Every ambassador (and every lower ranking diplomatic officer, e.g., consul, minister) has, under international law, diplomatic immunity.

The U.S. Constitution twice refers to "Ambassadors, other public Ministers and Consuls," once (Article II, $\S 2$ ) to provide for their appointment by the President with the advice and consent of the Senate, and again (Article III, $\S 2$ ), to extend the judicial power of the United States to all cases affecting them.

amber. An old Anglo-Saxon measure, thought to be equal to four bushels.

ambidexter ( ). An old term for an unscrupulous attorney who took compensation "with both hands," i.e., from both sides to a controversy. The term also came to be applied to a corrupt juror. 
ambiguity. A state of language in which the meaning to be conveyed is subject to uncertainty, in which the writing can plausibly mean one thing, or another, or still another or more. In legal writing, of course, it is always said that ambiguity is to be avoided, since people's rights and duties so often arise out of language and depend upon its meanings. But every natural language is to some extent ambiguous. Unlike languages of mathematical logic, which are designed for almost no purpose but to avoid ambiguity, ordinary languages have other jobs to do-to express nuance, to be pleasant to the mind and ear, subtly to reverberate word to word and context to context so as to express things not just accurately, but richly and fully. Thus, almost anything written in a real language can be seen to convey more than one precise meaning, and indeed the creation and use of ambiguity is one of the prime techniques of literature. In fact, intentional ambiguity is sometimes desired in law too, as when parties to a contract would. rather not face a potential issue, preferring instead to deal with the issue ambiguously and leave the solution of the problem, should it arise, to determination by subsequent litigation.

Hence, while unambiguous writing is important to law, even when desired it is an aim never fully realizable. One does the best one can. While there are famous instances of apparently perfect clarity being insufficient (as when "one thousand" turned out to mean "1200" in the rabbit trade, and "white selvage" was shown to refer to "dark selvage"), it is usually possible to write most things with enough exactness to serve the legal purpose at hand, i.e., to express only one plausible meaning in the particular context. Legal problems do arise, however, because one wants neither to bind people to things they did not mean, nor to allow every previous agreement and meaning to be opened up to the uncertainty of subsequent litigation. A contract should not ordinarily be at risk of a subsequent claim by a party that by "black" he meant "white." But what if he did-and the other party knew it?

The central problem is this: Once something is found "ambiguous" at law, it is up for grabs. There is, for instance, an "ambiguity exception" to the parol evidence rule. Testimony about unwritten understandings is allowed to clarify "ambiguities" in contract interpretation. There are even rules of thumb, e.g., that ambiguous language should be interpreted "contra proferentem," or "contra stipulatorem," i.e., against the profferer or writer thereof, or even "contra venditorem," i.e., against the seller in an ambiguous sales contract. And there is the practically important rule that all ambiguities in any insurance contract will be interpreted against the insurance company. The difficulty, then, is to take a language necessarily always somewhat ambiguous, and decide when it is ambiguous enough that one should allow subsequent argument about what it really was meant to mean in the face of a pretty clear "objective" meaning. See also ambiguity on the factum; latent ambiguity.

ambiguity on the factum. A form of ambiguity in legal writing which goes 
not just to the meaning of certain language, but to its very legal identity, e.g., whether a particular writing was meant to be a codicil to a will, or whether an entire clause, otherwise almost certainly to be expected, was accidentally left out of a will.

ambit ( ). A boundary or perimeter line; something indiciating a limit; usually used figuratively to refer to an area of power or jurisdiction, e.g., "Violations of rights in a New Jersey prison are beyond the ambit of a New York court's powers of redress."

amblotic ( ). An abortifacient.

ambulance chaser.- A term in legal slang referring to an attorney (or to one, sometimes called a "runner," who for the purpose is employed by an attorney) who actively seeks out the victims of accidents to solicit the business of representing them in any lawsuit which might arise out of the occurrence. The term is derogatory, because attorneys are thought to be ethically bound not actively to solicit business, but recent constitutional law holdings have validated at least some kinds of solicitation.

ambulatory ( ). In ordinary language, "capable of getting around," as in "the ambulatory wounded." This meaning shows up in "ambulatory court" (or "jurisdiction") referring to tribunals without a fixed situs, e.g., the old Court of King's Bench, which once followed the King around. There are few modern American ambulatory courts, though some Federal Courts of Appeal do sit in different cities within the geographic limits of their jurisdiction. But the more important legal meaning is "able to be revised"; or "not fixed or inalterable." A will, e.g., is in this sense "ambulatory"; it may be changed or indeed revoked by the testator at any time prior to his death, and (absent contract to the contrary) no one has any vested right under a will until the testator's death.

ambush. To lie in wait, hidden, and then launch an attack of some sort. While the primary context is military, the term is used figuratively in law, e.g., to describe the process of holding back information about a relevant fact only to spring it at a trial. Discovery practice in modern rules of procedure is supposed to decrease the chance [of] this form of ambush as much as possible.

a me ( ). A term in feudal grants meaning "from me," i.e., indicating direct tenure from the grantor lord. Also "de me."

ameliorating waste. See waste.

ameliorations. Betterments; improvements; softenings of harsh situations.

amenable ( ). Able to be made to do something, either because of the willingness of a person, or the power of someone else over him or the situation, e.g., "He was amenable to argument"; or "A domestic corporation is amenable to the process of this court." $C f$. obedient.

amend. To change, especially a statute or document. The implication of the 


\section{Leff Dictionary of Law}

linguistic root is "for the better," but the term is used to refer, nonjudgmentally, to any change.

amendable. In legal contexts, something like "not in such bad shape that it can't be changed so as to carry out its intended function," e.g., "amendable process" is legal process which is defective but not wholly void; it can be amended and then properly served.

amendable process. See amendable.

amendatory. Effecting an amendment, especially of a statute. See amendment of statute.

amended pleading. See amendment of pleading.

amended statute. See amendment of statute.

amende honorable ( ). In old law, a dramatized apology for past wrongdoing, part symbolic acceptance of guilt, part punishment, part expiation, usually ordered but sometimes self-imposed. When Henry II of England walked in penance and allowed himself to be whipped after the murder by some of his knights of Thomas á Becket, Archbishop of Canterbury, that was "amende honorable."

amendment. See amend.

amendment as of course. See amendment of pleading.

amendment by compulsion. See amendment of pleading.

amendment of constitution. The process for changing or adding to a constitution. For the U.S. Constitution, the process is set forth in Article V thereof.

amendment of judgment. A change in the terms of a court's judgment (as contrasted to a reversal, or voiding thereof), to correct errors therein, or to take account of new factors. Procedures to effect an amendment of judgment are regularly provided, e.g., by Fed. R. Civ. P. 59(e).

amendment of pleading. All procedural systems provide means pursuant to which a pleading may be amended; the resulting changed pleading is called thereafter an "amended pleading." Frequently, especially early in a proceeding, a pleading may be amended without leave of court or consent of the other party; it is often called an "amendment as of course." Thereafter, pleadings may be amended, but only with such leave or consent, in order better to state a claim or defense; under modern practice leave is freely given if the amendment will not unduly prejudice the other party. Indeed an "amendment to conform to the evidence" (or "proof") may also be permitted during or even after trial if there is a divergence between what was alleged and the evidence [at] trial, but again only if the other party would not be unduly prejudiced. See also departure. Under some circumstances a judge may compel amendment or amend a pleading on its own motion, e.g., to excise scandalous or prejudicial material. See Fed. R. Civ. P. 15 for the current Federal procedural rule on amendment of pleading. 
amendment of statute. A legislative change in a statute, the result of which is called an "amended statute." Amendment is to be distinguished from repeal of statute, which leads to the voiding and elimination thereof. But the distinction is frequently shadowy in practice, for one very common amendment process involves repealing a statute, and then enacting a slightly modified replacement, the net effect being a provision changed only somewhat from what previously had been in effect, i.e., an "amended statute."

amendment on court's own motion. See amendment of pleading.

amendment to conform to proof. See amendment of pleading.

amends ( ). Recompense or satisfaction given to make up for previous infliction of injury; almost never used except in the locution "to make amends for."

amenity ( ). In real property law in general, aspects of the property which, while not mecessary to the use to which it is to be put (e.g., as a dwelling place) make it more pleasant and desirable for that purpose, e.g., a splendid view, or access to a swimming place, communal hall, tennis court or park. Modern developments, especially cooperative apartment houses and condominiums vie with each other to provide such "amenities."

In the law of easements, amenity is another term for "negative easement," for which see affirmative easement.

amens ( ). See demens.

a mensa et thoro ( ). Literally "from table and bed," but usually translated "from bed and board." See divorce a mensa et thoro.

amentia ( ). An old term for idiocy or insanity.

amerce ( ). See amercement.

amercement ( ). Also "amenciament." In feudal law amercements were general, all purpose monetary penalties, imposed in all courts-royal, feudal, and local-for all kinds of derelictions by private individuals, public officers, and even governmental units like towns and counties. Once apparently totally discretionary (Lord Coke still distinguished amercements from fines on the ground that the latter were fixed) in fact many became fixed by law or custom. And after Magna Charta (1215) it was provided that amercements should not be beyond the subject's means, and should be "affeered," i.e., have their amount fixed by a group of the victim's peers. Amercements were widely used in regulation of the judicial process itself, e.g., a litigant could be amerced if he failed in his suit, a jury if it made a false presentment, etc. Sheriffs were regularly amerced by royal courts for failing to do what they ought to have done. In old reports, if someone is said to be "in mercy," that means he is subject to being amerced.

American. Pertaining to the Western hemisphere, i.e., all of North and South America, but used frequently (and not only in the U.S.) to refer to the U.S. alone. 
American Arbitration Association. A nonprofit institution which for a fee furnishes panels of arbitrators and other administrative services to those wishing to put disputes to arbitration.

American Bar Association. Widely known under its abbreviation "A.B.A." The largest national professional association of attorneys, with which many local bar associations are affiliated.

American Bar Foundation. An organization affiliated with the American Bar Association (though separate from it) engaged in doing and funding legal and law-related social science research.

American Civil Liberties Union. Widely known under its abbreviation "A.C.L.U." An organization of lawyers and others devoted to the legal protection of civil rights and civil liberties, traditionally with a heavy emphasis on vindicating and extending protections granted by the First Amendment to the Constitution.

American clause. In marine insurance, a provision in a policy that, even if the insured procures additional insurance, the insurer will pay the full amount stipulated in his contract, without any right to claim contribution from any subsequent insurer.

American depository receipt. Usually referred to as ADR. A document evidencing the ownership by an American of a specific number of shares in a foreign, e.g., French, corporation. The actual shares are held by a European bank acting as agent of an American bank which issues the ADR. The whole arrangement is to avoid the need for complex transfers of actual stock certificates when the foreign shares are traded, thereby facilitating the liquidity of the investment.

American experience tables. See mortality tables.

American Federation of Labor. See A.F.L.

American Institute of Architects. A national professional association of architects. Among other activities, it prepares and issues very widely used standard form contracts for the construction industry.

American Law Institute. A non-profit organization of lawyers, legal academics, and judges engaged in projects looking toward the clarification and improvement of the law. Its most notable attainments thus far have been the Restatements of the Law and (together with the National Conference of Commissioners on Uniform State Laws) the writing and enactment by almost all states of the Uniform Commercial Code.

American Lloyd's. See Lloyd's.

American mortality tables. See mortality tables.

American rule. See attorneys' fees.

ami ( ). French and Law French (also written "amy") for "friend," as in "prochein ami," i.e., next friend. 
amicable ( ). Friendly, or at least without hostility, as in that well known prelude to years of vicious litigation, "Can't we just sit down like adults and reach an amicable settlement of this little dispute?"

amicable action. A lawsuit set up by the parties, often on an agreed statement of facts, so as to get a legal issue important to both sides authoritatively determined.

amicable scire facies. A legal technique to revive a judgment of record while avoiding any judicial involvement. The judgment debtor signs a document in the nature of a scire facies with a confession of judgment included, and it is filed and docketed.

amicus curiae ( ). "Friend of the court." A procedure whereby an appellate court may be informed by persons not parties to a legal action, who are nonetheless particularly informed or interested in the outcome (or at least in the law being declared). Ordinarily "the amicus" (as he is usually called) will just file what is called an "amicus brief," but upon occasion he may even be permitted to take part in oral argument. Most courts permit amicus participation, but the practice is particularly used in the U.S. Supreme Court, where organizations deeply interested in an area of constitutional law, e.g., the American Givil Liberties Union with respect to a firstamendment case, will frequently petition for and be granted permission to participate as amicus curiae. On some occasions a court will invite amicus participation, especially by a government agency with special expertise on an issue, e.g., the Supreme Court will invite the S.E.C. to express its position in a pending private securities-law case.

amita ( ). An aunt on the father's side; "amita magna" is great aunt, "amita major" is great great aunt, and "amita maxima" is great great great aunt.

amitinus ( ). A cousin, particularly a first cousin.

amittere curiam ( ). "To lose the court," i.e., to be deprived of the right to attend court.

amittere legem terrae. See amittere liberam legem.

amittere liberam legem. "To lose one's free law" i.e., to be outlawed, at least to the extent of having no more legal rights than a serf, e.g., without power to appear in court to give evidence under oath. According to Blackstone, a participant in a wager of battle who cried "craven" was condemned "amittere liberam legem." "Amittere legem terrae," i.e., "to lose the law of the land," seems to have involved the same status.

amity. Friendship; peaceful relations (between people or nations).

amminet. Acronym for Automated Mortgage Market Information Network, a national quotation system listing mortgage loans for sale in the secondary mortgage market, i.e., the market for people who wish to buy and sell existing mortgages.

amnesty ( ). An act by a sovereign power excusing a person or class of per- 


\section{Leff Dictionary of Law}

sons from punishment (or, if begun, further punishment) for a previous illegal action. It does not necessarily imply that nothing unlawful had been done, but amounts more to a declaration that the sovereign would like to let bygones be bygones. "Amnesty" is ordinarily differentiated from pardon in that (a) it usually is granted not to a single individual but to some class of offenders; and (b) that class is often composed of those who have committed not garden-variety crimes, but offenses of a public nature with a political tinge. Hence amnesties are often given by new governments, especially winners in a struggle for government control (e.g., civil wars), to most of the losers, so that a new beginning can be made. See also act of grace.

among. Can be used to mean "mingled with" or "in the middle of," as in "among the alien corn." But the word is more frequently used as the equivalent of "between" when more than two entities are involved, e.g., "The remainder of my estate is to be divided among my brothers and sisters," where the implication is that the division should be made "equally" or "per capita."

among the several states. See commerce clause.

amortisement. See amortization.

amortization ( ). The root concept is "killing," or "wiping out," but as primarily used today, to refer to a process applied to a debt, the meaning is close to "eliminating according to a regular schedule."

Two kinds of debts are regularly amortized. The first most straightforward of them involves the kind of debt created by a loan from another, and the process is thus usually called "loan amortization." Let us say that B borrows $\$ 100,000$ from $L$ for five years. The deal could be that B will pay interest during the term of the loan, and then pay back the $\$ 100,000$ at the end of the term. (See also balloon loan). But it might instead be provided that B would, in addition to paying interest, pay back $\$ 20,000$ of the loan at the end of each of the five years, i.e., he would "amortize" the loan. Such a practice makes the loan far less risky as the borrower need not come up with the whole amount at once, but can plan so as to decrease his obligation over time. (See annual percentage rate for the effect of amortization upon the calculation of actual interest rates.) For this reason substantially all home mortgage loans are not only amortized but "fully amortized loans" (also called "self-liquidating loans"), i.e., arranged so that a series of equal periodic payments will, over the stipulated time, pay to loan, both interest and principal, to zero. For example, consider a $\$ 50,000$ 20-year mortgage loan of $n \%$ interest, payments to be made monthly. The lender will calculate what total amount of principal and interest the borrower would pay over twenty years at $\mathrm{n} \%$ interest, and then divide that total by the number of payments, in this case 240 . The resulting number is the monthly payment. Since the payment is applied first to interest and then to principal, and since much more interest is due early in the loan when most of the principal is still outstanding, this technique results in later payments going 
mostly to repay principal, i.e., to build up the borrower's equity in the house. (There are tables called "amortization schedules" showing the allocation between interest and principal for each installment, and the amount remaining after each payment). In addition, government and corporate bonds and debentures are frequently amortized, either by paying some off prior to maturity, or by paying regularly into a sinking fund.

The other usual meaning of "amortization" also involves the periodic repayment of a debt, but it is a more subtle kind: The debt in this instance is the internal "debt" which arises when owned property regularly decreases in value over time and will at some point become valueless. (See depreciation). Assuming that the property will have to be replaced, as time passes the enterprise "owes" to itself more and more toward the cost of eventual replacement. The clearest example would be a machine used in manufacturing which will wear out in ten years. After the first year the enterprise might be said to "owe" itself one-tenth of the value, after the second year two-tenths, etc. (Actually, given the effects of inflation, applicable tax provisions, the unpredictability of any particular asset's life, etc., calculating the actual amount to be "owed" can be much more complicated.) It makes excellent bookkeeping sense (and is required by sound accounting practice) for the asset to be amortized, i.e., that entries be made on the entity's books indicating this decrease in value and growing "liability." No actual payments are made, nor is a special identifiable fund for replacement necessarily created; all that is required is that the decreasing value be shown. This amortization process is not limited of course to physically depreciating tangible assets; intangible assets, e.g., patents, or purchased leaseholds which will eventually lose their value, also should be amortized this way.

For a very different medieval use of the term "amortization," see mortmain.

amortization profit. An inartistic term for the extra cash a seller of real estate will have due to the repayments of mortgage principal he made during the time he owned the property. The term is misleading because the extra cash is not profit; it is just the repayment of borrowed money, i.e., a further investment of his own money in replacement for the mortgage lender's. The terminology is, of course, not important, so long as the seller doesn't delude himself into believing that when he bought a building for $\$ 100,000$ (all supplied by a mortgage), paid off $\$ 25,000$ of the mortgage, and then sold it for $\$ 100,000$, he had a "profit" of $\$ 25,000$ just because he found himself, after the sale and his payment of his mortgage, with $\$ 25,000$ in cash.

amotion ( ). Expulsion, eviction, removal [from a place], e.g., "amotion of possession" which is equivalent to eviction or ouster, or "amotion of chattel," which is an improper taking. There can also be amotion from an office, e.g., amotion of a corporate officer. (If the officer is also a member of the organization, e.g., a membership corporation, his "amotion" takes away his office but not his membership, i.e., he is neither disinfranchised or expelled.) 
amount covered. In insurance, the portion of the amount of loss which an insurer is obligated to pay.

amount in controversy [or dispute]. It is a frequent practice to tie the jurisdiction of a particular court to some amount in controversy, either to deprive the court of jurisdiction when the amount involved is too high (see, e.g., small claims court), or not to grant it unless it is high enough, e.g., the diversity of citizenship jurisdiction of the Federal courts (see 28 U.S.C. $\S 1332$ ) depends on there being an amount in controversy in excess of $\$ 10,000$. Usually the court will accept the amount of plaintiff's claim as measuring the amount in controversy, and jurisdiction is not affected by an actual recovery below the jurisdictional amount, but a court may reject a claim obviously inflated just to reach the requisite amount, and may impose costs on the plaintiff who recovers too little. If specific property is claimed, its value, fairly estimated, is the "amount in controversy."

See also aggregation.

amount of loss. In general, the amount for which compensatory damages will be awarded. In insurance law, the diminution in value due to an insured cause, some or all of which may be paid by the insurer.

amount realized. A term defined in $\S 1001$ (b) of the I.R.C. as (subject to some arcane qualifications) the money, plus the fair market value of any property, received upon the sale or other disposition of property. It is one of the quantities that must be determined in order to calculate realized gain or loss for tax purposes.

amove. To carry out an amotion.

amoveus manus ( ). Literally "that you remove your hands." An old writ, abolished in 1661, pursuant to which a claimant to property seized by or escheated to the King for some reason, e.g., conviction of treason or felony, or a finding of suicide by a coroner, could get it back from the King if he could establish by some appropriate proceeding, e.g., a monstrans de droit, a superior right. The Law French equivalent was "ouster le main."

amparo ( ). A term in Spanish America, also appearing in U.S. jurisdictions affected by Spanish law, referring to a sort of temporary title document issued to a land claimant to be used until a survey could be completed and a more final document issued.

amphetamines ( ). A class of drugs useful for nasal decongestion and in weight-loss programs, but also operating as powerful nervous-system stimulants, access to them therefore being heavily regulated by the government.

amphiboly ( ). A form of ambiguity arising from grammatical construction rather than ambiguity of single words, or an argument based thereon. For instance, if one writes "The little girls' camp is on part of the land to be condemned," referring thereby to a "camp for little girls," and then argues that "the use to which a small portion of the land is put should not count in 
deciding whether to condemn or not," i.e., referring to a "little camp for girls," one has produced amphiboly.

Amtrak. The familiar name of the National Railroad Passenger Corporation, the public company formed to run that substantial portion of the U.S. railway system which has effectively been put through nationalization.

a multo fortiori ( ). Very strongly a fortiori.

amy. See ami.

an. See a. Also ( ), French and Law French for "year."

analogous ( ). See analogy.

analogy ( ). Perhaps the most important species of what is frequently but misleadingly called "legal reasoning" or "legal logic." It consists of classifying something-it might be a case, or an instance of behavior, or a document-such that it should be treated like other members of the class in which it is put, i.e., to which it is "analogized." The central importance of the process of analogy arises from two factors. First, it is a fundamental tenet of most systems of justice that identical things be treated identically; that is what "following a rule" means. Second, there is no such thing as an identical thing; everything is what it is and not something else. Hence a large part of doing justice consists of trying to treat "similar" things, i.e., things "essentially," or "really" identical the same, i.e., in analogizing one thing to another such that they should be treated as if they were "the same."

But what "counts" in the way of similarity or difference? There is always some similarity and some difference. Men and dogs are both "living" beings. Should intentionally killing a dog be "murder"? No, one says, dogs are dogs and men are human beings. Granted. How about men and foetuses? Well, they are both living instances of the same species but, well, the foetus isn't born yet, and may not be able to live outside the womb. Why is that legally significant if it is? When is something so like something else that it should be treated the same, or so unlike that it should not.

The key answer is that there is no simple "logical" or "linguistic" answer, no general set of classificatory criteria for making these decisions. There are, of course, some rules, often basic ones, especially ones about what cannot count, that are applied almost unconsciously; if, e.g., a case is in substantially all ways identical with another, it is not a ground for differentiation that the plaintiff in the first was named Smith and in the second Jones-that after all, is the meaning of "following precedent," and if you want a new result, you must overrule openly. But most processes of analogy are much more subtle. The critical thing to remember is that one reasoning by analogy is making decisions; he is trying to see if the "purpose" of a statute, or the "policy" of a case, or the "intention" of a legislature, which covers $\mathrm{X}$ also, by analogy, ought to cover $\mathrm{Y}$. He is practicing an art. See also category; classification. 
analytic ( ). The term seems in legal contexts to have at least two major meanings which are at best tenuously connected. In the more widespread usage, "analytic" seems to mean something like "tackling a problem by breaking it down into its parts and asking close questions about the status of each part and its relationship to each other part." The process is thought to require careful, thorough intellectual work, and to be, therefore, strongly differentiated from intuitive problem solving, or indulging one's "feelings." So to say around a law school that a person has "a fine analytic mind" implies that he is not in the thrall of instincts or emotions, but "thinks things through."

The other meaning of "analytic" is far less frequently encountered in legal discourse. In that usage, the term refers to a statement the predicate of which is contained in the subject, e.g., "This triangle has three sides," i.e., a statement the truth or falsity of which is wholly determined by definitions manipulated according to rules of logic. This is (loosely) contrasted with statements the truth or falsity of which are determined by factual determinations, e.g., "This triangle, when struck with a stick, gives off the note 'middle G'." $C f$. a posteriori.

analytical jurisprudence ( ). See jurisprudence.

anaphrodisiac ( ). Something with an effect opposite to that produced by an aphrodisiac.

anarchist ( ). An adherent of "anarchism," i.e., a "political" system in which there is to be no coercive governmental authority, but all people are to be perfectly free to govern themselves and their relations with others on the basis of voluntary agreement. Anarchists come in a large number of varieties; there are pacifist anarchists, syndicalist anarchists, revolutionary anarchists (some essentially indistinguishable from revolutionary nihilists) and elitist anarchists ( $c f$. libertarians). In American legal contexts, however, "anarchist" has usually not been used to refer to subtle positions of political philosophy but, especially in the 1920's and 1930's, as a pejorative rough equivalent of "revolutionary" or "terrorist" i.e., as one favoring the violent overthrow of the government, the assassination of public officials, indiscriminate bombing, etc.

anathema ( ). A curse; and that which is cursed. More narrowly, an ecclesiastical punishment by which the subject is ejected from the body of the church, all other members of which being enjoined from having anything to do with him. It is generally a more extreme sanction than excommunication; but there are formulas of excommunication which amount to the same thing as anathema.

anatomical gift ( ). A gift, made by will or some quasi-testamentary instrument, of all or part or parts of one's body (e.g., kidney, cornea, heart), to be taken after one's death for use in medical education or research, or for implantation in the body of some living person in grave need. Because of recent medical advances in transplantation of organs, these gifts are of in- 
creasing practical and legal importance (though a decedent's heirs could usually consent for such use of his body even without his own prior consent or conveyance). Almost every American jurisdiction has enacted the "Uniform Anatomical Gift Act," one of the Uniform Acts, which facilitates and regulates the making of anatomical gifts.

ancestor ( ). Any one of the persons from whom one is descended; a progenitor. The term is sometimes very broadly used to include both lineal ascendants, and collateral ancestors. Very occasionally, "ancestor" was used to refer to the person last seized of an estate, whether an ancestor or not. See also ancestral estate.

ancestral action ( ). An action to recover real property based on the prior seisin of an ancestor, e.g., morte d'ancestor.

ancestral estate ( ). An estate in real property coming to the holder from a relative by gift, descent, or devise, rather than acquired by purchase. Also called "ancestral property."

ancestry ( ). The line of one's ancestors leading to oneself. In most jurisdictions, it may be proved by reputation in one's family, such testimony also comprising an exception to the hearsay rule. See, e.g., Fed. R. Evid. 803(19); 804(b)(4).

anchorage ( ). A place where ships may be safely anchored; a tax or fee paid for the right to do so.

anchor tenant ( ). A shopping center tenant who will attract a large number of shoppers, thereby generating the traffic which will make the center attractive to other lessees. In a small neighborhood center, a reputable supermarket might be the anchor tenant; in large regional centers one or more large department stores may be anchor tenants. Since anchor tenants are absolutely necessary to shopping centers (for one thing, it is almost impossible to get mortgage financing without them), anchor tenants can and do extract various concessions and favorable terms in their leases with the center developers. In recent years, anchor tenants have even become joint developers.

ancient ( ). In ordinary language, referring to things a very long time ago, as far back as "ancient times," i.e., before the fall of the Roman Empire. In legal usage, however, something ancient need not be very old at all; in some jurisdictions, e.g., an ancient document may be only ten years old. As will be seen in some of the entries beginning with "ancient" below, ancientness in law generally confers upon a record or claimed right a presumption of accuracy and validity.

ancient deed ( ). See ancient documents.

ancient demesne ( ). Lands listed in Domesday Book as having been in the hands of the crown at the coming of William the Conqueror (1066).

Also a particular species of copyhold tenure. 
ancient documents ( ). These may be deeds, wills, contracts, judgments, records, maps, surveys, etc. which are sufficiently ancient that they will be presumed to be accurate, leading to loosened requirements for authentication. The time period varies from jurisdiction to jurisdiction, with the most frequent being thirty years (twenty years in Federal courts-see Fed. R. Evid. $901(\mathrm{~b})(8))$. It is ordinarily required that this easy authentication also depend on the document's being unsuspicious on its face, and [having] been found where, if authentic, it would be likely to be. Hearsay contained in an ancient document is also ordinarily admissible; see, e.g., Fed. R. Evid. 803(16).

ancient fence ( ). A fence which has stood for so long that it will be taken to mark the property boundary between parcels of property, the reference points for the original survey and description having disappeared.

ancient judgment ( ). See generally ancient documents. In the case of a judgment, ancientness also conveys a presumption of its regularity, i.e., proper issuance.

ancient lights ( ). A doctrine, of validity in England and to some extent perhaps in a few American jurisdictions, whereby an owner of land who has had uninterrupted access to light through windows for, say, ten years, can prevent an adjoining landholder from so building as to block the light. It is thus a form of "negative easement" (see affirmative easement) acquired by prescription (see adverse possession).

ancient map ( ). See ancient documents.

ancients ( ). Sort of a rank, based on seniority, attained by members of the English Inns of Court and Inns of Chancery, e.g., a grizzled old barrister might be one of the "ancients" in Gray's Inn, below a "bencher" but above a mere "barrister."

ancient sergeant ( ). The eldest of the English sovereign's sergeants.

ancient survey ( ). See ancient documents.

ancient wall ( ). See ancient fence.

ancient will ( ). See ancient documents.

ancient windows ( ). See ancient lights.

ancient writings ( ). See ancient documents.

ancillary ( ). A modifier indicating that the something is auxiliary or subordinate to, or in aid of, a fuller, or more central or more important thing. See entries below starting with "ancillary" for examples of the range of the term.

ancillary action. A term most frequently used (with "ancillary proceeding" used essentially as a synonym-see action) to refer to those proceedings brought in equity in order to get something done to or for an action in another court, e.g., in older practice a bill to perpetuate testimony could 
be filed in a court of equity to preserve evidence to be presented in some action in a law court. In modern practice, of course, the merger of legal and equitable jurisdictions into single courts, together with modern codes of practice, including discovery, has narrowed the need for and range of "ancillary actions" in that sense. But "ancillary action" is still used to refer to these auxiliary judicial proceedings, even if entertained in the same court.

See also ancillary jurisdiction.

ancillary administrator. An administrator appointed to carry out an administration of estate, but in a jurisdiction other than that of the main estate. If, e.g., a person dies domiciled in New York, but owning substantial assets in California, the administration of his estate will take place in New York, but an ancillary administration will be granted and an administrator appointed in California to collect, care for, and dispose of property there.

ancillary attachment. In times and jurisdictions that allowed a lawsuit to be commenced by attachment (or garnishment), "ancillary" would be added to "attachment" (or "garnishment") to indicate that it was, in that instance, a proceeding to preserve assets or collect a judgment and not the suitcommencing variety. Recent Constitutional law developments have doomed the practice of allowing suits to be commenced by attachments as a matter of course, and one expects that the need for a term like "ancillary" to distinguish ordinary from suit-commencing attachments eventually to fade.

ancillary bill. See ancillary action.

ancillary garnishment. See ancillary attachment.

ancillary jurisdiction. The jurisdiction of a court to determine matters and issue orders with respect to matters before it, or to property in its control, in order fully to carry out its primary jurisdiction, effectuate its previous judgments and orders, etc. Sometimes a court has jurisdiction to consider and determine matters ancillary to a matter properly before it, even if it would not have had jurisdiciton had only that matter been sought to be determined. See also pendent jurisdiction. It refers to essentially the same thing as "ancillary action" when taking place in a single court. Indeed, the original use of "ancillary jurisdiction" referred to the jurisdiction of courts of equity to issue orders to protect persons asserting legal rights in courts of law.

ancillary letters. Letters of administration issued for an ancillary administration.

ancillary proceeding. See ancillary action; ancillary jurisdiction.

ancillary process. Legal process in aid of a main action, e.g., attachment or garnishment. See also ancillary attachment.

ancillary receivership. The same as an ancillary administration, but involving a receivership.

ancillary suit. See ancillary action. 
ancipitus usus ( ). "Of doubtful use," or "of varies uses." In international law, an action or preparation for action of which it is difficult to tell the purpose, whether warlike or properly peaceful. A modern example might be the building of an atomic fuel plant, which might yield either fuel for generating electric power, or atomic weapons.

and. The general conjunctive or coupling word in English, meaning "also" or "together with" or "in addition." The word is usually considered to be the opposite of the general disjunctive word or, but the vagaries of English language make that idea too simplistic. In various contexts, "or" can mean "and," and vice versa. If, for example, a provision of a statute were to read "Anything previous to the contrary notwithstanding, a spouse may be disinherited if he or she has previously been guilty of the following: persistent adultery, desertion for more than two years, and attempted murder of the testator," it would be silly not to conclude that the "and" meant "or," i.e., any one of the three transgressions, and not only all of them together, would justify disinheriting. But "or" can sometimes mean "and" too; consider, e.g., the opening sentence of this entry. See also and/or; or.

and his heirs. Ordinarily a term of art that actually means "in fee simple," i.e., when a conveyance is made "to John Brown and his heirs" it just means that Brown gets an estate in fee simple; in the jargon of conveyancing, "and his heirs" are words of limitation and not "words of purchase." It is conceivable that one could use "and his heirs" to mean that the estate or other property was to go jointly to Brown and his heirs, but to do so would show appalling draftsmanship.

and/or. A term thoroughly detested by all commentators on draftsmanship for its dangerous and confusing ambiguity: does it mean "and," "or," or "any one or any combination"? One can, however, understand the source of the impulse which created "and/or." Let us say that one wishes to express the idea that, with respect to two or more items on a list, any one item or any combination of items on the list is to bring about a particular result, e.g., "Additional notice of the commencement of the suit must be given by registered mail to any defendant who is out of the jurisdiction, insane under the age of eighteen." Now, what does one put in the blank? "And" is obviously a bad idea, for the indicates that notice is to go only to insane minors who are out of the jurisdiction. "Or" is much better since it clearly means that either absence or insanity or minority triggers the notice provision. But technically, an insane minor is not insane or under eighteen but both insane and under eighteen; does the provision apply to him? Of course it does, at least to any sane interpreter, but wouldn't it be nice to be able to say so explicitly? Hence "and/or."

Nonetheless, "and/or" is a bad drafting idea. If the meaning of and/or had stabilized as "any one on the list, any combination of any number on the list, and all items on the list together," or "either one or both together" it wouldn't be an unhandy locution to have available in such short form for statements like "jurisdiction may be acquired by personal service and/or 
publication." But that is frequently not what the draftsman would want it to mean if he thought about it. In short, "and/or" is not just ambiguous, but conducive to plain old misdrafting. Thus, if one wants to say "any one or any combination," and is afraid plain "or" will not do the trick, one ought to use a few extra words to write out the idea "any one or any combination" unambiguously.

androgyne ( ). The term would ordinarily be used as synonomous with hermaphrodite, i.e., as a label for a person with primary sexual organs of both sexes. But see also androgyny.

androgyny ( ). May refer to the state of being a hermaphrodite, but much more commonly it is used to describe sexually ambiguous appearance or behavior. Of this use, there are two principal variations. Androgyny may refer to anbigious or variable sexual behavior, i.e., sexual activity with members of one's own sex (homosexuality), or sexual activity with members of one's own sex and with members of the other sex (bisexuality). See also AC-DC.

It may also refer to "masculine" appearance or behavior by a female, or "feminine" appearance or behavior by a male. This last usage is the most questionable. First, it is hard to know what "masculine" or "feminine" appearance or behavior might be when it's not actual sexual behavior. Second, there is no established correlation between homosexuality and even the most caricatured examples of effeminacy or masculinity; only a very small percentage of male or female homosexuals show overtly any surface behavior of the other sex, and many people who do so, so-called "sissified" men, or "masculine" women, are thoroughly heterosexual.

Indeed, while an allegation of androgyny is still most likely meant most of the time to be pejorative and insulting, even that seems slowly to be changing, and there may come a time when the term would also refer to a person who is not so locked in a particular surface sex identify as to be unable to relax and take [on] some of the appearance and roles traditionally assigned to the other sex.

androlepsy ( ). The practice by a nation of holding hostage citizens of another in order to make their country "do justice" in a dispute between the two. May include the old practice whereby a nation signing a peace treaty delivered hostages to secure its performance of the terms thereof. In the modern world, the closest analogue (though the word is never used) most likely occurs when some group seizes private citizens, e.g., on an airliner, and threatens to kill them unless their nation takes some action, e.g., releases other members of the hijacking group then imprisoned. If done openly by a sovereign, it would be an act of great hostility, one just asking for retaliation. But it may be being done subtly but frequently today, e.g., when a citizen tourist of the U.S. is arrested for a "crime" in Bulgaria and then traded for a Bulgarian spy previously captured in the U.S..

andromania. ( ). Another term for nymphomania. 
and so forth. See etc.

anecdotal evidence. A term of abuse in assessing a social science argument, as in "These grand generalizations are not buttressed by any statistically significant collection of data, but on anecdotal evidence only." The criticism is that not much in the way of generalization can safely be made of an incident or two. But it should also be recognized that much of what we know as individuals is, whether wisely or not, based on anecdotal evidence, e.g., the behavior of muggers when balked, or of lovers when jealously followed. The amount of statistically valid knowledge about ourselves and the world is in fact extremely small.

anecius ( ). The Latin equivalent of the Law French aisne, i.e., "eldest."

aneth letter. The name of a Federal Power Commission form requesting evidence of prices paid by natural gas pipe lines, contract terms, cost information, and other data.

an et jour ( ). Law French for "year and [a] day," a period frequently chosen to have legal significance, e.g., the length of a jail sentence that identifies the crime as a felony.

anew ( ). Over again from the beginning; the equivalent of "de novo" as in trial de novo.

angary ( ). Also "angaria." The root idea is "forced taking," particularly of service. Hence in feudal law, "angaria" was any annoying or vexatious personal service which had to be done by tenant or villein to his lord. In maritime law, the term described seizure or impressment of a vessel for public use. And in international law, it described the asserted right (called the "right of angary" or "just angarie" or "jus angarioe" of a nation at war to seize the property of neutrals, including and perhaps especially vessels, to help in the war effort.

angel. An ancient English coin, equal to ten shillings.

Also theater slang for an investor in or backer of a theatrical or musical performance, especially a stage play.

angild ( ). Sometimes also written "angilde," "anguilde," "angyld," and "angylde." In Saxon (pre-Norman conquest) law things, including persons, had certain stipulated money values, which were to be paid upon wrongful injury or destruction. Thus, e.g., if a cow were destroyed, the owner was entitled to the "angild" for a cow. A man's angild was generally called a "weregild," which was to be paid by one guilty of homicide (or his relatives) partly to the King and partly to the victim's relatives. The "were" of persons varied by rank, i.e., the king had the highest, nobles next, and so on all the way down to peasants. Double angild was called "twigild," and triple angild, "trigild."

Angleterre ( ). Law French for "England."

Anglia ( ). Old term for "England." 
Anglican Church. The established church of Great Britain, which came into being upon Henry VIII's break with the papacy; the Church of England.

anglice ( ). "In English." The term was put into old pleadings when a Latin term or passage was about to be repeated in translation. Often found in abbreviated form as "angl."

angst ( ). A German word which has found its way into pretentious English. Its best translation is "anxiety," especially that free-floating worry for which the sufferer can give no sufficient cause. But it has also come to be used as if it meant "anguish," in the sense of a general feeling of mental and emotional pain experienced in living in the current, allegedly horrible and inauthentic world. $C f$. anomie.

anguish. See mental anguish.

anblote ( ). An ancient English tax.

aniens [or anient] ( ). "Null," "void," "of no force or effect." "Anniented" meant "voided."

animal. Strictly, any living creature not a member of the vegetable kingdom. As ordinarily used in law, the term excludes humans, and almost always also excludes other large groups, e.g., fish, crustaceans, microscopic animals, etc. and, in some contexts, (e.g., "cruelty to animals") it excludes everything but mammals and marsupials with cute babies.

In the Roman law of property, animals were divided into various categories, which occasionally appear, in Latin or translated, in common-law cases, e.g.,

(a) "animals of a base nature," i.e., those in which property can be acquired by capture and taming, e.g., wild dogs and cats, bears, foxes, wolves, apes, etc., the taking away of which thereafter is tort and crime;

(b) "domestic animals" (or "animals domitiae naturae"), i.e., animals like cows, sheep, household dogs and cats; in such animals full property rights can be held by owners;

(c) "animals ferae naturae" (or "wild animals"), i.e., those which live in the wild state, e.g., wolves, bears, foxes, deer, etc.; property in these animals belongs to the first acquirer (or killer), provided, however, that one may not enter the land of another to take them;

(d) "animals mansuetae naturae," i.e., animals gentle by nature, e.g., some sheep and some cattle, which are generally these days "domestic animals."

It should be clear from the foregoing that the various animal categories are built on different classifying rules for different purposes, and thus the categories tend to be deeply overlapping and generally imprecise. See also animus revertendi.

animal husbandry. The science and art of breeding, raising, and marketing animals. 


\section{Leff Dictionary of Law}

animalia vagantia ( ). "Roving animals," for the damages done by which their owners, if any, may be legally responsible.

animal of a base nature. See animal.

animals domitae naturae ( ). See animal.

animals ferae naturae ( ). See animal.

animals mansuetae naturae ( ). See animal.

animo ( ). "With a purpose to" or "with intent to," e.g., "animo recipiendi," meaning "with intent to receive." The word "animus" means "the intention of," e.g., animus recipiendi, "the intention of receiving." In almost all instances (and with no obvious regularity), a term appearing in the "animo" form may appear in the "animus" form, and vice versa. Hence, if you do not find the term you are looking for under "animo ," look under "animus ;" and vice versa.

animo cancellandi ( ). With intent to cancel, void, repudiate. An important concept with respect to the law of wills, because tearing or other defacement of a will will void it, but only if done "animo cancellandi." The same concept is expressed by the term animus revocandi.

animo capiendi ( ). With intent to take, or to capture.

animo custodiendi ( ). With intent to care for, or take care of.

animo dedicandi ( ). With intent to dedicate, i.e., to donate. See dedication.

animo defamandi ( ). With intent to commit defamation.

animo derelinguendi ( ). With intent to abandon. See abandonment.

animo differendi ( ). With intent to delay.

animo donandi ( ). With intent to make a gift.

See donative intent.

animo et acto ( ). By intent and act. See also animo et corpore; animus et factus.

animo et corpore ( ). "By the mind and the body" or (more loosely) "in thought and deed." See also animo et acto; animus et factus.

animo felonico ( ). With felonious intent.

animo furandi ( ). With intent to steal; the specific felonious intent necessarily proven in order to support a conviction for larceny.

animo lucrandi ( ). With intent to profit.

animo manendi ( ). With intention to remain. In order to establish a new domicil, one must both physically move oneself and have "animo manendi" with respect to one's new location.

animo morandi ( ). With intent to remain, or to delay. $C f$. animo differendi. 
animo non revertendi ( ). With no intention of returning. See animus revertendi.

animo possidendi ( ). With intent to take possession.

animo recipiendi ( ). With intent to receive.

animo republicandi ( ). With intention to republish.

animus ( ). See generally animo. The word (also "anima") can be translated as "soul."

In addition, "animus" can mean "ill will" or "hostility," as in "He has an animus against George and all he stands for."

animus et factum ( ). To effect a change of domicil, there must be "animus," i.e., intention to reside in a place indefinitely, plus "factum," i.e., one's actual movement there. $C f$. animus et factus; animo manendi; animus revertendi.

animus et factus ( ) Intention and act; will and deed. See also animo et acto; animo et corpore.

animus quo ( ). "The intent with which" (an act was performed). Will often be found in the form "the animus quo," as in "he possessed the animus quo for it to be theft."

animus recuperandi ( ). The intention of recovering (a thing).

animus restituendi ( ). The intention of restoring, or returning (something). animus revertendi ( ). The intention to return. See also animo manendi; animus et factum; animus et factus.

The term is most frequently encountered in the context of "an animal with animus revertendi." If such an animal, e.g., a homing pigeon, or domestic dog or cat, leaves the possession of its owner, he does not lose his property rights in it. If, however, an animal ferae naturae (see animal) escapes, it belongs to whomever next reduces it to possession.

animus revocandi ( ). Same as animo cancellandi, but usually with particular reference to a will.

animus testandi ( ). The intention to make a will; testamentary intent.

A-95 review. Review administered by the Federal Office of Management and Budget pursuant to its OMB Circular A-95, the purpose of which is to assure awareness and comment by both governmental and private interests which might be affected by federally funded or facilitated real estate programs.

An, jour, et waste ( ). Law French for year, day, and waste.

annates ( ). See first-fruits.

annex ( ). As a noun, a smaller building attached to or attendant upon a larger one. For the verb form ( ), see annexation.

annexation ( ). In international and municipal law, "annexation" refers to 
the process by which a nation, or city, town, etc., acquires and joins to itself other territory, usually contiguous.

The term is also important in real property law, for which see fixture.

"Annexation" of a document means attaching it.

annexed to the freehold. See affixed to the freehold.

annez ( ). Law French for "years."

anniented. See anient.

anni nubilis ( ). Marriageable age for a woman, twelve years at the time of Coke (sixteenth-seventeenth century). Now set by statute in every jurisdiction, and now always higher than twelve. See also age of consent.

anniversary. The yearly recurrence of a particular date, usually marked off to celebrate an occasion (e.g., marriage anniversary) or mark an obligation (e.g., "Rent shall be paid on each and every anniversary of the date hereof .....").

Anno Domini. See A.D.

annotation ( ). A note, commentary, summary, or other cache of useful supplemental information, usually brief, and usually accompanying the material annotated, which may be a case, statute, treatise, etc. There is a whole legal genre of "annotated cases," "annotated statutes," etc.

announced. Under many procedural systems, a nonsuit becomes unavailable once a decision is "announced." This does not require issuance of any formal judgment, but only that the decision be communicated by the court.

annual ( ). Yearly; by the year; happening once every year.

Except in a very few instances, "annual" adds nothing to the meaning of a term except a description of its frequency of occurrence; thus, for any term modified by annual, see the term itself, e.g., for "annual depreciation" see "depreciation."

annual dividend. Most regular dividends on corporate stock are paid quarterly, but insurance policies which pay dividends almost without exception pay them annually.

annual meeting. Almost every corporation is obligated to hold at least one meeting of its stockholders every year. Most hold just one, it being "the annual meeting."

annual percentage rate. It is possible to quote interest rates in a bewildering variety of ways, e.g., in percent per month, or in percent per year, but applied to a declining balance of outstanding principal (see declining balance loan), or just in dollars of interest per week, or month or year. The Consumer Credit Protection Act provided that substantially all consumer interest rates were to [be] quoted in one form, to be called the "annual percentage rate" (frequently abbreviated "APR"), so that a person shopping for credit might compare the rates offered.

In fact, the actual calculation of an annual percentage rate can be enor- 
mously complex in certain circumstances, e.g., when principal is to be paid back at a variable rate. Hence there is a vast body of regulation, most of it impenetrable, dealing with how to calculate the annual percentage rate in various situations. (See Regulation Z.) But for almost all purposes, the annual percentage rate for closed-end credit can be calculated with sufficient accuracy by the following formula:

$\mathrm{R}=\frac{2(\mathrm{P})(\mathrm{C})}{\mathrm{A}(\mathrm{N}+1)}$

where:

$R$ is the annual percentage rate

$P$ is the number of payments per year

$\mathrm{C}$ is the dollar amount of the finance charge

$A$ is the principal balance, i.e., the amount

annual report. Almost every corporation not a close corporation issues, and substantially all are required by law to do so, an "annual report" to its stockholders, containing a detailed set of audited financial statements, full information on significant transactions during the year (especially remuneration of, and other actions involving, directors and officers), and usually a general report by management on how the year went together with management's plans for the future. Many of these reports are expensively printed on glossy paper with a full complement of elegant pictures of the company's products and operations (and officers).

A large number of corporations are also obligated by law to file an annual report with the Securities and Exchange Commission, for which see 10-K.

annuity ( ). Most broadly, any yearly payment to be received for a term or for life. The recipient is called the "annuitant." Hence, e.g., payments granted by rulers and noblemen to favorites or officials were called "annuities."

These days, though the term may be used figuratively to mean any regular payment (e.g., "A guy who actually finishes writing a law dictionary ought to have himself a sweet annuity"), it now primarily refers to a right to receive periodic payments from an insurance company or other large financial institution. One can buy an "annuity policy" from an insurance company for a lump sum, or with periodic payments. Much more commonly, however, people acquire annuities in two other ways. First, most life insurance policies provide that the beneficiary can choose to receive an annuity for a term of years certain, or for life, in lieu of lump-sum payment. Second, many pension plans are annuity plans, i.e., the employee is to get an annuity starting at his retirement based upon the amount contributed by him and his employer during his working years. (These plans ordinarily call for entitlement to a lump-sum payment should the employee die before retirement.)

There is also a growing use of what might be called life-care annuities: a 
person will transfer a substantial sum of money to an institution, say a nursing home, in exchange for its promise to care for him for life. (This used to be handled less formally when an older person attempted to provide for old age by conveying, or promising to leave by will, the old family farm to a favorite trusted child, nephew, etc., who in return promised life support.)

Some other terms relevant to annuities are as follows:

(a) "annuity certain": one payable for a specific period no matter when the annuitant dies.

(b) "joint and survivorship annuity": one payable to two named annuitants jointly until one dies, and then to the survivor for life. A "joint annuity" ceases to be paid when the first annuitant dies.

(c) "life annuity": one paid for the life of the annuitant only;

(d) "refund annuity": a "life annuity" in which provision is made for some refund of the amount paid should the annuitant die prematurely; it is often provided that all paid in to the company will eventually be paid out again (with the company presumably keeping the earnings on the amounts paid). Also called "cash refund annuity" and "installment refund annuity."

(e) "variable annuity": one in which the dollar amount eventually to be paid to the annuitant is not fixed as with a "straight annuity," but rather depends on the investment experience of the fund out of which the payments are to come. This is of course more risky for the annuitant, but in inflationary times is often thought to be well worth the risk. A variable annuity contract has been held to be a "security" subject to the jurisdiction of the SEC.

annuity bond. A bond without maturity date, designed to pay interest forever. annuity certain. See annuity.

annuity contract. See annuity.

annuity policy. See annuity.

annuity trust. A trust calling for fixed yearly payments to the beneficiary even if the income earned by the property in trust does not yield the stipulated amount, the additional amount needed being taken from the principal.

annul ( ). To void; to nullify; to render without further force or effect.

annulment of marriage. A judicial declaration that a supposed state of marriage never existed, as contrasted to divorce which voids a preexisting marital status. In fact, an annulled marriage was never really treated for all purposes as never having existed, e.g., in a state which treated fornication (unmarried sexual intercourse) as a crime, the intercourse of parties to a subsequently annulled marriage would never have been prosecuted. More important, in some jurisdictions alimony could be ordered with respect to this marriage which never was.

The grounds for annulment of marriage usually tended to be fraud- or mistake-related, e.g., falsely claimed virginity or potency, or failure to know 
of close blood relationship between the parties at the time of the marriage. And in some places a consummated marriage, i.e., one in which the parties had had sexual intercourse, could not be annulled. But especially in times and places in which divorce could be granted, if at all, only upon very limited grounds, e.g., solely for proven adultery, annulment was used as an ameliorating device to get married people parted. It was not infrequently the case that "fraud" was loosened almost to promissory misrepresentation (e.g., "She said she wanted babies"), and indeed many alleged grounds, e.g., impotency, were proved collusively, i.e., by the joint perjury of the parties.

annum, diem, et vastum ( ). Also annus, dies, et vastum. Latin for year, day and waste.

annus ( ). A year.

annus et dies. The Latin form for the Law French an et jour.

annus reditus ( ). Yearly rent; annuity.

anomalous plea ( ). A plea which combined affirmative and negative elements (which, at least in equity practice, was a horrible pleading sin).

anomie ( ). A term from the Greek meaning "no law," used originally by Emile Durkheim to describe a society which has lost its traditional normative code, i.e., in which telling right from wrong has lost its generally unproblematic character. The term later developed so as to overlap with the purposelessness and rootlessness meanings of alienation. $C f$. also angst.

anonymous ( ). Without a name, or at least a known name, as in, "The anonymous author of this pornographic trash . . . " Abbreviated "anon."

anonymous case. Those cases titled "Matter of X" or "Y v. Z," or "Doe v. Bolton" where, because of the sensitive nature of the proceeding, e.g., a minor petitioning for right to have an abortion, or an adoptive child's custody being determined, it is thought better not to publish the true names of one or both parties.

another action pending. See other action pending.

ansel ( ). Also spelled "ansul" and "auncel"; sometimes referred to as "ansel weight." A primitive weighing device consisting of a long pole (sometimes called a "steelyard") with baskets or hooks at either end. A fixed weight was put at one end, that which was to be weighed was put at the other end, and when the pole was held at its exact center, if it was exactly level, then the weight at each end was known to be the same.

answer. In ordinary language, a reply to a question or solution to a problem. Also, an undertaking to be responsible, as in, "I will answer for any losses his speculations might have caused."

In law, the most prominent use of the term (see, e.g., Fed. R. Civ. P. 8 \& 12 ) is to refer to the defendant's first pleading in a lawsuit (which at common law was usually called the "plea"). 
answerable ( ). Liable for, as in "answerable for the debts of another." answer in bar. See plea in bar.

antagonistic cooperation. A relationship between or among persons in which they join their efforts to produce something of value to the participants, while at the same time being in conflict over other things, most particularly the division among themselves of the product of their joint efforts. The term has some currency in sociology. It has, oddly enough, almost none in economics, even though the normal alliance of factors of production in modern economic aggregates, e.g., between labor and capital in a corporation, marvelously exemplifies the term and concept. Indeed, in a somewhat less obvious sense normal economic trading also exhibits antagonistic cooperation, in that parties to a trade can both increase their utilities by exchange, but still contend over the ratio between the traded goods, i.e., over the price.

ante ( ). Before (in time). Also, in locutions like "See ante pp. 16-18," it means the same as supra, i.e., previous, before, above.

ante bellum ( ). Before the war. In the U.S. at least, "ante bellum" refers to the time before the Civil War.

antecedent ( ). Preceding; going before; already occurred or existing.

antecedent claim. See antecedent debt.

antecedent debt. A previously contracted or already existing debt.

In contract law, an antecedent debt barred because of discharge in bankruptcy or the running of the statute of limitations will nonetheless ordinarily be sufficient consideration to support a new promise by the debtor to pay. But if a party owes an undisputed, liquidated sum, payment of which is due or past due, his promise to pay some or all of it ordinarily is not (absent special statute) consideration for any counter-promise by the creditor.

In the law of negotiable instruments, an instrument given for an antecedent debt is supported by consideration (see U.C.C. § 3-408), and a holder takes the instrument "for value" when he takes it in payment of, or as security for, any "antecedent claim" (see U.C.C. § 3-303(b)).

antecessor ( ). An ancestor, or a predecessor in title.

antedate ( ). To put a date on an instrument earlier than the date of its actual execution. Negotiability of a negotiable instrument is not affected by antedating (see U.C.C. § 3-114), but it is, after all, a lie, and in certain circumstances, e.g., antedating an instrument of gift so as to qualify for more liberal tax treatment, it may also turn out to be a fraud or a crime. See also postdate.

ante exhibitionem billae ( ). "Before showing the bill," i.e., before suit (in equity) is filed.

antejuramentum ( ). See praejuramentum.

ante litem ( ). Before commencement of lawsuit. 
ante litem contestatum ( ). Before trial of the case.

ante litem motam ( ). At a time prior to that at which a declarant had reason to fabricate statements with a view to litigation. Variously interpreted as before suit is commenced, or before the likelihood of controversy is perceivable. In fact, whether a statement is likely to have been "shaded" depends upon the situation, including the character of the declarant involved; some people always and continuously have an eye toward possible litigation.

\section{ante meridiam ( ). See a.m.}

ante mortem interest ( ). A "before death" interest in property which is extinguished by the death of the holder thereof.

ante mortem statement. A statement made just before the speaker's death. See also statement under belief of impending death.

antenatal ( ). Before birth; prenatal; a foetus.

antenatus ( ). A person "born before," i.e., before another person (so as to have prior right as heir), or before a particular event of legal significance, especially some grand political development like a revolution. The Constitution, e.g., provides that no one "except a natural born Citizen, or a citizen of the United States, at the time of the adoption of this Constitution" is eligible to be President; it would be proper, therefore, to refer to such a person as an "antenatus."

antenuptial ( ). Before marriage; done or occurring before marriage, e.g., antenuptial agreement.

antenuptial agreement. An agreement between two persons about to be married relating to and in contemplation of their new status. The traditional antenuptial agreement deals primarily with the division of wealth between the spouses upon the death of one, or their separation or divorce. It frequently involves either present transfers of assets, or arrangements whereby wealth is presently secured to one or the other, or to their children, and is often therefore called a "marriage settlement." It is common, e.g., for a younger second wife of a rich man with children by his first marriage to agree to waive her rights, including dower and any other statutory right to a portion of her husband's estate, in exchange for a promise of a certain sum (in one lump, or in installments, or in periodic payments until her death or remarriage) at his death, or upon the termination of their marriage. But similar arrangements are common when both the intended spouses both have children and wealth, and seek to assure the transmission of their own wealth to their own children when the marriage, for whatever reason, is terminated.

These agreements are ordinarily enforceable, i.e., are contracts, though they usually have to be in writing because of the Statute of Frauds, and it is important if they are to be upheld to be able to show that both parties were fully informed and acted freely. 


\section{Leff Dictionary of Law}

These antenuptial agreements and settlements should be distinguished from espousals or engagements to marry. These used to be (but only exceptionally are today) enforceable agreements to enter into marriage, for breach of which an action for breach of promise of marriage would lie. It was quite common, however, for these agreements to marry to be accompanied by antenuptial agreements and settlements, especially those by which some third party (especially the bride's father) agreed to transfer wealth to his daughter, his prospective son-in-law, or the married couple jointly.

There is also a recent trend toward antenuptial agreements which deal not only or not at all with matters of wealth allocation between the parties, but with the day-to-day rights and duties of the spouses during the marriage, e.g., responsibility for child care and housekeeping, rules governing marital and extramarital sexual behavior, allocation of free time for work or hobbies, etc. These agreements vary in specificity and level of detail, but some published examples are quite detailed, dealing, e.g., with dishwashing schedules, obligations for tucking in infants, etc. It is not clear to what extent, if any, these contracts are enforceable at law. It is possible, of course, for spouses validly to contract with each other, but there are questions about a court's willingness to inquire into domestic matters, and more serious questions of remedies in a context where specific performance is out of the question, money damages are exceedingly difficult to estimate, and the equivalent of rescission of contract still requires divorce or an equivalent; i.e., marriage cannot be dissolved for breach of contract.

See also palimony for the allied matter of agreements pertaining to quasi-marital relationships, i.e., for what might be called "antenuptial" contracts.

antenuptial contract. See antenuptial agreement.

antenuptial pregnancy. Pregnancy before marriage. If it can be shown that the eventual husband was not the father, this is a common ground for annulment of marriage and divorce.

antenuptial settlement. See antenuptial agreement.

antenuptial will. A will made before marriage. A subsequent marriage will usually void such a will unless it can be shown to have been made in contemplation of the marriage.

anthropometry. A system for the careful measurement of the human body, especially the size relationship among the parts thereof. For a brief time it was used in the legal system, though with indifferent success, as a means of identifying criminals and corpses; it was supplanted by fingerprinting as a means of identification. The most prominent system of anthropometry was the "Bertillon system."

antichresis ( ). A species of civil-law mortgage for immovables. Louisiana law still provides for it, but it is almost never used. 
anticipate. Several meanings: (a) To look forward to or expect, e.g., "He anticipated a large profit."

(b) Carrying out an action before required or expected, e.g., "He anticipated the note payment by a full year."

(c) Forestalling, or countering, e.g., "He anticipated Napoleon's occupation of the river bank by moving his own troops there first."

See also anticipation and terms so beginning, below.

anticipation. A term sometimes used in negligence cases to describe some degree of foreknowledge or expectation, e.g., in applying the doctrine of attractive nuisance some courts have required that the defendant have had some "anticipation" that children, or the child plaintiff, might appear. As usual, however, the term does not by itself indicate how explicit a foreknowledge, or how high a probability is required before the critical "anticipation" will be found.

For the patent law use of anticipation, see anticipation of invention.

anticipation of children. See anticipation.

anticipation of defense. An inartistic (and once upon a time insufficient) complaint which addresses matters which are expected to be raised in the defendant's answer. If, for instance, a complaint for breach of contract alleges agreement, consideration, breach, damage, and freedom from fraud, the last allegation is anticipating a defense not as yet (and maybe never) raised.

anticipation of income. A term in income tax law meaning that a taxpayer who has transferred property in an effort to shift income from himself has failed, and the income will remain taxable to him. See attribution of income.

anticipation of income [or revenue]. Committing income or revenue not yet due to some project, especially the repayment of debt. In a sense, almost all debtors expect to repay debt, especially long-term debt, out of income not yet due, and indeed not yet earned. But a taxing unit will nonetheless be said to be (accused of being) engaged in "anticipation of income" or "revenue" if it issues securities to be paid off out of taxes neither due nor even yet imposed-especially if the loans are to be used for current governmental expenses.

anticipation of invention. One of the central concepts in the law of patents, inasmuch as the requirement of novelty, a prerequisite to valid patentability (see patentable), cannot be met if the device or process for which patent protection is sought has been "anticipated," i.e., if the device or process, or one substantially similar, is known and in use. How similar that must be is, naturally, widely disputed and frequently litigated. It is said that the previous device must be such that a person skilled in the art could take the prior device or process and come up with the one sought to be patented without adding any further inventive skill of his own, but it is not clear how much practical help that definition is either. It does appear, however, that some high degree of similarity is required. See also prior art. 
anticipatory breach ( ). A breach of contract taking place before the time for performance by the breaching party, usually taking the form of an "anticipatory repudiation," i.e., a clear statement of intention not to perform, or an act rendering it very unlikely that performance can be tendered when due.

In almost all jurisdictions, an anticipatory breach gives to the innocent party a right immediately to sue for breach, without waiting for the other party's time for performance to pass. This is said to be required by the innocent party's need to rearrange his affairs to take account of the impending breach. In fact, for that result no right to immediate suit is necessary; all that is required is that the innocent party be relieved by the anticipatory breach of his obligation to treat the contract as still in force. That is, if the innocent party could disregard the breached contract and make a new one with another, and then still sue the breaching party after his performance date had passed, he would be as fully protected as he needed to be. Nonetheless, the law almost everywhere gives right to an immediate suit.

anticipatory nuisance. A condition which is not yet a nuisance, but will be one clearly and soon enough to justify an injunction being issued against it.

anticipatory repudiation. See anticipatory breach.

anti-communist affidavit [or oath]. See loyalty oath.

antidumping act [or duty]. See dumping act.

antigraph ( ). Also "antigraphy." A copy or counterpart of a written instrument, especially a deed.

anti-injunction act. See Norris-LaGuardia Act.

anti-lapse statute. A statute enacted in most jurisdictions to prevent a legacy or devise to a named legatee or devisee from lapsing, i.e., failing, upon the named person's death prior to the testator's. The statutes provide that in that eventuality the named person shall be deemed to have died immediately after the testator, the effect of which will be to pass the legacy or devise to the named person's heirs. Let us say, e.g., that $\mathrm{T}$ has a hated son $\mathrm{S}$ and a beloved nephew $\mathrm{N}$. He leaves his entire estate to $\mathrm{N}$, but $\mathrm{N}$ predeceases him. Under an anti-lapse statute, the estate will go to N's heirs and not, as would otherwise be the case, to $\mathrm{S}$. One can, however, by language in one's will, negative the operation of an anti-lapse statute.

anti-molestation clause. See molestation clause.

antinomia ( ). See antinomy.

antinomianism. A term from theology describing the belief that moral behavior does not involve following a set of detailed rules or laws, but instead is achieved by free expression of some less precise approach, e.g., love (for one's fellow man). Hence antinomianism is roughly associated with intuitionism (and situation ethics) in ethics, and cadi jurisprudence and equity in law. 
antinomy ( ). Two contradictory propositions each resting on premises and logical processes of equal validity.

antiqua custuma ( ). An ancient (thirteenth century) export duty on wool, wool products and leather.

Antiqua Statuta ( ). Also called "Vetera Statuta." A collective name for all English statutes passed before the start of the reign of Edward III (1326). These were first printed in 1508. The later statutes are called "Nova Statuta."

antiquation. See abrogation.

antiquity of custom. See custom.

Anti-Racketeering Act. See Hobbs Act.

antithesis ( ). Loosely equivalent to "opposite," as in "The behavior of the police was the very antithesis of fairness."

antithetarius ( ). An old term from old English law for an accused criminal who defended against the charge by alleging that his accuser is really the one who did it. $C f$. approver.

antitrust acts [or laws]. Statutes passed to cope with the persistent tendency of businesses to avoid competition in order to appropriate to themselves the lessened stress and greater success that can come to one who successfully garners monopoly profits, either by driving the competition out of business by improper means, or by conspiring and combining with it. The stated purposed of the antitrust acts is to forestall this development, which will raise prices to consumers and unfairly damage business. There is continuous controversy over what kinds of business practices have these bad effects, and what kinds of laws most cheaply and successfully counter them. The principal Federal antitrust acts are the Clayton Act, the Federal Trade Commission Act, the Robinson-Patman Act, and the Sherman Act.

anuels livres ( ). Another term (in Law French) for the Yearbooks.

any. The primary meaning is something like "some specified number (including "one") out of a larger set, which may be definite or indefinite." But it is a word much modified by its context, and can mean not only "one" or "some," but sometimes "every" and "all."

any bank [banker or trust company]. See pay any bank.

ap. A prefix in some old Welsh surnames, meaning "son of." Sometimes also written " $a$," as in John a Gaunt. Cf. the Irish " $O$ " as in O'Connor.

A.P.A. Abbreviation of Administrative Procedure Act. See administrative procedure.

apartheid ( ). An Afrikaans (i.e., South African Dutch) word meaning "apartness," denominating the South African governmental policy of strictly segregating (and almost totally subordinating) non-white residents of South Africa. 


\section{Leff Dictionary of Law}

apartment. See apartment house.

apartment hotel. See apartment house.

apartment house. A structure containing multiple independent dwelling units, "apartments" (in England and sometimes in the U.S. called "flats"), the occupants of which share common facilities, e.g., a central heating and hot water unit, hallways, stairways, elevators. The most common form of apartment house tenure involves a landlord who owns the entire building and rents the individual apartments to tenants who are also entitled to use the common facilities. But a multiple unit building held by a cooperative or as a condominium is also ordinarily called an "apartment house."

An "apartment hotel" is a similar structure, except that (a) leases or licenses to reside are ordinarily shorter; (b) the landlord provides additional hotel-like services, e.g., maid service and a restaurant; and (sometimes) (c) the tenants are not permitted to cook in their apartments.

See also SRO building.

apatasatio ( ). An agreement or compact.

aperta brevia ( ). Open, unsealed writs, to be distinguished from sealed writs called "literae clausae," or close writs.

apertum factum ( ). An overt act, e.g., one needed to convict for the crime of conspiracy.

apex juris ( ). The "summit of the law," referring either to a point of great cunning, subtlety, complexity, or technicality, what the Lord Chancellor in Iolanthe delightedly calls "a nice point," or to an extraordinary level of rigor, rigidity, or harshness in the law. (For this second branch of meaning "summum jus" is sometimes used, but it may connote something somewhat less extreme.) In either case, the argument hidden in the use of the term is "that can't be the law," i.e., that the point is too clever, amounting almost to sharp practice, or just too harsh. The plural form is "apices juris."

A term with essentially similar import is "apex [pl. "apices"] litigandi," i.e., "summit of litigation."

apex rule. A term in mining law for the rule specifying in detail the mining rights in veins and ledges of ore as they course through the land held by possessors of mining claims and patents in lands in the U.S. public domain. It is called "apex rule" because one of the key reference points is the "apex of the vein," i.e., its point closest to the surface. The rule is set out in 30 U.S.C. $§ 26$.

aphrodisiac ( ). Something that stimulates sexual desire. It could refer to any such stimulant, e.g., an attractive member of the opposite sex, but is usually used to mean a substance which, when ingested, vastly increases desire. Many cultures entertain belief in many substances, e.g., oysters, ground rhinoceros horn, ginseng root, "spanish fly," etc. as aphrodisiacs, but there is little evidence that any of them work. Nonetheless, "love potions" are still widely sold today, and occasionally an intended beloved will be fed some 
noxious substance with disasterous (and legally cognizable) effect. Alcohol is thought by some to have aphrodisiac qualities, but Shakespeare has no less experienced a participant observer than the porter in Macbeth state that it "provokes the desire, but it takes away the performance." Various street drugs, e.g., marijuana, are also said to have aphrodisiac qualities.

An "anaphradisiac" is a substance with a power to depress sexual desire; generations of schoolboys and soldiers believe saltpeter (potassium nitrate) is an anaphrodisiac, and that they have been fed it secretly by their headmasters and commanding officers; but there is no evidence that saltpeter has such effect, or that either school boys or soldiers have ever been so affected.

apices juris [or litigendi] ( ). Plural forms of apex juris and "apex litigandi."

apiculture. Beekeeping, in order to harvest the honey produced.

A.P.L. Insurance industry abbreviation for automatic premium loan.

apochae oneratoriae ( ). In old commercial law, a term for bills of lading.

apograph ( ). Also "apographa." A copy, or an inventory.

apostacy ( ). Sometimes spelled "apostasy." Strictly, the total renunciation of a religion for another religion or for no religion at all, e.g., the act of the Roman emperor Julian the Apostate in renouncing Christianity. The term has been widely used, however, to batter people who disagree as to the true tenets of a religion, i.e., as a near synonym for heresy. See also apostata capiendo.

apostata capiendo ( ). An obsolete English writ commanding the sheriff to seize an "apostate," in this case meaning a religious who had violated the rule of his order, and deliver him into the hands of his ecclesiastical superior.

a posteriori ( ). "From afterwards," i.e., from the effect to the cause. A mode of reasoning in which one looks to results and reasons back to what might have been their cause. Very loosely speaking, this is the reasoning mode of experimental science and utilitarian ethics, among other things. Compare a priori.

apostil ( ). Also "apostille." Law French for a marginal note, or brief comment or addition to a report, document, etc.

apothecaries' weight ( ). The name of the system for weighing drugs. The measures are as follows: 12 ounces to the pound; 8 drams to the ounce; 3 scruples to the dram; 20 grains to the scruple. See also avoirdupois weight; metric system; troy weight.

apothecary ( ). Now rarely used term for "druggist" or "pharmacist," but still extant in many statutes.

appanage ( ). Land or some other source of revenue assigned to a member of a ruler's family. 


\section{Leff Dictionary of Law}

apparatus ( ). A device with function and purpose, quite often used metaphorically to refer to the whole legal system, or some large component thereof, as in "the apparatus of justice" or "the apparatus of the judicial system."

apparent. A term with two almost opposite meanings. Apparent can mean obvious, clear to even a cursory inspection, as in, "That he was lying was apparent to everyone in the room." But, especially in the adverbial form "apparently," it can be roughly equivalent to "it appears that," i.e., can express mild doubt, or unwillingness to believe, or surprise, or at least only hearsay or another insecure evidence, whether something were actually the case, as in "I had apparently gone through the red light." See also heir apparent.

apparent agent. See agency; apparent authority.

apparent authority. The authority possessed by an agent which arises not out of any actual authority given him by his principal, but by the fact that the principal has clothed him with or allowed him to show such indicia of power to act for the principal that a reasonable person dealing with the agent would reasonably believe him to have such power. Very similar to agency by estoppel.

apparent danger. Danger that is apparent in the sense of obvious or clear. Sometimes used to describe the kind of danger to life and limb which justifies a killing in self-defense. Also, in the law of torts, a danger so obvious that a plaintiff who ignored it would himself be negligent. See also latent defect.

apparent defects. Defects in delivered goods which are so obvious that a buyer's failure to mention them will cost him the power to rely on them thereafter. Compare U.C.C. § 2-605 which speaks of defects "ascertainable by reasonable inspection." Also, in the law of torts, a defect so obvious or "patent," that a product user who ignored it might himself be found negligent. See latent defect.

apparent easement. An obvious, easily seen or otherwise ascertainable easement, e.g., a beaten path through another's property; to be distinguished from, e.g., an easement of quiet, i.e., an invisible right not to have one's neighbor make noise.

apparent heir. See heir apparent.

apparently ( ). See apparent.

apparitor ( ). In old English practice, an officer employed to serve process and bring offenders into ecclesiastical courts. Chaucer's loathesome "summoner" was apparently the holder of such an office.

App. Ct. Abbreviation for "appellate court" or "appeals court."

appeach ( ). See impeach. "Appeacher" is also an old word for accuser.

appeal. In legal language, a term of wide reference for the general process of 
bringing a matter before a "higher" tribunal that it might correct errors made in the hierarchically lower tribunal. An appeal is generally limited to review of the record of the lower proceeding, i.e., new evidence is not to be presented. An appeal may be from one court to another, or from an administrative agency to a higher tribunal in the agency, or to a court. There are appeals of right, and appeals which may be pursued only if the higher court (or, though rarely, the lower court) grants permission, e.g., the certiorari practice of the U.S. Supreme Court. There are a number of terms which still are used for particular varieties of "appeals," e.g., writ of error. And the equivalent of an appeal for limited questions can be achieved by other means, e.g., petition for a writ of mandamus or prohibition alleging an abuse of discretion by a trial judge. There may once have been a distinction between an "appeal," as a procedure in which matters of fact and law can be raised, and a "writ of error," which was limited to questions of law, but the distinction is gone by now.

The term "appellare" in Roman Law might mean to appeal, as above, but primarily it meant "to sue" or "to go to law." Hence the occasional use in old common law of "appeal" as describing the process of originating the suit, e.g., the appeal of felony.

See also approver, whose action was also sometimes called an "appeal."

appealable. An action by a lower tribunal which can be appealed. Not all lower court actions, even formal orders, are immediately appealable in most jurisdictions, it being considered better not to interrupt and delay the trial for the appeal of an interlocutory order, but to have everything reviewed at once at the end. But since some decisions would render a trial unnecessary, and that too would save time and expense, there is an unavoidable tension between allowing the immediate appeals of certain trial-court rulings, and forbidding them. See, e.g., Interlocutory Appeals Act for a statute trying to cope with the tension.

appealable interest. Only those who have some stake in the outcome of an appeal have an appealable interest, e.g., if a party to the original suit conveys his interest in the property involved prior to judgment or appeal, he ordinarily would have no right to appeal the trial court decision.

appealable judgment [or order]. See appealable.

appeal bond. It is frequently required, (see, e.g., Fed. R. App. P. 7) of one who wishes to file an appeal that he post a bond to cover the costs of the process should it fail, and sometimes to secure the payment of the judgment being appealed.

appeal in forma pauperis. See in forma pauperis.

appeal of felony. Under old English law (regularized by a 1487 statute), a private party could make an accusation of felony against a person, in the case of murder even if the latter had already been acquitted by a jury. The accused had the right of trial by battle (in this instance with 45-inch clubs and leather shields). In all felonies except mayhem (where the accuser got 
damages), the losing defendant got the penalty prescribed by law. The procedure fell into disuse and was disregarded until in 1817 an appeal of felony was brought against one acquitted of murder. The accused chose trial by battle (even literally throwing down a glove in court), the accuser backed off, and the appeal of felony was abolished by statute in 1819.

appeal of mayhem. See appeal of felony.

appear. In ordinary language, "to show up," or to be apparent. For the usual legal meaning, see appearance.

appearance. Broadly, any act by which a litigant invokes or submits himself to the jurisdiction of a tribunal; most commonly used to speak of the defendant's act. The act may be formal, e.g., filing a "notice of appearance" in stipulated form, but almost any overt act evincing an intention to take part in the litigation, e.g., filing a pleading, will amount to a submission to jurisdiction. A litigant can appear "by attorney," or he can show up in court himself, i.e., make an "appearance corporal."

Most appearances are "general," i.e., after the act is done the tribunal has jurisdiction over the person for all purposes of the litigation. Sometimes, however, a defendant might want to "appear" but only to contest the jurisdiction of the court over him, e.g., to argue that adequate service of process was not effected on him. This could pose a dilemma: If he did not appear, he might lose the action by default judgment (despite a meritorious defense), but if he did appear, it might amount to a general appearance, i.e., he might lose his right to contest the jurisdiction over him. Hence it is generally provided that a defendant may make a "special appearance" (sometimes "appearance de bene esse"), i.e., he may appear to contest jurisdiction without thereby submitting himself generally to the jurisdiction of the tribunal.

appearance bond. A bond issued to assure the appearance of a party to litigation by promising to pay a certain sum should he not do so. Nowadays essentially limited to criminal proceeding, and in that context usually called a bail bond.

appearance docket. An indexed list of appearances, usually including a brief abstract of all proceedings in a matter.

appear generally. To effect a general appearance.

appear gratis ( ). To make an appearance in a proceeding without having waited for any service of process.

appear specially. To effect a special appearance.

appellant ( ). The party who appeals. The other party is known as the "appellee," or "respondent."

The moving party in an appeal of felony is also called "appellant," with the target also being called "appellee."

See also approver. 
appellare adversus sententiam ( ). To appeal from a sentence.

appellate. Pertaining to the process of appeal, as in "appellate court," "appellate procedure," etc.

Appellate Committee of the House of Lords. Technically, the highest court in England is the House of Lords itself. In practice, that paramount judicial power is wielded by this committee of the House, to which all legal appeals to the full House are automatically referred.

The Lords of Appeal (also called "law lords") comprise the committee. They are (1) the Lord Chancellor and ex-lord chancellors; (2) such peers who are or have been members of the Judicial Committee of the Privy Council or of Superior Courts of Great Britain; and (3) present and past Lords of Appeal in Ordinary. This latter group is made up of persons who have ordinarily held high judicial office who are appointed to the House of Lords (as barons for life) for the particular purpose of serving as Lords of Appeal. At any hearing of a judicial appeal, at least three Lords of Appeal in Ordinary must be present.

In form, the committee reports to the full House of Lords but it is understood that only the Lords of Appeal actually decide the case.

appellate jurisdiction. The jurisdiction of an appellate court, i.e., to hear appeals rather than hold trials. There are rules, sometimes quite complex ones, governing which courts can hear appeals from which others, and sometimes limiting appellate jurisdiction by subject matter. In addition, some appellate jurisdiction is compulsory, i.e., the appellate court must have an appeal filed in proper form, while some is discretionary, e.g., under the U.S. Supreme Court's certiorari power. A few courts, e.g., the U.S. Supreme Court, have both appellate and trial jurisdiction (e.g., over trials between U.S. states). Almost all appellate courts have their own procedural rules, e.g., the Federal Rules of Appellate Procedure.

appellatio ( ). An appeal.

appellation ( ). A name.

appellee ( ). See appellant.

appellor ( ). See approver.

appendage ( ). Something accessory or attached to another thing, the latter being more important or larger. See also appendant.

appendant ( ). In general, a thing appendant is a thing attached to a thing more central or important, i.e., it is an appendage. The most important specific legal meaning, however, is in the context of conveyancing, where it refers to a thing of inheritance which passes along with another, e.g., an advowson which passes with an estate. See also appurtenance; regardant.

appendant power. See power appendant.

appendix ( ). In law, most frequently used to refer to that which is filed along with an appellate brief, i.e., the record on appeal. 
appensura ( ). A mode of payment in which money is measured by weight rather than by number.

appertaining ( ). "Relating to," especially an appurtenance.

appliance. Today the word almost always refers to a device for use in the home, especially the kitchen, as in "electrical appliance" or "kitchen appliance," e.g., stove, refrigerator, dishwasher, etc. It may or may not become a fixture, depending on contract, custom, and mode of attachment, i.e., how tightly it is "built in" to the structure. $C f$. white goods.

applicable ( ). Correctly to be applied; fit; appropriate. The word is often found in locutions like "the heirs are to be determined according to applicable local law," and "the applicable statutory provision is U.C.C. § 2-302."

applicant. One who applies for something, e.g., a job, an office, or an order of court. See also movant; petitioner.

application. That which is filed or submitted by an applicant, e.g., application for bail, or to an insurance company for issuance of an insurance policy.

Also, a use, e.g., the "application" of a bandage to a wound, or a new "application" of a patent. See also application of payments; apply.

application fee. A fee charged by an institution to which some application is made, e.g., universities for admission, or banks for loans, to cover the cost of processing (and also to deter the filing of frivolous applications). Under some usury statutes, the amount of the fee must be considered "interest," i.e., if the fee added to the stated interest produces payments in excess of the permissible rate, the loan will be considered usurious.

application of payments. The process by which payments received are apportioned to different purposes, especially to debts or to component parts of a single debt. For example, it is provided by U.C.C. $\S 9-504$ that a secured party may, after default, sell or otherwise dispose of collateral and that the "proceeds of disposition shall be applied in the order following to [a list of things to be paid off]." Payments on a typical mortgage are applied first to accrued interest and then to the principal outstanding.

apply. To make an application. Also widely used more particularly to describe the process whereby a law or rule is brought to bear on conduct, as in "the court will apply the Parol Evidence Rule to bar testimony about oral agreements."

appoint. See appointment.

appointment. The designation of a person to any office or position, the term primarily but not solely being used to refer to governmental positions, e.g., a governor making judicial appointments (subject to confirmation by the legislature). But a board of directors "appoints" corporate officers, a testator may "appoint" an executor, a settler of a trust may "appoint" a trustee, and so on. The term is often used in contradistinction to election, e.g., "In 
[the] state of West Carolina all judges are elected, but the Governor may fill judicial vacancies by appointment."

See also power of appointment for a quite different meaning in the law of trusts and estates.

apportion. ( ). See apportionment.

apportionment. A division and distribution of something, often but not necessarily in equal shares to all recipients. Both material things (e.g., pieces of candy) and immaterial ones (rights to vote) may be apportioned. For this important vote-apportionment issue, see reapportionment. See also pro rata and entries so beginning.

apportionment clause. The term might be used to refer to almost any contractual clause governing almost any apportionment, but it very frequently refers to a particular clause in automobile, fire, marine, etc., insurance policy, for which see pro rata clause.

apportionment of freight. See freight pro rata.

apportionment of local [or special] assessment. The apportionment of the burden of taxation arising out of a local or special assessment made to pay for locally beneficial governmental improvements, e.g., sidewalks or sewers. Various formulae are possible, e.g., linear feet of benefited property abutting the sidewalks, value of abutting houses, etc. Almost any rational, i.e., not arbitrary or discriminatory, formula will be upheld.

apportionment of representatives. See reapportionment.

apportionment statutes. The term might be used to refer to any statutes governing any apportionment, but it primarily refers to those almost universal statutes which provide that estate taxes payable out of a decedent's estate shall be apportioned to the beneficiaries of the estate according to a particular formula (usually pro rata), unless the testator shall have provided otherwise in his will.

apportum ( ). In older English law, an income, profit, or revenue coming to the holder of some right in some property; ordinarily applied to a pension or to income from some incorporeal hereditament.

appose ( ). See apposer.

apposer ( ). A now-abolished officer of the English exchequer whose job it was to "appose," i.e., check the financial accounts of, sheriffs who had dealt with royal monies, e.g., taxes or amercements.

appostille. Another spelling of apostil.

appraisal ( ). Any process for determining the "value" of something (other than by trading it in a market). Appraisal is an important process whenever, for one reason or another, things must be valued but cannot, at least not then, be sold, e.g., when an estate must be valued for estate tax purposes, or land valued in an eminent domain proceeding, or property with only a defective market, (e.g., shares in a close corporation), is to be trans- 


\section{Leff Dictionary of Law}

ferred. As one can imagine, a large variety of techniques can be and are used in order to come up with some reasonably acceptable value, e.g., actual sales prices of comparable properties, estimations of replacement cost, capitalizations of income, depreciated values, etc. But all methods have their problems, both conceptual and practical, and the process of appraisal can lead to strife and litigation. There are, however, professional appraisers and, as noted, when the things in question cannot be sold in a fair market, some alternative valuation technique must be used.

appraisal fee. A fee paid by a prospective borrower to have an appraisal made of property he offers for collateral to secure his loan. As with an application fee, the appraisal fee may be treated as part of the interest on the loan for purposes of the applicable usury statute.

appraisal remedy [or right]. By the terms of many codes of corporation law, when a major corporate restructuring is afoot, e.g., a merger or consolidation, shareholders who do not like the terms proposed, e.g., "1.92 shares of acquiring corporation for each one share of acquired corporation," may instead invoke a procedure whereby they must instead be paid in cash the "appraised value" of their shares.

appraise. See appraisal.

appraisement. A now essentially obsolete synonym for appraisal.

appraiser. See appraisal.

appreciable. Capable of being appreciated, i.e., sensed or appreciated; a palpable quantity, but not necessarily a large one, e.g., "Though the difference was not large, the quality of the goods varied appreciably from what had been promised."

appreciate. To rise in value, as in "The securities had by the time of sale so appreciated in value that a whopping capital gains tax had to be paid."

Also, to understand, used especially in insanity definitions for criminallaw purposes, e.g., "The question is whether he was able to appreciate the nature of his acts."

Also, to recognize and respond positively to the characteristics of a thing or a person, e.g., "He appreciated good wine," or "She appreciated his willingness to share household duties."

apprehend. To grab hold of; to capture, a term usable both of a person (e.g., "The police apprehended him at the border") or a concept, idea, or piece of information (e.g., "He fully apprehended that his next conviction would lead to a jail term").

apprehension. The state of having apprehended. Apprehension can be used almost as a synonym for arrest, e.g., "His apprehension at the border ended the manhunt." When used to describe a mental state, "apprehension," unlike "apprehend," gives off a clear connotation that that which is known is worrisome or frightening, as in "He was filled with a strong apprehension that the deal was not going to go through." 
apprentice. Today the term is mostly used non-technically, to refer to any person just starting out in a trade, craft, or profession, especially if he works among more experienced practitioners, e.g., "Every year Cravath takes on thirty apprentice lawyers just out of law school."

Apprentice is, however, still used more technically today, as a defined term and status in labor-law contexts, e.g., a union contract might provide lower hourly rates for "apprentices," defined as workers in the trade less than three years, or a court might order that minority group members previously excluded from "apprenticeship programs," i.e., programs to train entering members of the union, now be admitted on some fair basis.

For a very long period of history, continuing into the twentieth century (though less well developed in the U.S. than in England or Europe), "apprentice" described a very widespread formal and legal status: a young person with respect to whom a formal agreement (usually called "articles [or "indenture"] of apprenticeship," or "apprenticeship deed") had been signed (by him or his parent or guardian) pursuant to which the apprentice was to serve a master of some trade or profession for a determinate period of time (often seven years), in exchange for which the master was to teach the apprentice the trade, and support him as a member of the household. Depending on the labor market at the time, there might be attendant payments in either direction, i.e., the apprentice might have to pay to be taken on, or the master might have to "buy" the apprentice either by lump-sum payment, or by the equivalent of wages. In the medieval guilds, an apprentice was the lowest level of worker, below journeyman and master.

apprentice en la ley ( ). Law French for "apprentice at law," originally meaning, essentially, "law student," but coming to mean a practitioner below the rank of sergeant. The Latin forms were "apprenticius ad legem" and "apprenticius and barram," the latter term arguably the ultimate ancestor of the word "barrister."

apprenticius ad barras [or legem] ( ). See apprentice en la ley.

approach. See right of approach.

approaches. Roads, ways, passages, etc. giving access to a piece of property, e.g., approaches to a bridge, or to loading ramps. A conveyance "together with approaches" would also convey approaches or at least an easement of their use.

approbare ( ). To approve.

approbate and reprobate. An old and these days insufferably fancy way of describing the response of one who both likes and dislikes something, or likes some of it but not all of it.

Approbation des Lois. The Law French short-form title of a book which purports to set out the laws and customs of the island of Guernsey (one of the Channel Islands) as they were in 1580 . 
approbo non reprobo ( ). I approve what I do not disapprove, i.e., approved except to the extent affirmatively to the contrary.

appropriate ( ). As an adjective, the term means fit, proper, assigned correctly to, as in "He took all appropriate means to effect service of process."

For the verb form, see appropriation.

appropriation ( ). This word and its verb form, "appropriate" ( ), means generally the allocation or assignment of something to one's own, or to its own, proper place. Hence it is proper to speak of goods "appropriated to the contract," i.e., by some overt act set aside as being for the fulfillment of a particular agreement.

But the word has come to have two other particular meanings which are almost opposites. In one use it means taking into possession, either temporarily or as part of a claim of ownership, e.g., "The policeman appropriated the gun he found on the suspect," or "The appropriation of the ice was complete when it was cut out of the lake and stacked in sawdust." See also water appropriation.

But appropriate and appropriation in a context of legislation imports not taking but giving, i.e., assigning monies to some legislative purpose, as in "appropriations bill," "war appropriation," "They pass good laws but never appropriate enough money to carry them out."

appropriation bill. A proposed statute directing the raising and expenditure of public money. Article I, $\S 7$ of the Constitution stipulates that "all Bills for raising Revenue" must originate in the House of Representatives. Sometimes the distinction is made between appropriation bill and "revenue bill," the latter considered to refer more precisely to one levying taxes in the strict sense, not to one doing something that will incidentally raise revenue, e.g., ordering the sale of some public lands.

approval. Favorable response to, or active acceptance after knowledge of, an act or state of affairs, impliedly by one who has the power to disapprove it. In most legal contexts, the term is roughly equivalent to ratification and indicates a somewhat more active and positive response than mere acquiescence.

approval sale. See sale on approval.

approve. See approval. For an old criminal-law meaning, see approver.

approved [indorsed] note. A promissory note indorsed by someone with better credit than the maker so as to make the note more acceptable to the payee or indorsee.

approvement ( ). In old legal terminology, an improvement of lands, especially an enclosure or fencing for the purpose of cultivation.

See also approver for the old criminal-law meaning.

approver ( ). Also "appellor," "prover," "probator." There was a more-orless formal process called "approvement" in old English criminal law, whereby a person arraigned for treason or some capital felony could, in the 
hope of pardon or mitigation of sentence, confess his guilt but accuse others as his accomplices or co-felons, the others named being called "appellees." If the others defeated the approver in a trial by battle, or were acquited, the approver was hanged.

This procedure is wholly defunct, even in England, but it still exists as an informal process today both there and in the U.S.; for when a defendant "turns state's evidence" he is in effect behaving like an approver and for the same reason: to trade to the state the conviction of his companions in exchange for lighter treatment for himself.

approximately. Nearly; more or less. See also about. How much variation is permissible under a contract or conveyance using the term "approximately" will vary with the deal and the context, e.g., the sale of "a diamond of approximately 5.73 carats" would not allow very much variation, while the grant of "right to graze cattle on the Lucrative $Z$ Ranch, consisting of approximately 100,000 acres of land" might be fulfilled even if off by a square mile or so.

approximation doctrine. Also "proximation doctrine," and "equitable approximation doctrine."

See cy pres doctrine.

appurtenance ( ). Something appendant to another more primary or more important thing, which is ordinarily also conveyed when the principal property is, e.g., an easement belonging to real property, or extra parts for a machine being sold. When a ship is sold with "all appurtenances," all normal equipment is also conveyed, e.g., sails, rigging, lights, tackle, apparel, compass, etc. See also addition; regardant.

appurtenant. See appurtenance.

appurtenant easement. See appurtenant.

appurtenant power. See power appendant.

appurtenant way. One kind of appurtenant easement.

APR. Abbreviation of annual percentage rate.

a prendre ( ). Law French for "to take," or "to seize." See also profit a prendre.

aprés ( ). Law French for "after," e.g., "aprés le fait" means "after the act."

a priori ( ). In logic and law, a term for a mode of thought or reasoning "from before" or "from prior principles."

The nature of a priori reasoning, sometimes called "deduction," and its distinction from inductive, or a posteriori, reasoning, are subjects widely and hotly disputed now and for millenia. Very loosely stated, the a priori mode involves starting from certain premises or "givens," and then, by following certain rules of reasoning (e.g., avoid contradictions, never both affirm and deny the same proposition, never allow one term to have more 


\section{Leff Dictionary of Law}

than one meaning), reaching a conclusion required or "entailed" by those initial premises.

As a guide for action, e.g., in law, the a priori mode has obvious problems. The first involves the status of the initial premises. It is one thing to construct a logical or mathematical system in which every term, and every "proper" operation, is defined in the "let it be that" way; nothing is at stake in such a process, any more than anything is at stake in stipulating the permissible moves of a chess piece. But in a legal system, especially if initial premises or principles are to have such a large effect on outcomes, it is hard successfully to defend a system when the ultimate answer to any challenge is the assertion of an a priori definition not further defensible.

The second problem involves the operation of a deductive system in a real world. Such a process requires perfect definitions, i.e., one and only one meaning for each term, and perfectly unambiguous rules of operation, such that when one comes up with a contradiction, one can know it. But ordinary life, and the ordinary language in terms of which it takes place, know no such perfections. See ambiguity. This is not an accident of language or a defect thereof; the complexities of human behavior do not admit of easy definition; to pick one crude example, under a statute awarding custody to a parent who "cares for" a child (and forbidding it to one who "inflicts harm" on it), does one give custody to a parent who often hits a child "so he won't turn out bad?"

This leads to the third major difficulty with a priori reasoning as a fully adequate legal mode. The goodness or badness of law is today seen as at least a partial function of results. But causation is a far more complicated matter than "entailment," the process by which a logical conclusion flows from its defined premises. A good law is one with good results, and the goodness of those results is tested not by the consistency with which they flow from premises, but from their effects on people's lives. Determining that requires a large dollop of induction, of a posteriori reasoning.

In fact then, actual legal reasoning is necessarily neither a priori nor a posteriori, but some amalgam of both. To the extent an adequate legal system must involve "rules" and "principles," i.e., must, in order to be seen as "just," operate with some degree of non-contradiction, some a priori reasoning is necessary. But to the extent that logical consistency is neither possible in the world upon which law operates, nor indeed the only value to be achieved by it in that world, a priori reasoning is not sufficient to the doing of law.

See also analogy; deontic logic; Kantianism; utilitarianism.

apta viro ( ). Fit for a man (or husband), i.e., a female of marriage-able age.

aqua ( ). Water; also, in proper context, a body of water, e.g., a lake or stream.

Aqua cedit solo ( ). "Water follows the land," i.e., a conveyance of land also conveys whatever water, e.g., a pond, is on it. If the water forms the border of the land conveyed, complex rules sometimes obtain, e.g., and especially 
that the conveyance goes only to the middle of the bordering stream or river.

aqua currens ( ). Running water. "Aqua profluens" is synonomous.

aqua dulcis ( ). Sweet, i.e., non-salt, water. "Aqua frisca" means the same thing.

aquae ( ). Waters, i.e., the plural form of "aqua."

aqua fontanea ( ). Spring water.

aqua frisca ( ). See aqua dulcis.

aquagium ( ). An artificial waterway used for drainage or transport.

aqua pluvia ( ). Rain water.

aqua profluens ( ). See aqua currens.

aqua salsa ( ). Salt water.

aquatic rights ( ). Rights in or to the use of water, primarily fishing and navigation. See also riparian rights; water rights.

aqua viva ( ). Flowing water, i.e., in a stream rather than in a lake.

a quo ( ). From which, or from whom, e.g., a court or judge "a quo" is one from which a case has been removed.

A.R. Abbreviation meaning "in the year of the reign," e.g., "A.R. Eliz. II 17" would mean the seventeenth year of the reign of Elizabeth II, i.e., 1979.

arabant ( ). A form of villein tenure, held on service of plowing and tilling the Lord's manor lands.

arable land. Land suited to plowing and growing crops, as distinguished from, e.g., forest, desert, pasture, or swamp land.

arator ( ). A plowman.

aratura terrae ( ). Land plowing; the name of a species of feudal villein service.

arbiter ( ). A broad term to describe a person with the job of deciding a dispute, e.g., a judge, or an umpire at a baseball game. Sometimes a distinction is sought to be made between an arbiter, who decides according to rules, and an arbitrator, who is free to settle matters in his own sound discretion. But the distinction doesn't hold; arbiters often have huge amounts of discretionary power, and more important, most arbitrators today proceed according to elaborate rules, both procedural and substantive.

arbitrable. An arbitrable dispute is one that may properly (either by law, or by the terms of a governing contract) be submitted to arbitration.

arbitrage. A process for profiting by taking advantage of there being a different price for something of value in one market than in another. If, for instance, Japanese yen are selling for 300 to the dollar in New York, but 299.5 to the dollar in London, it is profitable to buy them in London and sell them 
in New York. These geographic variations are, of course, very small and short lived in well-developed open markets e.g., for currency or securities, if only because of the arbitrage practitioners themselves: When people buy in London to sell in New York, demand increases in London while supply increases in New York, and the prices in both places will thus swiftly converge.

A process like arbitrage may take place in any goods, e.g., buying antique stoves in Maine where there are plenty and they go cheap, to sell in California, where there are few and they command good prices. But the term "arbitrage" is usually limited to transactions in particular goods, currency (especially), securities, and commodities traded on commodities markets.

arbitrament ( ). The award of an arbitrator; what would be the "decision" if the decider were a judge.

arbitrary. An arbitrary decision or other act is one made according to whim or caprice, not according to any reasoning or good reasons. The word is often found in the conjunction "arbitrary and capricious," used to describe an official act or decision which, though ordinarily within the power of the actor, e.g., a judge or legislature, in the particular instance might be set aside as impermissible.

In its usual locus, the reach of the term arbitrary is difficult to define with precision. For a decision may be found "arbitrary" even when it is said to be within the discretion of the decider; indeed, if it is not a discretionary decision but must be made according to certain rules, when reversed or overturned it is more likely to be described as merely "wrong" or "incorrect" than as "arbitrary." One meaning of arbitrary in the context of discretionary act, therefore, is something like "according to improper procedures," e.g., a judge who decides a question within his discretion by flipping a coin, or after refusing to hear one or both sides at all, might be said to have acted arbitrarily.

But some decisions may be so characterized even if [the] procedure is proper, in which case the term means "without rational support" or "without any proper reason." The latter formulation is usually more accurate. Almost everything has some reason, e.g., a judge who decides against Jones because he hates people so named does have a reason; it's just not a sufficient one. And a legislature which bans the sale of any condensed milk at all on the ground that it might be confused with condensed skim milk also has a "rational" explanation.

The difficult legal (and political) question wrapped up in the term "arbi'trary" is really this: When is an act committed (by law or constitution) to the discretionary power of a particular official so stupid as to allow another official to undo it. Cf. Dr. Bonham's Case.

arbitration. A process for the decision of conflicts by persons other than governmental judicial officers. The process leads to a decision by the "arbitrators" which is binding upon the parties, and this distinguishes it from mediation 
or conciliation where the role of the third parties is to bring the contending parties to settle their disagreement themselves.

Arbitration is always voluntary, in the sense that no one can, as he can in a judicial law suit, be forced either to take part or lose the dispute. But a commitment to arbitration, of either a then existing dispute, or some or all disputes to arise in the future, and whether made by special agreement or pursuant to an "arbitration" clause in a contract, will ordinarily be enforced, i.e., a court will order a party who has so agreed to go to arbitration, and bar him from a judicial determination.

After some judicial hostility to arbitration (on the ground that parties could not oust courts of jurisdiction), the process was warmly embraced by courts, and the usual rule is that an arbitration award will be enforced by a court even if seemingly wrong, and will not be overturned unless the arbitration was corrupt, deeply defective procedurally, or arbitrary. Of course, the courts have the final power to pass upon the validity of any purported arbitration agreement or clause, and its scope.

It is frequently stated that arbitrators, especially when they are professionally involved in the industry in which the dispute arose, tend more than courts to come to "common-sense" decisions, or those that "split the difference," rather than stick to strict all-or-nothing determinations of rights. But there is little conclusive evidence on the matter overall. It is true that possession of intimate knowledge of the context of a dispute may well conduce toward less expensive and more knowledgeable decisions made in light of all really relevant factors, some of which might escape less knowledgeable judicial officers, and this factor has often been put forward in support of arbitration. Again, this belief is plausible but unproved.

See also labor arbitration for the several special varieties thereof.

Arbitration Act. Refers either to one of the Uniform Laws (adopted by about twenty states), or to a Federal statute (9 U.S.G. $\S 1$ et seq.) covering disputes in maritime transactions and in commerce.

arbitration and award. The name of a plea raised to bar a lawsuit on the ground that the matter had previously been determined by arbitration, i.e., a special form of the plea res judicata.

arbitration clause. See arbitration.

arbitration court. See International Court of Justice.

arbitratione facta. See de arbitratione facta.

arbitration of exchange. Arises when a person pays in one country by a bill of exchange drawn upon a person in another, thus creating another opportunity for arbitrage.

arbitrators. The persons chosen by disputing parties, either personally or pursuant to previously agreed procedures, to carry out an arbitration. A very common device is to have each party choose one arbitrator (sometimes from a list of available candidates), those two together to agree on a third, in 
default of which the third will be appointed by some neutral person or organization. See also American Arbitration Association.

arbor finalis ( ). A tree chosen to mark a boundary point or line.

arcana imperii ( ). State secrets.

arcarius ( ). In older English documents the term refers to a treasurer, or keeper of public funds.

archbishop. See bishop.

Archbishop of Canterbury. The highest ranking figure (except for the sovereign) in the Church of England, including its judicial system.

Archbishop of York. Subordinate in the hierarchy of the Church of England only to the sovereign and the Archbishop of Canterbury.

archdeacon ( ). An ecclesiastical officer in England, immediately subordinate to a bishop, for whom he administers a division of the diocese called an "archdeanery" or "deanery."

archdeacon's court. An English ecclesiastical court, the lowest in the hierarchy, with jurisdiction over spiritual matters, administration of decedents' estates, moral offenses (e.g., fornication) and, there is substantial evidence, at one time a good deal of what in modern times would be called tort and contract. Its non-ecclesiastical jurisdiction disappeared in modern times, but the court itself was not abolished until 1963.

archdeanery. See archdeacon.

archery ( ). A medieval feudal service and tenure, consisting of keeping a bow (by the fourteenth century in England, usually a longbow rather than a crossbow) for the lord's defense and for his use in supplying bowmen to his lords. The key part of the service, of course, was not the equipment, but knowing how to use it.

arches court. See Court of Arches.

archetype ( ). In legal contexts, the word refers to the original document, the one from or of which copies were made.

archiepiscopal ( ). Pertaining to an archbishop.

archiepiscopus ( ). Archbishop. "Archiepiscopus Cantor" is the Archbishop of Canterbury; "Archiepiscopus Ebor," the Archbishop of York.

archievesque ( ). A Law French term for "archbishop."

Archionomia ( ). Short title of a collection of Saxon laws published about 1600 , in Saxon with a Latin translation.

architect's certificate ( ). See certificate of architect [or engineer].

architect's lien. A statutory lien to secure payment of fees owed to an architect, which attached to property for which he drew the plans or the construction of which he supervised. 
archives ( ). A place where old books and documents are kept, and by extension, the books and documents themselves, as in "He consulted the archives of the archbishopric."

archpriest. An ecclesiastical term for the dean of a cathedral.

arcifinies ( ). In old law, lands which had natural boundaries, e.g., rivers, woods, mountains. Only "arcifinious" estates were said to have the right to alluvion. A tract of land, even a nation, having a natural defensive border might also be called "arcifinious."

arcium constructio ( ). See trinoda necessitas.

arcta et salva custodia ( ). "In close and safe custody," a term used to describe the way a defendant arrested on the writ capias ad satisfaciendum was to be kept.

ardent liquors [or spirits]. Intoxicating drinks containing alcohol, primarily referring to distilled liquors, i.e., things like whiskey, rum, and gin rather than beer and wine.

ardour ( ). An old Law French term for an incendiary; any arsonist or "firebug."

area pricing policy. A policy of the Federal Power Commission providing that proposed natural gas rates were to be approved on the basis of prices determined for various producing areas. The policy was massively litigated by the affected parties, but was finally largely upheld by the Supreme Court in 1968.

areaway. A space or room under a sidewalk.

area zoning. An important feature of most zoning regulations, specifying the amount of land surface which may be built upon. It includes, e.g., for individual dwelling units specifications of the size of front, rear and side yards, and how far houses must be set back, and for multiple-dwelling or high-rise business buildings, how much of the tract must be left as open space.

à rendre ( ). Law French for "to render," i.e., to give, pay or deliver, primarily on account of obligation. See profit a rendre.

areopagus ( ). A hill in Athens, in ancient times the situs of much of Athenian government, including the most important court.

A reorganization. See corporate reorganization.

arere ( ). Law French for behind; in back of; again.

aret ( ). See arret.

a retro ( ). Also "aretro." In arrears (in a payment or duty).

arg. An abbreviation for arguendo, frequently found in old reports.

argentum ( ). Silver, and by extension money in general.

argentum Dei ( ). "God's money," but referring to money not belonging to 
God, but given "before God" to bind a bargain; the same as earnest money.

argentum album ( ). Uncoined silver, or silver bullion, but also used to refer to coined silver.

arguendo ( ). "For the sake of argument," i.e., not admitting that the fact or intellectual position is really true, but only to be taken as true for purposes of the particular moment. In effect, a demurrer is a motion which admits "arguendo" all facts properly pleaded by the other party.

argument. Though one common ordinary language meaning is "oral dispute," i.e., a step up in heatedness from, say, "discussion," the legal meaning is something like "any verbal attempt to convince another, especially a court or jury."

Over the centuries a typology of argument has developed; for some of the principal types, see entries beginning argumentum.

argumentative ( ). A term used to characterize some legal utterance-a pleading, or judge's instruction to the jury, or question propounded to a witness at a trial一as in some way improperly attempting to convince another. A pleading will be called argumentative when, instead of merely alleging facts and law, it attempts to do a job more properly done in a brief or at the trial, e.g., "The defendant, obviously not caring how much damage he thereby inflicted on the plaintiff, did thereupon ...." A judge's instruction may be called argumentative if it indicates to the jury how he thinks the case ought to come out, e.g., "You have heard the defendant testify, with a straight face, that ...." (If serious enough, this can be grounds for reversal.) And an argumentative question to a witness might be something like "After telling that ridiculous story at your deposition, you have the nerve here to testify ... . But an "argumentative question" is also one that seeks to get the witness to assent to the questioner's own inferences from facts, e.g., "Knowing as you must that only a pickaxe could make that kind of wound, do you still testify that . ..."

argument of counsel. This may refer to counsel's opening statement or summation at a trial, or to the presentation, especially the oral part, made by counsel to an appellate court, i.e., "the argument on appeal."

In some case reports, especially older ones, the arguments of counsel are printed or summarized. In some instances, e.g., in the Yearbooks, it is occasionally difficult to tell whether the words reported are those of counsel or judge.

argumentum ( ). Argument. See the entries beginning "argumentum" below for some standard classes of argument.

argumentum ab autoritate ( ). Argument "from authority," including judicial authority, i.e., precedent. To argue or decide "from authority" is an intelligible strategy under certain circumstances: 1 . when a governing rule, e.g., a constitution, so directs. This would be the situation of a lower court 
judge binding himself by what a higher court had clearly declared to be the rule; 2 . when one believes that the "authority" is particularly capable, and what it declared is likely to be more correct than what one would oneself decide; 3 . when one believes that, as a matter of process, accepting prior determinations will in the long run generate a better (juster, fairer, more efficient) system of decision than one which permits freer ad hoc reconsideration of individual questions. Against these considerations should be placed the fact that things do change; and even if they haven't, people in the past, even admired and highly placed ones, can and do make mistakes. Or, as Holmes put it, it may be revolting to have no better reason for a rule than that it was so decided in the time of Henry II.

argumentum ab impossibili ( ). Argument from impossibility. Ordinarily the impossibility alleged is a logical one, e.g., "If you say that you are affirming both the affirmative and negative of a proposition," but it is perhaps possible to refer also to a factual impossibility, i.e., a strong form of an argumentum $a b$ inconvenienti.

argumentum $\mathbf{a b}$ inconvenienti ( ). Argument from inconvenience. This is a centrally important kind of argument in a legal system in which law is seen not, or not only, as an intellectual system (where logical arguments are important), but as a system of social ordering, i.e., one in which law is to be used to bring about, as efficiently as possible, good and useful effects in society. The form of this argument is "if you permit $\mathrm{X}$ the following bad things will happen," e.g., "If this statute is interpreted as proposed, before a lender can safely loan money against personal property security he will have to inquire at every county courthouse in America." There is an old maxim that this kind of argument "plurinum valet in lege," i.e., is very powerful in law.

argumentum ad baculum ( ). "Argument [adverting] to the club," i.e., a very direct argument of the general form "If you don't do things my way, very nasty violent things are going to happen to you." This is "argument" only in the sense that it often persuades, or at least adduces the desired action.

argumentum ad crumenam ( ). Argument directed to the purse, i.e., one which alleges how costly a failure to be persuaded will be. It is hardly an improper argument, e.g., when one is arguing that the cost is more than the benefit, or that there is a cheaper way to get the same result.

argumentum ad hominem ( ). An argument "to the man," i.e., saying bad things about a person in order to vitiate the strength of his arguments. Frequently silly in that the quality of a person's arguments are ordinarily independent of his virtues, i.e., there are a large number of intelligent and informed adulterers and thieves in the world, and saints are not necessarily intelligent or informed. If, of course, the "ad hominem" attack is an allegation of stupidity and ignorance, then it is at least relevant to the matter at hand. 
argumentum ad ignorantiam ( ). Argument to ignorance. This term seems to refer to two different kinds of argument. The first is one that just takes advantage of the ignorance of the audience, e.g., "Do you know that the opposing candidate's wife is a thespian?"

The second form is more technical, albeit equally fallacious. It is an argument that a proposition is true because it has not been shown to be false, or vice versa.

argumentum ad invidiam ( ). An argument appealing to hatred or prejudice, e.g., "Are you going to let 'those people' come into our fine neighborhood?"

argumentum ad misericordiam ( ). Argument invoking pity.

argumentum ad verecundiam ( ). Argument adverting to decency or, more generally, that kind of argument in which the speaker invokes "the right or decent thing to do" as seen by "all the right people." It is, then, a form of argumentum ab autoritate in which the "authorities" are not shown to have any particular competence or relevance. A modern example would be advertising a baseball player's opinion of the nutritional value of a breakfast cereal, or adverting to the political beliefs of a folk singer.

argumentum a simili ( ). Argument from similarity, or analogy. This is perhaps the most commonly used species of legal argument. See analogy.

argumentum baculinum ( ). Another form of argumentum ad baculum.

argumentum ex concesso ( ). An argument based on what has already been conceded by the opposition. Frequently combined with an argument a fortiori, e.g., "If you admit that pickpockets should be jailed, then you must certainly agree that burglars...."

aribannum ( ). In feudal law, a fine imposed on a vassal or other dependent who ignored a call from the King to appear for some royal martial venture.

arid. Very dry. May be used to describe land with too little rainfall for easy cultivation and, figuratively, to describe writings, speeches, ideas, etc., which are either boring or unproductive.

arise. To come into being, or to the attention; to originate.

Article II, § 2 of the Constitution extends federal judicial power to "all cases . . . . arising under this Constitution, the Law of the United States, and Treaties ...." and this has been said to give jurisdiction whenever the construction of the Constitution or a federal statute is required for decision. But the matter is in fact much knottier than that.

If a statute of limitations provides that its time period will begin to run from the moment a cause of action "arises," the word means essentially the same as "accrues."

arising out of [and] [or] in the course of employment. A critically important phrase in workman's compensation statutes, describing what kinds of injuries are covered. The phrase appears in both the conjunctive and disjunc- 
tive forms as above. An enormous amount of interpretative activity has been lavished on this language, and its ambit varies at least subtly from jurisdiction to jurisdiction. But very roughly, "arising out of . . . employment" imports a requirement of some causal connection between the job and injury, and "in the course of employment" imports some temporal and spatial connection. It would seem that whether the statute tied the two tests together with an "and" or an "or" would often be very important, but it is not clear that variations in the coverage of the statute from state to state correlate importantly with that particular linguistic variation.

arles ( ). Law French for earnest money. $C f$. argentum Dei.

arma capere ( ). To take arms; to be knighted.

arma dare ( ). To give arms, i.e., to knight.

arma libera ( ). Free arms, i.e., weapons (a lance and sword) given to an unfree feudal servant when he was made a freeman.

Armed Forces. The most capacious term for the U.S. military, including the army, navy, marine corps, coast guard, and whatever else there is.

Article II, $\S 2$ of the Constitution names the President as "commander in Chief of the Army and Navy of the United States," but it has never been doubted that his authority extends to the entire "Armed Forces," however subdivided.

armed neutrality. The status of a nation which declares itself unwilling to take sides in a conflict among other states, but quite willing to defend itself against any attempt by anyone to attack it or otherwise seek to compromise its neutrality. Not really the technical term for a formal status in international law, but just the description of a policy and attitude.

armed peace. The status of two states technically at peace with each other, but mutually mistrustful and staying ready for possible conflict. $C f$. cold war.

armed robbery. A form of robbery in which the perpetrator is armed with a deadly weapon, ordinarily an aggravated offense calling for a more severe sentence than for ordinary robbery. It is not necessary to make out the offense to prove that the defendant actually used the weapon to effect the robbery.

armed services. Another term for the Armed Forces of the U.S.

armed ship. A term used to refer to a ship which is not ordinarily armed, e.g., to a "merchantman" or merchant vessel. The locution "armed merchantman" is frequently employed, e.g., "The convoy included twenty fighting ships, if one counts the eleven armed merchantmen."

armiger ( ). A squire, i.e., one who in feudal times actually carried and took care of the Knight's arms when he wasn't wearing them.

Also, one entitled to heraldic arms, i.e., to have a "coat of arms."

armistice. A major, i.e., more than local and clearly temporary, interruption in the waging of a war, agreed to by the parties; a truce. 
Sometimes the armistice really signals the final end of the war, with formal peace treaties coming only later or not at all, e.g., the armistice which stopped the actual fighting of the First World War, the end of which was always celebrated on "Armistice Day."

arm of the sea. A portion of an ocean or sea which projects into a land mass and in which the tide still ebbs and flows. It is considered to extend up a freshwater river as far as the descending water is still pushed back by the tide. Arms of the sea sometimes have special status in treaties and other documents of international law.

arm's length. See at arm's length.

army. Generally, the land forces of a national military establishment. See Armed Forces. But also used figuratively to describe any large group, e.g., "When the [Republicans] won, an army of job seekers descended upon Washington."

arraign ( ). In older English legal writing, "arraign" meant to get ready, to get things ordered, to take the orderly preparatory steps, for a trial, e.g., "to arraign an assize."

For the modern criminal-law meaning, see arraignment.

arraignment ( ). The criminal-law proceeding at which, in open court, the charge against the defendant is read aloud, and he is asked to plead, i.e., to answer "guilty," "not guilty" or (if the plea is permissible) "nolo contendere." The procedure for Federal courts is set out in Fed. R. Crim. P. 10.

arraigns. See clerk of assize.

arrangement. While the term as generally used refers to almost any agreement or ordering of life, e.g., there can be a "flower arrangement," the primary legal reference is to a plan worked out by a debtor in trouble, i.e., either insolvent or in extreme danger of insolvency, with his creditors whereby, through extentions of time to pay, or agreements to accept lesser payments, or both, the debtor may be able to save his business or property from liquidation in bankruptcy. Under modern bankruptcy law, including the Bankruptcy Reform Act of 1978 (11 U.S.C. $\$ 101$ et seq.), the arrangement is not wholly consensual, while straight bankruptcy cannot be avoided without some creditor cooperation, the court has numerous powers to override some creditor objections to some aspects of a plan of arrangement.

The chief arrangement-with-creditors portions of the new Act (not called "arrangements" in the Act, by the way) are Chapter 9 (covering municipalities); Chapter 11 (covering business reorganizations); and Chapter 13 (covering wage earners plans).

These judicially supervised, only quasi-voluntary "arrangements" should not be confused with wholly private agreements between a debtor and his creditors and among the latter, which require near-unanimous agreement and, while enforceable in a court, are not otherwise judicially supervised. 
These are usually called compositions with creditors, or just "compositions" for short.

arrangement of words. It is sometimes said that this is that in which an author gets his copyright, for it is clear he cannot get it in the individual words themselves, nor in the "ideas" which the words express.

array ( ). The whole panel of potential jurors from the ranks of which individuals will be selected to form particular trial juries; also the list thereof. The words panel, venire, and grand venire are sometimes used as synonyms. See also challenge to the array.

arrearages ( ). Overdue payments; amounts which ought already to have been paid. Also called "arrears," though it is more common to use this latter form combined with "in," as in " $\mathrm{He}$ is in arrears on his alimony payments."

arrears. See arrearages.

arrect ( ). An obsolete term for charge or accuse, with the person so accused being the "arrectus."

arrent ( ). An old term for rent out or lease, used particularly when the leased property was royal or public, and the "lessee" was allowed to enclose and then cultivate forest land, or to keep a purpresture, upon paying rent. Also called "arrentation."

arrest. To arrest just means "to stop (at least for the time being)," and that broad meaning can be seen in legal terms like arrest of judgment. But the primary legal use of arrest is to indicate the stoppage and holding of a person, especially one suspected of a crime (though civil arrests are still legally possible).

An arrest can be effected by any acts or words which evince an intention to back up by physical efforts if necessary an intention to take custody of another. And it is sometimes important to be able to tell when or if an "arrest" took place, e.g., for a search incident to arrest, or with respect to the need for giving a Miranda warning.

See also terms below starting with or containing "arrest," e.g., arrest of ship; civil arrest.

arrest for debt. See imprisonment for debt.

arrestis bonis ne dissipentur ( ). An old writ, available to one claiming goods taken from him by another person who allegedly lacks sufficient assets to satisfy a judgment), to prevent the latter from selling or otherwise doing away with them pending the suit to recover them. Basically a special old version of today's general writ of attachment.

arrestment ( ). An old English term for what now would be called prejudgment attachment (or prejudgment garnishment).

arresto facto super bonis mercatorum alienigenorum ( ). An old writ pursuant to which goods of foreign merchants in England could be seized to 


\section{Leff Dictionary of Law}

make up for goods of an Englishman seized abroad. The writ is obsolete, though the practice, of course, is not, as when local assets of a foreign government or trading company are "blocked" or "frozen" after that nation has nationalized, allegedly with insufficient or nonexistent recompense, assets belonging to a domestic company.

arrest of judgment. A motion the gist of which is that, despite verdict, judgment ought not to be entered because of some serious and obvious error. In modern practice in civil cases, motions of this sort take various forms, e.g., Motion for Judgment Notwithstanding the Verdict (Fed. R. Civ. P. 50(a)), Motion for a New Trial (Fed. R. Civ. P. 59). And a motion [to] dismiss [for] lack of jurisdiction can also be made after verdict. (Fed. R. Civ. P. 12(b)(3)). In modern criminal practice (see, e.g., Fed. R. Crim. P. 34), a motion to arrest judgment can be made by a convicted defendant who claims the indictment charged no crime, or that the court was without jurisdiction.

arrest record. A record of an individual's criminal arrests, compiled by a police department or other law enforcement agency, and often presented to judges prior to sentencing. A common slang term for arrest record is "rap sheet."

Questions have been raised about the propriety-constitutional, legal, and social-of using prior arrests not leading to conviction as sentencing data, but the practice continues.

arrest warrant. See warrant of arrest.

arrest without warrant. Police officers, and even private citizens, [may] properly make arrests under certain circumstance[s] even if no warrant of arrest has previously been procured. While the rules are not wholly uniform, in general a police officer may arrest anyone who commits any crime, whether felony or misdemeanor, in his presence, and if he has reasonable grounds to believe a felony has been committed, though not in his presence, and the person to be arrested is the felon, he may arrest without a warrant. Private citizens can ordinarily only arrest for felonies committed in their presence.

The question of the validity of a warrantless arrest is often important because evidence seized without [a] search warrant but incident to an arrest is admissible only if the arrest without warrant was proper and valid under the circumstances. See probable cause [for arrest].

arret ( ). Also "aret." Law French for judgment (of a court); still used in French and French derived law, including that of Canada and Louisiana.

arriage and carriage ( ). An old and not very specific ("backing and carrying"?) feudal tenant service, abolished by statute in 1747.

arriere fee [or fief] ( ). In feudal tenure, a fee held of one holding a fee from a still higher lord, e.g., one holding from an Earl holding from the King. See also subinfeudation.

arriere vassal ( ). The holder of an arriere fee.

arrival. In general, coming to the place to which one was going. 
With respect to a ship, arrival (at a port) refers to an entry for some real purpose needing a stay, i.e., to more than a brief stop to pick up information or more safely ride out a storm. And for some marine-insurance purposes, a ship has not "arrived" such that an insured voyage is over until it has been safely moored for a day.

arrogate ( ). To assert a claim for something, or take it, without right, as in "He arrogated to himself all of the income from his wife's separate property."

arroyo ( ). A Spanish-American term for a stream or dry stream bed; the term is frequently used in land documents in the U.S. southwest and other Spanish-influenced areas.

arse ( ). A varient for "ass." Despite its superior unambiguity ("arse" never means "donkey"), the term is hardly ever used in the U.S.

arser [or arsure] in le main ( ). Law French for "burning the hand." The hand or thumb of persons who had claimed benefit of clergy to avoid a felony conviction was sometimes burned or branded. It is not clear how much this was punishment and how much a handy way to prevent a successful second claim of benefit of clergy.

arson. At common law, arson was the felony of burning down the dwelling house, or other appurtenant building with the curtilege of the dwelling, of another. Modern statutes have enlarged the definition to include not only dwellings but buildings of all sorts including those owned by the arsonist, the change having been made to cope with the more modern crime of arson committed to acquire fire-insurance payments. But in most jurisdictions arson of a dwelling, especially at night, is still a more serious felony than other kinds.

art. In ordinary language, one of the arts, e.g., painting, sculpture, literary creation, and the products thereof.

Also, a particular skill to bring about a desired result, impliedly a pleasing or useful one, by applying thought and work to materials. That is the term's primary legal meaning in patent law, where it refers to a method of treating materials to achieve a useful result.

"Art." or "art." is also an abbreviation for "article" in the sense of a division of a constitution, statute, or other document.

article. A term for a division of constitution, statute, or other legal document, e.g., "Article one, section 6 of the Constitution provides . . . ."

As a verb, "to article" can mean to enter into a contract. See, e.g., articled clerk.

articled clerk ( ). An apprentice to an English solicitor (or accountant), who enters into "articles," i.e., a contract, by which he agrees to render services for his principal in exchange for instruction and experience in the profession (and some renumeration in cash). 
articles of agreement. A written contract; a signed written memorandum of agreement.

articles of apprenticeship. See apprentice.

articles of association. The equivalent of a certificate of incorporation but for a non-stock company, e.g., a charitable or cooperative association.

Also sometimes used to describe the document filed with a state by a stock corporation to procure a certificate of incorporation.

Articles of Confederation. The name of the compact entered into among the thirteen original colonies after the success of the American Revolution, governing their relationship to each other. It was in effect from March 1, 1781 to March 4, 1789, at which point it was superceded by the Constitution.

Articles of Faith. Also known as the "Articles of Religion" and "Thirty-Nine Articles," the basic creed of the Church of England.

articles of impeachment. In an impeachment proceeding under the Constitution, the formal written charges which must be voted by the House of Representatives and sent to the Senate for trial. See Constitution, Article I, $\S \S 2,6$.

articles of partnership. The agreement signed among partners setting up the terms of their partnership.

Articles of Religion. See Articles of Faith.

Articles of the Clergy. A 1315 English statute dealing, among other things, with the respective jurisdictions of ecclesiastical and lay courts.

articles of the eyre. See capitula itineris.

Articles of the Navy. Statutes providing for the governance of the Navy.

articles of the peace. The complaint filed in a proceeding whereby the complaining party alleges that he is in danger from another person and seeks to have him ordered to keep the peace, and to post a bond to keep the peace to assure his compliance.

Articles of Union. See Act of Union.

Articles of War. See Code of Military Justice.

article-three judge. A federal judge appointed pursuant to Article III of the Constitution and as such having the jurisdiction, and being entitled to the protections (e.g., life tenure) thereof. Some federal officials with adjudicatory functions, e.g., Bankruptcy judges and administrative law judges, are not article-three judges.

articulated pleading. Pleading in "articles," i.e., arranging a pleading in single and often numbered paragraphs which separately state separable allegations, especially different "counts," i.e., stating a claim "in negligence" in a separate paragraph from one "in contract" arising out of the same facts, or separating two separate transactions out of which liability independently arises. See Fed. R. Civ. P. 10(b). 
articuli ( ). "Articles," in the sense of clauses or headings; some old English statutes and treatises are so named, e.g., Articuli Cleri.

Articuli Cleri ( ). The Latin title for the Articles of the Clergy.

articuli de moneta ( ). Old Statutes dealing with English money, especially a 1292 statute of Edward I.

Articuli Magnae Chartae ( ). The separate name sometimes given to the first 49 articles of Magna Charta.

Articuli Super Chartas ( ). "Articles on the charters." One of the most important statutes of the many enacted at various times confirming and providing for the enforcement of Magna Charta and the Charta de Foresta. This one was passed in 1300 during the reign of Edward I.

articulo mortis. See in articulo mortis.

artifice ( ). The term just means product of art; something made by an artist or artificer. But it almost invariably appears in legal contexts in settings like a "crafty scheme and artifice to defraud"; hence the implication of artifice is generally pejorative, connoting sneakiness.

artificer ( ). An artisan, i.e., a worker, impliedly a skilled one, able to make things requiring training and practice.

artificial. Greated by artifice, i.e., man-made rather than natural, e.g., a human being is a natural person, while a corporation is an artificial person, i.e., a person created by and only in the eyes of the law.

See entries beginning with "artificial" below for a few special legal usages.

artificial boundary. In real property practice, a boundary set (and evidenced) by human construction, e.g., a measured border marked by a stone set into the ground, as contrasted to a natural boundary, e.g., a stream or river.

artificial force. In patent law, a transformation of natural force, e.g., wind, such that it can do things more efficiently, and as such a patentable invention.

artificial insemination. Any method, other than sexual intercourse, for introducing male sperm into a female ovum so that it might be fertilized and develop into a new individual. It has recently been established for the first time [that] ova can be successfully fertilized outside the female's body with the fertilized egg [then] reimplanted for normal in utero development.

Artificial insemination has long been widely used in the breeding of livestock; a vial of frozen semen is much more portable than a bull, and its implantation by human functionaries is less dependent upon the sensual susceptibilities of the participants. With people, the process employing the semen of the husband has been used when physical incapacities prevent a couple from achieving normal intercourse, or when a fertile female married to a sterile male wishes to conceive.

The first technique, often called A.I.H. (for "Artificial Insemination- 
Husband") raises few legal issues. But the second (called A.I.D., i.e., "Artificial Insemination-Donor") involving as it does semen from someone other than the husband, has occasionally led to legal dispute, e.g., whether the insemination constitutes adultery, whether it is grounds for divorce, and whether the child is to be considered "illegitimate," at least with respect to his formal but non-biological father's estate. (The biological father is most frequently an unidentified medical student.) The case results are various, except it is exceedingly unlikely that artificial insemination would ever be deemed adultery for purposes of any criminal statute, however worded.

artificial intercourse. See intercourse.

artificial limb. See prosthesis.

artificial person. An entity which for some legal purposes is treated as if it were a natural, biological person. The classic instance is the corporation, and much legal controversy has swirled around how much like a natural person it ought to be treated, e.g., for the attribution of constitutional rights to due process and equal protection. The results of this discussion cannot be briefly summarized, except to say that, with the recognition that the rights of real persons are sometimes tied to those of artificial persons, some large accommodations of rights to artificial persons have been made.

artificial presumption. See presumption.

artificial succession. Property succession between artificial persons.

artisan. ( ). Somewhat more commonly used term essentially synonymous with artificer.

artisan's lien. The statutory right of an artisan to keep possession of (but not sell) an object he has worked on or repaired until he has been paid for his work.

artist. A person with special ability to produce works of art. In law, especially legal slang, used to describe a person with particular skills, e.g., "con artist" (see confidence man) or "escape artist."

art or process. In patent law, a common phrase for that which is applied to materials so that they do something new and useful.

a rubro ad negrum ( ). "From the red to the black," i.e., from the title of a statute (which used to be in red ink) to the body of the statute (in black ink). To argue "a rubro ad negrum" meant to seek to interpret the body of the statute by reference to its title.

as. Can mean "while," as in "As we go rolling along," or "like," as in "He is as silly as a goose," or "for example," as in "as in "As we go rolling along."

Also, an old weight, from the Roman pound, which was divided into twelve parts, and thus the word "as" came to be used for anything divisible or divided into twelve parts. 
a/s. An abbreviation of "at sight," or "after sight" in the negotiable instrument context, and of "alongside" in shipping.

as agent only. A tag added to a person's signature on a contract or other legal document, designed to assure that the signer does not thereby undertake any personal liability, and more certain to achieve such a result than the less explicit "as agent." See also agent for.

ASCAP. Abbreviation, always pronounced as a word, for American Society of Composers, Authors and Publishers. The organization, among other things, meters performances to make sure that its members receive all the royalties to which they are entitled. It also prepares standard form contracts for use in the entertainment industry.

as cash. See as paper.

ascend. ( ). To climb, or go upward; in law, property is said to "ascend" when on the death of a person it "goes up" to an older generation, i.e., to ascendants, e.g,, when a child dies and his property goes to his parents.

ascendents. Blood relations in an earlier generation, e.g., parents and grandparents.

ascertain. To determine with certainty; to fix and make certain, as by a judicial decree settling a question of title. But in ordinary usage, ascertain has become merely a fancy term for "find out," and that looser meaning has crept into legal discourse too.

ascribed status. See status.

aserualization ( ). An uncommon term uncommonly ambiguous about whether it refers to the process of rendering one unfit for reproduction (see sterilization; vasectomy) or for sexual intercourse (see castration).

Asian Development Bank. An international bank set up in 1966 to foster economic growth in the Far East. It has both Asian and non-Asian members including in the latter many of the leading Western economic powers.

as, if, and when clause. A provision in some contracts with real estate brokers that the broker is entitled to his commission only "as, if, and when" title to the property actually passes to the purchaser. This is to be contrasted to the more usual rule (both as specified in contracts, and as supplied at common law in the absence of contractual specification) that the broker is entitled to his commission when he produces a purchaser ready, willing, and able to buy the property on the terms specified by the vendor.

a simile. See argumentum a simile.

as interest may appear. A very common clause in insurance policies, especially fire and casualty contracts, by which the insurer agrees to pay the proceeds upon happening of the insured event to persons having an interest in the property as those interests turn out to be. For example, if mortgaged property is destroyed by fire, payment might be made to the mortgagee to the 
extent of his lien, with the remainder of the payment going to the mortgagor-owner of the property.

as is. Words accompanying and characterizing a particular kind of sale of goods in which the seller excludes all implied warranties, and says, in effect, that the goods may or may not be defective, but if the buyer nonetheless buys, he does so solely at his own risk. U.C.C. $§ 2-316(3)(a)$, and Comment 7 thereto, specify "as is," "with all faults," and "as they stand" as three of the expressions sufficient to achieve this elimination of implied warranty.

With coming of implied warranties of habitability for real property, the perceived need for a means of disclaimer of warranty has spread to that field of law and business too. While the question is in a state of flux, it is unlikely that the mere insertion of the words "as is" in a real property deed or lease will turn out to be sufficient totally to insulate the transaction from all warranties of habitability.

ask. Articulately to seek to get something, with the implied tone in legal contexts ranging all the way from demand to beg.

asking price. The price put about by a seller as that for which he will certainly sell. The usual implication is that he might also be willing to take less, but if you are willing to pay the asking price, the property is yours. $G f$. bid and asked.

as of course. A right to do something without seeking permission, e.g., a right as of course to effect an amendment of pleading.

as paper. A sort of banking slang to characterize the handling of commercial paper by a bank. Roughly, when the item is taken "as paper" or "as check," it is taken for collection only; when taken "as cash," it is bought by the bank.

as per. A legal and business barbarism for "in accordance with," as in "As per your instructions I have shipped . . . ." See also per.

aspersions. The term survives only as part of the cliche "cast aspersions on," i.e., to question or criticize, perhaps to the point of defamation, as in "How dare you cast aspersions on my honesty."

aspirin. A very widely used pain killer and anti-inflammatory drug. "Aspirin" used to be a particular manufacturer's trade or brand name for acetylsalicylic acid but, by virtue of one of the most important applications of the generic name doctrine, "aspirin" lost its trade mark protection.

asportation. Old word for the act of carrying something away, which is an essential element in some crimes, e.g., larceny and kidnapping. It is generally thought that some movement, however small, is necessary to make out an asportation.

ass. A donkey, and by extension a silly and stupid person. In Dickens, a character told of the legal fiction that a wife is deemed always to act under the 
direction of her husband, protests that if the law thinks that "the law is a ass." See also arse.

"Ass." is also an abbreviation for assize.

assailant ( ). One who commits an assault, ordinarily a physical assault including a battery.

assart ( ). An old term for deforesting, i.e., so treating trees in a forest that they will not grow again, thereby making the land fit for pasturage or planting. It also is the name of the land which results.

A tenant of forest land who "assarted" his land without license had it forfeited to the King until he redeemed it by a fine.

assassination. Murder, especially of a high public official. See, e.g., 18 U.S.C. § 1751. When used to refer to the murder of someone other than a high official, the term imports careful premeditation and stealth, and often the employment of a professional assassin. $C f$. hit man.

assault. Behavior of one person evincing an intent to inflict some immediate physical injury or unconsented physical contact on another person, i.e., to commit a "battery." The "assault" may consist of an attempted battery or any actions from which a reasonable person would be put in reasonable fear that a battery was immediately about to be committed, i.e., some communication of combined present intention and present power, but it is frequently held that mere words, unaccompanied by any more palpable threat, will not suffice to make out an assault.

Activity amounting to an assault may constitute a tort or a crime, i.e., there is both "civil assault" and "criminal assault." The same actions, however, usually constitute both; the only difference is that acts totally unperceived by the purported victim cannot constitute the tort of assault, though they might constitute the crime. "Assault" (and "battery") ordinarily require some improper intention in the actor; merely negligent acts will constitute the tort of negligence (but see technical battery), and to make out the crime some state of mind more culpable than mere negligence must also ordinarily be proved.

Modern criminal statutes generally distinguish gradations of assault usually with respect to the perpetrator's methodology and the nature of the battery intended. Assault with a dangerous or deadly weapon, for instance, is often more heavily punished, i.e., an aggravated assault, as is assault with intent to commit murder (or another homicide), assault [with intent] to commit rape, assault to commit serious bodily injury. The least serious gradation is often called "simple assault," and consists of any assault not in some way defined as aggravated.

Technically, "assault" and "battery" are separate offenses, the first being the threat or attempt, and the second being the consummation in the form of some physical contact. But in ordinary language, and even to some extent in legal talk, the two are conflated, and one who speaks of an assault frequently is referring to the whole incident, from the threat through its con- 
summation. Indeed, at least in ordinary understanding, use of the word "assault" most likely requires an actual battery; most people would not use "He got angry and assaulted her" to describe an incident in which no physical contact was made.

In any event, the two technically separate offenses of "assault" and "battery" are frequently combined not only in life but in law under a defined crime or tort denominated "assault and battery" (in police talk, "A \& B").

assault and battery. See assault.

assault with [intent]. See assault.

assay ( ). The term refers to any test of weight, measure, purity, etc., and can even be used with respect to abstractions, e.g., "He stepped back to assay his chances of breaking free." But the most common use is to refer to the testing of the richness and purity of ores and alloys, especially of gold, silver, and other precious metals, to determine their value. Most governments employ official "assayers" or "assay offices" whose job it is to keep watch on the purity and content of minted money.

assayer. See assay.

Assay Office. A division of the U.S. Bureau of the Mint charged with the job of carrying out assays of U.S. coinage.

assemblage. A real estate industry term for the process of assembling a number of parcels of land from different owners so as to combine them into a more valuable single tract. This is ordinarily done in secrecy, e.g., through multiple dummy buyers, etc., so as to mitigate the hold-out problem, i.e., to keep any seller from knowing there is a large profit in the working, for some part of which he can hold the developer up.

assembly. Most generally, any coming together of two or more persons, but ordinarily referring to reasonably large groups. Sometimes the official name of a permanent organization, e.g., in some states the name of one house of the legislature. See also General Assembly.

The First Amendment to the Constitution provides "Congress shall make no law . . . abridging . . . the right of the people peaceably to assemble ...." and the provision is sometimes called the "right of assembly" clause. While it has not been interpreted to bar all governmental regulation of public meetings (see, e.g., unlawful assembly), under it no general ban on meetings or assemblies would be constitutional, especially if the participants had any political motive in their coming together.

assensu curiae. See ex assensu curiae.

assensu patris. See ex assensu patris.

assensu suo. See ex assensu suo.

assent. A word meaning much the same as consent, though perhaps there is some implication that "assent" is more active and enthusiastic than "consent," the meaning of which sometimes slides over almost to "acquiescence." 
But though assent and consent are essentially synonymous, assent is the primary word of choice in the law of contracts. See, e.g., mutual assent.

assert. To proffer facts or arguments as true or correct; to state (with some implication of intensity).

assertory oath. A statement of facts under oath, as in an affidavit, as distinguished from a promissory oath, e.g., one taken upon being sworn into public office.

assess ( ). See assessment.

assessed value. See assessment.

assessment ( ). In the context of taxation, the process of putting a value on real or personal property, thereafter called the "assessed value," for purposes of a tax to be measured as a percentage of property values. The valuation is ordinarily done by a government official, the "assessor" or "tax assessor," who will sometimes hire a private professional to do the actual valuations. The process is marked by all of the problems involved in seeking to discover the value of something when that cannot be done by actual sale in an efficient market (see actual cash value), and the assessment process (and the property taxation dependent on it) is widely vulnerable to corruption and inequity. See also assessment ratio. Sometimes "assess" and "assessment" are used to refer to the process of actually demanding the tax, as in "They assessed a tax of $4 \%$ on all real property," i.e., to refer to the tax levy rather than to any property valuation, but the processes of valuation and imposition are, strictly speaking, different. See also special assessment; and, for income-tax usages, see deficiency assessment; jeopardy assessment.

In other contexts, e.g., corporation and insurance law, "assessment" refers to a process, like the levy of a tax, whereby pursuant to law or the certificate of incorporation or an agreement, a corporation or insurance company may call upon its stockholders or members to contribute additional funds to the company (or to pay for stock subscribed for) (See stock assessment). Stockholders of some banks, e.g., may be assessed an amount equal to the face value of the stock they own; members of mutual insurance companies may be "assessed" what are essentially insurance premiums; and members of mutual benefit societies may be assessed their shares of benefits to be paid out. See also assessment company.

"Assessment" is also used to describe the process by which, after judgment, a court determines the amount of damages to be awarded to the successful party.

assessment association. See assessment company; mutual benefit society.

assessment company. A now rare form [of] insurance company, in which benefits are paid by levying an assessment on all members. These were primarily life-insurance companies, but any type of insurance coverage could be thus organized. 


\section{Leff Dictionary of Law}

assessment contract. See assessment plan; assessment policy.

assessment district. The unit of territory, not necessarily coinciding with any more permanent political boundaries, e.g., of a town or county, the property of which will be made subject to the special assessment and levy of a tax.

assessment for benefits. See special assessment.

assessment insurance. See assessment company.

assessment labor. See assessment work.

assessment list. A list of taxable property and persons in a taxing jurisdiction. $C f$. grand list.

assessment of corporate stock. See stock assessment.

assessment of damages. See assessment.

assessment plan. The insurance plan of an assessment company. See also mutual benefit society.

assessment policy. A policy issued by an assessment company, especially one insuring against death.

assessment ratio. In working an assessment of property for taxation, the law frequently provides that property is not to be assessed at its market value, but at some percentage thereof, with this being the assessed value to which (as if the process were not already confusing enough) the tax rate will be applied. See assessment.

assessment work. Under the U.S. mining laws (see 30 U.S.C. $\S 28$ ), the holder of a mining claim in the public domain is required to do labor or make improvements on it of at least $\$ 100$ per year; this is called "doing assessment work."

assessor. A person charged with making an assessment, ordinarily a public official doing one for tax purposes.

assessors in admiralty. See nautical assessors.

Asset Depreciation Range. The range of years over which one may properly depreciate specific assets for income tax purposes, as specified in Internal Revenue Service regulations.

assets. Most broadly, all things of value, real and personal, tangible and intangible; things owned, as opposed to things owed, i.e., liabilities.

See also entries beginning with or including the words "asset" or "assets," e.g., admitted assets; assets entre mains.

assets entre [or enter] mains" ( ). Law French for "assets in hand," i.e., not just owed to one or expected. The term may still be found in modern probate or trust contexts referring to assets immediately available to meet current expenses. Contrast assets in futuro.

assets in futuro ( ). Things of value which might come into existence, or into 
possession or ownership, in the future. Contrast assets entre mains. See also expectancy; judgment of assets in futuro.

asseveration ( ). A solemn, formal, positive affirmation of facts, but ordinarily not made under oath.

assez ( ). Sometimes spelled "asses." Law French for "enough."

assign. As a verb, to make an assignment.

For the usual legal meaning of the term as a noun, see assigns.

assignable ( ). Transferable; capable of being made the subject of an assignment.

Also, able to be specified or pointed out, as in assignable error.

assignable error. An error allegedly committed at a trial or other adjudicatory proceeding capable of being specified for purposes of appeal. The papers on an appeal will often contain a list of these, called an "assignment of errors."

assignation ( ). An appointment of time" and place for a meeting of lovers, ordinarily for purposes of sexual dalliance, the term carrying connotations of secrecy and illicitness. A "house of assignation" most likely once referred to a place at which lovers could safely and secretly meet, but today it is just another euphemism for whorehouse.

assigned account. In accounts receivable financing, an account receivable which has been pledged as security to the creditor. The legal status of the assignee of assigned accounts is dealt with in detail by U.C.C. § 9-318.

assigned counsel. Legal counsel assigned to an indigent for purposes of some legal proceeding. As the Constitution has been interpreted to require the state [to] furnish counsel to those who cannot afford their own in all criminal prosecutions except the most trivial (see assistance of counsel), assigned counsel most frequently appear in criminal cases, though assignment of counsel to an indigent in a civil proceeding is within the power of many courts.

The assigned counsel may be a private practitioner assigned by a judge to represent the indigent with or without compensation (many statutes provide for paying stipulated fees to assigned counsel), but more frequently today assigned counsel will be associated with a public office or charitable organization charged with the provision of legal services to indigents. See Legal Aid Society; Legal Services Organization; Public Defender.

assigned risk plan. In the context of automobile liability insurance, a plan for the provision of insurance to applicants whose risk category or previous driving experience is such that no insurance company would ordinarily issue a policy to them. Some such plan is especially important in jurisdictions which will not issue a driver's license to anyone who has not first procured some minimal liability insurance coverage. Under a typical plan, if a seventeen-year-old male with a previous history of moving violations wishes to procure a policy, he will be referred to the assigned risk office, which will assign him to some insurance company, the office being charged with doing 


\section{Leff Dictionary of Law}

so in a way which will distribute these unattractive risks fairly among all insurance companies authorized to do business in the state, all of whom must agree to join the assigned risk plan. The rates charged such "assigned risks" are often very high.

assignee. One to whom an assignment is made. An "assignee in fact" is one to whom an actual assignment, or "assignment in fact" has been made voluntarily by a person having the power to assign, as contrasted with an "assignee in (or at) law," one who is automatically the recipient of title to something of value, e.g., the executor or administrator of a decedent's estate, or a trustee in bankruptcy.

assignee at [in] law. See assignee.

assignee clause. A provision in the Judiciary Act of 1789 denying diversity of citizenship jurisdiction to claims assigned by claimants of the same state to persons with the requisite diverse citizenship. In its modern version (28 U.S.C. $\S 1359$ ), the assignee clause bars only assignments made collusively for the purpose of conferring such jurisdiction.

assignee in bankruptcy. See trustee in bankruptcy.

assignee in fact. See assignee.

assignee in insolvency. See assignment for the benefit of creditors.

assignee's fees. The compensation of the assignee in an assignment for the benefit of creditors.

assignment. The transfer to another of one's property or interest in property. The term is usually used for transfers of intangible property, especially choses in action (other property being more frequently transferred by change of possession or delivery of a deed, etc.). Any evidence of intent to transfer one's interest may be sufficient to effect an assignment, though certain requisites and formalities are frequently required by law, e.g., for assignment of accounts receivable, see U.C.C. $\$$ 9-308. See also assigned account. In addition, an assignment will be deemed to transfer all of an assignor's interest unless the contrary is stated.

When property is transferred by assignment it is as a general rule impossible, without the consent of all affected persons, for an assignee to receive better or less encumbered title than the assignor had, i.e., if a third party had a lien or other security interest in the property the assignee will get the property subject to that interest. And if the assignor had no title, or subordinate or partial title, to the property, the assignee will get no more than the assignor had. But in many situations those general rules do not apply. If a creditor has failed to take steps provided by law, e.g., some requirement that a lien be publicly filed, an assignee may take free of the security interest; and under some circumstances an assignor with no title at all, e.g., a thief, may be able to pass to a bona fide purchaser title good even against the true owner. 
For special uses of the term "assignment," see entries beginning with or including the word, e.g., assignment of dower; equitable assignment.

assignment by delivery. Some assignments can be effected by mere delivery of documentary evidence of a chose in action, e.g., bearer paper.

assignment for the benefit of creditors. Sometimes called for short "general assignment." A transfer of all or substantially all of the property of a (usually insolvent) debtor to another person (the "assignee [or trustee] for the benefit of creditors") who is to collect what is owed the debtor, sell some or all of his property, and distribute the proceeds among the debtor's various creditors (with any excess going back to the debtor). This procedure, often regulated by state law, amounts to a sort of private bankruptcy proceeding.

Under the old Bankruptcy Act, an assignment for benefit of creditors was an act of bankruptcy; under the Bankruptcy Reform Act of 1978 it has the same effect, i.e., creditors who do not want to go along with this private bankruptcy can force it to be transformed into a formal federal bankruptcy proceeding. Hence an assignment for the benefit of creditor cannot succeed without the support of substantially all creditors. Nonetheless, there are successful assignments, and there are even persons and firms in the business of acting as assignees for the benefit of creditors.

assignment in fact. See assignee.

assignment in law. See assignment.

assignment of account. See assigned account.

assignment of contract. Almost any contract can be made assignable or unassignable by agreement of the parties. A large body of law has developed, however, over the question of the assignability of contracts in the absence of explicit provision for or against.

As a general rule, the performance of obligations under a contract cannot be assigned without the consent of the person entitled thereto, the obligee, if any substantial skill is required of the obligor. To take an obvious case, Andrew Wyeth could not assign to Andy Warhol a contract to paint a portrait without the other party's consent. Nor, almost undoubtedly, could a skilled carpenter, or indeed almost any craftsman or employee. It has been held, however, that one who has agreed to furnish tangible goods, e.g., wheat of a particular grade and description, might successfully assign the contract even without the buyer's consent. But in such a case the assignor remains liable to the obligee in the event the contract is not fully and correctly performed.

Somewhat more latitude is found when rights under a contract are sought to be assigned, especially when the assignor has fully performed and all that remains to be done under the contract is for the other party to pay. Even in such a situation, however, courts have sometimes held that, at least in the particular instance, the other party might be prejudiced by having the enforcement of his obligation pass into the hands of a third party, and thus no valid assignment could be made. 
In light of the complexity of the law, better practice (at least where custom is not perfectly clear) would be to have the question of assignability dealt with explicitly in the contract.

When the assignment of contract is not a matter of choice, i.e., an assignment in law is involved, e.g., when one of the parties goes into bankruptcy, or a contract becomes part of the estate of a decedent, the matter of the contract's assignment will be determined under the relevant law, e.g., the law of estates or of bankruptcy.

assignment of counsel. See assigned counsel.

assignment of dower. The judicially supervised process by which a widow's dower share in her deceased husband's estate is ascertained and set apart for her.

assignment of errors. See assignable error.

assignment of income. In income tax law, what one calls the attempt by a taxpayer to transfer income otherwise taxable to him to someone else whose income is taxed at a lower rate. For the rules governing the success of such efforts, see attribution of income.

assignor. One who effects an assignment.

assigns. A synonym for assignees, both immediate and more distant, usually found in some such location as "this contract shall be binding upon and inure to the benefit of the heirs, administrators, and assigns of the parties." In such a context, the use of the term "assigns" strongly indicates that the parties intended the contract, or at least rights thereunder, to be assignable.

The term is also used to indicate, in a conveyance, a covenant running with the land.

assimilation. The process of becoming "more alike." The term is used in sociology (and to a lesser degree in anthropology where "acculturation" seems to be the preferred word) to describe what happens when members of culture find themselves engulfed by a larger one, e.g., what allegedly happened when immigrants from foreign lands entered the U.S., i.e., the "melting pot" effect. The unarticulated belief that assimilation is a "good thing" seems to have been one of the forces behind the movement toward integration in the U.S. At present there is some doubt whether the melting pot effect ever really operated, and whether it would have been good if it had, this revisionist view correlating with the recent trend in the U.S. and around the world toward cultural distinction and separatism. There is some present feeling that fractional cultures can manage to reach accommodation with the majority without being assimilated, and that if they can't, they should be allowed to separate therefrom.

Also, in the language of finance, "assimilation" refers to the purchase of a new issue of securities by the public [at] which point its price will be established by trading on the applicable market, e.g., a stock exchange.

Assimilative Crimes Act ( ). A statute (18 U.S.C. § 13) transforming into a 
Federal crime any act taking place on Federal property which would be a crime under the laws of the state in which the property is located, even if there is no Federal law making the act criminal.

assisa ( ). See assize. And for terms beginning with "assisa," see those beginning with "assize."

assisa armorum ( ). See assize of arms.

assisa cadere ( ). A very old term for a judgment of nonsuit.

assisa continuanda ( ). An old writ, also known as "de assisa continuanda," addressed to the justices of assize granting an adjournment during which evidence then unavailable but necessary to a correct adjudication might be procured, e.g., when a charter relied upon by a party was not then available.

Assisa de Clarendon. See Assize of Clarendon.

Assisa de Foresta. See Assize of the Forest.

Assisa de Mensuris. See Assisa de Ponderibus et Mensuris.

assisa de nocumento ( ). See assize of nuisance.

assisa de nova disseisima ( ). See assize of novel dissersin.

Assisa de Ponderibus et Mensuris. The Assize of Weights and Measures. It was a detailed statute setting out a large number of weights and measures to be used in England, e.g., the weight of an English silver penny, how many pennies made up an ounce, etc., as well as more specialized measures, e.g., how many pairs of gloves would make up a "diker" thereof.

This particular statute is listed in Statutes of the Realm as one of the Statutes of Uncertain Date, but is set by some in 1303, during the reign of Edward I. An earlier and less detailed statute, called the "Assisa de Mensuris," is believed to have been promulgated during the reign of Richard I, in 1198. But both statutes are just part of the Crown's almost continuous effort to standardize weights and measures, which led to these frequent attempts at authoritative centralized specification.

assisa de ultima presentatione ( ). See assize of darreign pretentment.

assisa de utrum ( ). An old writ, abolished in 1833 but essentially obsolete by the sixteenth century, to try whether certain lands were held in civil or ecclesiastical tenure.

assisa friscae fortiae ( ). See assize of fresh force.

assisa generalis ( ). The "general assize," an old term for Parliament.

assisa mortis antecessoris ( ). See assize of morte d'ancestor.

assisa novae disseysinae ( ). See assize of novel disseisin.

Assisa Panis et Cerevisiae ( ). A statute of 1266, regulating measures and prices of bread and ale, was so titled. But there seems also to have been a general power, also given that name, to "assize," i.e., to look into, the 
weight and measure of bread and ale, which was given to the justices in assize when they were in the locality. See also assisa venalium.

assisa proroganda ( ). An old writ to stay an assize because one of the parties was necessarily away on the King's business.

assisa ultimae presentationis ( ). See assize of darrein presentment.

assisa vanalium ( ). An "assize" in the sense of examination or process of looking into (see assisa panis et cerevisae) with respect to all items exposed for sale in a market.

assise ( ). Another spelling of assize. For terms beginning with "assise," see those beginning with "assisa" and "assize."

assistance of counsel. The Sixth Amendment to the Constitution provides "In all criminal prosecutions, the accused shall enjoy the right . . . to have the Assitance of Counsel for his defense." This has been interpreted to entitle an indigent accused to have counsel appointed for him with respect to all but the most trivial criminal offenses. See assigned counsel.

assistance writ. See writ of assistance.

assistant. A word generally describing a person who assists, i.e., an aide or deputy. Sometimes the term merely describes rank in an organization, e.g., an assistant vice president in a bank is subordinate to, but need not actually assist, any vice president.

assisus reditus ( ). Fixed rent.

assize. Also spelled "assise," and sometimes used in the Latin form "assisa."

The word has had a large number of legal referents over the centuries. Its central concept seems to be measurement or determination, i.e., cognate to the equally complex more modern terms "assess" and "assessment," either through investigation of facts, or through authoritative definition or specification.

Thus one old meaning of "assize" was "statute" or "ordinance," as in the Assize of Clarendon and the Assize of the Forest, i.e., attempts to specify-measure and apportion-rights, duties, etc. It is perhaps significant that statutes dealing with measurements, e.g., the Assize of Bread and Ale (see Assisa Panis et Cervesiae), and the Assize of Weights and Measures (see Assisa de Ponderibus et Mensuris) were also called "assizes." Moreover, early taxes, i.e., statutes measuring amounts to be paid, were also sometimes called "assizes."

But "assize" also came to refer generally to processes for the determination of facts, what we would today call "investigations" or "inquiries," and what we would call "trials." As early as the reign of Henry II (1154-1189), the old process by which a feudal tenant had to defend his freehold by wager of battle (see writ of right), was supplemented by a right to have title determined by the decision of sixteen knights forming something like (but not much like) a modern jury. See grand assize.

But the widest use of the term "assize" came to be in connection with 
"trials" held by the King's judges not centrally at Westminister, but in the various counties of England. Magna Carta (1215) had provided (though most likely just confirming old practice), that the assize of morte d'ancestor and the assize of novel disseisin, the possessory assizes, should be taken not at the King's court of Westminster, but in the shire where the land was located. Royal justices were sent into the country, coming to be known as "justices of assize," or "commissioners of assize" (since they held a commission from the King). Earlier, also under Henry II (1154-1189), the institution of justices in eyre, i.e., traveling justices, had been instituted, though their earlier jurisdiction was uncertain, sporadic, and highly "administrative," i.e., they spent much of their time keeping an eye on the King's interests vis-à-vis local lords and vassals, the King's own sheriffs, and the local (taxpaying) commoners.

Eventually these traveling "commissions" came to be more regularized, and to some degree combined with the trial of the possessory assizes. In addition, by the 1285 Statute of Nisi Prius, it was enacted that the justices of assize should also supervise the local determination of fact issues necessary to decisions pending at the central courts. And eventually these functions were to some extent combined with the old jurisdiction of justices in eyre to try criminal matters, e.g., oyer and terminer and gaol delivery. All of this judicial and administrative activity finally came to be said to take place "at the assizes," which came to be regularly held four times a year.

In any event, at various times in legal history "assize" could be used to refer (a) to the grand assize; (b) to all or any of the possessory assizes, and any writs pertaining thereto; (c) to the "trial" of a fact at nisi prius for transmission to Westminister; (d) to criminal trials; (e) to the "jury" at any of the above proceedings; ( $f$ ) to the "term of court" at which all this took place (e.g., "I must attend the assize tomorrow,") as well as to (g) a statute; and (h) an investigation by royal officers, as set forth above.

See also entries beginning and containing assisa and assize for particular usages.

Assize of Arms. An English statute of 1181 requiring the keeping and furnishing of arms by all freemen was so named, but many other similar statutes were from time to time enacted.

Assize of Clarendon. A "statute," or more properly a royal promulgation, issued by Henry II in 1166, setting out rules to be followed by the royal justices in dealing with criminals and suppressing crime and disorder. Thought by some also to be the origin of the assize of novel disseisin (though that portion of the text, if there was such, is missing). Not to be confused with the roughly contemporaneous (1164) Constitutions of Clarendon, which had to do with royal-ecclesiastical rights and relations.

assize of darrein presentment ( ). An assize available to one claiming an advowson, i.e., a right to present to an ecclesiastical office. The complaining party would allege that he (or an ancestor) had the right to appoint, had appointed the last time (the appointee being installed), but this 
time someone else had purported to make the appointment. The assize of darrein presentment thus was used to do the job later done by way of the action quare impedit.

assize of fresh force. A town or borough court rough equivalent of the assize of novel disseisin, i.e., a possessory action brought by one recently put out of possession.

assize of mort d'ancestor ( ). The assize of "death of ancestor," the most important possessory assize for heirs. The demandant was an heir claiming the right to be put into possession of an estate of which one of his parents or uncles or aunts had died seised, but possession of which had been taken by someone else. In time other writs extended the remedy [to] other ancestors who had died seised: The writ of "aiel" covered grandparents; "besaiel" greatgrandparents; "tresaiel" greatgreatgrandparents; and "cosinage" almost any other ancestor of whom one was the heir.

At the assize the jury was to answer only three questions: (1) did the ancestor die seised; (2) had he died within some specified limitation period (e.g., since the King's last visit to Normandy); (3) was the demandant his heir. If the answers to all three questions were affirmative, the demandant was to put forthwith back into possession. It would then be up to the ousted defendant to try to regain title, e.g., by bringing a Writ of Right.

This was obviously an important remedy for an heir against some interloper (see abatement of freehold). But the best modern scholarship also points out that the assize of mort d'ancestor was an important, almost a final, step in the transformation of feudal property into inheritable property. For under older feudal law, the lord of whom the deceased ancestor had been a vassal would, upon the latter's death, have had the right to take seisin and possession, even if it were only for the purpose of giving it to the heir (as he could early be forced to do, though by much more cumbersome procedures). With the availability of the assize of mort d'ancestor (together with the 1176 Assize of Northampton, a statute which provided that an heir was to have immediate seisin, and only then seek out the law to pay his relief, do homage, etc.) the heir became more like a modern inheritor. $\mathrm{He}$ could use the assize of mort d'ancestor against his own lord, and came to be seen as a person who got "ownership" automatically, and not even in form through the act of a feudal lord in giving it to him.

Assize of Northampton. An enlarged reenactment (1176) of the Assize of Clarendon. See also assize of mort d'ancestor.

assize of novel disseisin ( ). The assize of "recent disseisin," perhaps the most important possessory assize, thought by some to have been instituted in the assize of clarendon (1166). This could be brought by any person who claimed to have been "disseised" (very roughly, ousted from possession-see seisin) within some limitation period (e.g., since the King's last trip to Normandy). If the "assize," i.e., the summoned panel of twelve men of the neighborhood, said that this had happened, the complaining deman- 
dant was entitled immediately to be put back into possession, leaving the now ousted claimant to make his claim less expeditiously, e.g., by way of writ of right. While the assize originally turned on the fact of dispossession without more, by the fourteenth century greater use was being made of the necessary allegation that the disseisin had been "unjustly" made, and in time the assize of novel disseisin turned into a widely used proceeding for trying disputed title to real property. See also ejectment.

As with the assize of mort d'ancestor, however, there is substantial evidence that the original target of novel disseisin was not any old disseisor but a very special one: the demandant's own feudal lord. The assize may have been a way of stripping from the lord the most expeditious technique available to him to discipline a vassal with whom he had a disagreement: physical seizure of the latter's land (and its chattels), either personally or by putting seisin in someone else. If, however, all that counted at the assize was the fact of dispossession, and not any justification for it, the result would always be an order that the vassal put back into possession. (Of course, whether the lord would obey is another matter, which varied with the power of the King, the power of the lord, the power of the vassal, and the bravery of the assize judges and jurors.)

assize of nuisance. A writ which lay against a man to abate a nuisance to the freehold of someone else, or to pay damages, and sometimes both. Early assizes of nuisance look as if they may have been used against feudal lords to restrain their encroachments on the rights of local freeholders, e.g., to common pasturage, or the use of mill streams. $C f$. assize of mort d'ancestor; assize of novel disseisin.

assize of the forest. Any one of many statutes or ordinances making rules for the governance and protection of the royal forest domains.

assize of utrum. See assisa de utrum.

assizer ( ). Also spelled "assiser." A member of the jury at an assize, including the grand assize.

Also an official in charge of overseeing the honesty and accuracy of weights and measures.

assize rent. A kind of rent paid by holders of certain freehold and copyhold estates, so called because it had been "assized," i.e., made certain and precise.

assizes. The sessions of judges sent from the central royal court at Westminster to try matters in the various counties of England. See also assize for further information and complication.

associate. Broadly, one joined with another or others in some joint endeavor. The most common reference in a legal context is to a person engaged in legal practice with a law firm, but as an employee rather than as a partner (or "member of the firm") or as stockholder in a professional corporation.

associate counsel. An attorney associated with the counsel of record in a legal 


\section{Leff Dictionary of Law}

proceeding. Frequently the associate counsel is the "real" counsel, the counsel of record being involved only formally because the "associate counsel" is not admitted to the local bar.

associate justice. The usual title of every justice of a court other than the chief justice or presiding justice. An associate justice has as much power and authority in adjudication as the chief or presiding justice, the latter having, however, certain extra administrative functions and perquisites.

association. A group of persons joined together for some common and usually continuous purpose or purposes. In law, a group may be called an association if it has institutional coherence but is not a corporation, a partnership or any other easily pigeonholed jural entity. It may indeed have no independent-entity status separate from that of its members at all, though it may be treated for certain purposes, e.g., taxation, or limited liability of participants, as if it were formally a corporation. See, e.g., Int. Rev. Code $\S$ 7701(a)(3).

Membership corporations, especially nonprofit ones, are also sometimes called "associations."

Association of American Law Schools. Usually known as the "AALS." An association, founded in 1900, of which most U.S. law schools are now members. While it in a sense accredits law schools (see accredited), in the sense of [requiring] certain financial and educational requisites to be met before a school will be admitted to membership, graduation from a member school of the Association is nowhere a precondition for admission to the bar; over thirty law schools on the approved list of the American Bar Association (not to mention the more than sixty schools not on that list either) are not members of the AALS.

The Association, besides overseeing the quality of its member schools (by regular visitations, often in tandem with A.B.A. visitors), holds scholarly meetings, and facilitates the hiring of aspiring and present law teachers.

assoil ( ). Also spelled "absoile," "assoile," "assoyle," and more. To absolve, acquit, forgive, or set free. Used especially in ecclesiastical law, where it means to deliver from or reverse an excommunication.

as soon as. In one usage, the phrase means something like "not until" as in "As soon as the goods are received, the buyer shall give notice to the seller of that fact." But in locutions like "as soon as possible," "as soon as practicable," "as soon as may be," "as speedily as possible," what is indicated is reasonably prompt action under the particular circumstances. That is, even the fact that faster action was technically possible or even practicable will not ordinarily render such a provision violated if the action was reasonably prompt, e.g., an insured obliged to notify the insurer of an accident "as soon as possible" is almost certainly safe if he waits for the next morning, even though the company could have been reached by telephone that afternoon or evening.

assume. To assume, in the sense of making an assumption, refers to the intel- 
lectual process of treating some proposition as true without requiring proof, as in "Assuming that capital punishment deters homicide, and assuming further that increasing the rate of capital punishment actually inflicted will further increase that deterence effect, then we ought to increase the rate at which capital punishment is inflicted." This intellectual process is absolutely necessary to discussion of any complex process; not every factual or causative proposition can be proved, and by assuming some, one can focus on others. But it is also necessarily a dangerous thought device, both because unproven assumptions can be wrong and, more insidiously, because it is never clear how much assuming one ought to do. In the above example, e.g., note what would happen if one also "assumed" that the infliction of capital punishment either gave the society a taste for killing in general, or that increasing the "price" of homicide relative to other crimes vastly increased the supply of other crimes, e.g., rape and armed robbery.

To assume in law, however, is to carry out the legally significant act or process of taking upon oneself responsibility for a duty or relationship, as in, e.g., assumption of mortgage and assumption of risk.

assumed name. See fictitious name.

assumed risk. See assumption of risk.

assumpsit ( ). "He undertook" or "he promised." Until well into the nineteenth century, the term was generally used (indeed occasional use continued into the twentieth) for what we would today call contract and quasicontract (or restitution). The legal history of assumpsit is enormously complex, and its early history, especially before the 16th century, obscure. What follows, therefore, is more classification or taxonomy than history or explanation.

Though something called "assumpsit" had early come to be legally associated with what we would now call the tort of negligence, i.e., carelessness leading to injury to someone else or his property (see Humber Ferry Case), it became in time much more bound up with another aspect of life, of less but still significant importance even in the middle ages and increasingly as time went on: the world of exchange and promise. What part was the law to play in situations where $X$ delivered goods or services to $Y$, at Y's request or to Y's knowledge, but Y refused to pay for them? Was there to be a remedy when $\mathrm{Y}$ agreed to sell wheat to $\mathrm{X}$ on a certain day at a certain price, but then failed to do so? And what was one to do when $Y$ refused to pay back to $\mathrm{X}$ the money which he had borrowed from him? Surely in all these situations, and many similar ones, any reasonably developed legal system would find some way to help out the distressed X.

And indeed the English legal system did, and from a very early date too. Local courts, especially in towns and between merchants, but more generally too, gave remedies in these exchange and promise situations. The ecclesiastical courts also had jurisdiction over various species of deceit and foreswearing, and this came to cover a not insignificant number of breachof-promise situations. And the common law, i.e., the law administered by 
the central royal courts, also had remedies touching upon most of these trades and transactions. There were (to mention only a sampling of important ones) the actions of debt, detinue, and covenant; there were actions of account, for accountings between partners and from agents; there were even equitable remedies for certain broken promises and unperfected trades.

But there were also problems. The local and ecclesiastical jurisdiction[s] [were] not complete and in any event were not an adequate substitute for the reach and power of the royal courts. The action of debt was perfectly designed for collecting money owed to a creditor, but alas, it was an action in which the defendant might defend by wager of law (formalistic oath), not the most satisfactory way of settling mercantile disputes. And while in "covenant" the common law possessed an action which would lie for almost any breach of promise, the courts had early decided that covenant could only be brought on promises under seal.

It is against this background (which was really much more complicated) that assumpsit, an action on the case which did not suffer from the procedural difficulties of the earlier actions, finally came to supercede the older approaches and become the general remedy for broken promises and troubled exchanges. Telescoping a great deal of development, by some time in the seventeenth century the common law of "contract" and "quasi-contract" (though the words were not used), which came also to be the law of the American colonies, was roughly as follows. There were still special forms of action available for promises under seal. But in Slade's Case (1602) it had been decided that a plaintiff might plead "indebitatus assumpsit," i.e., "being indebted he promised" when what had really happened is that the defendant had received something which he ought to pay for, but had not in fact promised to do so, either at the time of the transaction or thereafter. The alleged subsequent promise to pay was held nontraversable, i.e., it need not be proved, i.e., it became a legal fiction-the net effect of which was to make assumpsit an available alternative to the action of debt.

If one could not frame one's pleading so as to allege a sum certain owing to the plaintiff, one had available the "common counts," the most important of which (along with the "debt" form for money had and received) were "quantum meruit" and "quantum velebant." The former allowed suit for reasonable recompense for services rendered the defendant and the latter for reasonable payment for goods sold and delivered. In effect, indebitatus assumpsit with its common counts (which came also to be called "general assumpsit") became the remedy for contracts implied in fact (e.g., by knowing receipt of services) or implied in law (e.g., when the defendant had had money paid to him by mistake). The form of assumpsit, which lay for any express informal (i.e., unsealed) promise, both oral and written, came to be called "express assumpsit" or "special assumpsit" and came to be available even for a totally executory contract, i.e., when neither party had rendered any performance prior to the defendants failure to perform. 
assumption. See assume.

assumption clause. A provision in a deed, lease or other document of transfer by which the transferee assumes some obligation of the transferor chargeable against or otherwise pertaining to the property, ordinarily (assuming the obligee consents) eliminating the transferor's obligation.

Also, a provision in many mortgages specifically forbidding an assumption of mortgage without the express consent of the mortgagee.

assumption fee. A fee payable to a mortgagee in connection with his consent to an assumption of mortgage, supposedly to cover the mortgagee's administrative expenses in substituting a new mortgagor.

assumption of debt [indebtedness]. See assumption of obligation.

assumption of mortgage. The most common assumption of obligation. When mortgaged real property is transferred, various arrangements may be worked out among the mortagee, the vendor and the purchaser. The vendor may take part of the purchase price and pay off the existing mortgage, with the purchaser newly mortgaging the property if he wishes to do so. Or the purchaser may buy the property "subject to the mortgage." In such a case, the seller will retain his personal obligation to pay the mortgagee, and the purchaser will acquire no personal obligation, but the property remains charged with the lien of the mortgage, and if there is default in the mortgage payments the mortgagee may foreclose. In this eventuality, it is a matter of agreement between the vendor and purchaser as to which of them has ultimate responsibility to pay any amount still owed to the mortgagee after foreclosure and sale of the property.

But the parties may also agree to an "assumption of the mortgage." In that instance the purchaser agrees to be personally responsible for the mortgage debt. There are two principal varieties of this transaction. In an "assumption with novation," the mortgagee agrees to release any personal liability on the part of the vendor and take in its place that of the purchaser. In an "assumption without novation," the vendor is not released; he remains personally liable to the mortgagee and (in most jurisdictions) the purchaser also becomes personally obligated. But as between the vendor and purchaser, the latter is primarily liable, and the vendor may recover reimbursement from the purchaser for any part of the mortgage debt the vendor is forced to pay.

assumption of obligation. The undertaking by one person of an obligation previously owed by another, with or without novation, as in an assumption of mortgage.

assumption of risk. A defense in an action for negligence, the gist of which is that the plaintiff, fully knowing the danger to which he was exposing himself, and able with reasonable efforts to avoid it, nonetheless decided to go forward. A reasonably clear example might be a plaintiff who, with available alternative modes of transportation, decided to ride with a driver on a mountain road even though he fully knew that the driver had lost his 
glasses and could hardly see. The driver was obviously negligent in driving without his glasses, but the passenger may be said to have "assumed the risk" of that negligence.

It has been strongly argued that it is misleading to have a separate doctrine of assumption of risk, that all such "assumptions" can be covered by doctrines involving either the defendant's duty, or as instances of the general doctrine of contributory negligence. Part of this drive to abolish the separate defense seems to have arisen out of applications of the doctrine which were at best questionable. It was often held that a worker had "assumed the risk" of his employment by taking the job, and thus could not sue his employer for injuries suffered while at work; and this was applied despite the questionable "voluntariness" of many decisions to take jobs, especially in times of work shortage, and the unnecessary awfulness of many of the risks. Also, the doctrine was applied in automobile cases in which there were, at least socially, few alternatives for the plaintiff, e.g." "You're drunk, Tommy Thomas, and you're not driving me home from this party," is not the easiest speech for adolescent dates to make. The doctrine also got applied in cases (to which the rescue doctrine is now applied) to bar recoveries by persons injured while rescuing others from the defendant's negligence. And still further, in some jurisdictions which had comparative negligence rules, it somehow got held that any assumption of risk would nonetheless bar the plaintiff's claim totally.

Subsequent developments, statutory and decisional, have pretty much eliminated assumption of risk as a viable defense in most of the abovedescribed areas of special trouble; it is, e.g., no longer available in employee-employer suits under workman's compensation or otherwise, the "rescue doctrine" is almost universally the law, and most anomolies under comparative negligence rules have been eliminated. (Under no-fault insurance, of course, the defense is ordinarily irrelevant.) Some authorities are thus in favor of keeping the assumption of the risk as a defense separate from general contributory negligence to describe this particular kind: running a known and willingly appreciated risk, whether by contract or otherwise.

It should be kept in mind that assumption of risk is a defense to a claim for negligence, i.e., first one must prove that the defendant was negligent in creating a risk. A worker not covered by workman's compensation, e.g., could not successfully sue his employer for injuries suffered doing, on the job, something well-known to be dangerous, if there were no reasonable way to make it less dangerous, i.e., if the employer were not negligent.

See also volenti non fit injuria, a doctrine closely allied to assumption of risk but broader in application, e.g., encompassing intentional inflictions of injury too.

assurable. See assurance.

assurance. The word used widely in England, Ganada, Australia, etc., as essentially a synonym for the more common U.S. term, insurance, e.g., "assura- 
ble interest" would mean the same as insurable interest. Hence for many terms containing "assure" and "assurance" one should consult the same terms, but under "insure" and "insurance."

But "assurance" also is used widely, especially in England, to refer to any written instrument evidencing title to real property, and it is this usage which is at work in terms like assurance fund; collateral assurance; common assurances; and covenant for further assurances.

assurance fund. A fund set up in some jurisdictions having the system of registration of land titles to indemnify people who lose their property through fraud or error and have no realistic recourse against anyone else. It is hard to know if the "assurance" in this use is a twig on the "insurance" or "evidence-of-title" branch of the word; the ideas are here combined.

assure. In general, see assurance.

Assure is also used to mean "make certain," as in "He assured himself of the authenticity of the document" or "aver as certain," as in "He assured her that the document was authentic."

assured. See generally assurance and assure.

In insurance parlance, "the assured" frequently refers to the person who will be paid if the insured-against event takes place, especially if he procured the policy and pays the premiums. In life insurance contexts, "assured," somewhat less ambiguously than "insured," refers to the persons who will be paid rather than the person upon whose death payment will be made-but it's still somewhat confusing. See also cestui que.

assured clear distance [ahead]. A phrase found in traffic statutes in sentences like "The driver shall at all times operate the motor vehicle at a speed which will permit the vehicle to be brought to a halt within the space of the assured clear distance ahead." The idea is that the car ought to be able to be stopped before it hits anything the driver can see, e.g., at night one should drive no faster than a speed that allows one to stop within the range of one's headlights.

assurer. See assurance; assure.

as they stand. See as is.

astipulation ( ). Old term for an agreement or stipulation.

Also sometimes used for a record, or even a witness.

astrarius ( ). Also "astrer." In old English law, a householder; an owner or at least lawful possessor of a dwelling house.

astrarius haeres ( ). An heir, ordinarily an heir apparent who has had conveyed to him, or at least been put into possession of, a dwelling house which he will inherit upon the death of the prior owner.

astrer ( ). See astrarius.

astrict. A rare variant form of restrict.

astriction ( ). A servitude attaching to lands binding the tenant thereof to 
some particular act with respect thereto, e.g., "astriction to a mill" binds him to take the grain grown on the land to a particular mill for grinding at a stipulated price.

astrology. A pseudoscience pursuant to which the present and past can be explained, and the future predicted, with respect to the positions of heavenly bodies. It is almost certainly total twaddle, but while an opportunity for swindling, the practice of astrology is not ordinarily by itself legally punishable.

astrum ( ). Literally a hearth, but meaning a dwelling house.

as trustee. Words appended to the signature of a person executing a document in his capacity as a trustee. It is frequently added to eliminate the trustee's personal liability on the transaction, but is not very apt to the purpose; something like "as trustee but not individually" is much safer. $C f$. as agent.

asylum ( ). Broadly, peace and safety from danger of harm, but most frequently descriptive of a place where it may be attained, i.e., a sanctuary. In the middle ages certain churches, cathedrals, and other religious institutions were places of asylum for felons, for the "state" authorities could not enter to arrest. Of course, the person could not safely leave either, which was inconvenient for him and his protectors, and a procedure grew up whereby the felon could leave by taking oath to leave the realm. See abjuration. The closest modern equivalent to this kind of asylum is that given by the embassy or consulate of a foreign power to a political enemy of a regime. After the abortive revolution of the Hungarians against the Soviet Union in 1956, for example, the local Cardinal Archbishop fled to the U.S. Embassy and stayed there for years, neither the Hungarians nor the Soviets being willing to take the dangerous step of invading U.S. extraterritorial rights. (The Cardinal eventually left as part of an agreement of abjuration.)

The word asylum came eventually to be used to describe almost any place where lodging and care [were] given to an unfortunate of some kind, e.g., orphan asylum (see orphanage), insane asylum.

asylum state. A state, in either the domestic U.S. sense or the international law sense, to which one accused of crime in another state has fled. There are procedures for extradition both between U.S. states and, by treaty, internationally, which have limited the power of the fleeing party successfully to find asylum, but under some circumstances, e.g., for alleged political criminals, it is still possible.

at. A word used to specify location in space or time which exhibits, in legal contexts at least, considerable flexibility in level of exactitude. All one knows for sure is that "at" by itself never means "exactly at," e.g., "to be sold at 9:00 a.m." means "not too far off from 9:00 a.m.," how much being too much depending on the reasonable understanding of a reasonable person in the particular situation. And something like "at the death of $X$ the property shall be sold . . . ." means "no earlier than X's death, and during some reasonable time thereafter." 
at [any] bank. See payable at bank.

at any time. A phrase usually found with either an opening or closing specification, e.g., "at any time before," "at any time after," or both. As usual, it doesn't mean any time, but a time that makes sense in context. Hence a statute giving anyone with an interest in litigation the right to intervene "at any time" means "at any time before judgment is entered." And a provision giving right to demand payment "at any time" will be construed to mean "during business hours on a business day."

at arm's length. The phrase will ordinarily be found in some sentence like "The parties, after all, dealt at arm's length," appearing in an opinion upholding an agreement against a claim of, e.g., unconscionability or overreaching. The idea is that the parties were not in such a relationship that one was justified in being lulled into reposing trust in the other such that he wouldn't seek the best deal for himself, i.e., that they dealt with each other, or ought to have, with the healthy circumspection of businessmen facing each other in a marketplace. Naturally, there are things, e.g., fraud, misrepresentation, duress, which will vitiate a contract even if the parties were dealing "at arm's length."

at bar. Presently before the court. Most frequently found in the location "in the case at bar," which may refer to a pending case, or (especially in law school classes) to an already decided one then under discussion, as in "Well, Mr. Fish, what did you make of the case at bar."

at common law. See common law.

at [his] earliest [possible] convenience. A payment or duty to be rendered "at earliest convenience" is one to be carried out when the obligor determines in good faith that he can without undue inconvenience do so. It is not a warrant to transform polite accommodation into total non-obligation; there does come a point at which a successful suit will lay for an obligation mysteriously not yet "convenient" to carry out, i.e., when one's "earliest convenience" comes is not wholly a matter of one's subjective determination.

a tempore cujus contrarii memoria non existet ( ). "From a time when there is no memory to the contrary." See memory of man runneth not to the contrary.

a terme de sa vie ( ). Law French for "for the term of his life," i.e., words used to convey a life estate.

atheist ( ). One who affirmatively believes that there is no God. Compare agnostic.

atia ( ). See acia.

at issue. When the old process of pleading had reached the point at which the parties had framed between them a matter of fact which had to be determined, the case was said to be "at issue." The term is still used to describe 


\section{Leff Dictionary of Law}

cases today, but usually nontechnically to mean little more than at bar, i.e., "The case at issue" means "this case" or "the case we're talking about."

at large. Free to roam; unrestrained, as in "He lets his pet puma roam at large," or "After the jail break there were six dangerous felons at large in the state."

Also, in full; in detail, as in, "The charges were set out at large in the indictment."

Also, in elections, an official position to be filled by the votes of an entire larger political division (e.g., a city) rather than by voters in smaller subdivisions thereof (e.g., wards or districts). At large election has been the subject of some litigation inasmuch as it is a method of denying representation to compact groups of minority voters. If, e.g., Chicanos constitute $15 \%$ of a city's voters, and all live close together, it is likely that voting by districts will allow them to elect at least one local representative. But if all the elected officials are elected at large, then the residential compactness of the Chicanos becomes irrelevant, and they remain just 15\% of the electorate.

at law. Pertaining to law in all its manifold meanings, e.g., counsellor-at-law, but often used more precisely to distinguish law from equity (in its manifold meanings), or morality, as in "This is an action at law to which the doctrine of equitable estoppel is inapplicable," and "Whatever the moral position of the defendant, at law he is not obliged . . . ." So common is this distinguishing use of "at law" that it is sometimes wise to negative any implication that a distinction is being made, e.g., "At law and in equity the defendant is obliged...."

at law and in equity. See at law.

at least. . In drafting, a term used to express the idea "this amount or more, but no less," as in "On the first day of each month the seller shall deliver to the buyer at least 5,000 widgets, until the full number called for hereunder shall have been delivered."

at maturity. See maturity.

at my death. When used in a document conveying something, the term is almost always testamentary, i.e., no interest is to pass until the death of the donor.

Atomic Energy Act of 1954. A comprehensive statutory scheme (42 U.S.C. § 2011 et seq.) covering the development and regulation of atomic energy.

Atomic Energy Commission. A federal agency provided for in the Atomic Energy Act of 1954 to carry out many of the provisions of that Act. It was widely known under its initials, AEC. In 1974, the AEC was replaced by another agency, to be known as the Nuclear Regulatory Commission (abbreviated NRC).

at once. A term used to indicate a requirement of prompt action, as in "Upon receipt of the goods the buyer shall at once inspect them, and . . . "The words indicate action more speedy than, e.g., as soon as practicable, or even 
as soon as possible (see as soon as), but still ordinarily only require action as speedy as reasonably can be taken under the circumstances.

atonement. A process of taking steps toward reaching a reconciliation with another, or a return to his favor, after having behaved badly or wrongly. The term is primarily religious, where the steps involve acts like confession, fasting, giving recompense to the injured, solemn promises of better future behavior, etc., as with the Jewish "Day of Atonement" (Yom Kippur).

The word has also been occasionally used in divorce law to describe behavior by a spouse subsequent to his wrongful activities which might, so to speak, cancel out the grounds for divorce his earlier conduct had established. It does not seem ever to have been a widely adopted theory in divorce law.

at or before. In drafting, a term used to express the idea that something is to be done at a particular time, or earlier, but not later. The more common locution is on or before.

a tort ( ). Law French term meaning "wrongfully" or "unjustly."

at or upon. A legal redundancy inasmuch as, with respect to a date, "at" means about the same as "on" or "upon." Hence the term means no more than either of its parts, which mean "then or as reasonably close to then as the context and situation indicate."

at owner's risk. A term used by people who accept custody of other people's property-it may be a coat hung in a coatroom, or commercial paper taken for collection, or an automobile allowed into a parking lot, etc.- to convey the thought that the person accepting possession will not be responsible if the property is lost, damaged, or stolen. In some circumstances, e.g., when the term can realistically be said to have been agreed to by the owner, and there are no statutes making such a deal unenforceable, the custodian may thereby manage to escape liability with respect to the property, but almost never if the loss was the result of his own negligence or fault.

at par. See par.

at random. See random.

atrocious assault. An aggravated species of criminal-law assault and battery usually characterized by great physical brutality, e.g., maiming or other extensive and serious injuries. Not necessarily inflicted with any dangerous weapon.

atrocity. An instance of particularly revolting brutality. One instance would be the intentional machine-gunning of noncombatant women and children by armed forces in a war zone. But there is a bountiful supply of examples from all ages and places, in furtherance of all causes and aims.

ats. or ATS. Abbreviation of "at the suit of." See ad sectam.

at sea. A term describing the condition of a ship on a voyage, i.e., not in port. But in marine insurance contexts, "at sea" may describe a ship on a voyage 


\section{Leff Dictionary of Law}

including the times it is located in intervening ports. And for persons who get paid extra while "at sea," the period may include any time spent on or attached to a vessel afloat, even if it is in port.

at sight. See sight draft.

attach. To connect something to something else, either physically (e.g., "He attached the trailer to his car.") or conceptually (e.g., "He attached to the land a duty to keep the adjoining stream clear" or "Dower attaches at the moment of marriage."). The term also may be used as an equivalent of "fond of," as in "He was attached to his oldest and dirtiest pipe."

For the important legal meaning of attach as akin to "seize," see attachment.

attachable. Property which may legally be made the subject of an attachment.

attaché ( ). A word originally French, but now also English, most frequently used to describe a member of the staff of an embassy, consulate, or other diplomatic mission. Frequently the attaché will have his title further specified to indicate the matters upon which he concentrates his knowledge and efforts, e.g., "cultural attaché," "military attaché" or "commercial attaché." Most larger embassies and consulates also have "spying attachés," though they are not formally designated as such.

attached. See attach; attachment.

\section{attachiamentum ( ). Attachment.}

attachment. A process by which the person or property of another is, in connection with some legal proceeding but before judgment, seized either physically or symbolically (e.g., by having a sign placed upon it, or a notation placed where its title is registered), as a means to assure that any judgment ultimately won by the attaching party will be satisfied. The attachment process takes place at the inception or during the pendency of the proceeding, and is to be distinguished from execution, the process by which property is seized after, and to satisfy, a judgment. When the property seized is incorporeal, e.g., a debt due the defendant from a third party, the attachment is usually called a garnishment, or more particularly, a "prejudgment garnishment."

Attachment was historically a method for the commencement of a lawsuit; one got the defendant into court by seizing his property, or indeed by seizing him. See capias and entries so beginning. And in modern practice, it is still not uncommon to commence a lawsuit against one over whom one cannot gain personal jurisdiction, e.g., a non-resident, by attaching his property within the jurisdiction. This is sometimes called a "foreign attachment." See also in rem jurisdiction; quasi in rem jurisdiction. It is also still common to effect a "domestic attachment" of property of residents over whom personal jurisdiction may be, or indeed has been, obtained, when there is fear that the defendant may hide, destroy, or dispose of his property, or flee the jurisdiction. 
Moreover, until recently it was still ordinary everyday procedure in some states to commence a lawsuit by writ of attachment despite the personal availability of the defendant and despite the absence of any likelihood that he would flee or dissipate his property, and to do so without any real judicial supervision, i.e., by issuing the writ either ex parte before a judge, or by the non-discretionary action of a court clerk. But recent constitutional decisions have sharply limited, as violations of due process, the nonemergency issuance of writs of attachment with neither notice nor hearing.

attachment bond. A bond required of a plaintiff suing out a writ of attachment to secure payment to the defendant of his costs and damages should it be [adjudged] that the attachment was wrongfully made.

Also a bond which a party whose property has been attached may procure to secure payment of any judgment to be procured by the plaintiff, so that the attachment on his other property (e.g., goods which he has contracted to sell) may be released.

attachment execution. A confusingly named (because attachment and execution are usually distinguished) procedure in some states for garnishment in satisfaction of a judgment. It is most likely so named because while it is an "execution" from the point of view of the judgment debtor, i.e., the party who lost the lawsuit, it is an original proceeding from the viewpoint of the garnishee, who is for the first time ordered to show cause why execution upon the property of the defendant in his hands should not be had.

attachment garnishment. See attachment execution. The term may also sometimes be used in place of "prejudgment garnishment."

attachment lien. In some jurisdictions, the attachment of property impresses a lien upon it. (In others it merely subjects the property to the lawful possession of the court and places restrictions upon its transfer.)

attachment of risk. The time at which risk of loss of goods passes from the seller to the buyer of goods. See U.C.C. § 2-509.

Also, in insurance contexts, the moment at which the insurer's obligation begins. Usually the question is easy, e.g., under an insurance contract obligating the insurer to insure against theft "from January 1, 1979." It may not always be easy, as with a policy covering "a voyage," or property from time to time "acquired" by an insured.

attachment of the forest. See courts of the forest.

attack. See collateral attack.

attain. In older English law, a word for convicted of, or found guilty, as in "attain de disseisin," i.e., convicted of disseisin. Most likely a linguistic cognate of attaint and attainder.

attainder ( ). The status under old common law of a person who pleaded guilty to, was convicted after a trial of, or fled and was outlawed for, treason or felony. He was said to be civilly dead (see civil death), and all of his property was forfeited or escheated to the Crown. The attainder also en- 
tailed corruption of blood, i.e., he could no longer inherit or pass title by inheritance to his heirs. Attainder was abolished in England in 1870 (except for those attainted by outlawry), and never gained any substantial hold in the U.S., even before the enactment of the Constitution, with respect to which see bill of attainder.

attaint ( ). To pass sentence of attainder, or to be one against whom such sentence was passed.

Also, an old proceeding to "appeal" the verdict of a jury. If a writ of attaint was issued, a new jury of twenty-four (usually knights) was empaneled to retry the case, and if it reached a decision contrary to that of the first jury, the members thereof suffered a process not very different from attainder (albeit without the capital punishment). The penalty was later moderated to stiff fines. This whole "appeal" process was abolished by statute in 1825, and had fallen into disuse well before that; Blackstone found no instances after the sixteenth century.

attempt. In general, an unsuccessful intentional endeavor to bring about an effect. In criminal law, an attempt to commit a crime is itself a crime, though usually less heavily punished. It is ordinarily said to require both intent to commit the crime, and some overt act tending toward the crime's commission.

The law of attempts has often presented criminal law with lovely, knotty problems. First there is the problem of when mere preparation for a crime can be said to have transformed itself into an act of actual endeavor. Consider a terrorist bomber. Has he committed an "attempt to bomb" (a) when he arranges to have an alarm clock delivered to his home; (b) when he takes delivery; (c) when he starts to modify the mechanism for attachment to a detonator; (d) when he attaches it, even though he has not yet procured any explosive; (e) when he makes the bomb; $(f)$ when he starts out of his home with it; (g) when he hides it in a building . . . . etc.

But there are other conceptual problems too. Is it a criminal attempt when a person sets out to do something which would be a crime if he did it, but it cannot in fact be done, at least not that way? Can one be convicted of attempted murder for sticking a pin in the heart of a wax image of the intended victim? Do things change if the victim hears about it and in fact gets very sick? Is it enough that the victim would have committed the crime had the facts been as he believed them to be? In a famous English case, a defendant sought to bring Flemish lace into England hidden in the sides of a coach, which would have violated an English law against such importation. In fact, the alleged smuggler had been swindled, and had been sold English lace in Flanders as Flemish lace. Hence the defendant was in fact only bringing English lace into England, which violated no law. Could there nonetheless be a conviction for attempted smuggling? Under the Model Penal Code ( $\$$ 5.01), the answer would be yes, but the question has been much debated.

Insofar as these problems have any answer, the most fruitful approach 
seems to be to ask why there is a law of criminal attempts. If it is to convict dangerous people one might answer some of the questions one way. If it is to allow police to act effectively before any injury-producing crimes are committed, other answers might be made. The point is that nothing is required by the definition of a crime or of the crime of attempt; one must decide what it is that one wants to make criminal.

attendance officer. An employee of a school board whose job it is to keep track of the attendance of students, and to take such steps, including in rare instances taking the absentee into custody for delivery to the school, to assure that pupils do not miss school except for good reason. The other once common name of the job is "truant officer."

Attendance of Witnesses From Without a State in Criminal Proceedings Act. One of the Uniform Laws. Enacted in substantially all American jurisdictions.

attendant. As an adjective, the words mean accompanying, connected with, trailing along, as in "This contract, together with its attendant schedules ...."

An attendant is a person who accompanies another in order to help him and attend to his needs, e.g., a "court attendant."

attendant terms. In older English conveyancing practice, long terms of years (which often were actually mortgages) were left technically in place long after they had expired as a way of protecting the successor to the freehold or the real underlying leasehold from unknown intervening incumbrances or conveyances. These terms of years were known as "attendant terms." The practice was effectively abolished for freeholds in 1845, and for underlying leaseholds in 1925.

attending physician. In general, just a physician who takes care of a patient, especially in a hospital; but the term is also sometimes used as the "rank" of a physician at a hospital. An "attending physician," who may be a member of the hospital staff, or a physician with a private practice, has full privileges, and there may be such ranks as "assistant attending physician." Frequently the term is used without "physician," e.g., "Nurse Nightingale, who's the attending on this patient?"

atterminare ( ). To delay or postpone, especially the time for payment of a debt. "Atterminata" would mean adjourned.

atterminata ( ). See atterminare.

atterminer ( ). The Law French equivalent of atterminare.

attest. In general legal terminology, to attest is to bear witness to a fact, to testify that something is true or genuine. The most common instance of the process is more frequently called "attestation," which is the act of a person who watches the execution of a document and then signs it as a witness. This process of attestation is almost univeral with respect to the execution of wills, and almost as common for real property conveyances. The signa- 


\section{Leff Dictionary of Law}

ture of the "attesting witness" usually comes right after what is called the "attestation clause." In a deed the clause may be relatively simple, e.g., "signed, sealed and delivered in the presence of . . .," but in wills the clause may be considerably more elaborate, e.g., reciting that the signature of the testator was made of his own free will, that he regarded the document as his last will and testament, that he requested the witnesses to witness, etc.

"Attest" is also very uncommonly used as a synonym for a "witness."

See also attested copy; attesting witness.

attestation. See attest.

attestation clause. See attest.

attested copy. The term used to describe a copy of a document, usually a public document, e.g., a birth or death certificate, which has been compared with the original by some official and is accompanied by his certificate that it is a true and accurate copy.

attesting witness. Also called "subscribing witness." A person who watches the execution of a document, and then signs it himself as having witnessed its execution. Under modern evidence rules (See, e.g., Fed. R. Evid. 903), a document may be authenticated (see authentication) even without the testimony of an attesting witness, unless there is law specifically to the contrary, e.g., with respect to wills in some jurisdictions.

at the courthouse door. The place specified in some statutes for the posting of. certain notices, for judicial sales of property, or for various other official acts. Today, except in small towns (where the locus may still be sufficiently public and convenient), public notices tend to be published, and judicial sales are carried out in more specialized places.

at the earliest [possible] [practicable] moment. This means essentially the same as "as soon as [possible] [practicable]" though perhaps intended more strongly to emphasize the need for prompt action.

at the end of the will. Under a statute providing that as the place where the testator must sign his will, what is meant is the end of the writing, not of the paper, and even then the signature of the testator may properly be followed by the attestation clause (see attest) and signatures of the attesting witnesses.

at the market. An order to an agent, especially a securities broker, to buy or sell something at the price immediately obtaining in the market.

attorn. See attornment.

attornare ( ). To make an attornment.

Also, to transfer or turn over.

Also, to appoint an attorney.

attornati et apprenticii ( ). Attorneys and law students.

attorney. A term used to refer both to an attorney in fact and to an attorney 
at law; unless the context makes clear to the contrary, however, it ordinarily refers to the latter.

attorney at law. A person licensed to practice law in the U.S. Other terms of essentially identical meaning include "counsellor at law" and "lawyer." Distinctions still recognized in England, e.g., among barrister, solicitor, proctor, etc., are wholly absent in U.S. jurisdictions, though the growing movement toward specialization, especially for trial practitioners, may in time lead to something like the English barrister-solicitor distinction.

To become an attorney at law, it is ordinarily necessary to graduate from a law school recognized by the relevant jurisdiction (though apprenticeship is technically an available substitute in some jurisdictions) and then show at least minimal legal knowledge by passing a bar examination. (In some states, graduation of a state law school leads to immediate admission to the bar.) One is admitted only to the bar of a particular state; there is no national admission, though one can in time become admitted to the bars of more than one state, either through examination, or by motion after several (usually five) years of practice elsewhere.

attorney-client privilege. An evidentiary privilege pursuant to which confidential communications between an attorney and his client, made for purposes of legal representations, may not be disclosed without the express consent of the client. Some such privilege is recognized in every U.S. jurisdiction. There are exceptions (e.g., communications in furtherance of crime or tort; claimants through the same deceased client; joint clients) which vary in type and scope from jurisdiction to jurisdiction, but the variance is not wide. Problems arise in determining who "the client" is, e.g., when the attorney represents a corporation; who "the attorney" is, e.g., when an attorney employs an accountant to help him in a case; and, occasionally, whether a communication is "for purposes of legal representation," e.g., when an attorney is also a business advisor or officer of a corporation. A good summary of the usual scope of the privilege can be found in the proposed but not enacted Rule 503 to the Federal Rules of Evidence, and the advisory committee's notes thereto.

It should be noted that the attorney-client privilege is buttressed by the attorney's strong professional-ethical duty not to disclose communications from his clients or other facts about the client learned during legal representation. See Canon 4 of the Code of Professional Responsibility.

attorney general. The title given the chief legal officer in the executive branch of the U.S. and state governments. He is ordinarily in ultimate charge of all governmental litigation, and other legal work, including the rendition of legal opinions, formal and informal, to the legislature and chief executive. See opinion of the attorney general. The U.S. attorney general, being a member of the cabinet, also fills some of the role of a European "Minister of Justice." See also Solicitor General.

attorney in fact. A person appointed by another to act on his behalf, and to 


\section{Leff Dictionary of Law}

bind him, in a particular matter or for a wide range of transactions. The appointment, like that of any other agent, can be made informally, but it is common to execute and deliver to the attorney a written power of attorney which sets forth the scope of authority in some detail. See also attorney's implied authority.

attorney of record. An attorney of law who appears in the records of a court as lawyer for a litigant, either through the filing of a formal notice of appearance, or through having taken some formal step on behalf of the client, e.g., filing a motion, or appearing in court to argue. In the Federal courts, a pleading must be signed by the litigant or an attorney of record. See Fed. R. Giv. P. 11. Once a lawyer becomes attorney of record, he usually cannot withdraw without permission of the court.

The attorney of record is usually the attorney in charge of the matter, with other attendant lawyers being subordinate to him. See also of counsel. But that is not always the case. Sometimes the attorney of record is just a lawyer admitted to practice in a jurisdiction, with the client's "real" lawyer being technically just an associate of or advisor to the local attorney of record.

attorney's charging lien. See attorney's lien.

attorneys' fees. That which attorneys at law are paid for their services. The amount is ordinarily a matter of agreement between the attorney and the client, but in some circumstances must be approved by a court, e.g., when the fee is to be paid by a fiduciary, or the payment is part of the settlement of a class action. Some types of fees, e.g., contingent fees, are regulated by statute or court rule.

In some circumstances a court may order that the attorneys' fees of the winning party in an action be paid by the losing party. In England, indeed, it is the ordinary practice that the winner's legal fees be taxed as costs to the loser. This is known as the "English rule on attorney's fees," and there is a formal process in English courts for taxing fees as part of costs. In the U.S. the so-called "American rule" is the norm; under it attorneys' fees are not ordinarily paid by the losing party, though courts have power so to order when the loser is deemed to have litigated frivolously or in bad faith, and under certain statutes, e.g., some dealing with civil rights and conservation.

It is not clear what differential effect on litigation the American and English rules produce. In the ordinary American case, the litigant has a $100 \%$ likelihood of paying his own fees; in England, he has a percentage likelihood of paying no fees equal to his percentage likelihood of winning the case. Assuming that many cases that come to trial are toss-ups, i.e., 5050 chances, and further assuming that each litigant has an equal utility for money (i.e., $\$ 1,000$ is valued equally by both of them) and an equal utility for risk, then a $100 \%$ chance of paying one-half the fees should be no different from a 50\% chance of paying all the fees. But the assumptions of equal utilities and equal chances of success are rarely met, and thus the 
actual incentive effects of the two rules are difficult to determine in any particular case, or in general.

attorney's general lien. See attorney's lien.

attorney's implied authority. An attorney at law is in effect also an attorney in fact for many purposes; e.g., during the course of a trial the lawyer's decisions about many matters (whether to object; whether to call or crossexamine a witness) will bind his client, either because the lawyer has implied authority or apparent authority to do so, or just as a matter of legal custom.

A lawyer negotiating for a client also has great implied and apparent authority to bind him. But it is usually well understood that there are limits, e.g., a lawyer cannot without actual authority bind his client to a final settlement of a claim, and even in court there are some things he clearly has no implied or apparent authority to do, e.g., plead his client guilty. For that the judge will ordinarily require that the client himself enter the plea in open court (except for such things as traffic offenses).

attorney's license. The right of a person to practice law in a jurisdiction, issued upon admission to the bar. Lawyers themselves rarely refer to their license as such; the formal document evidencing admission to the bar they will call their certificate of admission, and when it is taken away the process is almost always called disbarment rather than "delicensure" or some such thing.

attorney's lien. An attorney at law ordinarily may have two different kinds of liens on his client's property. The first, sometimes called a "retaining lien" or "attorney's possesory lien," is a right to keep possession of (but not to sell) property of his client, e.g., books, documents, deeds, and not turn it over until the client pays whatever he owed the attorney. $C f$. accountant's lien; agent's lien. The second, sometimes called a "special lien" or "charging lien," is one that attaches to the proceeds of any litigation in which the attorney was involved on behalf of the client. It covers only charges made with respect to that litigation. If the proceeds are paid into court, the attorney may not reach them without judicial order. It is common practice to have recoveries, especially amounts paid in settlement of claims, made payable to the attorney, or to him and the client jointly, with the agreement being that the attorney may deduct amounts owing to him out of such proceeds.

attorney's possessory lien. See attorney's lien.

attorney's privilege [or immunity]. The right of an attorney at law to be free from criminal arrest, or service of process in a civil matter, while professionally engaged in court, or on his way there or back.

attorney's retainer. See retainer.

attorney's retaining lien. See attorney's lien.

attorney's special lien. See attorney's lien. 
attornment ( ). In feudal land law, a process, indeed a ceremony, by which a feudal tenant formally accepted or did homage, i.e., agreed to become the tenant, of a new lord who had received his estate as a reversion or a remainder. Until the early eighteenth century, when the requirement was removed by statute, attornment by all tenants was necessary to perfect the title of a reversion or remainder. In more modern real property law, the right of a new landlord to be treated as such by tenants is almost always covered by the lease, but to the extent the tenant's agreement to be tenant to the new landlord is necessary ( $c f$. assignment of contract), it will be implied by any act on the part of the tenant which treats the new owner as landlord, e.g., payment of rent to the new owner will amount to an attornment.

attractive agency. See attractive nuisance doctrine.

attractive instrumentality. See attractive nuisance doctrine.

attractive nuisance doctrine. Though the law is in process of change, it used to be the general rule that an owner of property owed no duty of care to trespassers upon it except not willfully to injure them. There then arose a common fact situation: A child trespassed upon the land of another and was injured by a dangerous condition thereon. Was the child to be left uncompensated? The earliest important American cases involved railroad turntables, i.e., devices onto which a locomotive could be driven and then turned so as to point the locomotive down a different track. These were increasingly common in the nineteenth century, were apparently very attractive to children as playthings, and were also apparently very dangerous. They also were owned by railroads, i.e., potential defendants with the wherewithal to pay judgments. Hence it was held as early as 1873 that the railroad had a duty to take some steps to protect children from injuring themselves on the turntables, even though they were, technically, trespassers. This became known as the "turntable doctrine."

In time the doctrine spread beyond railroad turntables to cover other dangerous instrumentalities on defendant's land. And it became unnecessary to prove that the attracting aspect of the land was also the injury producing one. But it was obvious that it was not feasible to protect all children from all risks they might run while trespassing on the property of others. That is, a landowner should not be made absolutely liable; he is entitled to use his land with some freedom if he is careful. Even if a warning sign were insufficient for a seven-year-old, a high enough fence might be enough, even though some seven-year-olds are able to get over anything built. In time it came to be appreciated that what had happened was that the immunity held by landowners against negligence claims by trespassers had been, in effect, abrogated when the trespassers were children (usually defined for these purposes as under twelve), and ordinary negligence rules would apply. Hence, as set forth in the Restatement (2d) of Torts $\S 339$, if the defendant (a) should expect that children will trespass; (b) should realize that some condition on his land is dangerous to them; (c) should guess that 
children will not be able to recognize the dangerousness; and (d) can at some reasonable cost eliminate or mitigate the danger to trespassing children, then the defendant must take reasonable steps to protect the children or be liable for negligence.

attribution of income. It is obviously beneficial to a taxpayer to manage to get income taxed at a lower rate than his own if he can at the same time get that income into the hands of a natural object of his concern (e.g., a child), or continue himself to have substantially all of the benefits of direct receipt (e.g., by having it paid to a spouse). Thus the draftsmen of the Internal Revenue Code, and the courts, have had to come up with ways to interfere with this process by "attributing" income to a purported transferor under many circumstances. Very roughly, under current law personal-service income will be taxable to the person who does the work no matter who actually receives it (though income from patents and trademarks will be taxable to the transferee). A gift of income-producing property will successfully transfer the taxable income to the donee as long as the gift is not revocable, or the transferred property left subject to too much donor control, or the income from it usable to pay the transferor's own expenses or obligations.

at wharf. An agreement by a seller to deliver goods to a buyer "at wharf" requires that the seller unload them from the ship onto the wharf at his expense and not the buyer's.

at will. See estate at will.

au (). See a.

auction ( ). A method for the public sale of property, with the goods going to the person making the highest bid, i.e., offering the highest price prior to the fall of the auctioneer's hammer. It is a method much favored for judicial sales because of its openness, e.g., sales of property upon which liens have been foreclosed.

Auction sales may be held under a wide variety of announced rules and customs. One key distinction, however, is between auction sales "with reserve" and "without reserve." In the former, an auctioneer is not obliged to accept any bid at all, i.e., he may withdraw the item from sale if it does not fetch a satisfactory price. In the without-reserve auction, however, once the auctioneer calls for bids, he is obliged to sell the item at whatever is bid. In both types of auction, however, a bidder may retract a bid until the auctioneer's hammer falls, but such a withdrawal does not revive any prior bids. See U.C.C. § 2-328 governing sales of personal property by auctions.

auctioneer. See auction. The auctioneer is considered the seller's agent for most purposes, but after the fall of his hammer he has been held also the agent of the buyer, at least for the purpose of binding both parties for purposes of the Statute of Frauds by his memorandum of sale.

auction [with] [without] reserve. See auction.

audience. A "hearing," but not in the sense of a judicial or administrative pro- 
ceeding, but rather in the sense of a "listening," i.e., a right granted to be heard by a person of power, e.g., a King may grant an audience to a foreign ambassador.

Audience Court. An ecclesiastical court in the judicial system of the Church of England, abolished by statute in 1963. It had the same jurisdiction as the Court of Arches, but was later established and never treated as its equal, being mostly given over to routine business like the confirmation of bishops.

audiendo et terminando ( ). "To hear and determine," a commission issued to named persons to look into a riot or insurrection, restore order, and punish the guilty. The Law French oyer and terminer is an exact translation, but refers to something else.

audit ( ). The legally most important use of the word is to describe an inspection and verification of the correctness of financial records, usually carried out by accountants, and involving various procedures and tests, e.g., taking physical inventory of goods, verifying payments with described payees, all designed to make sure that the descriptions of present financial condition and previous operations are accurate. Most large businesses employ independent auditors, i.e., accountants who are not employees of the audited business to prepare "audited financial statements," i.e., statements certified by the independent auditors as being prepared in accordance with generally accepted accounting procedure carried out on a consistent basis and, in the opinion of the auditors after examinations and tests, true and accurate.

"Audit" may also be used to mean "to ascertain," "to hear," "to adjust," "to examine"-but not very commonly.

Also, "audit" is used particularly to refer to the checking up by taxation authorities, especially the Internal Revenue Service upon the accuracy and honesty of tax returns, for the varieties of which see tax audit.

audita querela ( ). In old civil practice, a writ issued to afford a remedy to a defendant against whom judgment had been rendered, but who had new matter in defense (e.g., a release) arising, or at least raisable for the first time, after judgment. While the writ audita querela is no longer used even in England, there are procedures in all modern systems to cope with the problem of justified post-judgment relief, e.g., Fed. R. Giv. P. 60(b).

audited financial statements. See generally audit. Financial statements prepared, or at least closely reviewed, by independent auditors (almost always public accountants) as contrasted with unaudited statements, which are either (a) statements prepared by employees of the institution; or (b) statements prepared by independent auditors, but as to which there has not yet been time to apply all the tests and checking which constitutes a true audit. It is not uncommon for a business enterprise to release its audited year-end financial statements with an additional column, clearly labelled "unaudited," showing financial performance for the first three months of the new year.

audito. See ex audito. 
auditor. One who carries out an audit. The term is used to refer to auditors, both independent ones and employees, who audit the financial records of private persons and businesses, and as the title of public officers who carry out similar functions with respect to governmental finances.

In older litigation contexts, what is now called a master was often then called an auditor.

augmentation ( ). In general, any increase, expansion, or enlargement of something by the addition of more to it, e.g., "The city's purchase of the old Smith farm led to an augmentation in park land of forty acres."

For more particularized legal uses of the word, see augmented estate; Court of Augmentations.

augmented estate. A term used in the Uniform Probate Code ( $\$ 2-202)$ to describe the estate of a decedent after it has been reduced in value by certain specified expenses and claims and increased by adding back in certain transfers, and the value of property owned by a surviving spouse. The term is somewhat confusing because after such deductions and additions, the "augmented" estate may turn out to be smaller than the plain old estate.

aula regis (or regia) ( ). A court (judicial) established by William the Conqueror at his court (royal), composed of the great officers of state resident in the palace. Since the royal courts of feudal Kings travelled with the monarch, this judicial court was inconvenient, as one never knew where it might be. Magna Charta provided that common pleas (roughly, ordinarily civil actions) be tried in some "certain place." Thereupon the Court of Common Pleas (also called "Common Bench") was established at Westminster Hall (now in, then near, London), from which all the other English royal courts eventually developed.

auncel. See ansel.

aunt. Strictly, the sister of a parent, though ordinarily used to refer also to the wife of a parent's brother. For inheritance purposes in most jurisdictions, of the same degree of Kinship as an uncle, niece, or nephew.

aures ( ). A Saxon punishment for larceny, consisting of cutting off the thief's ears; apparently felt to be specially fitting for people who robbed churches.

aurum reginae ( ). Literally "queen-gold," a now obsolete revenue belonging to every English queen consort, i.e., wife of a King. It mainly took the form of a $10 \%$ surcharge on voluntary fines and fees paid the King for privileges, grants, etc.

aussi ( ). Law French (and modern French) for "also."

Austinian. An adjective formed from the name of the English legal thinker, John Austin (1790-1859), to characterize his jurisprudential position. It is principally set forth in Austin's 1832 work The Province of Jurisprudence Determined. See jurisprudence. 
Australian ballot system. The electoral system used in most U.S. elections, characterized by arrangements for secrecy in voting, and an official ballot preprinted with the names of the candidates (though provision for write-in votes is also made).

Austrian School [of Economics]. Name of a group of nineteenth century economists in Vienna who, among other important things, developed the utility theory of value. The Chicago School [of Economics] is strongly influenced by the Austrian School.

autarchy. In economics, the self-sufficiency of a nation or group of nations. The status is sought not for economic but for social or political reasons, e.g., fear of being economically colonized by other nations, or a desire not to be at the mercy of some future enemy for needed goods, for it is quite clear that any attempt at autarchy will lead to higher economic costs and loss of efficiency. See absolute advantage. So inefficient is true economic autarchy that few nations ever seek to achieve it totally, always engaging in some foreign trade.

au temps ( ). Law French for "at the time."

auter ( ). See autre.

auterfoi[t]s ( ). See autrefois.

authenticate. A process by which the authenticity of something is established, i.e., by which it is shown that a thing is in truth what someone claims it is or it purports to be. If, e.g., during a law suit about an alleged contract, a letter purportedly signed by the defendant saying "I accept your offer" is sought to be put in evidence, it will be necessary first to establish that the defendant actually wrote the letter, for only then is the "I accept" legally relevant. This can be done in various ways, e.g., by the defendant's admission that he wrote it, or by the testimony of an expert that the letter is in his handwriting. See Fed. R. Evid. 901-03.

The central tension with respect to the process of authentication is between safety and waste of time. Relatively few pieces of evidence are frauds or forgeries or even accidentally misascribed, and it would be wasteful to require complicated and expensive authentication procedures for everything offered into evidence. Hence the tendency has been to allow a piece of evidence to be sufficiently authenticated for admission by not very scientifically convincing evidence (e.g., nonexpert opinion on the genuineness of a signature), with more persuasive authentication techniques (e.g., expert testimony), being demanded only if an actual contest about authenticity is raised by the opposition. That is, in the absence of contrary evidence, not much is needed to authenticate, but if the opponent puts in evidence of inauthenticity, the proponent will obviously have to counter with better proof of his own. And some evidence, e.g., public documents under seal, is made selfauthenticating, i.e., it will be taken to be what it is labelled, without any need for any witness at all, the job of proving inauthenticity being shifted to the opponent 
It should also be noted that some documents are not even legally valid unless some formalities which render later authentication easier are met, e.g., the attesting witness requirements for the execution of valid wills.

authentication. See authenticate; certificate of authentication.

author. A person who produces a work of some sort, but in ordinary language usually referring to a writer. Under the copyright laws, however, "author" has a broader meaning; one can be the author not only of literary works, but of music, dances, pictures, sculptures, etc. See Copyright Act of 1976, 17 U.S.C. § 101 et seq., esp. § 102.

authority. Legitimate power to take some action or effect some purpose, as in "Our executive vice president has authority to speak for the firm while the president is on vacation."

Also, the source of asserted legitimate power is often referred to as authority, e.g., "By authority of 99 U.S.C. $\S 424$, I hereby close this restaurant until further notice," and "The case of Jones v. Mayer is authority for the proposition that ...."

authority by estoppal. Another (and less common) term for agency by estoppal or apparent authority.

authority coupled with an interest. See power coupled with an interest.

authorization bill. A proposed statute authorizing the expenditure of public money.

authorization card. A form signed by a worker stating that he wishes a particular union to represent him, or that he wishes there to be an election to determine if a majority of workers desire such representation. Thirty percent of workers in a bargaining unit must sign such cards before the NLRB will order an election.

authorize. To grant authority. When it is said, in a statute or otherwise, that a person is authorized to do something, it is usually implied that he is given the power, but not ordered or commanded, to do it, i.e., the authorization makes doing the act permissive, not mandatory. As usual, however, the context in which a word is embedded can sometimes overwhelm its usual meaning, and "authorized" used in a statute has sometimes been held to mean something like "ordered" or "directed," i.e., to be mandatory.

authorized capital stock. The maximum amount of capital stock that a corporation is permitted to issue under its certificate of incorporation. It may, of course, issue less.

author's advance. See advance.

authorship. See author.

autocracy ( ). A "self rule" form of government, but meaning not that everyone rules himself, but that one person himself rules everyone. It is a variety of absolutism. 
autograph. A document written in one's own handwriting; in common speech more particularly applied to a personal signature. A writing or a signature in someone else's hand is called an "allograph."

automatic. An automatic act or effect is one which will come about without any need for human action, e.g., in a legal context, an automatic continuance, i.e., one which is granted to a case which is not brought to conclusion before the end of a term and is therefore still pending when the next term begins.

Sometimes, however, "automatic" describes a result which require human action, but a different or lesser one, e.g., insurance coverage which will be [extended] for an additional period upon mere notice from the insured, without any need for a new application, giving of information, etc. And "automatic" may also describe an effect which depends upon human action but not upon human intent, e.g., the "automatic" termination of an agency relationship by the death of the principal or of a tenancy by the transfer of the fee interest (if the lease so provides).

automatic premium loan. A common provision in life insurance policies pursuant to which the company will automatically apply any cash value the policy has built up to pay an overdue premium so as to keep the policy in effect as long as the cash value lasts.

automatism. In criminal law, if a person accused of crime can establish that he had no control over the acts which would otherwise be criminal, e.g., he was sleepwalking at the time, or he struck the victim during an epileptic seizure, then he cannot be found criminally liable, even if the crime is one not requiring any mens rea.

automobile. In ordinary language, a self-propelled vehicle carrying passengers, i.e., what is more commonly called a "car." But in various contexts of legal significance, "automobile" may include trucks of various sorts, farm vehicles like tractors, even horse-drawn vehicles in a pinch. It will all depend on the sense of the context and the intention of the parties or policy of the law to be drawn therefrom, e.g., it is likely that an insurance policy covering damage to real property from "automobiles" would be held to cover a front window smashed by a runaway horse and carriage.

automobile collision insurance. See automobile insurance.

automobile comprehensive insurance. See automobile insurance.

Automobile Dealers' Day in Court Act. The official title of this Federal statute (15 U.S.C. § 1221 et seq.) is "Automobile Dealer Suits Against Manufacturers Act." It provides that automobile dealers may sue in Federal court for any damages sustained by reason of the failure of any autombile manufacturer to act in good faith in carrying out the terms of a franchise agreement, or in terminating it.

automobile guest. See guest doctrine.

automobile indemnity insurance. See automobile insurance. 
automobile insurance. A general term for a large variety of contracts insuring against risks associated with owning, operating and travelling in automobiles. There are the following principal types:

(a) "automobile liability insurance," in which the insurance company agrees to pay all amounts, up to the limits specified in the policy, which the insured shall become legally obligated to pay as damages for injuries to persons or property caused by an accident involving an automobile owned by or operated by an insured person, or for damages inflicted for which he may be otherwise responsible. Such policies ordinarily cover unowned automobiles driven by an insured, and owned ones driven by members of the insured's family, or by others with the permission of the insured. It is usually provided that there will be two maximums of coverage, one for each claim and the other for each accident; thus when one hears that the coverage is " $10,000 / 50,000$ " (which will more usually be expressed "ten-fifty") that means that the coverage is $\$ 10,000$ per claim, $\$ 50,000$ per accident. Some states require that some minimun amount of liability insurance be procured as a condition of registering and operating an automobile in the state. See also assigned risk plan. Most policies also include an "uninsured motorist clause," under which the insurance company will pay the insured for his own bodily injury losses if they were inflicted by the negligence of another motorist who (frequently in violation of state law) is not carrying liability insurance.

As part of these policies, the insurance company also agrees to undertake and pay for the insured's defense in any legal action arising out of a covered accident and, in fact, almost all automobile-tort defense counsel are retained or employed not by the titular defendants in the action, [but] by automobile insurance companies.

There was once a distinction between liability policies and automobile indemnity policies, the latter obligating the insurer to repay to the insured only those amounts which the insured actually paid to a claimant, not the amount he was found obligated to pay. This could be an important distinction if, e.g., the insured were insolvent and thus, despite a large judgment, could be made to pay very little or nothing. Under the impact of statutes and judicial opinions hostile to automobile indemnity policies, it has come to pass that substantially all policies currently written are liability policies.

(b) "automobile collision insurance," in which the insurance company agrees to pay to the owner of the automobile losses sustained by him because of damage to his automobile sustained in collisions or other accidents. These amounts will be paid without regard to fault, i.e., even if the insured was the negligent cause of the accident, the collision insurer will pay the loss. (Intentional damage inflicted on one's own automobile is, of course, not covered.)

(c) "automobile comprehensive insurance," in which the insurer agrees to pay the owner for all loss or damage to the insured automobile from essentially any cause, including theft, vandalism, fire, flood, etc. and collision. 
Contracts excluding or covering individually some of these losses are also available.

(d) "no-fault insurance," in which the insured is payed his own losses for his own personal injuries (and sometimes property damage) without regard to who was at fault or caused the losses. Under the statutes establishing nofault liability, an injured person may not sue another who negligently caused his damages unless the extent exceeds a certain amount, which varies [from] statute to statute (as do other details-see no-fault statutes).

It should also be noted that persons covered by general accident, health and hospital insurance policies may receive benefits thereunder even if their injuries were engendered by an automobile accident.

automobile liability insurance. See automobile insurance.

autonomous variable. In economics, a variable that depends at least in part upon factors not usually considered "economic," e.g., politics or morality, as when an investor refuses to buy securities issued by a business in some country with a revolting racial policy. Such variables can be spoken about in economic terms, e.g., "the utility of rectitude to the investor is greater than the difference between that investment and its closest substitute," but such efforts at translation seldom generate much more than tautology.

autonomy ( ). Self government. May be said of a person, referring to his independence of mind and freedom from the pressures of others, or of a nation, referring to its freedom from control by other nations.

autopsy ( ). See postmortem examination.

autoptic evidence ( ). Evidence of a sort which is put before the jury's "own eyes," i.e., real evidence (e.g., a bloody shirt in a murder trial) or demonstrative evidence (e.g., having the plaintiff show how stiff his arm is). The term is only rarely used today.

autoptic proference. The presentation in court of autoptic evidence.

autre ( ). Law French (and French) for "other" and "another."

autre action pendent ( ). Law French for other action pending.

autre droit ( ). Law French for "another's right," in the sense of an action taken or title held for another, e.g., a trustee has legal title for the "autre droit" of the beneficiary, and a guardian ad litem sues in the "autre droit" of a minor or incompetent.

autrefois acquit ( ). Law French for "formerly aquitted," the old plea made by one who claimed to have already been tried and acquitted of the crime with which he was presently charged. Autrefois acquit covered only some of the grounds of the modern double jeopardy defense, for the latter makes not only prior acquittal a defense, but also prior conviction (covered by the old plea of autrefois convict) and, under many circumstances, the mere prior inception of a trial of the same offense.

autrefois attaint ( ). Law French [for] "formerly attainted." This was an old 
English plea in bar to a criminal prosecution, alleging that since the defendant was under an attainder still in force, he could not be tried for another treason or felony because he was already "civilly dead." The plea was abolished in 1827.

autrefois convict ( ). Law French for "formerly convicted," a plea in bar to a subsequent indictment for the same crime. See autrefois acquit.

autre soile. See en autre soile.

autre vie ( ). Law French for "another's life," as in an estate pur autre vie, i.e., a life estate based on the life of someone other than the estate holder.

autri; autry. Alternative spellings of autre.

auxiliary ( ). Helping out; assisting; subsidiary; to be used if something else primary fails or needs help, e.g., the auxiliary engine of a sailboat, or an auxiliary chaplain, i.e., a parish priest's assistant.

In legal contexts, ancillary is usually the essentially synonymous word of choice, as in ancillary administration.

auxilium ( ). A Latin term for a feudal aid.

auxilium suriae ( ). In old English practice, an order of court issued at the request of a litigant to a person commanding him to appear and warrant something, typically a title.

available. Able to be availed of, i.e., there for the taking or using. In most legal contexts, the word impliedly modified by some term like "reasonably" or "without excessive cost and difficulty," with the key issue being how much effort and expense will have to be expended to avail oneself of whatever it is. If, e.g., a doctrine has it that one may not turn down "available work" and still qualify for unemployment compensation, the work must be reasonably fitted to the applicant's capacities, not too inconvenient to get to, etc. And an "available market" (e.g., when a disappointed buyer must cover in one) is a market which a person in his position might actually be able to get to and use with reasonable ease.

Also, in the locution "available means" used in mercantile contexts, "available" means "readily transformable into cash"; publicly traded securities negotiable promissory notes, etc. are "available means." See also avails.

available balance. In banking language, that portion of a customer's account which is not restricted by the bank and may be withdrawn at will. A check deposited by the customer but not yet collected by the bank may not be part of the customer's available balance.

avails. Proceeds of sale or other transaction; impliedly cash or some readily available substitute for cash.

aval ( ). In French law, the term for a guarantee on a bill of exchange.

avant. See en avant. 
avaria ( ). Average.

aver ( ). To state or allege, especially in a pleading.

Also, in old contexts (and pronounced), personal property, especially work animals. The connection of the word to work animals and ploughing led to rents and feudal taxes using "aver," e.g., aver land, i.e., land ploughed for the lord, and "aver penny," i.e., money paid in lieu of furnishing carriers to the King.

avera ( ). As used in Domesday Book, the value of a day's work by a ploughman, once said to be eightpence.

average. The arithemetical mean, i.e., that which results when a number of quantities are added together and the resulting sum is divided by the number of quantities, e.g., if one takes $2,7,19,30$, and 42 , adds them to get 100 , and then divides by 5 , the result, 20 , is the average of those numbers. It is a handy statistical device for determining and stating certain facts, e.g., the level of a student's performance on a series of tests, or the general level of income in a community. Like all statistical devices, however, it is not useful, and indeed may be dangerously misleading, in some circumstances. A student, e.g., who has test scores of 100,50 , and 50 , in that order, does have a 67 average, and is "passing," but is most likely in deep trouble in the course. And if there are in a community of 100 families, one with no income, 98 with $\$ 5000$ per year income, and one with $\$ 1,000,000$ per year income, the average income, just under $\$ 15,000$ per year, is a dreadfully misleading figure upon which to base social policy. Briefly, averages can be deeply distorted by the inclusion of only a few quantities widely differing from most of the others. Hence for many purposes other statistical measures should be used, as either alternates or supplements, e.g., the geometric mean (see mean), the median, the mode, etc., not to mention very much more sophisticated procedures, e.g., multiple regression analysis.

Average is also used loosely as a close synonym for "ordinary," or "not exceptional," as in, "He's just an average guy on an average day in an average town."

For the maritime law and insurance usages of "average," see general average. For the term as used in economics, see marginal analysis.

average adjuster. An employee of an insurance company specializing in adjusting maritime insurance claims. See adjust; general average.

average bond. See general average bond.

average clause. A provision in an insurance policy, especially fire insurance, providing that the policy shall apply to covered goods or buildings damaged or lost in the proportion that they bear to the total value of all the property covered.

See also general average for a different meaning in maritime law and insurance.

average daily balance. A method of calculating interest to be paid on an ac- 
count which will experience at least several charges and credits during any chosen interest period, e.g., a credit card account. Let us say that on June 1 st the account had an outstanding balance owed of $\$ 100$. On June 10th, another $\$ 100$ was charged. On June 20 th, a payment of $\$ 50$ was received. Thus on June 30 th, the total amount outstanding was $\$ 150$. To calculate the interest (say, at 1\% per month) for the month of June, the lender would see how much was outstanding at the end of each day in June, add those amounts together, and then divide by the number of days. Here $\$ 100$ was outstanding June 1-9; $\$ 200$ June 10-19; and $\$ 150$ June $20-30$. The average daily balance would be $\$ 151.67$, and the interest would thus be $\$ 1.52$ for June. Note that this is the essential equivalent of charging one-thirtieth of $1 \%$ interest on each day's outstanding balance.

average-taker. An expert specialist in adjusting general average claims, i.e., another name for average adjuster.

aver et tenir ( ). See to have and to hold.

averia ( ). Cattle, including oxen, sheep, and hogs. Since large domesticated animals were once the primary personal properties of value, "averia" could be used to mean chattel in general (which is from the same linguistic root as "cattle"). "Averum" also came to mean "property."

"Averium" (singular of averia) usually refers to the "best beast" due as a heriot (the tax due on the death of a tenant).

averia carucae ( ). Beasts of the plow. They were exempt from distraint, i.e., seizure for debt, unless one could not find enough other property to seize. The rule recognized in a loose way the salutary idea that it is by and large stupid and unnecessarily harsh to seize productive assets from a debtor before seeing if one can be made whole out of his "frills," e.g., silver plate.

averiis captis in withernam. Also called "de averiis . . . etc." A writ available to one whose cattle had been improperly distrained, i.e., seized on a claim, and then taken out of the county, where they could not be reached for recovery by a writ of replevin, e.g., by the writ "de averiis repleviandis." The writ authorized the sheriff to seize cattle belonging to the distrainor in the county and give it to him whose cattle had been unlawfully seized and driven away. The writ de averiis retornandis was similar.

averium ( ). See averia.

averment. Something averred, i.e., an allegation, especially in a pleading.

averment or information and belief. See information and belief.

averum ( ). See averia.

aviaticus ( ). See abiaticus.

Aviation Act. See Federal Aviation Act.

Aviation Administrator. The head of the Federal Aviation Agency.

Aviation Agency. See Federal Aviation Agency. 
a vinculo matrimonii. See divorce a vinculo matrimonii.

avis ( ). Law French for "advice" or "counsel."

avo. See de avo.

avocat ( ). A member of the French legal profession; very roughly equivalent to an English barrister. See also avoué.

avocatory. See letters avocatory.

avoid ( ). In legal contexts, "avoid" has at least two distinct, albeit conceptually connected, meanings. One is synonymous with the verb "to void" in the sense of nullifying, or rendering something of no force or effect, as in "the trustee in bankruptcy avoided the preferential lien." In this usage, "avoidable" is synonymous with voidable.

"Avoid," however, may also be used to mean "get out of the way of" or "prevent contact with or effect by," as in "He narrowly avoided the other car," and "By turning state's evidence, he avoided a longer sentence."

avoidable. See avoid; voidable.

avoidable consequences doctrine. A term sometimes used to describe the duty of a party injured by another's tort or breach of contract not only not to increase the amount of his injury, but to take some reasonable steps to prevent or even decrease its extent. There is no single doctrine of avoidable consequences or general rule on what steps are "reasonable steps"; but in the interstices of the law of torts, contracts, commercial transactions, trusts, and many other fields there are rulings under which a victim who made no effort or an insufficient effort to avoid or lessen damages found himself at least partially uncompensated. See also mitigation of damages.

avoidance. The term one uses to describe lawful and proper efforts totally to avoid or lessen the impact of some purported legal obligations, e.g., taxes, or the military draft. The term for unlawful or improper efforts to do the same thing is "evasion," as in, e.g., "draft evasion," "tax evasion."

avoirdupois weight ( ). The name of a system of weights, almost wholly confined to the U.S., England, and a few former colonies, the basic unit of which is the "pound," which is divided into sixteen "ounces." Most of the world uses the metric system for most ordinary weighings. Drugs are usually weighed everywhere in apothecaries' weight, and jewels and precious metals in troy weight.

avoucher ( ). Law French for the process of calling upon a warrantor of title to real property to appear at an action to defend the title against a challenge.

avoue ( ). In the French legal system, a kind of lawyer very roughly equivalent of an English solicitor. In Canada, the French language rough equivalent for the American "lawyer" or "attorney."

avow ( ). In general, to declare solemnly, as "With tears in his eyes, he avowed his innocence." 
Also, to make an "avowal" (see offer of proof) or an avowry.

avowal. See offer of proof.

avowry. A common law pleading by which the defendant in an action of replevin admits taking the property but justifies it as a proper distraint or repossession. It is a species of plea in confession and avoidance.

avowtry ( ). An obsolete word for adultery.

avulsion ( ). A sudden and perceptible addition or subtraction of land by the action of water, as by the sudden change in the course of a stream or river. When the watercourse is the boundary between lands (of private owners or states), if the shift amounts to an avulsion, then the boundary does not shift; it remains in the old bed of the watercourse. Since, however, land shifted by the less sudden process of accession (see also accretion) belongs to the new possessor, it is often very important whether the shift may be properly characterized as avulsion, and this leads to an unfortunate legal necessity occasionally to decide whether a land shift was sudden and perceptible enough. See also reliction.

avunculus ( ). A mother's brother, i.e., a maternal uncle. "Avunculus magnus" is a grandmother's brother, i.e., a great uncle.

award. To give something to a winner. It may be one who wins a legal action, or an arbitration, or an athletic event, or the contest to get a contract, etc. The decision of arbitrators or other nongovernmental dispute settlers is almost always called an "award."

award in gross. A award of alimony in gross.

See alimony.

away-going crop. Sometimes called "way-going crop." A crop sowed by a tenant of agricultural lands during his tenancy but which cannot be harvested until after the expiration thereof. Absent agreement or custom to the contrary, the away-going crop belongs to the tenant.

awm ( ). Sometimes written "aum" or "awame." A measure of wine mentioned in some old statutes, the equivalent of forty gallons.

AWOL. An acronym of "Absent (or Away) Without Official Leave," sometimes pronounced as a word (i.e., ). It refers to the military infraction of being away from one's duty station without permission and while not "on leave." "Going AWOL" in a battle zone or in the presence of enemy forces is desertion, but AWOL in peace time is a very much less serious offense.

axiom. A premise made one of the bases of a system of thought, of which independent proof is not required. The term is usually used to refer to the basic premises of logical systems, e.g., "the axioms of Euclidean geometry," but the term can also be used to describe assumed facts, as in "It is an axiom of our penal system that criminals can be deterred." $C f$. a priori.

axis. See allies. 


\section{B}

b. Second letter of the English alphabet but, unlike a, blessedly not a preposition in any known Western language.

Also, abbreviation of the formal title of judges of the English Court of Exchequer, who were called "Barons of the Exchequer." Hence, "Parke, B. delivered the opinion of the court" is a locution like "Frankfurter, $J$. delivered . . . " "C.B." refers to the Chief Baron.

Also, another frequent participant in legal hypotheticals, with a tendency toward victimization, as in "A hits B."

baby bond. Financial-community slang for bonds in denominations of $\$ 100$ or less, designed to be more easily sold to small investors.

B.A.C. Common abbreviation of "blood alcohol content," used in reporting on blood tests for drunken driving, etc.

bachelor ( ). An unmarried male of marriageable age.

Also, the holder of the first undergraduate college degree, e.g., Bachelor of Arts.

See also Knight.

back. To back means to lend one's support to another's endeavor. In legal contexts, however, two different pictures coalesce to produce the single meaning. Not only is there the ordinary-life image of one person "standing behind" another, "backing him up," but there is the specifically legal image of signing the back of a document, thereby taking some responsibilities for whatever is on the front, e.g., making an endorsement of a negotiable instrument.

Hence, to say that $\mathrm{X}$ has backed Y's note often means that he has endorsed it.

Used as an adjective, back often means past due, as in back dues, back pay, back taxes.

See also backing a warrant.

backadation. Also called "backwardation." In stock market parlance, a fee paid by a seller for the privilege of delaying the delivery of securities past their normal delivery date.

backbear. See backberend.

backbencher. This bench is a legislative seat. In England, where the cabinet and shadow cabinet sit in the front rows of Parliament, a backbencher is one low in seniority and presumably low in party influence. There is some implication that backbenchers will ordinarily go along with whatever the party leaders want, and their power to initiate legislation on their own (see private member's bill) now exists essentially only in theory. Backbenchers are, however, useful for crude heckling which their leadership might consider beneath its dignity, or too offensive if coming from the front benches. 
Backbenchers do sometimes "revolt" though, and locutions like "the government is under considerable pressure from its own backbenches to ...." are reasonably common.

Low-seniority members of the U.S. Congress are also, but only infrequently, called backbenchers.

backberend ( ). Also spelled "backberinde," "backverinde," and doubtless other ways too. The term is mostly Saxon and means "bearing on one's back," but more particularly it refers to a thief caught carrying the loot. (When he was found holding it in his hand, he was "[backberend].") Being so caught led to much more summary criminal procedures. See also with the manour.

For the specialized forest-law significance of "backberend," see stablestand.

backberinde. See backberend.

back-bond. An indemnity bond given to a surety.

back carry. English for backberend.

backdating. Putting on a document a date earlier than that of its actual execution. Backdating will not rob a negotiable instrument of its negotiability (see U.C.G. § 3-114). But if done with fraudulent intent, it may be a civil fraud or a crime, e.g., if one backdates a deed of gift so as to qualify it for more favorable tax treatment than was available at its actual date.

backdoor financing. See public debt transaction.

backdoor spending. See tax expenditure.

back dues. See back.

back-end income. A real estate term for taxable income created when previous deductions (especially for depreciation) taken with respect to a piece of real property must be "reversed" because the property is voluntarily or involuntarily disposed of before the mortgage on it is fully amortized.

back-freight. What a shipper of goods owes the carrier for bringing back goods which, through no fault of the carrier, cannot be delivered as specified by the shipper.

backing. In general, see back.

Also, the last sheet of a legal document (e.g., pleading, motion, will), usually of heavier paper; when the document is folded, the backing will form a protective cover upon which is often written information about the document inside, e.g., the names of the parties, the nature of the document, the name and address of the lawyers, etc.

backing a warrant. At one time a criminal warrant in England could only be served in the jurisdiction in which it was issued unless a justice in the other jurisdiction endorsed it, i.e., "backed" it. See generally back.

backlash. Contrary reaction to a movement, brought on by a feeling that things 
are going too far, i.e., that oneself might stand to lose something of value. The growing resistance to the civil rights movements brought on by affirmative action and similar developments is more particularly called "white backlash."

back line. The line on a building lot further back than which one cannot rightfully build, established either by zoning law or restrictive covenant.

back pay order. A judicial or administrative order that a worker is to be paid wages theretofore withheld from him. The most common back pay order is that issued by the NLRB when an employee has been discharged or denied promotion in violation of a labor law, e.g., for helping to unionize a business, but such orders are also employed in cases involving unlawful racial or sexual discrimination in employment.

backside. An English conveyancing term for that part of a dwelling-house lot Americans would call the "back yard."

back-to-back lease. In real estate talk, what a lessee has gotten when a lessor, anxious to land him, takes over the remainder of his lease elsewhere.

backverinde. See backberend.

backwardation. See backadation.

back wards. Mental hospital wards housing more severely disturbed patients. They need not, of course, be architecturally "in the back" at all; the locution calls attention rather to their position out of the casual sight of visitors.

\section{Bacon-Davis Act. See Davis-Bacon Act.}

baculus ( ). The stick or wand delivered from vendor to purchaser in effecting livery of seisin.

baculus nuntiatorius ( ). The baculus, i.e., rod or staff, set up on the land of the defendant in a real action to notify him of its commencement.

bad. The opposite of good, i.e., a general pejorative evincing disapproval of whatever is so labelled, e.g., bad debt, bad moral character. In modern slang, however, bad can be used to mean good in the sense of powerful and dangerous, as in "bad machine" (for a monstrous motorcycle) or (used of a person) "He's real bad."

bad character. See character evidence.

bad check. A check which is dishonored, i.e., not paid when presented because, e.g., there are no or insufficient funds in the account against which it was drawn, or there is no such account. Knowingly writing a bad check is a crime almost everywhere; in some places it is criminal even without proof of knowledge or intention, but such statutes are of doubtful constitutionality.

bad debt. A debt which cannot be collected. Under some circumstances (for which see business bad debt), the amount thereof may be deducted in calculating the disappointed creditor's income tax.

bad debt reserve. See reserve for bad debts. 
bad faith. See good faith.

badge. A symbolic representation of office or status, usually a physical object worn on the person, e.g., a police badge (which, because of its usual shape, most police refer to as a "shield").

badger. In older legal contexts, the name given to one who bought goods in one market and carried them to another to sell at a profit. The social utility of the process was recognized by exempting badgers from liability for engrossing.

badger game. A crude but common congame. In the classic play, the victim is lured to an isolated place by promises of sexual activity, either professional or gratuitious, where at a compromising moment he is met by a menacing ally of the enticer who relieves him of all his valuables by threat or force. Often the ally pretends to be the enraged husband or boyfriend of the woman. The game can also be played with other lures, e.g., illicit drugs. $C f$. Murphy game.

badges of fraud. In the law of fraudulent conveyances, the term for various indicia that raise a suspicion that the transaction in question was not on the up and up, but was instead made to delay or defeat creditors. Among the many such badges are seller insolvency, transaction secrecy, grossly inadequate or fictitious consideration, family relationship between the parties, transfer of all assets in one transaction, etc. No one or more of these indicia necessarily establishes "fraud," even in the special sense that term has in fraudulent-conveyance law, but each is cause for inquiry.

badges of servitude. A term in constitutional law for the vestiges of slavery, e.g., refusals to sell or lease property to Black persons, which the Congress may constitutionally legislate against under the thirteenth amendment. See also Civil Rights Acts; Jones v. Alfred H. Mayer Co.

bad moral character. See good moral character.

bad weather. When used in a charter party, the term refers to weather not reasonably fit for the process of loading a ship given the available equipment, e.g., heavy rain might be "bad weather" for loading from lighters but not for loading from dockside.

baga ( ). A bag or purse. See also petty bag office.

baggage lien. A lien which a carrier has on the baggage of a traveller to secure the payment of travel fees. In an age of prepaid travel, it is of minimal significance.

bag man. Political and criminal slang for a go-between in illicit deals, e.g., judicial or administrative corruption, the "bag" being the container for the pay-off money. In a recent celebrated case it was held libelous for one political figure to call another a "bag woman."

bail. In modern law the term refers almost exclusively to a procedure in criminal law whereby an undertaking is made that a person accused of crime 
will voluntarily submit himself to the jurisdiction of the court (and thus need not be kept in jail pending trial), in default of which a sum of money in an amount judicially predetermined will be forfeited to the court. It may be the criminal defendant himself who offers the undertaking, securing it with a pledge of money or property, but it is most often made by a person in the business of making them, a "bailbondsman," (also called "bondsman") who receives a fee from the defendant in exchange for his furnishing security to the court for the defendant's appearance. (In some instance the bailbondsman will go after a fleeing defendant and bring him back to custody so as to avoid having to forfeit the money he has promised the court.) In modern contexts "bail" refers to deposited money or to the undertaking; in older texts it refers more frequently to the person who undertakes. See also mainprise.

In U.S. criminal law, bail is supposed to be set in an amount no greater than that reasonably necessary to assure the defendant's appearance, and this requirement is given constitutional warrant by the Seventh Amendment which (following the English Bill of Rights of 1688) begins "Excessive bail shall not be required . . . ." The bail process, however, is increasingly controversial. First, it tends to disadvantage poor criminal defendants; even relatively modest bail will be more than such a person possesses, and he often will be unable to come up with the fee or security a bailbondsman will require for his services. Hence, poor defendants will tend more frequently to be incarcerated before trial than richer ones and, it is argued, therefore less able to assist in preparing their defenses.

Second, while bail is supposed to be set only so as to assure appearance, there is a great temptation to manipulate it to serve other purposes, notably to keep dangerous people off the street while their trials are being readied. If a person is charged with a serious crime of violence, and if it is thought likely that he did it, it is hard for a judge to let him roam free, especially if there is some suspicion that he might prepare too well for his trial, e.g., by threatening or killing potential witnesses. Prohibitively high bail may sometimes be justified in such cases without violating the theory of bail by arguing that a most-likely-guilty violent criminal who faces a long sentence is very likely to flee if given any chance at all. Sometimes, however, there is little danger of fight, even if the defendant is dangerous; but when a judge properly releases him and while on bail he commits some enormity, the releasing judge is subjected to harsh criticism.

It should be noted that this criminal-law bail is but the last modern vestige of a very old and once almost totally pervasive system of assuring judicial power. In old law, both civil and criminal, jurisdiction over a party was often acquired by arresting him and locking him up. The technique of having either property or the undertakings of others substituted for the person developed early to soften the rigors of jurisdiction by incarceration. The waning of arrest on civil process has almost ended the use of bail in civil cases; but it should be noted that when property is seized in civil cases, a 
bond is often put up to release the property, and this is roughly equivalent to "bail" for a thing.

bailable. The term has two almost opposite meanings. It may refer to a situation in which bail may be permitted, as in "bailable offense" and "bailable process," i.e., one in which the defendant may be released on bail (which in the U.S. includes all offenses except perhaps forcible rape and capital crimes, and even those categorical exclusions are of uncertain constitutionality). But in older contexts "bailable action" referred to a legal proceeding where bail was required, i.e., unless the defendant supplied bail he must stay incarcerated.

bailable action. See bailable.

bailable process. See bailable.

bail above. See bail below.

bail below. In civil actions in which the defendant might be arrested, there were two key moments at which bail might have to be supplied. When the writ (capias ad respondendum) was issued and the defendant arrested thereon, bail might be supplied to free him on an undertaking that he would appear in court on the return day of the writ. This was known as "bail below" or "bail to the sheriff."

"Bail above" (also "bail to the action," "bail special," or "special bail") referred to bail furnished on that return clay, the undertaking being that the surety would, in the event of a judgment against the defendant, either pay it or surrender the defendant into custody.

bail bond. The bond, i.e., formal undertaking to pay a sum of money, issued by a defendant or another on his behalf, so that the defendant might be admitted to bail. Very frequently the bail bond is accompanied by a pledge of money or property (or a lien thereon) deposited to secure the obligation; this is sometimes called a "cash bail bond," or "secured bail bond" to distinguish it from a mere unsecured undertaking to pay upon the defendant's nonappearance. When this unsecured bond is executed by the defendant alone, it begins to approach a release on own recognizance.

\section{bailbondsman. See bail; bondsman.}

bail common. Also called "common bail." A now superceded fictitious English procedure serving no purpose other than formally to enter the defendant's appearance, having the form of special bail (see bail below) but with imaginary persons, e.g., John Doe and Richard Roe, for sureties.

bail court. A now abolished English court, auxiliary to King's (or Queen's) Bench, at which points of pleading and practice used to be argued. It existed between 1830 and 1854 .

bail de la seisine ( ). A Law French equivalent for livery of seisin.

bailee. See bailment.

bailee's lien. The (usually statutory) right of a bailee (see bailment) to retain 
possession of bailed goods until paid what he is owed in connection with the bailment.

\section{bailee for hire. See bailment}

bailiff ( ). In any legal system there will be a number of official odd jobs to be preformed in connection with adjudication which cannot be performed by judges, notably serving legal process (including arrest if that is called for), and executing judgments. These functions are constant, but neither the name given to such officials, not their placement in the politicaladministative structure of the state, is foreordained. Persons wielding civil and criminal state power with particular reference to adjudication have been called, in addition to bailiff, reeve (in Saxon times, and in ecclesiastical courts), sheriff, clerk, marshall, deputy, and more. Sometimes they and their deputies have been the representatives of one level of government within the territory of another level, e.g., the feudal sheriff (who employed bailiffs to assist him) was the King's chief agent in the shire or county of a great feudal lord (the very word "sheriff" coming from "shire reeve"). And at one time any royal officer, but especially the King's chief officer in a hundred, was called a bailiff.

At other times and places these officials have been technically employees of the judiciary, e.g., the mashalls in modern federal courts, and the bailiffs of modern federal judges.

In addition, the word bailiff ("steward" is essentially a synonym) has been used to describe the general manager of a large landed estate, i.e., the chief administrative officer of the private owner of property who ordinarily had almost plenary power to act on behalf of his employer.

bailiff errant. An old term for a bailiff's deputy, especially one whose job it was to go about serving legal process.

bailiffs of franchises. See bailiffs of liberties.

bailiffs of hundreds. Persons appointed by English sheriffs to carry out the role of bailiff within that subdivision of the sheriff's jurisdiction called the hundred.

bailiffs of liberties. In feudal England there were some places in which, because of granted royal franchises to have a monopoly over local justice, or liberties from royal justice, the King's writs could not be executed by the King's sheriffs. In such privileged jurisdictions, officers other than the sheriff's deputies had to be appointed to carry out the bailiff roles.

bailiffs of manors. Bailiffs appointed by feudal lords to act within their lands.

bail in error. A kind of bail provided by one taking an appeal and wanting to stay execution of the judgment below, undertaking to pay the judgment below if affirmed, and other costs and damages of the appeal. A more modern term is bond on appeal.

bailivia ( ). Another term for bailiwick. 
bailiwick ( ). An old mixed Saxon-French term for the jurisdiction of a bailiff or sheriff or indeed, of anyone else who had a jurisdiction, e.g., the holder of a franchise.

bailment. What in law is called a bailment is in life a very common happening: Jones owns or at least has a right to possession of some item of personal property. He gives it into the physical possession of Smith. There thus arises a split between Jones's title or right and Smith's actual physical possession. Jones did not transfer the thing to Smith as a gift, or in payment of a debt, or sell it or rent it to Smith, nor did Smith find it, or steal it, or otherwise improperly come into possession of it. It is still "Jones's thing," but Smith rightfully has it. To put the matter in legal terms, Jones, the "bailor," has made a "bailment" of the thing to the "bailee," Smith.

Obviously, a law of bailments must be developed to cope with such things as what happens when the bailee won't give the thing back, or gives it to someone other than the bailor, or harms or destroys the thing, or it is harmed or destroyed in his possession (with or without his negligence), or the bailor won't carry out some promise made in connection with the bailment, and so on. Such a wide variety of practical problems will certainly need some set of legal answers.

The most general legal answer is, not suprisingly, that whatever the bailor and bailee agree upon is all right with the law, i.e., the parties can write their own contract of bailment. But what happens if the parties do not expressly or by implication address a particular question, e.g., responsibility for the destruction of the bailed goods, or misdelivery to a third party? The law has responded with answers, the general tendancy being (a) to treat the bailee as having less absolute and total responsibility than a trustee or other fiduciary would have; (b) strictly to scrutinize form contacts by which bailees seek to limit their responsibilities, especially with respect to their own negligence, and most especially if they are common carriers, innkeepers, or public warehousemen, or run public parking lots; and (c) to impose upon a bailee who is being paid or otherwise profiting from the bailment (called "bailment for hire," "lucrative bailment," "bailment for compensation," or "bailment for mutual benefit") greater duties than upon a "gratuitous bailee," i.e., one who is just accommodating the bailor by holding his things. In this connection it should be noted that a bailee who gets possession in order to do compensated work on the bailed item, e.g., an auto mechanic, is considered a bailee for hire or compensation.

bailment for compensation. See bailment.

bailment for hire. See bailment.

bailment for mutual benefit. See bailment.

bailment for sale. See consignment sale.

bailment lease. A commercial device whereby a person is put into possession of some item of personal property (e.g., and especially an automobile) in ex- 
change for periodic payments, with the right to acquire title either automatically after some number of payments have been made or upon payment of some additional amount. It differs from, e.g., a conditional sale in that the bailee does not affirmatively promise ever to pay the sum necessary to acquire title.

bail money. Formally, cash deposited as bail as contrasted with a bond or undertaking, but in colloquial legal talk it encompasses all forms of bail, as in "Get that bondsman down here with the bail money, and I mean now."

\section{bailor. See bailment.}

bailout. Tax slang for any technique for getting profits out of a taxable entity, e.g., a corporation, in such a way that they will be taxed to the owners at a favorable rate, e.g., at capital-gains rather than ordinary-income rates. See, e.g., preferred stock bailout.

The term is also used for the practice of acquiring an entity so as to acquire its tax advantages, e.g., its accumulated losses to apply to the acquiring company's gains so as to reduce taxes. The practice is regulated by I.R.C. $§ 269$.

\section{bailout stock. See preferred stock bailout.}

bail piece. The formal document evincing the undertaking of bail, formally for "bail above" (for which see bail below).

bail to the action. See bail below.

bail to the sheriff. See bail below.

Baine's Act. English statutes of 1848 and 1849, called after their strongest parliamentary advocate but formally the "Criminal Procedure Act" and the "Quarter Sessions Act" which, among other things, made accessories before the fact (see accessory) and principals equally liable for crimes.

bair-man. In older English practice, a poor insolvent debtor who swore he was "bare," specifically that he was not worth more than five shillings fivepence.

bait and switch. A species of deceptive selling in which a retailer advertises attractive goods at splendid prices as bait in order to lure customers to his store, and then tries to get them switched to more profitable items, usually by having his sales force disparage the advertised items. The artifice is a powerful one because the customer has already expended the time and effort to come to the store, and nerved himself to buy, and that momentum can easily be taken advantage of by a trained salesman. While bait and switch is an unlawful deceptive trade practice in most jurisdictions, it is difficult to enfore, at least if the retailer has taken the precaution of actually having for sale a reasonable number of the advertised items. For it is not improper to talk a customer into buying a more expensive item than he originally wanted to buy, and it is even a service to him if the more expen- 
sive item is better, e.g., longer lasting by an amount in excess of its additional cost.

Bakke case. A key case testing the constitutionally permissible scope of affirmative action. The case (Regents of the University of California v. Bakke, 438 U.S. 265 (1978)), seems (there are several opinions, aggregating 150 pages, and none of them may safely be said to be "the court's") to have held that while state educational institutions may not (unless there is a finding of previous racial discrimination) admit applicants on the basis of racial quotas, they may take race into account as a positive factor in order to faciliate the admission of students from disadvantaged minority groups. See also Weber case.

balance. When something is in balance with something else, it is equal to it. $A$ balance, however, is what is left over after a prior balancing of two quantities, as in "Deposits aggregated $\$ 10,000$, withdrawals $\$ 8,000$, leaving a balance of $\$ 2,000$." See also entries beginning with or containing the word, e.g., balance sheet, credit balance.

For the term's important conceptual legal use, see balancing; scales of justice.

balanced budget. The equalization of governmental revenues and expenditures over a period of time, usually one fiscal year. It is strongly argued that the practice fosters governmental prudence and responsibility, preventing the easy sloughing off into a later period (to be faced by later politicians) of the political costs of cutting back on government programs or raising taxes to fund current ones. It is also argued, however, that balanced budgets exacerbate both inflations and recessions, i.e., that budget balancing is often bad macroeconomic policy. See also Keynesianism.

balance due. The amount still owing on a debt or obligation after some payment or partial performance has been made.

balance of convenience. A term sometimes used in opinions explaining why a requested injunction was or was not granted, referring to the ratio between the hardship to the defendant of granting the relief and the hardship to the plaintiff if it is not granted. Another term with a roughly equivalent message is "balance of equities," but there the implication is that one side has more ethically going for it than the other.

balance of equities. See balance of convenience.

balance of payments. An important term in the economics of international trade, referring to the difference between all payments made from a country into all other countries, and all of their payments flowing back. If outflow exceeds inflow, a country has a "negative balance of payments"; if inflow exceeds outflow, the balance is "positive." The economic effect of a negative or positive balance is complex and not thoroughly understood, though it is generally thought "a bad thing" to have a large persistent positive or (especially) negative balance. 
If capital transactions, payments for services, and gold shipments are excluded from the calculation, it is called the "balance of trade."

balance of power. In international diplomacy, a term for a situation in which force available to nations is so distributed that no single nation or discrete alliance is in a position to impose its will on any other nation or group. It is never thoroughly achieved (e.g., one now knows that Hungary is not the beneficiary of any balance of power if the Soviet Union feels threatened, and it would be very unwise for Cuba to try to mount a large number of atomic missiles pointing at the U.S.), but at present there seems to be at least a temporary balance between the U.S. and Soviet blocks with respect to direct aggression against each other's closest and nearest allies.

balance of trade. See balance of payments.

balance sheet. One of the principal formats used by accountants for reporting the financial condition of a business, the balance sheet presents data on that condition as of a particular date, usually the close of the entity's fiscal year. It ordinarily displays, in a column on the left of the page, the value of that date of all assets, and in a column on the right all liabilities, together with the difference between assets and liabilities which is called "surplus" or "stockholders equity" or some such label for the net worth of the company.

Almost any number of categories of assets and liabilities may be used, depending on how much fine detail one desires to show, but it is almost always the case that, among the assets, cash and similar assets are shown separately from less liquid assets like plant and buildings, and that current (due-within-one-year) liabilities are separated from long term obligations.

Many difficult decisions go into the preparation of an adequate balance sheet, especially about valuation, e.g., should one continue to show land at cost even though its fair value is now vastly higher?; how does one value as a liability a one-billion dollar lawsuit brought by what one's lawyer considers a crank? Footnotes often are provided to give more detail about balance sheet entries, but even using them liberally, perfect disclosure can never be achieved. There are, however, detailed rules and standards followed by accountants in preparing these reports. See generally accepted accounting principles.

See also profit and loss statement.

balance sheet test. See insolvency.

balancing. The metaphoric term generally used in the law to describe an exceedingly important conceptual operation. In almost all conflicts, especially those that make their way into a legal system, there is something to be said in favor of two or more outcomes. Whatever result is chosen, someone will be advantaged and someone will be disadvantaged; some policy will be promoted at the expense of some other. Hence it is often said that a "balancing operation" must be undertaken, with the "correct" decision seen as the one yielding the greatest net benefit.

That some such process must be a part of any practical legal system is 
undeniable. But that should not blind us to the extreme danger of too facile a use of "balancing" in a system of justice. The metaphor is drawn from the process of weighing, more particularly from weighing in balance pans. But actual weighing is only possible because all matter is equally affected by the force of gravity, i.e., with respect to physical weight there are no relevant qualitative differences between things being weighed against each other: There is a universally applicable unit of measurement in terms of which everything can be described and arranged on a smooth scale vis-a-vis everything else.

But that is not necessarily the case with respect to what is subject to metaphorical weighing in a legal system. Consider, for just one instance, the status of certain rights under the U.S. Constitution, e.g., the Fifth Amendment right not to be a witness against oneself. The constitutional decision seems clearly to have ruled out as improper one kind of weighing, for no mere statute can eliminate the right in question, i.e., it takes more than a preponderance (another weighing metaphor) of votes to outweigh the right.

Similarly, judges may not "weigh" the effects of any individual exercise of the right to remain silent. It is clearly improper for a judge to say, "I have weighed this right against its mischievous effect in this case and have decided, on balance, that the defendant must testify." This kind of right, within the metaphorical universe of "weighing," must be seen in our present legal system to be, if not of quite infinite "weight," then very, very "heavy."

All this is not to say that metaphorical, conceptual weighing is a "mistake" of legal reasoning. There are even whole philosophical systems which suggest that everything can be measured on one single scale. See utilitarianism; economic analysis of law. It is to say, however, that not all legal questions are thoroughly amenable to the same process by which lumps of matter are compared for gravitational attraction.

And see scales of justice for a further problem with the use in law of any weighing metaphor.

balancing of interests. May be generally used to describe, with respect to interests, the process discussed under balancing.

But the term is also used more particularly to refer to the interests of state and federal governments with respect to state legislation affecting commerce, with the general rubric being that if the state has a clear interest with respect to regulating some aspect of intrastate commerce, even if the state regulation also affects interstate commerce it will be upheld unless Congress has shown an intent to preempt the field.

balancing test. A term from U.S. constitutional law describing a test of constitutionality to be applied when two rights under the Constitution, or a citizen's right and an apparently necessary governmental power, clash: The rights or the right and power must be balanced. On some questionable aspects of this process, see balancing. 
Balfour Declaration. An official statement of the British government in the form of the letter dated November 2, 1917 from the then Foreign Secretary, A.J. Balfour, to Lord Rothschid, viewing "with favour the establishment in Palestine of a National Home for the Jewish People." But the same letter contained a proviso that nothing be done to "prejudice the civil and religious rights of existing non-Jewish communities in Palestine." The British turned out to be no better at coping with that contradiction than, even after three or four wars, the Palestinian Arabs and Jews.

baliva ( ). Also spelled "balliva."

Law Latin for bailiwick.

balivo (or ballivo) amorendo ( ). An old writ brought to remove a bailiff because he fell short of the statutory property qualifications for the job.

ballastage ( ). A fee or toll paid for the privilege of taking on board soil from a port bottom to serve as ballast for the ship.

ballistics. Most broadly, the science having to do with all aspects of the firing and flight of explosively propelled projectile, e.g., cannon balls, shells and bullets, and the devices that fire them. In law, the portion of the science most in evidence is identification of bullets with the particular guns which fire them. This, naturally, is an important element in the proof of most shooting crimes, e.g., if a bullet was found in the victim's head, and it can be shown to have been fired from a gun found in the defendant's possession, proof of an important element of the prosecution's case is strongly advanced.

balloon loan [or mortgage or note]. A loan the repayment schedule of which calls for a last payment substantially larger than any prior payment, e.g., a loan of $\$ 100,000$ to be repaid in twelve monthly installments, the first eleven of $\$ 5,000$ each and the twelfth of $\$ 45,000$. In some instances, the earlier installments pay off only the interest as it accrues, with the last payment covering all of the principal.

Statutes regulating consumer lending sometimes ban, or at least mandate clear disclosure of, balloon loans, because many consumers, faced with the last whopping payment, must either default or accept a refinancing loan to pay off the balloon.

See also amortize.

ballot. The physical medium for a vote, e.g., little black and white balls for voting on proposed new club members, or a paper listing the candidates for political office with a place to mark one's preference. In this broad sense, a voting machine is also a ballot, but it would be considered odd so to refer to one.

As usual, the concrete embodiment of an abstract power comes to stand for it in ordinary language. Hence "ballot" also means "power to vote," as in "Give women the ballot." 
ban. A prohibition, as in "The ordinance put a ban on new fast food shops." See also bann.

banc ( ). Law French for "bench," i.e., where judges sit. Also by a process of personification, used to refer to a panel of judges.

banci narratores ( ). An old term for those persons with the right to appear and argue orally in court, especially the Court of Common Pleas.

banc la reine ( ). Law French for "Queen's Bench."

See Court of King's Bench.

banc le roi ( ). Law French for the Court of King's Bench.

banco ( ). Another spelling of banc, e.g., "in banco" is another form of en banc.

bancus reginae ( ). Queen's bench.

See Court of King's Bench.

bancus regis ( ). See Court of King's Bench.

bancus superior ( ). "The upper bench," what the Court of King's Bench was called between the execution of Charles I (1649) and the restoration of Charles II (1660), i.e., at a time when calling anything "King's" was a serious political error.

band. Into the seventeenth century, an alternate spelling and pronunciation for bond.

b \& d. See bondage.

bandit. An armed robber and killer; an outlaw.

A slot machine is sometimes called a "one-armed bandit."

bandwagon effect. A term used in social psychology, sociology and political science (and in everyday speech) to describe the phenomenon whereby more and more people espouse a position or join a cause as it becomes dominant. That such a phenomenon exists seems beyond doubt; its conditions and extensiveness are far less clear. A good deal of political and commercial artistry goes into the construction of purported bandwagons upon which more and more people will seek to ride. $C f$. bubble; ponzi.

bane. A very bad guy; a source of trouble. From the same linguistic root as bandit, but now usually used more softly, as in "My crazy boss is the bane of my existence."

baneret. Also spelled "banneret." See Knight.

bani ( ). Another word for deodand.

banishment. A punishment for crime (or for backing the wrong side in a political upheaval) in which a citizen is sent away from his native land, for a time or forever. See also transportation. It is not a permissible punishment in the U.S. But $c f$. deportation, i.e., the enforced return of a non-citizen 
from the U.S. to his country of origin upon proof of fraudulent entry or subsequent crime.

bank. A financial institution the central economic function of which is to be the efficient marketplace where those with money to lend can be matched with those wanting to borrow it. The basic technique of all banks is to accept deposits of money (which are actually loans from the depositors to the bank-see bank deposit) and loan it out to borrowers, with the profit coming from the difference between what is paid the depositors and what is charged the borrowers. The "payment" to depositors often includes certain conveniences the bank supplies, e.g., safekeeping for their money, the power to write checks against deposited funds, etc. This last function also makes banks facilitators for the transfer of money in exchange for goods and services, i.e., the banks are linked in a system for transacting with each other and with and among their respective customers.

The borrowing, lending, and exchange facilitating activities of banks take many forms, including lending on the security of real and personal property (mortgages), the purchase of bills of exchange, promissory notes and other kinds of commercial paper, the supply of unsecured loans to businesses, etc. Some banks do many of these things; some are restricted to only a few. For further details see entries for particular kinds of banks, e.g., commercial bank; savings and loan association; savings bank.

bankable. An adjective which means that an obligation is of such quality that a bank would be willing, in the ordinary course of its business, to purchase it or lend money against it as security. Hence, a "bankable note," is one either made or endorsed by an obligor with a good credit rating, and a "bankable contract" is one in which a financially secure obligor promises, subject to almost no contingencies, to make stipulated payments.

bank acceptance. See banker's acceptance.

bank account. The account of the customer of a bank, i.e., the statement of who owes what to whom. Cf. U.C.C. § 4-104(1)(a). But the term is used colloquially to mean the amount of money one has "in the bank," as in "I've got a bank account with $\$ 11,000$ in it." See also bank deposit.

bank bill. See bank note.

bank book. A booklet, left in the possession of a bank customer, in which transactions pertaining to a bank account in a savings bank or similar institution are recorded.

Also called "passbook."

bank cashier. See cashier.

bank check. The term may refer to either (a) an ordinary check drawn by a depositor on a bank; (b) a bank draft; or (c) a cashier's check. For this reason, the term should be avoided whenever precision is important.

bank circulation. See bank note. 
bank collections. The process by which banks pass around to each other negotiable instruments, especially checks, so as to effect payments, loans, and repayments-among themselves; between themselves and their customers; and among their customers. Article 4 of the U.C.C. is devoted wholly to "Bank Deposits and Collections."

bank commissioner. The title commonly given to the head of the administrative agency regulating banks in a state.

Bank Conservation Act. A federal statute (12 U.S.C. § 204 et seq.) providing for the appointment of a conservator to protect the assets of a failing national bank while an attempt is made to rescue and reopen it.

bank conservator. The official appointed under the Bank Conservation Act to preserve the assets of the failing bank.

bank credit. A right granted by a bank to a customer enabling him to borrow up to a certain stipulated limit without individually negotiating each loan. See also overdraft.

bank credit card. See credit card.

bank deposit. A loan by a person to a bank, ordinarily in exchange for stipulated interest and a promise to repay the loan either on demand, or at some agreed time after demand. Deposits in commercial banks, "checking accounts," are demand deposits and until recently did not bear any interest, but one could write orders to the bank ("checks") to pay one's creditors. Also until recently, deposits in savings banks paid interest but (at least formally) the bank could delay repayment for some period, and did not permit checks to be written against their accounts. Now and increasingly both kinds of banks pay interest and permit the functional equivalent of check writing and both also issue certificates which, to receive the promised interest rate, one must hold for a stipulated period, e.g., six months. Given this growing functional convergence, it is unlikely that the formal and institutional distinction between commercial and savings banks can long survive.

bank note. A promissory note issued to bearer, and meant to pass freely as currency. Once many banks, state and federal, were authorized to issue such bank notes; they were called "banks of circulation" or "banks of issue." At the present time, the only banks authorized to issue bank notes as currency are the federal reserve banks, i.e., instrumentalities of the federal government.

bank discount. See loan discount.

bank draft. A check drawn by a bank on another bank in which it maintains an account. Since a bank is likely to have a pretty good bank account, its check is more acceptable to a creditor than his debtor's and thus many transactions call for payment by bank draft or by certified check or cashier's check. In addition, it is often stipulated in transactions involving large sums that payment be made in funds in the payee's locality so as to preclude his having to wait several days for the check to clear (during which 
period the money is earning no one anything). Hence if a contract between a California buyer and a New York seller calls for payment in "New York funds," the buyer, to comply, may have his California bank draw a check on its account in a New York bank.

banker. An officer or reasonably highly placed employee of a bank.

Also, in gambling talk, the person who runs a game of chance (as contrasted with merely participating) and, in some contexts, the stakeholder in a betting situation.

bankerout. Old form of bankrupt.

banker's acceptance. A bill of exchange drawn upon and accepted by a bank.

banker's blanket bond. A fidelity bond protecting a bank from losses through employee dishonesty, and usually conjoined with coverage against loss from robbery, burglary, forgery, and mysterious disappearance.

banker's lien. A lien, ordinarily statutory, which a bank, absent agreement to the contrary, has on all customer assets in its possession, to secure payment of all obligations owed by the customer to the bank.

It should be also noted that with respect to ordinary bank deposits, the bank is a debtor of the customer, and has the usual power to set off against debts owed to it by a creditor the debts it owes to him, i.e., to charge the customer's bank account with whatever the customer owes the bank.

banker's note. A bank note issued by a private, unincorporated bank or banker.

bank examiner. The common generic title of those federal and state government employees whose job it is to examine the books and accounts of banks to determine their safety, efficiency, and solvency.

Bank for Cooperatives. A central bank and twelve district banks set up under the Farm Credit Act of 1933 to provide credit for farmers' cooperatives.

bank holding company. A corporation controlling one or more commercial banks, or a commercial bank and some other enterprise. There are primarily two varieties, correlating with two strategies for evading regulation. The first type was set up to get out from under restrictions on branch banks; if "a bank" couldn't have branches, then corporations were set up to control several banks, thus getting the economies and competitive advantages the statutes sought to prevent. These are traditionally called "multibank holding companies" or MBHCs.

The second variety, usually called "one-bank holding companies" or OBHCs, arose to allow banks to take part in allied financial businesses sought to be barred to them by other statutes. If "a bank" could not, e.g., also run a finance company, then a holding company might be formed which owned a bank and a finance company-and maybe a credit card company, an insurance brokerage firm, etc.

At present the activities of both MBHCs and OBHCs are regulated in detail under the Bank Holding Company Act. 
Bank Holding Company Act. A federal statute (12 U.S.C. § 1841 et seq.) regulating the permissible ownership of voting securities of more than one bank, and (as recently amended) to regulate the activities of bank holding companies, particularly to prevent the easy creation of large bankingindustrial combinations.

bank holiday. Any weekday upon which banks are not open for business, which generally coincide with ordinary holidays, e.g., Christmas, New Years, Thanksgiving.

The term also refers to the week in March, 1933 during which all banks in the federal system were closed by presidential proclamation to inhibit runs on a bank and give some time for the banking system to make plans to cope with the financial panic then occurring.

banking. See bank. $C f$. investment banking.

Banking Act. Any statute regulating the business of banks. Almost all states have one, and all of 12 U.S.C. (entitled "Banks and Banking") is devoted to such regulation at the federal level.

banking day. Defined in U.C.C. § 4-104(1)(c) as ". . . that part of any day on which a bank is open to the public for carrying on substantially all of its banking functions."

banking game. A gambling game, more particularly one in which there is a banker or a "house," i.e., a participant who runs the game and receives for his role a percentage in his favor in the design of the game. In roulette, for instance, one or two numbers are reserved "for the house"; if the ball lands there, everyone playing anything other than the specific house number (e.g., playing red or black, odd or even) loses to the house. Similar edges are given to the banker in dice, faro, slot machines, "21"-indeed in any game of chance one can find in a gambling hall or casino. Over the long run, the house will always win (hence the lavish entertainment supplied by the operators in Las Vegas, Reno, Monte Carlo, etc.), but any particular player can still win, indeed may even "break the bank," i.e., win so handsomely that the bank runs out of money.

banking hours. Usually includes not only the hours a bank is open to the public (see banking day), but all those during which the bank carries on its functions before or after closing its doors to the public. So a note to be presented "during banking hours" is usually correctly presented if it arrives after the public doors close at three but before everyone goes home at five.

bank lien. See banker's lien.

Bank Merger Act. A federal statute (12 U.S.C. § 1828 et seq.) regulating the acquisition of banks by other banks and holding companies. See also Bank Holding Company Act.

bank money order. See money order.

bank night. A scheme to increase attendance at an event, widely used in movie 
theaters during the 1930's, in which persons who register by signing a book are assigned numbers, a drawing of which is made at a performance. If the holder of the winning number appears shortly after his number is drawn, he gets a prize; otherwise other numbers are drawn until the prize is claimed.

Bank night was always set up so that it was technically not necessary for anyone to pay any admission either to get his number or claim his prize; the registration book was in the outer lobby, and the winning number was announced both in and outside the theater. In fact, it was much more convenient to attend the performance, but the fact that it wasn't necessary to do so made it possible to argue that the gimmick was not an unlawful lottery, for the players were not obliged to pay anything for their chance. This argument at least sometimes succeeded.

Many modern "contests" take advantage of the same theory in differentiating themselves from lotteries. One may, e.g., enter lotteries connected to magazine-promotion schemes even if one checks the "don't enter a subscription" box, and if one doesn't want to buy any cigarettes before entering the "Tareyton Million Dollar Giveaway," one can enclose, in lieu of the end panels of two packs, the word "Tareyton" neatly printed on a piece of paper. Judging from the popularity of these contests today, the no-lottery legal theory is widely accepted by the authorities. And the contests work because deep down most entrants suspect (most likely incorrectly) that no one who doesn't buy the magazine or cigarettes is going to come up a big winner.

bank of discount. See discount.

Bank of England. A bank privately chartered in 1694, now publicly owned and controlled and functioning as the British central bank. For reasons one must presumably be English to understand, sometimes referred to as "The Little Old Lady on Threadneedle Street."

bank of issue. See bank note.

Bank of North Dakota. The only bank in the U.S. owned and operated by a state.

bank of river. See river bank.

bank receiver. Either (a) a bank acting as a receiver (e.g., of the estate of a bankrupt) or (b) a person appointed as receiver for an insolvent or otherwise troubled bank.

bank reserve. See reserve requirements.

bank run. See run on a bank.

bankrupt. Technically, a person, natural or artificial, who has been so declared in a bankruptcy proceeding. In ordinary usage, however, it may refer to a failed person or business, whether or not any formal bankruptcy proceeding ever took place, as in "the new supermarket in the neighborhood undersold him so badly he went bankrupt." The term may also be used figuratively, e.g., "Professor Snort's article is bankrupt of ideas." 
bankruptcy. A legal proceeding, regulated in the U.S. by the federal Bankruptcy Act, in which an insolvent debtor, by surrendering his non-exempt assets for distribution to his creditors, may be granted a discharge from substantially all of his obligations. The Bankruptcy Act also provides for reorganization of debtors, i.e., a procedure for the rehabilitation rather than liquidation of the debtor's estate or business.

Bankruptcy Act. The most recent version of this federal act regulating bankruptcy is styled the "Bankruptcy Reform Act of 1978" (11 U.S.C. § 101 et seq.). Previous major bankruptcy acts had been passed in 1800, 1841, 1867, and 1898 which last, as extensively amended by the Chandler Act in 1938, was to continue to apply to a limited extent until April 1, 1984.

bankruptcy adjudication. See adjudication in bankruptcy.

bankruptcy clause. A clause in many contracts, especially those involving real property, terminating or permitting one party to terminate the relationship (e.g., a lease) or accelerate its maturity (e.g., a mortgage) if the other is the subject of a voluntary or involuntary bankruptcy proceeding.

bankruptcy court. See court of bankruptcy.

bankruptcy discharge. See discharge in bankruptcy.

bankruptcy distribution. See distribution in bankruptcy.

bankruptcy forms. See forms for bankruptcy.

bankruptcy proceeding. See proceeding in bankruptcy.

bankruptcy receiver. See receiver.

bankruptcy schedules. See forms for bankruptcy.

bankruptcy trustee. See trustee in bankruptcy.

bankrupt's estate. See estate of bankrupt.

Bank Secrecy Act. A federal statute (31 U.S.C. \& 1051 et seg.) which, under threat of both civil and criminal penalties, requires a report from: banks and similar financial institutions with respect to certain cash transactions of more than $\$ 10,000$; anyone who ships or carries more than $\$ 5,000$ in cash into or out of the U.S.; and any U.S. taxpayer with a foreign bank account.

bank stock lien. A statutory or contractual lien which a bank has on shares of its own stock to secure payment of obligations from a stockholder to the bank, especially the obligation once commonly attached to ownership of bank stock to contribute additional capital when necessary. See superadded liability.

bank teller. See teller.

bank yield. See yield.

banleuca ( ). Also spelled "banleuga," with "bannum" having roughly the same meaning. The term refers in old law to an area of land around the outside walls of a city, monastery, or manor, but still "part of" it, and 
sometimes having special local privileges. $C f$. the modern French word "banlieue" meaning "suburb."

banlieue ( ). See banleuca.

bann. Also spelled "ban"; "bannus" is the Latin. An old term for almost any proclamation or public notice, especially commands and prohibitions. The term survives in modern times in banns of matrimony.

banneret. Also spelled "baneret." See Knight.

banni ( ). See banning.

banning. Old synonyms are bannitio and bannition. In older contexts, the term might refer to something as strong as banishing or outlawing a person (turning him into a "banni" or "bannitus"), but the modern meaning is "forbid," as in "They have decided to continue banning 'Deep Throat' as pornographic."

banni nuptiarum ( ). See banns of matrimony.

bannitio[n] ( ). See banning.

bannitus. See banning.

banns of matrimony. Formal proclamations in church of intention to be married. In Church of England marriages, unless a bishop or archbishop dispenses with the requirement, these banns must be audibly published for three Sundays prior to the marriage, and as recently as 1959 it was held that a form of marriage entered into knowingly without publication of the requisite banns was void. The practice of requiring banns was and is designed to discourage hasty and inconsiderate marriages, especially between the young and reckless, by making the process take more time during which the parties may change their minds and their friends and relatives (now having been given notice) might work to that end.

bannum ( ). Essentially the same as banleuca.

bannus ( ). A proclamation (see bann), but of old particularly referring to a summons to court.

baptismal register. A church record of baptisms, a very important source of geneological data when births were typically at home and were not registered in hospital or other public records.

bar. In legal contests, there are two important uses of the term. First, bar may refer to a barrier (which may be real or imaginary) between the public areas of a courtroom and the space available only to the professional initiates, i.e., lawyers and judges. It delineates, within the "sacred" space of the courtroom, the area reserved to the "priests." Hence it has come by extension to refer to the court itself (as in "the case at bar") and to the special right to take part in the processes held there, as in "admission to the bar," i.e., certification as a lawyer. And that usage, by further extension, has 
made "bar" unable to refer to the whole profession in a jurisdiction, as in "The bar is steadfastly opposed to prepaid legal service plans."

Also, however, the central pictorial meaning of bar as barrier has been used in law to describe the blockage or destruction of a right as in, e.g., a plea in bar which, if accepted, defeats the plaintiff's claim, or in "bar the entail," i.e., a legal proceeding the effect [of] which is to destroy the right of person to whom the land was entailed.

bar admission. See admission to the bar.

bar association. A lawyer's professional organization at any geographical level, from nationwide (e.g., American Bar Association) to very local (e.g., Queens County Bar Association). Like any professional organization, a bar association generally has multiple functions usually including symbolic celebrations, lectures and courses for further professional education, lobbying on political issues pertaining to their expertise (including the evaluation of candidates for judgeships), and promulgating and enforcing rules of proper professional behavior. Many state level bar associations have at least quasipublic status and powers. In some states anyone admitted to the bar must be a member of the bar association, and hence subject to its discipline (see integrated bar), and in others the disciplinary machinery of the state is delegated to bar associations at the initial trial stage, subject to judicial supervision and appeal. It has recently been held that a bar association which enforces rules which restrict competition may be guilty of violating antitrust laws. See Goldfarb case.

barbican ( ). A watch tower.

barbicanage ( ). An exaction or donation for maintaining a barbican.

barbiturate. A class of sedative drugs, central nervous system depressants, which may be dangerously addictive, for which reason their sale and distribution is heavily regulated by the federal government.

bareboat charter. See charter party.

barel-folk. Also "borel-folk." Country people, "hicks."

bare licensee. See licensee.

bare [Patent] license. A grant of authority to use, make, or sell a patented item, but without any right to exclude other users, makers, or sellers from doing the same thing at the same place and time.

baret ( ). Law French for a particularly nasty and contentious litigation. $C f$. barretry.

bare trustee. See dry trust.

bar examination. A written examination which must ordinarily be taken (experienced members of the bars of other states may be admitted on application) in order to achieve admission to the bar of any state. The examination is an attempt to test whether the applicant has minimal intellectual and informational resources for the practice of law. There is a growing trend to 


\section{Leff Dictionary of Law}

have at least part of the examination the same in all jurisdictions (the "multistate bar examination"), with the remainder designed to test the specifics of the jurisdiction's own law. See also character committee.

bar fee. In old English law, a fee which had to be paid to a sheriff or other court functionary by every person who was charged with a felony but not convicted, in order to get discharged from custody. The outrageous practice was finally abolished in 1845.

bargain. The process of reaching an agreement ("They bargained out the terms for the sale"), or the agreement thus reached ("OK, here's our bargain"). Bargains, however, can be reached without bargaining, as when a deal is proffered on a take-it-or-leave-it basis and the offeree takes it. See adhesion contract. Thus, insofar as the bargaining process is supposed to supply justification for validating an apparently one-sided deal, it is not enough to point to the existence of an agreement as proof that any process of reaching it ever occurred. $C f$. unconscionability.

Colloquially, "bargain" is used to mean not just a deal but a good deal, as in "Malleys has some great bargains in TVs this week." $C f$. bargain sale.

bargain and sale. In real property conveyancing, a method of conveying land. Let us say that a contract is entered into between vendor and purchaser. (Under the Statute of Frauds this contract must ordinarily be written.) The purchaser pays the consideration he has promised. From a very early time the English Court of Chancery held that at that point the vendor held the land "to the use of" the vendee, i.e., in modern terms, as trustee for the vendee. By the Statute of Uses (1535), such uses were "executed" in favor of the purchaser, i.e., he came to have in his own right the same title (including seisin) that the vendor had had prior to the bargain and sale. This made secret conveyances possible, as the transfer of legal title was now possible without deed and livery of seisin, etc. This in turn led to the long series of statutory enactments in both the U.S. and England designed to prevent secret conveyances (e.g., by requiring registration of land titles) and to cope with the parties' continuous desire to evade the requirement of publicity, e.g., by bargaining and selling leasehold interest. See lease and release. But the bargain and sale contract still may function as a deed, i.e., an instrument of conveyance, and it will often be effectual between the parties, or if in compliance with applicable title registration statutes, in general.

"Bargain and sale" is also used to describe the process of selling personal property which involves first an executory agreement to sell (the "bargain") followed by a completed "sale."

bargain and sale deed. The name of a deed which recites the consideration received for the conveyance. See also bargain and sale.

bargain collectively. See collective bargaining. 
bargainee. The purchaser in a bargain and sale. The seller is called "bargainor."

bargaining agent. See collective bargaining agent.

bargaining power. The power, based on personality, acquired skills and the market structure, to get more of what one wants in exchange for something wanted by the other. See adhesion contract for some of the intricacies attending upon a loose deployment of the concept.

bargaining unit. See collective bargaining unit.

bargain money. Essentially a synonym for earnest money.

bargainor. See bargainee.

bargains marked. The British term for their list of daily stock market quotations.

barganizavit et vendidit ( ). "He has bargained and sold."

barge. Once used to describe a ship-of-state, especially for monarchs as in ("The barge she sat on, like a burnished throne, burned on the waters"), but now descriptive of either a flat-bottomed river vessel used for the transport of heavy cargoes, usually towed rather than self-powered, or a lighter.

bar integration. See integrated bar.

barleycorn. An old measure, equal to one-third of an inch.

Also a commonly stipulated nominal rent in old leases.

barmote courts ( ). Also spelled "barghmote," "berghmoth," and "berghmote." There are two of them-the Great Barmote and the Small Barmote-and they administer the mineral laws and customs in certain lead mining areas of Derbyshire, England. They were already old when some of their customs were confirmed in 1287, and they still sit today, albeit now regulated by mid-nineteenth century statutes.

Barnard's Inn. One of the inns of chancery.

baro ( ). A word which in its earliest usages seems to have referred to any man-slave, serf, or free-but came in time to cover only freemen, then admirable freemen, and finally came to be roughly equivalent to baron.

baron. While at an early time most likely a word meaning nothing more particularized than "man" or "free man" (see baro; baron et feme), and while in some contexts used to stand for the English nobility generally, i.e., those who held their estates directly of the King (e.g., the "barons" who cornered King John and screwed Magna Charta out of him), at present the term primarily describes a particular rank (the lowest) of English noblemen.

"Baron" was also the title of the judges in the English Court of Exchequer.

baronage. The estate of a baron; his form of tenure; the collectivity of all barons; and sometimes the English nobility in general. 
baron and feme. See baron et feme.

baron (or baron's) court. See court baron.

barones scaccarii ( ). Barons of exchequer.

baronet. A hereditary dignity someplace between knighthood and membership in the nobility. The rank was created in 1611 by James II, who sold baronetcies for $£ 1080$ each to any knight or esquire meeting certain minimum land ownership requirements. Baronetcies do not, like some titles of nobility, ever descend in the female line.

baron et feme ( ). Law French for "man and wife" or "husband and wife."

barons of the cinque ports () . Once referred to any freeman in the cinque ports, but by the eighteenth century had come to refer to any member of Parliament from one. Such members taken as a group were called the "combarones."

barons of the exchequer. The title of judges of the Court of Exchequer. In law reports their titles were given by the abbreviation "B.," as in "Bramwell, B." The chief baron's title was abbreviated "C.B."

barony. Essentially a synomym of baronage, and the more common term of the two for a baron's estate and his lands.

barony of land. An old quantity of land, thought to be fifteen acres.

barra ( ). An old term for a plea in bar, and a general variant form of bar.

barrasterius ( ). A barrister.

barrator. See barratry.

barratrous ( ). Actions amounting to barratry; or, in some old contexts, more generally "fraudulent."

barratry ( ). Also spelled "barretry." In general legal contexts, the term refers to the practice of stirring up quarrels and litigation, either one's own or among others. One who did so was called a "barrator" or "barretor," and there was a common law offense (abolished in England in 1967) of being a "common barrator." How much the offense was used by justices of the peace and other government officials to control what today would be called agitators or "outside agitators" is unclear. When, however, the barrator was a lawyer, and the stirring up was to get business, the lawyer could be disbarred.

This last use of barratry-as a way of disciplining lawyers for stirring up litigation-has come under recent constitutional reconsideration in the U.S. There is a thin line between "stirring up litigation" and "making exploited citizens aware of their legal rights." On these developments, see solicitation by lawyers; $f$. lawyer's advertising.

In maritime law, barratry refers to a serious and intentional wrongful act committed by the master or crew of a ship to the prejudice of the owner or charterer, e.g., running off with the ship or cargo, or deserting, or scuttling. 
A shipowner is generally exempt under the terms of the bill of lading from liability to the charterer (renter) of the ship for barratry, but "barratry of master and mariners" is one of the perils ordinarily insured against in a standard policy of marine insurance.

barred. See bar.

barrel. A measure of volume, the amount of which varies from country to country and trade to trade. For example, in England it is a liquid measure of 36 (imperial) gallons. In the U.S., it is a liquid measure of $31 \frac{1}{2}$ gallons, except for beer, where it is 31 gallons; but a barrel of petroleum contains 42 gallons. As a dry measure, a barrel of fruits or vegetables contains 105 dry quarts (just short of 4 bushels), but a barrel of cranberries contains only 87 dry quarts. And so it goes.

A barrel is also a kind of container. It used to be made up of curved wooden staves bound by metal bands, but a modern beer barrel is usually an aluminum drum, and other goods, (e.g., chemicals) now must frequently come in plastic containers.

barretor. See barratry.

barretry. See barratry.

barring the entail. See common recovery; entail.

barrister. The English bar is divided into barristers and solicitors. Barristers, who must be members of one of the four Inns of Court, are limited to trial practice, and have exclusive right to practice before the House of Lords and Privy Council (sitting as appeals courts), and the Supreme Court of Judicature.

The English barristers are subject to numerous rules which seem odd to U.S. lawyers, e.g., they cannot sue for their fees, which are instead regarded as gratuities; they cannot go into partnership with other barristers, or split fees with solicitors; they cannot make contingent fee arrangements; they cannot deal directly with clients, but only through solicitors; they cannot do any advertising or self-promotion; they are totally immune to any action for malpractice, and from libel actions based on any words spoken in the course of a case. See also Queen's Counsel.

bar sinister. A symbolic expression for bastardy, originally referring to a device on a coat of arms.

barter. The exchange of things of value without the intermediation of money. But "bartering" has come to be a synonym of "bargaining," and thus "barter" may also cover ordinary sales.

bas ( ). Law French for low, minor, inferior, etc.

bas chevaliers ( ). Law French, literally "low knights," i.e., those knights inferior in "rank" to knights banneret and barons.

base. As a noun, that upon which other things rest, as in "The house was erected on a base of poured concrete," or "the base of his argument was 
U.C.G. § 2-207"; or a starting point or headquarters, as in "He made the motel his base."

As an adjective, base means low, inferior, even vile and corrupt.

base animal. See animal.

baseball. See professional baseball.

base coin. See adulterated coinage.

base court. In older English law, a tribunal not a court of record, e.g., the court baron and the court leet.

base estate. The estate of a base tenant. Not to be confused with base fee.

base fee. Medievally, base tenure. Now used to describe an estate in fee, i.e., one that may last forever in the hands of the tenant and his heirs, but which may be terminated by the happening of some contingency. A conveyance "to A and his heirs so long as no liquor shall be drunk therein," e.g., would be a "base fee," i.e., it could, but need not, continue forever. All conditional fees and determinable fees are base fees.

base line. See range.

base nature. See animal.

base period. See price index.

base property. An obsolete concept that certain kinds of property, e.g., dogs and cats, were of so inferior a nature that their removal could not be larceny. Civil remedies, e.g., trover for conversion, could, however, always be maintained. Base property is not to be confused with base estate or base fee.

base services. See base tenants.

base tenants. Essentially the same as villeins, i.e., persons whose place in feudal society was dependent upon their performance of "base services," i.e., manual labor, especially agricultural, rather than "higher" services like counsel to the lord, or military support.

base tenure. The tenure of villeins.

BASIC. In computer programming, a popular and comparatively simple compiler language; almost anyone (under forty) can learn to use it quite easily.

basic norm. See Grundnorm.

basic patent. Also called "basis patent" and "pioneer patent." The patent on an invention which becomes the foundation of a product, process or even industry, and with respect to which improvement patents are issued. The precise coverage of the term is imprecise, but Alexander Bell's telephone patent, and the original xerography patent, are clear examples of basic patents.

basileus ( ). One of the Greek words for "King," sometimes used by and of 
the Byzantine emperors, and reportedly applied to English Kings before the Norman conquest.

basing-point system. A pricing system in which the seller quotes a list price and adds transportation charges from a fixed base point which is not necessarily his plant. Thus, a steel company might charge a New York buyer the transport costs from Pittsburg, even though the goods are made in Newark, N.J. or Chicago. Most likely now unlawful under the antitrust laws.

basis. In ordinary language, the conceptual twin of the more physical term base.

In income tax law, "basis" is a technical term used in calculating capital gains, and in computing depreciation. While special and complex rules apply when the property has been acquired in certain ways (e.g., upon conversion from personal to business use, or by gift or inheritance), when the relevant property has been acquired by purchase, the basis is ordinarily the same as its actual or constructive cost, modified by certain statutory adjustments (see adjust). This "adjusted basis" is then deducted from the "amount realized," the remainder being the capital gain. If a depreciation computation, this "adjusted basis" is that to which the allowable depreciation percentage is applied. See I.R.C. $\S \S 1011-1023$ for the details, see also stepped-up basis; substituted basis.

In the property tax context, "tax basis" ordinarily refers to that legally specified portion of the actual value of the property to which the applicable tax rate is to be applied.

basis of bargain. Under U.C.C. § 2-313, any affirmation of fact, promise, description, or sample or model delivered by the seller with respect to the goods, which becomes part of the "basis of the bargain," creates an express warranty that the goods will conform thereto. It is hard to imagine what statements, etc. would not become "the basis of" any particular bargain; are there situations in which the buyer would still do the deal at the same price if something he was led to believe about the goods turned out to be false? The statute seems to think so. See also essence.

basis patent. See basic patent.

basis point. A unit of measure for bond and note interest rates equal to $.01 \%$, i.e., 100 basis points equals $1 \%$.

basket money. Many lenders, especially quasi-fiduciaries like insurance companies, are severely restricted as to the kinds of investments they may make. But many regulatory statutes allow some small proportion of their funds to be put in more speculative investments, and this is the "basket money," i.e., the "basket" of noncategorized discretionary transactions.

basket price. A slang term in the financial community for the price of a group of different securities which must be purchased together for a single consideration. An issuer might sell a bond with a face value of $\$ 1000$, ten shares of common stock, and options to acquire 100 additional shares, all at 
a price of $\$ 1200$ for "the whole basket." As one can readily imagine, this sales technique raises hob with trying later to find one's basis for any one of these securities when one tries to calculate the capital gain upon its subsequent sale.

basset. A old variety of faro.

bastard. A term of general abuse, but technically the legal status of a person conceived while his biological parents were not married to each other. More euphemistic equivalents include "illegitimate child," "child born out of wedlock," "natural child," and "love child."

At common law a child was not a bastard if its parents intermarried at any time before its birth. Under the civil law, following canon law, if the bastard's natural parent's at any later time intermarried, the child ceased to be a bastard, but that rule was rejected in England in 1235 and for 700 years thereafter until a statute of 1926 . The U.S. situation varies from state to state, but usually conforms by statute to the civil law rule.

At common law a bastard could not in general inherit real or personal property; his own property could pass only to heirs of his own body; and rules of testamentary interpretation provided that references to "heirs," "sons," "children," "issue," etc. would be construed prima facie to refer only to legitimate ones. Most of that has been changed in England and, in varying degrees, in many U.S. states. The laws of those states which still discriminate against bastards in these and other matters have been subjected to recent constitutional challenge, but the Supreme Court has not yet seen fit to declare all such discriminations unconstitutional.

See also adulterine bastard; bastard eigné.

bastard eigné (or ainé) ( ). Law French for "bastard elder." At common law, if a couple had a bastard son, then intermarried, and then had another son, the elder was a bastard eigné and had some rights of inheritance to real property.

bastardize. Judicially to declare someone a bastard; or to give evidence to that effect.

bastardy. The state of being a bastard; a male's role in producing one.

bastardy proceeding. See filiation proceeding.

bastinado ( ). A term from the Spanish for "stick" or "club." "The bastinado" usually refers to a form of torture or punishment in which the soles of the victim's feet are repeatedly beaten.

baston ( ). In old English contexts, a baton, staff, or club. Also at one time a name for the wardens of the Fleet and Marshalsea prisons in London, and their assistants.

batable ( ). An obsolete form of debatable. See batable ground.

batable ground. Land the title to which is not clear, notably applied to certain 
lands on the border of England and Scotland prior to the union of the Kingdoms in 1707.

bataille. Law French for battel (or battle).

battel. The usual spelling of "battle" in old legal terms like wager of battel.

battered child [syndrome]. See child abuse.

battery. See assault; assault and battery; technical battery.

battle of the forms. The standard term for a conundrum in the law of contracts and sales. Buyer sends an order to seller. His form contains terms $A$, B, C, D, and E. Seller "confirms" the order on his form, which contains terms $A, B, C, \bar{D}$, and $F$. Is there a contract between seller and buyer, and if so, what are the terms?

Under older views of contract law, there would be no contract. Unless $D$, $\mathrm{E}$, and $\mathrm{F}$ were totally trivial, seller's form would not be an acceptance of buyer's order, but a counter offer; there could be no contract unless the parties agreed to substantially the same set of terms.

But what if buyer and seller, after exchanging their discordant forms, behave as if they do have a contract? Should not the law treat them as if they do? But if they do, what are its terms? A, B, and C, upon which they agree, cause no trouble. But is buyer's term $E$, not reproduced or accepted in seller's form, part of the contract? Is seller's term F? And what of term D- $\overline{\mathrm{D}}$, i.e., a term proposed by buyer's form and specifically negatived in seller's? And does it make any difference if either or both of the forms contains a clause saying "whatever deal we have we have on my terms and my terms only"?

The truth of the matter seems to be that in many instances neither party wishes (or, given the volume of modern bureaucratic business practice, is economically able) to devote the attention necessary to get actual agreement to all terms of a deal. Each would prefer to have the contract wholly on its own terms, but would prefer to "no deal" a deal on the terms mutually accepted, with the question of the other terms left to subsequent determination, either by not becoming relevant in the instance (e.g., the disclaimed warranty is never breached), or by subsequent negotiation or litigation. The parties will each maneuver to make their terms the terms, but not to the extent of actually bringing about unambiguous actual agreement. But what is the law to do when $D$ is a fall warranty, $\bar{D}$ is a disclaimer of any warranty, and the warranty question becomes important? There is no technical solution. But see U.C.G. § 2-207 for a recent (and not notably successful) statutory attempt to come to grips with it.

batture ( ). Solid material that aggregates under water, forming something like a shoal which may or may not be covered at low water. If the batture if not covered even at high water, it becomes an island. If it is against the bank and ceases to be covered, it becomes alluvion, i.e., land added to the bank by accretion. 
bawd. Originally referred to a panderer, i.e., a broker of sexual relations for money. It then came to be applied to the madam of a whorehouse, and then even more loosely to any whore, whether holding an executive office or not. Though the term is not totally obsolete, it has by now a thoroughly archaic ring.

bawdy house. A synonym for whorehouse still found in older statutes.

bay. A shoreline indentation which almost but not quite totally encloses part of a body of water, especially the sea. When a mere dent in the shore becomes a bay is an unanswerable question.

bayley. Another term for bailiff used, among other places, in some colonial New England statutes.

bayou ( ). A slow moving creek or stream traversing and draining a swamp.

bazaar ( ). A marketplace, especially one consisting of many small stalls and shops.

B.C. See A.D.

B.C.E. See A.D.

bcf. Abbreviation for billion cubic feet, a staggering measure regularly used in the natural gas industry.

beach. This may once have referred to that portion of seashore between the lowest and most high tides. It has by now lost whatever preciseness it may once have had, and refers to any reasonably flat and usable land alongside an ocean or lake, though especially if it is sandy or pebbly.

"To beach" refers to the process of driving a ship ashore, especially when it is done intentionally so as to prevent sinking, or burning up afloat.

beaching. See beach.

beacon. One ancient meaning was a pile of readily inflammable materials kept ready for firing as a warning of invasion.

Beacon also referred anciently to any prominent features identifiable from a ship (e.g., church steeples; notable stands of trees) which might help a mariner calculate where he was. It then came to cover structures especially erected for this purpose, particularly those fitted with lanterns or lights for night viewing, and by now refers almost wholly to navigational lights, especially those in lighthouses.

beaconage. An old tax imposed for the maintenance of beacons.

beadle. Also (though rarely) spelled "bedel," or "bedell." A common law parish officer among whose jobs were giving notice of church meetings, summoning ecclesiastical juries, and serving church papers. In some modern churches a servant employed to keep order during services is still called a beadle, but he has no legal status or role.

bear. Well known securities-market slang for an investor who expects the prices of securities to fall, and thus sets out to profit thereby, e.g., by engag- 
ing in short sales. See also bull. When the market is falling, especially if the fall is either steady or sharp, it is called a "bear market," i.e., one to the taste of the bears.

bear arms. See right to bear arms.

bearer. One in possession of bearer paper or bearer securities. See U.C.C. $\S$ 1-201(5).

bearer bond. See bearer securities.

bearer form. Bearer paper and bearer securities which are explicitly made payable to bearer or bearer's order (rather than so payable by reason of endorsement) are said to be in "bearer form." See U.C.C. §§ 3-111, 8-102.

bearer instrument. See bearer paper.

bearer paper. Commercial paper, e.g., bills, checks, notes, is "bearer paper," i.e., payable to whomever is in possession of it, if it (a) is in bearer form; (b) is made payable to "cash" or "the order of cash" or to any other designee not purporting to be a specific payee (e.g., "bills payable," "one keg of nails" (U.C.C. § 3-111)); or (c) carries a blank indorsement.

bearer securities. Securities, e.g., bonds, are bearer securities, i.e., payable to whomever is in possession, if they (a) are in bearer form (See U.C.C. § 8102) or (b) carry a blank endorsement.

bearing arms. See right to bear arms.

bearing date. The legal-pretentious term for "dated," i.e., with a date on its face, as in "An agreement bearing date January 6, 1979."

bearing interest. A debt "bearing interest" is one which cannot be discharged merely by paying the principal amount, i.e., one must pay "rent" for the use of the money.

bear market. See bear.

bear raid. An attempt by stock market bears to drive the market down by continuous short-selling, thereupon to profit when the bottom drops out. The dangers of bear raids have been met by SEC requirements that a short sale must always be made on an "up tick," i.e., at a price higher than the last previous sale.

beasts. Generally used to refer to four-footed, warm-blooded animals; impliedly excluded are reptiles, birds, and amphibians.

beasts of the chase. Beasts which traditionally were chased by men, especially men on horseback, e.g., fox, wolf, and deer. Also called "beasts of the forest" and "beasts of the park."

beasts of the forest. See beasts of the chase.

beasts of the park. Mounted hunters often maintained parks as private game preserves to supply them with animals to be chased. Hence "beasts of the park" are essentially beasts of the chase. 
beasts of the plow. Animals used to do the jobs done on modern farms by tractors; in the West, primarily horses, mules, and oxen.

beasts of the warren. Rabbits, hares, etc.

beat. To beat is to hit another, either repeatedly or heavily or both. In pleadings alleging assault and battery, however, a phrase like "defendant thereupon did beat" might describe a single touching.

Also, in games and sports, to be victorious over.

Also, a slang term for the territory covered by a policeman.

Also, in some parts of the U.S. South, a subdivision of a county something like a township, or even a voting precinct.

beating of the bounds. An old English custom in which the minister or curate of a parish led a yearly walk around its boundaries so as to re-memorialize them.

beaupleader ( ). Law French for "fair pleading." Also, an ancient and obsolete writ arising out of the Statute of Marlbridge (1267), directing the sheriff not to take a fine, or amerce, for bad (defective; bad faith) pleading.

because of vicinage. See common because of vicinage.

bed and board. Traditional term for marital home, especially in the phrase "My wife having left my bed and board, I will no longer be responsible for her debts . . . ." See also divorce a mensa et thoro.

bedel. See beadle.

bedelary ( ). The jurisdiction of a beadle.

bederepe ( ). Also spelled "bedrip" and "biderepe." A feudal tenant service of reaping the lord's grain.

bedlam ( ). The term comes from the corruption of the name of an ancient London hospital for the insane, St. Mary's of Bethlehem. It once stood for insane asylums in general, but now is often used to describe any noisy and confused scene, as in "With everyone trying to talk at once, the nominating convention was bedlam."

bed of a river. The channel in which it runs.

bed of justice. See lit de justice.

bee. An insect with a happy propensity to make honey, and frequently a less happy one to inflict painful stings on enemies, including those wanting the honey. No one has property in wild bees or their honey, but once confined to an owned hive, the bees and their produce are the property of the owner. It is generally thought that if a swarm leaves, the owner has rights in it superior to any "finder" so long as he can see and identify the swarm. As one can imagine, litigation has been sparse.

beer. An alcoholic beverage ordinarily made by fermenting malted (i.e., steeped and partly germinated) grain flavored with hops. "Ale" is a similar product, though often heavier and more alcoholic. During prohibition in the 
U.S., and even now during no-alcohol times (e.g., Sundays in some places), a much less alcoholic and generally revolting product which has come to be called "near beer," is lawfully served.

before. Prior to ("Come before noon"); in advance of ("The drum major marched before the band"); in front of or in the presence of ("On the 6th of May, 1979, before me appeared Tom Jones . . . .").

before the fact. See accessory.

beg. To solicit charitable contributions, usually directly and for oneself and family. Because of its unsightliness, its propensity to cause guilt, and the ease with which it can turn into mere fraud, begging in the streets is frequently forbidden, but enforcement is sporadic and unenthusiastic.

beget. To lay the sexual groundwork which led to the birth of a child; generally used only of male begetters, and rarely used today at all.

begging the question. A form of a fallacious argument in which the conclusion to be proved is embedded in one of the premises. Also called "petitio principii" and (of one variety) "circular reasoning." An example might be "One may do whatever one desires with respect to one's own body; hence, it is not wrong to abort a fetus," where it is assumed that a fetus is nothing else but part of the aborter's body. See also logical fallacies and entries beginning argumentum, for similarly fallacious arguments.

The term is often used imprecisely as a characterization of almost any logical fallacy.

behalf. See on behalf of.

behavior. See good behavior.

behavioral sciences. Those that study the behavior of higher animals, especially people, notably psychology, sociology, and anthropology (and their subcategories, e.g., social psychology), and perhaps history too.

behaviorism. An approach to psychology which, either for methodological or ideological reasons, abandons any consideration of mental processes, and focuses upon the objective behavior of animals, including and especially people. In effect, the subjects are considered as black boxes; one sees what they do under various conditions, and seeks to generate the laws of their behavior without reference to any subjective happenings. It should be pointed out that behaviorism does not require a firm belief that there is no such thing as mental process ("dogmatic behaviorism"), but only that paying attention only to objective actions is scientifically fruitful, and perhaps necessitated by the "invisibility" of the subjective ("methodological behaviorism"). Many modern economists, including most practicing economic analysis of law, are implicit behaviorists in this last sense.

behavior modification [therapy]. Techniques to change behavior considered personally or socially pathological, e.g., phobias or violent criminal activity, either by associating the bad behavior with pain or other unpleasantness (as 


\section{Leff Dictionary of Law}

by giving an electric shock in association with drinking alcohol), or by associating a reward with good behavior (candy to an infant every time it shows some sphincter control). The former, often called "aversion therapy," is frowned upon when used in prisons to modify prisoner behavior; but a prison, of course, like all punishments, itself is an attempt at aversion therapy.

behoof. Older form of "behalf." See on behalf of.

being. The state of existence. By extension, an existing living thing, especially a human being. See also in being, lives in being.

being understood. See it being understood [and agreed].

belief. Subjective conviction that a fact or state of the world is the case. "I believe" is thus equivalent to "I am convinced," "To my mind it is true that ...." and similar locutions. "I know" sounds stronger than "I believe," and is often used to express that nuance of intensity. But, strictly speaking, all one can know is what one believes; hence "know" tends to mean "believe on the grounds of evidence which I believe to be very persuasive." ("I suspect" is often used to convey "I believe, but I'm hard pressed to specify sufficient evidence for my belief.") It is sometimes argued that "knowledge" is used to describe what comes from the senses while "belief" comes from other sources (e.g., argument, inference, the testimony of others), but the distinction, if it ever existed, seems not be be strongly recognized today.

See also information and belief.

believe. To have a belief.

belligerency ( ). In international law, the state of being "lawfully" at war, declared or not. It is a status which may be accorded nations, or non-nation aggregations of revolutionaries, or parties to a civil war. Special "belligerent rights" are accorded "belligerents" which would not be accepted from nations at peace, e.g., blockades of enemy waters; the right to have its fighting men, when captured, treated as prisoners of war. But the status of belligerency does not give the possessor the right to do anything it feels useful or even necessary to win a war, e.g., attack neutral shipping in international waters.

Also, as an adjective applied to natural persons (and only by extension to nations), belligerency refers to a cast of mind and behavior unduly aggressive, hostile, and war-like.

bello parta ( ). Spoils of war.

bell-shaped curve. See normal-distribution curve.

bellum ( ). War.

belly stiff. In the argot of conmen and other rogues, one who, in league with the proprietor of a game of "chance," pretends to win so as to encourage other players. $C f$. shill.

belong. To be the property of, or appended to, as in "The wallet belongs to 
Doe." Also, to be properly part of a category or group, as in "He belongs with the Republicans."

belongings. Those things which belong to a person, which may include everything owned but more usually refers to personal effects; it would be very odd to refer to real property as "belongings."

below. See above.

bench. The structure, both seat and desk, on and at which a judge sits. By the common rhetorical device of metonymy, it has come to stand for the judges themselves, and especially for the judicial branch of government, as in "bench and bar."

bench blotter. See police blotter.

bench conference. A conference at the bench between counsel and judge typically to discuss some point of law, especially evidentiary, out of the hearing of the jury. It is properly "on the record," i.e., the colloquy is taken down by the court reporter, but it is common for the judge (with tacit consent of counsel) to put parts of it off the record, e.g., "How about an early break for lunch?" and "Do you have to object to everything?"

benchers. The senior (and governing) members of the English Inos of Court. See also ancients.

bench legislation. See judicial legislation.

bench mark. Also "benchmark." Originally a surveyor's mark cut into some durable surface, e.g., a stone or wooden post, as a guide for measuring elevations and hence distances. Now used metaphorically to mean any fixed standard, as in "Our statute will become a benchmark for all future legislation on this subject."

bench trial. One without a jury, especially when a jury trial has been waived.

bench warrant. In the U.S. all warrants of arrest must be issued by judicial officers, but most of them are issued more or less automatically by low level judges, on the basis of police affidavits. When, however, a person is in contempt of court in a particular proceeding, or has ignored a subpoena, or has been indicted but has not appeared, or has jumped bail, a judge of a court of general jurisdiction may issue a "bench warrant" for his arrest.

bene ( ). A general commendatory-good; correct; proper; well.

beneath. Underneath; lower than-either physically or hierarchically. See also below.

benedicta ( ). Literally "blessèd," i.e., worthy of heaven, but used in old texts as a strong commendatory.

bene esse. See de bene esse.

benefice ( ). The Latin is beneficium. In feudal law, an estate held in ecclesiastical tenure. In post-feudal times, most broadly, any ecclesiastical office or living, e.g., an archbishopric, bishopric, deanery, etc. But usually used to 


\section{Leff Dictionary of Law}

describe the office and living (i.e., right to maintenance, e.g., tithes) of one directly charged with the "cure of souls," e.g., rectors and vicars of parish churches. See also advowson.

beneficence. Good will; charity; generous behavior.

beneficia ( ). An ancient term for feudal tenancies in general, but soon transformed to refer to benefices.

beneficial. An adjective widely employed in legal contexts to distinguish a right or power one possesses for his own use and enjoyment from one possessed for the use and enjoyment of another. The primary locus for this distinction is found in the law of trusts: The trustee has legal title to the trust property, but he holds it on behalf of the beneficiary of the trust, the latter having the "beneficial interest." Similarly, the vendee under a contract for the sale of real property is said to be "beneficial owner," even though the vendor still holds title.

Most property, of course, is held both legally and beneficially, i.e., the person with title also has the right to use and enjoyment. Indeed so much is that taken for granted that it would be odd to describe the owner of a fee simple interest in real property as the "beneficial owner," or to say that he has the "beneficial enjoyment," or owns the "beneficial estate," or is "beneficially entitled" to ownership; he is just "the owner," and that he owns it for himself is just assumed.

It should also be noted that while "beneficial" ordinarily implies "for the good of," the beneficial owner is also usually the one who ultimately is responsible for duties associated with ownership, e.g., taxes on property in trust.

beneficial association. See mutual benefit society.

beneficial devise. A devise which vests in the divisee a beneficial interest in the property devised. This can, but need not, include legal title.

beneficial enjoyment. See beneficial.

beneficial interest. In general, see beneficial. The term, however, is sometimes wide enough to encompass the interest of one who has a potential but certain right, e.g., one who is kept from total ownership only by some trivial technicality not within anyone's power to prevent fulfillment.

Beneficial interest is also sometimes used to mean "valuable interest," or "profitable interest."

beneficially entitled. See beneficial; beneficial interest. The term is also widely used to describe the particular status of a person with a present right to receive legal title, e.g., the vendee under a contract for the sale of land who has "title" by equitable conversion, i.e., "beneficially entitled" may be used to mean "holder of equitable title entitled to receive legal title too."

beneficial ownership. See beneficial; beneficial interest; beneficially entitled. 
beneficial power. A power, e.g., a power of appointment, which the holder may exercise to benefit himself.

beneficial society. See mutual benefit society.

beneficial title. See beneficial.

beneficial use. See beneficial.

beneficiary. One who is to or does benefit from some legal act or arrangement. Thus, e.g., the person for whom a trustee acts, the cestui que trust, is the beneficiary of the trust (see also Uniform Probate Code $\$ 1-201$ ). The person who is to receive life insurance payments on the death of the insured is the beneficiary of the policy; the person who is to receive a distribution from the estate of a decedent is the beneficiary thereof; etc. The beneficiary of a letter of credit is anyone who under its terms is entitled to draw or demand payment.

For the beneficiary of a contract, see third-party beneficiary contract.

beneficio primo [ecclesiastico habendo] ( ). An old writ from the King to the Lord Chancellor or Lord Keeper directing him to appoint to the first benefice of a particular value the person named therein. Also called "primo beneficio."

beneficium. See benefice; beneficia. Also a right, privilege, profit, or advantage in general.

\section{beneficium clericale ( ). See benefit of clergy.}

benefit. Anything of positive value: advantage, profit, gain, etc.

Also, an artistic or athletic performance the profits from which are to go to some special, usually charitable, cause rather than be distributed as they would ordinarily be to the impressario and performers, as in "Jerry Lewis did a benefit for the Multiple Sclerosis Foundation."

See also entries beginning with benefit; benefits; consideration; costbenefit analysis; special benefits.

benefit association. See mutual benefit society.

benefit building society. See savings and loan association.

benefit insurance. See mutual benefit society.

benefit of bargain rule. A rule for the calculation of damages in actions for fraud, which gives the successful plaintiff not just his out-of-pocket loss, i.e., the difference between the price he paid and the market value of the property on the date of sale, but what he would have had had the defendant spoken the truth. Thus, if a plaintiff pays $\$ 10,000$ for property falsely claimed to be worth $\$ 15,000$, which is really worth $\$ 5,000$, he gets $\$ 10,000$ in damages (the difference between its real worth and its pretended worth) rather than $\$ 5,000$ (the difference between its real worth and what he paid). Of course, why a buyer should expect to get for $\$ 10,000$ what he is told is "worth" $\$ 15,000$ is an abiding mystery. $C f$. contract damages. 
benefit of clergy. Sometimes called "privilege of clergy" ("privilegium clericale"). At least formally, all felonies were capital offenses at common law. Various evasions of such rigor predictably developed; one was "benefit of clergy." As a result of the same great twelfth-century church-state dispute that led to the murder of Archbishop Becket at the hands of Henry II's knights, the principle developed that criminal jurisdiction over ordained clergy belonged to the church courts. The procedure evolved that the defendant would be tried as if he were a layman but then, if he could establish his ecclesiastical status, he would be turned over to the church. Since the church tried by wager of law, however, and its penalties were often farcical, benefit of clergy actually came to be for its beneficiaries a practical exemption from criminal penalties. By the sixteenth century, indeed, the practice of turning the defendant over to the church was abandoned; he was just set free (though the justices could imprison him up to a year).

It thus became literally a matter of life and death to identify who "clergy" were. The definitional aspect of this problem seems to have been settled by treating as clergy almost any church functionary, ordained or not. The empirical problem was handled by testing whether the claimant could read, with the assumption being that if he could, he was a clergyman. As a practical matter this led to extending the privilege to all literate people and, since the same fragment of the same psalm (see neck verse) was usually chosen as the test text, a little preparation could be a life saver even for the functionally illiterate. In the sixteenth century peers (literate or not) got a similar privilege, in the seventeenth century parliament extended the privilege to some women (who by no stretch of the imagination could be ordained), and by the eighteenth century, one no longer had to prove literacy.

Ways to restrict the privilege also developed, however. It became established that a person could be thrust from the church for felony, and then it was assumed that he had been. Hence, one could ordinarily claim benefit of clergy only once. It became a practice to brand a clerical felon, usually on the thumb, so he could be later identified as a second offender. And it became common for parliament to declare that some crimes, e.g., piracy, were to be "without benefit of clergy."

Benefit of clergy was not finally abolished in England until a statute of 1827. One of the earliest U.S. statutes declared it inapplicable in U.S. criminal law in 1790.

benefit of counsel. See assistance of counsel.

benefits. Shorthand term for social welfare payments, e.g., unemployment compensation, social security payments, etc., and for fringe benefits.

benefit society. See mutual benefit society.

benefits-received principle [of taxation]. A tax theory that the beneficiaries of government services should pay most of the taxes for them. A tax on gasoline to pay for road building and repairs is one such tax; a sewer assessment on landowners to be served by the sewers is another. The principle is of 
limited usefulness, however; it is often hard to know who is benefiting from a governmental activity, and it is often the whole point of a governmental service to benefit those without money at the expense of those with.

benefit theory. See quasi contract; restitution.

Benelux countries. Belgium, the Netherlands, and Luxembourg, which are parties to a comprehensive treaty providing for the free flow of capital, goods, and people among them.

bene placitum ( ). At pleasure, i.e., so long as the grantor wishes.

benerth. Feudal services rendered with plough and cart.

benevolence. See benevolent.

benevolences. A form of ancient English taxation, formally voluntary loans but in fact impositions by early Kings upon rich subjects, and the focus of continual conflict between them and the throne. Benevolences were declared illegal by a statute of Richard III in 1483, but imposed thereafter anyway, notably by Henry VII. They were finally ended by statute in the early seventeenth century.

Lords also occasionally imposed taxes called benevolences on their tenants in times of distress, these being abolished by statute in 1660 .

benevolent. A cast of mind or type of activity meant to promote the happiness of others, motivated neither by hope for material gain, nor out of any belief that one is legally obligated to be kind. The term is broader than charitable or philanthropic, as one can be benevolent to the non-needy, and it is thus not totally safe to provide funds for "benevolent" purposes if it is desired to reap whatever tax advantages accrue to "charitable" trusts, bequests, etc.

benevolent associations. See mutual benefit society.

benevolent corporation. A now rare synonym for non-profit or charitable corporation.

benevolentia regis habenda ( ). The tag in old writings averring purchase of royal pardon, as in an averment that the party had given the King 100 marks "pro benevolentia regis habenda," i.e., to get the King's good will.

benevolent insurance company. See mutual benefit society.

Benthamism [-ite]. See utilitarianism.

bequeath. To make a testamentary gift of personal property; "devise" is the correct term for a testamentary gift of real property. But the distinction has long been fading, and if the context makes it at all proper, a court will find that "bequeath" includes or even means "devise," and vice versa.

bequeathment. Obsolete synonym for bequest.

bequest. That which is bequeathed.

berbiage. Rental paid for pasturing one's sheep on the land of another.

bercarious ( ). Also "bercator." A shepherd. "Bercaria" means sheepfold. 
bereft. The state of being deprived, as of a loved one. "Bereft of reason" may mean feebleminded or insane.

berghmoth [or berghmote]. Other spellings for barmote.

beria ( ). Also "berra," "berie," and "berry." A large open field.

bernet. Saxon law term for arson.

Bernstein letter. A letter from the State Department informing a court that the foreign policy of the U.S. did not require application of the act-of-state doctrine in the pending case. The practice was apparently disapproved in the Sabbatino case.

Bernstein test. See blood test.

berry. See beria; bury.

Bertillon system. The most widely adopted system of anthropometry.

berton ( ). A large farm; or its barnyard. Also (though more often spelled "barton" or "burton") the unrented home lands of a manor.

bes ( ). An obsolete term for two-thirds of something, especially used of an inheritance.

besaiel ( ). See assize of mort d'ancestor.

besoin ( ). Law French for "need."

besotted. Rendered brainless or silly, primarily by alcohol, drugs, or love.

best bid. Ordinarily, the "best bid" at an auction would be the highest; at the competitive bidding for a governmental contract, the lowest. But the quality of a bid is not necessarily measured solely by its explicitly monetary component, e.g., a bid on a public contract at a somewhat higher monetary price than several others might still be the "best bid" if the bidder were more financially secure, offered a better performance bond, etc.

best-efforts selling. See investment banking.

best evidence. See primary evidence. $C f$. best evidence rule.

best evidence rule. The traditional (and dangerously misleading) name of the law-of-evidence doctrine now also called the original document rule.

bestiality. See abominable and detestable crime against nature; buggery.

best of his knowledge and belief. See knowledge and belief.

bestow. To make a gift of. No particular legal procedure is implied; one may bestow by inter vivos gift, by trust, by will, etc., and even affection may be "bestowed."

bet. See accepting wagers; gamble; wager.

betrayal. The violation of some duty of loyalty, e.g., to friend, country, client, or patient, as in "It was a betrayal of his client to give aid to counsel for the other side." 
betrothal. Synonyms include "betrothment" and "engagement to marry." An agreement between persons to be married in the future, after which they may be said to be "betrothed" to each other, and may be referred to as each other's "betrothed." Even into the twentieth century these agreements were contracts for breach of which an action at law would lie, but now betrothals are, by and large, social rather than legal obligations. See also affiance; breach of promise [of marriage].

betrothed. See betrothal.

Better Business Bureaus. Business-supported local organizations, loosely affiliated into a national association, the aim of which is to decrease business fraud, chicanery, and shoddy practices. Individual bureaus advertise their availability to hear complaints against local businesses, and will disclose to inquiring consumers the extent and nature of complaints received about particular named businesses. They also engage in some attempts to mediate disputes between businesses and customers, and carry out more general standard setting and educational programs.

better equity. When two parties each possess equitable rights, the party having the right declared to prevail over the other is said to have "better equity."

betterment. An improvement to real property which increases its value by some substantial amount; more extensive than ordinary repair. Also used to describe the effect on property of some public improvement.

betterment acts. See occupying claimant acts.

betting book. See bookmaking.

betting slip. Slips of paper upon which betting data, e.g., what horse in what race; what number has been played, etc., is written. When found, strong evidence of an unlawful betting operation, for which reason some betting slips are made of water soluable paper for fast and easy destruction (even by swallowing) in a crisis.

between. Properly used, in the space separating, or distributed to, two other things, as in "He was standing between Harry and Abe," and "He divided his estate between Harry and Abe." But it is very common for between to be used where among would be the proper term, i.e., with respect to more than two entities. Thus courts will read between to mean among when the context makes that sensible, e.g., "I divide my estate between my three brothers."

Also, when an act is to be done "between" two dates, it is generally held that it must be done before the start of the second date. But if a statute attaches status to an age range, e.g., "between seven and twelve years of age," the subject has that status from his seventh birthday until his thirteenth.

between Scylla and Charybdis. See Scylla and Charybdis. 
beyond a reasonable doubt. See reasonable doubt.

beyond the [four] seas. Inflated phrase for "out of the jurisdiction," originally used in England to mean "not in the British Isles," and occasionally adopted in the U.S.. In England, while a person was "beyond the seas" the statute of limitations once would not run, but that has been sharply modified by a 1939 and subsequent statutes.

beyond the jurisdiction. Out of the reach of the legal process of the jurisdiction.

b.f. Abbreviation of bonum factum, i.e., good or proper act or deed; used as the equivalent of "approved" or "OK" when indorsed on a document.

biannual. See biennial.

bias. A predisposition against or in favor of one or another side in a lawsuit which, under certain circumstances, is grounds for disqualification of a judge or exclusion of a juror. It is frequently said that bias in this context refers to an attitude toward a party rather than to the subject matter of the litigation, but that is certainly false. A judge who announced that he would never countenance a plaintiff's verdict in an antitrust case, or a juror who openly maintained that he thought crimes against property were always justified, would be removable, as they would if they declared a firm preformed opinion on the particular case.

Most disqualification for bias does not depend upon any finding of an actual state of mind, but is legally presumed from particular relationships, especially consanguinity (at common law, within the ninth degree) or other family relationships, personal financial stake in a case's outcome, previous legal representation of a party (or even prior non-legal employment), etc. See, e.g., Canon 3C (Disqualification) of the Canons of Judicial Conduct.

bicameral. "Two chambered," i.e., a legislature which has two houses, e.g., Commons and Lords, House and Senate, elected or otherwise constituted on non-identical principles. Each chamber, if it is to be seen as part of the legislature, must have some role in validating at least some kinds of legislation (e.g., the House of Lords' vestigial power to delay the enactment of English laws), but the system is still bicameral if only one house has a role in some matters (e.g., the U.S. Senate's sole power over treaty ratifications).

biconditional. The name of the connective "if and only if," as used in logical discourse. In formal logic, the connective is expressed by the sign "”." See necessary and sufficient.

bid. The more general and now almost archaic meaning is "ask," "request," or "tell" as in the last line of Hamlet: "Go, bid the soldiers shoot."

The more specific and more legally relevant modern meaning is to state one's terms, especially one's price, for entering into a transaction, especially at auctions of one sort or another, and in competitive bidding situations.

See also entries beginning with or containing "bid" and its cognates, e.g., bid and asked; bidding up; responsible bidder. 
bid and asked. In the securities industry the format of price quotations in over-the-counter market. The "bid" quotation is the highest price any prospective buyer has offered to pay. The "asked" is the lowest price a potential seller has offered to accept. This is used instead of the last-salesprice used for stock exchange transactions, because in slowly trading or thin markets the last actual sale price may be too out of date for current use.

bid bond. A bond from a surety often required of participants in competitive biddings to indemnify the other party against loss should the winning bidder attempt to withdraw his bid or refuse to enter into the contract awarded him. Sometimes persons letting contracts through competitive bidding insist that bidders deposit cash or other "bid security" (not necessarily a bond) which will be forfeited upon the successful bidder's default.

bidder. See responsible bidder.

bidding up. The process of raising the price of goods at an auction by making successive higher bids. If this comes about through competition among bidders to get the goods, then it is only what is contemplated at an auction. "Bidding up" may refer, however, to a process whereby bidders with no desire themselves to purchase, collusively enter increasing bids just to drive up the final price in which they have an interest, e.g., a secret share in the proceeds of the sale; a desire to enhance the value of similar goods which they own. Bidding up thus motivated is allegedly very common in the international art market, where even actual purchases at inflated prices are said to be made. Or the motive may be just to punish an "outsider" who dared to show up at a "public" auction thought by professionals (e.g., jewelry dealers) to be "really" their exclusive preserve. In any event, no matter how motivated, collusive bidding up is fraudulent and unlawful. Contrast chilling bids.

bid in. When a foreclosure sale of property given as security is held, the holder of a mortgage or other lien will often "bid in" for the amount of his lien, i.e., bid the amount he is still owed. This is to prevent anyone from acquiring the property for less than the outstanding debt. If the lienholder's bid is the highest, he will acquire the property for no additional cash outlay, the amount of his debt being credited against his own bid. Naturally, the lienholder need not bid in; if the property is worth no more than another's bid, he may allow the property to go for that amount, and try to recover from the debtor the amount still unpaid.

On occasion, the owner or a friend will also "bid in" at an auction so as to prevent property from going for too much less than they had hoped, especially because of chilling bids.

bid off. Successfully to purchase something by bidding at an auction, as in "The Metropolitain bid off three Greek vases at the last Sotheby auction."

bid price. See bid and asked.

bid security. See bid bond. 
bien ( ). Law French for "well," "lawfully," etc.

biennial ( ). Once every two years. Some U.S. States have their legislatures meet only biennially, though there is a clear trend toward annual sessions. A two year period is called a "biennium," as in "The Connecticut legislature has appropriated $\$ 136$ million for education for the 1980-1982 biennium."

Biennial should not be confused with "Biannual" which means the same as "semi-annual," i.e., twice every year, i.e., every six months. But the confusion is understandably epidemic, and it is safest to say explicitly "every two years," "twice a year," etc. when that's what one means.

biennium ( ). See biennial.

biens ( ). A term of old English (and present French) law for all kinds of property, real and personal.

bifurcated trial. A "split" trial or other hearing, i.e., one at which one or more issues are addressed separately from one or more others, all of which are relevant to the particular matter. Common examples are the separate consideration of guilt and penalty at criminal (especially capital) trials and the separate trial of liability before damages at a personal injury case. But (though not usually so thought of) many actions for preliminary relief actually entail bifurcation, e.g., when property is sought to be repossessed for non-payment of debt, it is not uncommon to try first only a limited number of issues, e.g., were the goods sold by the seller/lender and were they paid for, in deciding whether possession is to go back to the seller, with all buyer defenses put over to a later trial on the merits of the claim.

It is argued in favor of bifurcated trials that they can save litigation effort (e.g., if in a personal injury case the defendant wins on liability, there will be no need to try the complex question of damages), and that they prevent the transfer of irrelevant and prejudicial information between segments of the same case, e.g., the horribleness of the plaintiff's injuries might tempt the jury to find the defendant liable no matter what, just to get the plaintiff some recompense. The plaintiffs' bar, naturally, hates bifurcated trials because its members believe that the jury should know that real and awful injuries are involved.

bigamist. One who has committed the crime of bigamy.

bigamy. The crime of marrying or purporting to marry a second spouse knowing that one's prior marriage is still subsisting. Under Model Penal Code § 230.1 , it is only a misdemeanor, and reasonable belief in one's eligibility to remarry is a defense.

Under old English ecclesiastical law, any second marriage, or even a man's first marriage, but to a widow, was bigamy.

$C f$. polyandry; polygamy.

big board. A common nickname for the New York Stock Exchange. See exchange. 
big eight. Common mode of reference to the eight largest national accounting firms.

bigotry. Strongly held prejudice against large classes of persons, especially on the bases of their race, religion, or national origin. There is also political, social and economic bigotry, and some people use "fascist," "communist," and even "bourgeoisie" not very differently than others use "nigger," "kike," and "wop." But the primary reference of "bigotry" is still to race, religion, and nationality.

big with child. Pregnancy, however far advanced, i.e., even though the visual bigness may not yet have shown up.

bilagae ( ). Also sometimes "bilagines." Town or city laws or by-laws. Also used for the by-laws of very old "corporations."

bilan ( ). French for "balance sheet"; usage confined in the U.S. to Louisiana.

bilanciae ( ). Balances; apparatuses for weighing.

bilanciis deferendis ( ). A long-obsolete writ for commanding that scales or balances be taken to a particular place to weigh wool about to be exported.

bilateral contract. See unilateral and bilateral contracts.

bilateral monopoly. In economics, a situation in which an entire market consists of one seller and one buyer. Given the rarity of true monopoly in the real world, true bilateral monopoly is even rarer, perhaps nonexistent. As a theoretical construct, however, bilateral monopoly is interesting, especially for the light it may shine on a more common phenomenon, "bilateral oligopoly," i.e., transactions in markets with few sellers and few buyers. Moreover, transactions between persons already tied to each other in some way (e.g., parties to a contract; joint participants in an automobile accident) tend to partake of many of the indicia of bilateral monopoly transactions, notably that there is no determinate solution to their conflicting claims, the "rational" end-point of their bargaining coming at any point between their respective positions depending on their relative bargaining power.

bilateral oligopoly. See bilateral monopoly.

bilboes. A seagoing version of the stocks.

bilge. The lowest interior space of a ship, and what accumulates there, usually dirty and foul-smelling water.

If combustibles accumulate on the surface of the water there can be a nasty explosion, so bilge is by law required frequently to be emptied, and constantly ventilated.

By extension, any stupid and useless remark can be called "bilge."

biline. Old term for "collateral" when used of a family line.

bilinguis ( ). In older English practice, a jury made up one half of aliens, 
demandable by an alien being tried, once in all actions, then only in criminal ones.

bill. From the Latin for seal, it came to refer to any sealed instrument, and then to almost any formal written document. Hence the term found employment in numerous contexts, including pleading (e.g., bill in equity); legislation (where a bill is a proposed statute); negotiable instruments law (e.g., bill of exchange); and general commercial practice (where bill is the ordinary language term for account rendered).

For the full range of its application, see the entries below beginning with bill. And $c f$. bull.

billa ( ). A bill.

billa cassetur. See quod billa cassetur.

billa excambii ( ). A bill of exchange.

billa exonerationis ( ). A bill of lading.

billa vera ( ). See true bill.

billboard. A structure for the display of political or commercial advertising messages (sometimes still called "bills," as in "post no bills"), especially common in cities and along train and auto routes. While there are those who on a long trip find billboards considerably more interesting than countryside, others find the blockage of "nature" by commercial messages outrageous. These last have by and large won out, at least with respect to the federal highway system, which has very severe limitations against billboards which can be seen from the road.

bill-book. A book in which record of one's commercial paper, whether payable or receivable, is kept.

bill broker. A dealer, either for others or for his own account, in bills of exchange (and usually other kinds of commercial paper too).

billet ( ). Once a "ticket" given to soldiers to give to persons upon whom they were to be lodged, ordering the latter to supply the lodging. Now used for the lodging itself ("Captain Flagg is billeted up at the officers club"). It was this richly resented practice of forcibly lodging military personnel in civilian homes which is the subject of the Second Amendment to the U.S. Constitution, which forbids it in peacetime and regulates it during war.

billeta ( ). In older English parliamentary practice, a bill (i.e., proposed statute), or a petition.

bill for a new trial. A bill in equity praying for an injunction against enforcement of the judgment in an earlier action at law and a new trial thereof. The grounds were either that the petitioner's defense was good but not available at law, or that he was prevented from presenting it there by fraud or mischance, with no negligence or wrongdoing on his part. 
bill for cancellation. A bill in equity praying the cancellation of some written instrument on some ground recognized in equity.

bill for foreclosure. See foreclosure.

bill for reformation. See reformation of instrument.

bill for specific performance. See specific performance.

bill-head. The printed letterhead upon which a merchant will ordinarily send out his account rendered.

bill in aid of execution. Just what it sounds like, but with particular reference to attempts to have alleged fraudulent conveyances set aside.

bill in chancery. English synonym for bill in equity.

bill in equity. A pleading seeking equitable relief from a court of equity; the equity equivalent of a complaint at law, i.e., the plaintiff's first pleading. Under modern U.S. practice, all "civil actions" (which include both legal and equitable actions) are commenced by filing a "complaint." See Fed. R. Civ. P. 3.

bill in perpetuan rei memorium ( ). See bill to perpetuate testimony.

bill in the nature of a bill of review. See bill of review.

bill in the nature of a bill of revivor. See bill of revivor.

bill in the nature of a supplemental bill. See supplemental bill.

bill in the nature of interpleader. See interpleader.

bill not original. See original bill.

bill obligatory. An unconditional promise or bond to pay a sum certain on a date certain, differing from a promissory note only in its being a sealed instrument. Also called "bond single," "bill single," "single bill," or "single bond." Most old penal bonds were bills obligatory, but not vice versa.

bill of adventure. A formal written statement by one in whose name goods are shipped (who may be a merchant, ship master or ship owner) that the goods are really the property of another, and are shipped at the other's risk.

bill of appeal. The plaintiff's initial pleading in the (now obsolete) appeal of felony. Also a term for a notice of appeal or other document seeking appellate review.

bill of attainder. Article $1, \S 9$, clause 3 of the Constitution provides "No Bill of Attainder or ex post facto Law shall be passed [by Congress]." Article 1, $\S 10$, clause 1 provides "No State shall ... pass any Bill of Attainder ...." These clauses have been uniformly interpreted to bar both federal and state government not only from legislatively imposing an attainder on any person, but from any legislative imposition of punishment for any alleged crime, i.e., before being punished for [a] crime one must first be accorded a judicial trial.

bill of certiorari ( ). In English practice, a formal request for the issuance 
of a writ of certiorari, i.e., a request that a matter be moved to a court or to a higher court for appeal. In U.S. Supreme Court practice, the request for the writ is called a "petition" for certiorari.

bill of conformity. A bill in equity brought by an executor or administrator who found the estate so complex or muddled that he dared not administer it except under the direct supervision of the Court. The bill was brought against all of the alleged creditors; when the proposed order for distribution to them was confirmed by the Court, they would have no credible claim against the estate or its representative.

bill of costs. An English solicitor's formal statement of his costs in a legal matter, prepared for submission to his client. (In England, "costs" include not only court fees and disbursements, but attorneys' fees.)

The term is also sometimes used in the U.S. to describe the formal and sometimes sworn or certified statement of court "costs" served by the party who was awarded them on the party who was ordered to pay.

bill of credit. A bill of exchange or promissory note issued by a government against its own credit and meant to circulate as lawful paper money. The U.S. federal reserve note is a modern example of a bill of credit.

See also letter of credit.

bill of debt. An old term which encompassed promissory notes (including the sealed ones called bills obligatory) and bonds for the payment of money.

bills of discovery. A bill in equity seeking to have an opposing party in litigation compelled to make facts in his possession, including documents, available to the moving party. It encompassed much of what is now covered by Rules 26-37 of the Federal Rules of Givil Procedure and its state-level analogues.

bill of divorcement. A fancy translation of the Hebrew "get," the formal statement unilaterally made by a husband sufficient under Jewish Law to divorce a wife. The procedure is much more complicated for the husband than appears on the surface, e.g., financial provision had to be made for a guiltless divorced wife.

Also a term which may sometimes have been used to describe the formal request for a divorce filed in a legislature back when civil divorce could be procured only by legislative action.

bill of entry. A certificate given to customs officials by an importer giving details about goods being imported (e.g., nature, cost, port from which shipped), required to gain possession of the goods. In England a similar certificate must be given with respect to goods being exported.

bill of evidence. An old term for a transcript of trial testimony, especially when prepared for use as part of a bill of exceptions.

bill of exceptions. A formal statement, prepared for use on appeal of a trial judgment, of the objections and exceptions taken to rulings, charges, and other actions of the trial judge, together with the reasons alleged for their 
incorrectness. It ordinarily had to be signed by the trial judge to attest its accuracy. In modern practice (see, e.g., Fed. R. App. P. 10), no separate certified bill of exceptions need be prepared, it being sufficient to file as part of the record on appeal the relevant portion of the trial transcript showing timely entry of exceptions and objections at the trial. If there is no transcript available, something like a bill of exceptions (appellant prepares statement, appellee objects or proposes amendments, trial judge approves final version) is still necessary. See Fed. R. App. P. 10(c).

bill of exchange. One of the two most important types of commercial paper (the other being the promissory note). It is a three-party written instrument in which the first party (the "drawer") orders a second party (the "drawee") to pay to a third party (the "payee"), a sum certain in money, either on demand or on some specified future date. The term "draft" has long been a synonym, and remains so under U.C.C. § 3-104(2)(a). (The modern check is actually a demand bill of exchange the drawee of which is a bank.)

Bills of exchange were developed to cope with two key problems of commerce: (1) how to effect payment to distant debtors without having to risk transferring cash; and (2) how safely to give credit to a distant and not thoroughly known potential debtor, especially one located in a foreign jurisdiction the legal system of which one does not totally understand or trust.

The original purpose of bills of exchange (perhaps used as early as the twelfth century in Italy) seems to have been to cope with the first problem. Let us say that someone in Verona wishes to transfer wealth to someone in London (as a loan, or in payment of some obligation). He could send cash-gold or silver originally - from Verona to London, but that would be very cumbersome and risky. Instead he could leave cash in some place of safety in London (the early depositories seem to have been goldsmiths) and send, in place of coin, a written order which, when presented to the London goldsmith, would direct him to pay a certain portion of the local cache to the London transferee. And if people in London who owed the Veronese money paid it not to him in Verona but to his London goldsmith, the London cache could be continuously replenished.

It became apparent reasonably quickly that the bill of exchange could also be used to facilitate credit transactions between comparative strangers. Let us say that a London merchant wished to sell goods to a Verona merchant and was willing to wait some time before being paid. He could of course, just accept his Veronese customer's promise to pay the debt when it came due. But he might not know very much about the promisor's financial health, and the idea of having to sue and enforce payment in Verona would make the Londoner's blood run cold. If, however, the Verona merchant had someone known to and trusted by the Londoner in London who would agree to make the payment when due (either the holder of a cash horde of the Veronese, or just someone willing for other reasons, perhaps longstand- 
ing business relations, to vouch for the foreigner), then the grant of credit would become much less risky.

The following general techniques thus developed. A bill of exchange would be drawn (either by the Veronese or the Londoner) ordering the London drawee to pay a sum certain to the London creditor on a particular date. This would be presented to the drawee. The drawee would "accept" or "honor" the bill, by writing his acceptance on it. By that act he would add his credit to that of the local debtor. (If the bill were not accepted, or [not] paid after being accepted, it was said to be "dishonored," in which case the debtor would still be liable to the payee-creditor.)

In time, of course, the process of accepting bills of exchange became a business; drawees did it for profit. Banks are now engaged in the business (their accepted bills are called "bankers' acceptances") as are more specialized institutions sometimes called "acceptance houses." In modern international trade, potential debtors arrange in advance with the drawees for the acceptance of their bills, usually by procuring a letter of credit. (See documentary sale.) And while most modern checks are used mainly to effect non-credit transfers, they too can be used as a credit enhancing device; a certified check is essentially a demand bill of exchange drawn on and accepted by a bank.

See also acceptance for honor; bank draft; foreign bill of exchange; inland bill of exchange; protest of negotiable instrument; sight draft; time draft; trade acceptance.

bill of goods. A list of items purchased, originally referring for the most part to the checklist of goods used by wholesalers' itinerant salesmen, or "drummers," when selling to retailers. The expression "He sold me a bill of goods" meaning "He put one over on me" most likely arises from the fasttalking-drummer dramatic situation.

bill of health. In maritime law, a formal document given to the master of a ship by a responsible official of a port the ship is about to leave, describing the state of health of the port. The paper is to be exhibited at the ship's next port of call. If there is no known infectious disease, the master will be given a "clean bill of health." If there is no knowledge, but reason to fear pestilence, the bill of health will be "suspected." If pestilence is known to exist, the master is issued what is charmingly called a "foul bill of health," and the ship is quarantined outside its next port.

The expression "clean bill of health" has passed into ordinary language to mean that a person or organization has been examined and found sound, as in "The brokerage house was investigated by the SEC, and eventually given a clean bill of health."

bill of indemnity. An act of the English Parliament passed yearly until 1869 (when a more general statute rendered further yearly enactment unnecessary) indemnifying officers who had accidently or unavoidably failed to take their oaths of office for any liability thereby incurred. $C f$. act of indemnity. 
bill of indictment. The formal written charges of crime presented to a grand jury for its consideration. When the grand jury has made its additions and modifications if any, and found a "true bill," i.e., decided that the defendant should stand trial, what it issues is called the indictment.

bill of information. The same as a bill of indictment, but for a criminal-law information.

Also, in older English practice, the name of a "petition" filed by the Crown with respect to an alleged trespass or debt affecting Crown property.

bill of interpleader. See interpleader.

bill of lading. A receipt given by a carrier for goods put into its possession, together with its promise to ship and deliver them, and other contractual provisions. A "clean bill of lading" is one without special conditions or instructions written in the margin. A "straight bill of lading" is one naming a particular consignee; only he can claim the goods. A bill may have negotiability, however; if made out "to bearer" or "to X or order," or otherwise recognized as negotiable by the customs of international trade (see U.C.C. $\S$ 7-104), it may be transferred by endorsement and any holder has the right to claim the goods. (A negotiable bill of lading is sometimes called an "order bill.") Negotiable bills of lading make it possible to transfer the right to goods without delivering the goods themselves, which is useful in general and especially in connection with a documentary sale.

See also bills in a set; foul bill [of lading]; overseas bill of lading; through bill [of lading]. And $c f$. warehouse receipt.

bill of lading with draft attached. See documentary sale.

bill of Middlesex. The English Court of Kings Bench did not originally have general jurisdiction over purely civil actions, though it did have jurisdiction over trespass. To acquire wider civil jurisdiction, it developed [the] following scheme. The court would issue a command to the sheriff of Middlesex directing him to arrest the civil defendant for a (purely imaginary) trespass. If he was found in Middlesex and brought before the court, they just tried the case really at issue. If the sheriff could not find him in Middlesex, he so reported and the court ordered the sheriff of the county in which he could be found to bring him in, pretending that he had really escaped thence from Middlesex. Then they tried the actual dispute. Eventually, the court dropped the vain search in Middlesex, and the whole charade was finally rendered unnecessary by an 1833 statute.

Cf. ac etiam; legal fiction.

bill of mortality. A statement of the number of deaths in a particular locality over a particular time. A particularly important document when plague and pestilence were to be feared and required the earliest possible discovery.

bill of pains and penalties. A milder form of bill of attainder, brought with respect to lesser crimes than felonies and prescribing lesser penalties than 
death. It too is deemed to be forbidden in the U.S. by the bill-of-attainder provisions of the Constitution.

bill of parcels. An invoice.

bill of particulars. In criminal procedure, a formal statement delivered by the prosecution to the defendant (often by order of court) giving further details about the crime alleged in the indictment, e.g., the precise time, place, and manner of its execution. The purpose is to aid the defendant in preparing his legal and factual defense by giving him facts not necessarily conveyed by the formalistic language of indictments. See, e.g., Fed. R. Crim. P. 7.

In civil procedure, a similar document was sometimes required, but in modern practice its place is generally taken by the whole arsenal of modern civil discovery (e.g., Fed. R. Civ. P. 26 et seq.). But Fed. R. Civ. P. 12(e), authorizing a "Motion for More Definite Statement" which may be brought before filing a responsive pleading, serves almost the same specific purpose as the old civil bill of particulars.

bill of peace. A bill in equity (and one developed early in its history) filed to procure what is in effect an injunction against further litigation of claims repeatedly and recently litigated. If, for instance, a claimant had brought ejectment against a landholder contesting his title, and lost, and then brought another action and another and another, the defendant in ejectment might file a bill of peace to make him finally stop his harassing behavior. Another old use of bills of peace was in coping with continuing disputes between a lord and all the tenants of a manor; it was, in effect, an attempt to cope with some of the problems caused by the unavailability of any procedure like the modern class action. See also quia timet; quieting title.

bill of privilege. An old common law form of action to be used when suing an attorney or other court attendant privileged from arrest (at that time arrest being the ordinary process by which a court acquired jurisdiction).

bill of proof. In early versions of the process of attachment and garnishment, notably those pursuant to the custom of London, the person whose property was seized as belonging to the defendant could not raise as a defense that some third party was the actual owner. That third party, however, could raise his own title by way of a bill of proof. Modern procedures of intervention provide similar powers to modern third-party claimants.

bill of review. Essentially an appeal to an equity court asking it to reverse or modify its own prior decision. The bill might allege error apparent on the face of the record, or newly discovered evidence, or fraud. A "bill in the nature of a bill of review" was one brought by a non-party to the original trial. In modern practice provision is still made for seeking relief on grounds of mistake, fraud, etc., from judgments and orders from the very court which rendered them, e.g., Fed. R. Giv. P. 60.

bill of revivor. When an action in equity abated for some technical reason, e.g., a party died or (in older practice) a woman married, this bill was filed 
to start the suit up again once the party-adjustment procedure (e.g., substitution of the deceased party's executor) had been completed. A "bill in the nature of a bill of revivor" was used when the abatement-causing event might have so materially transformed the ownership of the subject matter of the litigation that an original bill would be required (and the new rights in the subject matter litigated).

bill of revivor and supplement. A bill of revivor combined with a supplemental bill, i.e., one which prays revival of a temporarily abated action, while also alleging new relevant facts.

bill of rights. In the U.S., the popular name for the first ten amendments to the Constitution. All state constitutions also have similar provisions.

In England, the declaration (afterwards statute) of William \& Mary upon ascending the throne in 1688, promising never to do the offensive things that the Stuart Kings they were replacing had regularly done, e.g., punish speech in Parliament, levy money without the consent of Parliament, permit excessive fines and bail, etc..

bill of sale. A written instrument evidencing the sale of described personal property from seller to buyer. At one time, the instrument had to be under seal, but thereafter even an unsigned bill of sale might be found to have transferred title prior to transfer of possession of the goods. Bills of sale are less significant now that Article 2 of the U.C.C. makes technical passage of title of less legal significance. But even before the coming of the U.C.C., in ordinary language a bill of sale had come to refer to any document listing what was sold and its price (e.g., those received in department stores), and was understood to have no legal significance except as proof of purchase and payment, useful mainly when trying to return the goods.

Bill of Sewers. A 1531 English statute dealing [with] land drainage and flood prevention (and not with "sewers" in the modern sense at all).

bill of sight. A declaration made to a customs officer by an importer who does not yet know exactly what is in the import shipment being declared, and hence must describe it only to the best of his information and belief. The importer, however, must within a limited time make a more detailed and certain description and pay the applicable duties. The term should not be confused with sight draft.

bill of stores. A customs document permitting the duty free reimportation of local goods previously exported to another country.

bill of supply. An old term for an appropriations bill, i.e., a legislative provision for the costs of government.

bill original. See original bill.

bill penal. See penal bond.

bill pro confesso ( ). See decree pro confesso.

bill quia timet. See quia timet. 
bill rendered. See account rendered.

bills and notes. Another term for commercial paper in general. Also, a law student name for the course more commonly called "Negotiable Instruments."

bills in a set. Also called "bills in parts." Both bills of exchange and bills of lading are sometimes (especially in international trade-see documentary sale) drawn and executed in sets, i.e., several copies identical in every way but separately numbered are prepared. Each states that it is to be honored unless another copy of the set already has been. Members of the set are sent separately, the idea being to keep a deal from foundering just because a document gets lost in the mail.

bills in eyre. Complaints of divers grievances addressed to the justices in eyre, praying in non-technical format for the kinds of relief later available from the chancellors. The practice flourished for about fifty years at the turn of the fourteenth century, and then died out.

bill single. See bill obligatory.

bills in parts. See bills in a set.

Bills of Exchange Act. The Canadian version of the U.S. Negotiable Instruments Act.

Bills of Lading Act. A federal statute (49 U.S.C. $\S 81$ et seq.) regulating aspects of the law of bills of lading, based upon but materially modifying a now defunct uniform law.

bills payable. The bookkeeping term for one's accepted bills of exchange, outstanding promissory notes, and other commercial paper. It comprises a subcategory of accounts payable (see accounts receivable). The term "bills receivable" is the bookkeeping term for such items when one is the obligee rather than the obligor.

$C f$. payable to bills payable.

bills receivable. See bills payable.

bill to carry a decree into execution. A bill in equity brought to get further relief from the court when, for one reason or another, it appears that carrying out a previous decree will be impossible absent such further judicial assistance.

bill to examine witnesses de bene esse. See bill to perpetuate testimony; de bene esse.

bill to marshal assets. See marshaling assets.

bill to perpetuate testimony. A bill in equity brought to get on record the testimony of a party or witness who might not be available when the legal action finally comes to trial. It could be filed as an ancillary action in equity even when the action was to be tried in a court of law and the testimony there used. 
This procedure was also called a "bill to take testimony de bene esse," though that may once have referred only to such a bill filed after the underlying lawsuit had been commenced, while the bill to perpetuate testimony might be brought before any action was commenced. Modern procedural devices, e.g., Fed. R. Civ. P. 27, cover both situations.

bill to quiet [possession] [title]. See cloud on title; quieting title.

bill to remove cloud on title. See cloud on title; quieting title.

bill to suspend a decree. A bill in equity brought to suspend a prior decree, alleging some ground therefor, e.g., fraud, hardship.

bill to take deposition [or testimony] de bene esse. See bill to perpetuate testimony; de bene esse.

billy. Traditional term for a male goat, and also for a policeman's traditional club, also called a "nightstick."

bimetallism ( ). A monetary system in which the units are defined in relation to two metals (usually gold and silver) which are given a fixed rate of mutual exchange. Such systems break down because of the difficulty of stabilizing the values of the two metals. In any event, the withdrawal from metalbased monetary standards has rendered bimetallism (once the subject of William Jennings Brian's "Cross of Gold" speech) no longer controversial.

bind. To create a legally enforceable obligation, as in "If you sign the contract you will bind yourself to carry it out." One may be bound, however, without consent; negligence may bind one to pay damages, and a statute, to pay taxes.

binder. When one applies for insurance, the policy itself is not ordinarily issued until the application is accepted at the insurer's home office. But selling agents of the company are usually authorized to issue a "binder" (also called "agreement for insurance," "binding slip," "interim receipt," "binding receipt," "conditional binding receipt"), which will give insurance protection to the applicant while the company is deciding on the application. This protection usually will apply unless the applicant has been guilty of fraud, material misrepresentation, or something similar, but in some instances the coverage is more extensively conditioned.

Also, in connection with sales of real property, a memorandum of a deal, signed by either or both parties, designed to "hold" the deal until a formal contract can be signed. These are frequently not meant, by at least one of the parties, to be legally enforceable, but if the document looks like a contract, and is accompanied by consideration, the party who thought he was not legally bound may be in for a nasty surprise. Hence, explicit statement of the non-binding character of this kind of binder is strongly to be recommended.

binding agreement. A contract.

binding authority. Legal authority which a judge must follow (or at least dis- 


\section{Leff Dictionary of Law}

tinguish away), e.g., decisions of a higher court, or acts of legislation, in the same jurisdiction. Other authorities, e.g., decisions in another state, may be persuasive, but the judge has no duty to follow them, or even bother to mention them.

binding instruction. A somewhat misleading term, since all instructions from judge to jury are binding, in the sense that it is the jury's duty to heed them. A binding instruction is one in the more particular form "If you find facts $X, Y$, and $Z$, and do not find facts $P$ or $Q$, then you must find for the plaintiff."

binding over. The process by which a court extracts a binding promise, often buttressed by requiring that bail be furnished, from a criminal defendant or some other litigant or witness, that he will appear at some subsequent proceeding, or take some other act, e.g., keep the peace. See also affidavit to hold to bail; bond to keep the peace; $c f$. abearance.

The term is also used to describe the process whereby a lower court judge or magistrate, having determined that there is probable cause to believe that a defendant has committed a crime, refers him for further proceedings to the grand jury or a higher court. Often the process is combined with that of arraignment.

binding receipt. See binder.

binding slip. See binder.

bind out. To make one an apprentice, as in "The father decided to bind out his son to the blacksmith, so as to give him a useful trade."

bingo. A game of chance much favored by institutions like churches as a means of raising money. The player buys a card bearing randomly numbered squares. Numbers on little balls are picked at random and called out. The winner is ordinarily the first to fill a contiguous line of squares. The profit to the game operator is the difference between the amount bet (by buying the card) and the amount paid to the winners. For some reason bingo appears to its charitable sponsors less disreputable than similar games like roulette and dice.

binomial distribution. In statistics, the theoretically expected distribution of a series of random samples drawn from a population divided into two categories, e.g., male/female. It will give, e.g., the number of samplings that, if randomly made, would come up $100 \%$ male, $90 \%$ male, $80 \%$ male, etc., against which one can measure the actual result of actual samplings, thus to discover if the result in the actual case indicates the presence of a significant variable or is just as likely to be the result of randomness.

bipartisan. In systems with two dominant political parties, a course of action in which both parties work together, submerging partisan disputes from some perceived greater national good, as in wartime "bipartisan foreign policy," (which more often was called nonpartisan).

In some instances, certain organs of government, e.g., some municipal 
boards, and federal administrative agencies, are required by law to be bipartisan. This only rarely means that they must have equal membership from each party, but rather than there be some representation of each, with the usual pattern being that the minority be assured only one vote less.

bipartite. "In two parts," especially used of an agreement executed in two copies, one being given to each signatory. But the term is sometimes corrupted to mean "having two parties," as in "the bipartite agreement between Austria and Poland."

bircher. See John Birch Society.

birds. If domestic (e.g., hens, duck, tame pigeons), taking them is larceny. If wild (e.g., untamed hawks), no one has property, and they belong to the first appropriator.

Birkenhead's Acts. A large number of very important English statutes relating to real property and estate administration, all passed in 1925.

birretum ( ). Also "birretus." A cap or coif anciently worn by English judges and sergeants. See also black cap.

birth. The actual delivery of a fetus from its mother to the outside world. At that point, unlike an unborn fetus it becomes for certain a "person" for all legal purposes. $C f$. abortion.

birth certificate [or record]. A document formally recording the fact, date, time, place, etc. of birth of a person, kept available on file in some local records office and usable as a means of officially establishing the recorded facts. Under the Federal Rules of Evidence, these certificates are selfauthenticating, benefit from specially liberal rules about the admissibility of copies, and are covered by an exception to the hearsay rule. See Fed. R. Evid. 902, 1005, and 803(9).

birth control. Once essentially a synonym for contraception, but of late sometimes encompassing abortion, i.e., including prevention of live birth as well as initial conception.

bis ( ). Twice.

bisaile. Alternate spelling of "besaiel." See assize of mort d'ancestor.

bi-scot. An ancient English two-shilling fine for failure to keep up banks, causeways, and ditches.

bisextile. An extra day added to make a calendar come out more accurately. In our solar calendar system, the bisextile day is February 29th, added every fourth year. With lunar calendars, about a month must from time to time be added.

bisexuality. Being sexually interested in, and sexually active with, members of one's own and the opposite sex, though not necessarily to an exactly equal degree. See also AC-DC; androgyny.

bishop. A high ecclesiastical officer in a church, especially Roman Catholic, 
Episcopal, or Anglican. A bishop usually has jurisdiction over some number of priests, and is himself within the jurisdiction of an archbishop. For purposes of holding property and effecting legal and business transactions, a bishop is a corporation sole. See also suffragan.

bishopric. See diocese.

bishop's court. See consistory court.

bis petitum ( ). Twice demanded or asked.

biting rule. A rule of construction that, once a will or deed grants an apparent fee simple, a subsequent attempt in the instrument to cut down the fee to a lesser interest will be held inoperative.

bkpt. Standard abbreviation of bankrupt.

black. A synonym for negro, in recent years preferred thereto by large numbers of people, including many of those so identified. Frequently capitalized.

Blackacre. Fictitious name of a tract of land, useful for legal discourse, especially law school hypotheticals addressing questions of real property law. When additional tracts are needed for forwarding discussion other colors are used, with "Whiteacre" being the usual next choice.

Black Act. A 1723 English statute (also called the "Waltham Black Act") which, ostensibly passed in response to the activities of a group of people who blackened their faces and poached and destroyed deer and trees in Waltham Forest, created a huge additional number of offenses against property punishable by death. It was finally repealed in 1827 .

Black Book of the Admiralty. A very old compilation of laws and commentary on maritime law, thought to have been begun under Edward III (1326-1377) and completed under Henry VI (1422-1461).

\section{Black Book of the Exchequer. See Red Book of the Exchequer.}

black-box theory. A mode of scientific description used in lieu of explanation which merely notes a repeated close association between phenomena without offering any description of the mechanism by which they are associated. Associating sunrise with the passage of time is a black box theory; knowledge of the rotation of the earth turns it into something else. In dealing with human activities, so little is firmly known about what goes on "inside" people, that most theories of personal and social behavior are mostly black-box. Since such theories do not pretend to know what variables are actually implicated in the association, e.g., between acts to be deterred and threatened punishments, they tend to be much more open to disappointingly poor prediction and manipulation. Law itself, of course, at least when seen as prescriptive command, is itself based upon black-box theories of behavior.

black cap. A square black hat worn by English High Court judges on state or solemn occasions, including the imposition of a death sentence. See also birretum. 
black codes. Statutes in effect in most southern states prior to (and for a short time after) the Civil War, regulating, segregating, and systematically disadvantaging blacks. Whatever other purposes the 1866 Civil Rights Act might have had (see Jones v. Alfred H. Mayer Co.), one aim was totally to abolish the black codes.

blackjack. A weapon made by encasing lead or other heavy metal in a leather pouch with a flexible handle. Used both by the bad guys and (occasionally) the police. It is usually deemed a "deadly weapon" for purposes of "assault with a deadly weapon."

Also, another name for the gambling game twenty-one.

blackleg. An uncomplimentary epithet, used to describe, among others, professional gamblers, scabs, and strikebreakers.

black letter. The Old English or Gothic typeface of ancient manuscripts and the earliest printed books. Originally very different from boldface type, but today "black letter" pretty much means "boldface" except to those in the printing profession.

black letter law. Informal legal locution for the basic principles of law in any field, as in "It is black letter law that without mutual assent there can be no contract." As the example indicates, much of the time black letter law isn't very accurate. The term may derive from the practice of printing treatises with boldface summaries at the head of paragraphs, with the finer points relegated to ordinary print.

blacklist. Any list of persons to be punished or avoided, circulated within a particular group. Common examples include lists of employees discharged as "troublemakers" (usually meaning "union organizers") circulated among employers, and lists of poor credit risks circulated among businessmen. A famous recent blacklist was of people in the entertainment industry suspected of Communist leanings, circulated to, and used by, the radio, television, and movie industry during the height of McCarthyism.

The word can also be used as a verb, as in "Dashiel Hammett was blacklisted in the 1950's."

Black Lung Benefits Act. A federal statute (30 U.S.C. $\S 902)$ providing benefits to miner victims of "black lung," a disease caused by long-term inhalation of dust.

blackmail. The crime of extorting money from another by threat of making known his previous criminal or other deeply embarrassing conduct. Often included in statutes that also cover extortion by threat of inflicting personal or property injury, but today usually distinguished from extortion by threat of force.

Blackmail is an interesting crime in that one can be convicted for collecting money for not doing what one has a legal right to do, unlike extortion by physical threat where the threatened act, if carried out, would itself be tortious or criminal. 
Also, another term for "black rents," for which see alba firma.

black maria ( ). Common slang term for the locked van used by the police to transport prisoners from place to place.

black market. A government will sometimes forbid or extensively regulate trading in certain goods, e.g., when goods are rationed in wartime and are not supposed to be sold except to those authorized to receive them, who are in addition to pay only a government stipulated price. Others desiring the goods but not entitled to them will seek to acquire them by paying a much higher price, and some people will seek to meet that demand. The "market" in which they trade is called the "black market." Sometimes the term is also loosely used to include sales of totally contraband goods, e.g., heroin, automatic weapons, etc.

Cf. gray market.

Black Muslims. An organization of American Blacks founded in 1930 combining religious adherence to Islam with strong doctrines of racial purity and pride. It became increasingly important and publicly visible in the U.S. in the 1960's, and remains at least viable today.

blackout period. In insurance parlance, that period-between the time her youngest child reaches eighteen and she herself reaches sixty-two-during which a widow will not receive any social security payments.

Black Panthers. A militant black organization, prominent at least in the media during the late 1960's and early 1970's, thereafter to decline (through external harassment and internal strife) into eventual practical nonexistence.

black rents. See alba firma.

Black Rod. The full title of this English functionary is "Gentleman Usher of the Black Rod," the name coming from his symbol of office, a black rod topped by a gold lion, which he carries on formal occasions. He anciently was an important officer of the Order of the Garter and technically still is, but his more significant present function is to attend upon the House of Lords when Parliament is in session, acting as the Crown's chief herald (e.g., summoning Commons to Lords when the King makes his address from the throne), and as a sort of Sergeant-at-Arms. Into his custody all peers impeached for crime were, and are, committed.

Blackstone. The author, and hence the short title, of Commentaries on the Laws of England, the last great attempt to restate and rationalize all of English law. Written by Sir William Blackstone (1723-1780), and first published between 1765 and 1769, it went through an enormous number of editions and was immensely influential, in England and perhaps even more in its colonies, especially American: There eighteenth and nineteenth century legal apprenticeship often consisted of little more than committing much of Blackstone (usually in versions modified for the American market-see, e.g., Kent and Tucker) to memory. A massive attempt to show that "the common law" was basically rational and, in a sense, inevitable, 
the Commentaries have been criticized as "vicious rationalism," apologetics for the political and social status quo. But the success of the work was not solely a result of its political conservatism; it was and is quite a scholarly performance, full of old learning and almost forgivable ingenuity.

blada ( ). Grain of all kinds.

blada a solo separata ( ). Harvested grain.

blada crescentia ( ). Growing grain.

blada nondum a solo separata ( ). Grain not yet harvested.

bladarious ( ). Grain dealer.

blanc ( ). Law French for "white," and for "blank" in the sense of unmarked, as in "blank sheet of paper."

blanc bar. See blank bar.

blanche firme ( ). Law French equivalent of alba firma.

blanch-farms. Variant of "blanche firme."

See alba firma.

blancus ( ). Same as blanc.

blank. Totally empty as in "He took out a blank sheet of paper." $A$ blank is a space on a form or other document not yet filled in.

blank acceptance. An acceptance on a bill of exchange made by the drawee/ acceptor in advance and delivered to the drawer or payee.

blank bar. A plea in bar interposed by the defendant in an action of trespass quare clausum fregit, the effect of which was to force the plaintiff to specify exactly where the alleged trespass was committed. Also called "common bar," most likely because the practice was principally confined to the court of Common Pleas.

blank bill. A bill of exchange with the payee's name not specified; as a practical matter, bearer paper. $C f$. blank check.

blank check. A check signed, but with the payee, or amount, or both, left blank. This is obviously a dangerous thing to do, for the drawee of the check is entitled to pay whatever amount is filled in, leaving the drawer only the holder of the check to go against if a fraudulently or mistakenly excessive amount is filled in. Blank deeds are also sometimes (but one hopes rarely) executed and delivered.

The expression "gave a blank check" has come to mean "left everything (especially spending decisions) to the recipient's discretion," as in "He made him president of the subsidiary and gave him a blank check to clean up the mess."

blank deed. See blank check.

blanket. An adjective usually used in legal contexts to denote multiple application or coverage, as in blanket bond, blanket mortgage, blanket policy, 
blanket search warrant. But it can be used of judicial actions too, as in blanket injunction.

blanket bond. An indemnity bond covering more than one risk-producing project, or given to dissolve more than one lien.

blanket injunction. An injunction issued against multiple activities, or against multiple parties with respect to the same activity, or both. A schoolintegration injunction, e.g., is usually a blanket injunction.

blanket insurance. See blanket policy.

blanket mortgage. A mortgage covering more than one piece of property given to secure a single debt.

blanket policy. A policy of insurance covering more than one item (or all items) of property at a given location, or all items of a particular type of property at several places, or both. The term may also be more loosely used to describe some kind of group insurance as in "I've got a blanket life and health policy covering all my employees."

blanket position bond. A fidelity bond protecting the employer from losses caused by employee dishonesty, especially embezzlement. Cf. banker's blanket bond.

blanket rate. A special insurance premium rate for blanket coverage, replacing the rate which would apply if all the separate items covered were charged at their normal individual rates.

blanket search warrant. A search warrant authorizing either (a) search and seizure at more than one specifically described location; or (b) search at one location but seizure of everything there. The latter is like the old general warrant and is unlawful both at common law and under the Fourth Amendment.

blank indorsement. An indorsement of a negotiable instrument, which specifies no indorsee, i.e., which does not restrict the person to whom the indorsed instrument may properly be paid. An instrument endorsed in blank becomes bearer paper, and is negotiable by mere delivery. See U.C.C. § 3204(2).

A stock certificate, bond, etc. in registered form bearing a blank endorsement is also thereby transformed into a security payable to bearer. See U.C.C. § 8-308(1) and (2).

blasarious ( ). An arsonist; "firebug."

blasphemous libel ( ). See blasphemy.

blasphemy. The utterance of statements denying the existence of God or other basic tenets of religion, or committing the equivalent of defamation of the Deity or his servants. Blasphemy (and its written form, "blasphemous libel") is a misdemeanor at common law, but in the U.S. the First Amendment makes its criminalization unconstitutional. $C f$. heresy. 
blees ( ). Garbled Law French for "grain." ( $C f$. the French "ble" meaning "wheat.") "Blees scies" is cut or harvested grain.

blended fund. A fund of money produced from more than one source, e.g., the fund that arises when a will instructs an executor to sell all real and personal property.

blessed letters. Ex parte letters from the Federal Reserve Board administrators of the Truth-in-Lending Act immunizing lenders from civil penalties if they follow the disclosure practice approved in the letter.

bleta ( ). An old word for peat.

blighted area. A term sometimes used to denominate a locality on its way to becoming a slum, but now used as a rough synonym for "decayed area" or "slum" in statutes providing for slum clearance or urban redevelopment. See, e.g., 42 U.S.G. $\S 1460$ (a). The term turned out to be as hard to define in practice as its synonyms, though the government has spent miles of regulations trying.

blind. See blindness.

blind alley. A dead end from which one can retreat only the way one came. Thus by common metaphorical extension, an unsuccessful attempt at the solution to a problem.

blind corner. One at which a driver, because of the angle of intersection or obstructing structures, cannot see vehicles on the crossing road.

blindcraft. Useful items made by blind people, especially those in institutions; frequently produced for sale to help defray the costs of their maintenance.

blind drive [or driveway]. A private driveway entering a public road in such a way that drivers on the road cannot see it, drivers on it cannot see the road, or (frequently) both. Signs are often put up to warn those on the road, and it may be negligent not to do so.

blindness. The condition of being without sight. It may be total or partial, e.g., one may suffer from blindness but be able dimly to detect moving shapes. Blindness is variously statutorily defined, often in terms of percentage of normal vision or by other technical criteria, for divers purposes, e.g., receipt of disability payments, and one may be "legally blind" for some purposes even though one retains a substantial measure of sight.

See also color blindness.

blind pig [or tiger]. Now quaint Prohibition-time synonyms for speakeasy, itself a term quickly growing quaint. "Blind pig," however, may still be used to refer to places where liquor is sold after lawful hours in the particular jurisdiction.

blind-pool offering. A real estate syndication offering in which, at the time of the offering, no specific properties are listed for acquisition, the potential investors being advised only of the criteria to be used in choosing properties. This is also sometimes called a "nonspecified-property offering." The alter- 
native technique in which the specific properties are described from the beginning, is called a "specified-property offering," and when only one property is specified, it is a "single-property offering."

bloc ( ). A group that for at least some purposes acts in concert, e.g., the "farm bloc" or "nonaligned bloc [of nations]." Cf. en bloc.

block. Properly, an area within a city or town bounded by (usually) four streets. But the term is often used to refer to one of the streets and the houses fronting on it, as in "Sure I know Joey; he lives on my block."

blockade. One nation's interdiction by force or threat of force of any movement in or out (or both) of the territory of another nation. It is recognized in international law as an adjunct to war between the blockading and blockaded powers. (But see also pacific blockade.) A blockade must bar all neutral powers or none; it cannot properly be selective among neutrals. And it must be "effective," not just a "paper blockade"; if not enforced in fact it need not be heeded.

A blockade is "strategic" if it is part of a military campaign in the area (in which case it is usually part of or combined with a siege). It is "commercial" if the aim is just to cut off the blockaded territory, but not in connection with military activities there. If it blocks only ingress, it is a "blockade inward"; if egress, a "blockade outward," but most blockades are total.

A power may decide to blockade only the vessels (which include airplanes) of the blockaded power and its allies. But the most common and most effective blockades also bar neutral powers. If a neutral vessel (with notice-see de facto blockade) nonetheless seeks to get through (see violation of blockade), it and its cargo may be seized and, after trial in a prize court, be confiscated by the blockading power. Naturally, if the neutral power puts up a fight and refuses to recognize the blockade, the neutral and the blockading powers may eventually find themselves at war.

blockage rule. A rule applied in the valuation of corporate stock, especially for gift and estate tax purposes, which permits large blocks of stock to be valued at some substantial discount from their apparent market value. The theory is that if a large block of stock were in fact put on the market, that fact alone would depress the market price (which depends, of course, on the relation between supply and demand), with the extent of the depression dependent on how large a proportion of the total the block comprises. But [a] block large enough to confer control of the company on the buyer may actually fetch a premium price.

block booking. The practice (eventually found to violate the antitrust laws) in the motion picture industry of agreeing to license some films to theatre owners only if they would agree also to take others released by the same distributor.

blockbusting. A technique for increasing real estate brokerage income by playing upon the racial fears of homeowners. The blackbusting broker buys up 
a few properties in a neighborhood adjacent to a minority one, often paying premium prices. He then sells it to minority buyers, sometimes at a loss. He then starts rumors that the neighborhood is "turning" and aggressively solicits other owners to sell quickly, lest they be left behind either to have to sell their severely devalued properties later or to have to live among (to them) unattractive neighbors. Sometimes the first minority members moved in are not bonafide buyers at all, but straws imported to behave as offensively as possible. In effect, the blockbuster is seeking to create a bandwagon effect, a vastly increased volume of panicky home sales, for he stands to gain solely from the increased number of sales commissions and has no regard at all for the ensuing decrease in property values. Blockbusting is outlawed by state and national law (including the Civil Rights Act of 1968) but it is the very devil to prove if handled with any sophistication. See also fair housing laws.

blocked account. An account in a bank or similar institution access to which by the owner is, by government action, totally forbidden or sharply restricted. The most common restriction is against transfer of the deposits out of the country, instituted to cope with a growing flight of assets. Sometimes a nation will allow its citizens or temporary residents to receive foreign currency but only if it is "blocked," i.e., it has to be spent locally. Indeed some currencies may be "blocked currencies," i.e., it is illegal to export them whether deposited in a bank or not. A country will block all of the locally deposited assets of another (and its citizens) when war breaks out between them, or as an act of retaliation for the other's committed and threatened hostile acts, e.g., the 1979 U.S. decree blocking Iranian assets in the U.S.

This process should be distinguished from that which takes place when, in connection with litigation, courts order restrictions placed upon bank accounts which are the subject of the action, or should be kept intact to pay any damages awarded. $C f$. garnishment.

blocked currency. See blocked account.

block grant. Any governmental grant which, instead of being made for a particular purpose, is made to another entity, especially a lower level of government, to be allocated and administered by it. The term is used especially to describe a federal community development grant to an organ of local government.

block limits. The maximum amount of fire insurance a company will write for any city block; the limit is imposed to reduce exposure should the whole block burn.

block policy. A term for a blanket policy, especially one that covers essentially all risks on all property of the insured.

block to block rule. A rule pursuant to which owners of property in a block of a city or town are assessed for the cost of opening a street through it. 
blood. Both the complex liquid which flows within the bodies of many animals and, metaphorically, shared genetic inheritance. See also consanguinity.

See also entries beginning with "blood," e.g., blood brother, and those containing the word, e.g., half blood.

blood brother. A brother by commonality of parentage, rather than by adoption or intermarriage of the surviving members of each pair of parents. See stepchild. It is unclear if "blood brother" is used for children related by half blood, i.e., those sharing only one biological parent. See brother. (The usage for female siblings would seem to be "blood sister," but it is hardly ever seen.)

"Blood brother," however, is most commonly used to emphasize a close relationship with a person not related to him by blood; when a person says another is his "blood brother" he ordinarily is asserting that he is like one (in loyalty, identification of interests, etc.) despite the lack of biological connection. Sometimes a ceremony turning on the double meaning of blood (physical substance and shared heredity) is involved: The "blood brothers" superficially wound themselves and mingle the blood that flows. But this seems confined today to "primitive" tribes and romantic young boys.

blood feud. A state of private war between groups each of which is related by blood. It is also frequently bloody in fact and, because the group identification is hereditary rather than geographic, ideological, or acquisitive, etc., it has a tendency to continue down through generations. It has been frequently suggested, and sometimes believed, that the early history of criminal law and what we now call the law of intentional torts is rooted in the social need to oust the blood feud as the primary means of protection against violence.

blood grouping test. See blood test.

blood heirs. See heirs by blood.

bloodhound. A dog trained to use its astonishingly developed sense of smell accurately to follow the trail of a person or other animal. Such a dog may be used to follow and find a fleeing felon or escaping prisoner. It may also establish the movements of a relevant person for use at a trial, especially that a criminal defendant was at, and fled from, the scene of a crime. Bloodhounds, of course, are not infallible, but the powers of these organic tracking devices have been well enough established scientifically to render testimony about their performance admissible.

The name "bloodhound" is that of a particular breed, but is also used for other breeds with similar powers.

blood money. The term seems to have three separate common references. The first is money paid in compensation for the death of another as a means of averting retributive vengeance. See, e.g., angild.

The second reference is money paid by way of encouragement or as reward to one who turns in a person charged with an offense, especially if capital. Judas' thirty pieces of silver would be "blood money" in this sense. 
The third meaning (which seems rare) is money paid to a hired killer.

blood stains. Stains left by blood, the identification of which is important in many criminal actions. Once "set," blood stains are longlasting and almost impossible to remove because they are in effect the rust stains left by the iron compounds in the blood. If reasonably recent, a great deal about the source of the blood can be scientifically determined, including not only what species it belonged to, but even sometimes which individual animal.

See blood test.

blood test. Of the many kinds of scientific tests which can be performed on blood, four are of particular legal significance. One is the test (there are several now) to detect the presence of syphilis or other venereal disease, the successful (i.e., negative) passage of which is, in many jurisdictions, a precondition to the issuance of a marriage license. The "Wasserman test" for syphilis was the earliest (early twentieth century) successful one, and it is still in use.

The second legally important group of blood tests are those designed to identify with precision the source of a particular blood stain or other blood sample. Early tests (e.g., the early "Bernstein test") used as the method of dfferentiation only the four main blood types $(A, B, A B$, and $O$ ) and thus, while it was sometimes possible to exclude someone as source of the blood, it was impossible to make a positive identification. Subsequently, much more sophisticated tests made the positive identification of particular blood sources generally possible, and these can be applied to almost any bodily fluid, e.g., saliva, semen, and sweat, or indeed to any body cell.

The third use of blood tests is to detect and measure the amount of alcohol in the blood of the subject, from which a great deal about his sobriety can be inferred. (A similar test can be made on the breath of the suspect. See breath test.) These tests are, of course, widely used with respect to allegedly drunken drivers, and in some states refusal to submit to such a test after an arrest or accident is grounds for immediate suspension of one's license to drive (a practice declared constitutional by the Supreme Court in 1979).

The last major legally relevant blood tests are those which are designed to detect genetic connections between individuals, e.g., to determine if one person is the biological parent of another. The earliest tests were sufficient only to establish the impossibility of parentage, though later refinements have made positive identification also feasible. (Modern genetic testing makes positive identification essentially certain, but it can be operated on any cells of the two relevant bodies, and thus the most modern tests are not necessarily blood tests any more.)

bloody handed. Similar to redhanded, but particularly applicable to one found with the blood of poached deer still fresh on his hands. See stablestand for the forest-law significance.

blot on title. A defect on title to real property which, if not corrected, will free 
one who was to have purchased the property from his obligation to go forward. $C f$. cloud on title.

blotter. See police blotter; rough minutes.

bludgeon ( ). A heavy club; and the act of using one.

blue chip investments. High quality securities, combining low risk with reasonably adequate return under the circumstances. See also first-class investments.

blue collar worker. See white collar worker.

Blue Cross. Trade name of one of the most widespread of private hospitalization insurance plans. "Blue Shield" is the trade name of its associated medical and surgical payments plan.

blue laws. Once, laws regulating moral conduct strictly and in detail, e.g., criminalizing profanity, disrespect of authority (especially religious), failure to attend church, sexual looseness, etc. Now almost wholly confined to laws forbidding commercial activities on the Christian Sabbath. Present versions of such laws are riddled with exceptions, and are regularly (but not always) declared unconstitutional on divers state and federal grounds.

blue list. A daily listing of municipal bond offerings.

blue notes. Promissory notes accepted by some insurance companies in lieu of immediate cash payments of premiums, the policy being in force until payment of the note is defaulted.

blue ribbon jury. A jury selected so as to be comprised of particularly well educated or "solid" citizens. Use of a blue ribbon petit jury to try a criminal case is quite clearly unconstitutional, but blue ribbon grand juries are still regularly used, especially for investigations into alleged governmental corruption.

Blue Shield. See Blue Cross.

blue sky laws. Law-slang for state laws regulating the sale and sellers of investment securities, designed with the aim of preventing state residents from buying a piece of "blue sky," i.e., nothingness disguised as an opportunity for profit. The statutes vary from state to state, ranging from the perfunctory (and hardly administered) to aggressively enforced detailed regulations of the quality of securities, i.e., not just their mode of sale and level of information disclosure. For the federal statutes pertaining to securities, see securities laws.

blumba. Transliteration of the Yiddish word for a tag attached to meat certifying that it is kosher.

blunderbus. An old non-rifled firearm, usable only at short range because it so scattered its load on firing. The term is used by lawyers to deride legal writing (complaint, brief, etc.) more notable for energy than aim, especially 
one that seeks to cover everything rather than concentrating on what is actually important.

blunt instrument. A weapon which is used to pound and beat rather than to pierce and cut.

board. Widely used designation for a group of persons with powers (managerial, investigatory, supervisory, etc.) exercisable jointly, generally bound to act by some internal rule like majoritarianism. There are governmental boards (e.g., "board of education") and private ones (e.g., "board of directors"). The word is almost as ubiquitous as committee, though the implication is usually that a board is more likely to have final power than a committee.

It might be noted that the sinister-sounding "junta" (as in "Panama is now governed by a revolutionary junta") is just the Spanish word for board. Cf. commissar.

Also, "board" may refer to the furnishing of meals, as in "room and board" meaning "lodging and meals." (In certain contexts, however, "board" may also encompass the furnishing of lodging.)

boarder. One who boards, i.e., takes his meals on a regular basis in a particular place, paying by the week or month, usually with the clear (but not necessary) implication that he also lodges there.

board foot. A standard lumber measure: one foot by one foot by one inch.

boarding. The act of getting on a conveyance like a plane, train, ship, or bus. Also, receiving board, in the sense of meals.

boardinghouse. A place where lodging and board is furnished, usually to longer term tenants than a hotel's. Boardinghouses often are created by reconditioning homes in residential neighborhoods, and are thus often regulated, and frequently banned, by zoning.

boardinghouse keeper's lien. See innkeeper's lien.

board of adjustment. One of the common names for a quasi-judicial localgovernment body created to hear appeals from initial zoning decisions, especially those dealing with requested variances. Another common name is "board of zoning appeals."

board of aldermen. Common name for a municipal body with governmental, especially legislative, powers.

board of appeals. A group within some administrative agencies which nonjudicially reviews certain agency decisions.

board of audit. A body created by statute in some states to keep an eye on the books of municipalities, other local governmental units, and certain public officers.

board of directors. See directors.

board of education. A governmental body charged with overseeing the opera- 


\section{Leff Dictionary of Law}

tion of a school system. These boards may be appointed or elected and are sometimes required by law to be either nonpartisan or bipartisan. Another common name for such a body is "school board."

board of equalization. See equalization of taxes.

board of examiners. A body created in many states charged with examining applicants for licenses to practice a trade or profession to determine their competence and character. They frequently are charged with administering and grading a written examination, e.g., the ubiquitous bar examination. The examiners are ordinarily members of the trade or profession entry into which is sought, but there is some recent movement toward adding to their number one or more laymen as representatives of consumers.

board of fire underwriters. See underwriters associations.

Board of Governors of the Federal Reserve System. The governing body of the federal system of reserve banks. There are seven members having fourteen-year terms, who are not subject to direct control by either the executive or legislative branches of government. The Board has general supervision over the operation and policies of the twelve regional banks and their branches, but its most important, or at least most salient, function lies in its power to affect the availability and price of credit, principally by modifying the reserve banks' discount rate, thus controlling the amount of money available to banks for lending to the public.

board of health. A governmental body existing in most states and many municipalities with supervision over matters of public health. Some also have regulatory jurisdiction over hospitals.

Board of Immigration Appeals. An administrative adjudicatory body within the Department of Justice which hears appeals from decisions made by the Immigration and Naturalization Service on excluding and deporting aliens.

board of pardons. A state body with the power to grant pardons to convicted prisoners and to mitigate their punishments. In some states they have the power only to recommend action to the Governor, with whom the pardoning and clemency powers are lodged. In almost all cases the Governor is an ex officio member of the board. Compare parole board.

board of parole. See parole board.

board of regents. See regents.

board of registration. A body in some states having roughly the same functions as a board of examiners.

board of review. The name of a wide variety of governmental units with jurisdiction over divers matters, but very frequently applied to bodies authorized to hear complaints about property tax assessments. See also police review board. 
board of supervisors. The most common title for the governing body of a county in the U.S. See also county court.

Board of Tax Appeals. See Tax Court.

board of trade. An organization of businessmen formed to further their joint interests, either generally or in some particular line of trade.

Also an organization making a market and running an exchange for the trade of commodities, e.g., the Chicago Board of Trade.

board of underwriters. See rating bureau; underwriters associations.

board of zoning appeals. Another name used for boards of adjustment.

boat. Technically, small watercraft; according to sailors, a larger one is properly called a "ship," the rough rule being that a boat can be carried on a ship. And some use "boat" to describe a vessel used on inland waterways. But the distinctions are not much observed in ordinary discourse, and nothing legal (in statute or contract language) ought to turn on them.

boatable waters. A term sometimes applied to waterways (rivers, streams, etc.) upon which boats are able to operate, especially minor waterways about which there might be some doubt. In some contexts, the term excludes privately owned waterways, i.e., those physically but not legally open. The more legally significant term in this area, however, is navigable waters.

boatel. A cutesy term for a combination motel and marina, i.e., a motel serving people travelling in small boats.

boat livery. Boat rental, and the business thereof.

boatswain. A merchant-marine petty officer, the seagoing equivalent of an army top seargent, or an industrial foreman. Usually pronounced, and frequently spelled, "bosun" or "bos'n."

bobby. English slang for policeman, especially a foot patrolman. Said to be so named after Sir Robert Peel (1788-1850) who as Home Secretary organized in 1829 the first reasonably professional police force in London.

boc $[k]$ ( ). Old term for a written instrument, especially a deed or charter and coming to include a book. For entries so beginning, see those beginning with book.

boddemerey or bodemerie ( ). Variant old spellings of bottomry.

bodily. Pertaining to the physical body, often used in contradistinction to mental, emotional, or other nonmaterial states or conditions. See also entries so beginning.

bodily exhibition. An alternative euphemism to indecent exposure, found in some criminal statutes dealing with sexual transgressions.

bodily harm. Essentially synonymous with bodily injury.

bodily heirs. See heirs of the body.

bodily hurt. Essentially synonymous with bodily injury. 
bodily infirmity. See physical infirmity.

bodily injury. Any physical injury to the body of a person, primarily from external cause. The term is seemingly less inclusive than personal injury in that the latter is more frequently used also to cover mere injuries to dignity (e.g., unconsented but physically harmless touching) and mental or emotional injuries. The linguistic distinction is not sharp, however, and nothing legally important ought to turn merely on the choice of one locution over the other. See also grievous bodily injury.

bodily issue. See heirs of the body.

body. Generally used to refer to the whole physical manifestation of a person or other animal, but sometimes used to differentiate the central portion of the body, the "trunk," from the usually attendant head and limbs, as in "The crash decapitated him, throwing his head one way and his body another."

Body is also used to refer to the whole or main part of anything, whether corporeal or conceptual, as in "body of a county" (i.e., the whole county, not a part of it), "body of the instrument" (i.e., the substantive part, excluding recitals, signatures and procedural boiler plate) and "body of the laws," (i.e., all of them, written or not).

Also, "body" is used for a group with powers or functions as such, as in "legislative body," "body corporate," etc.

See also corpus (the Latin for body) and entries so beginning.

body corporate. A fancier term for corporation, found more frequently than it should be in legal writing (e.g., "Defendant is a body corporate, organized and ....").

body execution. See execution against the person.

body heirs. See heirs of the body.

body of a county. See body.

body of an instrument. See body.

body of the crime [or the offense]. See corpus delicti.

body politic. A term usually used to refer to whole political structure of a nation or subdivision thereof, not so much the formal institutions but the whole citizenry regarded in their political rather than private and personal nature. Only rarely used as an inflated locution for a political body.

The term is one of the large numbers of organic-person metaphors often and for a long time used of the state ("The King is the head of the Commonwealth, the knighthood the right arm, the clergy the soul, the people the trunk and legs ... . etc.") and as such, like all metaphors, dangerously misleading, e.g., if you cut off a head, a body dies; a state just changes its structure when you depose a King.

body politic and corporate. An old formal description of a municipal corporation or (U.S.) county.

body snatching. Stealing buried corpses from their graves, a crime almost eve- 
rywhere. It used to be done in order to get cadavers to sell to medical schools for instructional dissection. (Those body snatchers were also called "resurrection men"; see also Burking.) Now medical schools have other sources of supply, and body snatching has lost most of its point (though recently the body of Charlie Chaplin was stolen and held, unsuccessfully, for ransom).

bogey. In business and industry slang, a performance standard expected of an employee. If exceeded, it may lead to a commendation or bonus; if not met, to demotion or discharge.

bogus. Phony; spurious; falsely imitative.

bogus check. One drawn on an imaginary account, or knowingly on one without funds or with insufficient funds, without expectation that it would be paid. The word would most likely not be used to describe a check innocently or even negligently drawn against insufficient funds. Also called "bouncing check" because, upon presentation to the drawee, it is "bounced" back toward the person who presented it for payment.

boiler insurance. Insurance covering damage to the boiler, and to persons and property, caused by its explosion.

boilerplate. The common name of those solid blocks of language used in legal documents of all kinds to do standardized law jobs. Common examples include the executor-powers provisions in wills, act-of-God paragraphs in contracts, and disclaimer-of-warranty terms in consumer-sales slips. But boilerplate can show up almost anyplace.

Its value is obvious: it is to legal practice what ready-made garments are to the clothing industry and standardized parts are to building and manufacturing. Customizing any product is expensive, and to the extent that one can get essentially the same result with a standardized element of production there is a true gain in efficiency, i.e., you can produce and sell the same product for less. Moreover, it is frequently the case that the safety and utility of something, including a block of language, can be established only through wide use; if it holds up, "works," over a long period in divers contexts, it acquires an attractive solidity in which one can gratefully repose trust.

But the use of boilerplate also has its costs, some obvious, some less so. Since the value of boilerplate lies in its not being thought about in every deal, it is possible to overlook it too thoroughly, ending up with boilerplate which is just totally wrong for a particular document, or more subtly, just not as good as it could have been with just a little tinkering. That is, the area covered by boilerplate tends to become technologically backward; no one is trying to optimize its quality any further, and merely "good enough" reigns.

Moreover, the safety and workability of boilerplate provisions is often overstated. A block provision may be used hundreds of times without causing trouble only because that kind of trouble only rarely arises, e.g., one's 
act-of-God provision may in fact be terrible for coping with assigning losses due to piracy, but one won't find that out until a corsair strikes-when it's too late to redraft.

But more basically, as with any mass-production device boilerplate must usually be drafted in such a way that it can fit many different deals, situations, and contexts, i.e., it must be imprecisely drafted, its language largely freed of particularization and sharpness. The same powers, e.g., must be given by the same clause to any executor, whether it be the Chase Manhattan Bank or an unsophisticated surviving spouse. This demands language which is likely not to be clear when, in fact, some interpretative crunch comes.

All of this is not to say that boilerplate should not be used. Legal service at reasonable cost is impossible without it. But recent developments in the general technology of word reproduction makes cautionary advice more pressing. It used to be that boilerplate, whether changed or not between uses, had to be physically redone for each use. The four or so pages of executor powers had to be retyped into each new will. Thus, tinkering by the lawyer prior to any use would cost him extra time, but not his typist. But now with word processing machines capable of exactly reproducing pages of materials without even secretarial intervention, any change will interrupt what would otherwise be an almost cost free routine. So the temptation to act as if boilerplate is off limits to lawyerly consideration will be even more intensified. As noted above, that would be costly in many other ways.

boiler room. Common slang in the securities industry for an operation in which securities of doubtful value are sold over the telephone to targets on a mark list by a crew of dangerously persuasive high-powered salesmen, all gathered in a room with many telephones and no other assets or accoutrements. $C f$. bucket shop.

The term may also be used to describe telephonic money-raising efforts by "charitable" organizations of doubtful benevolence.

boiling to death. In England, between 1530 and 1544, the prescribed punishment for murder by poison.

bois ( ). French for a wood or forest.

Bold Buccleugh. See The Bold Buccleugh.

bolita. Also "bolito." A species of lottery.

In the New York numbers game, a play on two, rather than all three, of the winning numbers, the pay-off being roughly one-tenth of that on a correct selection of all three.

boll. An old measure of grain, equal to six bushels.

bolshevism. See communism.

boltings. Also "bolts." Now discontinued student legal arguments held before 
senior members at Inns of Court (or of Chancery) as training for aspiring lawyers. These, unlike the similar moots, were held in private.

bomb. Widely used slang term for any deeply unsuccessful venture; may be used of a product, a financing, even a broadway show, and either as a noun or a verb (e.g., "We bombed in New Haven").

bomb scare. It has long been a criminal offense falsely to give notice of an explosive device located and set to go off in a public building or vehicle. With the rise of sky-jacking in recent years, the practice has become a federal felony. See 49 U.S.G. § 1472(m).

bon ( ). Law French and French for good (as an evaluation).

bona ( ). As an adjective, the evaluation "good." As a noun, "goods," i.e., chattels, wares, merchandise. In Roman law the word referred to all kinds of property, but perhaps principally to real estate; in the older common law it referred to moveables, i.e., chattels.

bona confiscata ( ). Roman Law term for what was called at common law forisfacta.

bona et catalla ( ). "Goods and chattels," i.e., all moveables.

bona felonum ( ). Goods of one convicted of felony (which were usually forfeit to the King).

bonae fidei emptor. See bona fide purchaser.

bonae fidei possessor. See bona fide possessor.

bona fide ( ). Being or acting in good faith. The term is used even today in both this Latin form and in translation, so for particular terms one should consult entries beginning both with "bona fide" and with "good faith."

"Bona fide" is also regularly used almost as a synonym for genuine or unfeigned as in "That's a bona fide good deal I'm offering you" and "This is bona fide mink."

See bona fides for the Roman Law significance.

bona fide debt. A debt untainted by fraud or bad faith (see good faith). Also, a genuine (i.e., not phony) debt.

bona fide holder [for value without notice]. See holder in due course.

bona fidei ( ). See bona fide; bona fides; good faith.

bona fide judgment creditor. Holder of a bona fide debt arising from judgment of a court.

bona fide mortgage. A mortgage attendant upon a bona fide debt.

bona fide possessor. One who possesses real property believing himself to have paramount right to do so, unaware of anyone who contests his claim.

bona fide purchaser [for value without notice]. Ordinarily one who sells something cannot convey better title than he has. If, e.g., a thief sells a diamond ring he has just stolen, the buyer does not get title as against the 
true owner. And if one buys title to a house from a mere lessee, one might get the rest of his lease, but one does not get the house; it wasn't the less[ee]'s to sell.

Under some circumstances, however, a buyer may get title good against the whole world even if his immediate seller didn't have it. More particularly, this will often occur when the buyer is a "bona fide purchaser for value without notice" (frequently referred to in shorthand merely as "bona fide purchaser" or even "bfp"). If the buyer bought in good faith, gave value for whatever he bought, and had neither actual knowledge nor notice (nor, in some contexts, reason to inquire) of any defect in his seller's title or limitation upon his seller's full power to convey what he purported to convey, such a purchaser will get title even if his seller was really unauthorized or even a thief. The idea seems to be that since there are two innocent people involved (the theft victim and the bona fide purchaser), someone guiltless will have to take a loss, and it may sometimes be fair to let it be the original true owner.

The precise factual contours of what constitutes "bona fides," or "good faith," "value," (e.g., is cancellation of a pre-existing debt "value"?) and "notice" (e.g., how stupid can one be about not inquiring?) vary from jurisdiction to jurisdiction and context to context. Special rules abound, e.g., sales made in the apparent ordinary course of business to consumers almost everywhere pass title free of any other person's title or lien. (See U.C.C. § 2-403.) And in the real property area, recording laws mandating public record of titles and liens govern title acquisitions (if for no other reason [than] that the record would constitute "notice"). The U.C.C. deals with the issue in various places: U.C.C. § 2-403 (sale of goods); U.C.C. § 6-110 (bulk transfers); U.C.C. § 7-501 (negotiable documents of title); U.C.C. § 8-302 (investment securities). In one important area, negotiable instruments law, the allied concept of holder in due course prevails. See U.C.C. §§ 3302 to 3-306.

bona fide residence. For some purposes, this means a genuine residence, one not established as a sham to acquire some right or power, e.g., a right to vote, or diversity of citizenship giving access to the federal courts.

The term is also used, however, as a synonym for domicil.

bona fides. The state of good faith.

bona fide sale. A genuine (i.e., not sham) sale. But also a sale made to a bona fide purchaser, and also one made by a seller who has no notice of defect in his title or restrictions upon his right to sell.

bona forisfacta. See forisfacta.

bona fugitivorum ( ). Goods of fugitives, generally forisfacta, i.e., forfeit to the King, under old English law. Goods of persons outlawed, "bona utlagatorum," were similarly treated.

bona gestura ( ). Good behavior. 
bona gratia ( ). With good grace; not under compulsion; freely and with full assent.

bona immobilia ( ). "Immoveable goods," i.e., land, buildings, corporeal real property.

bona mobilia ( ). "Moveable goods," i.e., chattels and the other corporeal personal property.

bona peritura ( ). Perishable goods, e.g., fresh foodstuffs.

bona utlagatorum ( ). See bona fugitorum.

bona vacantia ( ). "Vacant goods," i.e., stray or unclaimed goods of which no one claimed ownership. A finder would ordinarily have title good against everyone but the true owner should he appear, but some became the property of the King, e.g., straying domestic animals-though the King had to give elaborate public notice to allow the owner to reclaim.

For modern practice, see escheat.

bona waviata ( ). Stolen goods thrown away by a thief in his flight. They were forfeited to the King, allegedly to punish the owner for not chasing the thief himself. Hence if the owner did chase the thief, he got to reclaim the thrown away goods.

bond. A promise, almost always sealed, to pay a sum of money upon the happening of an event-which may be, and frequently is, the passage of a certain period of time. (If not stipulating a fixed sum, the document may once have been more properly called an undertaking, but the distinction is now at best tenuous, especially with respect to surety bonds.)

Presently, bonds fall into three main categories. First, there are investment securities, bonds which are essentially pretentious promissory notes, ordinarily issued by corporations and governments. They may or may not be secured by specified property (see debenture).

A second large category of bonds encompasses promises to pay, upon a happening, a loss that will be thereby suffered. These include indemnity bonds, surety bonds, fidelity bonds, etc.

The third use of bond occurs in the procedural law, to describe the promise by a person, often a professional bonding company or bondsman, to pay if the party to litigation defaults in an obligation, e.g., an appeal bond, a bail bond, etc. And "bond" is sometimes used in place of the word bail itself, as in "Lefty Louie made bond and took off for Venezuela."

All of these kinds of bonds come in many subvarieties with divers special provisions tailored to particular needs. See generally, terms beginning with and containing "bond."

bondable net lease. A long term, unconditional, totally net lease, the tenant under which has a credit rating so high that a lender to the lessor feels secure in advancing money against the likelihood that it will be repaid out of the rent. Since such a lease is almost equivalent to a high-rated corporate 
bond, the lender's interest charge is often lower than that normally applicable to commercial mortgages.

bondage. The status of being bound. Usually used today as a synonym for slavery, but once also encompassing villeinage. See villein.

Also, a species of perversion in which one derives sexual satisfaction from being, or seeing and acting upon someone else, tightly bound with ropes or chains, often naked and in humilating or painful positions. Sometimes referred to as "boundage and domination," most frequently abbreviated (e.g., in advertisements seeking partners) "b\&d."

bond and mortgage. The more complete term for what is usually just called a mortgage, emphasizing that the device includes both a promise to pay a sum of money (the bond) and a lien on the property given as security for the payment (the mortgage).

bond broker. A stockbroker who also or exclusively deals in bonds.

bond conversion. The act of exchanging a convertible bond [or debenture] for the other securities to which it entitles one.

bond coupon. See coupon bond.

bond creditor. One who holds an obligation secured or represented by a bond.

bond discount. Bond discount (and bond premium) are adjustments made in the market price of bonds to reflect market changes, especially in the prevailing interest rates, for fixed income securities. Let us say, for example, that XYZ Corporation has sold bonds to the public bearing an interest rate of $10 \%$. While these bonds are on the market, however, other corporate bonds, comparable in risk, are also on the market, and they offer $12 \%$ interest. Obviously, any potential purchaser would be crazy to buy the XYZ bonds "at par," i.e., paying $\$ 10,000$ for each $\$ 10,000$ bond; he would then be accepting $10 \%$ when he could get $12 \%$ interest. One way to make [the] $10 \%$ bond competitive would be to change its interest rate to $12 \%$, but it is too late for that; the bonds are out at the fixed $10 \%$ rate. So the only way to change the effective rate is to change the price at which the bond is purchased. Thus, the XYZ bonds will tend to be sold (either by the original issuer or a subsequent purchaser) for such amount under par as will yield the buyer $12 \%$ on his investment to maturity. This difference between the face amount of the bond and the amount actually paid for it is called "bond discount."

Conversely, if an available bond offers a higher interest rate than other comparable bonds, buyers will be willing to pay more than its face amount to acquire it, which amount over the face value of the bond is called "bond premium."

bonded debt. Debt of a public or private borrower represented by bonds. Especially when the debt is public, there is an implication (though no legal or linguistic necessity) that special measures have been taken to provide for 
orderly payment, e.g., a formal allocation of future tax revenues to the particular bonded debt.

bonded goods. See warehouse system.

bonded indebtedness. See bonded debt.

bonded liquor. See warehouse system.

bonded warehouse. See warehouse system.

bond fo: costs. See security for costs.

bond for payment of tax. A bond securing the ultimate payment of income tax due, which may be required by the Internal Revenue Service as a condition of granting an extension of time to pay.

bond for support. A bond securing the payment of child support, required of one who has earlier abandoned or otherwise failed to meet this obligation.

bond for title. See title bond.

bond indenture. The contract regulating the rights and duties of the issuer and holders of bonds. It is almost always formally a contract between the issuer and a trustee for the bondholders, known as the "indenture trustee," whose job it is to protect the rights of the widely scattered bondholders, e.g., by declaring a default when one occurs and then taking the requisite steps to minimize the holders' risk.

bond issue. The entire process of getting into the hands of holders the bonds representing a public or private borrowing; also, that aggregate of bonds once issued, as in "The 1978 school bond issue is in default."

bond on appeal. A bond executed by an appellant or on his behalf to indemnify parties who might be prejudiced by the delay attendant upon a judicial appeal, especially to assure them that the judgment rendered below, and costs, will be paid. The old term was "bail in error."

bond post obit. See post obit bond [or note].

bond premium. See bond discount.

bond rating. Evaluations of the quality (which, by and large, means safety) of bonds, both public and private, systematically carried out by several bond rating companies. Since, as a general rule, the safer the bond the less interest the issuer must pay, a drop in rating is costly. And if the rating drops so far as to indicate a real risk that the borrower's obligations will not be paid, the borrower may be effectively shut out of the bond market until its position improves, e.g., New York City's situation in the late 1970's.

bond redemption. See redeemable bond.

bond single. See bill obligatory.

bondsman. A surety, especially the issuer of a surity bond, but usually used to refer to a writer of bail bonds, also called a "bailbondsman." 
bond-tenants. Holders of land in non-free feudal tenancy, e.g., holders of copy-hold estates.

bond to keep the peace. A bond or recognizance by the terms of which a sum of money is to be paid if a named person breaches the peace, i.e., commits an assault or a nuisance. It is procured at the instance of a judicial officer by the named person as a way of assuring his future good behavior after an earlier peace breaking event. A common situation giving rise to such a bond involves quarreling neighbors, where a magistrate may make one or both parties execute one in an attempt to get them to cool the ardor of their dispute. As such it is an alternative to convicting one or the other of assault and conditioning probation on future peaceful behavior. See also abearance; articles of the peace.

bones gents ( ). Law French for "good men," used in old contexts to specify members of a jury, or persons fit to serve on one.

Bonham's case. A 1610 case (8 Co. Rep. 114) in which Lord Coke, in dictum, asserted the power of the courts to void an act of Parliament which was "against common right and reason." What Bonham's case actually held and meant is a very complicated story, but it is clear that this asserted power judicially to control Parliament never caught on in England-if indeed it was actually asserted.

boni [et legales] homines ( ). Essentially the same as bones gents, but more particularly referring to free tenants of a lord who judged other free tenants in his feudal court.

bonification [of tax]. Remission, refund, or nonimposition of a tax, especially on goods intended for export, so as to allow such goods more effectively to compete in a foreign market. Varieties of bonification come into play when nations agree to lower tariff barriers, e.g., in the Common Market, for bonification is a functionally effective way to favor one's own nation's goods without technically breaching the tariff treaties, i.e., one doesn't tax incoming goods but rather removes taxes on outgoing goods which other nations' goods may have to pay at home.

bonis. See ex bonis; in bonis, and terms so beginning.

bonis asportatis. See trespass de bonis asportatis.

bonis non amovendis ( ). An old writ directing the sheriff [to] assure that the losing party in a trial not remove or dispose of his goods while a writ of error (i.e., an appeal) is pending.

bonne foy. See en bon foy.

bono et malo. See de bono et malo.

bono gestu ( ). Good behavior.

bonus. An extraordinary payment; something in addition to ordinary or legally obligatory compensation. A bonus is not necessarily a gift, however. Some payments called bonuses are just separately denominated components of or- 
dinary compensation, e.g., a payment made to a baseball player to induce him to play for a particular team is called a "bonus," but it is obviously, together with his promised salary, just part of his compensation package. And if a corporate officer is promised a "bonus" if the company's profits go up $10 \%$, the payment is obligatory if the condition is fulfilled. Indeed, many companies have a "bonus plan" covering many officers and employees, tying their final compensation level to corporate results.

Some bonuses, however, are not obligatory, and if paid are gifts, e.g., a $\$ 1,000$ "bonus" paid to a long-term employee on retirement in lieu of, say, a gold watch. Hence for most legal purposes, especially taxes, the key question is not whether something is called a bonus, but whether it is or is not a gift.

Also, in Latin, bonus is an adjective meaning good, profitable, worthy, etc.

See also terms beginning with bonus.

bonus depreciation. An additional depreciation deduction (pursuant to I.R.C. $\S 179)$ for the first year of use of personal property.

bonus plan. See bonus.

bonus share [or stock]. Two meanings. One refers to the securities industry equivalent of retailing's "buy two, get the third free" merchandizing, i.e., a way of decreasing the net cost of a commodity without openly cutting its per unit cost. This is a useful technique when selling debt securities, which may then be sold at par at a not too horrendous interest rate if the buyers are also given, as a "bonus," some equity interest in the company, i.e., some entitlement to profits over and above the stipulated interest. This bonus, however, is obviously not "free" or a gift; if it were not "thrown in," the buyers would not buy at the same price.

In the second usage, however, "bonus" does mean free; it refers to stock issued for no, or almost no, consideration, usually as part of a fraudulent scheme by insiders. As such, "bonus stock" means roughly the same as watered stock.

boodle. The proceeds of illegal activity, especially nonviolent kinds, e.g., bribery, fraud, etc., and even more particularly those committed by public officials. The term already has a quaint ring to it, foretelling imminent disappearance except in jocular use.

book. See entries beginning with or containing the term, e.g., book account; hand book, etc.

book account. Record of debts owed to and by a merchant, arising out of his business transactions and traditionally kept in his book of account. These days such accounts are likely instead to be stored in the merchant's computer. A debt for which one has separate written evidence, e.g., a promissory note, would not be called a book account-though a book recording such instruments might also be kept. 
book debt. An alternative (and rarely encountered) old name for the common law action of account.

book depreciation. The depreciation shown on the books of the owner, which may be different from that used for tax purposes. There is nothing improper in this; the owner may use accelerated depreciation schedules available to him under tax law to increase his deduction, but still seek to reflect on his books what he considers a more realistic rate of physical depreciation.

booked. See booking.

booker. See booking agency.

bookie. Common slang for "bookmaker"-see bookmaking.

booking. Most generally, putting some sort of entry or record into a book or other written record. More particularly, booking is used to refer (a) to the activities of a booking agency; (b) to the police-station procedure for making record of an arrest and the details pertaining thereto (often including the taking of photographs and fingerprints); and (c) to the reservation of particular time and space for persons or goods on a common carrier, as in "We're booking you onto TWA flight 26 to Keokuk."

booking agency. An organization, also called a theatrical agency, which for remuneration matches entertainers with those needing entertainment services. Sometimes the agency is agent for the entertainers, sometimes it is sort of an employment agency for the employers, and sometimes it is a combination of both.

booking contract. An entertainer's contract of employment, usually shortened to "booking," as in "I've got a booking at the Playboy Club on June 5th."

bookkeeping. The process of keeping the financial records of a person or firm, especially a business or government. It can be a technical and complex endeavor. $C f$. accountant.

bookland. Also called "charterland," this was land held by deed for certain money rent and free services, not essentially different from land held by free socage.

bookmaker. See bookmaking.

bookmaking. The business of accepting wagers on uncertain events, especially sporting contests like football and horse racing. The bookmaker, in effect, is one who makes and operates (in the U.S. usually unlawfully-but $c f$. accepting wagers) a marketplace for trading in risky predictions, and like many market makers he is often linked up with wider markets where he can trade ("lay off") some of his bets if his operations expose him personally to too much risk. As usual with professional gamblers, the bookmaker so adjusts the odds he will give that over a long enough time he must come out ahead, e.g., in an "even money" situation the typical bookmaker might make his customer, no matter which side he takes, bet at 6 for 5 odds. 


\section{See also gamble.}

book-oath. An old term for the classic courtroom oath made with a hand on the "book," i.e., the Bible.

book of account. See book of original entry; books of account.

Book of Assize [or the Assizes]. See Liber Assisarum.

Book of Fiefs. See Liber Feudorum.

book of original entry [or entries]. Also sometimes called a "day-book," "journal," "shopbook," or "waste-book," the place (it may today be a computer memory) in which a merchant immediately and in the ordinary course of business first enters his record of transactions as they occur. These particular records are given special legal significance by the shopbook rule.

books and papers. A term found in many discovery motions, usually set in a context like "all books and papers pertaining to," seeking production of written materials relevant to litigation. Fed. R. Civ. P. 26(b)(1) refers to "books, documents, or other tangible things," but "books and papers" is often used anyway.

books of account. The singular, "book of account," was often used synonymously with book of original entry. The plural, however, now refers loosely to all the books recording his transactions that a businessman might maintain.

books of exact science. An old term for those compilations of undoubted data, e.g., tide tables, weights and measures, which, once authenticated, are admissible at trials and effectively conclusive on the matters they cover. In effect, the judge make take judicial notice of the facts to which such books speak. See Fed. R. Evid. 201(b)(2).

book value. A term usually used in explicit or implicit contradistinction to the going-concern value or market value of property, especially a business. It is (very roughly) the net value of all assets after all liabilities have been subtracted. Hence, a corporation the balance sheet of which shows total assets of $\$ 1,000,000$ and total liabilities of $\$ 750,000$, would have a book value of $\$ 250,000$; if there were 50,000 shares outstanding, each would have a book value of $\$ 5$.

As with all valuations based upon business balance sheets, book value is not the most useful measurement of the worth of a reasonably healthy business. Aside from the normal difficulties of valuing individual assets and liabilities (e.g., real property with unrealized gains; contested claims), an operating business' worth is more realistically some function of its earnings (as a going concern), or of the desires of people to acquire it (on the market) than it is some additive function of its individual parts. Only when a business is likely to stop being a going concern, e.g., when it is in deep financial difficulty, does book value become much more interesting, for if the business does go under it may indeed fetch in liquidation no more than the sum of its unintegrated parts. 
book warranty. See iron safe clause.

boomage. A charge made in the logging industry for the use of a boom, i.e., a water borne structure for collecting and holding floating logs.

Also, a sort of easement to go on waterside property to set up and fasten booms.

boon days. In feudal law, days upon which occupiers of copyhold estates were obliged to perform services for their lords.

boondoggle. Any job or grant more pleasurable to the holder than useful to the donor, or to anyone else. It originally covered waste of government funds on no-work or make-work projects doled out to party supporters or needy voters. It has come to encompass things like foundation-sponsored travel by well-connected professors to places like Switzerland, to discuss there the problems of Newark, N.J.

boosted fire. A fire, usually arsonous, which has been started or helped along by an "accelerant," i.e., a fire intensifier like gasoline, kerosene, etc.

boot. Perhaps a whimsical back formation from "to boot" as in "I gave her my love, and a pretty nice necklace to boot," i.e., something extra thrown in on one side of a transaction. In the slang of tax lawyers, "boot" refers to cash or other property not qualifying for tax-free treatment in an exchange of like property or in a corporate reorganization.

Also, an old Saxon term roughly equivalent to estovers. See bot[e].

boothage ( ). A customary fee paid to one (usually, in feudal days, the local lord) who had the right to hold a fair or market, for the privilege of setting up a sales booth there.

booting corn. Also "boting corn." Grain paid as rent.

bootlegger. During Prohibition, one in the illegal business of making or selling alcoholic beverages. Now sometimes used to describe people who smuggle goods from low tax states to evade a locally higher tax, e.g., "cigarette bootleggers" from North Carolina to New York.

bootstrap sale. In the terminology of corporate acquisitions, a transaction in which a corporation manages to acquire another at least partly with the latter's own assets.

In tax talk, a transaction in which corporate earnings which ought to have been taxable at ordinary-income rates are converted into capital gains. Much attention is given in the tax code to trying to prevent this result.

booty. Things of value taken by forceful and unlawful means, as by a plundering army or a thief. $C f$. boodle.

booze. Slang for alcoholic beverages, and the drinking thereof.

bord. Saxon for "cottage" and "table."

bordage ( ). A base feudal tenure (but not as base as that of villeins) calling 
for minor personal services or the supply of small provisions. The Latin was "bordagium."

bordagium ( ). See bordage.

bordarii ( ). See bordars.

bordars ( ). Feudal tenants who held by bordage. The Latin was "bordarii."

bord-brigch ( ). Also "borghbrech." Saxon term for a breach of faith, trust, or suretyship.

border. The boundary between one nation or other political subdivision and another or, where not contiguous to another polity, between a nation and the sea.

border search. A search conducted at any U.S. national border to detect smuggling and illegal entry. The constitutionally mandated probable cause and warrant requirements for a non-border detention and search are not equally, if at all, applicable to border searches.

bord-halfpenny ( ). Also "broad-halfpenny;" "brode-halfpenny." A traditional boothage.

bord-lands. Lands held in bordage tenure, or more generally, lands designated by the lord for the supply of his own "bord" or table, i.e., a homefarm.

bordlode ( ). An old feudal service of base feudal tenants, consisting of carrying wood from the lord's forest to his house.

Also, the rent paid by boarders.

borg[h] ( ). In Saxon, a pledge or suretyship.

borgesmon ( ). In Saxon administration, the head of a household, at least for purposes of tax liability.

borghbrech ( ). See bord-brigch.

born. Delivered from the womb to the world. The word is sometimes used in testamentary documents to distinguish between biological and adopted descendants, e.g., "All the rest and remainder to my children born . . .," but more explicit language is advisable.

See also birth.

born alive. A status, the determination of which, when legally relevant today (e.g., for inheritance or homicide purposes), suffers from all the problems of empirically determining "life" in an age of extensive machine-assisted biological function. See alive. Older cases tended to equate newborn "life" with its breathing or attempting to breathe, though some accepted other signs of biological function, e.g., heartbeat, circulation through the umbilical cord, voluntary muscular movement.

born dead. See alive; born alive.

born out of wedlock. See bastard. It should be noted that a child is "born out 
of wedlock" even if its mother is married at the time of its birth, if she is not married to the child's biological father.

borough ( ). In England, originally a fortified town or castle, the term came to refer to a town entitled to send a representative to Parliament (see also rotten borough). After 1890, the term came not only to cover these "parliamentary boroughs," but also incorporated towns and cities given certain powers of internal self government, called more completely "municipal boroughs." By statute effective in 1974, all of these boroughs (except in London and the Scilly Isles) ceased to exist.

In the U.S., "borough" is sometimes used to designate a town with a municipal charter and powers, but the most famous are the five boroughs (Manhattan, Brooklyn, Queens, Richmond, and the Bronx) that comprise New York City. They retain as such some small vestiges of political function and power, and each is also a county (in which avatar, however, Manhattan is called "New York County," and Brooklyn is "Kings County").

borough courts. Courts of record but of limited jurisdiction in boroughs, especially older English ones. In modern England, they were little used, and were abolished as of 1974 .

borough English. Also called "postremogeniture," and "ultimogeniture." A rule applicable by custom in some parts of England by which the youngest rather than the eldest son inherited his father's estate. It did not apply to true freehold tenures, but did to estates held in socage, including especially burgage tenures. Insofar as the rule was actually applied in modern England, it was abolished by statute in 1925 .

borough-head. See headborough.

borougholder. Either a headborough, or one who holds by burgage tenure.

borough reeves. Roughly equivalent to mayors, but of pre-1835 English boroughs.

borough sessions. Courts of limited criminal jurisdiction in English boroughs.

borrow. See loan.

borrowed capital. Broadly, all assets of a company received as loans rather than as investments, i.e., corporate assets contributed by creditors rather than stockholders. More narrowly, however, the term is used for loans from stockholders, especially in the form of dividends declared but not paid, instead with the consent of the stockholders kept to be used in the business.

borrowed employee [or servant]. See loaned servant.

börse ( ). See bourse.

borsholder ( ). See headborough.

borstals. Modern English institutions for the detention of juvenile offenders.

bos'n. Also "bosun." See boatswain.

bosom of the court. See breast of the court. 
Boston interest. Interest calculated as if each month had thirty days.

bot[e] ( ). Sometimes spelled "boot." A term of wide meaning in old English law, encompassing recompense or compensation (see man-bote), and also something of value to which one was entitled (see, e.g., firebote; housebote).

boteless ( ). In old English law, without remedy or way of making amends, especially without the privilege of discharging criminal liability by making a compensatory payment. It came generally to mean unavailing; $c f$. Shakespeare's "When in disgrace with fortune and mens eyes,/I all alone beweep my outcast state,/And trouble deaf heaven with my bootless cries ...."

both. Strictly, the one and the other member, together, of any set of two. But under sufficient contextual pressure, the term has occasionally been interpreted to mean "all" when applied to more-than-two-member sets.

bothagium ( ). See boothage.

both-to-blame clause. A standard clause in maritime bills of lading seeking to allocate liability for cargo losses when two ships collided through joint fault. The U.S. Supreme Court invalidated the clause in 1952.

botiler of the King ( ). An officer at the ancient English court who provided the King's wines. $C f$. butler.

botleas ( ). Boteless crimes.

bottomage ( ). Law French for bottomry.

bottom land. Land formed by the overflow and recession of a river, hence extremely rich for farming. If still in the flood plain of the river, however, such land is subject to repeated flooding unless protected by dams, levees, etc.

bottom line. The final result of any venture; the result which really "counts." The reference is to the bottom line of an income statement which is always "net profit (loss)."

bottomry [bond]. A maritime loan agreement (characteristically in the form of a bond) pursuant to which the master or owner of a ship borrows something, often materials or money to buy materials necessary to the continuation of a voyage, and often in a foreign port, giving as security a lien on the ship. The interesting wrinkle in the usual bottomry contract (there are variations) is that if the ship be lost during its current voyage (or sometimes during the stated period of the loan), the obligation to repay is discharged.

Thus, the lender shared to some extent the perils of the sea, and bottomry bonds were, understandably, an early development [in] the history of ship financing, dating from the period when ships were more regularly lost to tempest, and insurance had not fully developed. They (along with "respondentia," i.e., bottomry bonds covering cargo) are now totally obsolescent. 
bottoms. Maritime slang for "ships," as in "I've got sixteen bottoms waiting to be loaded."

botulism. An often fatal disease caused by eating food poisoned with the toxin of the bacillus clostridium botulinum. The germ is anaerobic, i.e., it flourishes only in the absence of oxygen, and thus is a serious modern threat in improperly canned goods. Hence there is a substantial amount of governmental regulation of commercial canning.

bouche ( ). From the French for "mouth," a feudal right to free food, e.g., while on active military service for a lord, or while attending him or the King at court ("bouche of court"). Also "budge."

bought. Acquired by payment. There is some implication that the transaction is further toward completion than a "contract to buy," especially that the price has been paid and perhaps also that the goods have been received, but the implication is not always present in ordinary usage. One might well say, "I just bought 1000 shares of IBM" even though neither payment or delivery had been made.

bought and sold notes. Brokers' memoranda of transactions, the "bought note" going to the buyer, the "sold note" to the seller. (Warning: Sometimes in the past it was the "bought note" which went to the seller, and the "sold note" which the buyer got.)

boulevard rule. A traffic regulation directing anyone driving on a side street approaching a "boulevard," i.e., a more-or-less through road, or at least a wide one, to give absolute right of way to cars traveling on it before entering or crossing it oneself.

boulwareism. A labor-contract negotiating strategy in which an employer decides what he thinks is a fair offer, or at least one close to the predicted eventual settlement point, and refuses to budge from it no matter what the other party does, while at the same time trying to convince the rank-and-file workers of the offer's fairness. The term is named after its most prominent recent exponent, a chief negotiator for the General Electric Company. The strategy was subsequently declared an unfair labor practice under the NLRA.

bouncer. A man chosen for his intimidating appearance and firm nature, to cope, even to the point of physical ejection, with disorderly or otherwise unwelcome guests, e.g., in saloons, at rock concerts, etc. Bouncers are ordinarily not peace officers, and their overenthusiastic interpretations of their functions sometimes lead to actions in tort.

bouncing check. See bogus check.

bound. Tied up, as with rope, but in legal contexts obligated, as in "You signed the contract and you're bound by it."

Also, in transportation, an indication of destination, as in "The S.S. Peerless, bound for Bombay." 
Also, a somewhat archaic synonym for boundary. See, e.g., metes and bounds.

boundary. The utmost edge of real property where it touches another parcel thereof. The boundary may consist of a natural feature (e.g., a stream) or an artificial one (e.g., a stone wall), but it may also be but an imaginary line determinable only by surveying. Indeed, even when a real object marks the spot, the actual legal boundary often is actually some imaginary line through it-though some boundary markers are deemed to be held in common.

boundary action. A legal proceeding, at law or in equity, designed to determine the correct boundary between lands. There are some actions specifically created for this law job, but any action to test title, e.g., ejectment, is bendable to the task.

bound bailiffs. Officers employed by English sheriffs, and bound to them by sureties for their good behavior, used especially to track down and arrest debtors. Also called "hound bailiffs" (it being unclear whether hound is a corruption of bound or vice versa), and "bum bailiffs" (with bum a corruption of bound, the extra linguistic dividend being that bum in England means buttocks).

bounded by a road [or highway, etc.]. Term in a conveyance which will give title to the middle of the road unless the context or other provisions indicate otherwise.

bounded tree. A tree marking the corner of a tract of land, i.e., giving a reference point for two boundaries.

bounden. Archaic form of bound.

bounders. Artificial visible markers of a boundary, especially those set up by surveyors.

In English slang, what a "cad" always also is, i.e., an impolite, untrustworthy and faintly disreputable male.

bound over. See binding over.

bounty. In ordinary langauge, a gift, especially one from someone higher in some hierarchy to an inferior.

In most legal contexts, a reward promised or paid for doing an act desired by the donor, e.g., a payment made to one who signs up for the army, or for each predator (human or animal) captured or killed. See also reward.

Bounty of Queen Anne. The fund created by Queen Anne's donation of certain revenues belonging to the crown to trustees for the benefit of poor clergymen.

bourg ( ). In old English law, a borough or village.

bourgeois ( ). A member of the bourgeoisie. 
bourgeoisie ( ). Originally "townspeople," but, by extension, manufacturers, traders and financiers rather than farmers or laborers, landed gentry, or nobility. In Marxist terminology, the capitalist middle class, expropriators of the surplus labor value of the workers, which has been in ascendency since the end of feudalism but which is soon to be replaced by the workers.

Especially among artists and intellectuals, the adjective "bourgeois" is used contemptuously to refer to the supposed crass materialism, hypocrisy and philistinism of the class, but there is little evidence that those traits are more strongly represented among the bourgeoisie than any other group, e.g., artists and intellectuals. See also proletariat.

bourse ( ). French for "purse" or "exchange" but usually referring to the Paris Stock Exchange. The German is börse.

bovata terrae ( ). In old English law, such quantity of land as could be cultivated using one ox. One assumes that, at least for tax purposes, the defined area was standardized, but, though numbers have been suggested (thirteen acres; eighteen acres), no one seems to know for sure. In any event, eight of them added up to one "carucate."

bow-bearer. Sort of a deputy sheriff for enforcing the forest law, charged with catching poachers and holding and presenting them for trial and punishment.

boxcar discovery. A lawyer's term for an opposing laywer's attempt to acquire by discovery every piece of paper which might possibly have some bearing on a case. $C f$. fishing expedition. A lawyer's term for his own wide discovery motion is "adequate preparation."

boxed weight. In mercantile terminology, the weight of a product after it has received its ordinary and necessary packaging.

boxing. A sport in which it is the aim of each of the two participants to render the other unconscious by blows of the fist. Since, unlike football, hockey, lacrosse, etc., physical injury to one's opponent is the purpose of boxing rather than a by-product of the proceedings, the sport is almost everywhere heavily regulated, and is indeed banned in many jurisdictions.

boy. A human male short of adulthood by a wildly variable distance depending on context. While it has been said in legal opinions that to be a "boy" one must be short of puberty, there is no fixed legal meaning or usage; even a father will sometimes seem to his father a boy. But when an adult male is addressed as "boy," the usage is usually intended and perceived as insulting, especially by adult black males to whom that insulting usage is particularly familiar. $C f$. girl.

boycott. An express or tacit agreement among several persons not to have anything to do with a particular person or firm, either to punish the victim for past acts, or to coerce him into future ones.

Boycotts are of legal significance in several contexts. First, a boycott is a potent weapon in the hands of customers, suppliers, or competitors of a 
business firm who, by agreeing not to deal with it, can coerce the victim into changing certain aspects of its business which the boycotters find objectionable, e.g., price cutting. This kind of boycott, also called a "concerted refusal to deal" or a "group boycott" is, generally speaking, violative of the antitrust laws, especially the Sherman Act.

Boycotts are also important in labor law. While it has been established (though not without some struggle) that the refusal among workers in a union to work for a particular employer until he meets their demands is not itself violative of the antitrust laws, it is also generally the law that workers and unions may not take part in a "secondary boycott," i.e., employ economic weapons, especially picket lines, to coerce an employer with whom the union has no labor dispute to cease doing business with one with whom it does. Thus, e.g., it would be an unlawful secondary boycott (under $\S 8(\mathrm{~b})(4)(\mathrm{ii})(\mathrm{B})$ of the NLRA) for the union representing an automobile manufacturer's workers to picket in front of an auto retailer's showroom. Secondary boycott doctrine does, however, have several niceties. It is, e.g., all right to picket the "innocent" secondary employer if it is done at the work place of the primary one, i.e., the one with which the union has a labor dispute. And one can picket at a secondary site if the intent is to persuade purchasers not to buy one product of the many the target sells, e.g., it does not violate the law to picket against apples at a large supermarket. But if the single product is the only thing the secondary party sells, then the secondary boycott activities do violate the act.

Boyd rule. One of the catch-phrase terms for the rule (no [longer] generally in force) that in a corporate reorganization, no junior security may get any participation in the reorganized firm until all nonconsenting senior securities have had their claims fully satisfied.

bozero ( ). See abogado.

bpd. Abbreviation of "barrels per day," used in the oil industry.

B.R. Abbreviation of bancus reginae and bancus regis, i.e., Queens Bench and King's Bench. See Court of King's Bench.

brabant ( ). An ancient English coin.

bracery ( ). The practice of buying and selling titles and fictitious claims, so named in a 1541 English statute making the practice unlawful. Not to be confused with the offense of embracery, but it frequently is.

brachium maris ( ). An arm of the sea.

Bracton. The name by which the thirteenth-century legal treatise De Legibus et Consuetudinibus Angliae (Of the Laws and Constitution of England) is generally known (even though its reputed author, a royal justice, seems really to have been named Henricus de Bratton). The work is much more detailed and voluminous than Glanville, and is based to a degree striking for the time upon decided cases (Bracton's collection of which has been discovered and published as Bracton's Note Book). The Treatise seems on the 


\section{Leff Dictionary of Law}

surface also to have been influenced by Roman Law, many of the categories and distinctions of which are used. But it has been argued that actual influence is small, the Roman aspects being merely an artificial setting for "true" common law. In any event, Bracton was extremely influential upon later treatise writers, including and especially Coke.

brain death. With the growing capability of modern medicine to use machines to take over the performance of human life functions, thus to keep moribund people from "death" in the old sense of cessation of breathing, heartbeat and circulation, (see alive), there has come to be a felt need for some other legally sufficient definition of death, usable, e.g., to decide when the parahuman machines may properly be shut off. An increasing number of jurisdictions, by statute or decision, have adopted for this purpose the concept of brain death, i.e., the total cessation of brain function, evidenced by the absence for twenty-four consecutive hours of (a) reaction to external stimulii, (b) reflex or voluntary movements (including breathing), and (c) any electroencephalographic brain waves.

braking distance. The distance a vehicle traveling at a particular rate of speed will continue to travel after the brakes are first applied. These data are frequently material in automobile negligence cases, and standard tables of braking distances are available.

branch. When used in the context of a family, an extension of the "family tree" metaphor which would include all lines of descendants from a common ancestor. When used (incautiously) in a testamentary document, it usually refers to a branch of direct descent from the testator (i.e., children and children's children, etc.) rather than to collaterals (i.e., children of siblings or more distant relatives).

Also, in some parts of the U.S., a small stream, as in "bourbon and branchwater."

Also, an extension of some institution away from its original or home situs, as in branch bank.

branch bank. An office of a bank physically separate from its main or home office, especially one offering full banking services (i.e., not just an office for deposits, cashing checks, etc.). In some states, in an apparent attempt to keep small, especially rural, banks from having to compete with branches of large metropolitan banks, branch banking is forbidden or severely restricted (e.g., to the same city as the bank's main office).

branch line. See feeder; lateral railroad.

branch of the sea. At common law, this included rivers in which the tides ebbed and flowed, as well as true sea inlets.

brand. To brand is to mark an animal or person with some distinctive symbol by burning it into the flesh, usually with a heated branding iron. The process is used on animals to provide indelible identification of ownership. On people it was used as a particularly punishing way of identifying a malefac- 
tor, e.g., one who had once claimed benefit of clergy after committing a felony, so that the offender would forever after be known (in a society which knew neither fingerprinting nor good personal records) to have previously committed a crime.

The mark produced is called a brand. By extension it has also come to cover a product distinctively identified to the public whether or not it bears the name of its manufacturer, e.g., Michelob Beer which is a brand name of the Busch breweries. See also trademark; tradename.

Brandeis brief. An appellate brief which includes, in addition to "legal" citation and argument, substantial additional data, especially economic and sociological studies presented in statistical form, about the social setting of the case and the likely social impact of the court's ruling. The earliest use of such briefs is attributed to Louis D. Brandeis, practicing law prior to his appointment to the Supreme Court in 1916, but he was only the most prominent user. And it should be noted that crude arguments in this form have always been a staple of appellate argument, e.g., "This statute, if upheld, will totally destroy [the] codfish industry."

brand name. The name tying a product to a particular producer under which its product is sold to the public. It may be the producer's or seller's corporate name, e.g., Kodak, but it need not be; Sealtest Milk is produced by the Kraft Corporation. A brand name may or may not also be a trademark, e.g., "Coca-Cola" is a brand name, but only "Coke" is a valid trademark.

brank ( ). A sort of bridle used as part of the punishment of a convicted common scold.

brassage. See seigniorage.

brass knuckles. A weapon, originally made of brass but now of any metal, worn over the fingers such that a blow of the fist will do enormous damage to the victim while the user's hand remains protected. While not necessarily a deadly weapon, certainly use of brass knuckles would constitute aggravated assault.

braw1. Today, any noisy quarrel or public uproar, usually including physical conflict. In older English law, such conduct carried on in or around a church, which was specially made an offense by a mid-sixteenth century statute.

breach. A breaking, which may be of one's obligation, as in breach of contract and breach of trust, or may be more physical, as in breach of close and breach of the peace.

breach of close. Trespass involving intrusion on the land of another, i.e., trespass quare clausum fregit.

breach of contract. Unexcused failure to comply with one's obligations under a contract. In its broadest interpretation, this includes not only failure to do or not do what one promised, but also (sometimes called-dangerously-"constructive breach") taking steps rendering one's 


\section{Leff Dictionary of Law}

own or another party's performance impossible, and repudiating the contract before one's performance was due, i.e., anticipatory breach.

breach of covenant. See breach of contract; covenant.

breach of pound. Animals taken under a warrant of distraint were kept in a pound, i.e., an animal shelter. The owners were often tempted to break in and take their animals back, or at least, to spite the distrainor, to set them free. Giving into that understandable impulse constituted "breach of pound."

breach of privilege. An offense by a legislator in going beyond what is deemed proper behavior as determined by the legislature in which he sits.

Also, exceeding the bounds of a limited privilege to make, without liability, communications otherwise defamatory. See defamation; privileged communication.

breach of promise. A term broad enough to encompass any breach of contract, but generally referring to the act of, and action for, breach of promise of marriage. While breaking one's promise to marry is, one assumes, as common as ever if not more so, almost all jurisdictions have abrogated any legal action based thereon. See also affiance. There is some evidence that during its nineteenth-century heyday the action was frequently used as a euphemistic alternative to an action alleging sexual seduction.

breach of the peace. A loosely defined offense consisting of being noisy, obstreperous, or particularly annoying to passersby or agents of authority in some public place, or of inciting others so to behave. It is sometimes used as a catch-all with which to charge persons irritating policemen, and as so used runs into constitutional trouble from time to time. See vagueness.

breach of trust. Any violation of any kind of any fiduciary duty, i.e., any improper behavior by an express, implied or constructive trustee, whether active, passive, innocent, negligent, or intentional. It should be noted that one may be in breach of trust even if one did not benefit from the improper activity, i.e., breach of trust does not require embezzlement or any other self aggrandizement, but requires only violation of the rules (of law or of the trust instrument) directing the trustee.

breach of warranty. See warranty.

breachy animal. A domestic animal with a propensity for getting out of confined areas, e.g., by breaking through or going over fences. Prior discovery of such a propensity may effect the result of lawsuits about damages inflicted by or on such animals.

bread. Bread, of course, but also, in fast-fading slang, money.

breakage. Damage done to chattels, especially during shipment. Some manufacturers make a precomputed allowance to customers to cover breakage during shipment, thereby avoiding the costs of having to receive back and pass upon broken items. In some bills of lading, the carrier is exempted 
from responsibility for breakage (not caused by its negligence), though the provision has been held not to cover living animals.

Breakage also refers to fractional sums in financial computations, "odd pennies," which may for simplicity be ignored as trivial, e.g., in computing interest or the betting pay-off at a horse race. When many transactions are involved, however, who gets the "breakage" is not a trivial question, e.g., banks computing interest to be paid to depositors ordinarily cannot just keep breakage, though they may keep all under, and pay a full cent for all over, half a cent.

break and take. An old fashioned salesmanship technique in which the buyer is offered, along with his purchase, a chance to win something additional, i.e., goods and a raffle ticket sold together. Occasionally prosecuted, especially by the FTC, as an illegal lottery, but not presently of much practical importance. $C f$. punchboard.

breakeven point. That volume of sales at which a business neither makes nor loses money; it is used in businessmen's calculations of the optimal mix of sales volume and price.

breaking a case. Informal discussion of a case by judges during the process of their joint deliberations but prior to announcement of decision.

breaking a close. Entry upon land, which, if upon the land of another, constituted trespass quare clausum fregit (literally, "because he broke the close.").

breaking and entering. Two elements of the common law felony of burglary, requiring a finding that the defendant has used some physical force in the course of effecting some actual penetration onto the premises of another. How much force and how much penetration has often been litigated (e.g., is lifting a latch "breaking"?; is putting a hand through a broken window "entering"?), with reasonably unpredictable results.

There is a certain irony in these close discussions, inasmuch as "breaking and entering," as originally formulated, was merely a redundant doublet, in which "breaking" was the Anglo-Saxon term for which "entering" was the latinate equivalent.

Modern criminal statutes play many variations on the central breakingand-entering theme, some making entering without breaking a crime, some making entering without breaking a crime, some formulated in terms of breaking or entering (occasionally leading to a holding that "or" means “and"), etc.

breaking a will. Achieving the judicial declaration that a will is not valid, because of inauthenticity, or some formal defect in its execution, or some improper behavior like undue influence surrounding its creation. When a will is broken, those who, but for the will, would have taken by intestate succession are the beneficiaries of the process, and they usually are the ones who commence the challenge. 
breaking bail. The crime committed when a bailee (see bailment) broke open a package put into his possession and made off with some of the contents. See breaking bulk. Since "bale" was an old quite general term for "package," it may be that the term was originally or alternatively "breaking bale."

breaking bulk. At common law, if a carrier or other bailee of goods (see bailment), with criminal intent broke open a package of goods entrusted to him, and converted them to his own use, he committed the felony of larceny; but if he merely stole the whole unopened package, he committed no felony (though the owner, of course, was entitled to get his goods back). Why there should ever have been such a doctrine has been the subject of much explanation, which has left the matter inexplicable. See also breaking bail.

The concept of "breaking bulk" has also figured in U.S. constitutional law, for which see original package doctrine.

breaking into. See breaking and entering.

breaking jail. See jail breaking.

breast of the court. Where a litigated case is metaphorically located between final argument and the announcement of the court's decision.

breathalyzer test. See breath test.

breath test. A chemical test permitting the operator to infer, by an analysis of a measured sample of the breath of a subject, the amount of alcohol in his bloodstream. The test is much used in gathering evidence of drunken driving, and its results are admissible evidence, and over a certain level may raise a rebuttable presumption of intoxication. See also implied consent.

bredwite. In old English law, an amercement or penalty for breaking one of the statutes regulating the manufacture and sale of bread.

brehon law. The indigenous Irish legal system in place until Ireland's conquest by Henry II in the twelfth century-and most likely more then merely interstitially effective for a long time thereafter. ("Brehon" was Irish for "judge.")

brenagium ( ). The Latin form for brennage.

brennage ( ). A low feudal tenure, service consisting of furnishing bran for the lord's hunting dogs.

brethren. An old form for the plural of brother, now used, if at all, only to refer to persons only symbolically brothers, e.g., the Justices of the Supreme Court; members of the Senate. In some wills "brethren" has been interpreted to include the testator's sisters-presumably under the pressure of context or natural equity.

bret[h]walda ( ). Another term for an Anglo-Saxon King.

Bretts and Scots. See Laws of the Bretts and Scots. 
breva ( ). See breve.

breve ( ). A writ; a brief. See also capias.

breve de recto ( ). A writ of right.

breve domini regis non currit ( ). "The King's writ does not run," i.e., the matter is not within the jurisdiction of the King (or his courts).

breve formatum ( ). See brevia formata.

breve innominatum ( ). A writ reciting the matter at issue in only the most general terms-an early medieval version of notice pleading.

breve nominatum ( ). The opposite of breve innominatum, i.e., a writ setting out the matter involved in considerable detail.

breve originale ( ). A writ which commenced an action (as contrasted with writs which were issued before commencement or during the course of the litigation).

breve perquirere ( ). To purchase a writ, i.e., to buy (for an eventually standard sliding scale of fees) the right to use the system of royal justice.

brevet. In the military, a term describing a rank one notch above his actual rank conferred upon a military officer, which, however, confers no additional salary or, ordinarily, scope of command. In the U.S. once quite frequently conferred upon an officer who showed bravery or uncommon efficiency, especially as a form of retirement present. Hence one finds numerous references in the form ". . . retired with the brevet rank of Major." The verb form is "brevetted" or "breveted," as in ". . . brevetted Major for conspicuous gallantry at Bull Run."

brevet d'invention ( ). In French law, a patent (on an invention).

breve testatum ( ). The singular form of brevia testata.

brevia ( ). Plural form of breve.

brevia adversaria ( ). Adversary writs, i.e., commencing a true contest (especially over rights in land); to be contrasted with "brevia amicabilia," i.e., "friendly writs," i.e., ones issued with the consent of the opponent, e.g., to be a judicial determination of title.

brevia amicabilia ( ). See brevia adversaria.

brevia anticipantia ( ). Anticipatory writs, designed to prevent something from happening, i.e., old writs with some of the functions of injunctions out of Chancery. At common law there were six: audita querela; curia claudenda; mesne; monstraverunt; ne injuste vexes; and warrantia chartae.

brevia de cursu ( ). Writs "of course," i.e., which would be issued as a matter of course upon application, i.e., writs to which one had a right. These tended, of course, to be brevia formata, though not all of those were "brevia de cursu." 


\section{Leff Dictionary of Law}

brevia formata ( ). A formal writ for a well-established cause of action, to be contrased with "brevia magistralia," which were, so to speak, custom crafted by Chancery clerks to fit the situation when no formal writ quite fit.

brevia judicialia ( ). Judicial writs.

brevia magistralia. See brevia formata.

Brevia Placitata (). An important mid-thirteenth-century collection of standard writs and counts (see counting), interesting because the writs, in fact always submitted in Latin, were there translated into French (the then language of the courts and the upper classes), indicating that the book was also for the use of persons other than specialized lawyers.

Breviarium Alaricianum ( ). See Law of Alaric.

brevia selecta ( ). "Selected writs," i.e., a compilation of specially useful ones.

breviate ( ). A short statement or abstract, especially one accompanying a bill in parliament; also a brief.

brevia testata ( ). Written memoranda listing the names of witnesses to an oral grant (which might be accompanied by transfer of a written deed, with which the memorandum was associated), so as to decrease later disputes about the making of the grant. The witnesses did not themselves sign. (Blackstone theorizes that many of them could not write, but it is also possible that they did not want to be mistaken for warrantors.)

brevibus et rotulis liberandis ( ). A writ to a sheriff directing him to turn over to his successor all writs and records in his possession.

Brezhnev doctrine. A doctrine announced in 1968 by Leonid Brezhnev, then First Secretary of the Communist Party of the USSR, after crushing by armed invasion a Czechoslovak government which had seemed to be relaxing totalitarian control over the people, to the effect that any time a previously Communist government seemed to be on the verge of transformation to something else, the "Socialist community [as] a whole" had the right to interfere with force to stop it. The doctrine has most recently (1980) been used (though not avowedly) in Afghanistan.

bribe. See bribery.

bribery. A crime (the exact scope of which varies somewhat from jurisdiction to jurisdiction) of giving or promising, or soliciting or receiving, something of value to influence, in the performance of official duties by a public official, or by one (e.g., a voter, witness, or juror) with a temporary official role. Some statutes also cover union officials, employees of businesses (see commercial bribery), and participants in sporting contests.

Modern interpretative problems center on what constitutes a corrupt transfer of something of value to the official (a vote for him? getting out the vote? a campaign contribution, where no specific favor is asked in return?), and the status of payments to governmental officers in other countries where 
such payments are lawful, or only formally unlawful. See questionable payments.

bribery at election. Buying votes. See bribery.

bribour ( ). Law French for a petty robber or thief. (Not a person who gives or takes bribes.)

brick construction. A type of building construction; for fire insurance purposes, technically defined (so many inches of wall thickness, etc.) and receiving a favorable rate.

bricolage ( ). See bricoleur.

bricoleur ( ). French word for a particular sort of handyman, one who fixes things by modifying whatever materials are at hand to serve his then purposes. If, e.g., a small pipe joint were leaking, a bricoleur might use the chewing gum in his mouth to pack the joint, rather than buy a commercial caulking or actually replace the defective part. The process (called bricolage) was popularized by Claude Lévi-Strauss as a description of the way in which primitive societies use concepts, i.e., putting the limited number in currency to work to handle innumerable conceptual jobs. It has been taken over to a limited extent by legal writers to describe a similar process in law, by which judges and scholars bend concepts or rules to serve divers purposes rather than create new ones more particularly crafted to the job at hand. Consider, e.g., the many uses to which the concepts of consideration and privacy have been put; and $c f$. legal fictions. It is not clear that this legal use of the French term clarifies much, however.

bridewell ( ). In England, any prison or penitentiary, the term having been generalized from a particular one founded in London in the sixteenth century.

bridge financing. See interim financing.

bridle. A device like a horse bridle fitted over the head of a common scold as part of her public punishment, the device, the status, and the punishment now being obsolete.

brief. Originally any writing, especially in letter form; also any summary or condensed statement. $C f$. briefing a case. Today the term refers to a formal legal genre: a written argument presented to a court by counsel, most commonly to an appellate court. While the precise format varies from jurisdiction to jurisdiction, the typical brief includes a summary of previous legal proceedings; a short statement of the relevant facts found below; a formulation of the questions properly on appeal; an argument in favor of one's position, citing relevant legal authorities, statutory and decisional; and a conclusion stating the relief sought. See, e.g., Fed. R. App. P. 28.

In some jurisdictions trial briefs are sometimes required to be submitted to the judge before a trial. They constitute a statement of what is sought to be established including a summary of evidence to be presented and legal 


\section{Leff Dictionary of Law}

rules being relied upon. (Such a document may also be prepared by a lawyer for his own use in organizing his trial presentation.)

In England, a document from solicitor to barrister instructing him about a case to be litigated, including the whole file of relevant documents.

brief of title. See abstract of title.

briga ( ). Debate; litigation; strife.

brigbote ( ). Also spelled "bragbote," "brugbote," "bruckbote." In AngleSaxon times, an obligation, in the form of a charge placed on land, to contribute to the cost of maintaining castles, walls and bridges.

bright line. A common term in legal rhetoric, found in formulations like "what is needed is some bright line test for illegality," i.e., some easily perceived, easily administrable standard to be applied. In defining statutory rape, e.g., "sexual intercourse with a female not able to appreciate the significance of her act" would not be a bright line standard, but "sexual intercourse with a female under the age of sixteen" would. $C f$. age of majority.

bring. To move something closer (to the speaker).

bring about. Cause to happen; accomplish.

bring-down search. See title search.

bringing action [or suit]. Commencing litigation.

bringing money into court. See payment into court.

Bristol bargain. An old form of loan, the distinctive feature of which was that the borrower was to repay an amount equal to one-fifth of the principal each year for seven years. It comes to about $11 \%$ per year.

British Commonwealth [of Nations]. See Commonwealth.

British North America Acts. A series of statutes governing the Dominion of Canada, forming, in effect, its Constitution (in the U.S. sense). The acts cannot be amended by the Dominion but only by Parliament, though no new acts are passed except at official Canadian request.

Britton. The name given to a late-thirteenth-century work on English law, written in Norman French (rather than Latin). The work seems to be based heavily on Fleta and to some extent on Bracton, but it is organized more around remedies for the vindication of rights than around any classification of the rights themselves.

broad construction [or interpretation]. See liberal construction [or interpretation].

\section{broad-halfpenny. See boothage.}

Broadmoor. The name of an early and famous English institution for the criminally and dangerously insane.

broadside objection. An objection, especially to the admission of evidence at a trial, which specifies no grounds, or specifies all conceivable grounds, e.g., 
"I object on the grounds that the evidence is irrelevant, immaterial and incompetent."

broad tape. See ticker.

brocage ( ). Old form of brokerage.

brocards ( ). An old (and rare) word for legal maxims, especially collections of conflicting maxims of the civil (i.e., continental) law.

brocarius ( ). A broker.

brocator ( ). A broker.

brode-halfpenny ( ). See boothage.

broken lot. A quantity of goods smaller than the smallest ordinarily offered for sale, e.g., less than 100 shares of stock (see odd lot), or (from wholesaler to dealer) less than one case of wine.

broken stowage. The portions of a ship not filled by her cargo.

broker. A person engaged, ordinarily as an occupation, in any form of brokerage. For particular types of brokers, see entries containing the word, e.g., insurance broker; marriage broker; pawnbroker; stockbroker. See also commission merchant; factor.

brokerage. The economically useful role of effecting, for remuneration, as an agent on behalf of some other person, the purchase, sale, lease, etc. of any item of property of any kind. One effecting a brokerage transaction does not have any ownership interest in the property, and rarely has possession; his job, in effect, is to bring parties to a deal together, and usually also to handle the negotiations and the incidental technicalities of the market, e.g., a stockbroker will actually effect the transaction via a stock exchange. In effect, a broker sells expertise in operating on a particular market to people who use that market too occasionally to justify developing much skill of their own.

The broker's remuneration (also sometimes called "brokerage") is generally a fixed fee, either absolute or a percentage of the price paid, and has no relation to the amount of effort expended: if the broker is not successful he gets nothing; if he is successful with no substantial effort, he gets the stipulated fee. The brokerage contract also usually stipulates that that remuneration is earned the payable as soon as a ready, willing, and able buyer or seller is found for the broker's client on his terms, even if the deal never goes through. But some recent cases have cast doubt on the validity of such a provision, at least if the client is an unsophisticated nonprofessional. See also exclusive right of sale; listing contract.

In practice, it is common for one involved in brokerage also to be involved in similar transactions involving his own property, e.g., a stockbroker will often effect purchases and sales of securities not only between strangers but between himself and third parties, including his own customers. This leads to situations ripe for conflicts of interest (e.g., selling out of 
one's own inventory rather than effecting a better deal with a third party) and thus to reasonably detailed governmental regulation of brokerage, especially licensure requirements.

brokerage contract. See brokerage.

brokerage listing. See brokerage; listing contract.

broker-dealer. See stockbroker.

brokering. Lawyer's informal term for the practice of forwarding cases upon which one does no work to other lawyers in exchange for forwarding fees. Though formally unethical (see Code of Professional Responsibility DR 2107), the practice is reputed to be widespread.

broker's lien. A lien on property, proceeds of its sale, or anything else of value coming into the possession of a broker, to secure the payment of his remuneration earned, and expenses incurred on behalf of his client, in connection with a brokerage transaction.

brothel. See whorehouse.

brother. A male sharing with oneself one or both biological parents. If both are shared, he may be called a "full brother"; if only one, a "half brother," or "brother of the half blood." In testamentary instruments, and most intestate laws, "brother" will be interpreted to include half brothers. See also blood brother; stepchild.

In the civil law (and in Blackstone), if the brothers have the same father they are "consanguine brothers"; if the same mother, "uterine brothers"; and if they share both, they are "brothers germane."

"Sister" describes exactly the same relationships, except that the person so described is female; similar cognate terms and legal rules ordinarily apply.

brother-in-law. A term of variable usage, covering the brother of one's wife, the husband of one's sister, and also (though less commonly) the husband of one's wife's sister and (to a wife) the husband of her husband's sister.

"Sister-in-law" describes the same relationship, but with a female subject.

brothers and sisters. A term which, when appearing in an intestate law or testamentary instrument, will ordinarily be deemed to include brothers and sisters of the half blood. See brother.

\section{Brougham's Act. See Lord Brougham's Acts.}

Brown case. The celebrated case, Brown v. Board of Education of Topeka, in which the Supreme Court declared segregation in the public schools violative of the equal protection clause of the Constitution.

There were actually two significant decisions in the case, reported at 347 U.S. 483 (1954) and 349 U.S. 294 (1955), respectively. The first ("Brown I") reversed the rule of Plessy v. Ferguson, 163 U.S. 537 (1896), in which the provision of "separate but equal," i.e., racially segregated, facilities (in 
that instance, involving railroad passengers) had been upheld. In Brown I the Court held that, at least in the context of public education, separate was inherently unequal. In the second opinion ("Brown $I I$ ") the Court, addressing the question of remedy, delegated carrying out desegregation to the lower federal courts, enjoining school officials to make a "prompt and reasonable start" and directing the courts to effect the transformation "with all deliberate speed."

In short order, the Brown holding against racial discrimination was extended beyond public education to substantially all governmental functions (see state action). The decision coincided with the beginning of the era of dramatic agitation for racial equality (see sit-ins) but, as usual, it is unclear if the case was a major cause or just a symptom of a process more widely coming to life. $C f$. affirmative action; Bakke case; quotas and targets; reverse discrimination.

brutum fulmen ( ). An empty noise, i.e., a toothless threat, as in "If no injunction coud be issued against this act, our declaration of its wrongfulness would be but a brutum fulmen."

bubble. A recurrent species of financial hysteria in which something (e.g., tulip bulbs, Florida land, shares in the South Sea Company-to pick three well known examples) is subject to wild price escalation, eventually culminating in a total collapse of prices wiping out those unfortunate enough to have bought at, or held to, the end of the game. While pathological, bubbles testify to the fact that whatever the value of something, its price is a function of someone else's willingness to pay. Hence one can rationally purchase an exotic tulip bulb for the equivalent of $\$ 100,000$ if one's judgment is correct that someone will take it up the next day for $\$ 110,000$. Some bubbles are the result of fraud, e.g., willfully disseminated knowingly false information about the worth of the things being bought, but some seem as mysteriously spontaneous as the medieval dancing sickness or outbreaks of mystical visions in a convent school. $C f$. chain letter; ponzi.

Bubble Act. An English statute passed in 1721 upon the collapse of the South Sea Company bubble designed to thwart similar occurrences in the future. It took the inartistic form of a prohibition on doing business in corporate form without explicit authorization by Parliament. The act remained formally on the books until 1825 .

bucketing. Operating a bucket shop.

bucket shop. An illegal operation in which orders are taken for the buying and selling of securities without any of the orders being actually executed. Instead, the operators in effect bet on the movement of the stock prices: If the buyer demanded the stock he paid for, it could be delivered to him easily if its price had declined below what he paid; if it had appreciated in value, the bucket shop runners often had to run. In some cases, the investors apparently knew that no securities were to be bought, and that the bucket shop was, in effect, a bookmaking operation involving securities prices rather 
than horse races. In this latter form, the customers presumably expected to be paid if they won. $C f$. boiler room.

budge of the court ( ). Another term for bouche of court.

budget. A document showing predicted income and expenditure-amounts, sources, and applications-for a determinate period of time, usually one year. Any entity, even a family, may choose to formulate a budget, but businesses almost always are forced to do so by the demands of rational operation, and governmental units are too, by that, and usually also by statutory compulsion.

buffer zone. A strip of land, of variable width, established between two others to help mitigate or eliminate conflict between them. The conflict may be aesthetic, e.g., between an industrial and residential area in a city, the buffer zone being established by the zoning board to contain uses transitional between those in the separated areas. A buffer zone between hostile nations is also sometimes established in order to decrease border frictions and the ease of sudden attack. In such cases the buffer zone is usualy also a demilitarized zone.

bug. Slang term for a concealed listening device installed to listen in on private conversations, either telephonic or face-to-face. The term can be used as either a verb or a noun, as in "They tried to bug the Democratic National Committee by installing a bug in its Watergate office." Bugging by police is subject to a great deal of regulation generated by, and subject to, Fourth Amendment considerations.

buggery. A sexual crime encompassing perhaps as unspecifiable a range of activities as abominable and detestable crime against nature, but generally used to refer to sexual relations between men involving oral or anal penetration, also often called "sodomy." Buggery may also include sexual relations between humans and animals, more specifically called "bestiality."

building. Any more or less permanent structure designed to enclose persons, animals, or things. So broad is the term that when its interpretation is legally significant, one must rely on context and apparent intent. For mechanics lien purposes, e.g., a foundation without more has been held a "building," and a wall may be a "building" within the intent of a restrictive covenant.

building and loan association. See savings and loan association.

building association. See savings and loan association.

building code. A set of regulations, usually municipal but sometimes statewide, providing, in various degrees of detail, specifications for the construction of buildings, enacted to insure certain levels of safety and convenience. It is usually provided that a building permit must be procured before beginning construction, and that a certificate of occupancy will not be issued unless the building code is complied with, or noncompliances are formally approved. 
Some (but only some) building codes are notoriously either out of date, excessively conservative, technologically irrational, slanted to protect vested construction interests (e.g., banning plastic piping to aid plumbers), or all of the above. Also, since some of their requirements are both unnecessary and expensive, building codes provide a rich medium in which to grow bribery and other forms of political corruption. See also housing code.

building contract. See construction contract.

building coverage. The percentage of land at a building site covered by the building on it. Zoning rules typically limit the coverage to some percentage of the lot less than 100 .

building inspector. A governmental employee charged with investigating compliance with building codes and housing codes. Also called "housing inspector."

building is covered. A phrase in an insurance binder, meaning that the building is insured under the standard terms of a normal policy until the formal policy is issued, or notice of rejection of the application is received.

building lease. A lease of unimproved land, usually long term (especially ninety-nine years), in which the lessee agrees to pay rent ("ground rent"), and to build or maintain one or more structures. Also ground lease.

building lien. Any lien on a building, but especially a mechanics lien.

building line. Also called "setback line" and "front line." A line, usually established by municipal ordinance but sometimes by restrictive covenant, in front of which no one may erect any structure on his lot. The purpose is to produce a uniform line of facades facing a particular street, for aesthetic purposes or at least to assure that persons on the sidewalk will have space to walk. See also back lines; side lines.

building loan agreement [and mortgage]. See construction loan.

building permit. A license to erect a building or effect major additions or renovations on one, which must be procured in most places before starting work. One must ordinarily submit plans and estimates of costs and pay a fee before getting the permit, the purpose of which procedure is, ostensibly, to make sure that the building will be in accord with the building code. Incidental effects include making the local authorities aware of newly taxable construction, and providing one more reason to hire people to do construction rather than to try to do it oneself. Construction contracts ordinarily are made conditional upon the issuance of a building permit.

building restrictions. Limitations upon the type, height, style, etc. of building which may be constructed on one's property. They may be privately provided in restrictive covenants (where they are sometimes also called "type restrictions"), but are most likely to be found governmentally imposed, as part of zoning regulations or building codes, or independently by aesthetic zoning regulations. 
building society. British term for what in the U.S. was called a "building and loan association," for which see savings and loan association.

building-to-suit [lease] agreement. An [agreement] by which a builder promises to build (or modify or renovate) premises to the specifications of a tenant, the latter agreeing to lease the premises upon completion.

built-up district. A zoning term referring to an area no longer having much in the way of vacant land.

bulk. "The bulk of" means "most of." Bulk may also refer to merchandise sold without particularized weighing, measuring, etc. but as all contained in an unbroken package, or all located in a particular place, as in a bulk sale. See also breaking bulk; laden in bulk; open bulk.

bulk envelope. The three dimensional space on a building site which may under zoning codes be filled by the structure constructed. These rules, designed to assure sufficient light, air, and open space, are often called "bulk zoning regulations."

bulkhead. A strong upright partition or wall designed to subdivide a larger space, especially one holding cargo, or to contain and resist the spread of flood waters, fire, etc. The term was originally nautical, but can now be used of such structures in planes, trains, and perhaps warehouses.

bulk mortgage. A mortgage of personal property in bulk, i.e., of an aggregate of various kinds of property (e.g., "all goods, wares, and fixtures"), usually in a particular place (a shop or a warehouse). The term is perhaps usable to describe a mortgage under one instrument of two or more parcels of real property.

bulk sale. Might refer merely to a sale of goods in bulk, but the primary referent is to a sale of all or a major part of the merchandise of a trade or business made other than in the ordinary course of business. Because of the risk that bulk sales might be used to defraud the seller's creditors, statutes called Bulk Sales Acts were passed in most states to regulate them, notably by requiring timely notice of the sale to be given to creditors. The Bulk Sales Act currently applicable almost everywhere comprises article 6 of the U.C.C.

Bulk Sales Act. See bulk sale.

bulk transfer. See bulk sale.

bulky property. Property the size and cumbersomeness of which justifies legal treatment differing from that which would be accorded more easily moveable property, e.g., upon lien foreclosure, bulky machinery might be "seized" by notice rather than physically taking possession, and bulky writings (e.g., tombstones or massive complications) might not have to be brought into court under the applicable original document rule (e.g., Fed. R. Evid. 1006).

bulk zoning regulations. See bulk envelope. 
bull. In Roman Catholic ecclesiastical law, a sealed legal instrument issued by the Pope, containing and effecting a public act, e.g., a grant, decree, commandment, etc. $C f$. bill. The seals of Roman emperors were called "bulla."

In stock market slang, a bull is an investor who expects the market to rise; hence a "bull market" is one dear to bulls, i.e., a rising market. See also bear.

bulla. See bull.

bullet [sentence]. In criminal law slang, a flat sentence without any range, especially one year.

bulletin. A term, with no particular determinate legal meaning, for a public notice of some kind. The implication is of something reasonably short and timely, and in "news bulletin" that implication is intensified to mean "hot news" or "flash."

bulletin des lois [or legislatif] ( ). In France, the official publication of newly enacted laws, decrees, etc.

bulletproof. Lawyer's slang for a document without loopholes. $C f$. ironclad.

bullion. A precious metal in its uncoined state, usually kept in ingots.

bullio salis ( ). An old measure of salt, reputed to be twelve gallons.

bull market. See bull.

bull pen. In prison slang, a place of close confinement, but especially a large locked cell in a police station or courthouse where groups of prisoners are temporarily kept pending processing.

bum-bailiffs. See bound bailiffs.

bum-boat. A lighter which comes out to a larger ship in a harbor to sell ships stores and other merchandise for the ship and for the crew's personal use.

bumping. The practice whereby employees with greater seniority displace those with less seniority when layoffs occur. In the military, being bumped out of some privilege by a person of higher rank, e.g., off a military transport or from desirable housing, is still common.

Also, the airline practice of dislodging passengers with reservations from their flights because too many tickets have been sold to accommodate everyone. Under current regulations, airlines must first try to get volunteers for bumping by offering them money, and must take other steps to mitigate the sometimes harsh effects of being bumped.

bump off. To kill.

bunco [game]. Earlier forms included "bunkum" and "buncombe." The term seems originally to have meant false and bombastic talk, but it now refers to any of the large number of swindlers' games called congames.

bunda ( ). In old English law, a boundary or limit.

bungalow court. An old fashioned term for what is now called a motel. 
buoy ( ). A floating marker, sometimes containing a light, a bell, or both, placed so as to delineate a channel, warn of a hazard, or mark out a course. Their construction and placement are widely regulated by federal law.

burden. A weight or impediment; something to be borne. In legal contexts, often used figuratively, as in burden of proof, to indicate allocation of responsibility for something. The figurative use is predictable, given the importance in legal discourse of weighing metaphors, e.g., balancing, scales of justice, etc.

burdened vessel. In maritime parlance, a ship which, under the applicable navigation rules, is obliged to keep out of the way of another.

burden of coming forward. See burden of proof.

burden of evidence. See burden of proof.

burden of going forward. See burden of proof.

burden of persuasion. See burden of proof.

burden of producing evidence. See burden of proof.

burden of proof. This term conflates, and often confuses, several distinguishable jobs that must be allocated in any trial. The first is introducing enough evidence really to inject into a case an issue of some sort, in default of which that issue is deemed not present. If, e.g., fraud is pleaded by the defendant in a contract action, but he puts in no evidence of fraud, he has not met this burden (sometimes called the "burden of coming forward"), and the issue, so to speak, disappears.

Closely allied, however, is what is sometimes called the "burden of evidence" or "burden of producing evidence" or "duty to make a prima facie case." This involves producing enough evidence such that the judge will let the issue go to the jury for determination, unless the opponent's evidence is overwhelming.

Burden of proof, however, may also refer to what is also called the "burden of persuasion," i.e., the obligation ultimately to establish a particular issue by the applicable standard, e.g., by a preponderance of evidence, by clear and convincing evidence, beyond a reasonable doubt, etc. This is a burden such that if no evidence from any quarter is introduced on a particular material issue, or the trier of fact finds itself in equipoise on it, the party to whom the burden is allocated loses.

It is understandable that these various meanings of burden of proof tend to get confused. Most frequently one with the burden of persuasion also has the burden of coming forward and the duty to make a prima facie case, so disentangling the meanings is unimportant. But under some circumstances one party has a duty to come forward, i.e., really to raise an issue, even though the other will have the burden of persuasion once the issue is raised, e.g., a defense of duress in a criminal case. And since "burden of proof" in the sense of "burden of going forward" involves the duty to come up with enough to avoid a judicial (as opposed to jury) determination of the issue, 
that burden may shift back and forth between the parties as the trial progresses, i.e., at any given moment the state of the evidence may be such that, absent new evidence produced by one party, the judge will find against him without submitting the question to the jury.

burden on interstate commerce. See commerce clause.

bureau. A unit of bureaucratic organization, mostly used of governmental operations. In the U.S. federal government, a bureau is usually a significant subdivision of a department, e.g., the Federal Bureau of Investigation, a part of the Department of Justice. See also entries containing "bureau," e.g., Census Bureau.

bureaucracy ( ). A form of organization, as an ideal type characterized by a hierarchically organized control structure, specialized participants carrying out differentiated roles, and impersonal, formal, and formally rational procedures. Bureaucracy has been said to be to politics and administration what the assembly line is to manufacturing, and as such it has been seen as indigenous to, or perhaps even necessitated by, any large scale enterprise, public or private, which seeks efficiency and predictability.

In many quarters "bureaucracy" has become a term of abuse, with the word having come to stand for its worst aspects: cold impersonality, nondemocratic authority, formality in human interaction and communication (engendering nonresponsiveness and red tape), and the ultimate inefficiency, unpredictability, and unfairness of a structure seeking to treat the administration of human wants, needs, and rights as a matter solely of rules and regulations. That actual bureaucracies are often characterized by such results is easily established.

What is harder to create, or even imagine, [is] some superior replacement. Can large-scale enterprises be run efficiently on the basis of individualized decisions, not defined or constrained by more or less general rules? If they could, would not the informality and strong discretion thus given decisionmakers generate the apparent injustice of similar things (and people) being treated differently? Could, say, the U.S. Social Security Administration be run as some kind of colossal Gemeinschaft, a group of friends and brothers?

In any event, most real bureaucracies fall short in actual operation of their ideal type, with a good deal more of individuation, human interaction, discretion, and independence from hierarchy than their formal organization would imply. For some of them this leads to a softening of bureaucracy's worst tendencies; for others, it adds to those all of the worst tendencies of nonbureaucratic modes of organization.

bureau of customs. See customs duty.

Bureau of Investigation. See Federal Bureau of Investigation.

Bureau of Labor Standards. A division of the U.S. Department of Labor charged with developing health, safety, education, and other standards to 


\section{Leff Dictionary of Law}

improve working conditions. It gathers data and drafts laws and regulations.

Bureau of Labor Statistics. A division of the U.S. Department of Labor charged with compiling and disseminating information concerning labor.

Bureau of Land Management. A federal bureau (the "BLM" for short) within the Department of the Interior charged with managing most federal public lands not in the national park or national forest systems. About half a billion acres (over 750,000 square miles) are involved, comprising about $60 \%$ of all federally owned lands. About two-thirds of BLM land is in Alaska.

Bureau of the Budget. An agency of the U.S. government attached to the Executive Office of the President, charged with coordinating the budgets of the various federal agencies, and negotiating amounts and allocations with congressional committees. It has the usual substantial power of any entity holding the coordinating nexus of a complex process.

burg. Once a fortified place or town, especially one elevated for defense. It then came to be another word for borough. But it has come to be used in American urban slang to refer deprecatingly to any small town, as in "Whattaya do in this burg after sundown?"

burgage tenure. A now abolished species of socage tenure, by which tenants held houses and lands (once part of an ancient borough) directly from some great lord (especially the King) for a rent certain. In fact, the rent was often nominal, the holdings were almost free of any feudal complications on transfer or descent, and burgage tenure often approached a modern fee simple interest.

burgator ( ). Old form of "burglar."

See burglary.

burgbote. In old English law, contributions (i.e., taxes) for the repair of castles, defensive walls, etc.

burgenses ( ). Old form of burgesses, though there was some implication of being engaged in trade in the town.

burgesses. Originally referred to free inhabitants of a borough, but came in time to refer to specially notable ones, e.g., representatives of a borough in Parliament. In the colonial U.S., sometimes came to mean political representative more generally, as in the Virginia "House of Burgesses."

burgh ( ). Saxon for "house." Also an alternate spelling of burg. Several terms which in later years begin with "borough" earlier began with "burgh," e.g., "borough English" was originally "burgh English."

burgh-brech[e] ( ). A fine on an old Saxon town for some breach of the peace therein.

burg[h]mot[e] ( ). An old Saxon court. 
burglar. One guilty of burglary.

burglariter ( ). Law Latin for (roughly) "burglarously," a word which was required in any old pleading alleging burglary. $C f$. "feloniously."

burglary. At common law, this felony consisted of breaking and entering a dwelling house after dark with intention to commit a felony (notably, theft) therein. Under modern statutes, while burglary still has to involve unlawful entry with criminal intent, it now usually encompasses entering structures of all kinds, and in daytime too-though nighttime entry into a dwelling house may still constitute a more severely punishable degree of burglary.

burglary tools. Tools adapted to committing the crime of burglary. In some jurisdictions, knowing possession of burglary tools with an intent to commit a burglary with them is itself by statute a crime. Since with some exceptions, e.g., specialized lock-picking devices, tools fit for burglary are fit for more innocent purposes too, this crime is dangerously inchoate, often being used to make a case against "known burglars" picked up this time prior to actually committing a burglary.

burgle ( ). An old term for the act of committing burglary, having a quaint or facetious flavor whenever used today.

Burgundian law. See Lex Burgundionum.

burgwharl ( ). Saxon for burgess.

burial. Disposition of a dead body by putting it into the earth, or into some special structure designed to receive it, e.g., a burial vault or mausoleum. When a person dead at sea is consigned to the waters, that too is a burial. In some contexts, e.g., burial insurance, the term is sufficiently general to include other standard methods of corpse treatment, e.g., cremation. $C f$. funeral.

burial expenses. See funeral expenses.

burial ground. See cemetery.

buxial insurance. A promise to provide some specified amount to be applied to the expenses of burying the insured. The most common burial insurance is provided by or through religious or fraternal organizations, usually on a mutual basis. $C f$. mutual benefit society. Social Security death benefits include a sum for burial of the deceased, thus decreasing the age-old fear of being unceremoniously dumped in a pauper's grave, or more ceremoniously given to a medical student.

burial lot. See cemetery.

Buridan's Ass. See ceteris paribus.

burking. Committing murder in order to have a corpse to sell for dissection. Named after the principal protagonist (one Burke) in a famous earlynineteenth-century case, whose own method involved suffocation of the victim. Hence "burking" may also be used for murder by suffocation. The 
general hostility to human dissection made allegations of burkism wildly more frequent than instances of it, corpses having never been all that valuable.

burlesque. Also spelled "burlesk." A show featuring striptease acts interspersed with vulgar comedy skits. In less permissive times, the apogee of available near-pornography, frequently banned and raided by the police.

burned and unburned clause. A provision in a fire insurance policy calling for the proration of insurance coverage of any covered location to the burned and unburned portions of the whole property.

burning in the hand. See benefit of clergy.

bursar ( ). A college financial officer, once the chief or only one, but today in the U.S. often subordinate to a "treasurer," who may himself be subordinate to something like a "vice president for finance." The modern bursar is usually charged with internal billing to students and faculty. The Latin is "bursaria," from "bursa," meaning "purse."

bursarium scissores. Cutpurses, i.e., those who, when valuables were kept in a bag attached by thongs to the owner, cut the thongs to get the bag, i.e., the criminal-law equivalent of a pickpocket before there were pockets to pick.

bursary. The office of a bursar. Students at a college employed by it part time to supplement their income have sometimes been called "bursary boys," though the term seems to be dying out.

bury. Also spelled "berry." A borough or castle (cf. burg). Also, the act of effecting a burial.

burying ground. Another term for cemetery.

bushel. A measure of volume, extensively used for the sale of dry produce, e.g., grain, conventionally equal to four pecks, i.e., 32 quarts, i.e., 2150.42 cubic inches. But the size and weight of the "bushel" is defined by divers statutes, leading to some variation from jurisdiction to jurisdiction.

Bushell's case. A 1670 case involving one Bushel, foreman of a jury which acquitted two Quakers, who was fined and imprisoned for the verdict. $\mathrm{He}$ was released on habeas corpus, thus establishing the freedom of jurors from punishment for decisions not to the liking of the judge.

bushw[h]acker. Originally one who cleared away brush or bushes, e.g., to make farming or grazing land. Came primarily to refer to one who fought irregularly or from ambush, especially (during and after the Civil War) to Confederate soldiers who formed up troops of guerrilla forces, or turned into roving bands of outlaws.

business. At its broadest, any regular activity engaged in for gain. But the word is rarely used at its broadest. Sometimes it is used in contradistinction to sport, game, or hobby, to emphasize the gainfulness of the enterprise. At other times, it is used to distinguish mercantile or manufacturing enterprise from employee or worker status, thus emphasizing the partial work auton- 
omy of a businessman. Or it can be used to distinguish trade and manufacture from the work of artisans (e.g., plumbers), artists, or professionals (e.g., lawyers). Then again, business may distinguish white collar from blue collar occupations (as in "She work at the factory? No, she goes into business everyday at an accountant's"). Moreover, business is often used to describe a complex social and political orientation generally toward capitalism and profits and away from government regulation and wealth redistribution (as in "The business of America is business").

The thing is, the term business doesn't have $a$ meaning, and thus when its use has legal signifiance, one must look to context and intent; there is no way of knowing merely from the word's employment in, e.g., the phrase "tax on business" whether the income of a lawyer, a plumber, an artist, a hobbyist, a charity, or even a manufacturer is subject to it-though a dress shop in the jurisdiction pretty clearly is.

See also entries beginning with "business," below, which serve to illustrate the range of the word's practical usage.

business affected with a public interest. A phrase used in early (nineteenth century) Supreme Court cases upholding state regulation of business activities beyond the scope then thought generally proper. While no definition was ever successfully promulgated, certain touchstones developed, e.g., the market power of the enterprise (e.g., the only grain elevator in a locality); the closeness of its connection with necessities of life and health (e.g., milk production and marketing); and especially combinations of those two factors (railroads; utilities).

The more recent (post-1930's) ubiquity of state and federal regulation of business activities has made the concept unimportant, indeed almost quaint.

Cf. public utility.

business agent. Frequently the title of the chief operating officer of a union local, roughly equivalent to the general manager of a corporate division.

business bad debt. These are deductable against ordinary income; noncorporate "non-business bad debts" are not, though they may be treated as short term capital losses. I.R.C. $\S 166$ and its attendant regulations manfully attempt to distinguish between the two kinds. See also reserve for bad debts.

business broker. A broker of going businesses. Business brokers very frequently act as financial matchmakers, seeking out good candidates for merger or acquisition and, for a commission, bringing them together.

business capacity. When a governmental unit owns what looks like an ordinary business, e.g., a local water works, its operation of it is said to involve its acting in a business, rather than a governmental, capacity. This may have legal significance, e.g., certain governmental immunities from suit may not apply to governmental activities in a business capacity. See also public corporation.

business compulsion. See duress of property. 
Business Conditions Digest. A monthly publication of the Department of Commerce which brings together many indexes showing business and economic trends. It is much relied upon by planners, private and governmental.

business corporation. The ordinary garden-variety corporation, formed under a state's general corporation law for some profit-making purpose, e.g., manufacturing or selling; to be distinguished from charitable, non-profit, municipal, etc. corporations, which usually are governed by specially drafted corporation laws. Not all profit-making corporations, however, are under general corporation laws; banks, e.g., and public utilities often have special statutes too.

business day. A day upon which private or public business is ordinarily transacted, in most instances today, Monday through Friday. Many statutes and contracts, when specifying time periods, will use locutions like "shall given notice thereof no less than ten business days prior thereto." $C f$. business hours.

business enterprise. A term adopted to describe a business carried out in any organizational format: corporation, partnership, sole proprietorship, business trust, etc.

business entry. See book of original entry; business entry rules.

business entry rules. Rules facilitating the introduction into evidence of regularly kept written records of business and governmental transactions, over objections on the grounds of hearsay, failure to comport with an applicable original document rule, insufficient authentication, etc. This effort to get ordinary records more easily into evidence may be seen, e.g., animating Fed. R. Evid. 803(6) (covering hearsay); 901(b)(7) and 902(1)(4) (authentication); and 1005, and 28 U.S.C. $\$ 1732$ (original document rule). When a single "business entry rule" is mentioned, it usually refers to the hearsay exception, which is also called the "business entry [or 'record'] exception."

business expense. See ordinary and necessary [business] expense.

business guest. See business visitor.

business hours. The hours during which, on any business day, public or private business is transacted, ordinarily (except for local variations, or those prevailing in certain lines of business, e.g., banking) 9:00 a.m. to 5:00 p.m. Statutes and contracts often contain clauses like ". . . shall be tendered during business hours ....."

business insurance. Most broadly, any insurance involving any risk to a business, its operators or its property. More particularly, either business interruption insurance or key man insurance.

business interruption insurance. An insurance contract, or clause in one, promising to indemnify the insured against loss of profits over a period dur- 
ing which the the business is rendered inoperable through an insured cause, e.g., fire or flood.

business invitee. See business visitor.

business judgment rule. Very roughly, a rule that immunizes management (and the directors) or a corporation from liability for losses if the decisions were within the normal business judgment or such persons, i.e., not ultra vires, fraudulent, in bad faith, self-serving, etc. Briefly, management ordinarily has no liability to a corporation or its stockholders for ordinary errors made in the ordinary course of business.

business league. "[A]n association of persons having some common business interest, the purpose of which is to promote such common interest and not to engage in regular business . . . [A]n organization of the same general class as a chamber of commerce or board of trade." (Treas. Reg. § 1.501(c)(6)-1). It is exempt from income tax under I.R.C. § 501(c)(6), and the status of particular organizations claiming to be "a business league" has been extensively litigated.

business month. A standardized thirty-day month, e.g., for calculating and prorating interest. See also Boston interest. Twelve of them form a "business year" of 360 days.

business name. The name under which one does business, which can be one's own name, the combined names of partners, or just some made-up name, e.g., Acme Widgets. A business name may or may not also be a trade name.

business purpose. The term (along with "business use") is sometimes found in covenants or zoning law restricting certain property to or from use for business.

The term is always important in income tax law, where it refers to some sensible business reason for taking a tax-decreasing step other than that it decreases taxes, in the absence of which the step may be disregarded as a mere artifice.

business record exception. See business entry rules.

business records. See book of original entry; business entry rule.

Business Records Act. See business entry rules.

business situs. When intangible assets (e.g., notes, mortgages, etc.) are, as by being used in a business there, closely enough attached to a location as to be taxed there, they are said to have there a business situs.

business trust. See Massachusetts trust.

business use. See business purpose.

business visitor. It once was quite generally the law, and still is to some extent in a few jurisdictions, that the duty of care owed to one present on one's property depended on characterizations of that person's methods and mo- 
tives for getting there. Thus, e.g., if one were a trespasser, i.e., had entered without actual or implied invitation, he might be owed nothing except freedom from intentional harm, and perhaps not even that, while one invited onto property to have tea with the owner thereof was owed some greater level of care. It came to be held, e.g., that a "business visitor" ("business guest" and "business invitee" were also used), i.e., one invited onto premises to do business with the owner, was owed a high degree of care, being protected against ordinary negligence, while an ordinary social guest, even if invited, might be protected only against gross negligence, because the business visitor was there for the owner's purposes and potential gain. These nice distinctions, however, are fast dying out (except perhaps with respect to the one between trespassers and all other enterers), and a good thing too. See also guest; guest doctrine; invitee; trespasser; visitor.

business year. See business month.

busing. (Also properly spelled "bussing.") Moving people on a bus, a process which, in the context of school desegregation law, is an issue of some emotional intensity. As noted under affirmative action, when it is found that schools are segregated, one way to unsegregate them is to reassign the students until a more representative mix of races is enrolled in each. In most places that will require having some students ride buses, because either through other government action, private proclivities, or the prior or present segregation of the schools themselves, most neighborhoods are also segregated. Despite the fact that school busing has been widely used in the past, often to maintain school segregation, when desegregatory busing is not voluntary (as to a magnet school), and involves majority-race children too, many majority parents (and some minority) become intensely hostile, especially when the plan also involves young children, long distances, and lack of proof (sufficient to the aggrieved parents) that the segregation was caused by official discrimination. The apparent injustice of having one's children pay for previous generations' acts of discrimination, joined to race and class bias, makes for a powerful force, and there is some evidence (though the data are much less than conclusive) that one result is white flight, the movement of majority students to suburban or private schools, which in time leads to even greater educational segregation.

As for the law of busing, it is clear that courts may order busing as a remedy when there is proof of prior official educational segregation. It also seems clear that students may not be bussed to or from segregated suburbs without proof of the suburbs' participation in a pattern of segregation. It appears that busing cannot be ordered, without some proof of prior official discriminatory purpose (and Congress has passed laws banning busing orders in such circumstances), but orders mandating system-wide busing when the proof has established only less-than-system segregation have been upheld by the Supreme Court.

busones comitatus ( ). The barons or influential landowners of an English county. 
bussing. See busing.

bust. Slang for "arrest"; genteel alternative to "breast."

but-for test. See causation.

butler. Originally the servant in a royal or noble household in charge of wines ( $c f$. botiler of the King), frequently becoming an officer of high influence and power, roughly a major domo or "foreman" of servants. At royal courts the titular butler was often a high-ranking courtier, but his deputy (i.e., the "real" butler) also wielded great power within the household. In those few modern instances in which servants are kept, the butler is still the boss of them all.

butlerage. An ancient royal hereditary duty (i.e., import tax) on wine, originally taken in kind, later in the form of a money exaction. It was imposed on foreign shippers and alien wine importers.

butt. An old liquid measure, said to be equal to two hogsheads of 56 imperial gallons each (i.e., 135 U.S. gallons in total). But the gallonage actually varied rather widely over the years and in different markets. The term was used in ordinary speech as a name for any large wine or beer cask or barrel, and sometimes even for a bottle. Not to be confused with buttals or butts.

buttals. Short for abuttals.

butted and bounded. An old conveyancing term introducing the land description, meaning in effect "ended and surrounded" as in "butted and bounded on the east by ...." See abuttals.

button. In U.S. criminal slang, a low level member of some crime syndicate especially the "Mafia"; "soldier" is another slang equivalent.

butts. In old English land terminology, those portions of a field at the ends, where the plow was turned around. Also called "headlands." "Sidings" were similar unplowed portions at the sides, i.e., parallel to the plow lines.

Also, archery targets.

butts and bounds. A locution like metes and bounds. See butted and bounded.

buy. To acquire in exchange for a valuable consideration; "purchase" is the most common synonym. See also acquired.

buy and sell agreement. An agreement between or among the owners of a business, which may be organized as a partnership or corporation, addressing what is to happen to the interest of one of them who dies or otherwise leaves active involvement in the enterprise. The agreements admit of many variations, though most commonly the core provisions require the remaining owners (or the company-in which case the contract is sometimes called an "entity buy and sell agreement") to acquire the interest of the exiting party, on specified terms, he being also obliged to offer it to them.

Such agreements are important for tax purposes, but they are also impor- 


\section{Leff Dictionary of Law}

tant to provide a mechanism whereby co-owners of a business who fall out can disentangle from each other without destroying the business or each other.

buyer. One who buys; a purchaser. Under U.C.C. $§ 2-103(1)(a)$, "buyer" includes one who has contracted to buy. In real property transactions, often called a "vendee."

In retailing, a buyer is an executive who, for a department or the whole store, chooses which goods of which manufacturers to stock.

buyer in ordinary course of business. A status carefully defined in U.C.C. $\S$ 1-201(9) which, when achieved, gives the possessor generally superior rights over competing title claimants and lien holders. The ordinariness of the sale, the good faith of the buyer, and his furnishing new consideration are the heart of the status, but the details are also important.

buyer 60 contract. In the stock market, a contract under which a securities buyer pays a premium over market price in exchange for sixty days in which to pay.

buyer's market. One to the taste of buyers, i.e., when supply exceeds demand.

buyer's surplus. See consumer surplus.

buy in. Another locution for bid in.

buying [dormant] titles. Committing bracery.

buying long. See short sale.

buying on margin. See margin.

by. Depending on context, can mean "near to," "no later than," "causing," "as agent," and much else. When a statutory or contractual provision says something must be done "by" a particular date, it causes trouble because it is not entirely clear if the day of the date is to be counted or not.

by-bidding. Making phony bids at an auction in an attempt to drive up the price, usually as part of a corrupt arrangement with the owner or auctioneer.

by bill [without writ]. Under old English practice, some actions were commenced by original writ, others by original bill. In King's Bench, e.g., most actions came to be commenced by a bill of Middlesex.

by estimation. In conveyancing, a term with equivalent purpose to "more or less."

by God and my country. The defendant's formally correct answer under older English criminal practice when asked how he would be tried.

by inch of candle. See sale by the candle.

by-laws. A set of rules for the procedural administration of a private club, corporation or other organization. These internally adopted rules are often 
quite detailed, but they are subject to and cannot contradict the terms of the entity's charter, certificate of incorporation, etc. $C f$. municipal by-law.

by operation of law. Automatically, so to speak, and not through a contractual or other purposeful juridical act of a person. If, for example, a statute were passed providing that all leasehold interests longer than ninety-nine years were to become fees, then one would be vested with fee title "by operation of law."

by reason of. Because of, as in "Not guilty by reason of insanity."

bystanders. See talesmen.

by the bye. In ordinary usage, now means something like "oh, incidentally." Once referred to a now disallowed English practice of filing a declaration against one already in the custody of the court (on another matter) without suing out new process.

by virtue of. By authority of; by reason of; through-as in "By virtue of the authority granted to me . . . I now pronounce you man and wife."

Byzantine Code. See Basilica.

Byzantine law. See Roman law. 


\section{C}

C. Third letter of the English alphabet. An abbreviation (among many other things) of "chancellor," as in Lord High Chancellor, and of "chapter" as of a book.

$\mathrm{C}$ is also the third character in the more complex and interesting legal hypotheticals, those in which $\mathbf{A}, \mathbf{B}$, and $\mathbf{C}$ divide up the requisite roles, e.g., two knaves and a victim; a fool, a knave, and a victim; two victims and a knave, etc.

ca. Abbreviation of the Latin circa, used (especially with dates) for "around" or "approximately," as in "This legal trend reached its zenith ca. 1900."

C.A.B. Abbreviation of the Civil Aeronautics Board.

cabal ( ). A small coterie of scheming plotters, especially one engaged in secret political machinations. The term is sometimes said to be made up from the initials of members of one such group at the court of Charles II, but that is most likely twaddle, for the French cabale had a similar meaning from before the seventeenth century.

caballaria ( ). A feudal tenure, the holder being obligated to furnish the lord a fully equipped horseman when needed.

caballeria ( ). A Spanish land measurement differently defined from place to place. In one case involving the territory acquired by the U.S. by the Gadsden Treaty it was said to be equal to 105.75 acres, but other equivalents have been given for other once-Spanish lands.

caballero ( ). Spanish for "Knight," or at least "gentleman." Cf. the English "cavalier."

cabaret ( ). A public place where food, alcoholic beverages, and entertainment, especially musical, are provided together, i.e., a night club with a classier name. Like all assertedly pleasurable things of dubious morality (e.g., tobacco, liquor, gambling), sometimes subject to special taxation, a "cabaret tax."

cabinet. In the U.S., the heads of the various major departments of the executive branch of the government taken as a collectivity. The Constitution assumes that such persons would exist (Article II, § 2 gives the President power to "require the Opinion, in writing, of the principal Officer in each of the Executive Departments"), but no explicit collective role is spelled [out]. From earliest times Presidents have convened them as a group to consult them or convey to them his will on matters of policy, but in recent years their collective role has been in eclipse compared to the President's White House staff. As a constitutional matter, it appears that the President could decline altogether to consult them as a group, [or] individually, and it is not clear if he need even appoint any. What is clear, however, is that any 
appointee he did name would be what the Constitution calls an "Officer of the United States," i.e., would need Senatorial confirmation.

At present, the U.S. Cabinet consists of the heads of the following departments: State, Treasury, Commerce, Interior, Justice, Labor, Health and Human Services, Education, Defense, Housing and Urban Development, Agriculture, Transportation, and Energy. Each is the "Secretary" of his department except that the head of Justice is called the "Attorney General." See also kitchen cabinet.

In England "cabinet" refers to that inner group among members of Parliament of the majority party with whom the Prime Minister regularly confers on matters of policy. Many have ministerial duties, e.g., the Chancellor of the Exchequer runs what we would call the Treasury Department. But not all ministers are members of the cabinet, nor are all cabinet members actually in charge of a ministry, i.e., some are ministers without portfolio. See also shadow cabinet.

cablish ( ). Brushwood, or dead wood blown down by the wind.

cabotage ( ). See coasting trade.

cachepolus ( ). Also "cacherellas." See catchpole.

cadastre ( ). Also spelled "cadaster." An official register of the quantity, value, and ownership of real property in a jurisdiction, made for purposes of apportioning and imposing taxes. Domesday Book, e.g., was a species of cadastre. $C f$. grand list.

cadat a cause sua ( ). He shall lose his case.

cadaver. A corpse, primarily a human one.

cadena ( ). A Spanish term for a punishment roughly equivalent to "imprisonment at hard labor," but sometimes used to refer to "mere" imprisonment.

cadere ( ). A Latin verb meaning to fall, to fail, to abate, to end, in legal contexts indicating that whatever it was that was tried didn't work. See entries containing "cadere" and various other forms of the verb, e.g., "cadat," and "cadit."

cadere assisa ( ). To be nonsuited (at an assize).

cadere causa ( ). To lose a case.

cadet ( ). In the military, something like an apprentice, a military candidate not yet having a commission or post. In the U.S., persons enrolled in the official military academies are called cadets.

More generally, cadet refers, especially in England, to a younger brother, especially in a landed or titled family, who is not ordinarily slated to inherit, and he and his descendants may be referred to as a "cadet branch" of the family.

cadet branch. See cadet. 


\section{Leff Dictionary of Law}

cadi jurisprudence. See qadi jurisprudence.

cadit ( ). A form of the verb "cadere" which describes the failure of whatever is conjoined to it, e.g., cadit actio means "the action fails," cadit warrantia means "the warranty fails," etc. "Cadit questio," in the mouth of a judge, may be translated as "Go on to your next point; this question admits of no further argument."

caduca ( ). A (civil law) term for the lapse of a testamentary disposition. But the term is sometimes used to describe property that passes via that lapse, or escheats because of it. "Caducary" was used most frequently in this last meaning, to indicate forfeiture or escheat.

caducary ( ). See caduca.

caeteris paribus ( ). "Other things being the same" (or "equal"). The term is widely used, either in Latin or translated, in sentences like "When two parties claim the same property, caeteris paribus it will be awarded to the one with present lawful possession."

As the example indicates, the term stands for a mode of reasoning of enormous power-and danger. First of all, it is in fact never the case that all other things are equal. Especially when used in legal contexts, caetris paribus really means "all-other-things-which-by-the-substantive-law-aremade-relevant-to-this-determination being equal," i.e., only a limited number of real variables are to be considered.

Second, it is frequently the case that some variables, in theory highly relevant, are one way or another less easy to prove than others. Hence caeteris paribus often means "in default of proof of nonequality of other things, then . . . " which, if that proof cannot really be forthcoming, determines the issue.

In brief, the caeteris paribus move is made somewhat artificially to highlight $a$ factor to be made potent in a legal decision by suppressing the saliency of other factors which are, substantively or procedurally, just as important perhaps, but nonetheless to be barred from consideration in the particular decision process. $C f$. classification.

caeteris tacentibus ( ). "The others being silent," i.e., the other judges. A tag found in old reports after statements or an opinion by one member of a judicial panel.

caeteros. See inter caeteros.

caeterorum ( ). An administration of estate in which, a limited administration having been given to another, this one will cover the unadministered residue.

c.a.f. The British English equivalent of c.i.f.

cafe ( ). For most legal purposes a synonym of restaurant. There is some implication in terms like "cafe society" that it is a fancy one, perhaps with entertainment also provided, but there are an awful lot of cheap restaurants calling themselves cafes. 
cafeteria plan. A plan under which workers can choose from among a "menu" of additional fringe benefits a selection aggregating a certain maximum dollar value.

Cairne's Act. See Lord Cairn's Act.

calaboose ( ). Rather fey slang for jail, especially a local lock-up. The etymology seems to be Spanish.

calamity. Extreme misfortune; disaster, e.g., plague, earthquake, deep (economic) depression.

calculated. Planned out in advance; premeditated to produce a particular effect, as in "He struck her with calculated malice."

calefagium ( ). A feudal right to take fuel (i.e., wood) from the King's forest or the Lord's estate.

calendar. See court calendar.

calendar call. See court calendar.

calendar days. Sometimes held to mean consecutive days as shown on a calendar, i.e., as distinguished from "working days" or "business days." But the term has also held to be the same as working days, i.e., the term itself is a not very useful ground upon which to make any juridically determinative distinctions.

calendar month. A month as shown on a calendar, e.g., February or June, as distinguished from a month's worth of days, e.g., thirty. Hence "by the end of the calendar month" would mean "when June ends," not something like "thirty days from now."

calendar of causes. Old term for court calendar.

calendar week. Any consecutive seven-day period, but usually calculated as Sunday through Saturday.

calendar year. January first through December thirty-first; usually used in contradistinction to some other way of measuring a year, e.g., academic year, fiscal year.

calends ( ). In Roman law and (very roughly), the first day of the month.

call. A term of wide legal application, the constant core meaning of which is the attempted initiation of another's act under claim of right. Because call is closer to demand than to request, it often is accompanied by some formality. Thus certain members of organizations may be empowered (e.g., by bylaws) to "call" a meeting, and by the terms of some obligations (e.g., notes, bonds) the creditor may be given the right to "call" them under certain circumstances (e.g., the borrower's insolvency), i.e., to demand early payment. An important modern use of "call" refers to a right to demand that a certain quantity of securities, especially shares of common stock, be delivered at a particular price by a particular date (for more details on which see put, call, and straddle). See also option. 


\section{Leff Dictionary of Law}

"Call," however, is used very differently by conveyancers, to mean any reference in a real property description (e.g., to an artificial marker, a natural object, a distance between or among them, etc.) used to delineate the extent and shape of the property being conveyed or encumbered.

callable bonds. See redeemable bonds.

callable preferred [stock]. See redeemable bonds.

called upon to pay. As usual with legal uses of call, this implies that the caller has the legal right to require payment.

call girl. A whore whose arrangements are generally made over the telephone, either directly or through her agent. Call girls thus dispense with the degrading and dangerous process of publicly parading their availability, and often with the need to use madams and pimps. To get away with this mode of merchandising ordinarily requires the strong market position consequent upon having a superior product to sell, and thus call girls tend to be more attractive and expensive than the generality of whores. N.B. that not all whores are female, though "call boy" seems not or not yet to be a viable locution. $C f$. gigolo.

calling. A term for one's way of earning a living broad enough to encompass everything except perhaps blue-collar labor.

calling the plaintiff. An obsolete English method by which a plaintiff procured a nonsuit (which would not as thoroughly bar relitigation as an adverse verdict) in the face of an imminent loss. Just before the jury announced, the plaintiff and counsel would absent themselves and, upon their not answering the court crier's call, the nonsuit would be awarded. This seems to have been a litigation variant of breaking a quorum to avoid an undesired vote; and it is hard to believe it could long have survived unless the practice in some way also served the defendant's interests, e.g., as a compromise decision to allow, in effect, a withdrawal without prejudice.

calling to the bar. Admitting to practice as a lawyer, which may once actually have involved an audible call to material bar in a real court.

calling upon a prisoner. See allocution.

call loan. A loan which the lender may call, i.e., require to be immediately paid at any time, another term for which is demand loan or demand note.

call option. See put, call, and straddle.

call premium. With respect to redeemable bonds or similar securities, a premium above face or par value which must be paid by borrower in order to call them in for redemption.

calumnia ( ). A false charge; a calumny. But in some older texts any legal claim or demand.

calumniae jusjurandum. See calumny.

calumniare ( ). See calumny. 
calumniators. See calumny.

calumny ( ). Today, tends to be a nontechnical synonym for the more specifically legal terms "libel," "slander," and "defamation." While earlier usage included those more general meanings, it sometimes (especially in Latin forms, e.g., calumniare, i.e., to calumniate) also encompassed the more specific wrong of falsely bringing suit, e.g,, out of malice. Hence an oath taken that a suit was brought in good faith might be called calumniae jusjurandum, i.e., oath against calumny. See affidavit of good faith. And in some instance "calumniating" (or the Latin calumniare) might refer merely to the bringing of a suit, even if in good faith. See also calumnia for a Roman Law usage.

Calvin's case. A 1608 case in which it was held that persons born in Scotland after the 1603 personal merger of the Crowns of England and Scotland in the person of James I were not aliens (and thus unable to inherit English land). In effect, the decision established that the merger of England and Scotland had also taken place at a political level, and not just as a matter [of] late medieval dynastic law.

Calvo doctrine. See Drago doctrine.

cambellanus ( ). A chamberlain.

cambiator. See cambium.

cambipartia ( ). Champerty. A participant was a cambiparticeps.

cambist ( ). See cambium.

cambium ( ). Exchange. "Cambiale jus" would be the law of exchange. The exchanging might once have involved land, money, debts, etc., but in recent civil-law usage would refer mainly to trading in negotiable instruments. Hence "cambist" refers today to a bill broker; though it and the older form "cambiator" might also refer to a money changer.

camera ( ). A chamber, or room; sometimes a chest or coffer used to keep treasure. Used to name courts once held in particular ones, e.g., camera scaccerii, i.e., the Court of Exchequer Chamber. See also in camera.

cameralistics. The science of taxation, or of public finance in general.

camera regis ( ). Literally, the King's room; used to refer to something a subject of the King's particular interest, especially taking the form of a royal privilege, e.g., a protected city or market. London was particularly so described.

camerarius ( ). A chamberlain or other treasurer, i.e., an official in charge of public monies. But also applied to bailiffs.

camera scaccarii ( ). See Court of Exchequer Chamber.

camera stellata ( ). See Court of Star Chamber.

Campaign Finances [or Fund] Act. Popular name for the statute, 26 U.S.C. § 9001 et seq., also called the Presidential Election Campaign Fund Act, 


\section{Leff Dictionary of Law}

which regulates expenditures to be made by or on behalf of candidates for nomination or election to the presidency.

\section{Campbell's Act. See Lord Campbell's Act.}

campers ( ). The champertor's share of the proceeds of the lawsuit he improperly finances. See champerty.

campfight. A battle between champions, especially in connection with a wager of ballel.

campum partere ( ). See champerty.

campus. As Latin, any open field, i.e., not limited, as in today's English, to the physical precincts of a college or university.

can. To have the power or capacity to do something. This may be distinguished from having the right to do something, [or] it being permissible to do it. Thus one might say "Of course you can enter and cross Mr. Ferrall's land, but you may not do so without his permission." But the distinction is frequently violated in ordinary language, and in legal contexts, in which the question is more likely to be about legal permissibility than physical ability, one is even more likely to say "can" when, strictly speaking, one ought to say "may," e.g. (between client and lawyer), "Can I cross Ferrall's land?" "No, you can't."

canal. A wholly or partly artificial waterway. Its artificiality will not by itself prevent a canal from constituting or being part of navigable waters.

cancel. One of the may legal words (e.g., abrogate, annul, expunge, obliterate, repeal, rescind, revoke, terminate) for processes whereby the vitality and validity of something of legal significance is ended. While there is some implication that cancelling involves some act of physical cancellation, e.g., crossing out, mutilation, tearing up, it is only an implication: it is quite proper to speak of "cancelling a debt" which never had any physical embodiment and thus cannot have any physical destruction. Cancel seems to have no especially technical usage in any field of law like, e.g., that of "rescind" (see rescission) in contract law. But $c f$. cancellation clause.

cancellaria ( .). "Chancery," but referring usually to the Court of Chancery. cancellarius ( ). A chancellor; most particularly, the Lord High Chancellor.

cancellation. As a process, see cancel. As a thing, some physical indicium of that process, e.g., as with a cancelled check.

See also U.C.C. § 2-106(4), where "cancellation" is distinguished from "termination" by the fact that the former refers to an action taken because of another's breach while the [latter] covers all other sources of contract nullity, e.g., pursuant to the terms of the contract.

cancellation clause. A contractual provision permitting one or both of the parties to terminate the relationship under certain circumstances. The implication is that the circumstances do not amount to breach, and the cancellation 
creates no liability. But clauses allowing cancellation for particular breaches, or calling for some payment by the cancelling party might still properly be called cancellation clauses.

cancellatura ( ). A cancellation. See also cancel.

cancelled check. A check which, having been paid by the bank upon which it was drawn and charged to the account of the drawer, is returned to the drawer bearing notation of those transactions. It is useful as a receipt, e.g., against the payee's claim never to have received the check.

cancelli ( ). Lines drawn on a document, especially a will, to indicate its cancellation.

candidate. A person put forward, by himself or by others, for election or selection to an office, honor, or privilege. One may also be a candidate running for nomination to an office, etc. In most instances attaining to status of candidate entails numerous formalities, e.g., being nominated by a party, procuring some stated number of voters' signatures, etc.

candle. See sale by the candle.

Candlemas [Day] ( ). A Christian feast day, falling on February 2nd. Used as a date in older legal contexts, as in "Trial to be held the first Monday after Candlemas."

canfara ( ). A species of trial by ordeal, this one involving hot iron.

cannabis ( ). The plant Cannabis Sativa Linne, more commonly known as marijuana.

cannot. See can.

canon ( ). A rule, originally and presently ecclesiastical as in "... that the Everlasting had not fixed his canon gainst self-slaughter," but having also come to denote some secular rules, especially fundamental ones, as in canons of construction and canons of descent. See also canon law.

A canon is also a Christian ecclesiastical dignitary, for which see dean and chapter.

canonic[al] ( ). Pertaining, primarily, to canon law; something "canonical" is in accord with the ecclesiastical rule. But one might use the adjective to refer to some fundamental and well settled rule of secular law.

canonical disability. One of the canonical impediments (to a wholly valid marriage) was impotency. Hence this term was frequently used as a euphemism for that unhappy state.

canonical impediments. Under canon law there were various grounds, e.g., affinity, consanguinity, impotence, which rendered an otherwise valid marriage voidable, i.e., subject to annulment. When all of marriage law was canon law these were very important, inasmuch as divorce was, strictly speaking, impossible. Now, when marriage is a creature of secular law, the doctrine of canonical impediment is less directly important. But the canoni- 


\section{Leff Dictionary of Law}

cal impediments still frequently turn out to be grounds for secular annulment-though the details (e.g., what degree of consanguinity constitutes secular incest) may be different.

canonist. A professor of, or other expert in, canon law.

canon law. The law of the Christian church, originally and primarily the Roman Catholic one, but carrying over pari passu into Protestantism, especially the Church of England. Following the pattern of Roman Law, with which it had a long history of mutual influence, it was formed out of the "statutes" of the Popes, and answers by them and by specially designated members of curia, to questions posed by private litigants, all subject to a continuing effort at systemization and codification.

Canon law more pervaded society when the church did; large segments of what is now within the exclusive care of secular law-marriage and divorce, inheritance, contract, criminal law-once was exclusively or concurrently in the ecclesiastical jurisdiction. But even now, when canon law as such is (at least in England and the U.S.) exclusively the internal law of the church, many of its principles, e.g., the doctrines of contractual good faith, and unconscionability (the latter a disguised version of the medieval fair price doctrine), can be discerned in modern secular rules, especially those developed in Equity. (It should not be forgotten that quite late in English history the English chancellors were high ecclesiastics.) And, while canon law had its own special sources (e.g., the writings of church fathers), there was, of course, substantial borrowing between those two main heirs to Roman Law, canon law and what we have come to call civil law, i.e., the law of modern western Europe.

canons of construction. Fundamental rules for the interpretation of legal writings both private and public, e.g., the doctrine of ejusdem generis. In fact, any legal system which in theory seeks to figure out the meanings attached to words by their writers, and then carry out those intentions, i.e., any system in which words are to function as anything but incantations, will find canons of construction deeply unsatisfactory. In areas of law where the writers are legal professionals, e.g., the draftsmen of most statutes and wills. One may be aided by the theory that they too knew the canons of construction and sought the meaning their application would bring, but the job commanded of the judges is still to determine what the draftsmen meant. But in situations where the writers may not even be presumed to know that canons of construction exist, it is hard, with a straight face, to find that they meant the meanings the canons would produce. Hence, modern interpretation is far less dependent upon canons of interpretation, i.e., upon a reasonably small number of rules of meaning than on a less structured attempt to figure out what these words might have meant to their users. The canons are now used, or at least ought to be, only when the language is so ambiguous and opaque as to defy understanding, but some decision has to be made. Then the fiction, of "the meaning" may have to be indulged. 
canons of descent. The archaic term for a jurisdiction's rules of intestate inheritance.

Canons of Judicial Ethics. A codification of rules governing the professional conduct of judges, enacted by the American Bar Association in and subsequently by most states. Now superceded by the Code of Judicial Conduct. This latter still contains, forming a sort of summary of fundamental principles, numbered "canons."

Canons of Professional Ethics. A codification of rules governing the professional conduct of attorneys, enacted by the American Bar Association in 1908, and subsequently adopted in most states. Now superseded everywhere by the Code of Professional Responsibility. This latter enactment still contains, as sort of topic sentences for its various parts, summary statements called "canons."

cant. Originally, cant referred to any special, esoteric, technical language, as "thieves' cant," "lawyer's cant." Its present primary reference is to stale, repetitive, clichéd expression. In the case of lawyer, the two meanings may sometimes coalesce.

Cantaur ( ). "Canterbury," as in "Archbishop of."

cantred ( ). In old English law, a hundred villages. (In Wales, the equivalent of an English hundred.)

canvass ( ). Primarily, to examine the returns and/or count the ballots at an election, either as governmental employees, or for private pollsters. But the term is also used to cover those persons who go from door to door to check if the voters there registered still reside there (or ever did), and to solicit their votes. And people [who] go door to door to solicit commercial orders, signatures on petitions, and charitable donations are also called canvassers.

capable. Able to effect some end-as a matter of law or fact, as in "He is capable of murder." See also ability, capacity.

capacity. The legal or physical power to effect something, with frequent implication of mental capacity, i.e., ability to formulate a plan, understand what he is about, etc. $C f$. criminal capacity; testamentary capacity.

Also, "role," as in "In his judicial capacity he is permitted to perform marriages."

Also, how much can fit in, as in "The capacity of the tank is twelve gallons."

capacity of testator. See testamentary capacity.

capax doli ( ). See criminal capacity.

capax negotii. The capacity to effect contractual or commercial transactions; usually referring to legal rather than natural power.

cape ( ). An obsolete English judicial writ to recover realty upon the default of a tenant. "Cape magnum" (also "grand cape") lay before the tenant's 
appearance, "cape parvum" ("petit cape") after. There are a lot of details which, with luck, will never interest anyone again.

Also, a blunt peninsula, e.g., the Cape of Good Hope.

capias ( ). Literally, "that you take," the opening words of a large number of old writs addressed to a sheriff by which the person (and less frequently, the property) of a litigant might [be] taken into custody. Very frequently, any such writ might just be called "a capias," with context supplying which kind it was. See below for some of the most common varieties.

capias ad audiendum judicium ( ). A writ to bring before the court a defendant found guilty (in absentia, once a more widely permissible procedure) of a crime to hear its judgment and sentence.

capias ad computandum ( ). A writ forcing the defendant in the early abandoned action of "account render," against whom an ignored judgment of quod computet had been issued, personally to appear before the auditors (or court).

capias ad respondendum ( ). Once a very common writ for securing prior to trial, the attendance of a defendant to answer many civil and some criminal charges. While capias early was replaced by warrant in criminal actions, it lingered much later in civil practice and, under various names (e.g., civil arrest), still exists today under extraordinary circumstances. Until the early nineteenth century, it was the writ by which an ordinary action at law was commenced when injury by force was involved, or when the defendant had failed previously to appear, and was frequently just called "a capias" and abbreviated "ca. resp." Under most circumstances the defendant was ordinarily not really kept in custody, but forced merely to appear and post bail.

capias ad satisfaciendum ( ). The post-judgment equivalent of a civil capias ad respondendum, commanding the sheriff to take the judgment debtor into custody and hold him until the judgment was satisfied. It was extremely common, almost always being abbreviated "ca. sa." As a very nasty (and perhaps counterproductive-see Dickens' Pickwick Papers) way to coerce the debtor into paying, or at least well securing, a judgment, by the mid-nineteenth century in England (and soon thereafter to almost all U.S. jurisdictions) this execution against the person was abolished except in the most extraordinary circumstances.

capias in withernam ( ). In an action of replevin, or upon a distraint the plaintiff might come into possession of particular goods claimed also by the defendant. The plaintiff might also, under certain circumstances (e.g., the goods involved had been concealed), get a writ directing the sheriff to seize equivalent goods of the defendant. Now, if the defendant got a judgment directing the goods to be returned, and the plaintiff eloigned, i.e., took the goods out of the jurisdiction, then this writ capias in withnam might be issued commanding the sheriff to seize equivalent goods of the original plaintiff on behalf of the original defendant. When the latter "uneloigned," so to speak, he could get his own goods back. 
capias pro fine ( ). Roughly, the form of capias ad respondendum used to compel the payment of a fine imposed under statute. It also covered amercements.

capias utlagatum ( ). A writ for the arrest of an outlaw. If "general," it covered only his person; if "special," him and his property.

capita ( ). See caput; in capita; per capita.

capital. In economics, one of the factors of production.

In corporation law and accounting, a term of variable meaning, with the primary ambiguity being among (a) all assets used for the production of profit by a business; (b) a subset of those assets ordinarily called capital assets; and (c) another subset of those assets comprising the stockholders' equity in the business, specifically designated, by law and/or accounting practice, to be protected, on behalf of creditors, against depletion, by dividend (or other) payments made to stockholders.

The aim of the latter restrictions was to forestall what would effectively be fraudulent conveyances made by the "owners" of the corporation to themselves. In time, however, so many means of lessening or even totally evading these restrictions were devised and judicially acccepted, that they pretty much ceased to be relied upon by creditors to protect their interest. Large creditors took to protecting themselves by specific and detailed contractual provisions, and smaller unsecur[ed] creditors focussed their attention less on the balance sheet protections afforded by concepts of protected "capital," and more on the repayment potential of the debtor as shown on its income statement. That doesn't mean that the legal and accounting rules and tests have disappeared (see, e.g., stated capital; capital surplus), but only that their practical importance, whatever it might once have been, is today but a pale shadow of itself.

In any event, see terms beginning with and containing the word "capital" for further details of the corporation-law meanings, as well as for quite different usages, e.g., "capital offense," "capital account."

capital account. In corporate accounting and law, that entry on the books of the corporation covering the stockholders' equity in the business, their investment, which at least formally (see capital) ought not to be available for distribution to them by dividend or otherwise.

Also, in a law of future interests and trusts, some expenses and gains must be allocated between persons with present and future beneficial interests. It is frequently the case that that allocation will be made by asking if the item is for the "capital account," or is a "capital improvement" or is "chargeable to capital." If so, it is to be entered for or against the holder of the more distant interest.

capital assets. Business assets representing larger, more stable investments, e.g., property, plant, and equipment. See also capital; capital gains.

capital case. See capital offense. 
capital contributions. Things of value (cash, property, services) contributed by partners to a partnership, ordinarily measuring their interest therein. With respect to corporations, while the term might refer generally to capital invested by the shareholders, its more precise reference is to capital, especially additional capital, invested in the corporation but not reflected by the issuance of further stock. For income tax purposes, the capital contribution is added to the stockholder's basis for his stock, and is not treated as income to the corporation. See I.R.C. § 118.

capital costs. See capital expenditure.

capital crime. See capital offense.

capitale ( ). Obsolete term for an item of stolen goods, or its value.

capital expenditure. In corporation law, an expenditure made from those accounts reflecting the portion of a corporation's capital not lawfully available for distribution.

Also, expenditure for long-term improvements to property which, for tax purposes, ought not be treated as an expense, but rather added to the basis of the improved property, and then depreciated over time. See I.R.C. $\$ 263$.

capital gains. For income tax purposes, gain upon the sale of certain property, "capital assets," chiefly corporate securities and real estate, is taxed at a lower rate than ordinary income, e.g., wages and ordinary business profits. "Long term capital gains," i.e., gains on property held for more than one year, get particularly generous treatment. This favored tax treatment is generally justified as a way of avoiding the "bunching" of accrued property appreciation (especially in light of persistent inflation, when what would be taxed would not be "real" gain), and as a way to greater investment mobility. While the details of capital gains taxation are very complex (as they must become any time certain income can receive favored tax treatment, thereby producing an incentive to devise ways to convert non-favored income into it), the general rule is simple: If what is sold is a capital asset, one subtracts the basis of the property from its sales price and pays the capital gains tax on the remainder. If the calculation yields a loss, that is ordinarily deducted as a "capital loss." See also realized gain or loss.

capital goods. Sometimes used to refer to goods incorporated or consumed in the production of other goods, i.e., an antithesis [of] consumer goods.

capital impairment. Invasion of that portion of the capital of a corporation which by law or accounting practice ought not be allowed to fall below a certain amount.

capital improvement. See capital account.

capitalis ( ). In older English law, at the head; principal; chief; most important as in "capitalis justiciarus," i.e., "chief justice."

capitalis baro [scaccarii] ( ). In older English law, "chief baron" (of the English Court of Exchequer). 
capitalis custos ( ). Chief magistrate or warden. In some contexts "mayor" would be the best translation.

capitalis debitor ( ). The "principal debtor," i.e., to be distinguished from one with secondary liability, e.g., a surety.

capitalis dominus ( ). "Chief lord," i.e., the one of whom one ultimately holds one's tenure, rather than him of whom one holds mediately or immediately.

capitalis justiciarius [totius Angliae] ( ). Chief justiciar [of all England]. Very early in English history, the highest officer of state under the King himself, essentially his viceroy when the King was abroad. By the time of Henry III (ca. 1250), the office had declined to something more "judicial" in the modern sense. He presided in the court aula regis, the precursor of the Court of King's Bench.

capitalis justiciarius ad placita coram rege tenenda ( ). "Chief justice for holding pleas before the King." From around 1250, this was another form of the title of the chief justice of the Court of King's Bench.

capitalis justiciarius banci ( ). From around 1300, the title of the chief justice of what became the Court of Common Pleas.

capitalis plegius ( ). "Chief pledge" or "chief surety," but more commonly used of old to refer to a headborough, i.e., (very roughly), a mayor.

capitalis red[d]itus ( ) Principal rent.

capitalization. The total amount of securities, e.g., common stock, preferred stock, bonds, issued by a firm (especially a corporation) and at present outstanding.

Also, when one for accounting purposes treats an expenditure benefiting a future period not as a current expense but as an asset (ordinarily subject of depreciation), one may be said to have effected a capitalization. See also capitalize.

capitalize. See present value.

capital loss. See capital gains.

capital market. Most broadly, all those institutions which, taken together, perform the function of supplying business with financial wherewithal. Hence not only the New York Stock Exchange but, e.g., commercial banks, etc., indeed even depositors therein, which are lenders to business, may be said to be part of the capital market. But the term is usually used to describe those institutions the function of which is to supply and price longer term investments, e.g., stocks and bonds.

capital offence. Those crimes which can cost you your head, i.e., which are punishable by death. It is not necessary to be a "capital offense" that a death sentence actually be imposed but only that it might have been. See also capital punishment. 


\section{Leff Dictionary of Law}

capital punishment. A euphemism for state-imposed death. In the early 1970's the Supreme Court trembled on the edge of declaring capital punishment in all circumstances unconstitutional under the Eighth Amendment as "cruel and unusual punishment." By the mid-1970's it had firmly retreated from that position, finding some circumstances in which capital punishment would remain permissible. Deciding what those circumstances might be is still in process.

capital return. See return of capital.

capital stock. Corporate securities issued and outstanding representing the interest of stockholders in their role as owners, in effect, their entitlement to whatever is left over after all creditors have been paid off in full. Sometimes, of course, the line betwen this ownership of the residuum of the corporation and an ownership of "mere" debt is a fine one; preferred stock in AT\&T is both more secure and less residual than many bonds. But the distinction, in the main, applies. See also authorized capital stock; net capital stock.

capital stock tax. Either (a) a tax imposed on capital stock in the hands of stockholders; or (b) a tax upon the privilege of doing business in corporate form, measured by the amount of capital stock outstanding. The last federal tax of the latter type was repealed in 1945.

capital structure. The mix of capital stock, short-term debt, long-term debt of a corporation. Also, what remains on the asset side of a balance sheet after all liabilities are removed.

capital surplus. An entry on the balance sheet of a corporation representing neither ordinary earnings, nor capital stock, but rather amounts paid in by stockholders above the amount formally allocated to their ownership interest. See stated capital for one way that state of affairs can come about.

capital transactions. Transactions involving capital assets, or involving the capital structure of a corporation. See also capital gains.

capitaneus ( ). On holding by tenure in capite. Also, a naval commander. But the term may sometimes have been used as broadly as captain.

capitare ( ). To front on, or abut.

capitatim ( ). By the head, i.e., by the individual, as in capitation tax.

capitation grant. A grant, e.g., of lands, of a certain amount per individual. $C f$. capitation tax.

capitation tax. A tax imposed "per head," i.e., on individuals [without] regard to anything but their existence as such. It is to be distinguished from other taxation criteria, e.g., property or income owned or earned by the taxed individual. Moreover, while sometimes called a poll tax (one by the "poll," i.e., head), that term is presently reserved for a tax on going to polls, i.e., on voting.

capite ( ). See tenure in capite. 
capite doli. See ex capite doli.

capite fraudis. See ex capite fraudis.

capite minutus ( ). In Roman Law, one who had suffered capitis diminutio. capitis aestimatio ( ). In Saxon, the stipulated price of a man's life, used, e.g., for the calculation of angild, i.e., the amount to be paid in compensation for homicide.

capititium ( ). A head covering, mentioned in very old statutes seeking to regulate which kinds could be worn by which classes of society. The impulse may have been either sumptuary (see leges sumptuariae), or related to that which insists upon distinctive rank insignia in the armed forces, and most likely both.

capitus diminutio. Another spelling of capitus deminutio.

capitula ( ). The same as capitulary.

Also, a collection of ecclesiastics. $C f$. dean and chapter.

capitula coronae ( ). See capitula itineris.

Capitula de Judaeis ( ). A register of all mortgages made to Jews, established in the late twelfth century and soon obsolete.

capitula itineris. Also called "articles of the eyre," a long catechism prepared for and to be delivered by the justices in eyre to the twelve representatives of each hundred charged with reporting breaches of the civil and criminal law. It was, so to speak, a checklist of questions about things that might lead to announcements, i.e., fines payable to the Crown. The "capitula coronae" was a somewhat more detailed formulation.

capitulary ( ). A collection of civil or ecclesiastical statutes and ordinances, organized under "headings" (hence the Latin root).

capitulate. To surrender, especially to an enemy in war but, more generally, e.g., on an intellectual matter or an affair of the heart.

capitulum ( ). A heading, section, or chapter especially of a statute but properly of any writing. Sometimes abbreviated in old statutory references "cap.," as in "Stat. 3 Eliz. I, cap. 17." But "C." was interchangeable, and eventually triumphed.

capitur pro fine ( ). Same as capias pro fine.

capper. A conman's confederate or assistant, the various duties of whom are hard to pin down. May act as a belly stiff or roper, or as one who enters sham bids at auctions, or even as a solicitor for an ambulance chaser.

caprice. What one commits while being capricious.

capricious. Changeable, unpredictable, whimsical; without any apparent motivation other than self-will. In legal contexts, frequently seen in the dyad "arbitrary and capricious," used in the course of reversing an administrator or lower-court judge. See arbitrary. 
captain. While today principally describing a particular military, especially nautical, rank (and an important one in the latter case, for a captain is ordinarily one in command of a ship), "captain" once described more generally any commanding officer. Only later were the various ranks of captains distinguished, e.g., by calling one with authority over several others "captain general," i.e., general captain whence our modern "general."

captain general. See captain.

captain-of-the-ship doctrine. In medical malpractice law, a doctrine which makes surgeons, like ship captains, responsible for the errors of everyone in the operating room, even those who are employed by another, e.g. [the] hospital, and over whose activities whom they have no actual control (and, arguably, no right of control, e.g., anesthesiologists). The doctrine, which originated in and was largely developed in Pennsylvania, has been defended as an extension of the loaned-servant doctrine. But it really arose as an attempt to get recompense for the victim: the doctrine of charitable immunity once protected most hospitals, and lack of funds protected most hospital employees; if the surgeon and his insurer couldn't be reached, the savaged patient would be out of luck. With the waning of charitable immunity leading to the procurement by hospitals of comprehensive insurance covering its employees, the need for the captain-of-the-ship doctrine, and its actual application, has similarly decreased.

captation ( ). A term from the civil law, roughly equivalent to undue influence.

captio ( ). In older English law, a taking or "capture" of something or someone. Also, a caption.

caption ( ). The "heading" of a legal instrument, especially a pleading, motion, etc., consisting of information useful for quickly identifying and using it, e.g., parties, file number, court, nature of document, etc. The rules about what should be in a caption vary, even locally, from jurisdiction to jurisdiction; see, e.g., Fed. R. Civ. P. 10(a).

captive. A person or thing that has been captured, and is presently held. The "capture" [need] not involve force; a "captive supplier," e.g., may be one integrated into the captor's production processes by ownership or long-term contract.

captor. One who has effected a capture. Also more technically (in admiralty and international law) one who has taken a prize.

capture. Any forceful taking (but see captive) of persons or property, with particular reference to acts done in time of war, e.g., taking booty or prisoners of war. See also prize; rule of capture.

capus lupus ( ). Literally, "wolf's head," i.e., one who has been outlawed. Equivalent terms included caput genere lupinum and caput lupinum. 
caput ( ). Singular of capita, and with as wide a range of meanings (for some of which see terms so beginning, below).

Also (usually today) pronounced ( ), destroyed, dead.

caput anni ( ). The beginning (head) of the year.

caput baroniae ( ). The castle or principal manor of a baron.

caput comitatis ( ). The head of a county; usually applied to a sheriff, but conceivably applicable to a high feudal lord, e.g., an earl.

caput jujunii ( ). The beginning of Lent, i.e., Ash Wednesday.

caput portus ( ). In old English law, the chief town of a port.

car. Obviously from "carriage," and today principally referring to automobiles and railroad cars (of all kinds).

carat ( ). A weight measurement for diamonds and other precious gems, now internationally standardized at 200 milligrams.

Also, a purity measure of gold. Twenty-four carats is taken to be absolute purity, with lesser numbers expressing the percentage thereof, e.g., "18 carat gold" means gold $75 \%$ pure.

caravaning. Towing another vehicle, especially to offer the latter for sale. With the coming of modern multi-vehicle car carriers, the practice (and its legal regulation) has faded.

carbon copy. A copy made by striking a typewriter ribbon and carbon paper under it simultaneously. Easily qualifies as a "duplicate" under Fed. R. Evid. 1001(4).

carcanum ( ). Prison

carcare ( ). To load, as a ship. "Carcatus" means loaded.

carcelage ( ). Jail or prison fees. See carcer.

carcer ( ). A place to keep persons secured; not, strictly speaking, to punish them.

cardholder. One with formal membership in an organization, e.g., a labor union.

cardinal. A high dignitary of the Roman Gatholic church, ordinarily active in its administration, and charged with the election of the Pope.

care. See negligence.

careless[ness]. See negligence.

careless driving. See negligence; reckless driving.

carelessly and wantonly. See negligence.

ca. resp. See capias ad respondendum.

careta ( ). A cart; a cart load. 


\section{Leff Dictionary of Law}

car float. A vessel for the transportation of railroad cars. It is filled with tracks onto and off of which the cars can be driven.

cargo. That which is loaded on a carrier, especially a ship, for transporting elsewhere. See also freight.

cark. An old English wool measure, thirty of which made a "sarplar," itself said to be equal to 2,240 pounds.

carl. See churl.

Carlisle tables. Among the earliest life and annuity tables, compiled at Carlisle, England around 1780.

carload. A quantity (made more or less precise by commercial usage in each trade) equalling the contents of an ordinary railroad freight car, so loaded as to accommodate the commodity.

chiltern hundreds. A member of Parliament may not resign. Nor may he hold "an office of profit under the Crown." The stewardship of the Chiltern Hundreds is such an office, though it carries no duties and nominal fees. So when a member of Parliament wants to resign, he asks the Chancellor of the Exchequer for grant of the Chiltern Hundreds and upon getting it, his seat in Parliament is vacated. Ah, the British .... 
HeinOnline -- 94 Yale L. J. 2252 1984-1985 